
\%
$8: 8$
\%8.

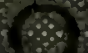

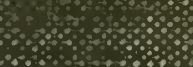
$\mathrm{ROT} \triangle \mathrm{NV}$

$\because 8$

$$
B \circlearrowleft \triangle A N
$$

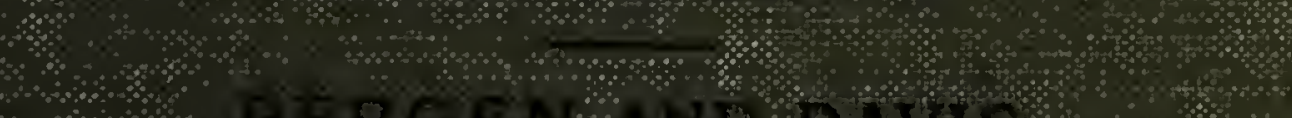
GERGEN AND DAVIS

$\therefore \therefore-0$ $\because \because 80$

\&o

o

$\therefore 0$

$\therefore \%$

- 0 \% 
NUNC COGNOSCO EX PARTE

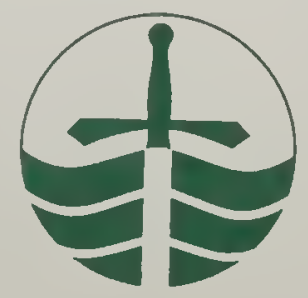

TRENT UNIVERSITY

LIBRARY 
D. Mirte

101 Blecter It.

147 Qbanlyre Sve Forouts. Sut. 



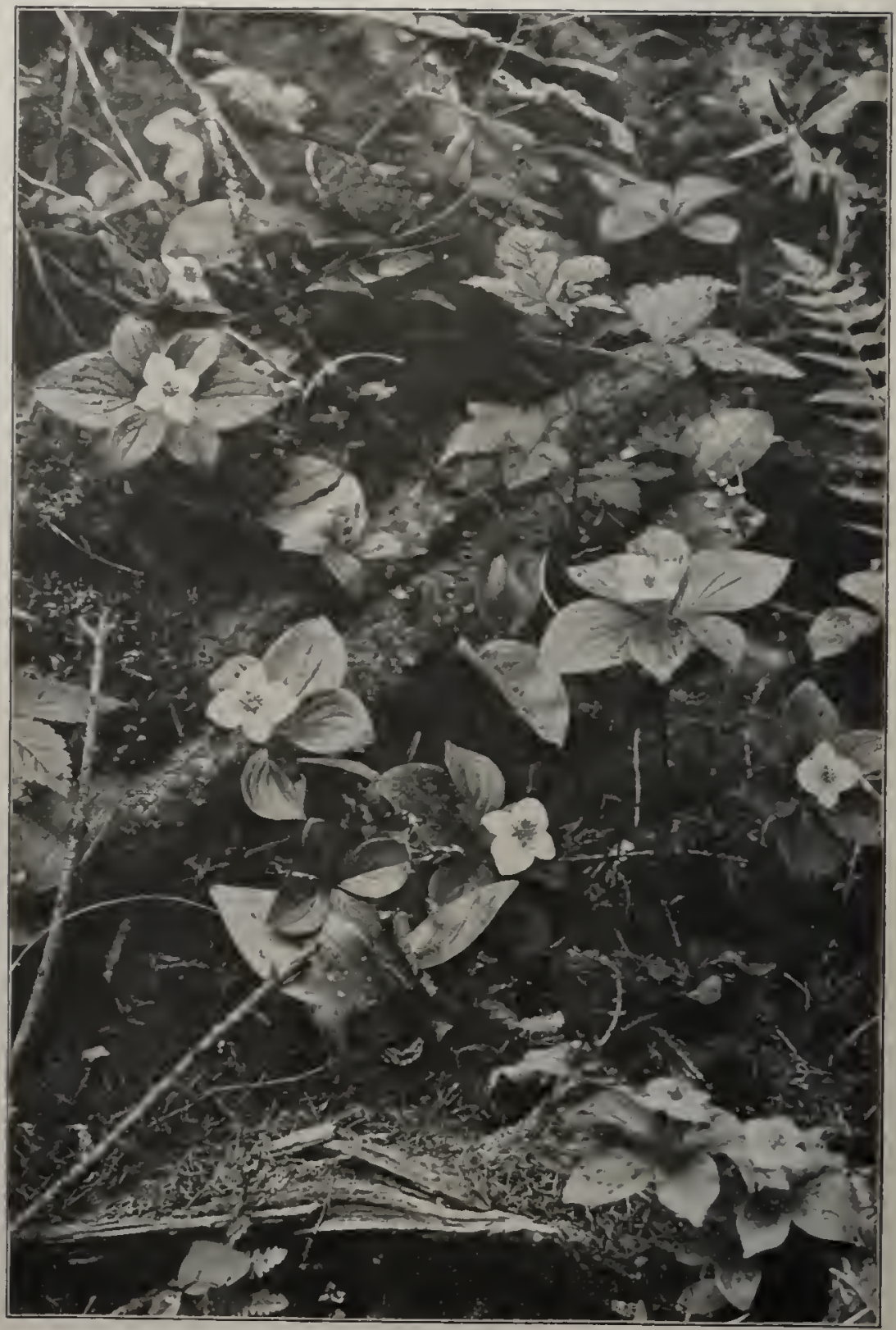

Attractiveness for insects in showy involucres of Cornus canadensis 


\section{PRINCIPLES OF BOTANY}

BY

JOSEPH Y. BERGEN, A.M.

AUthor OF "ElEMENTS OF BotANץ," "Foundations of BotaNy," "PRiMER OF DARWLisM," etc.

AND

BRADLEY M. DAVIS, Ph.D.

ProfESSOR OF BOTANY IN THE UNIVERSTY OF PENASILVANI

GINN AND COMPANY

BOSTON - NEW YORK - CMCAGO LONHON

atlaNta - DALlas - COLUMBUS - SAN FRANCISCO 
COPYRIGHT, 1906, BY

JOSEPH Y. BERGEY AND BRADLEY M. DAVIS

ALL RIGHTS RESERVED

323.2

ebe Atbenaum press

GINN ANI COMPANY - IJRO-

I'RIETORS - BOSTON - U.S.A. 


\section{PREFACE}

The present work owes its existence to the favorable reception accorded to Bergen's Foundations of Botany. Whatever betterments have been suggested by five years' use of the earlier book in the hands of expert teachers will be found here incorporated. The Principles of Botany also attempts to supply what many feel to be one of the most valuable portions of botany for educational purposes, namely, a consecutive series of studies of representative spore plants, so treated as to outhine the evolutionary history of the plant world. Botanical technology cannot figure largely in any brief general botany. The authors have however touched frequently upon the economic side of the subject, and the last two chapters are wholly devoted to practical topics.

The subject-matter has been divided into three parts, treating respectively:

I. The structure and physiology of seed plants (Bergen).

II. The morphology, evolution, and classification of plants, being an account of the critical morphology of plants upon which is based their relationship by descent (Davis).

III. Ecology and economic botany (Bergen).

The whole will furnish material for a full year's work, and it will usually be found necessary to omit portions and thus shape a course adapted for the exact conditions under which the work in each case is to be done. It is not the intention of the authors to frame an inflexible course, but rather to present in orderly fashion the material from which a thoroughly practical one can be planned. Indeed, the authors believe that a half-year course can be readily arranged by selections from the more general sections of the book. 
The planning of a course will be materially assisted by the use of the author's' Laboratory and Field Manual, which is so arranged as to off cr a choice between the general requirements of a shorter, elementary course and the details which arc only possible when more time can be given to the subject, under cxeellent conditions of laboratory equipment and with fairly mature students. A glossary of botanical terms employed in this book will be found in the Laboratory Manual.

Some instructors will prefer to devote most of the year to a study of secd plants; others will cloose to make the story of plant evolution the chief feature and may even prefer to begin with Part II. This portion of the book is the outgrowth of ten year's' experience of the junior author in the University of Chicago, where he offered a year's course in general morphology along somewhat similar lines. The treatment giren to the thallophytes in Part II will seem to some reader's long in proportion to that allotted to the other groups of plants. This cannot however be avoided in any account which attempts to present an outline of plant evolution with the important topics of the origin and evolution of scx and of the sporoplytc. Furthermore, it is very desirable to describe a range of types from which selections may be made according to the material available in different regions of the country. The adaptation of the book to scveral methods of approach has obviously nccessitated slight repetitions of fundancutal matter in certain parts.

Whatever the order of trcatment, the autliors would urge tlic importance of sending the student to the plants for as nany as may be of his facts and then linking thesc together by reading and class discussion. Undigested laboratory work is little better than none at all, while a reading coursc without type studies and physiological cxperiments is a quarter of a century behind thic best practice of to-day. No matter where it is to end, the study of botany should begin with a first-hand knowledge of plants themselves, _ best of all, with a kilowledge of their 
life in their own natural environment. At the outset there may be far more botany and more reasoning power gained in finding out for one's self the light relations of locust or bean leaves, or in ascertaining why one pool is teeming with Spirogyra and another with Oscillatoria, than in much reading of botanical literature.

'The earlier chapters of Part I are considerably less difficult than most of the later portions of the book. It is therefore suggested that care should be exercised not to consume too much time in covering this ground, together with the laboratory work which it presupposes. Classes should rather be carried along somewhat rapidly to such more clifficult topics as are discussed in Cliapters $\mathrm{V}, \mathrm{VIII}, \mathrm{XII}$, and $\mathrm{Xv}$, and in Part II.

Except where acknowledgment is made in the text, the fignres and plates are all new or from the Foundations or Elements of Botany of the senior author. Most of the illustrations of P'art II arc original and by Dr. Davis. Special thanks for photographs and plates either reproduced in half tone or redrawn for zinc etchings are due to F. W. Atkiuson, F. Börgesen, F. E. Clements, E. M. Frecman, G. T. Goodale, D. S. Jordan, Conway MacMillan, J. H. Schaffner, and Hermann von Schrenk. W. M. Davis, A. E. Frye, and F. Roth have kindly permitted the use of a number of woodeuts and maps.

Parts of the manuscript werc read by A. T. Bell, F. E. Clements, I. S. Cutter, IV. F. Ganong, R. A. Harper, W. M. Hays, J. C. Jensen, Miss Iillian J. MacRae, and Miss Caroline E. Stringer. Proof was read by W. J. Beal, F. E. Clements, W. N. Clute, I. S. Cutter, H. S. Pepoon, B. M. Stigall, and Miss Lva O'Sullivan. To all of these the authors wish to express their great appreciation for kindly criticisms and most helpful suggestions.

J. Y. B.

B. M. D.

Cambribge, August, 1906 



\section{CONTENTS}

INTRODUCTION

\section{PAR'T I}

THE STRUCTURE AND PHYSIOLOGY OF SEED PLANTS

\section{Cinapter}

I. The Seed and its Germination . . . . . . . . . . . 5

II. The Storage of Food in the Seed . . . . . . . . . . 8

III. Movements, Development, and Morilology of the SeenLING • . . . . . . . . . . . . . . 12

IV. Roots . . . . . . . . . . . . . . . . . . . 19

V. Sone Properties of Cells and tileir functions in the

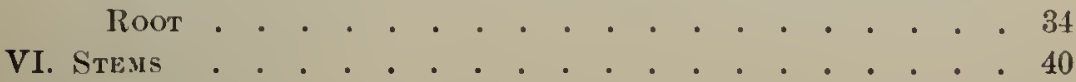

VII. Structure of the Stem . . . . . . . . . . . . 57

Vili. Livikg Parts of the Stem; Work of the Stem . . . . . 71

IX. Butes . . . . . . . . . . . . . . . . 80

X. Leaves . . . . . . . . . . . . . . . . . . 88

Xi. Leaf Arrangement for Exposure to Sun axd Air; Heliotropic Movements of Leaves and Siloots . . . . . . 94

XII. Minute Structure of Leaves; Functions or Leaves . . . 102

XiII. The Flower of the Higher Seed Plants . . . . . . . 123

XIV. Inflorescence . . . . . . . . . . . . . . . . 132

XV. Origin and Structure of Floral Organs; Pollination and

Fertilization . . . . . . . . . . . . . 138

XVI. The Fruit . . . . . . . . . . . . . . . . . 146

\section{PART II}

\section{THE MORPHOLOGY, EVOLUTION, AND CLASSIFICATION OF PLANTS}

XViI. The I'minciples of Morphologr, Evolution, and Classifi-

Cation . . . . . . . . . . . . . . . . . . 151

XViII. Tue Lowest Organisms and the Cell as tife Life Unit • . 156

Xix. The Thallopirtes . . . . . . . . . • . . . 172 
Cmapter

PAge

XX. The Alfa, the Lowest Green Plants . . . . . . 173

XXI. Sumiri of tile Life Histuries axd Erolltion of the

ALGA . . . . • . . . . . . . . . . 221

XXII. Tile Fusgi axd tileir Relation to Fempertation axo

DISEASE . . . . . . . . . . . . . . . 227

XXIII. Summar of tile Life Histories and Frolutiox of tile

FuxgI . . . . . . . . . . . . . . 272

XXIV. The Bryopiytes and tine Establishment of Alternation

OF GEXeratioss . . . . . . . . . . . . 275

XXV. The Pteridomintes and the Appearance of IIEterogroik 300

XXVI. Altersation of Generations . . . . . . . . 345

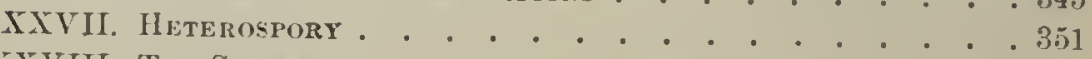

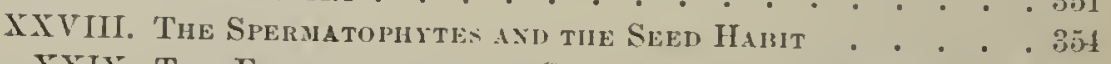

XXL. The Erolution of tile Siorophte and Degeneration

of the Gametophyte: . • . . . . . . . 402

\section{PART III}

\section{ECOLOGI AND ECONOMIC BOTANY}

XXX. Parasites ayd Carjivorous Prants . . . . . . . 407

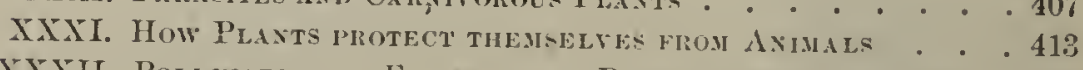

rX.iI. Pollisation of flowers and Protection of Pollex • . 420

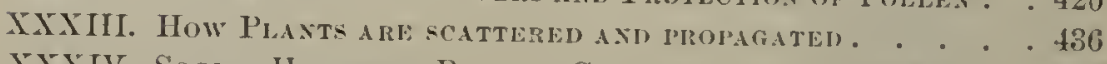

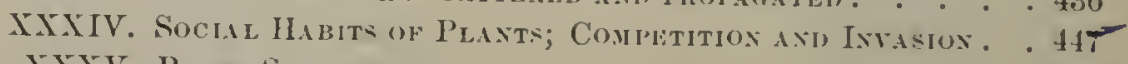

IXIV. Plant fieccessions. . . . . . . . . . . . tjut

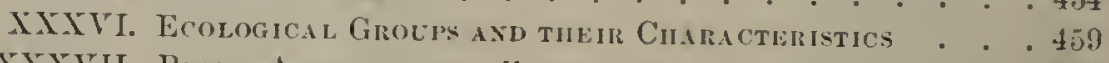

XXXYil. Plant Associations; Zoxition . . . . . . . . 474

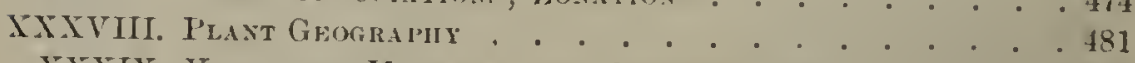

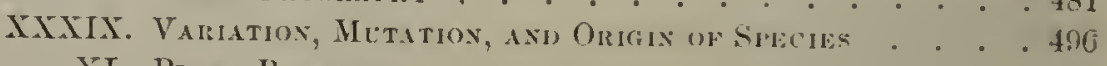

Xl. Plaxt Breening. . . . . . . . . . . . . 500

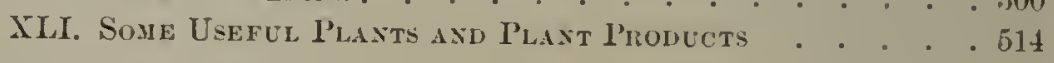

APPENDIX . . . . . . . . . . . . . . . . 537

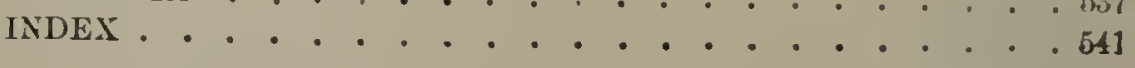




\section{LIST OF PLATES}

Froxtispiece. Attraetion for pollinating inseets in Cornus canadensis, a shade plant of eold woods with inconspieuons perianth, but a large and showy white involucre, the whole head appearing like a flower.

facing page

Plate I. Sand dunes with sea rye grass (Elymus arenarius). A sand binder, deep-rooted, with extensively ruming rootstocks .

PLate II. Exposure of leaves to sunlight. All the leaves are arranged at suel an angle as to receive the maximun illumination. Balsam spruee forest along a brookside, east slope of Pikes Peak. Species represented: Actua eburnea, Chamanerion angustifolium, Heracleum lanatum, Rubus strigosus.

Platr: III. Cypress swamp, with Spanish moss (Tillandsia), an epiphytie seed plant practieally leafless, the work ordinarily done by leaves devolving on the slender stems. The eypress trees are furnished with "knees," or projections from the roots, which are thought by some to absorb air .

PLAt: IY. Rockweeds exposed at low tide . . . . . . . . . . 204

Plate V. A eommon tree lichen (Physcia stellaris) . . . . . . 254

PLATE VI. A wound parasite (Pleurotus ulmarius) on a maple tree $\quad 270$

PLATl: VII. Tree ferns (Dicksonia antarctica) from Tasmania . . . 310

['LATE VIII. A probable landscape in the Carboniferous Age . . . 340

Piati: IX. Belt of trees along a Nebraska river, showing dependenee of forest on water supply.

Nerophytie grissses on Nebraska sand hills.

PıAT: X. Zonation about a pond in southwestern Ohio. The plate shows the nurth end of a pond of about eleven acres in area partially surrounded by seven zones begimning with subnerged aquaties and ending with a forest zone (in the portion next the pond, malinly of maples, elms, ashes, and willows) . . . . . . . . . . .478

PLATE XI. Leaning trees at timber line on I'ikes Peak . . . . .486

P'LATE XilI. A coniferous forest interior of central Coloralo. The trees are Douglas spruce (Pseudotsuga mucronata). The light intensity is so feeble, from the dense shade, that the only seed plants on the forest floor are saproplytic or parasitic orchids and a few little Pyrolas.

Plate XIII. A tropieal forest in the Philippines, showing charreteristic dense regetation, the trees of many speeies, mostly palns 



\section{PRINCIPLES OF BOTANY}

\section{INTRODUCTION}

Botany is the science which treats of plants. It considers the structure and functions of individuals, recognizes their neighborhood relations as citizens of plant communities, and studies their positions as members of the plant kingdom more or less closely related by common descent. The study of the individual plant embraces a variety of topics, and the examination of its relation to others introduces many more subjects.

Morphology is the science of form and structure. Under this head are studied the forms of plant bodies and the portions of which they are composed. All plants except the very simplest are made up of parts, called organs, which are structures developed for particular kinds of work. Thus the stems, roots, and leaves are organs, and so are also the parts of a flower. Morphology establishes the relationships of organs which seem at first glance very dissimilar, as when leaves take the form of bud scales or spines or tendrils. Morphology traces the degeneration of parts which frequently cease to perform the work for which they were originally developed and become much simplified in structure or almost disappear. Thus the tendrils of the woodbine are shown to be morphologically branches reduced to mcre organs of attachment. Although morphology deals with the plant with less regard to its character as a living being, it sliould never be entirely separated from physiology, but should go hand in hand with that sister subject, equally necessary to an understanding of plant life. 
Plant physiology treats of the plant in action, how it lives, respires, feeds, grows, and produces others like itself. It discusses the nature of the material in which the life activities of the plant have their origin, and the conditions as regarls light, heat, air, and moisture under which life is possible. It considers the raw materials out of which plant food is made, the processes by which the manufacture is carried on, and the means by which food once produced is trausported throughout the plant body. The mode of growth of plants is an extended and most important topic, and the processes by which reproduction is carried on are so numerous and complicated that they constitute one of the most difficult and interesting departments of botany. In order to go far into the details of the life activities of plants one needs to know a good deal of chemistry and some physics. But there are many of the phenomena of plant physiology which can be taken up with profit in an elementary way and investigated with rather simple apparatus.

Plant geography discusses the distribution of the various kinds of plants over the earth's surface.

Paleobotany, usually studied along with geology, considers the history of plant life on the earth from the appearance of the first plants until the present time.

Taxonomy, or systematic botany, is concerned with the classification of plants. By this is meant the arrangement or grouping of the kinds of plants to show their relationships to one another. It attempts to express the final results of the long processes of plant evolution, and is far more than the conventional study of flowering plants, which occupy only the highest grades in the claborate system of plant evolution and classification.

Plant ecology treats of the relations of the plant to the conditions under which it lives, together with the origin and development of plant associations. Under this division of the science are studied the effects of soil, climate, and friendly or lostile animals and plants on the external form, the internal structure, and the habits of plants. The main lesson to be learned from 
the study of ecology is that the plant is not an organism of fixed form, structure, and habits, sprung from a long line of precisely similar ancestors and destined to leave an indefinite series of forms like itself to succeed each other in the same area. On the other hand, each generation is a little more or less numerous than its predecessors, covering more or less territory than they did, and rarying from them this way or that under the influence of changing conditions of life. This is an interesting departinent of botany, but it lias to be studied mainly out of doors.

Economic botany is the study of the uses of plants to man.

Many of the topics suggested in the above outline cannot be studied in detail in an elementary course. It ought, however, to be possible for the student to learn a good deal about the simpler facts of morphology and of plant physiology. It is necessary to study plants themselves, to take them to pieces and to make out the connection of their parts, to examine with the microscope small portions of the exterior surface and thin slices of all the variously built tissues of which the plant consists. Among the lower plants there will be found a most attractive study of cell structure, reproductive processes, and life histories, - all requiring the use of the compound microscope. Living llants must be watched in order to ascertain what kinds of food they take, what kinds of waste substances they excrete, how and where their growth takes place and what circumstances favor it, how they move, and indecd to get as complete an idea as possible of what has been called the behavior of plants.

Since the most familiar plants spring from sceds, the beginner in botany may well examine at the ontset the structure of a few faniliar seeds, then sprout them, and watch the growth of the seedlings which spring from them. Afterwards he can study in a few examples the organs, structure, and functions of seed plants, trace their life history, and so, step by step, follow the process by which a new crop of seeds at last results from the growth and development of such a seed as that with which he began. 
After lie has come to know in a general way about the structure and physiology of seed plants, the student may become acquainted witl some typical spore plants. 'This will open up a new world, illustrating some of the most interesting and fundamental principles of biological science; for an understanding of the cell theory of organization and derelopment, the nature of sexual processes, and the evolution of the plant kingdon with its remarkable alternation of generations, can only be gained by tracing the chief steps in the processes through the various groups of algie, fungi, liverworts, mosses, and ferns.

For user's of the book who wish to begin in the autumn witl the study of some seed plant as a whole the following scheme is suggested:

1. Examine a seed plant in flower, to get an idea of its gross anatomy. Then study the development, structure, and modes of dissemination of the fruit. Outline the structure of seeds and follow the germination of some types. Next take up the structure and physiology of the vegetative members of the plant body, root, stem, and leaf.

2. Cover as much as may be of Part II, working out the story of the evolution of plants.

3. Devote the remainder of the year to study of floral structures, field work on families of angiosperms, ecological topics, and an outline of economic botany.

If desired, the course in botany may begin with the simplest spore plants, tracing the evolution of the plant kingdon through a consecutive study of types, as described in Part II, followed by somewhat detailed work on the structure and physiology of seed plants (Part I), and ecology (Part III). 


\section{PART I}

\section{THE STRUCTURE AND PHYSIOLOGY OF SEED PLANTS}

\section{CHAPTER I}

\section{THE SEED AND ITS GERMINATION}

The seed. A seed is a miniature plant, or embryo, with some accessory parts, in a resting or dormant state, and capable under suitable conditions of reproducing the kind of plant which bore it.

The power of producing seeds is peculiar to the higher plants (seed plants, or spermatophytes) and sharply distinguishes them from all lower forms of plant life.

The embryo may nearly or quite fill the interior of the seed, as in Fig. 1, or it may constitute only a small part of the bulk of the latter, as in Figs. 3, 4.

2. Form and position of the embryo. The embryo show's great diversity of form; it may have one, two, or several seed leaves, or cotyledons (Figs. 1, 3, 12). These may be straight, as in the squash seed, or much curved and folded, as in the seed of the four-o'clock, morning-glory, or buckwheat,

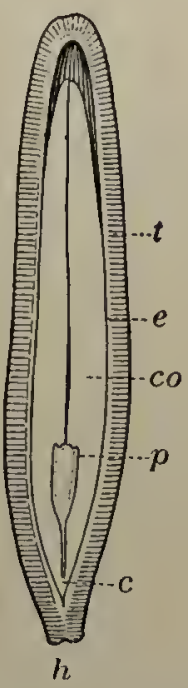

Fic. 1. Lengthwise sec tion of a squash seed c, hypocotyl; co, cotyledon; $e$, endosperm; $h$, hilum; $p$, plumule; $\ell$, testa. Magnified about two and a half times but they are almost always closely packed for economy of space 
The cotyledons are usually borne on a little stem, called the hypocotyl (meaning beneath the cotyledon) (Fig. 1, c; Fig. 2, c). Often a little seed bud, or plumule (Fig. 3), is easily recogni-

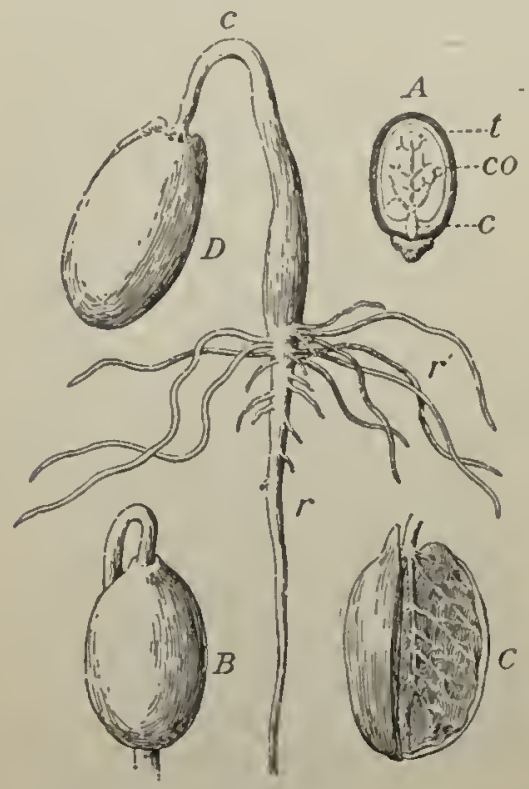

Frr. 2. The castor bean and its germination

$A$, lengthwise section of ripe seed : $t$, testa ; co, cotyledon; $c$, hypocotyl. $B$, sprouting seed covered with endosperm. $\quad C^{\prime}$, same, with half of endosperm removed. $D$, seedling: $r$, primary root; $r$, secondary roots; $c$, arch of hypocotyl

in the young seedlings themselves), in comnection with the present chapter, something about the following topics:

1. The anatomy of a few typical seeds.

2. Some of the conditions for germination.

3. Some of the chemical changes produced in germinating seeds, and their effect upon the surrounding air.

4. The early steps in the development of seeds into plants.

The brief outline of the structure of the seed just given should be much enlarged by the details learned in the laboratory. 
Every observing person who has grown plants from the seed has learned that heat and moisture are neeessary to insure germination, but the student will readily diseover, too, that air is necessary for anything more than the beginning of gemination.

5. Oxidation involved in germination. Germinating seeds, like all living things, eonsume mueh oxygen, the gas everywhere present in the atmosphere whieh supports the eombustion of coal and other fires and of lamps and gas flames. In plaee of the oxygen which they absorb, sprouting seeds return to the air carbon dioxide, - the gas which is produeed by burning charcoal, and whieh is one of the produets of burning most kinds of fuel and of the respiration of animals.

A thermometer with its bulb immersed in a jar of sprouting peas will mark a temperature somewhat

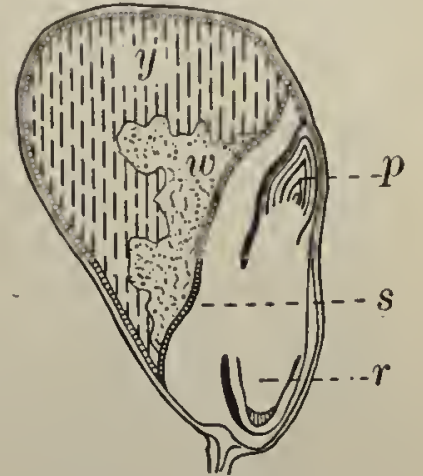

F1G. 3. Lengthwise section of grain of corn

$y$, yellow, proteid part of endosperm; $w$, white, starchy part of endosperm; $p$, plumule; $s$, the shield (cotyledon), in contact with the endosperm for absorption of food from it; $r$, the primary root. Magnified about three times. - After Sachs higher than that of the room in which they stand. 'The elevation of temperature is at least partly due to the union of oxygen with eombustible materials in the peas. Such a combination is known as oxidation. This kind of chemieal ehange is universal in plants and animals while they are in an active condition, and the energy whieh they manifest in their growth and movements is as directly the result of the oxidation going on inside them as the energy of a steam engine is the result of the burning of eoal or other fuel under its boiler. In the sprouting seed, mueh of the energy produced by the action of oxygen upon oxidizable portions of its eontents is expended in produeing growth, but some of this energy is wasted by being transformed into heat which esenpes into the surrounding soil. It is this eseaping lreat whieh is deteeted by the thermometer. 
CHAPTER II

\section{THE STORAGE OF FOOD IN THE SEED}

6. Importance of stored food for growth of the seedling. A very large part of the food of man and of many of the higher

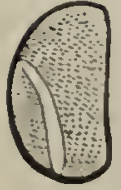

A

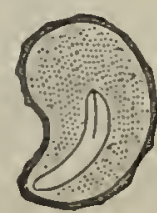

$B$

Frg. 4. Seeds with endosperm, longitudinal sections $A$, asparagus (magnified); $B$, poppy (magnified). - After Decaisne animals consists of seeds of various kinds, particularly of the grains. Every kind of seed contains some stored food material, though the amount in the poppy seed is but an insiguificant fraction of that in a horse-chestnut. Very often, as has already been learned, the food is stored directly in the embryo, especially in the cotyledons. Frequently, however, most of it is deposited in the endosperm, which surrounds or lies alongside of the cotyledons (Figs. 2, 3, 4). In either case the slow germination and subsequent growth of seeds from which part or all of the food material has been removed shows that its presence is most important in forcing along the growth of the seedling (Fig. 5).

7. Usefulness of rapid growth of seedlings. The very existence of the young plant may depend upon its being able to nake a rapid start in life. Most areas of fertile land contain far more seeds

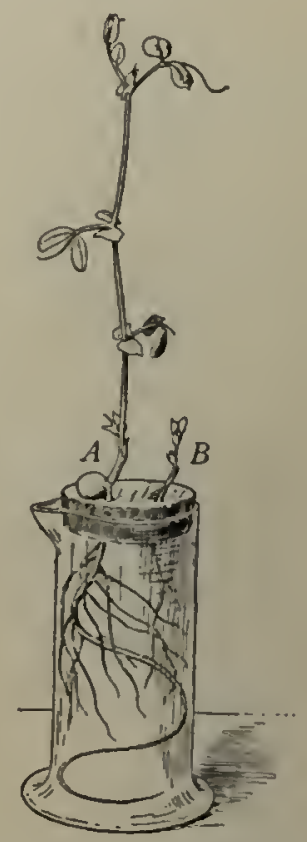

Fig.5. Germinating peas, growing in water, one deprived of'its cotyledons 
than can mature plants under the conditions of competition with one another which they must encounter, and so plants which shoot up rapidly at first possess a decided advantage. There is also a much better chance for seedlings growing in woodlands if they can attain considerable size before they are too much shaded by the foliage of the trees above them. This, of course, does not apply to evergreen woods.

8. Kinds of food stored in seeds. The three principal kinds of plant food, or reserve material stored in seeds, are starch, oil, and albuminous substances, or proteids. ${ }^{1}$ A single seed may contain all three of these in considerable proportions, or it may contain proteids together

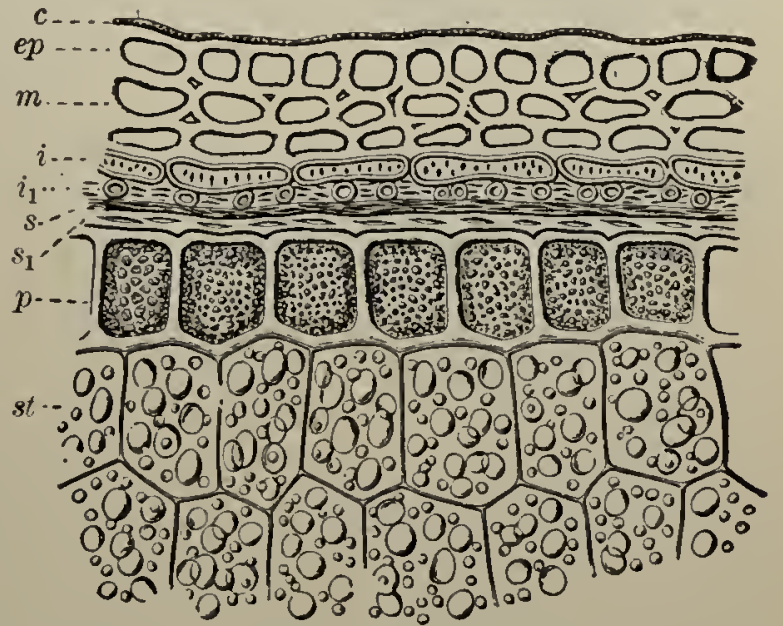

Fig. 6. Section through exterior part of a grain of wheat

$c$, cutiele, or outer layer of bran; ep, epiderınis; $m$, middle layer; $i, i_{1}$, layers of hull next to seed coats; $s, s_{1}$, seed eoats; $p$, layer eontaining proteid grains; $s t$, cells of the endosperm filled with starch. Greatly inagnified. - After Tschirch

with either starch or oil. Some proteids are always present, since the power of the seed to live and grow depends upon these compounds.

9. Starch. Every one is familiar with the appearance of starch in its commercial form. As found in seeds it occurs in microscopic compartments known as cells (Fig. 6). Each cell contains many small starch grains, usually of a nearly round or an ovoid

$1 \mathrm{As}$ in general throughout the book, the statements of the text presuppose a suitable amount of laboratory work; for example, that of the manual of the aut!ors. 
shape. The shape and markings of a starch grain, whether found in the seed or in some other part of the plant, arc often sufficiently definite to serve to identify the kind of plant from

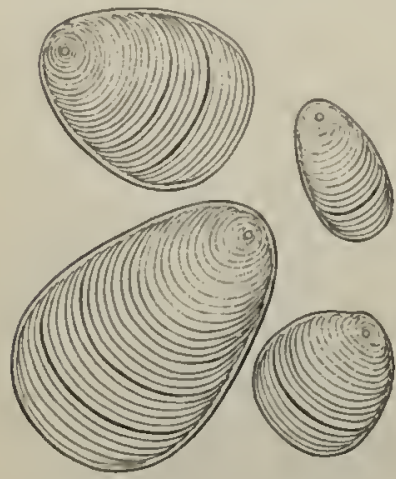

FI(i. 7. Canna starch

Magnified 300 diameters

which they came. Frequently the narkings are very regular and beautiful, as in canna starch (Fig. 7). They arc due to the successive layers deposited as the starch grain is formed. During the growth of the seedling, seeds containing stareh rapidly lose it, and microscopical examination of a sprouting grain of corn or of the cotyledons of a beau plant scveral weeks old shows the cells comparatively emptied of starch and those grains which remain much eaten away, as described bclow.

10. Action of ferments. A substance which can produce or excite any one of the chemical changes known as fermentation is called a ferment. The most familiar kinds of fermentation are the aleoholie, by which alcohol is produced, and the aeid, by which solutions of alcohol (such as fermented cider) are turned into vinegar, and by which the sugar of milk is changed into lactic acid when sweet milk turns sour.

All these fermentations and many others are caused by the development within the fermenting substances of minute living organisms, either yeasts or baeteria, described in Chapter XxI, which are consequently known as organized ferments.

There is a class of substances which, without the presence of yeasts or bacteria, can produce active fermentation. From the abscnce of the organisms above-mentioned, these are called unorganized ferments, and they arc also known as enzymes. One of these, diastase, plays a most important part in sceds during germination, transforming starch into sugar. Diastase is found in considerable quantities in malt, which is barley sprouted and then quickly killed by moderate heating. Naturally, as a 
result of the action of its diastase, malt tastes much sweeter than barley. The capacity of this enzyme to cliange starch to sugar is extraordinary, any quantity of diastase sufficing to transform ten thousand times its weight of starch.

11. Oi1. Oil occurs in many seeds - as, for example, flax, cotton seed, and corn - in sufficient quantity to make it worth while to extract it by pressure. It may be seen under the microscope in extremely minute droplets, inclosed in the cells of certain regions of the seed.

12. Proteids. Sometimes, as in Fig. 6, at p, the proteid constituents of the seed occur in more or less regular grains, but often they have no well-defined form and size. They hare a chemical composition very similar to that of white of egg or the curd of milk, and when scorched produce the familiar smell of burnt hair or feathers, which serves as a rough test for their presence.

13. Other constituents of seeds. Besides starch, oil, and proteids, other substances occur in different seeds. Some of these are of use in feeding the seedling, others are of value in protecting the seed itself from being eaten by animals or in rendering it less liable to decay. In such seeds as that of the nutmeg, the essential oil which gives it its characteristic flavor probably makes it unpalatable to animals and at the same time preserves it from decay.

Date seeds are so hard and tough that they cannot be eaten and do not readily decay. Lemon, orange, horse-chestnut, and buckeye seeds are too bitter to be eaten, and the seeds of the apple, cherry, peach, and plum are somewhat bitter.

The seeds of larkspur, Datura, ${ }^{1}$ croton, the castor-oil plant, nux vomica, and many other kinds of plants, contain active poisons.

1 Cozmonly called jimson weed. 
MOVEMENTS, DEVELOPMENT, AND MORPHOLOGY OF THE SEEDLING

14. How the seedling breaks ground. As the student has already learned by his own observations, the seedling does not always push its way straight out of the ground. Corn, like all the other grains and grasses, sends a tightly rolled, pointed leaf vertically upward into the air; but seedlings in general are not found to do anything of the sort. The squash seedling is a good one in which

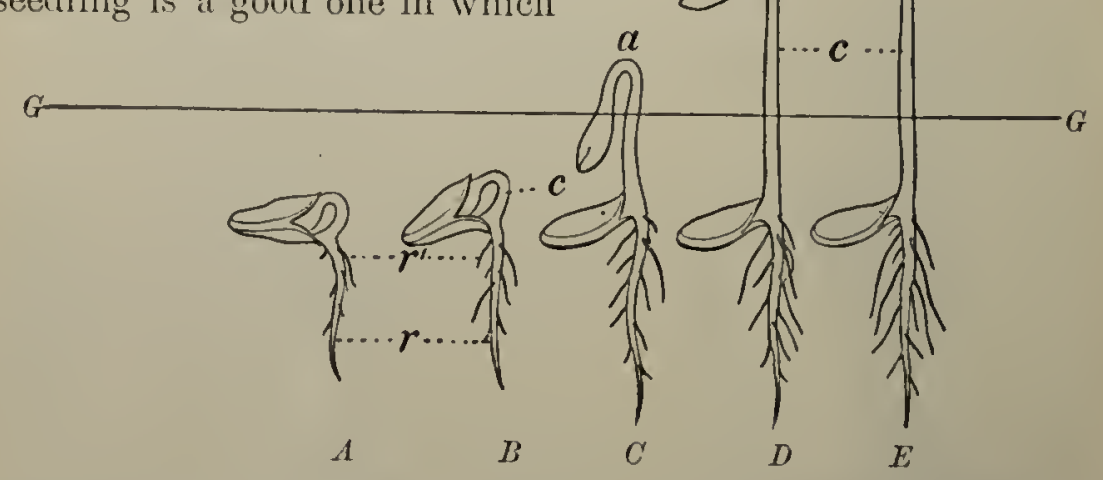

FIG. 8. Successive stages in the life history of the squash seedling $G G$, the surface of the ground; $r$, primary root; $r^{\prime}$, secondary ront; $c$, hypocotyl; $\alpha$, arch of hypocotyl; co, cotyledons

to study what may be called the arched type of germination. If the seed when planted is laid horizontally on one of its broad surfaces, it usually goes through some such changes of position as are shown in Fig. 8 .

The seed is gradually tilted until, at the time of their emergence from the ground (at $C$ ), the. cotyledons are almost vertical. The only part above the ground line $G G$, at this period, 
is the arched hypocotyl. Once out of ground, the cotyledons soon rise, until (at $E$ ) they are again vertical, but with the other end up from that which stood highest in $C$. Then the two cotyledons separate until they once more lie horizontally, pointing away from each other.

Whether the first part of the seedling to emerge from the ground is a pointed, rolled-up leaf, as in Indian corn, or the hypocotyl arch, as in Figs. 2 and 8, the result is to force the earth aside without injury to the plumule or the cotyledons.

15. What pushes the cotyledons up? A very little study of any set of squash seedlings, or even of Fig. 8, is sufficient to show that the portion of the plant where roots and hypocotyl are joined neither rises nor sinks, but that the plant grows both ways from this part (a little above $r^{\prime}$ in Fig. $8, A$ and $B$ ). It is evident that as soon as the hypocotyl begins to lengthen much it must do one of two things: either push the cotyledons out into the air or else force the root down into the ground as one might push a stake down. The plantlet, in passing from the stage shown at $A$ to that of $B$ and of $C$, develops many lateral roots, thus making it harder and harder for the root to be thrust bodily downward.

16. Getting rid of the seed coats. In seeds with thin coats the latter usually burst open irregularly and allow the opening cotyledons to escape. But in seeds with as thick a testa as that of the squash, and still more in the case of nuts, the cotyledons find their way out through a slit, or opening, which appears in a definite part of the seed. If for any reason the seed cont does not open, the embryo cannot grow. In many cases the moisture and freezing and thawing of a winter in the earth are almost essential to germination, and some seeds grow more promptly if they have been scorched by fire, or if they are cracked open before plantiug.

17. Discrimination between root and hypocotyl. It is not always easy to decide by their appearance and behavior what part of the seedling is root and what part is hypocotyl. In a 
seedling visibly beginning to germinate, the sprout, as it is commonly called, which projects from the seed might be either root or hypocotyl, or might consist of both together, so far as its appearance is concerned. A microscopic study of the cross section of a root, compared with one of the hypocotyl, would show decided differences of structure between the two. Their mode of growth is also different, as the pupil may infer from his own observations.

18. Final position of the cotyledons. As soon as the young plants of squash, bean, and pea liave reached a height of three or four inches above the ground, it is easy to recognize important differences in the way in which they set out in life.

The cotyledons of the squash increase greatly in surface, acquire a green color and a generally leaf-like appearance, and, in fact, do the work of ordinary leaves. In such a case as this the appropriateness of the name seed leaf is evident enough, one recognizes at sight the fact that the cotyledons are actually the plant's first lenves. In the bean the leaf-like nature of the cotyledons is not so clear. They rise ont of the ground like the squash cotyledons, but then gradually shrivel away, though they nay first turn green and somewhat leaf-like for a time.

In the pea, as in the acorn, the horse-chestnut, and many other seeds, we have quite another plan, - the underground type of germination. Here the thick cotyledons no longer rise above ground at all, because they are so gorged rith food that they could never become leaves; but the young stem pushes rapidly up from the surface of the soil.

19. Development of the plumule. The development of the plumule seems to depend somewhat on that of the cotyledons. The squash seed has cotyledons which are not too thick to become useful leaves, and so the plant is in no special haste to get ready any other leaves. The plumule, therefore, cannot be found with the magnifying glass in the unsprouted seed, and is almost microscopic in size at the time when the hypocotyl begins to show outside of the seed coats. 
In the bean, pea, and corn, on the other hand, since the cotyledons cannot serve as foliage leaves, the later leaves must be pushed forward rapidly. In the bean the first pair are already well formed in the seed. In the pea they cannot be clearly made out, since the young plant forms several scales on its stem before it produces any full-sized leaves, and the embryo contains only hypocotyl, cotyledons, and a sort of knobbed plumule, well developed in point of size, representing the lower, scaly part of the stem.

20. Root, stem, and leaf. By the time the seedling is well out of the ground the plant body, in most cases, possesses the three kinds of vegetative oryans, or parts essential to growth, of ordinary seed plants; that is, the root, stem, and leaf, or, as they are sometimes classified, root and shoot. All of these organs may multiply and increase in size as the plant grows older, and their mature structure will be studied in later chapters; but some facts concerning them can best be learned by watching their growth from the outset.

21. Elongation of the root. We know that the roots of seedlings grow pretty rapidly from the fact that each day finds them reaching visibly farther down into the water or other medium in which they are planted. A sprouted WVindsor bean in a vertical thistle tube will send its root downward fast enough so that ten minutes' watching through the microscope will suffice to show growtl.

22. Root hairs. Tery young seedlings of the grains, or of mustard or red clover, afford convenient material for studying root hairs. These are most abundantly developed when the seed is sprouted in air that is not very moist. Only a certain zone of the young root is covered with live hairs; the younger portions have not developed them and the older portions show only dead ones. Examination with a good lens or a low power of the microscope shows the gradual lengthening of the liairs, from very young ones near the root tip to full-grown ones fartlier up. 
The root hairs in plants growing under ordinary conditions are surrounded by the moist soil and wrap themselves around microscopical particles of earth (Fig. 9). Thus they are able rapidly to absorb through their thin walls the soil water, with whatever mineral substances it has dissolved in it.

23. The young stem. The hypocotyl, or portion of the stem which lies below the cotyledons, is the earliest formed portion

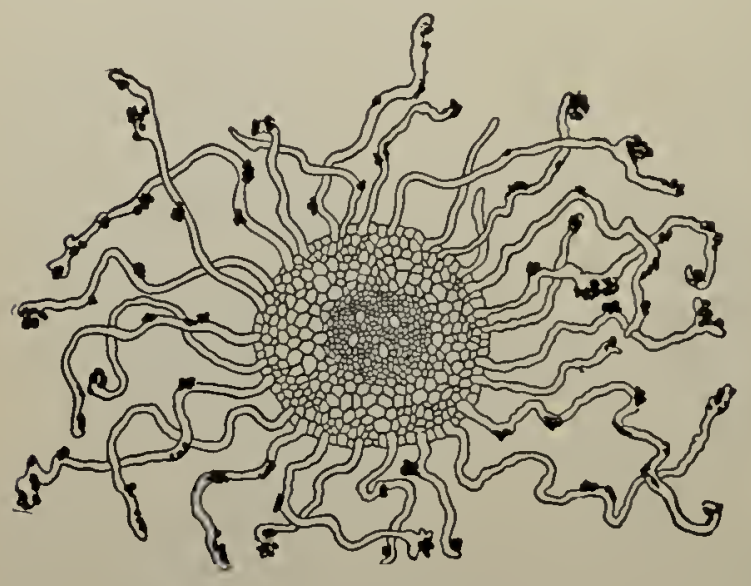

Fig. 9

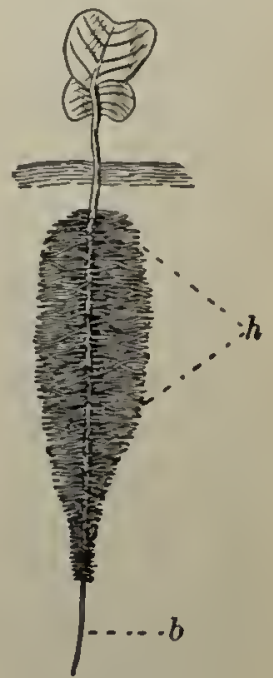

FIa. 10

F1g. 9. Cross section of a root

A good deal magnified, showing root hairs attached to particles of soil, and sometimes enwrapping these particles. - After Frank and Tschirch

Fig. 10. A turnip seedling, with the cotyledons developed into temporary leaves

$h$, root hairs from the primary root; $b$, bare portion of the root, on which no hairs have as yet been prodnced

of the stem. Sometimes this grows but little; often, however, the hypocotyl lengthens enough to raise the cotyledons well above ground, as in Fig. 10.

The later portions of the stem are considered to be divided into successive sections called nodes (places at which a leaf, or a scale which represents a leaf, appears) and internodes (portions between the leaves). 
The stem increases in lengtl by the simultaneous elongation of several internodes, as shown by Fig. 11. It will be noticed that in the plant figured the greatest increase in length is neither in the oldest nor the youngest internodes wlich are growing at all, but in an intermediate region.

Every portion of the entire shoot, shown in the figure, has elongated except the interval 21-22.

Counting from the top the lengthening of several of the segments is as follows:

$$
\begin{aligned}
& \text { INTERYALS } \\
& \text { Per Cent lncrease }
\end{aligned}
$$

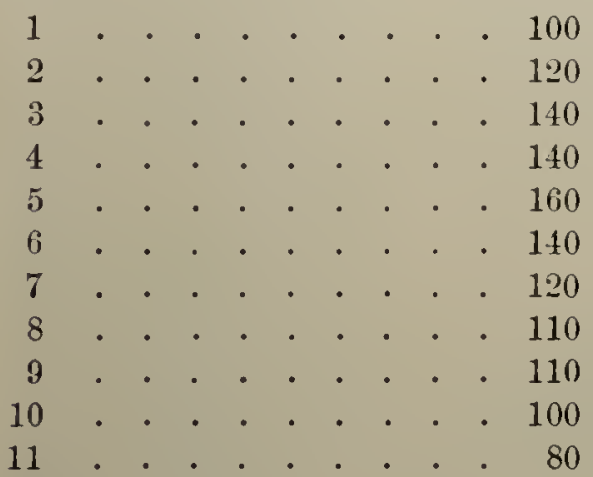$$
\text { IX LENGTII }
$$

24. The first leaves. The cotyledons are, as already explained, the first leaves which the seedling possesses. Even if a plumule is found well developed in the seed, it was formed after the cotyledons. In tliose plants whicl have so much food stored in the cotyledons as to render them unfit ever to become useful foliage leaves, as in the pea, there is

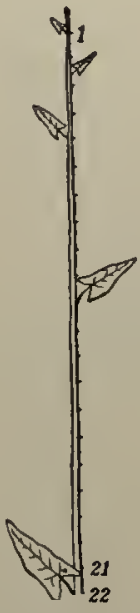

A

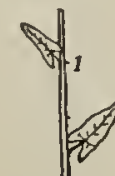

Fig. 11. Growth in a horizontal shoot of hedge bindweed 1

$A$, the shoot divided by ink marks into 22 equal segments; $B$, the same, twenty-four hours later.After Bonnier and Sablon little or notling in the color, shape, or general appearance of the cotyledon to make one think it really a leaf, and it is only by studying many cases that the botanist is enabled to class all

1 Convolvulus sepium. 
eotyledons as leares in their nature, even if they are quite unable to do the ordinary work of leares. In seeds whieh have cndosperm, or food stored outside of the embryo, the cotyledons usually become green and leaf-like, as they do, for example, in the four-o'elock, the morning-glory, and the buekwheat; but in the seeds of the true grains, which eontain endosperm, as in the familiar instance of Indian eorn, a large portion of the single cotyledon remains throughout as a thiekish mass buried in the seed. In a few cases, as in the pea, there are seales instead of true leaves formed on the first nodes above the eotyledons, and

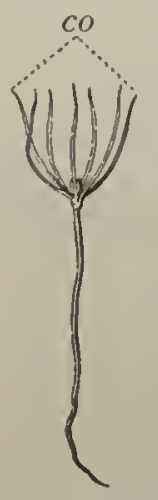

Fı. 12. Germinating pine co, cotyledons it is only at about the third node above that leaves of the ordinary kind appear. In the bean and some other plants which in general bear one leaf at a node along the stem, there is a pair produced at the first node above the eotyledons, and the leaves of this pair differ in shape from those which arise from the succeeding portions of the stem.

\section{Classification of plants by the number of} their cotyledons. In the pine family the germinating seed often displays more than two cotyledons, as shown in Fig. 12; in the majority of eommon seed plants the seed contains two eotyledons, while in the lilies, the ruslies, the sedges, the grasses, and some other plants there is but one eotyledon. Upon these faets is based the division of the largest assemblage of seer plants, angiosperms, into two great groups: the dicotyledonous plants, which have two seed leaves, and the monocotylcdonous plants, which have one seed leaf. Other important differences nearly always aceompany the differenee in number of cotyledons, as will be seen later. 


\section{CHAPTER IV}

\section{ROOTS}

26. Origin of roots. The primary root originates from the lower end of the hypocotyl, as the student learned from his own observations on sprouting seeds. The branches of the primary root are ealled secondary roots, and the branches of these are known as tertiary roots. Those roots which occur on the stem or in other unusual places are known as adventitious roots. The roots which form so readily on cuttings of willow, southernwood, Tropæolum, French marigold, cultivated "geranium" (l'elargonium), Tradescantia, and many other plants, when placed in damp earth or watcr, are adrentitious.

27. Aërial roots. While the roots of most familiar plants grow in the earth, thcre are others which are formed in the air, called aerrial roots. They serve various purposes: in some tropical air plants (Fig. 13) they fasten thic plant to the tree on which it establishes itself, as well as take in 
water which drips from branches and trunks above them, so that these plants require no soil and grow suspended in mid air from trees which serve them merely as supports; many such air plants are grown in greenhouses. In such plants as the ivy (Fig. 14) the aërial ro $九$, which are also adventitious, hold the plant to the wall or other surface up which it climbs.

In the Indian corn (Fig. 15) roots are sent out from nodes at some distance above the ground and descend until they enter

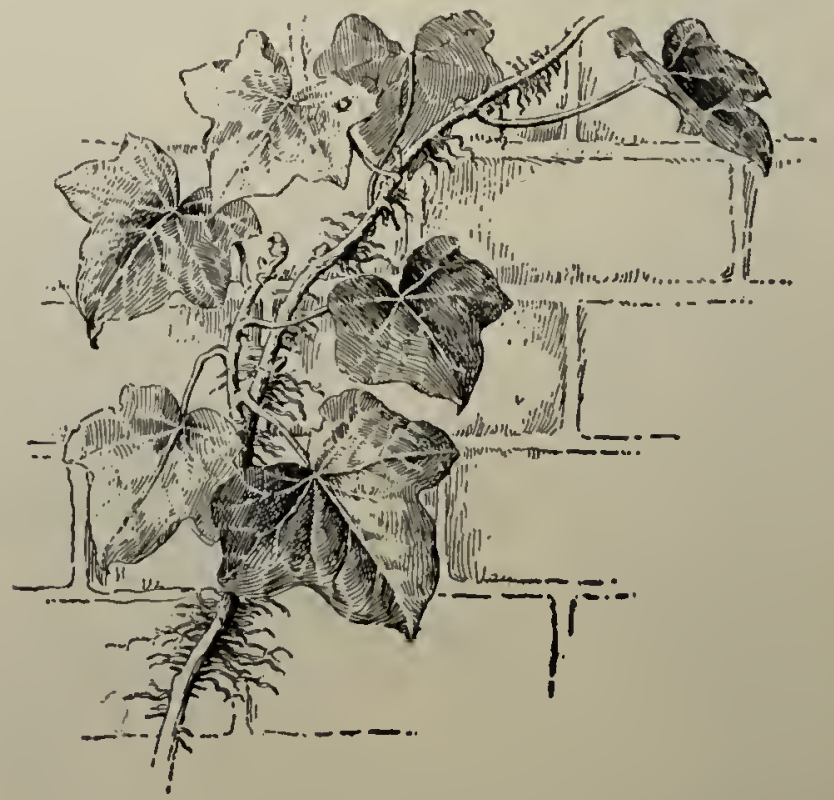

Fra. 14. Aërial, adventitious routs of the ivy

the ground. They scrve to anchor the cornstalk so that it may resist the wind, and to supply additional water to the plant. They often produce no rootlets until they reach the ground.

28. Water roots. Many plants, such as the willow, readily adapt their roots to live either in earth or in water, and some, like the little floating duckweed, regularly produce roots which are adapted to live in water only. 'These water roots often show large and distinct shcaths on the ends of the roots, as, for instance, in the so-called water hyacinth (Eichhornia). 


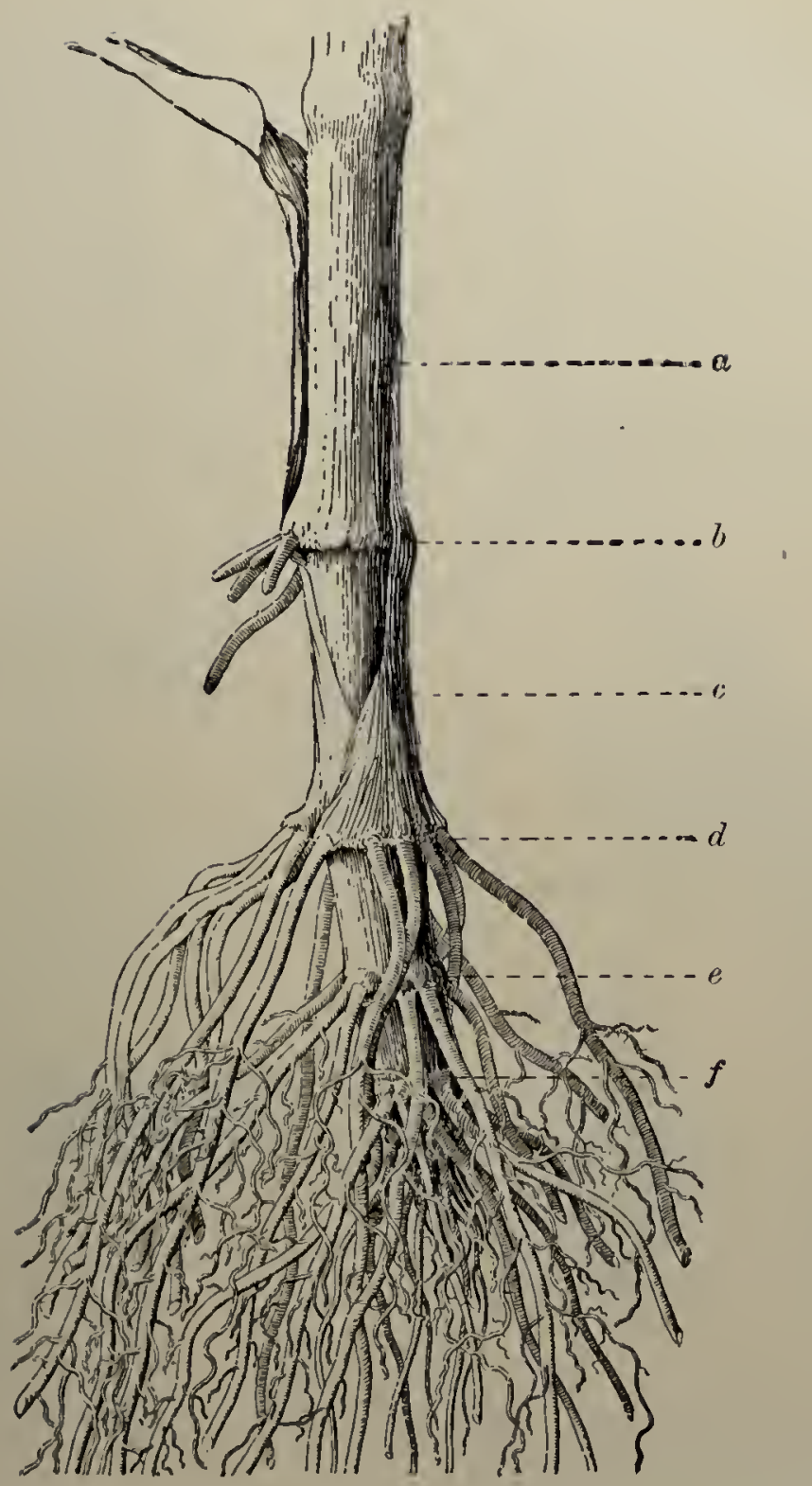

FıG. 15. Lower part of stem and roots of Indian corn, showing aërial roots ("brace roots")

$x, c$, internodes of the stem; $b, d, e, f$, nodes of various age bearing roots. Most of these started as aërial roots, but all except those from $b$ have now reaehed the earth 
29. Parasitic roots. The dodder, the mistletoe, and a good many other seed plants are called parasites, since they live, at least in part, upon food which they steal from other plants

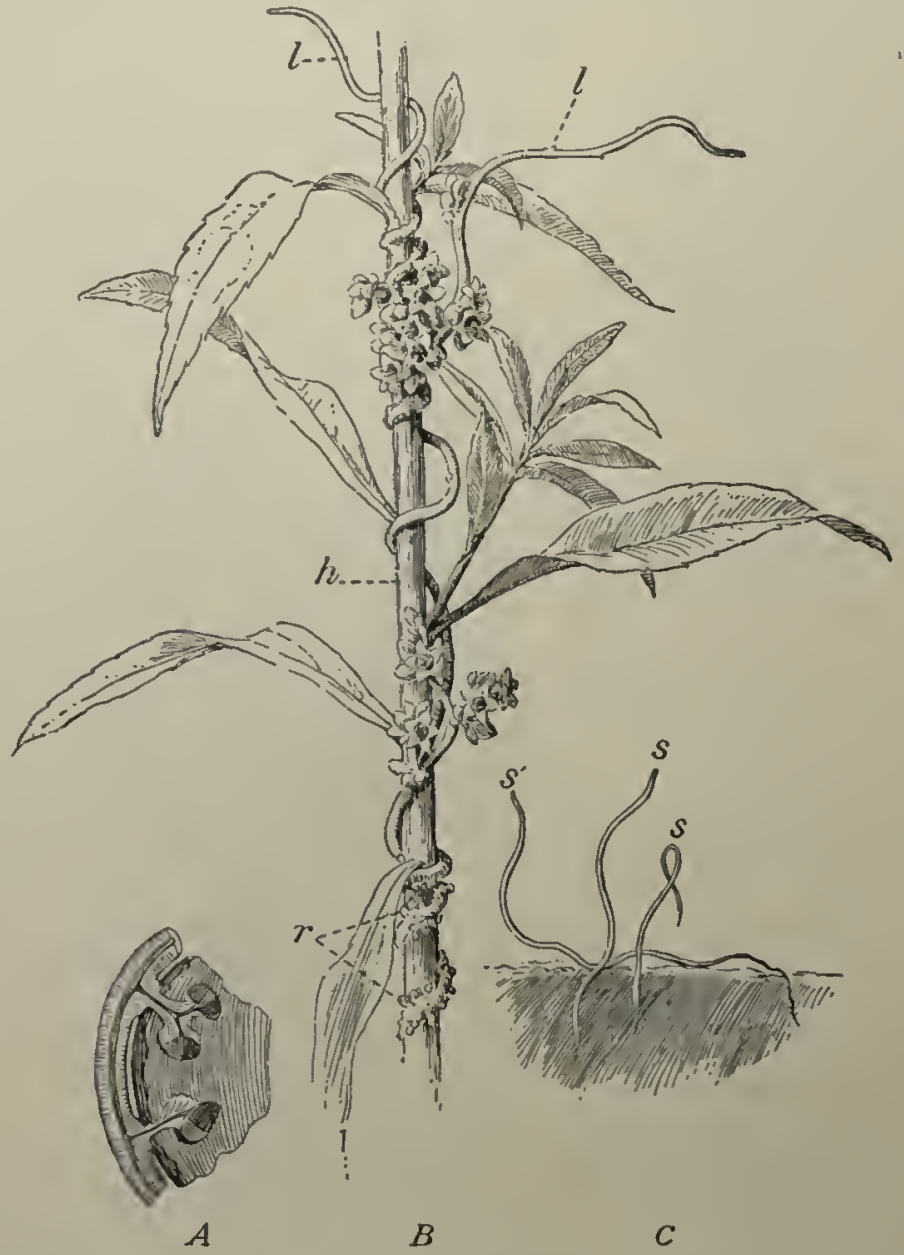

FIG. 16. Dodder, a parasitic seed plant

$A$, magnified section of stem penetrated by roots of dodder; $B$, dodder upon a golden-rod stem; $C$, scedling dodder plants growing in earth; $h$, stem of host; $l$, scalc-like leaves; $r$, sueking roots, or haustoria; $s$, seedlings. $A$ and C'after Straslurger

called their hosts. Parasites develop peculiar roots, which penetrate the tissues of the host and form most intimate comnections with the interior portions of the stem or root of the latter. 
In the dodder, as is shown in Fig. 16, the seedling parasite is admirably adapted to the conditions under which it is to live. Rooted at first in the ground, it develops a slender, leafless stem, which, leaning this way and that, no sooner comes into permanent contact with a congenial host than it produces sucking roots at many points, gives up further growth in its soil roots, and lengthens rapidly on the strength of the supplies of readymade sap which it obtains from the host.

30. Forms of roots. The primary root is that which proceeds like a downward prolongation directly from the lower end of the

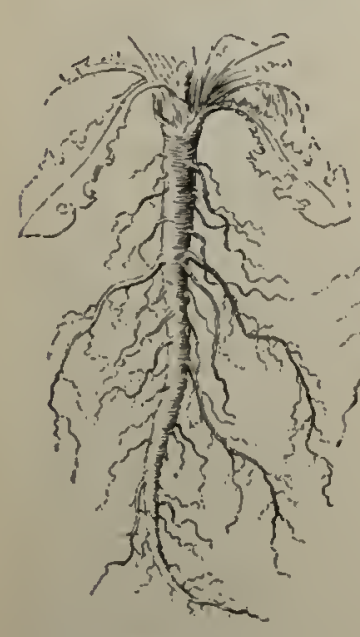

FIG. 17

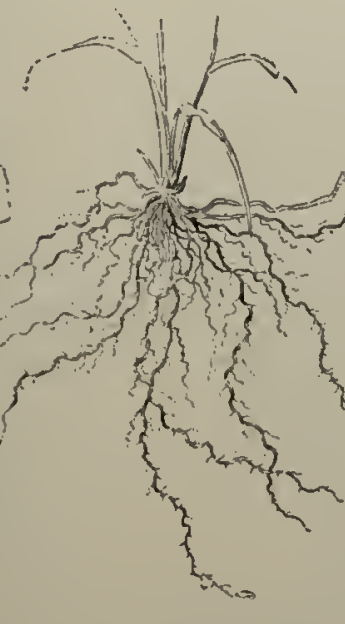

FIG. 18

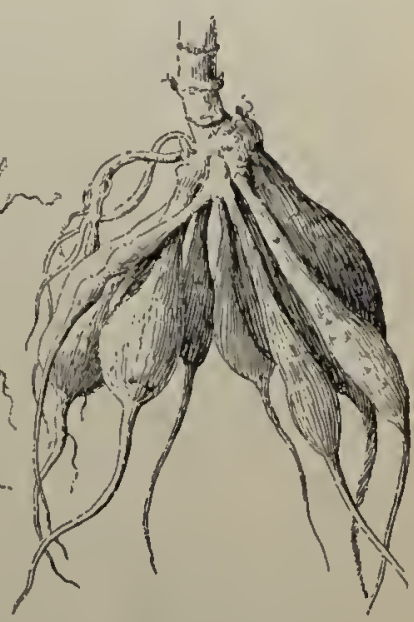

FIG, 19

$\Lambda$ tap root Fibrous roots Fleshy and cilustered roots

hypocotyl. In many cases the mature root system of the plant contains one main root much larger than any of its branches. This is called a top root (Fig. 17).

Such a root, if much thickened, may assume some such form as that of the carrot, parsnip, bect, turnip, or radish, and is called a fleshy root. Some plants produce a cluster of roots from the lower end of the lrypocotyl. Such roots often become thickened, as in the sweet potato and the dahlia (Fig. 19).

Roots of grasses, ctc., are thrcad-like, and known as fibrous roots (Fig. 18). 
31. General structure of roots. The general structure of the very young root can be partially made out by examining the entire root with a moderate magnifying power. Often the whole is sufficiently translucent to allow the interior as well as the

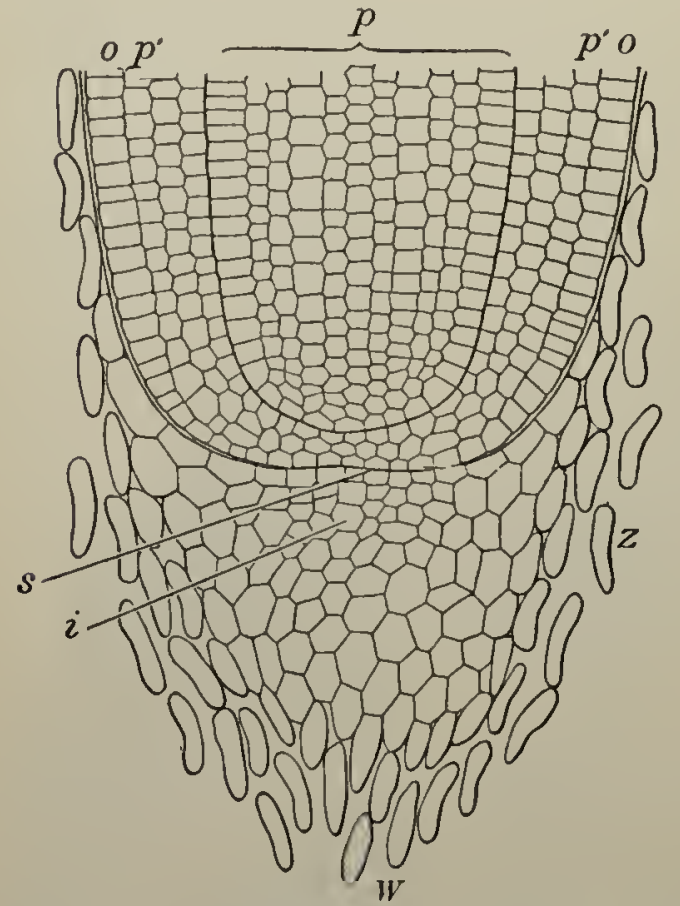

FIG. 20. Lengthwise section (somewhat diagrammatic) through root tip of Indian corn. $\times$ about 130

$W$, root cap; $i$, younger part of eap; $z$, dead cells separating from cap; $s$, growing point; $o$, epidermis; $p^{\prime}$, intermediate layer between epidermis and central cylinder; $p$, central cylinder, in which the fibro-vascular bundles arise. - After Wiesner exterior portion to be studied while the root is still alive and growing.

The main bulk of the root is composed of a central cylinder and the cortical portion which surrounds it. The outermost part of the cortex is a layer of cells forming a thin skin known as the epidermis. The tip of the root is covered by a mass of loosely attached cells forming the protective root cap.

On examining Figs. 20 and 21, the cylinders of which the root is made up are easily distinguished, and the main constituent parts of each can be made ont withont much trouble. The epidermal cells are seen to be somewhat brick-shaped, many of them provided with extensions into root hairs. Inside the epidermis lie several layers of rather globular, thin-walled cells, and inside these a boundary layer between the cortical or bark portion of the root and the central cylinder. This latter region is especially marked by the presence 
of certain groups of cells, shown at $w, d$, and $b$ (Fig. 21), the two former serving as channels for air and water, the latter (and $w$ also) giving toughness to the root.

Roots of shrubs and trees more than a year old will be found to have increased in thickness by the process described in Chapter VII, and a section may look unlike that shown in Fig. 21.

\section{Storage of re-} serve material in roots. Many roots contain large quantities of stored plant food, usually in the shape of starch, sugar, proteids, or all three together. Parsnips, carrots, turnips, and sweet potatoes are familiar examples of storage roots.

Beet roots contain so much sugar that

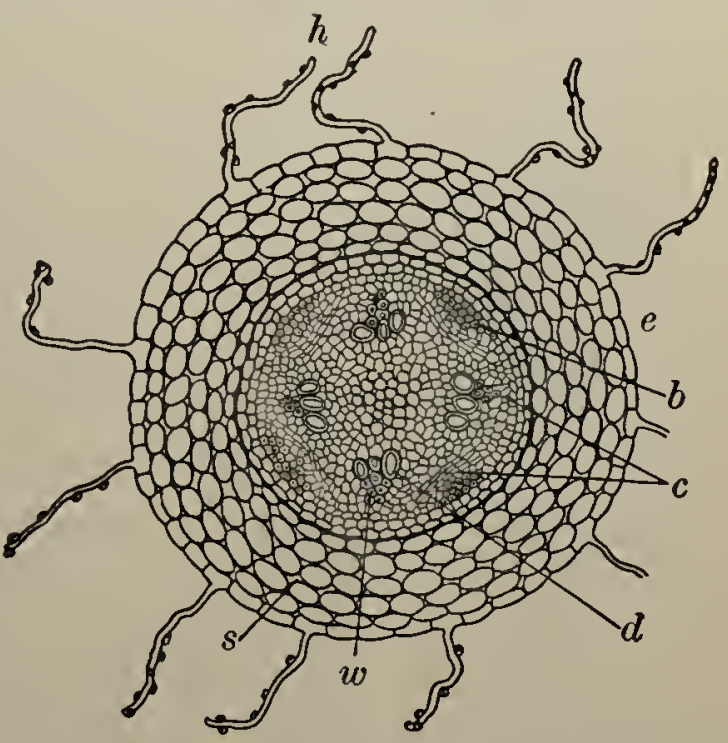
a large part of the FIG. 21. Much magnified cross section of a young sugar supply of Europe, and an in- $h$, root hairs with adhering bits of sand; $e$, epicreasing portion of our own supply, is obtained from them. Oftentimes the bulk of a fleshy root is exceedingly large as compared with that of the parts of the plant above ground.

Not infrequently roots have a bitter or nauseous taste, as in the case of the chicory, the dandelion, and the rhubarb; and a good many, like the monkshood, the yellow jasmine, and the pinkroot, are poisonous. Evidently the plant may be benefited by the disgusting taste or poisonous nature of its roots, which renders them uneatable. 
33. Use of the food stored in fleshy roots. The parsnip, beet, carrot, and turnip are biemnial plants; that is, they do not produce seed until the second summer or fall after they are planted.

The first season's work consists mainly in producing the food which is stored in tlie roots. To such storage is due their characteristic fleshy appearance. If the root is planted in the following spring, it feeds the rapidly growing stem which proceeds

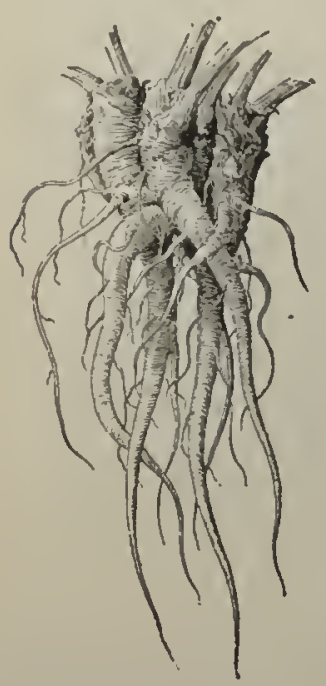

Fig. 22. Fleshy roots of garden riubarb. About one fifteenth natural size from the bud at its summit, and an abundant crop of flowers and seed soon follows; while the root, if examined in late summer, will be found to be withered, with its store of reserve material quite exhausted.

The roots of the rhubarb (Fig. 22), the sweet potato, and of a multitude of other perennials, or plants which live for many years, contain much stored plant food. Many such plants die to the ground at the beginning of winter, and in spring make a rapid growth from the inaterials laid up in the roots.

34. Extent of the root system. The total length of the roots of ordinary plants is much greater than is usually supposed. They are so closely packed in the earth that only a few of the roots are seen at a time during the process of transplanting, and when a plant is pulled or dug up in the ordinary way a large part of the whole mass of roots is broken off and left behind. A few plants have been carefully studied to ascertain the total weight and length of the roots. Those of winter wheat have been found to extend to a depth of seven feet. By weighing the whole root system of a plant, and then weighing a known length of a root of avcrage diameter, the total length of the roots may be estimated. In this way the roots of an oat plant have been calculated to measure about 
154 feet; that is, all the roots, if cut off and strung together end to end, would reach that distance.

Single roots of large trees often extend horizontally to great distances, but it is not often possible readily to trace the entire depth to which they extend. One of the most notable examples of an enormously developed root system is found in the mesquite of the far Southwest and Mexico. When this plant grows as a shrub, reaching the height, even in old age, of only two or three feet, it is. because the water supply in the soil is very scanty. In such cases the roots extend down to a depth of sixty feet or more, until they reach water, and the Mexican farmers in digging wells follow these roots as guides. Where water is more abundant, the mesquite forms a good-sized tree, with much shorter roots.

35. The absorbing surface of roots. The soil roots of most seed plants are provided with a highly efficient means for absorbing water in the slrape of a coating of root hairs, with which their younger portions are thickly covered. Some idea of their abundance may be gathered from the estimate that on the hairbearing portions of the roots of the common pea about 1437

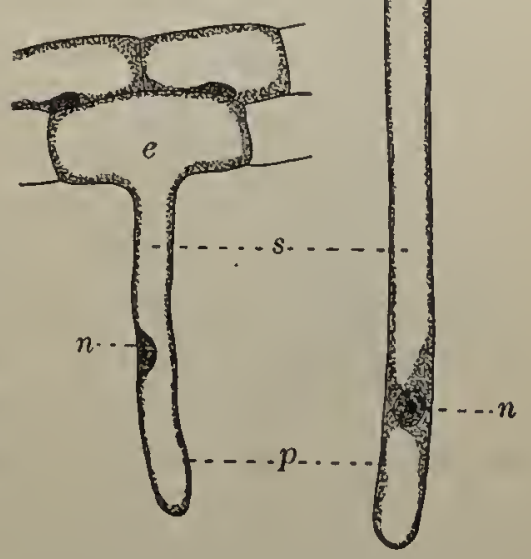

A Fig. 23

B

$A$, a very young root hair; $B$, an older one (both greatly magnified); e, cells of the epidermis of the root; $n$, nucleus; $s$, watery cell sap; $p$, protoplasm lining the cell wall. - After Frank hairs occur on every hundredth of a square inch of surface.

A root hair is an extremely thin-walled tubc, springing from an cpidermal cell, into which it opens. The way in which the cells give lise to hairs is well shown in Figs. 21 and 23 . 
Most water roots are destitute of root hairs, and absorb water through the general epidermal surface of their younger portions.

Aërial roots, like those shown in Fig. 13, are in many cases provided with an external absorbent layer of spongy tissue, by means of which they retain some of the water which trickles down them during rains. This stored moisture they gradually give up to the plant.

36. Absorption of water by roots. Just how much water some kinds of plants give off (and therefore absorb) per day will be discussed when the uses of the leaf are studied. For the present it is sufficient to state that even an annual plant during its lifetime absorbs through the roots very many times its own weight of water. Grasses have been known to take in their weight of water in every twenty-four hours of warn, dry weather. This absorption in most soil roots takes place mainly through the root hairs. Their walls are extremely thin, and have no holes or pores visible under even the highest power of the microscope, yet the water of the soil penetrates very rapidly to the interior of the root hairs. The soil water brings with it all the substances which it can dissolve from the earth about the plant; and the closeness with which the root hairs cling to the particles of soil, as shown in Figs. 9 and 21, must cause the water which is absorbed to contain more foreign matter than underground water in general does, particularly since the roots give off enough weak acid from their surface to corrode the surface of stones which they enfold or cover.

37. Substances required by the plant for nutrition. Ordinary seed plants require for their nutrition ten of the chemical elements. By far the greater part of the weight of the plant body is usually due to compounds of carbon, hydrogen, oxygen, and nitrogcn. Besides these there are present the six elements, sulphur, phosphorus, potassium, calcium, magncsium, and iron. In ordinary green meadow grass there is about 80 per cent of water and 20 per cent of dry matter. On drying the grass into hay and then burning the latter, some 2 per cent of ash will remain, 
and in this will be found the six elements - sulphur, phosphorus, potassium, calcium, magnesium, and iron - in the form of ineombustible salts (sulphates, phosphates, and so on).

The plant gets its carbon and oxygen from the air, as will be explained in Chapter XII. Deprived of air, all green plants soon die. The hydrogen is obtained from water.

The importance of the six ashforming constituents mentioned above is most readily studied by means of water cultures in which plants are grown with suitable proportions of dissolved salts. If any one of the six elements is onitted from a solution, the plants grown in it are dwarfish and unhealthy.

Ordinary soil water contains sufficient salts in solution for the nutrition of plants, but not always enough to stimulate rapid growth.

38. Sap pressure. Not only does much water gain admission to the plant through the roots, but under ordinary circumstanees it is found forcing its way on, into, and through the stem (for explanation see Secs.48-51). The

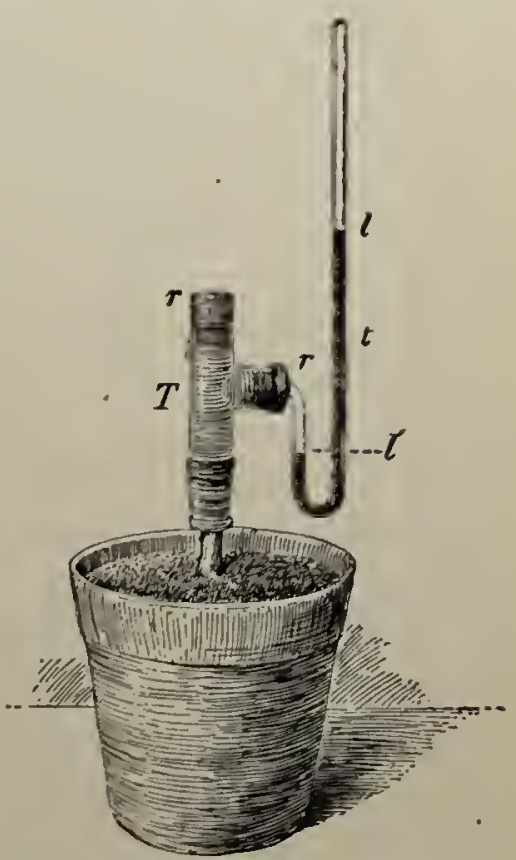

Fıa. 24. $\Lambda$ pparatus to measure sap pressure

$T$, large tube fastened to the stump of the dahlia stem by a rubber tube; $r, r$, rubber stoppers; $t$, bent tube containing mercury ; $l^{\prime}, l$, upper and lower level of mercury in $T$. - After Saclis force ealled sup pressure with which the upward-flowing current of water presses may be estimated by attaehing a mercury gauge to the root of a tree or the stem of a small sapling. This is best done in early spring after the thawing of the ground, but before the leaves have appeared. The experiment inay also be performed indoors upon almost any plant with a moderately firm stem, through which the water from the soil rises freely. 
A dahlia plant or a tomato plant answers well, though the sap pressure from one of these will not be nearly as great as that from a larger shrub or a tree growing out of doors. In Fig. 24 the apparatus is shown attached to the stem of a dahlia. The difference of level of the mercury in the bent tube serves to measure the pressure. For every foot of difference in level there must be a pressure of nearly six pounds per square inch on the stump at the base of the tube $T .^{1}$

A black birch root tested at the end of April has given a sap pressure of thirty-seven pounds to the square inch. This would sustain a column of water about eighty-six feet high.

39. Root absorption and temperature of the soil. The temperature of roots and the earth about them has much to do with the rate at which they absorb water. Some plants can absorb it at temperatures as low as $25^{\circ} \mathrm{F} .\left(-4^{\circ} \mathrm{C}\right.$.), while others cannot do so at any temperature below $39^{\circ} \mathrm{F} .\left(4^{\circ} \mathrm{C}\right.$.). This fact of the power to get water from the soil ceasing at temperatures in the neighborhood of the freezing point has most important consequences, since it implies that a plant may die for lack of water with its roots immersed in cold, wet soil. Hence the parched appearance often noticed in leaves killed by frost.

40. Movements of young roots. The fact that roots usually grow downward is so familiar that we do not generally think of it as a thing that needs discussion or explanation. Since they are pretty flexible, it may seem as though young and slender roots merely hung down by their own weight, like so many bits of wet cotton twine. But the root of a young Windsor bean seedling or of a sprouting pea will force itself down into mercury. By comparing the weights of equal bulks of mercury and Windsor bean roots, it is found that the mercury is about fourteen times as heavy as the substance of the roots. Evidently, then, the submerged part of the root must have been held under by a force about fourteen times its own weight.

${ }^{1}$ For a more accurate method see IIandbook. 
A more accurate measurement of the force exerted by the root may be made by confining it so it cannot bend, and letting it push down on a spring. In this way it is found that the root of the Windsor bean can push with a pressure of about ten ounces.

Making fine equidistant cross marks with ink along the upper and the lower surface of a root that is about to bend downward at the tip readily shows that those of the upper series soon come to be farther apart, - in other words, that the root is foreed to bend downward by the more rapid growth of its upper as compared with its under surfaee.

41. Geotropism. The property which plants or their organs manifest, of assuming a definite direction with reference to gravity, is called geotropism. When, as in the case of the primary root, the effect of gravity is to make the part, if unobstructed, turn or move downward, we say that the geotropism is positive. If the tendency is to produce upward movement, we say that the geotropism is negative; if horizontal movement, that it is lateral. It was stated in the preceding section that the direct cause of the downward extension of roots is unequal growth. We might easily suppose that this unequal growth is not due to gravity, but to some other cause. To test this supposition, the simplest plan, if it could be carried out, would be to remove the plants studied to some distant region where gravity does not exist. This of course cannot be done, but we can easily turn a young seedling over and over so that gravity will act on it now in one direction, now in another, and so leave no more impression than if it did not act at all. Or we can whirl a plant so fast that not only is gravity done away with, but another force is introduced in its place. If a vertical wheel, like a carriage wheel, were provided with a few loosely fitting iron rings strung on the spokes, when the wheel was revolved rapidly the rings would all fly out to the rim of the wheel. So in Fig. 25 it will

1 Gravity means the pull which the earth exerts upon all objects on or near its surface. 
be noticed that the growing tips of the roots of the sprouting peas point almost directly outward from the center of the disk

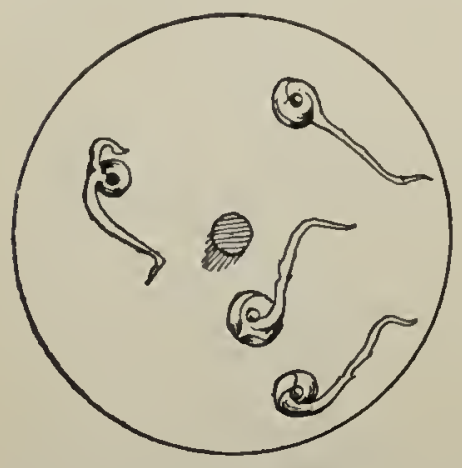

Fig. 25. Sprouting peas on a rapidly whirling disk

The youngest portions of the roots all point directly away from the axis about which they were revolved. - After Detmer on which the seedlings are fastened. In this case the so-called "centrifugal force" due to the rotation of the wheel is sufficient wholly to overcome geotropism.

42. Direction taken by secondary roots. As the student has already noticed in the seedlings which he has studied, the branches of the primary root usually make a considerable angle with it (Fig. 2). Often they run out for long distances almost horizontally. This is especially eommon in the roots of forest trecs, above all in eone-bearing trees, such as pines and hemlocks (Fig. 26). This horizontal, or nearly horizontal, position of large secondary roots is the

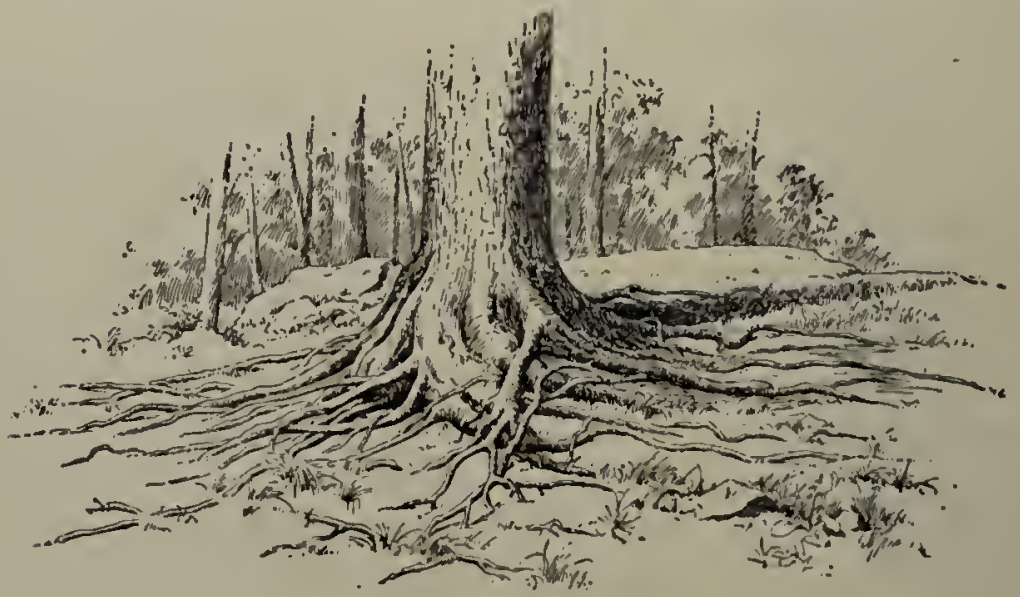

FIG. 26. Roots of a white pine

most advantageous arrangement to make them useful in staying or guying the stem above to prevent it from being blown over by the wind. 
43. Fitness of the root for its position and work. The distribution of material in the woody roots of trees and shrubs and their behavior in the soil show many adaptations to the conditions by which the roots are surrounded. The growing tip of the root, as it pushes its way through the soil, is exposed to bruises; but these are largely warded off by the root cap. The tip also shows a remarkable sensitiveness to contact with hard objects, so that when touched by one it swerves aside and thus finds its way downward by the easiest path. - Roots with an unequal water supply on either side grow toward the-moister soil; when unequally heated they grow in the direction of the : most desirable temperature, and they, usually grow away from 3 the light. Roots are very tough, because they need to resist strong pulls, but not as stiff as stems and branches of the same size, because they do not need to withstand sidewise pressure, acting from one side only. The corky layer which covers the outsides of roots is remarkable for its power of preventing evaporation. It must be of use in retaining in the root the moisture which otherwise must be lost on its way from the deeper rootlets (which are buried in damp soil), through the upper portions of the root system, about which the soil is often very dry. 


\section{CHAPTER V}

\section{SOME PROPERTIES OF CELLS AND THEIR FUNCTIONS IN THE ROOT}

44. Definition of cell. This is not the best place to consider the nature of cells in much detail (see Chapter XrinI); but some of the facts learned in Chapter Ir cannot be understood without a few words of explanation of cell structure and functions.

Protoplasm is the nitrogenous living substance of which the most rapidly growing parts of plants are mainly composed. The activities of the plant are due to the peculiar qualities and powers of protoplasm. A cell is a unit of protoplasm, called a protoplast. The protoplast of plants is usually inclosed in a case or covering whose walls (cell walls) are composed of a substance known as cellulose. Each protoplast usually contains a single denser protoplasmic structure, called the muclcus.

In form and size cells vary greatly. Those of the root hair (Fig. 23) are good examples of the slender, thread-like form; those of Fig. 27 well illustrate forms commonly assumed when cells are pressed upon by others on all sides, as they usually are in the interior portions of the organs of higher plants.

45. Growth and reproduction. The most remarkable property of cells is their power of growth and reproduction. Growth results not only from an increase in the size of cells but also in their number as a result of ccll division. This is the separation of a protoplast, generally into two independent protoplasts or daughter cells, and is the fundamental cause of all growth and development. The full-grown seed plant, composed of millions of cells, arises from the embryo (with perhaps only a few thousand), which had its beginning in a single cell. Cell division is preceded by division of the nucleus (Fig. 170). 
Reproduction, or the formation of new organisms similar to the parents, is possible only for protoplasm, not fol any other known substance.

46. Irritability. Another characteristic of protoplasm is its irritability. $\mathrm{By}$ this is meant its power of responding in some way to an application of energy which serves as a stimulus. A famous plant physiologist ${ }^{1}$ has illustrated the matter very simply thus: A woundup alarm clock, which is not going, is given a shake (stimulus), whicl starts the clock, and after an interval of time (latent

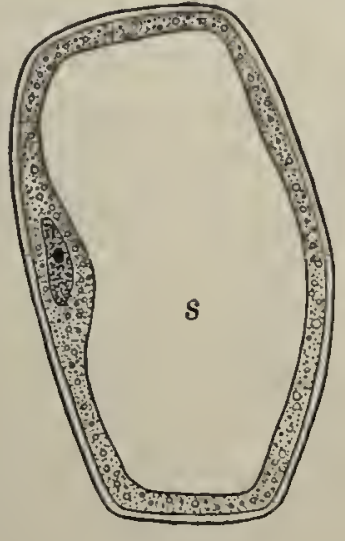

C
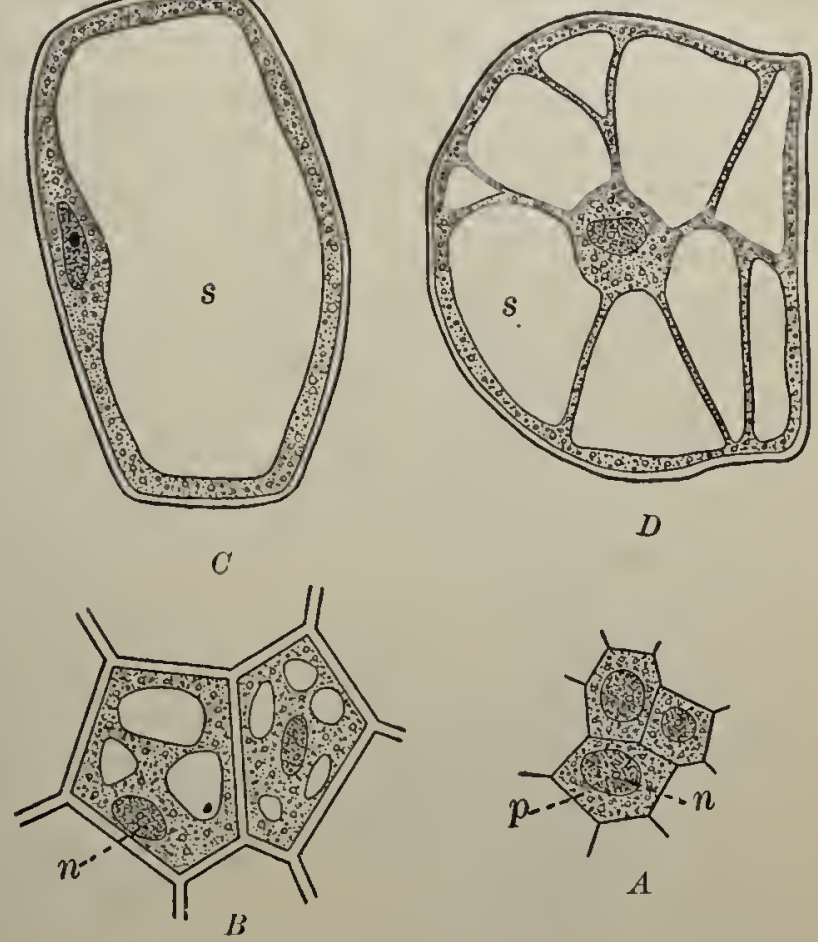

Fig. 27. Protoplasts in ovule and fruit of snowberry (Symphoricarpus racemosus)

$A$, cells irom ovule $(\times 340) ; D$, cells from an ovule further developed $(\times 340) ; C, D$, cells from pulp of fruit $(\times 110)$; $n$, nucleus; $p$, protoplasm; $s$, cell sap. - After Prantl

In the young and rapidly growing cells $A$ and $B$ the cell sap is not present, or present only in small quantities, while in the older cells $C$ and $D$ it occupies a large portion of the interior of the cell

period) rings the alarm (result). The sensitiveness of the clock to any jar which sets it going corresponds to the irritability of living protoplasm. This extremely delicate responsiveness may be inanifested in a simple cell or in an organ or entire plant composed of multitudes of cells.

1 Professor W. Pfeffer, of Jeipzig, Germany. 
Some of the most important stimuli which call out manifestations of irritability in protoplasm are heat, light, electricity, gravity, pressure of external objects, and contact with substances which act chemically on the protoplasm. Many instances of irritability will come up in later chapters. A notable example of response to a stimulus is the beginning of germination in seeds subjected to a suitable degree of heat in presence of moisture.

The ways in which the responses to stimulation may show themselves are very numerous, and the same individual or organ may be favorably affected by a certain amount of a given stimulus and unfavorably by a greater amount of the same stimulus. Every one has had the experience of drawing near to a moderately heated stove in cold weather and then retreating from it when the fire grew too hot. So, too, certain microscopic unicellular plants, living in water, move toward the light until it reaches a certain intensity, but when that intensity is passed, they move in the opposite direction, toward the dark.

47. Selective absorption. Another extremely important power of live protoplasm is that of selective absorption. By this is meant the ability to take up from liquids or gases certain substances and leave unabsorbed other elements or compounds which are also present.

Thus plants of two different species, both growing in the same soil, usually take from it very various amounts or kinds of mineral matter. For instance, barley plants in flower and red clover plants in flower contain about the same proportion of mineral matter (left as ashes after burning). But the clover contains $5 \frac{2}{3}$ times as much lime as the barley, and the latter contains about 18 times as much silica as the clover. This difference must be due to the selective action of the protoplasm in the absorbing cells of the roots.

48. Osmosis. The process by which tro liquids of different densities separated by membranes pass through the latter and mingle, as soil water does with the liquid contents of root hairs, 
is called osmosis. It is readily demonstrated by experiments with thin animal or vegetable membranes. For instance, when prunes, raisins, or other dried fruit, are put in water to soak, water penetrates the outer skin and swells the seed or fruit, while some of the material from within comes out through the skin and flavors or discolors the water. If whole cranberries, cherries, or plums are put into boiling sirup, a similar exchange takes place, but in this case the fruit is shriveled.

A still better experiment is that with an egg from which a bit of the shell has been chipped away at the bottom, arranged as shown in Fig. 28. The entrance of water is shown by the rise of some of the contents of the egg in the tube.

\section{Inequality of osmotic} exchange. The nature of the two liquids separated by any given membrane determines in which direction the greater flow shall take place unless what would naturally be the direction of flow is overuled by the selective action of living protoplasm.

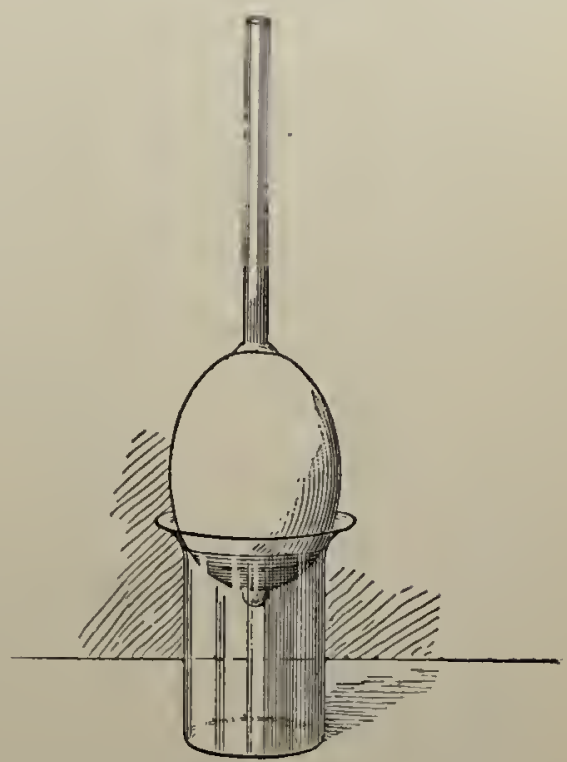

FIG. 28. Egg on beaker of water, to show osmosis

The tube is cemented to the eggshell, into which it opens. At the bottom a large piece of the shell has been chipped away, leaving the thin skin which lines the egg in contact with the water in the heaker

If one of the liquids is pure water and the other is water containing solid substances dissolved in it, the greater flow of liquid will be away from the pure water into the solution, and the stronger or denser the latter, the more unequal will be the flow. This principle is well illustrated by the egg-osmosis experiment. Another important principle is that substances which readily crystallize and are easily soluble, like salt or 
sugar, pass rapidly through membranes, while jelly-like substances, like white of egg, can hardly pass through them at all.

50. Study of osmotic action of living protoplasm; plasmolysis. The obvious parts of most living and growing plant cells are a cell wall, which is a skin or inclosure made of cellulose, and the living, active cell contents, or protoplasm (Sec. 44). Every one is familiar with cellulose in various forms, one of the best examples being that afforded by clean cotton. It is a tough, white, or colorless substance, and clemically rather inactive.

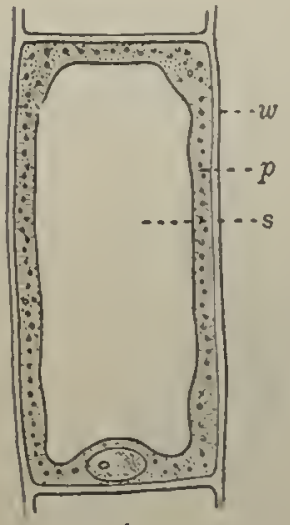

A

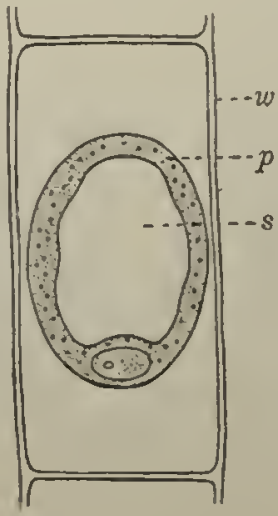

$B$ Often, in living cells, the spaces between strands and protoplasmic lining are filled with a watery liquid called the cell sap.

The action of living protoplasm in controlling osmosis is well shown by the process known as plasmolysis.

If thin-walled cells

FIG. 29. Cells from root of Indian com

$A$, in natural condition; $B$, plasmolyzed in 5 per cent solution of potassium nitrate; $w$, cell wall; $p$, denser part of protoplasm; $s$, cell sap. Much magnified. - After Pfeffer with liquid or semiliquid protoplasm, such as those of one of the pond scums, are put into a salt solution, the cell contents will shrink away from the cell wall (Fig. 168, li) because the direction of flow, toward the denser liquid, draws water out of the cell. Repeating the experiment with a cell which has been killed by a few minutes' immersion in a poisonous solution (e.g. of chromic acid) shows no plasmolysis.

So, too, slices of a red beet impart little color to water in which they are placed, but after the cells are killed by boiling the color comes out freely. 
51. Osmosis in root hairs. The soil water, practically identical with ordinary spring or well water, is scparated from the unore or less sugary or mucilaginous sap inside of the root hairs only by their delicate cell walls, lined with a thin layer of protoplasm. This soil water will pass rapidly into the plant, while very little of the sap will come out. The selective action, which causes the llow of liquid through the root hairs to be almost wholly inward, is due to the living layer of protoplasm, which covers the inner surface of the cell wall of the root hair. Traveling by osmotic action from cell to cell, a current of water derived from the root hairs is forced up through the roots and into the stem, somewhat as the contents of the egg was forced up into the tube shown in Fig. 28.

But thcre is this inportant difference in the two cases, that while the process in the tube was all due to the impulse received at the start from the egg mombrane, in the plant stem the original pressurc due to osmosis in the root hairs inay be affected by osmosis in countless thousands of cells higher up.

52. Behavior of roots due to irritability. In Chapter IV a little was said about the gcotropism of roots, their tendency to put themselves into the most favorable conditions as regards moisture, heat, and light, and their manner of aroiding obstacles. All these aetions are manifestations of irritability.

The subject of geotropism of roots is a very complicated one, but it seems pretty ccrtain that gruxity somehow acts as a stimulus on the sensitice cells of the root tip, this stimulus is trensmitted to the colls of the most rapidly growing portion of the root ("ittle frother barli), unequal grouth of the upper and under cells of this portion follows, and so the root is bent, if its position was not vertical in the beginning.

Moisture and heat (in the case of Indian corn u1, to $99.5^{\circ} \mathrm{F}$. or $37.5^{\circ} \mathrm{C}$ ) are farorable to the growth of roots, and so as stimuli prorluce growth towarl the souree of moisture or heat, while light is usually slightly unfavorable and therefore generally results in growth of the root towarl darkness. 


\section{CHAPTER VI}

\section{STEMS}

53. Nature of the stem. The work of taking in the raw materials which the plant makes into its own food is done mainly by the roots and the leaves. These raw materials are

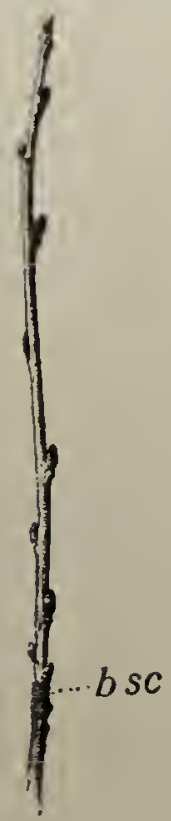

Yir. A quickly grown twig of r. he r r y, wi th lateral and terminal buds in October

b sc, bud-scale scars. All above these scars is the growth of the spring and summer of the same year taken from earth, from water, and from the air (see Chapter XII). The stem is that part or organ of the plant which serves to bring roots and leaves into communication with each other. In most seed plants the stem also serves the important purpose of lifting the leaves up into the sunlight, where they can best do their special work.

The student has already, in Chapter III, learned something of the development of the stem and the seedling; he has now to study the external and internal structure of the mature stem. Much in regard to this structure can be learned most easily from the examination of twigs and branches of our common forest trees in their winter condition.

54. Position of leaf buds. The winter buds of most of our trees and shrubs are formed at points on the twig just above the origins of the leafstalks, as shown in Fig. 79. After the fall of the leaves the buds by their positions indicate where the leaves were formerly attached. They may be arranged in pairs, a bud on one side of the stem and its mate exactly opposite, or they may form a spiral around 
the stem, as shown in Fig. 30. Since every leaf bud - that is, every bud which contains rudimentary leaves — will, if successful, grow into a branch, the position of the buds is most important in determining the shape of the tree.

55. Opposite branching. Trees with opposite leaves and buds show a tendency to form twigs in four rows about at right angles to each other along the sides of the branch, as shown in Fig. 31.

This arrangement will not usually be perfectly carried out, as most of the

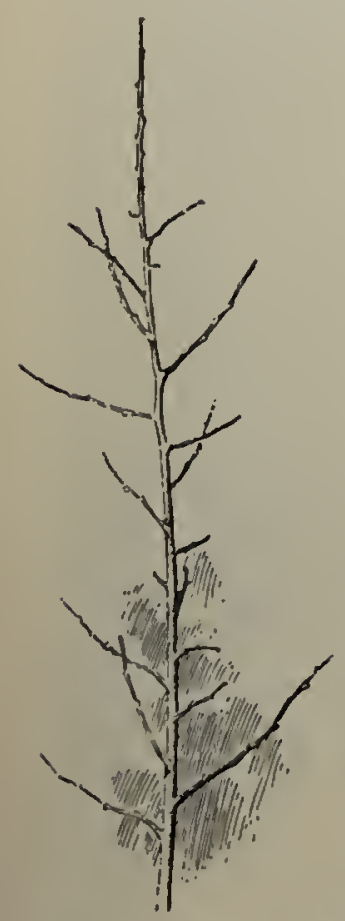

Fir. 32. A Itelliate branching in a very young apple tree buds never grow, since they are shaded and starved, or some may grow much faster than others and so make the plan of branching less evident

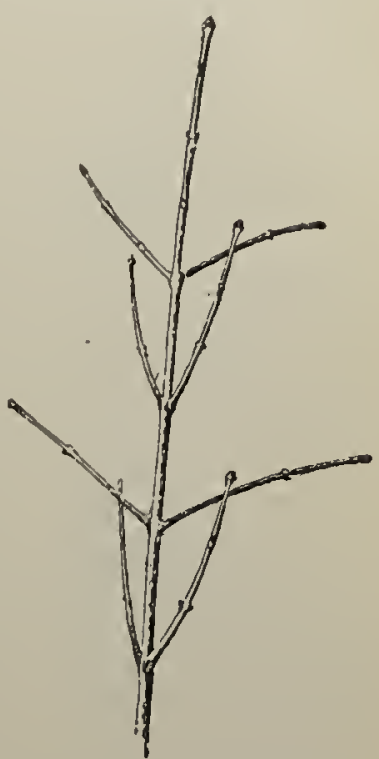

Fic. 31. Opposite branching in a very young sapling of ash than it would be if all grew alike.

56. Alternate branching. In trees like the beech the twigs will be found to be arranged in a more or less regular spiral line about tlie branch. This, which is known as the alternate arrangement (Fig. 32), is more commonly met with in trees and shrubs than the opposite arrangement. It adnits of many varieties, since the spiral may wind more or less rapidly round the stem. In the apple, pear, cherry, poplar, oak, and walnut, one passes over five spaces before coming to a leaf which is over the first, and in doing this it is necessary to make two complete turns around the stem (Fig. 100). 
57. Growth of the terminal bud. In some trees tlie termi-

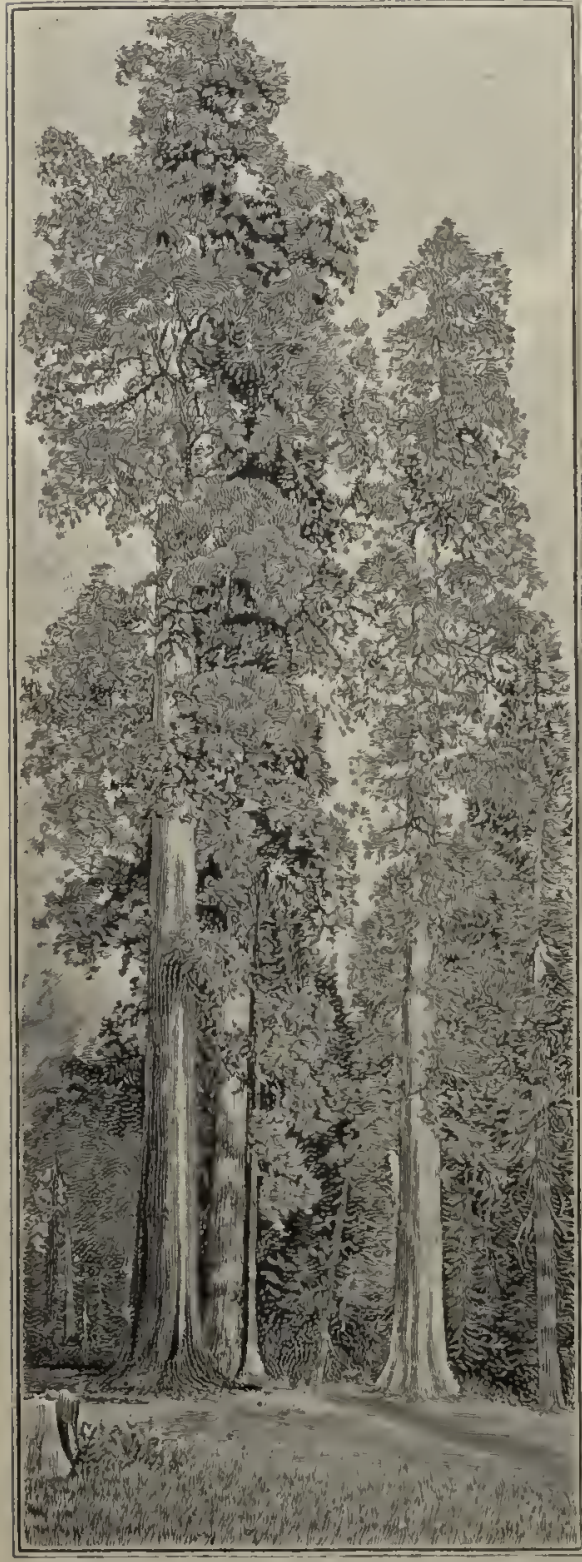

Fig. 33. California giant redwoods (Sequoia), illustrating upright growth After J. II. White nal bud from the outset keeps the lead and produees a slender, upright tree (Fig. 33), as in the pines, spruces, and firs.

In such trees as the apple and many oaks the terminal bud has no preëminenee over others, and the form of the tree is round-topped and spreading (Fig. 34). Most forest trees are intermediate between these extremes.

Branches owe their charaeteristics to several faetors. Most of our trees and larger shrubs make a definitcannual growth, with the buds ripened before the coming of winter (Fig. 79). In these the terminal bud is likely to grow and eontinue the branch. Sueh shrubs and trees as the raspluerry and blackberry, the sumaeh and the ailanthus, make an inclefinite unnual grouth, that is, the tips of the branelies are usually killed by frost, and so the tree forks often. Terminal flower buds (Figs. 36, 37) also cause forking and allow the tree to form no long, straight lranches.

If the terninal buds of branches keep the lead of the 


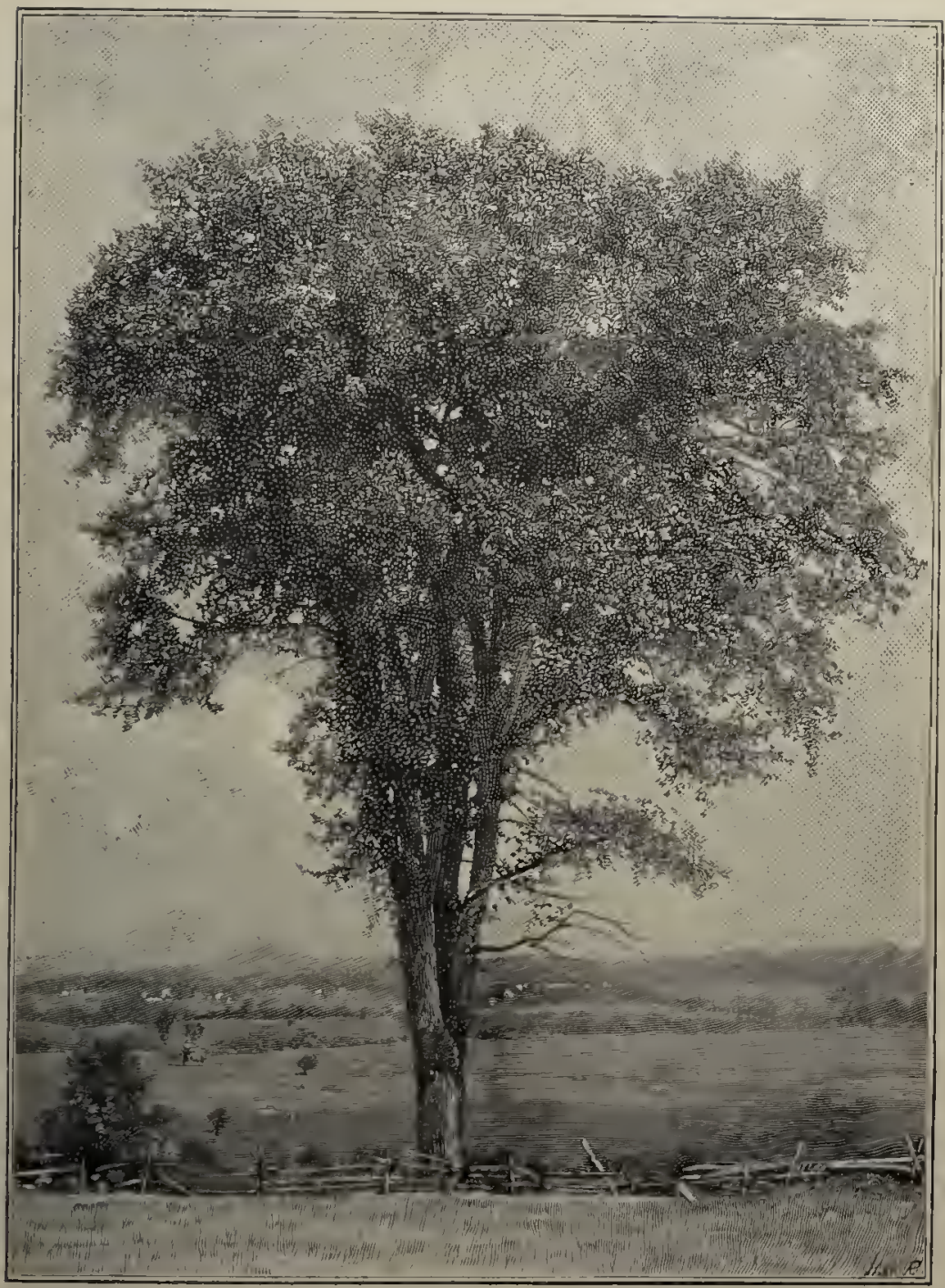

Fig. 34. An American elm, illustrating spreading growth

lateral ones, but the latter are numerous and most of those which survive grow into slender twigs, the delicate spray of the elm and many birches is produced (Fig. 38).

The general effect of the branching depends much upon the angle which each brauch or twig forms with that one from which 
it springs. The angle may be quite acute, as in the birch (Fig. 3S); or more nearly a right angle, as in the ash (Fig. 31). The inclination of lateral branches is due to geotropism, just as is that of the branches of primary roots. The vertically upward direction of the shoot which grows from the terminal bud is also due to geotropism, which, however, in the shoot, is exactly opposite to that in the root.

This is really only a brief way of saying that the growing tip of the main stem of the tree, or of any branch, is made to take and keep its proper direction, whether vertically upward or at whatever angle is desirable for the tree, by the steering action of gravity. After growth has ceased this steering action can no longer be exerted, and so a tree that has been bent over - as, for instance, by a heavy load of snow cannot right itself unless it is elastic enough to

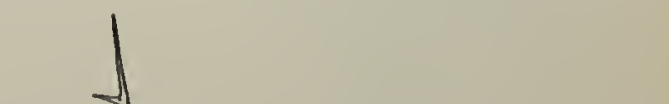
spring back when the load is removed. The tip of the trunk and of each branch can grow and thus become vertical, but the old wood cannot do so.

58. Thorns as branches. In many trees some branches show a tendency to remain dwarfish and incompletely developer. Such imperfect branches may form thorns, as in the familiar wild crab-apple trees and in the pear trees which occur in old pastures in the northeastern states. In the honey locust very formidable branching thorns spring from adrentitious or dormant buds on the trunk or limbs. They sometimes show their true nature as branches by bearing leaves (Fig. 35). 
59. Trees, shrubs, and herbs. Plants of the largest size, with a main trunk of a woody structure, are called tress. Shrubs differ from trees in their smaller. size, and generally in having several stems which proceed from the ground or near it, or in having much-forked stems. The witch-hazel, the dogwoods, and

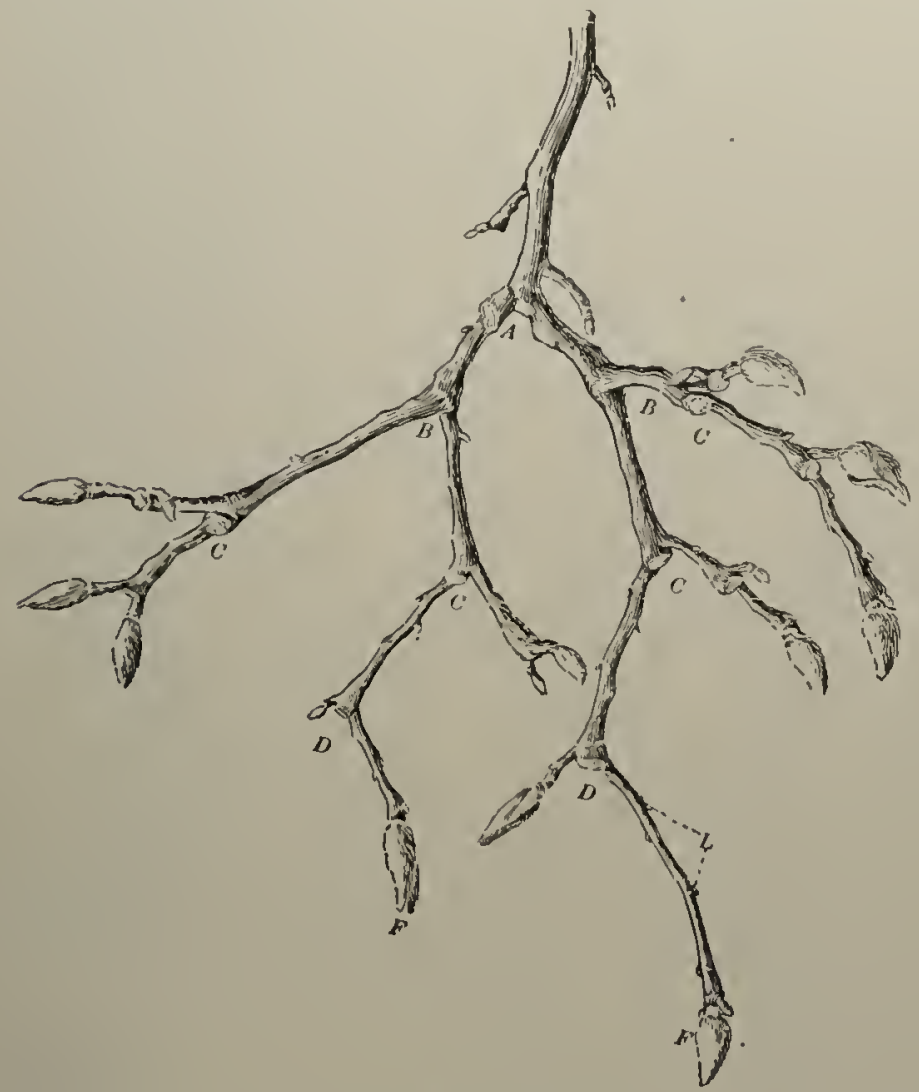

FıG. 36. Tip of a branch of magnolia, illustrating forking due to terminal flower buds

$A$, oldest flower-bud sear; $B, C, I)$, sears of successive seasons after $A ; L$, lea? luds; $F$, flower buds

the alders, for instance, are most of them classed as shrubs for this reason, though in height some of them equal the smaller trees. Some of the smallest shrubby plants, like the dwarf blueberry, the wintergreen, and the trailing arbutus, are only a few 
inches in height, but are ranked as shrubs because their woody stems do not die to the ground in winter.

Herbs are plants whose stcms above ground die every winter.

60. Annual, biennial, and perennial plants. Annual plants are those which live but one year, biennials those which live two years or nearly so.

Some winter anuuals do not flower until their second summer. This is true of the evening primrose and the

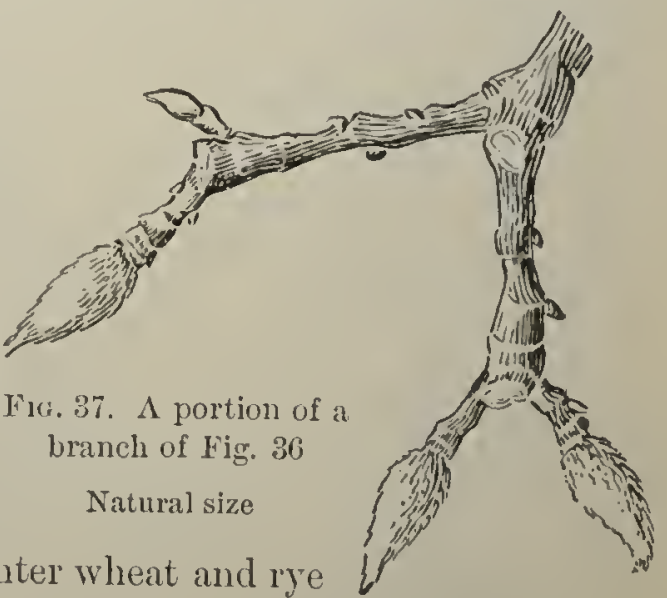
fringed gentian, and of winter wheat and rye among cultivated plants.

Perennial plants live for a series of years. Many kinds of trees last for centuries. The California giant redwoods, or Scquoias (Fig. 33), which reach a height of over 300 feet under

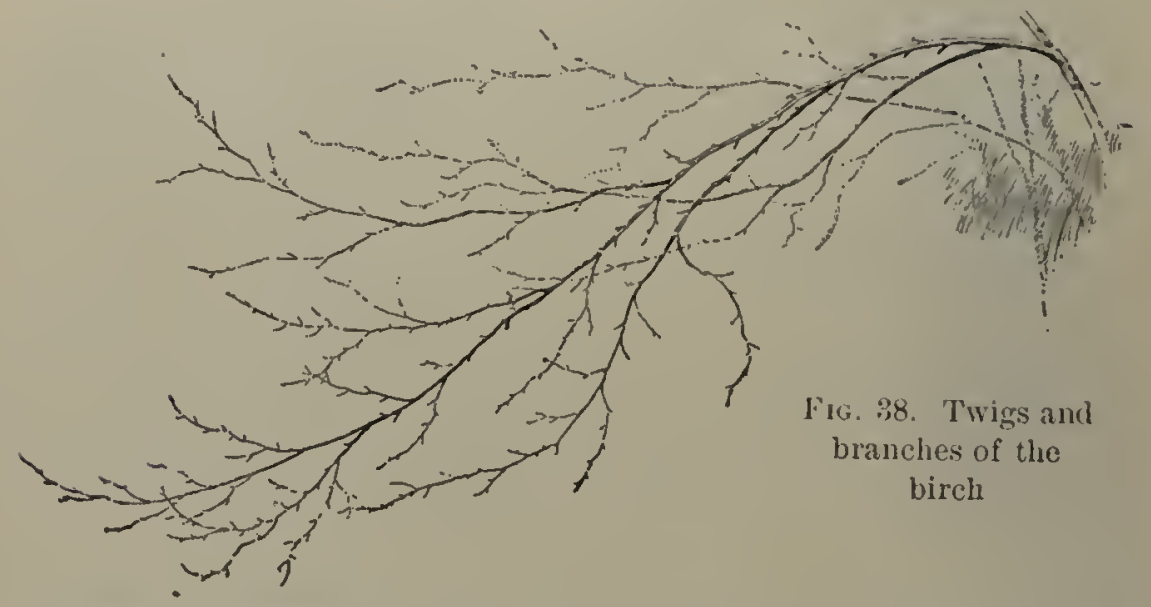

favorable circumstances, live nearly 2000 years; and sone enormous cypress trees found in Mcxico were thought by Professor Asa Gray to be from 4000 to 5000 years old. 


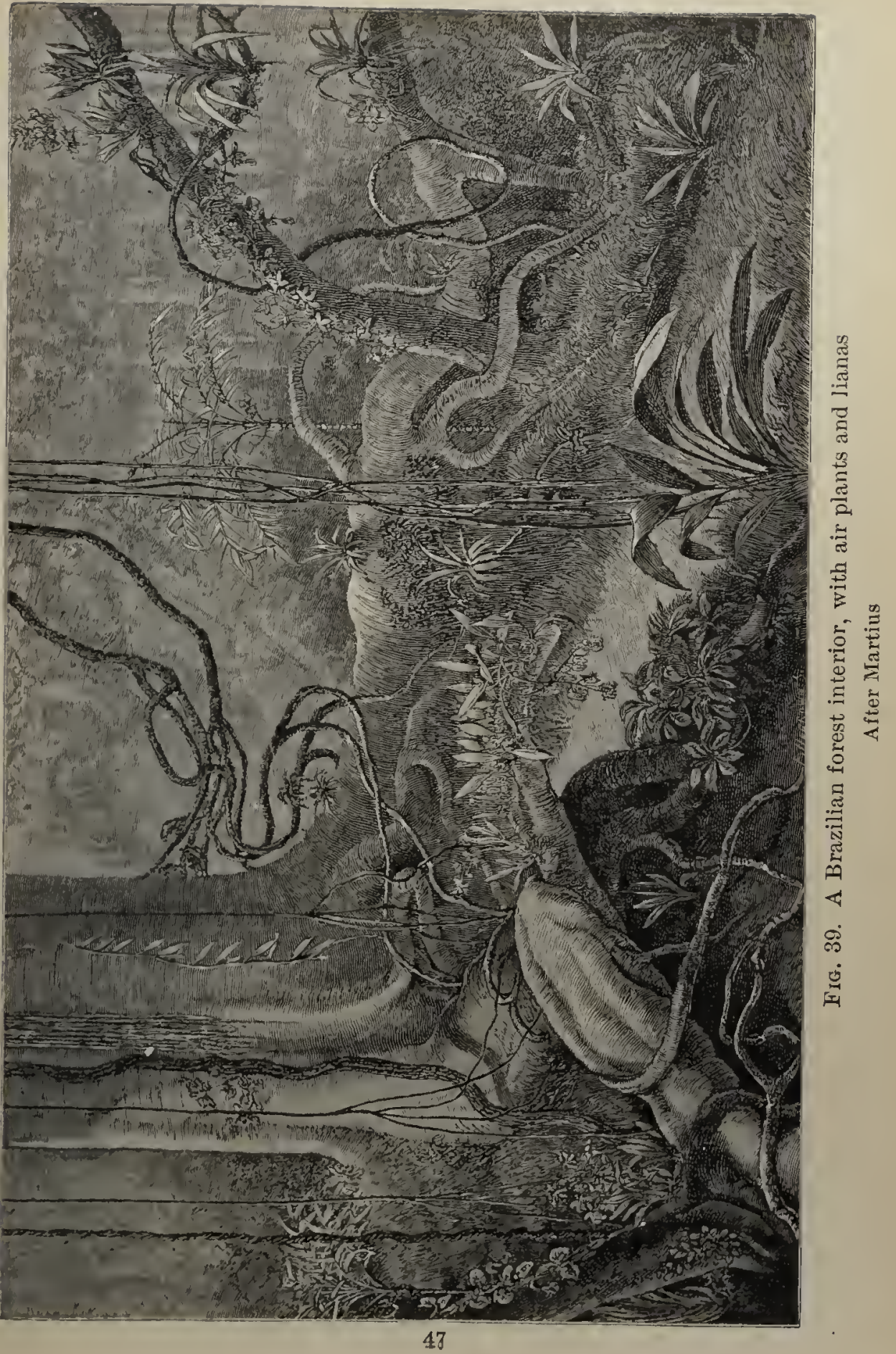


61. Climbing and twining stems. ${ }^{1}$ Since it is essential to the health and rapid growth of most plants that they should have free access to the sun and air, it is not strange that many should resort to special devices for lifting themselves above their neighbors. In tropical forests, where the darkness of the shade anywhere beneath the tree tops is so great that few flowering plants can thrive in it, the climbing plants, or lianas (Fig. 39), often run like great cables for hundreds of feet before they can emerge into the sunshine above. In temperate climates no sueh remarkable climbers are found, but many plants raise themselves for considerable distances. The principal means by which they

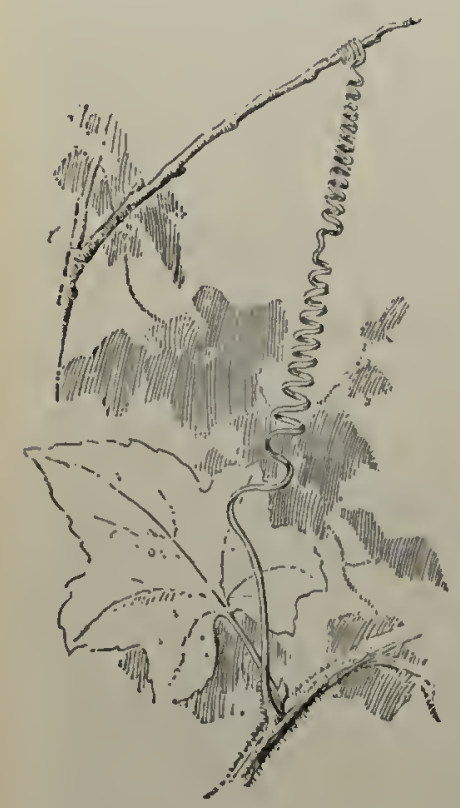

FIG. 40. Coiling of a tendril of bryony

After Sachs accomplish this result are:

1. Producing roots at many points along the stem above ground and climbing on suitable objects by means of these, as in the English ivy (Fig. 14).

2. Laying hold of objects by means of tendrils or twining branches or leafstulks, as shown in Figs. 40 and 41 .

3. 'Twining about any slender upright support, as shown in Fig. 42. .

4. Clambering upon bushes and other supports by means of hooked prickles, as is done by some roses, blackberries, and cleavers (Galium).

62. Tendril climbers. The plants which climb by means of tendrils are important subjects for study. Continued observation soon shows that the tips of tendrils sweep slowly about in a circular or oval eourse until they come in contact with some object around which they can coil. A fter the tendril has taken a few turns about its support, the free part of the tendril coils into a spiral and thus draws the whole stem toward the point

${ }^{1}$ See Kerner and Oliver, Natural IIistory of Plants, Vol. I, p. 669. 
of attachment, as shown in Fig. 40. Some tendrils are modified leaves or stipules, as shown in Fig. 98 ; other's are modified stems,

63. Irritability of tendrils. The coiling of tendrils is due to their irritability, aroused by the stimulus of contact with a solid object. After a latent period, varying with different species from a few seconds to more than an hour, the bending begins. It is caused either by contraction of the side in contact or by expansion of the opposite side; the exact mechanism of the process is not yet fully understood. The tendrils of the passionflower plant will respond to the

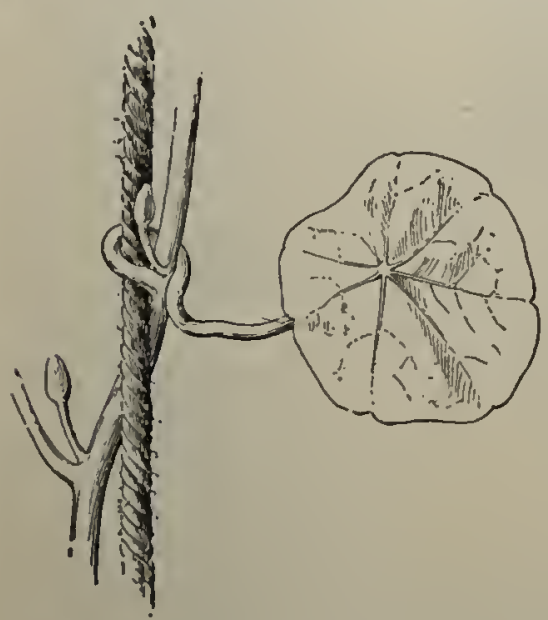

Fig. 41. Coiling of petiole of dwarf nasturtium (Tropcolum)

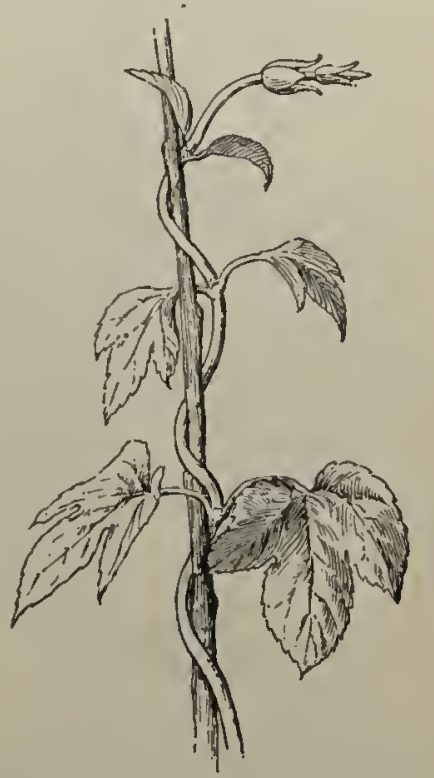

Fig. 42. Twining stem of hop After Decaisne

pressure of a bit of thread, hung on the tendril and kept in motion, whose wcight is only a few millionths of a grain.

64. Twiners. Only a few of the upper internoles of the stem of a twiner are concerned in producing the novements of the tip of the stem. This is kept revolving in an elliptical or circular path until it encounters some roughish and not too stout object, about which it then procceds to coil itself.

The inovements of the younger intcrnodes of the stems of twiners are among the most extensive of all the movements 
made by plants. A hop vine which has climbed to the top of its stake may sweep its tip continually around the circumference of a circle two feet in diameter, and the common wax plant (Hoya) of the greenhouses sometimes describes a five-foot circle, the tip moving at the rate of thirty-two inches per hour.1

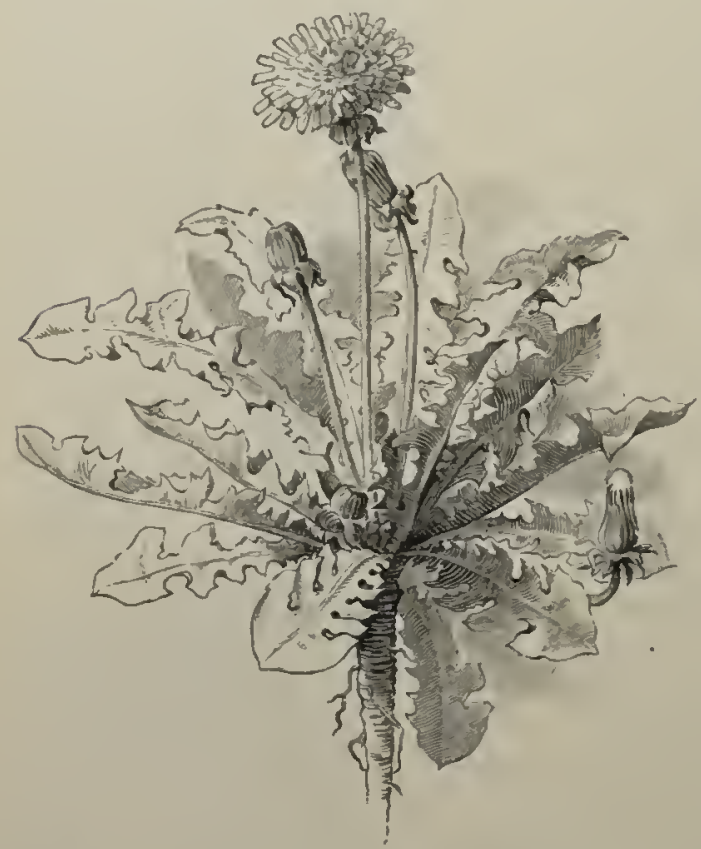

Fic. 43. The dandelion, a short-stemmed plant

This circular motion is produced by unequal growth of the two sides of the stem. ${ }^{2}$

The direction in which twiners coil about a supporting object is almost always the same for each species of plant, but not the same for all species. In the hop it is as shown in Fig. 42, but in many plants the morement is in the reverse direction.

65. Short-ste m med plants. As will be slown later (Chapter xxxIv), plants live subject to a very fierce competition among themselves, and they are exposed to almost constant attacks from animals.

While plants with long stems find it to their adrantage to reach up as far as possible into the sunlight, the dandelion, the cinquefoil, the white clover, some spurges, the knotgrass, and liundreds of other species, living in open places, have found safety in hugging the ground. The dandelion, fall dandelion,

1 See article on "Climbing Plants," by Dr. W. .T. Ieal, in the American Naturalist, Vol. IV, pp. $405-415$.

2 See Strasburger, Noll, Selienck, and liarsten, Text-Biouk of Botriny, pp. 281-28t, Loudon, 1908. 
shepherd's purse, and the like, with radiating leaves, are known as rosette plants, while those with radiating stems, like knotgrass,

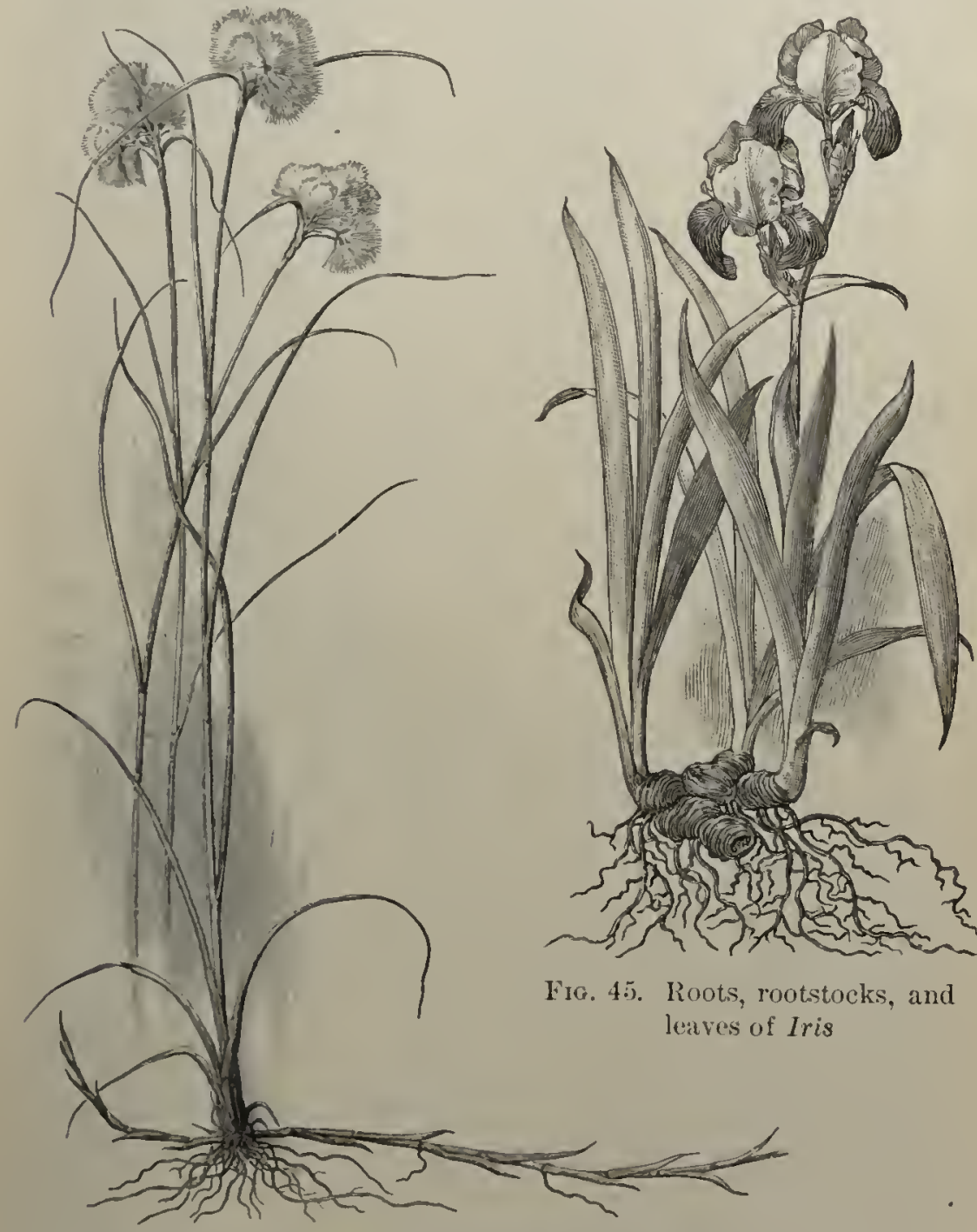

Fig. 44. Rootstock of cotton grass (Eriophorum)

the clovers, and black medick (.Medicuyo), are known as mat plants.

Any plant which can grow in safety under the very feet of grazing auimals will be especially likely to make its way in 
the world, sincc there are many places where it can flourish while ordinary plants would be destroyed. The bitter dandelion, which is almost uneatable for most animals on account of its taste, which lies too near the earth to be fed upon by grazing animals, and which bears bcing trodden on with impunity, is a type of a large class of hardy weeds.

The plants incorrectly called "stemless," like the dana'elion (Fig. 43) and some violets, are not realy stemless, but send out

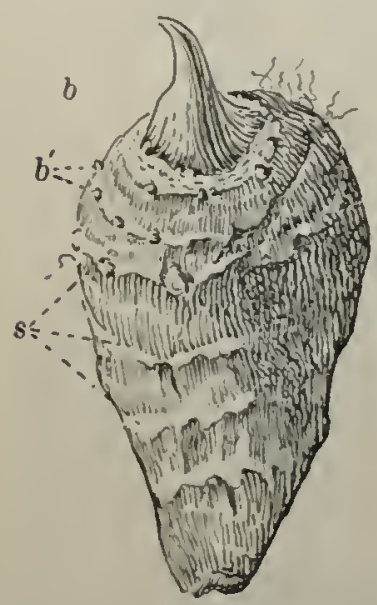

F1G. 46. Rootstock of caladium (Colocasia)

$b$, terminal bud; $b^{\prime}$, buds arranged in circles where bases of leaves were attached; $s$, sears left hy sheathing bases of leaves

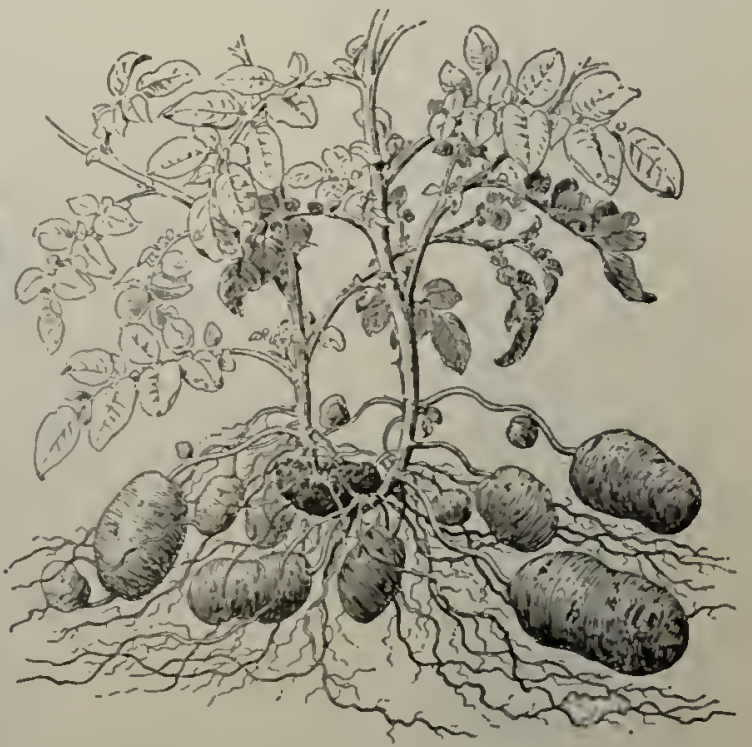

Fig. 47. Part of a potato plant

The clark tuber in the mildle is the one from which the plant has grown

their leaves and flowers from a very short stem which hardly rises from the surface of the ground.

66. Underground stems. Stems which lie mainly or wholly underground are of frequent occurrence and of many kinds. Some of the simplest kinds are called rootstocks. Familiar cxamples are those of some mints, of bloodroot, of Solomon's scal, and of many grasses, sedges, and ferns. The real nature of the crecping underground stem is frequently shown by the presence upon its surfacc of many scales, which are reduced leaves. 


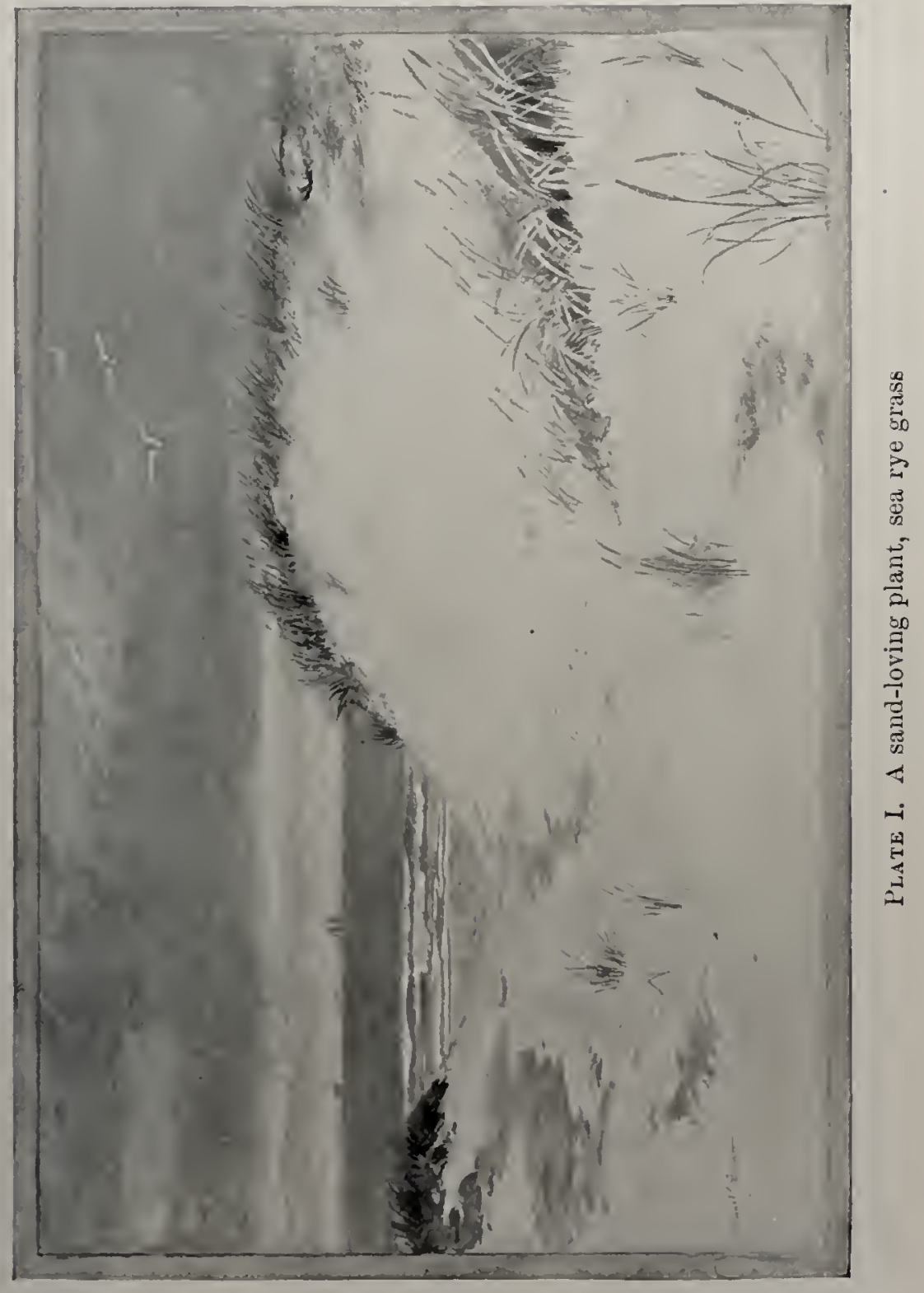



Rootstoeks of this sort often extend lorizontally for long distances in the ease of grasses like the sea rye grass (Plate I),
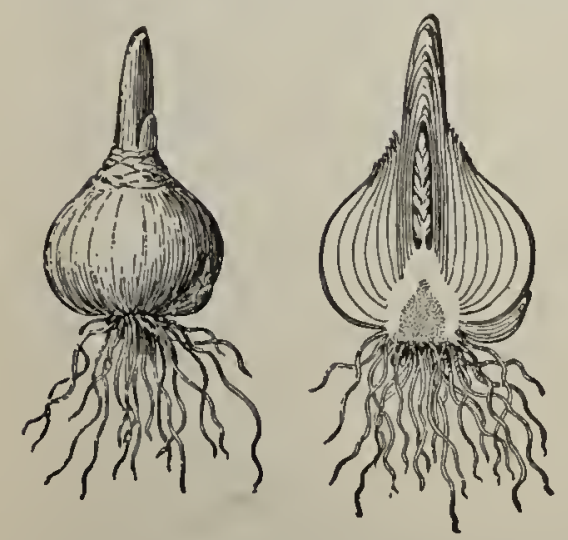

Fig. 48. Bulb of hyacinth

Exterior view, and split lengthwise. After Faguet which loots itself firmly and thrives in slifting sand dunes. In the stouter rootstoeks, like that of the iris (Fig. 45) and the caladium (Fig. 46), this stem-like character is less evident. The potato is an excellent example of the short and much-thickened underground stem known as a tuber.

It may be seen from Fig. 47 that the potatoes are none of them borne on true roots, but only on subterranean branches, which are stouter and more eylindrical than most of the roots. The "eyes" of the potato are rudimentary leaves and buds.

Bulbs, whether coated like those of the onion or the hyacinth (Fig. 48), or sealy like those of the lily, are merely very short and stout underground stems, eovered with elosely erowded seales or layers whieh represent lcares or the bases of leaves (Fig. 49).

The variously modified forms of underground stems just discussed illustrate in a marked way the storage of nourisliment during the winter, or the rainless season, as the case nay be, to provide the material for rapid growth during the active season. It is inter-

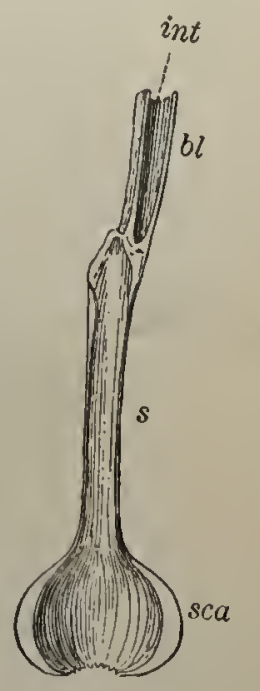

Fig. 49. Longitudinal section of an onion leaf

sca, thickened base of leaf, forming a bulb scalle; $s$, thin sheath of leaf; $b l$, blade of the leaf ; int, hollow interior of blade. After Sachs esting to notice that a majority of the early flowering licrbs in tcmpcrate climates, like the erocus, the snowdrop, the spring 
beauty, the tulip, and the skunk eabbage, owe their early blooming habit to richly stored underground stems of some kind, or to thick fleshy roots. Many of these very early blooming plants are woodland species which must hurry through most of the season's growth and begin to mature seed before the shade of the trees above them cuts off most of the neeessary supply of light and before the drought of summer begins.

67. Condensed stems. The plants of desert regions require, above all, protection from the extreme dryness of the surround-

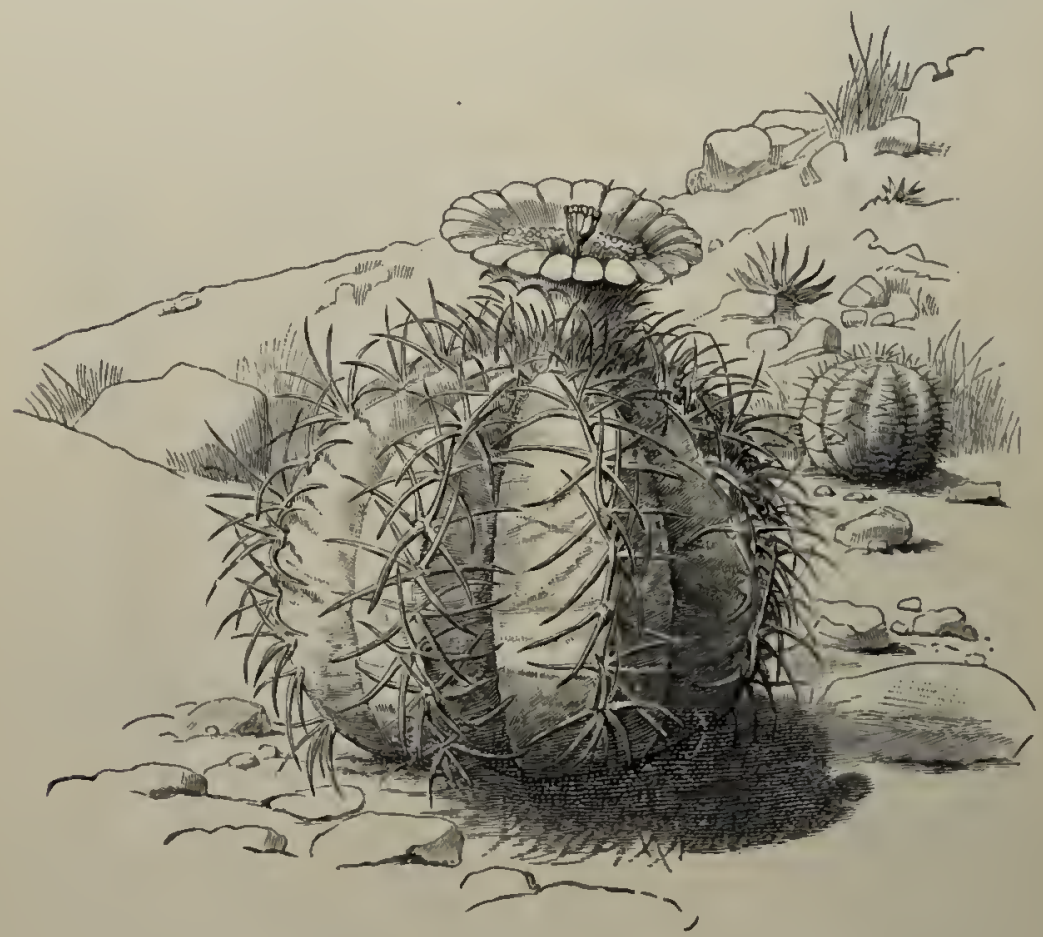

Fis. 50. A globular cactus

ing air, and usually from the excessive heat of the sun. Accordingly, many desert plants are found quite destitute of ordinary foliage, exposing to the air only a small surface. In the globular cactuses (Fig. 50) the stem appears redueed to the shape in which the least possible surface is presented by a plant of given bulk, -- that is, in a somewhat spherical form. Other 
cactuses are cylindrical or prismatic, while still other's consist of flattened joints; but all agree in offering much less area to the sun and air than is exposed by an ordinary leafy plant.

68. Leaf-like stems. The flattened stems of some kinds of cactus, especially the common showy Phyllocactus, are sufficiently like fleshy leaves, with their dark green color and imitation of a midrib, to pass for leaves. There are, however, a good many cases in which the stem takes on a more strikingly leaflike form. The common asparagus sends up in spring shoots that bear large scales which are really reduced leaves. Later in

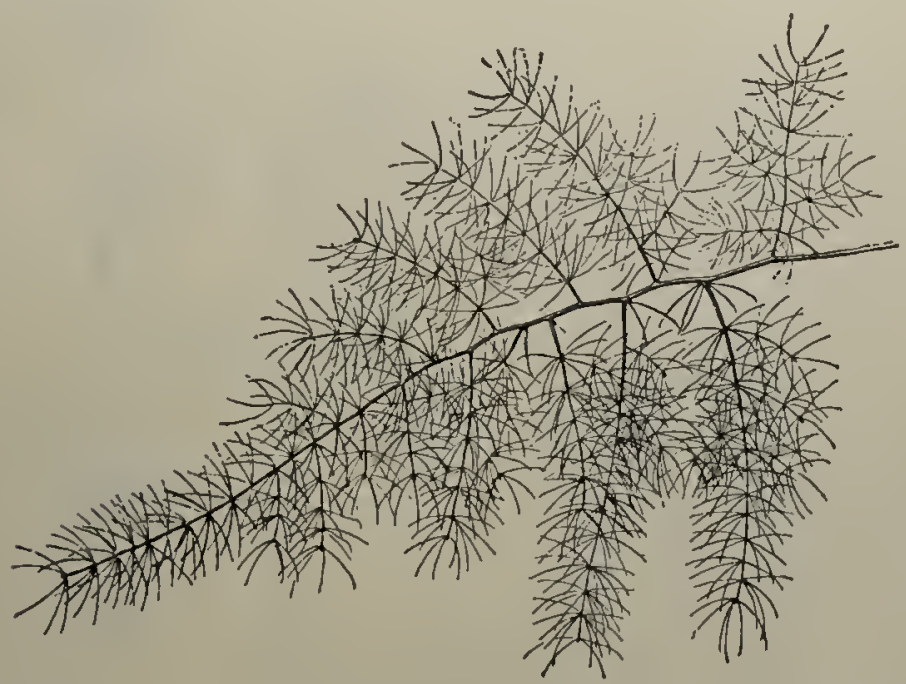

Fig. 51. $\Lambda$ spray of a common asparagus (not the edible speeies)

the scason, what seem like thread-like leaves cover the muchbranched mature plant, but these green threads are actually minute branches, which perform the work of lcaves (Fig. 51). The familiar greenhouse climber, wrongly known as sinilax, properly called Myrsiphyllum, bcars a profusion of what appear to be delicate green leaves (Fig. 52). Close study, however, shows that these are rcally short flattened branches, and that each little branch springs from the axil of a truc lcaf, $l$, in the form of a minute scale. Sometimes a flower and a leaf-like branch spring from the axil of the same scale. 
Branches which, like those of Myrsiphyllum, so closely resemble learcs as to be almost indistinguishable from them are called cladophylls, meaning branch leaves.

69. The range of modification of the stem. The stcm may reach a length of many hundred feet, as in the tallest trees, in the great lianas of South American forests, or in the rattan of Indian jungles. On the other hand, in such plants as the primrose and the dandelion the stem may be reduced to a fraction

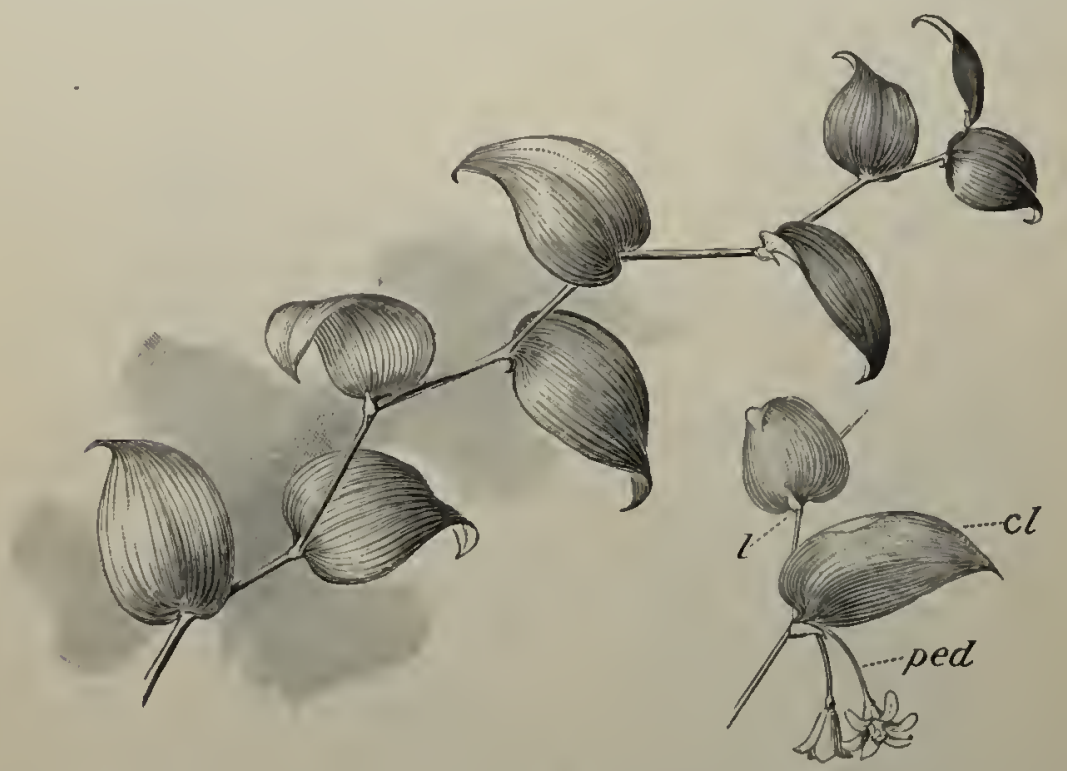

Fı. 52. Stem of Myrsiphyllum

$l$, scale-like leaves; $c l$, cladophyll, or leaf-like branch, growing in the axil of the leaf; ped, flower stalk, growing in the axil of a leaf

of an inch in length. It may take on apparently root-like forms, as in many grasses and sedges, or become thickened by underground storage of starch and other plant food, as in the iris, the potato, and the crocus. Condensed forms of stem may exist above ground, or, on the other hand, branches may be flat and thin enough closely to imitate leaves. In short, the stem manifests great readiness in adapting itsclf to the most varied conditions of existence. 


\section{CHAPTER VII}

\section{STRUCTURE OF THE STEM}

\section{STEM OF MONOCOTYLEDONOUS PLANTS}

70. External characters. The most familiar of the larger monocotyledonous plants are the grass-like ones, such as Indian corn, broom corn, and bamboo, the green briers (Smilax), and the palms. The stem of Indian corn consists of a series of smooth, slightly tapering internodes connected by enlarged nodes. Palm stems often have a very uneven surface, due to the projecting remains of old leafstalks (Fig. 53).

71. Internal structure. A cross section of a cor'n stem shows it to be composed of a liard, flinty rind, inclosing a

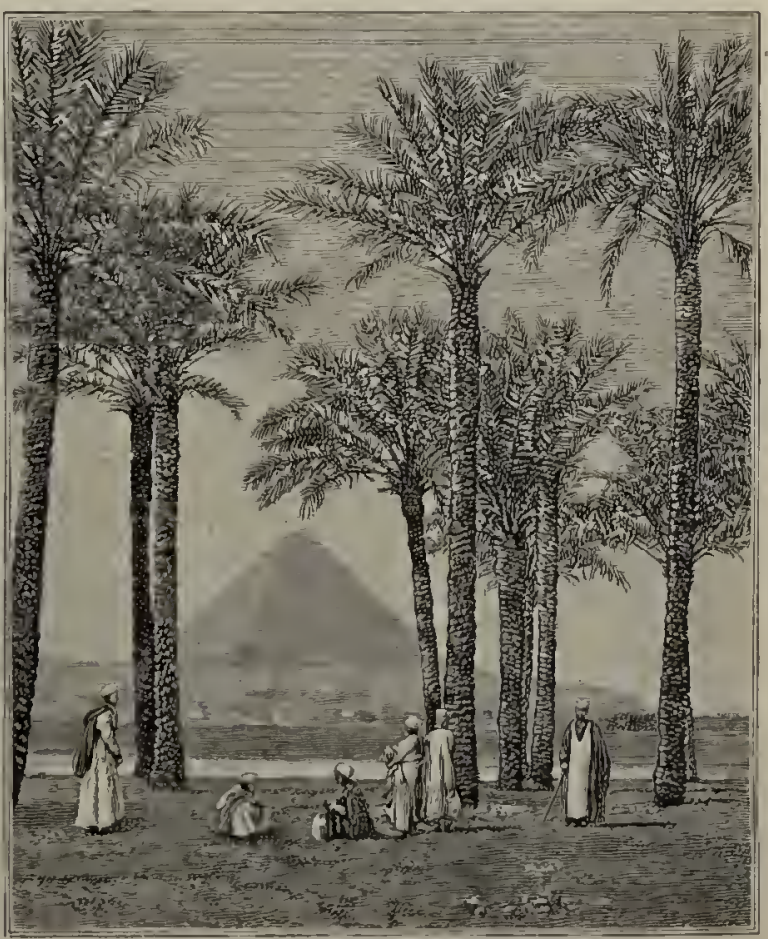

Fig, 53. Group of date palus very soft pith, which is traversed lengthwise by many slender fibers (Fig. 54). The fibers arc arranged in a somewhat definite way, the sinaller ones thickly clustered near the rind, the larger ones, less abundant, toward the center. 


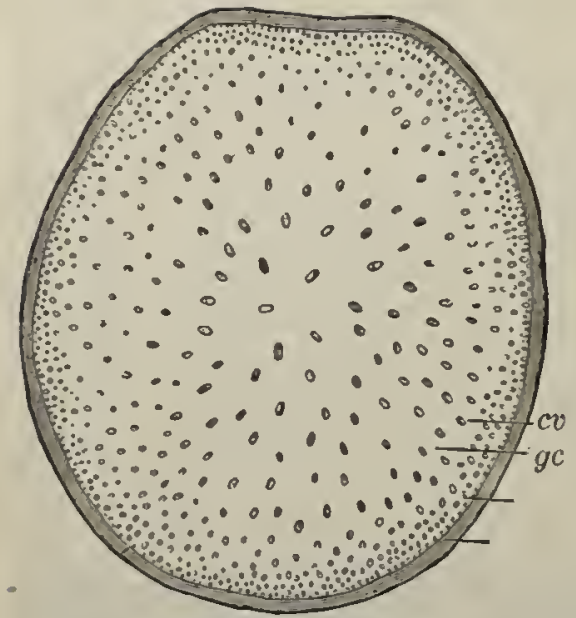

FIG. 54. Diagrammatic cross section of stem of Indian corn

$c v$, fibro-vaseular bundles; $g c$, pithy material between bundles. - After Strasburger

together and much harder than in the corn stem. The outer rind of the latter is composed of long, thick-walled, slender cells, containing wuch silica and known as sclercnchyma fibers.

72. Mechanical function of the manner of distribution of material in monocotyledonous stems. The well-known strength and lightness of the straw of our smaller grains and of rods of cane or bamboo are due to their form. It can readily be shown by experiment that an iron or steel tube of moderate thickness, like a piece of gas pipe or of bicycle tubing, is much stiffer than a solid rod of the same weiglit per foot. The oat straw, the stems of bulrushes, the cane of our southern canebrakes, and the banboo are hollow cylinders; the corustalk is

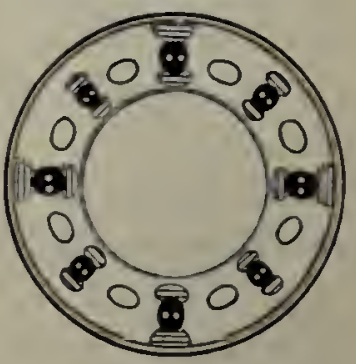

Fig. 55. Diagrammatic cross section of stem of bulrush (Scirpus), a hollow cylincler with strengthening fibers

After Kerner a solid cylinder, but filled with a very light pith. The flinty outer layer of the stalk, together with the closely packed sclerenchyma 
fibers of the outer rind and the frequent fibro-vascular bundles just within this, are arranged in the best way to secure stiffness. In a general way, then, we may say that the pith, the bundles, and the sclerenchymatous rind are what they are and where they are to serve important mechanical purposes. But they have other uses fully as important (see Chapter viII).

73. Growth of monocotyledonous stems in thickness. In most woody monocotyledonous stems, for a reason which will be explained later in this chapter, the increase in thickness is strictly limited. Such stems, therefore, as in many palms and in rattans, are less conical and more cylindrical than the trunks of ordinary trees, and are also more slender in proportion to their height.

\section{STEM OF DICOTYLEDONOUS PLANTS}

74. External characters. It is not easy to make any general statements about the extermal character's of dicotyledonous stems, on account of their very great variety of form. The student in his examination of twigs in connection with Chapter vi has learned a little about the appearance of a few woody stems. In general, the nodes are much less marked than in stems of corn, bamboo, and other grass-like forms. In the case of deciduous-leaved dicotyledonous plants, the scars left by fallen leaves are characteristic, quite unlike those mentioned in Sec. 70.

75. Internal structure. ${ }^{1}$ If one begins his study of the structure of dicotyledonous stems with the one-year-old stem of a woody plant or with the stem of some such robust annual as hemp, sunflower, or the great ragweed, he will find it to be composed of a somewhat cyliudrical pith, surrounded by a layer of wood usually of pretty even thickness, which is in its turn surrounded by a layer of bark (Fig. 56). ${ }^{2}$

1 For an account of the structure of the pine stem, see Sec. 351.

2 Of course these layers are nearly cylindrical tubes, filled by pith or by wood and pith respectively. They are not of perfectly circular cross section, and they taper somewhat. 
The wood cylinder may be discontinuous, that is, broken up into separate fibro-vascular bundles, as shown in Fig. 57 ; but even then the position of the wood between an inclosed pith

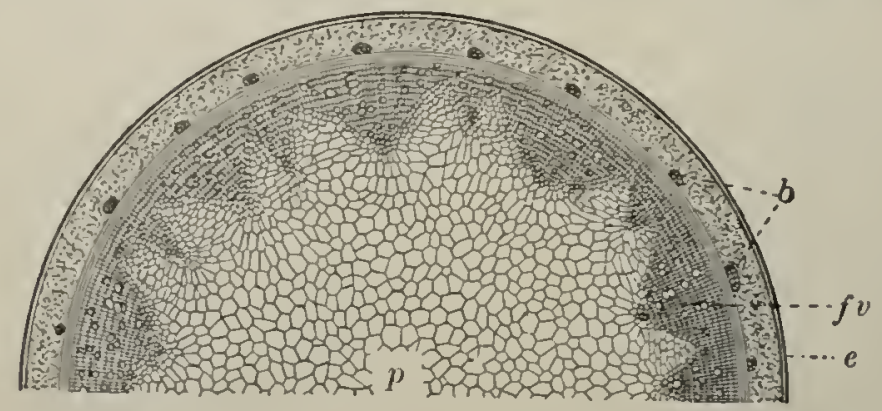

Fic, 5). J Jiagrammatic closs section of an annual dicotyledonous stem $p$, pith; $f v$, woody or filro-vaseular buntles; $e$, epidermis; $b$, bundles of hardbast fibers of the bark. Somewhat magnitied. - After Frauk

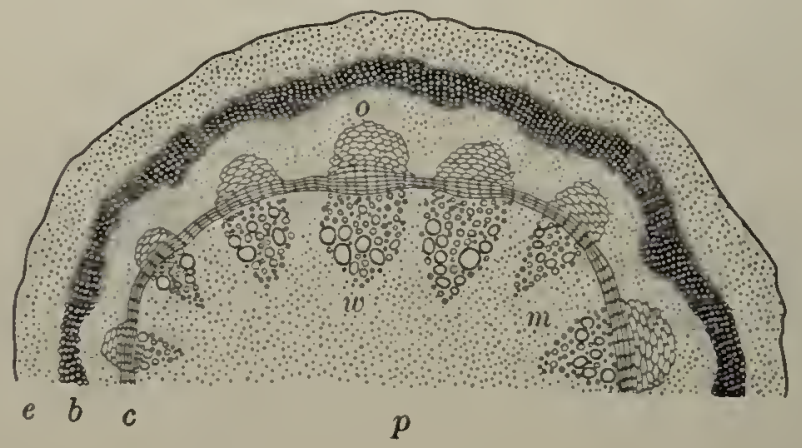

Fig. 57. Diagranmatic cross section of one-year-old Aristolochia stem

$e$, region of epidermis; $b$, hard-bast fibers; o, outer or bark part of a bundle; $v$, inner or woody part of bundle; $c$, cambium layer; $p$, region of pith; $m$, a medulliry ray. Consilerably nagnified

The space between the harl bast and the bundles is oceupied by thin-malled, somewhat cubical cells of the bark 1

and an inclosing bark is notably different from the way in which the bundles are scattered in monocotyledonous stems.

1 In this and the following figure the relative prominence of the cambium layer is a good leal exaggerated. 


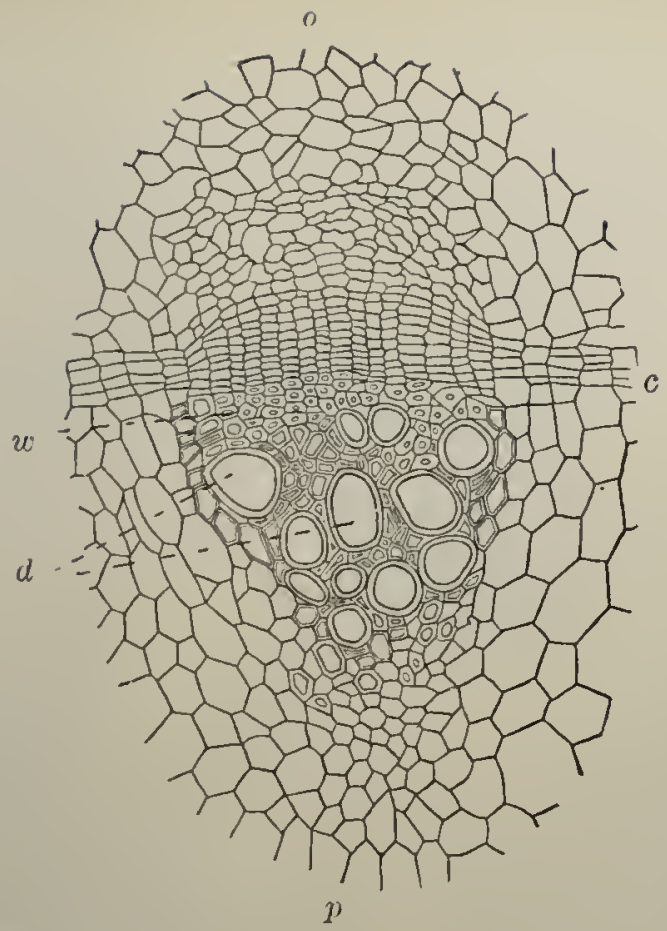

Fig. 58. One bundle from the preceding figure

10, woorl cells; $d$, vessels. The other letters are as in Fig. 57 . Sieve cells occur in the suft bast region ontside of the cambium of the bundle. $\times 100$

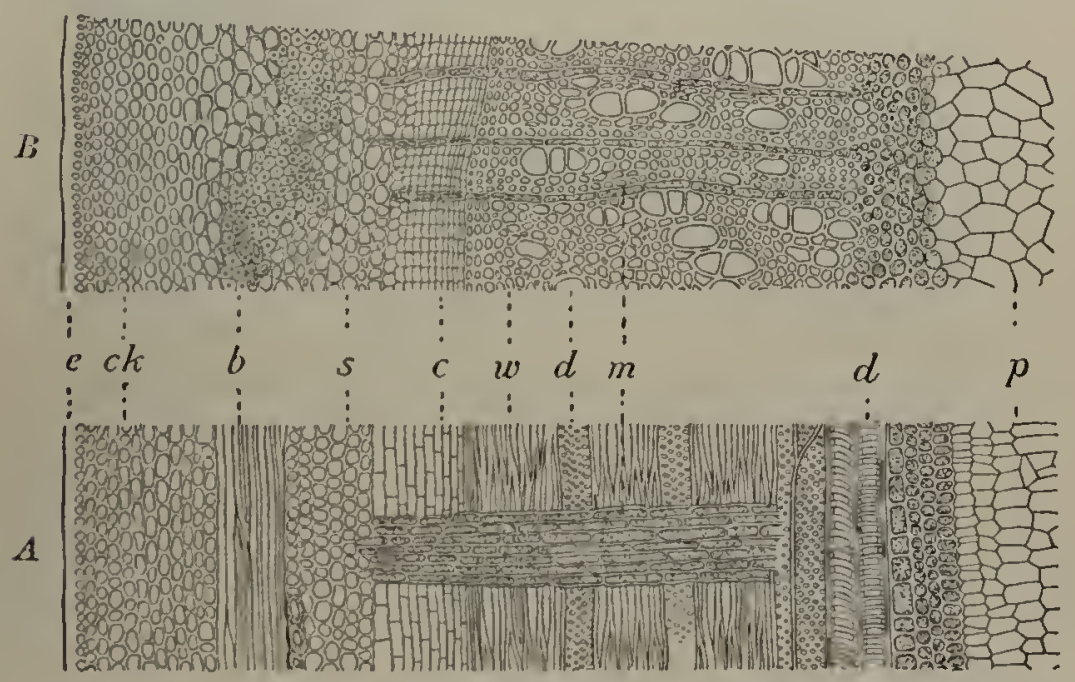

Fis. 59. Sitem of box elcler one year old

$A$, lengtluwise (radial) sertion: $B$, cross section; $e$, epidermis; $c k$, cork; $b$, hard bast; s, sirverells: c, rambium; w, wool cells; m, melullary rays; $d$, vessels; $p$, pith. Much magnified 


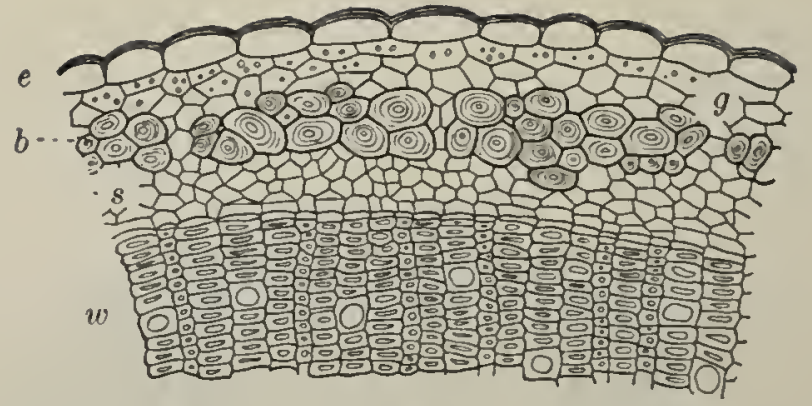

FIG. 60. Part of cross section of stem of flax

$e$, epidermis; $b$, hard bast; $s$, sieve cells; $w$, wood. Much magnified.-After Tschirch

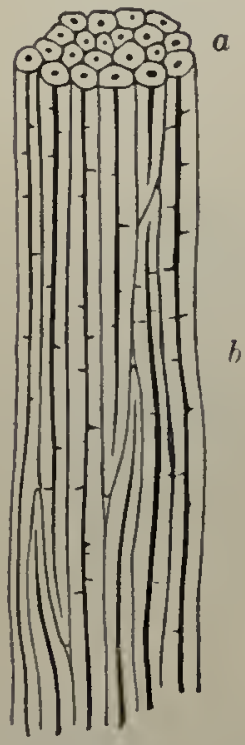

Fig. 61

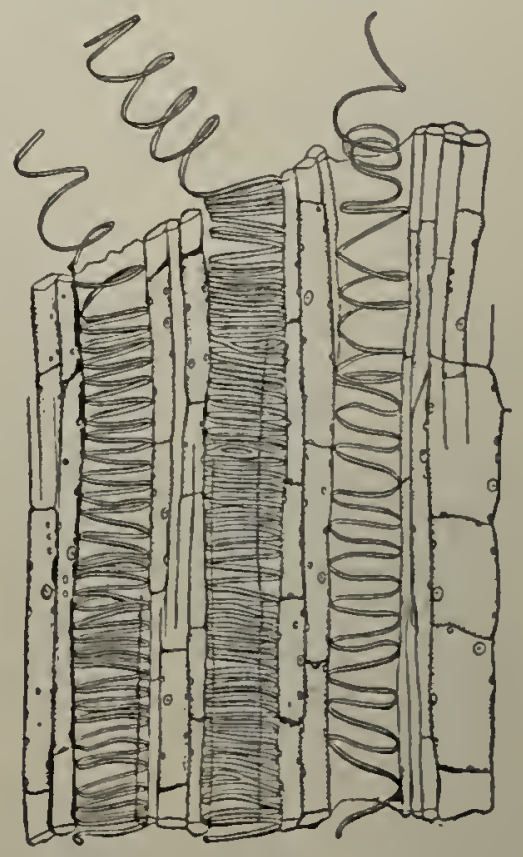

FIG. 62

Fig. 61. A group of lard-bast fibers

$a$, cut-off ends; $b$, lengthwise section of fibers. Greatly magnifierl. $-A$ fter Tschirch

Frg. 62. A lengthwise section of a group of spiral vessels from the stem of sunflower

At the top of the figure some of the spiral threads which line the vessels are seen partly uncoiled. Greatly magnified. - After Frank 
76. Disposition of material for strengthening purposes. Onty tro of the many was in which the stem is strengthened need be mentioned here. In a majority of cases it ores its stiffness mainly to the wood, as shown in Fig. 56. But not infrequently

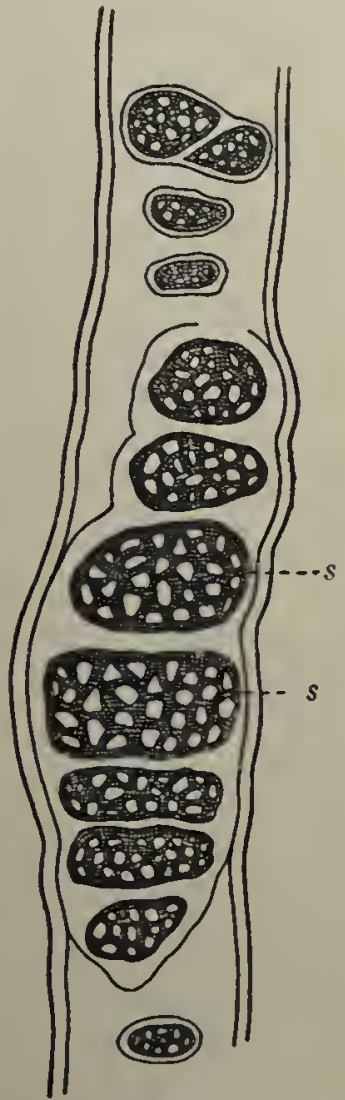

Fin. 63

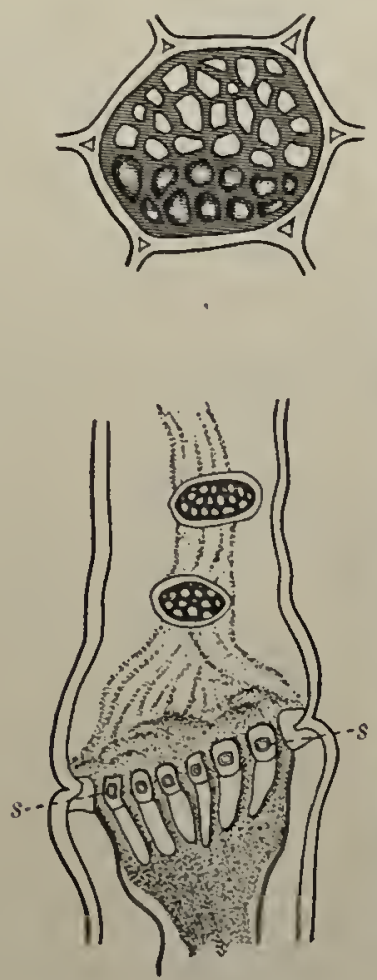

Fig. 64

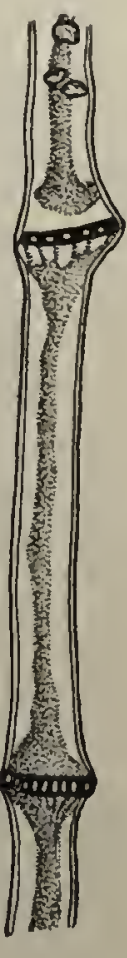

Fig. 63. Part of a sieve tube from linden

Fig. 64. Parts of sieve tubes as found in plants of the gourl family $s$, a sieve plate seen ellgewise; above it a similar one, surface view. Greatly maguified. - After Tloomé

most of the stiffening material consists of the hard-bast fibers found in the bark. It is this layer in flax (Fig. 60) which is utilized in the manufacture of linen thread and linen fabrics. 
77. Structural units of the dicotyledonous stem. The student should already, from his own examinations, have learned a good deal about the kinds of cells and cell aggregates which compose the stem. The preceding figures (Figs. 56-60) will serve to illustrate the most important of these, and Figs. $61-6 \pm$ show some of them more in detail.

78. Parenchyma, prosenchyma, and collenchyma. A mass of similar coöperating cells is called a tissuc. 'Two of the principal classes not previously mentioned which occur in the stem are parenchymatous tissue and prosenchymatous tissue. Parenchyma is well illustrated by the green layer of the bark, by wood parenchyma, and by pith. Its cells are usually somewhat roundish or cubical, at any rate not many times longer than wide, and at first rather full of protoplasm. Their walls are not generally very thick. Proscnehyma, illustrated by hard

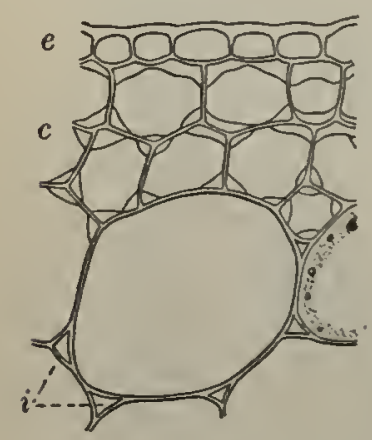

Fig. 65. Collenchymatous and other tissue from stem of balsam (Impatiens)

$e$, epidermis; c, collcnchyma ; $i$, intercellular spaces between large parenchyma cells. After Strasburger bast and masses of wood cells, consists of thick-walled cells many times longer than wide, containing little protoplasm and often having little or no cell cavity.

As a rule the stems of the most highly dereloped plants ore their toughness and their stiffness mainly to prosenclymatous tissue. In some stems, particularly the fleshy ones, the stiffness is, however, largely due to collcnchyma, a kind of parenchyma in which the cells are thickened or reënforced at their angles, as shown in Fig. 65 .

79. The early history of the stem. In the earliest stages of the growth of the stem it consists entirely of thin-walled and rapidly dividing cells. Soon, howerer, the various kinds of tissue which are found in the full-growi: stem begin to appear.

1 See Strasburger, Noll, Schench, and liarsten, Text-Book of Botany, pp. 97-100, London, 1908. 
In Fig. 66 the process is shown as it occurs in the castor bean. At $m$, in $B$, is the central column of pith surrounded by eight fibro-vascular bundles, $f v$, eacl of which contains a number of vessels arranged in a somewhat regular manner and surrounded by the forerunners of the true wood cells.

In $C$ the section shows a considerable advance in growth: the fibrovascular bundles are larger and are now connected by a rapidly growing layer of formative tissue $c$.

As growth continues, this layer becomes the cambium layer, composed of thin-walled and rapidly dividing cells, as shown in Figs. 67 and 68 .

80. Secondary growth. From the inside of the cambium layer the wood cells and ducts of the mature stem are produced, while from its outer circumference the new layers of the bark proceed. From this mode of increase the stems of dicotyledonous plants are called exogenous, that is, outside growing. The presence of the cainbium layer on the outside of the wood in early spring is a fact well known to the sclioolboy who pounds the cylinder cut from an alder, willow, or lickory branch until the bark will

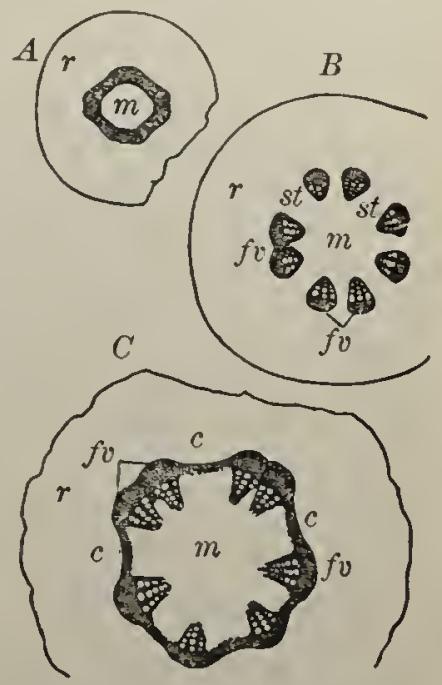

Fig. 66. Transverse section through the hypocotyl of the castor-oil plant at various stages

$A$, after the root has just appeared outside the testa of the seed; $B$, after the hypocotyl is nearly an inch long; $C$, at the end of germination; $r$, cortex (undeveloped bark); $m$, pith; st, medullary rays; $f v$, fibro-vascular bundles; $c$, layer of tissne which is to develop into cambium. Considerably magnified. - After Sachs slip off and so enable him to make a whistle. The sweet taste of this pulpy layer, as found in the white pine, the slippery elm, and the hasswood, is a familiar evidence of the nourishment which the cambium layer contains. It is also, as might be supposed, very ricli in proteids. 
With the increase of the fibro-vascular bundles of the wood, the space between them, at first large, becomes less, and the pith, which extended freely out toward the bark, becomes compressed into thin plates so as to form medullary rays. These are, as the starch test shows, useful in storing food which the plant in cold and temperate climates lays up in the sum-

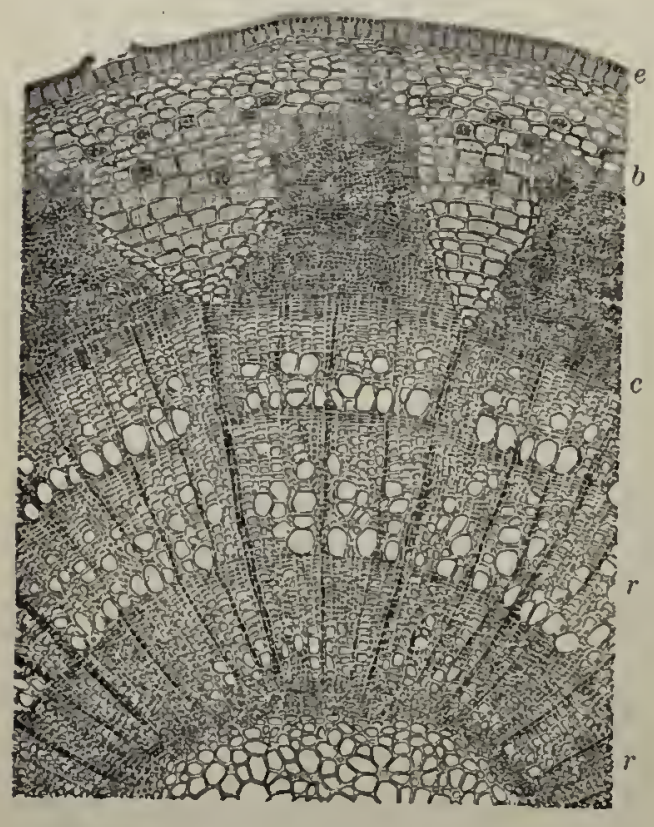

Fig. 67. Cross section of a three-year-old linden twig

$e$, epidermis and corky layer of the bark; $b$, bast ; $c$, cambium layer; $r$, annual rings of wood. Much maguified. - After Kny mer and fall for use in the following spring, and in the very young stem they serve as an important channel for the transference of fluids across the stem from bark to pith, or in the reverse direction. On account, perhaps, of their importance to the plants, the cells of the medullary rays are among the longest lived of all vegetable cells, retaining their vitality in the beech tree sometimes, it is said, for more than a hundred years.

After the interspaces between the first fibro-vascular bundles have become filled up with wood, the subsequent growth must take place in the manner shown in Fig. 68. The cambium of the original wedges of wood $f c$, and the cambium ic formed between these wedges, continues to grow from the inner and from the outer surface, and thus causes a permanent increase in the diameter of the stem and a thickening of the bark, which, however, usually soon begins to peel off from the outside and thus remains pretty constant in thickness. 
It is the lack of any such ling of cambium as is found in dicotyledonous plants, or even of permanent cambium in the separate bundles, that makes it impossible for the trunks of most palm trees to grow indefinitely in thickness, like that of an oak or an elm.

81. Stem structure of climbing shrubs. Some of the most remarkable kinds of dicotyledonous stems are found in climbing shrubs. The bundles, as shown in Fig. 57, are much more distinct than in most other woody stems. It is evident that this

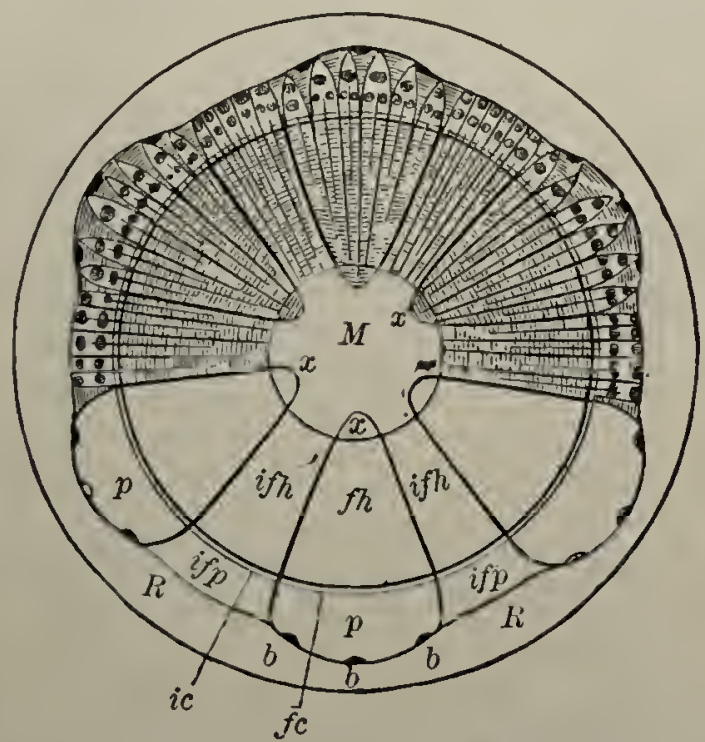

F1g. 68. Diagram to illustrate secondary growth in a dicotyledonous stem $R$, the first-formed bark; $p$, mass of sieve cells; if $p$, mass of sicve cells between the original wedges of wood; $f c$, cambium of wedges of wood; $i c$, cambium between welges; $b$, groups of bast cells; $f h$, wood of the original wedges; ifh, wood formed between wedges; $x$, earliest wood formed; $M$, pith. - After Sachs

is for the sake of leaving the stem flexible for twining purposes, just as a wire cable is adapted to be wound about posts or other supports, while a solid steel or iron rod of the same size would be too stiff for this use.

82. Interruption of annual rings by branches; knots. When a leaf bud is formed on the trunk or branch of a dicotyledonous tree it is connected with the wood by fibro-vascular bundles. 
As the bud develops into a branch, the few bundles whieh it originally possessed increase greatly in number, and at length,

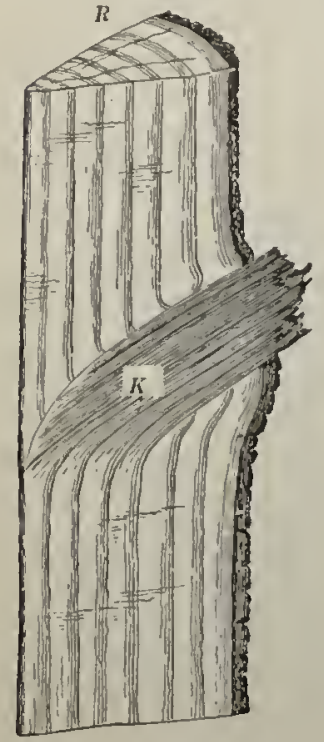

Fra. 69. Formation of a knot in a tree trunk

$R$, eut-off end of stiek, showing annual rings; $K$, knot forined by growth of a branch.After Roth as the branch grows, form a cylinder of wood which euts across the annual rings, as shown in Fig. 69. This interruption to the rings is a knot, sueh as one often sees in boards and planks. If the branch dies long before the tree does, the knot may be buried under many rings of wood. What is known as "elear" lumber is obtained from trees that have grown in a dense forest, so that the lower branches of the larger trees were killed by the shade many years before the tree was felled. In pruning fruit trees or shade trees the branehes whieh are removed should be cut close to the trunk. If this is done, the growth of the trunk will bury the sear before deeay sets in.

83. Grafting. When the cambium layer of any vigorously growing stem is brought in eontaet with the same layer in another sten of the same kind or a elosely similar kind of plant, the two may grow together to form a single stem or branch. This proeess is ealled grafting, and is mueh resorted to in order to seeure apples, pears, ete., of any desired kind

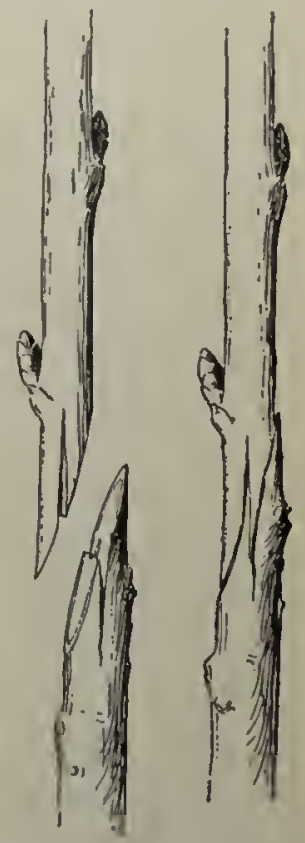
Fig. 70. Grafting

At the left seion and stock are shown ready to be united; at the right they are joined and ready to cover with grafting wax. - After Percival (Fig. 70). A twig known as the scion from a plant of the chosen variety may be grafted upon another individual of similar kind 
known as the stock, and the resulting stems will bear the wished-for sort of fruit. Often one species is grafted on another, as the pear on the quince or the apple. Rarely trees differing as much as the chestnut and the oak may be grafted together.

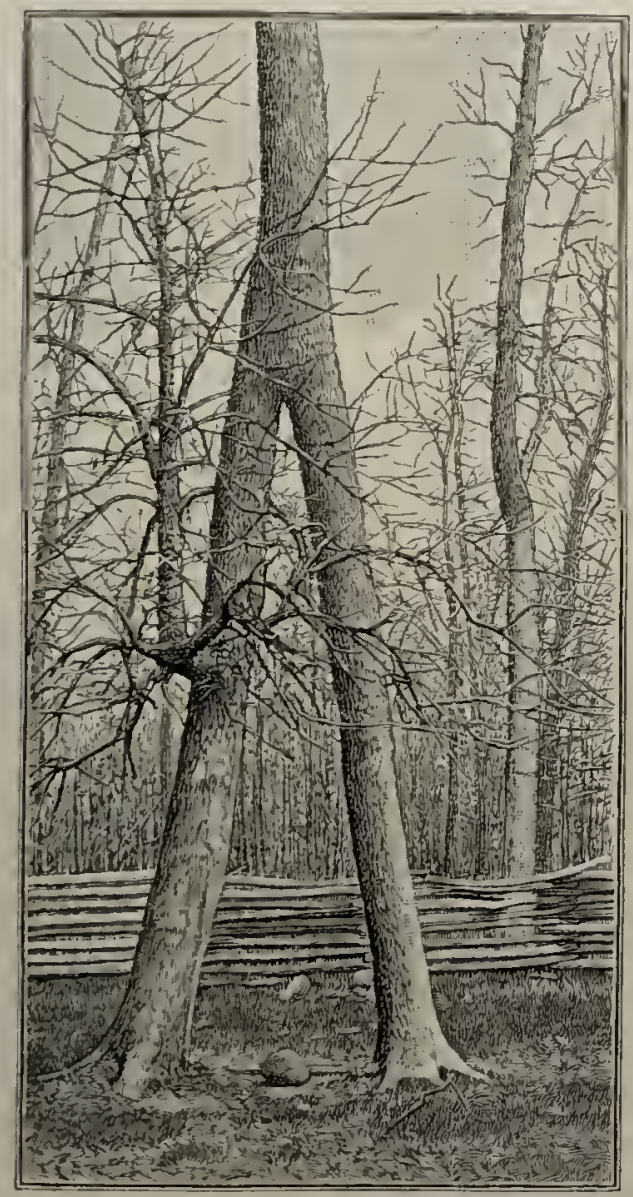

FIG. 71. 'Two ash trees naturally grafted together

After Werthner

Sometimes grafting comes about naturally by the branches of a tree chafing against one another until the bark is worn away and the cambium layer of each is in contact with that of the other, or two separate trees may be joined by natural grafting into a nearly cylindrical double trunk, as is shown in Fig. 71. 
84. Comparison of the monocotyledonous and the dicotyledonous stem. ${ }^{1}$

MoNocotyledonous

STEM

General

Structure :

A haril rind of rather uniform structure. Bundles intermixed with the pith.

\section{DICOTYLEIONOUS STEM}

A complex bark, usually on young shoots, consisting of an epidermis, a corky layer, a green layer, and a layer of bast. $A$ layer of cambium. Wood in annual rings. Pith in a cylinder at the center.

Structure of

Bundles :

Bundles clasect; that is, without permanent cambium.

Growth in

Cells of mature parts

Thickness: of stem expand somewhat, but (iu most palms) new ones are not formed.
Bundles open, with permanent cambium.

New wood cells formed throughout growing season from cambium ring.

1 This comparison applies only to most of the woody or trec-like stems. 


\section{CHAPTER VIII}

\section{LIVING PARTS OF THE STEM; WORK OF THE STEM}

85. Active portions of the stems of trees and shrubs. In annual plants generally, and in the very young shoots of shrubs and trees, there are stomata (singular stoma, meaning mouth), or minute openings, which occur abundantly in the epidermis, serving for the admission of air and the escape of moisture, while the green layer of the bark answers the same purpose that is served by the green pulp of the leaf (Chapter XII). For years, too, the spongy lenticels, which succeed the stomata and occur scattered over the external surface of the bark of trees and shrubs, serve to admit air to the interior of the stem. The lenticels at first appear as roundish spots, of very small size; but as the twig or shoot on which they occur increases in diameter, the lenticel becomes spread out at right angles to the length of the stem, so that it sometimes becomes a longer transverse slit or scar on the bark, as in the cherry and the birch and the elder. But in the trunk of a large tree often no part of the bark except the inner layer is alive. The older portions of the bark, such as the highly developed cork of the cork oak, sometimes cling for years after they are dead and useless except as a protection for the parts beneath against mechanical injuries or against cold. But in many cases, as in the shellbark hickory and the grapevine, the old bark soon falls off in strips; or as in birches it finally peels off in bands around the stem.

The cambium layer is very much alive, and so is the young outer portion of the wood. Testing this sapwood, particularly in winter, shows that it is rich in starch and proteids.

'The heartwood of a full-grown tree is hardly living, unless the cells of the medullary rays retain their vitality, and so it is 
probable that wood of this kind is chiefly useful to the tree by giving stiffness to the trunk and larger branches, thus preventing them from being easily broken by storms.

It is therefore possible for a tree to flourish, sometimes for centuries, after the heartwood has much of it rotted away and left the interior of the trunk hollow, as shown in Fig. 72.

86. Uses of the components of the stem. There is a marked division of labor among the various groups of cells that make up the stem of ordinary dicotyledons, particularly in the stems of trees, and it will be best to explain the uses of the kinds of cells as found in trees rather than in herbaceous plants. A few of the ascertained uses of the various tissues are these:

The pith forms a large part of the bulk of very young shoots, since it is a part of the tissue of comparatively simple structure amid which the fibro-vascular bundles arise. In mature stems it becomes rather unimportant, though it often continues for a long time to act as a storehouse of food.

The medullary rays in the young shoot serve as a channel for the transference of water and plant food in a liquid form across the stem, and they often contain much stored food.

The vessels carry water upward through the stem in certain plants.

The wood cells of the heartwood are useful only to give stiffness to the stem. Those of the sapwood, in addition to this work, have to carry most of the water from the roots to the leaves and other distant portions of the plant.

The cambium layer is the region in which the annual growtl of the tree takes place.

Sieve tubes form the most important portion of the inner bark, carrying elaborated plant food from the leaves toward the roots.

The green layer of the bark in young shoots does inuch toward collecting nutrient substances, or raw materials, and preparing the food of the plant from air and water, but this work may be best explained in connection with the study of the leaf (Chapter XII). 


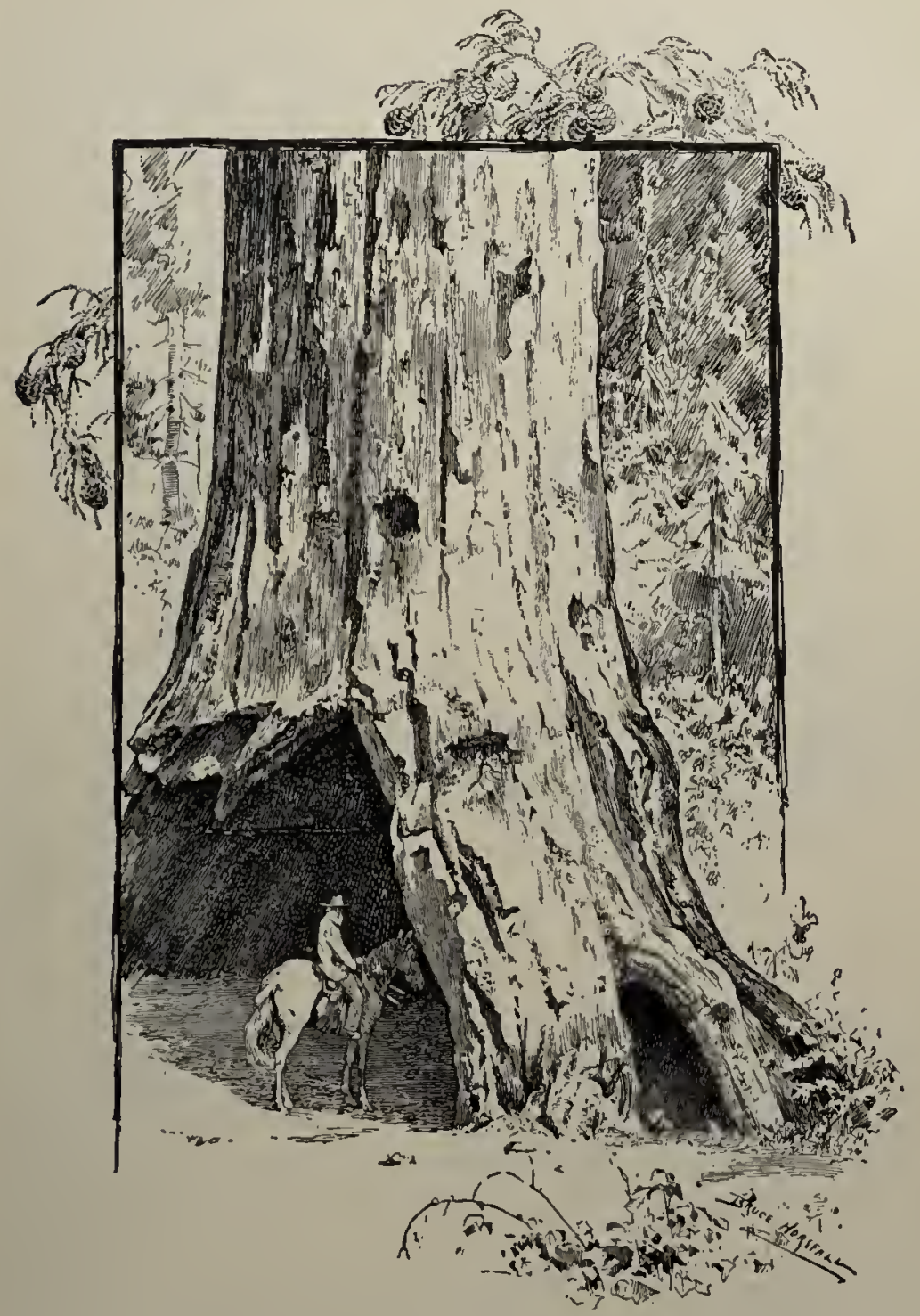

F1G. 72. Pioneer's cabin, a hollow giant redwood (Sequoia)

After White

87. Movement of water in the stem. The student has already learned that large quantities of water are taken up by the roots of plants. 
Having become somewhat acquainted with the structure of the stem, he is now in a position to investigate the question how the various fluids, commonly known as sap, travel abont in it. ${ }^{1}$

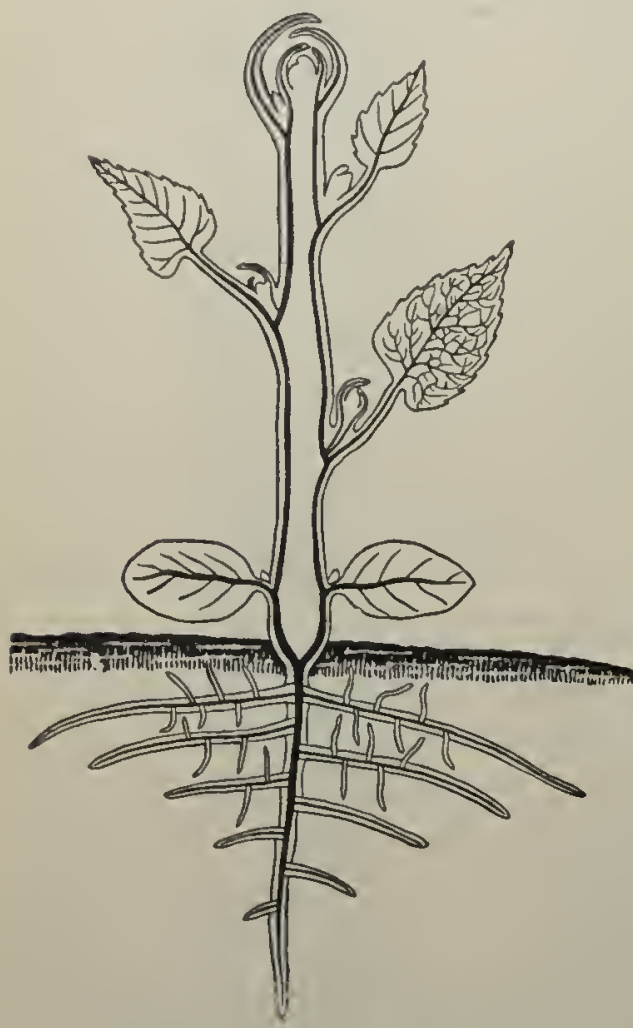

FIG. 73. Channels for the movement of water, upward and downward

The heavy black lines in roots, stems, and leaves show the course of the fibro-vaseular bundes through whieh the prineipal movements of water take place.-After Frank and Tsehirch

while the elaborated sap which is sent so abundantly into the ear of corn at its period of filling out, or into the growing pods of beans and peas, or into the lapidly forming acorn or the chestnut, contains great stores of food suited to sustain plant or animal life.

${ }^{1}$ See the paper on "The So-called Sap of Trees and its Movements," by Professor Charles R. Barmes, Science, Vol. XXI, p. 535.

It is important to notice that sap is by no means the same substance everywhere and at all times. As it first makes its way by osmotic action inward through the root hairs of the growing plant it differs but little from ordinary spring water or well water: The liquid which flows from the cut stem of a "bleeding" tree or grapevine which has been pruned just before the buds have begun to burst in the spring is mainly water, often with a little dissolved organic acids, proteids, and sugar. The sap whicl is obtained from maple trees in late winter or early spring, and is boiled down for sirup or sugar, is richer in nutritious material than the water of the grapevine,

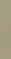

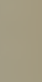


From the familiar facts that ordinary forest trees apparently flourish as well after the almost complete decay and removal of their heartwood, and that many kinds will live and grow for a considerable time after a ring of bark extending all round the trunk has been removed, it may readily be inferred that the crude sap in trees must rise through some portion of the newer layers of the wood. A tree girdled by the removal of a ring of

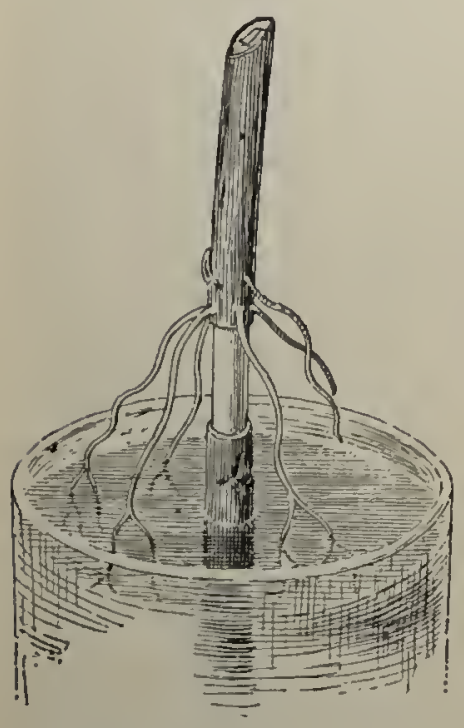

Fis. 74. A cutting girdled and sending down roots from the upper edge of the girdled ring

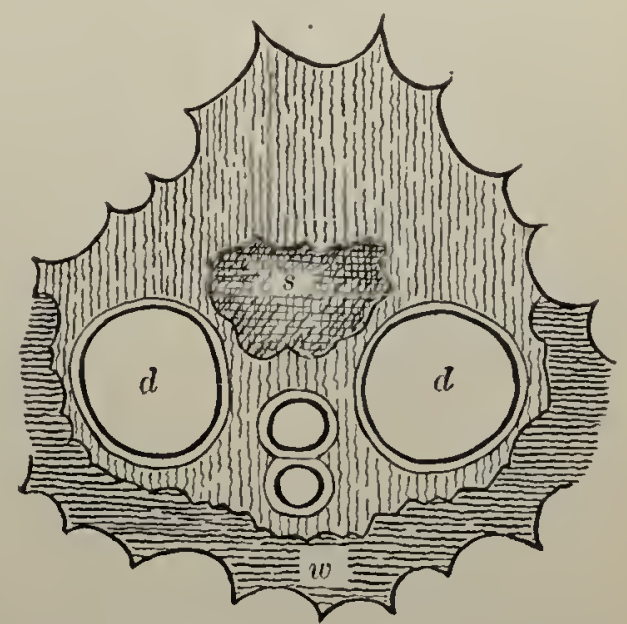

Fig. 75. Diagrammatic cross section of a buudle from sugar cane, showing channels for water and dissolved plant food

Water travels upward through the vessels $d$ and possibly through the wood cells in the region marked $w$. Water with dissolved plant food travels downward through the sieve tubes in the region $s$. Magnified

sapwood promptly dies. After the removal of a ring of bark a tree dies from starvation of the roots (See. 88; also see Fig. 394).

88. Downward movement of liquids. Most dicotyledonous stems, when stripped of a ring of bark and then set in water, as shown in Fig. 74, and eovered with a bell jar, develop roots only at or near the upper erge of the stripped portion. This would seem to prove that such stems send their building matcrial - the elaborated sap - largely, at any rate, down through 
the bark. Its course is undoubtedly for the most part through the sieve tubes (Figs. 63,64), which are admirably adapted to convey liquids. In addition to these general upward and downward movements of sap, there must be local transfers laterally through the stem, and these are at times of much importance to the plant.

Since the liquid building material travels straight down the stem, that side of the stem on which the manufacture of such

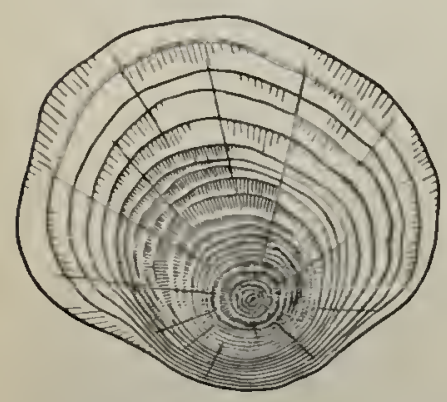

Fig. 76. Unequal growth of rings of wood in a nearly horizontal stem of juniper Natural size material is going on most rapidly should grow fastest. Plant food is made out of the raw materials by the leaves, and so the more leafy side of a tree forms thicker rings than the less leafy side, as shown in Fig. 76.

\section{Rate of movement of water in} the stem. There are many practical difficulties in the way of ascertaining exactly how fast the watery sap travels from the root to the leaves. It is, however, easy to illustrate experimentally the fact that it does rise, and to give an approximate idea of the time required for its ascent. The best experiment for beginners is one which deals with an entire plant under natural conditions; that is, by allowing a plant to wilt from lack of water, then watering it freely and noting how soon the leaves begin to recover their natural appearance and positions.

The interval of time will give a very rough idea of the time of transfer of water through the roots and the stem of the plant. From this, by measuring the approximate distance traveled, a calculation could be made of the number of inches per minute that water travels in this particular kind of plant, through a route which is partly roots, partly stem, and partly petiole. Still another method is to immerse the cut ends of leafy stems in eosin solution and note carefully the rate of ascent of the coloring liquid. This plan is likely to give results that are too 
low; still it is of some use. It lias given results varying from 34 inches per hour for the willow to 880 iuches per hour for the sunflower. A better method is to introduce the roots of the plant which is being experimented upon into a weak solution of some chemical substance which is harmless to the plant and which can readily be detected anywhere in the tissues of the plant by chemical tests. Proper tests are then applied to portions of the stem which are cut from the plant at short intervals of time.

Compounds of the metal litlium are well adapted for use in this morle of experimentation, if a spectroscope is available to test for its presence.

90. Causes of movements of water in the stem. Some of the phenomena of osmosis were explained in Secs. 4S-51, and the work of the root hairs was described as due to osmotic action.

That portion of the sap pressure which originates in the roots (Sec. 38), being apparently able to sustain a column of water only 80 or 90 feet high at the most (and usually less than half this amount), would be quite insufficient to raise the sap to the tops of the tallest trees, since many kinds grow to a height of more than 100 feet. Our California "big trees," or Sequoias, reach the height of over 300 feet, and an Australian species of Eucalyptus, it is said, sometimes towers up to 470 feet. Root pressure, then, may serve to start the soil water on its upward jouruey, but some other force or forces must step in to carry it the rest of the way. What these other forces are is still a matter of discussion among botanists.

The slower inward and downward movement of the sap may be explained as due to osmosis. For instance, in the case of growing wood cells, sugary sap descending from the leaves into the stem gives up part of its sugar to form the cellulose of which the wood cells are being made.

This loss of sugar leaves the sap rather more watery than usual, and osmosis carries it from the growing wood to the leaves, while at the same time a slow transfer of the dissolved 
sugar is set up from leaves to wood. The water is thrown off in the form of vapor as fast as it reaches the leaves, so that they do not become distended with water, while the sugar is changed into cellulose and built into new wood cells as fast as it reaches the region where such cells are being formed.

Plants in general ${ }^{1}$ readily change starch to sugar, and sugar to starch. When they are depositing starch in any part of the root or stem for future use, the withdrawal of sugar from those portions of the sap which contain it most abundantly gives rise to a slow movement of dissolved particles of sugar in the direction of the region where starch is being laid up.

91. Storage of food in the stem. The reason why the plant may profit by laying up a food supply somewhere inside its tissues has already been suggested (Sec. 33).

The most remarkable instance of storage of food in the stem is probably that of sago palms, which contain an enormous amount, sometimes as much as eight hundred pounds, of starchy material in a single trunk. But the commoner plants of temperate regions furnish abundant examples of deposits of food in the stem.

92. Storage in underground stems. The branches and trunk of a tree furnish the most convenient place in which to deposit food during winter to begin the growth of the following spring. But in those plants which die down to the ground at the beginning of winter the storage must be either in the roots or in underground portions of the stem.

Rootstocks, tubers, and bulbs seem to have been developed by plants to answer as storehouses through the winter (or in some countries through the dry season) for the reserve materials which the plant has accunulated during the growing season. The commonest tuber is the potato, and this fact and the points of interest which it represents make it especially desirable to use for a study of the underground stem in a form most highly specialized for the storage of starch and other valuable products.

1 Not including most of the spore plants. 
It is evident that in the potato we have to do with a very highly modified form of stem. The corky layer of the bark is well represented, and the loose cellular layer beneath is much developed; woor is almost lacking, but the pith is greatly developed and constitutes the principal bulk of the tuber. All this is readily understood if we consider that the tuber, buried in and supported by the earth, does not need the kinds of tissue which give strength, but only those which are well adapted to store the requisite amount of food.

93. Occurrence of sugar in the stem. Grape sugar is an important substance anong those used for food by the plant. It received its name from the fact that it was formerly obtained for chemical examination from grapes. Old dry raisins usually show little masses of whitish material scattered over the skin which are nearly pure grape sugar. Commercially it is now manufactured on an enormous scale from starch by boiling with diluted hydrochloric acid. In the plant it is made from starch by processes as yet imperfectly understood, and another sugar, called maltose, is made from starch in the seed during germination. Sugar is not as well adapted for reserve deposits as starch, since it ferments easily and may escape by osmosis from tissues which contain it. In the onion bulb it is stored in considerable quantities and may be detected by a simple chemical test. 


\section{CHAPTER IX}

\section{BUDS}

94. Structure of winter buds. Dissection of most winter buds shows that they are composed of an outer covering of

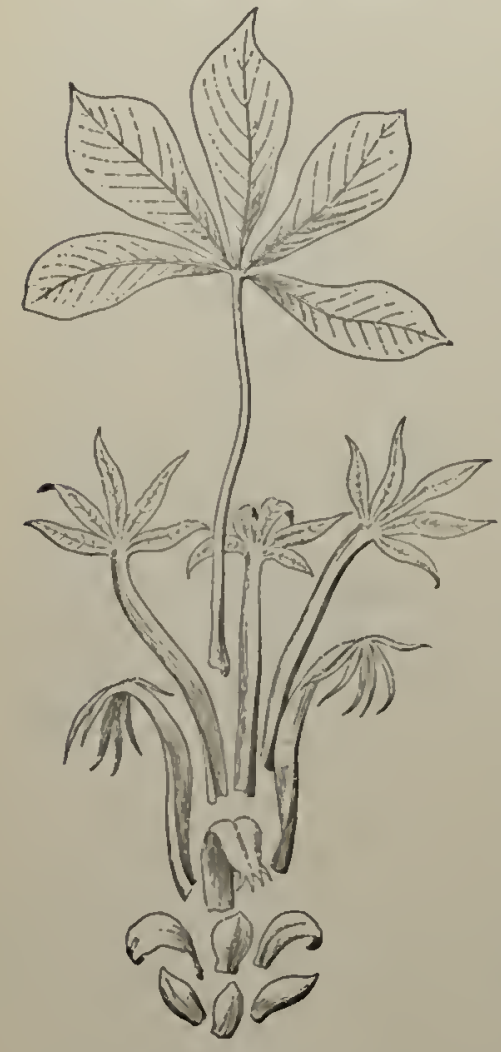

Fur. it. Dissected bud of buckeye (AEsculus macrostachya), showing transitions from bud scates to leaves tough, often hairy or resin-covered seales and an interior mass of small undereloped leaves, closely packed together. Not infrequently a rudimentary flower cluster oceupies the central portion of the bud.

95. Nature of bud scales. The fact that the bud scales are in certain cases merely imperfeetly developed leaves or leafstalks is often clearly manifest from the series of steps connecting the bud scale on the one hand with the young leaf on the other, which may be found in many opening buds, as illustrated by Fig. 77. In other buds the scales are not imperfect leares, but the little appendages (stipules, Figs. 89, 90) which occur at the bases of leaves. This kind of bud scale is especially well shown in the magnolia and the tulip tree and in the familiar "rubber plant" (Ficus elastica).

96. Naked buds. All the kinds above mentioned are resting buds, and in temperate or cold climates winter buds, capable of 


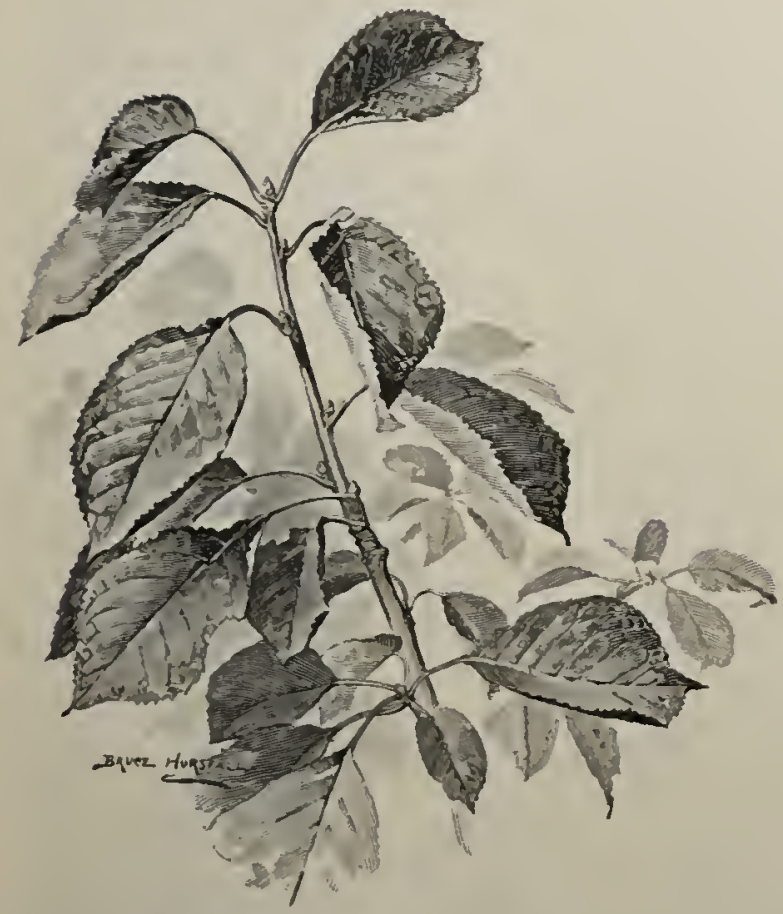

FIG. 79. Alternate leaves of cultivated cherry, with buds in their axils, in October

living through the colder months of the year, and are also scaly buds.

In the herbs of temperate climates, and even in shrubs and trees of tropical regions, the buds are often naked; that is, nearly or quite destitute of scaly coverings (Fig. 78). These are best suited for a season or a climate which is both warm and moist. The scales, of whatever sort, with their coatings of hair or of resinous material, are of use mainly in protecting buds from sudden clanges of temperature or too rapid loss of water. The latter, in climates like that of southern California or the Mediterranean coast, would be during the rainless summer.

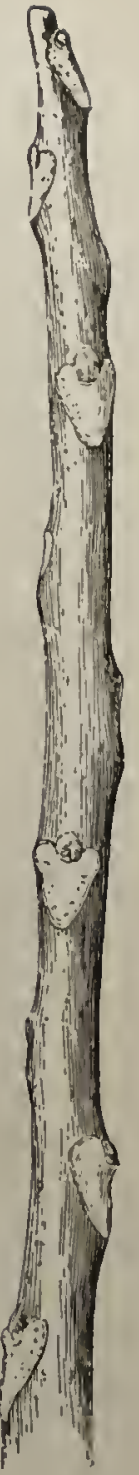

FIG. 78

Tip of brancli of Ailanthus in winter condition, showing very large leaf scars and nearly naked buds 
In most cold or temperate climes it would be during the winter, when little water can be drawn from the soil (Sec. 39).

97. Position of buds. The distinction between lateral and terminul buds has alrealy been alluded to (Sec. 57 ).

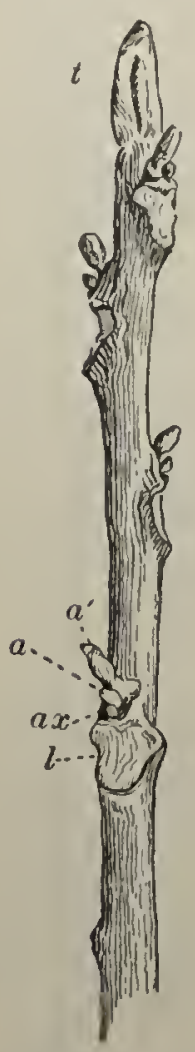

Fig. 80. Accessory buds of butternut

$l$, leaf sear; $a x$, axillary bud; $u, a^{\prime}$, accessory buds; $t$, terminal burl. Reduced.

'The plumule is the first terminal bud which the plant produces. Tateral buds are usually axillary, as shown in Fig. 79, that is they grow in the angle formed by the leaf with the stem (Latin, axilla, armpit); but not infrequently there are several buds grouped in some way about a single leaf axil, either one above the other, as in the butternut (Fig. S0), or

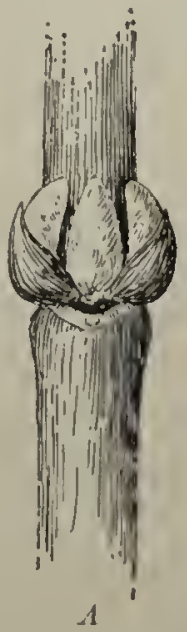

Fig. 81. Accessory buds of box elder (Negundo)

$A$, front view of group ; $P$, two groups seen in profile. Magnified

grouped side by side, as in the red maple, the cherry, and the box elder (Fig. 81).

In these cases all the buds, except the axillary one, are called accessory or supernumerary buds. Those which appear in 
irregular positions, as on roots, on unusual parts of the stem, or on leaves (Fig. SS), are called adrentitious buds.

98. Leaf buds and flower buds; the bud an undeveloped branch. Buds are of three principal classes: leaf buds, in which the parts inside of the scales develop into leaves, and their central axes into stems; mixed buds, which contain both leaves and flowers in an undeveloped condition; and flower buds, which contain the rudiments of flowers only.

Sometimes, as in the black walnut and the butternut, the leaf buds and flower buds are readily distinguishable by their

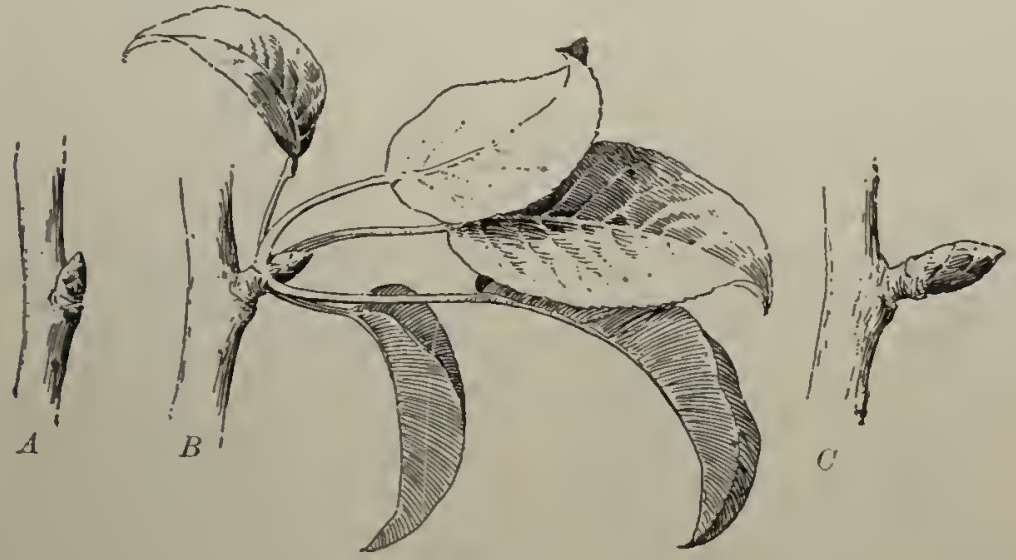

Fig. 82

$A$, a pear leaf bud in autumn; $B$, a leafy shoot derived from $A$, as seen in the Iniddle of the following summer, with flower bud at tip; $C$, the fruit spur, $B$, in autumn, after the fall of the leaves. - After Percival

difference in form; while in other cases, as in the cultivated cherry, the difference in form is but slight. In many plants, as the lilac, there is a notable difference in size.

The rings of scars about the twig, shown in Figs. 79 and 84 , mark the place where the bases of bud scales were attached. A little examination of the part of the twig which lies above this ring, as shown in Fig. 79, will lead one to the conclusion that this portion has all grown in the one spring and summer since the bud scales of that particular ring dropped off. 
Following out this suggestion, it is easy to reckon the age of any moderately old portion of a branch, since it is equal to the

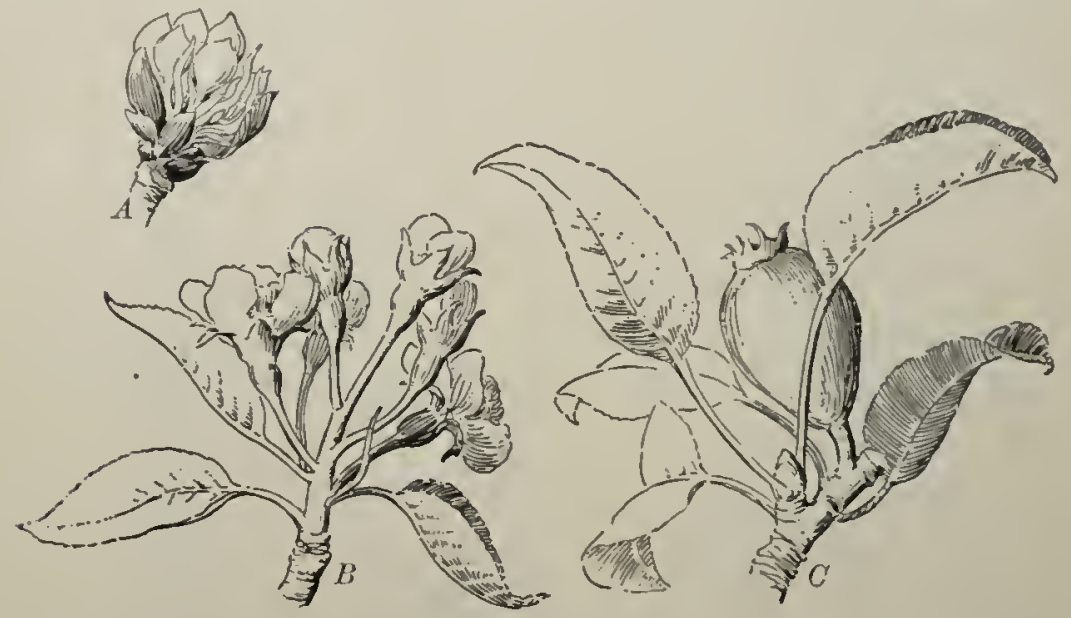

Fig. 83. Fruit bud of pear (same as $C$, of Fig. 82), showing its developinent $A$, opening in spring; $B$, later, developing flowers and leaves; $C$, later still : only one flower las produced a fruit, the rest luaving fallen off. Below it is a lateral bud which will continue the spur next year. - After Percival

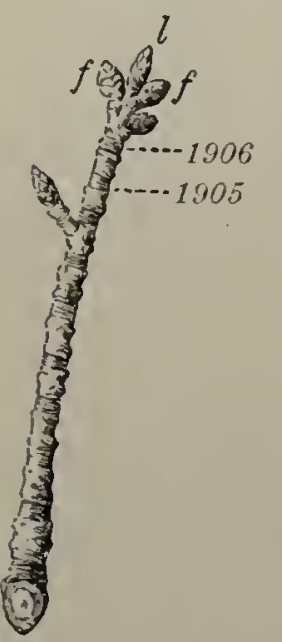

FIg. 84. A slowly grown twig of cherry, three inches long and about ten years old

The pointed bud $l$ is a leaf bud; the more obtuse accessory bu: Is $f, f$ are flower buds number of segments between the rings. In rapidly growing shoots of willow, poplar, and similar trees, five or ten feet may be the growth of a single year, while in the lateral twigs of the hickory, apple, or cherry, the yenrly increase may be but a fraction of an inch. Such "spurs" as are shown in Figs. S2-84 are of little use in the permanent growth of the tree, and poplars, elms, soft maples, and other trees shed the oldest of these every year. In any case the growth is but the development of the bud, which may be regarded as an undeveloped stem or brauch, with its internodes so shortened that successive leaves seem almost to spring from the same point. 
99. Vernation. The arrangement of leaves in the bud is called vernation; some of the principal modes are shown in Fig. 86. In the cherry the two halves of the leaf are folded together flat, with the under surfaces outward; in the walnut the separate leuflets, or parts of the leaf, are folded flat and then grouped into a sort of cone; in the snowball each half of the leaf is plaited in a somewhat fan-like manner, and the edges of the two halves are then brought round so as to meet; in the lady's mantle the fan-like plaiting is very distinct; in the wood sorrel each leaflet is folded smoothly, and then the three leaflets packed closely side by side. All these modes of vernation, and many others, often characteristic of groups of plants, have received descriptive names by which they are known to botanists.

\section{Importance of verna-} tion. The significance of veruation is best understood by considering that there are two important purposes to be served: the leaves must be stowed as closely as possible in the bud, and upon beginning to open

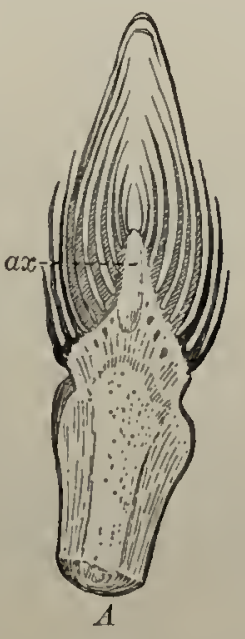

Fig. 85

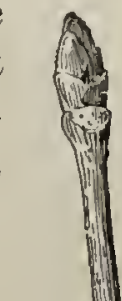
they inust be protected from too great heat and dryness until they have reached a certain degree of firmness. It may be inferred from Fig. 86 that it is common for very young leaves to stand vertically. This protects them considerably from the scorching effect of the sun at the hottest part of the day. Many young leaves, as, for instance, those of the silver-leafed poplar, the lear, the beech, and the mountain ash, are sheltered and protected from cold, dryness, and the attacks of small 
insects by. a coating of wool or down, which they afterwards lose. The leares of the tulip tree are inclosed for a little time

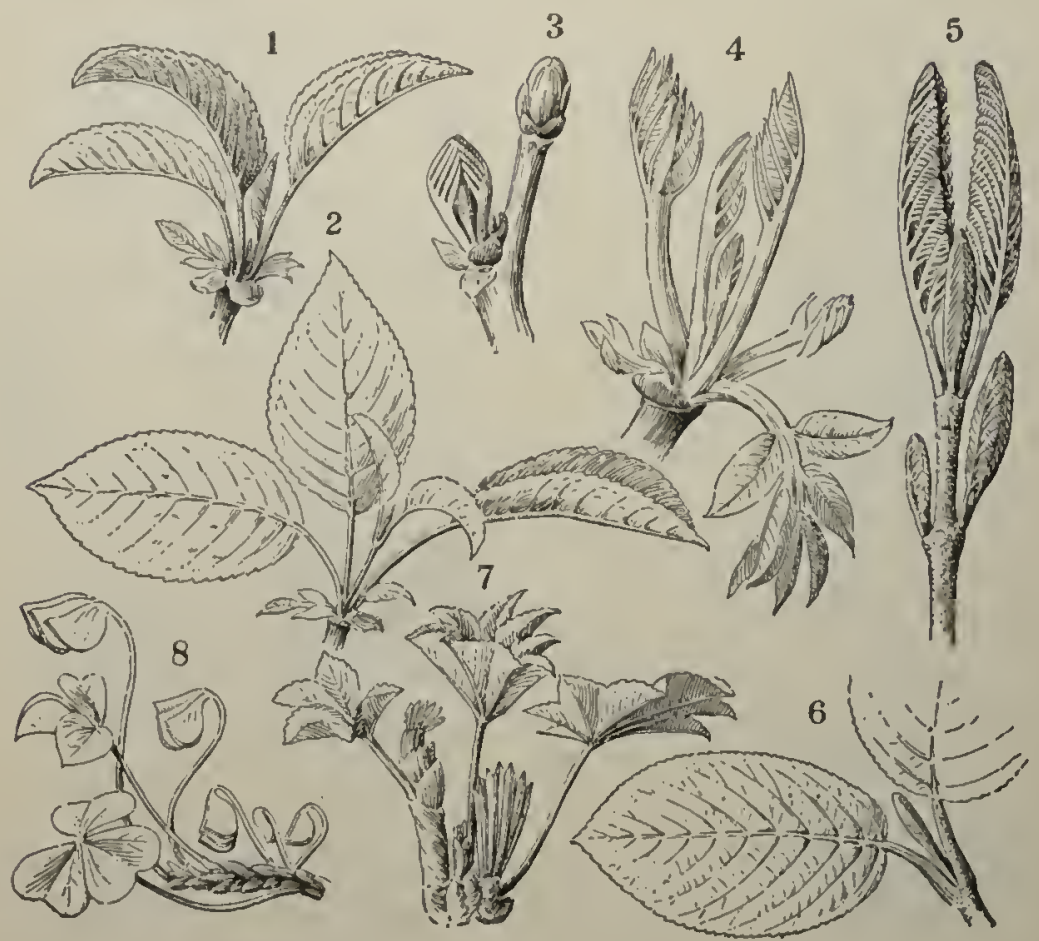

FIG. 86. Types of vernation

1,2 , cherry; 3,4 , European walnut ; 5,6 , snowball; 7 , lady's mantle; 8 , oxalis. After Kerner
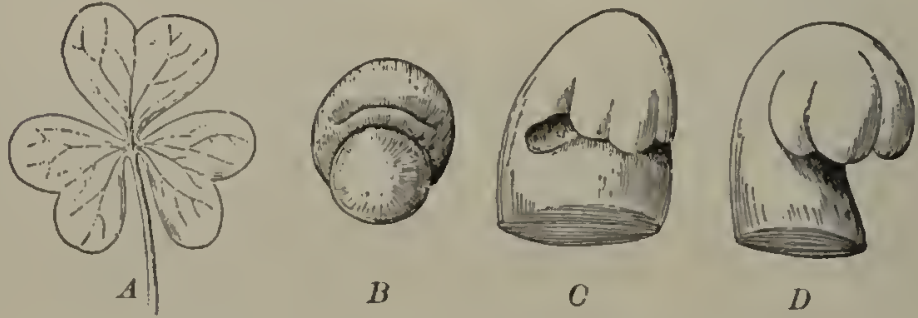

Fig. 87. Development of an oxalis leaf

$A$, full-grown leaf; $B$, rulimentary leaf, the leaflets not yet evident; $C$, more advancerl stage, the leaflets appearing; $D$, a still more advanced stage. $B, C$, and $D$, cousiderably magnified. - After Frank 
in thin pouches, which serve as bud scales, and are thus entirely shielded from direct contact with the outside air.

101. Dormant buds. Generally some of the buds on a branch remain undeveloped in the spring, when the other buds are begimuing to grow, and this inactive condition may last for many seasons. Finally the bud may die, or some injury to the tree may destroy so many other buds as to leave the dormant ones an extra supply of food, and this, with other causes, may force them to develop and to grow into branches.

Sometimes the tree altogether fails to produce buds at places where they would regularly occur. In the lilac the terminal bud usually fails to appear, and the result is constant forking of the branches.

102. Adventitious buds. Buds which occur in irregular places, that is, not terminal nor in or near the axils of leaves, are called adventitious buds; they may spring from the roots, as in the silver-leafed poplar, or from the sides of the trunk, as in our Ainerican elm. In many

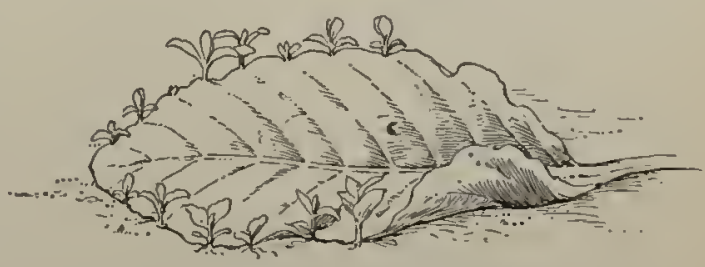

Fig. 88. Budding leaf of Bryophyllum trees, for instance willows and maples, they are sure to appear after the trees have been cut back. Willows are thus cut back, or pollarded, in order to cause them to produce a large crop of slender twigs suitable for basket making.

Leaves rarely produce buds, but a few kinds do so when they are injured. Those of the Bryophyllum (Fig. 88), a plant allied to the garden live-forever, when they are removed from the plant while they are still green and fresh, almost always send out buds from the margin. These do not appear at random, but are borne at the notches in the leaf margin and are accompanied almost from the first by minute roots. This plant seems to rely largely upon leaf budding to reproduce itself, for in a cool climate it rarely flowers or seeds. 


\section{CHAPTER X}

\section{LEAVES}

103. The leaf as a member of the plant body. Among seed plants the plant body consists of root and shoot. The latter

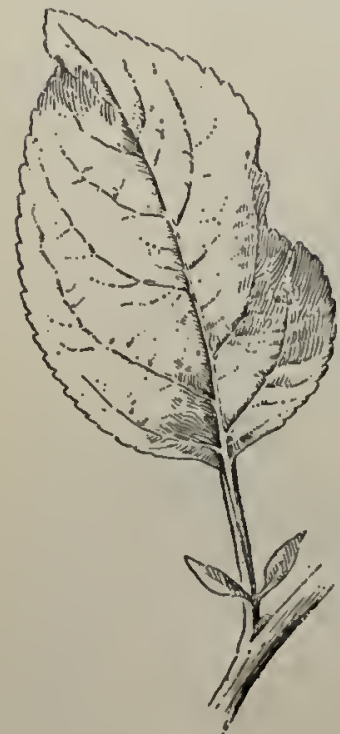

Fig. 89. Leaf of apple, with stipules

After Thomé is made up of stem and leaves. It is difficult to frame a simple and exact definition for the leaf, but every one is sufficiently familiar with the appearance of the ordinary foliage leaves of plants, and there is no difficulty in identifying these. The unusual scale-like, bristle-shaped, tendrilshaped, or pitcher-form leaves are often hard to recognize as such.

104. Parts of the leaf. In the typical foliage leaf there are three parts, - the expanded portion, or blade (lamina), the leafstalk (petiole), and a pair of appendages at the base of the petiole known as stipules. Many leaves have no petiole and are said to be sessile (meaning sitting). Others liave no blade and perform their functions as foliage by means of a flattened petiole or large stipules. Most Fig. 90. Leaf of leaves are bilaterally symmetrieal; that is, they have a right and a left half, which, if folded together along the middle line of the leaf, would

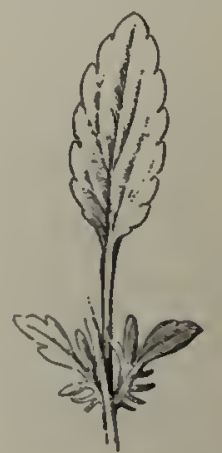
nearly coincide. Usually the upjer and the under surface differ from each other in color, smoothness, and other respects. 
105. Veining. The blade of the leaf is traversed by a framework of fibro-vascular bundles known as veins. These are arranged in many ways, but the two principal types are closed, or parallcl-veined, and open, or netted-reined, leaves. In the former the veins run more or less nearly parallel, either from base to tip of the leaf, or from a midrib outward. In the latter the veins are branched so as to form a network.

106. Palmate and pinnate veining. In netted-veined leaves scveral ribs may radiate from the end of the petiole, like the sticks of a fan. Such veining is said to be palmate. If

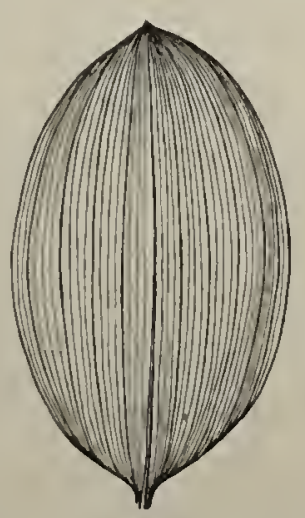

Fig. 91. Parallel-veined leaf of Solomon's seal

After Strasburger

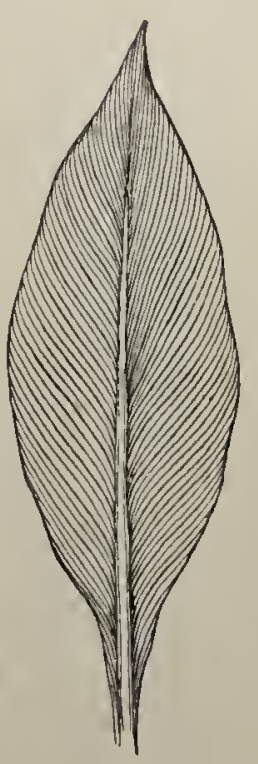

FIa. 92. Parallel veining in canna. Veins l'tuning frow midrib to margin there is only one midrib, from which smaller ribs extend both ways, the veining is said to be pinnate (menning feather-like).

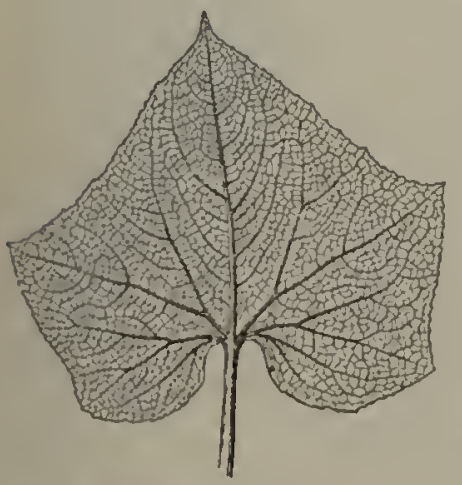

FIG. 93. Netted veining (palinate) in leaf of melon After Decaisne Often the reining is intermediate between these two types.

\section{Relation of shape to mode of} veining. Since the water supply of the leaf is carried through the veins, and since they support the softer parts between them, one would expect to find that the form of the leaf would bear a close relation to its mode of veining. This is the case, and in general palmately veincd leaves are roundish, while pinnatcly 
reined ones are longer than they are wide. These differences are particularly noticeable in leaves in which the leaf blade is not all of one piece, - dirided leares (Kigs. 95, 96).

Usually veins, near their origin, follow a pretty straight course. 'This is desirable, in order to carry water as speedily as possible from the base of the leaf to its tip. The arrange-

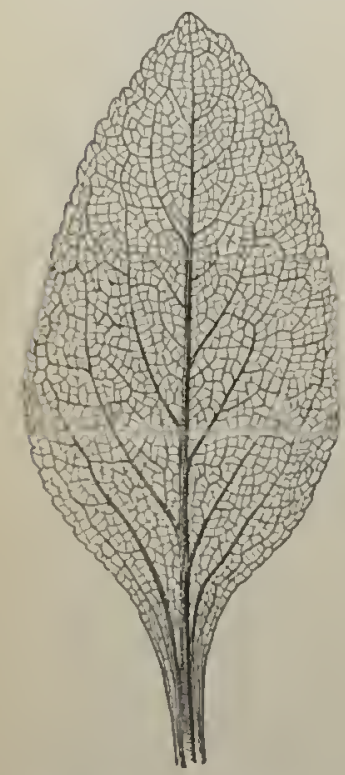

Fig. 94. Netted veining (pinnate) in leaf of foxglove

After Planchon ment of the veins in the leaves of most land plants is admirably adapted to strengthen the leaf and protect it from being torn. In inany eases the last-named result is secured by a sort of "binding" of looped veins running around the margin, as is fairly well shown in Fig. 94.

108. Description of leaf forms. The various forms of leaves are classed and described by botanists with great ininuteness, ${ }^{1}$ not simply for the study of leaves themselves, but also because in classifying and describing plants the characteristic shapes of the leaves of many kinds of plants form a simple and ready means of distinguishing them from eacl other and identifying tliem.

\section{Occurrence of netted or parallel} veining. With few exceptions, the leaves of monoeotyledonous plants are parallel-reined and tlose of dicotyledonous plants netted-reined.

The needle-like leaves of the pines, spruees, firs, larclies, and other coniferous trees have but a single vein, or two or three parallel ones; but in their case the veining could hardly be other than parallel, since the leaves are so narrow that no veins of any considerable length could exist except in a position lengthwise of the leaf.

I See Kemer and Oliver, Natural History of Plants, Vol. I, pp. 623-637. See also Appendix to this book. 
Monocotyledonons plants seldom have leaves with notched or cut margins, while dicotyledonous plants frequently have them.

A certain plan of venation is found mainly in plants with a particular mode of germination, of stem structure, and of arrangement of floral parts, and this is but one of the frequent cases in botany in which the structures of plants are correlated in a way which is not easy to explain.

No one knows why plants with two cotyledoms should have netted-reined leaves, but many such facts as this are familiar to every botanist.

\section{Simple and compound leaves.} The leares so far studied are simple leares, that is, leaves of which the blades are more or less entirely united

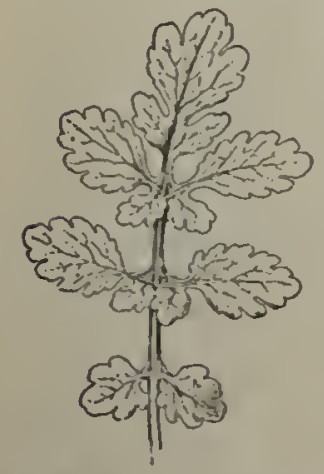

Fig. 06. Pinnately divided leaf of celandine

After Decaisne into one piece. But while in the elm the margin is cut in only a little way, in some maples it is

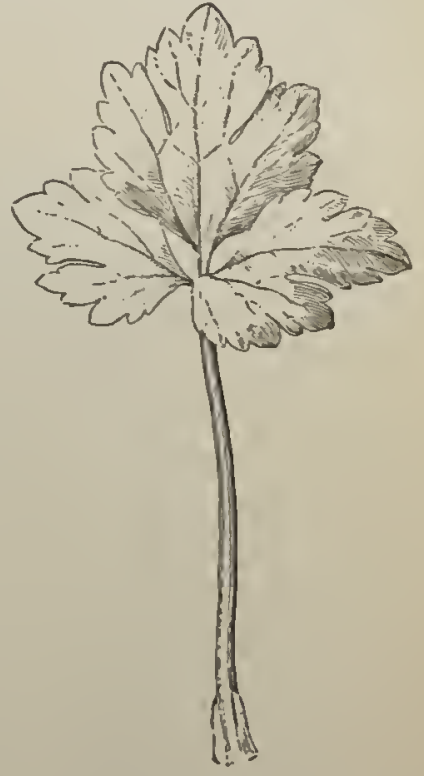

FIG. 95. Palmately divided leaf of buttercup

The blade of the leaf is discontinuous, consisting of sereral portions. - After Decaisue deeply cut in toward the bases of the reins. In some leaves the gaps betreen the adjacent portions extend all the way down to the petiole (in palmately reined leaves) or to the midrib (in pimnately reined ones). Such divided leaves are shown in Figs. 95 and 96 .

In still other leaves, known as compound laces, or lnanched leares, the petiole, as shown in Fig. 99 (pulmutely compound), or the midrib, as shown in Fig. 97 (pinnutely compouml), bears what look to be separate leares. These cliffer in their nature and mode of origin from the 
portions of the blade of a divided leaf. One result of this difference appears in the fact that some time before the whole leaf is ready to fall in autumn, the leaflets of a compound leaf are seen to be jointed at their attachments. In Fig. 99 the horse-chestnut

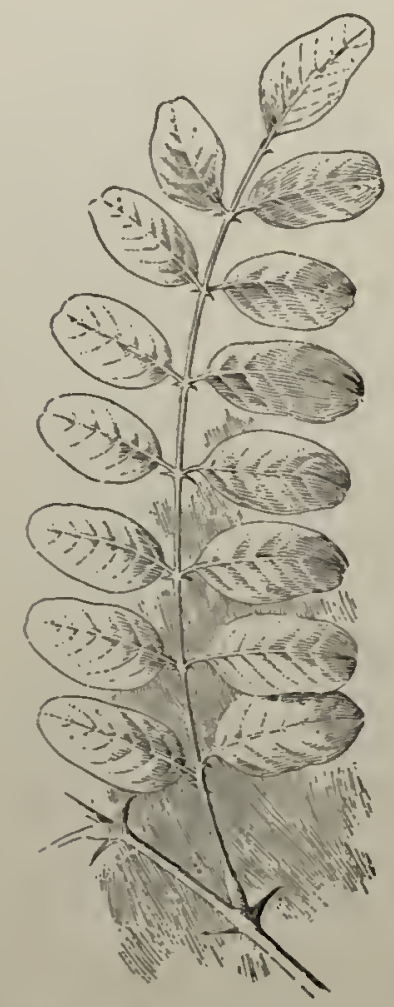

F16. 97. Pinnately compound leaf of locust, with spines for stipules

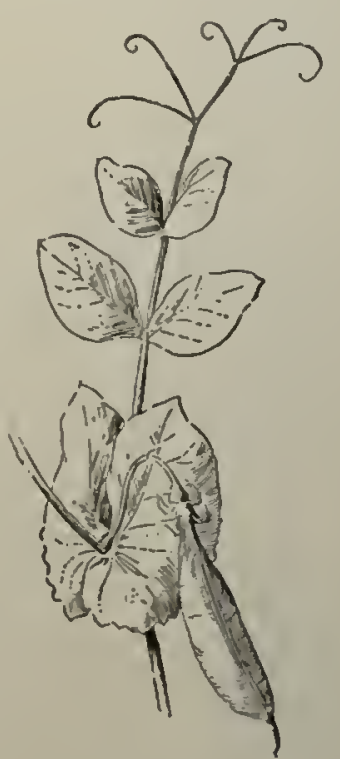

FIG. 98. Pinnately compound leaf of pea

A tendril takes the place of a terminal leaflet

leaf is shown at the time of falling, with some of the leaflets already disjointed.

That a compound leaf, in spite of the joints of the separate leaflets, is really only one leaf is shown: (1) by the absence of buds in the axils of leaflets (see Fig. 97); (2) by the horizontal arrangement of the blades of the leaflets, without any twist in their individual leafstalks; (3) by the fact that their arrangement on the midrib does not follow any of the systems of leaf 
arrangement on the stem (Sec. 111). If each leaflet of a compound leaf should itself become compound, the result would be to produce a twice compound leaf (Fig. 108).

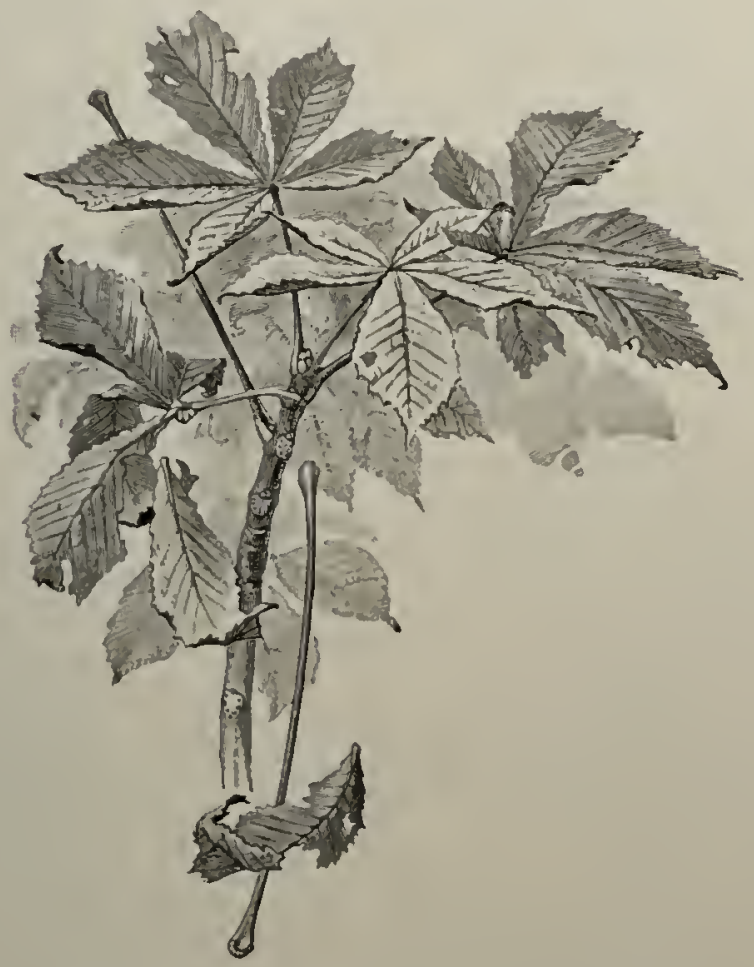

Fig. 99. The fall of the horse-chestnut ieaf 


\section{CHAP'TER XI}

\section{LEAF ARRANGEMENT FOR EXPOSURE TO SUN AND AIR; HELIOTROPIC MOVEMENTS OF LEAVES AND SHOOTS}

111. Leaf arrangement. ${ }^{1}$ Leaves are quite generally arranged so as to secure the best possible exposure to the sun and air. This, in the vertical shoots of the elm, the oak (Fig. 100), the apple, beech, and other alternate-leaved trees, is quite consistent with their spiral arrangement. In horizontal twigs and branches

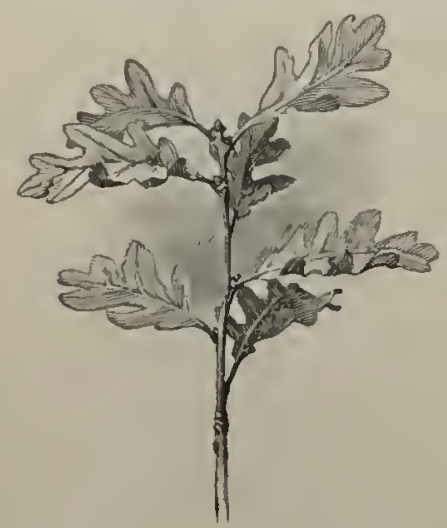

FIG. 100. Leaf arrangement of the oak

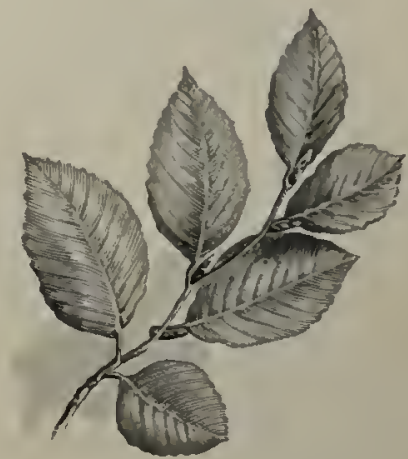

FIG. 101. Leaf arrangement of European beech

of the elm, the beech (Fig. 101), the chestmut, the linden, and many other trees and shrubs, the desired effect is secured by the arrangement of all the leaves in two flat rows, one on each side of the twig. The rows are produced, as is easily seen on examining such a leafy twig, by a twisting about of the leafstalks. The adjustment in many opposite-leaved trees and shrubs consists in having each pair of leaves corer the spaces hetween the pair below it, and sometines in the lengthening of the lower

1 See Kerner and Oliver, Natural History of Plants, Vol. I, pp. 3M-424. 


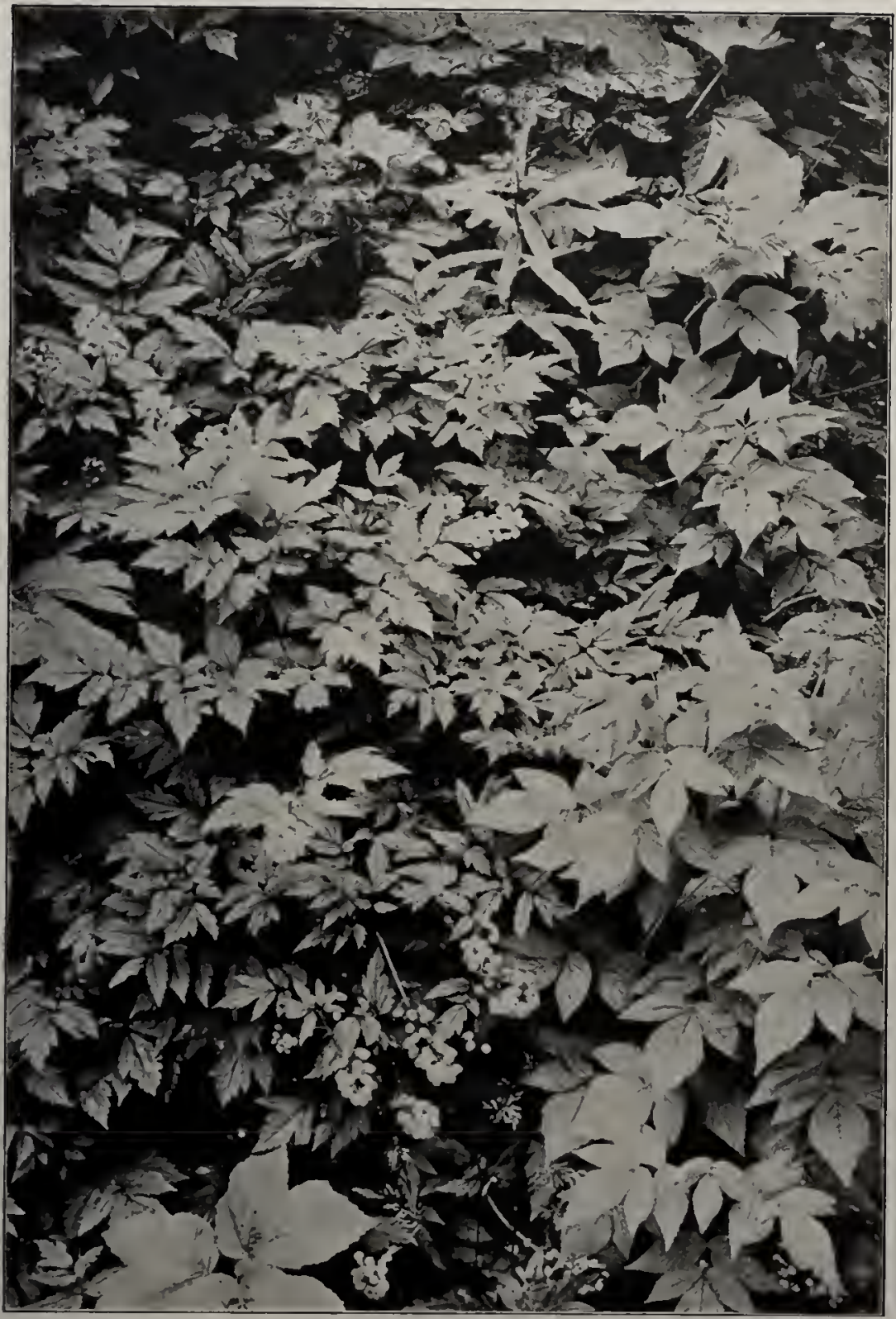

PLate II. Leaves arranged for maximum illumination After F. E. Clements 

leafstalks so as to bring the blades of the lower leaves outside those of the upper leaves. Examination of Figs. 102 and 103 will make the matter clear.

The student who observes the leafage of trees of different kinds on the growing tree itself may notice how circumstances modify the position of the leaves. Maple leaves, for example, on the ends of the branches are arranged much like those of the horsechestnut, but they

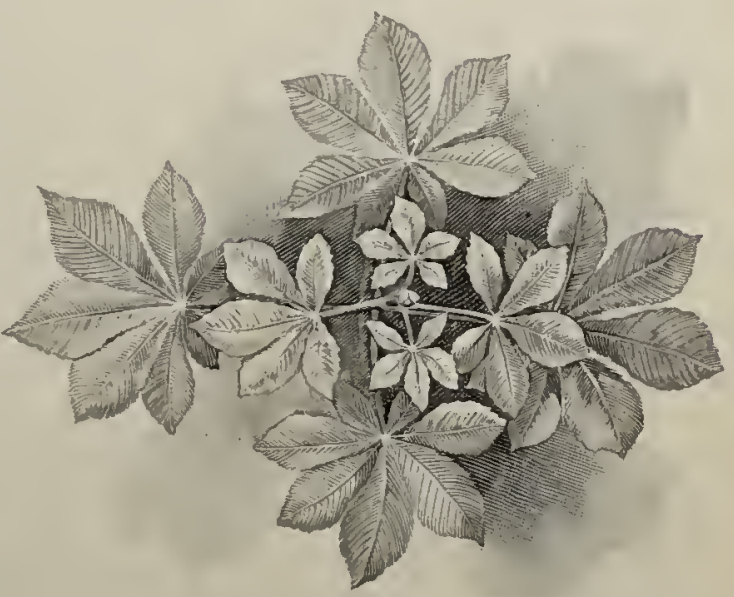

Fig. 102. Leaf arrangement of horse-chestnut on vertical shoots (top view)

After Kerner are found to be arranged more nearly flatwise along the inner portions of the branches, that is, the portions nearer the tree.

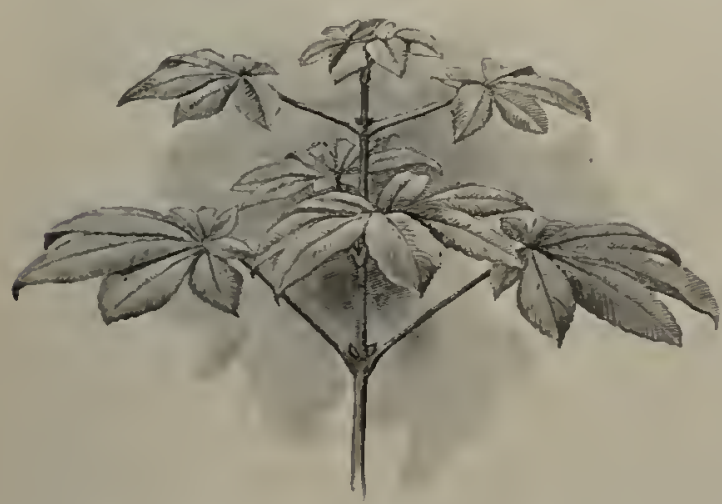

Fia. 103. Leaf arrangement of horse-chestnut on vertical shoots (side view)

After Kerner

Figs. 104 and 105 show the remarkable difference in arrangement in different branches of the Deutzia, and equally interesting modifications may be found in alternate-leaved trees, such as the elm and the cherry.

112. Leaf mosaics.

In very many cases the leaves at the end of a shoot are so arranged as to form a rather symmetrical pattern, as in the horse-chestnut (Fig. 102). 
When this is suffieiently regular, usually with the spaees between the leaves a good deal smaller than the areas of the leaves themselves, it is ealled a leaf mosaic (Fig. 106). Many of the most interesting leaf groups of this sort, as in the figure above mentioned, are found in the rosettes of the so-called root leaves of plants. Good examples of these are the dandelion, ehieory, fall dandelion, thistle, hawkweed, Pyrola, and plantain. The leaves of these plants are kept from shading eaeh other, sometimes by

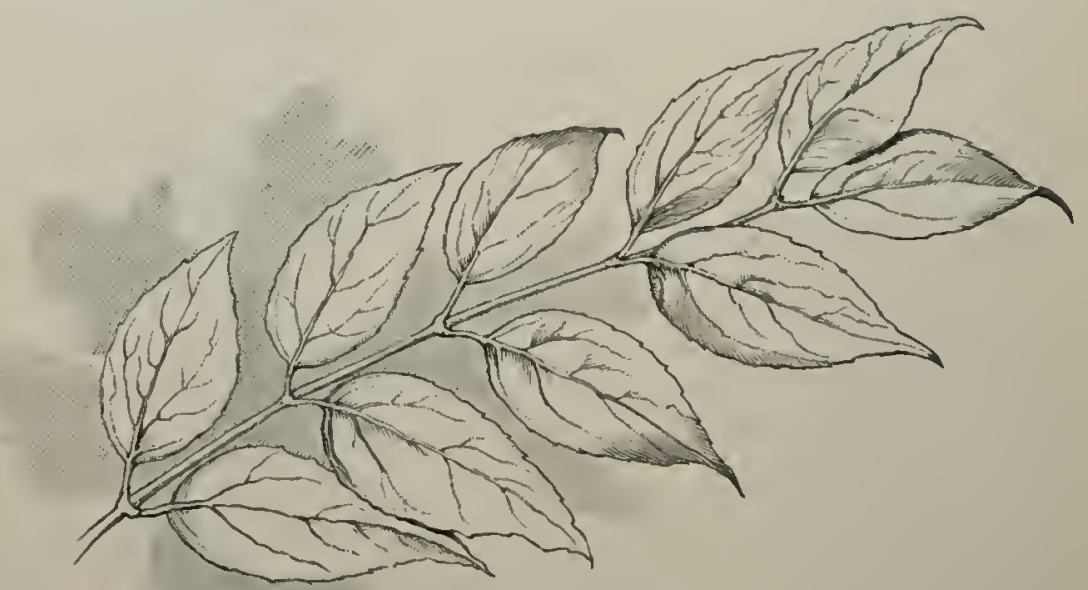

Fig. 104. Opposite leaves of Deutzia ${ }^{1}$ (from the same shrub as Fig. 105) as arranged on a horizontal branch

the narrowness of the leaves and sometimes by the lengthening of the leafstalks of the lower ones.

113. Much-divided leaves. Not infrequently leaves are cut into slender, fringe-like divisions, as in the earrot, tansy, southernwood, wormwood, yarrow, dog fennel, cypress vine, and many other eommon plants. This kind of leaf seems to be adapted to offer eonsiderable surfaee to the sun without eutting off too mueh light from other leaves underneath. Sueh a leaf is in mueh less danger of being torn by severe winds than are broader ones with undivided margins. The same purposes are served by

1 Deutzia crenata. 
compound leaves with very many small leaflets, such as those of the honey locust, the mimosa, acacia (Fig. 10S), and other trees and shrubs of the pea family.

114. Daily movements of leaves. Many compound leaves have the power of changing the position of their leaflets to accommodate themselves to varying conditions of light and temperature. Some plants have the power of direct-

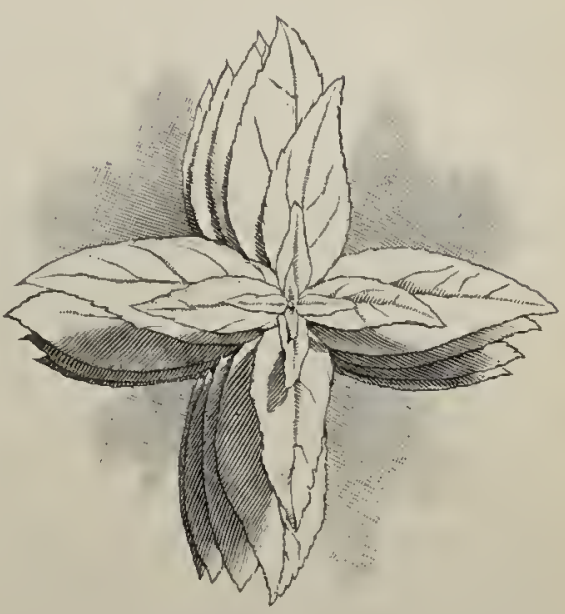

FIG. 105. Opposite leaves of Deutzia, as arranged on a vertical branch 1 ing the leaves or leaflets edgewise towards the sun during the hottest parts of the day, allowing them to extend their sur-

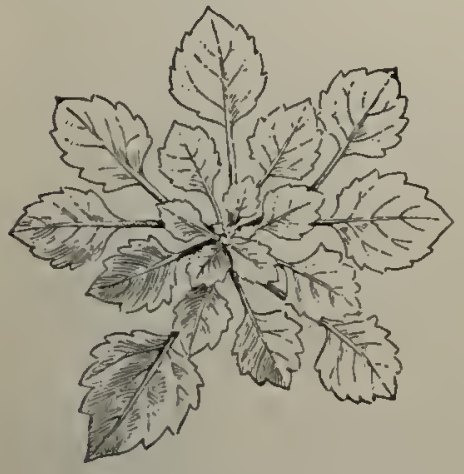

FIG. 106. Leaf mosaic of a Campanula

After Kerner faces more nearly in a horizontal direction during the cooler hours.

The so-called "sleep" of plants has long becn known, but this subject has been most carefully studied rather recently. The wood sorrel, or oxalis, the common bean, clover's, and the locust tree are some of the most familiar of the plants whose leaves assume decidedly different positions at night from those which they occupy during the day. Sometimes the leaflets rise at night, and in many instances they drop, as in the red clover (Fig. 107) and the acacia (Fig. 108). One useful purpose, at any rate, that is served by the nocturnal position of the leaf is protection from frost. It has been proved experimentally that when

${ }^{1}$ It will be noticed that the exposure to sunlight is here not nearly as favorable as in Fig. 104. 
part of the leaves on a plant are prevented from assuming the folded position, while others arc allowed to do so, and the plant is
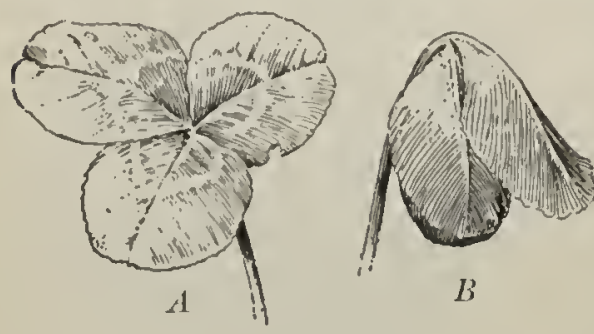

Fig. 107. $\Lambda$ leaf of red clover $A$, leaf by day; $B$, the same leaf at night then exposed during a frosty night, the folded ones may escape, while the others are killed. Since many plants in tropical climates fold their leaves at night, it is ccrtain that this movement has other purposes than protection from frost, and probably there is much yet to be learned about the meaning and importance of leaf movements.

115. Self-induced movements; sensitive plants. Some leaves, notably those of the so-called telegraph plant, ${ }^{1}$ have the power of maintaining pretty rapid movements without external stimuli. The small lateral leaflets of this plant, through a considerable range of temperatures above $72^{\circ} \mathrm{F} .\left(22^{\circ} \mathrm{C}\right.$. $)$, in light or darkness alikc, continue to nove first up, then down, so that their tips make a complete

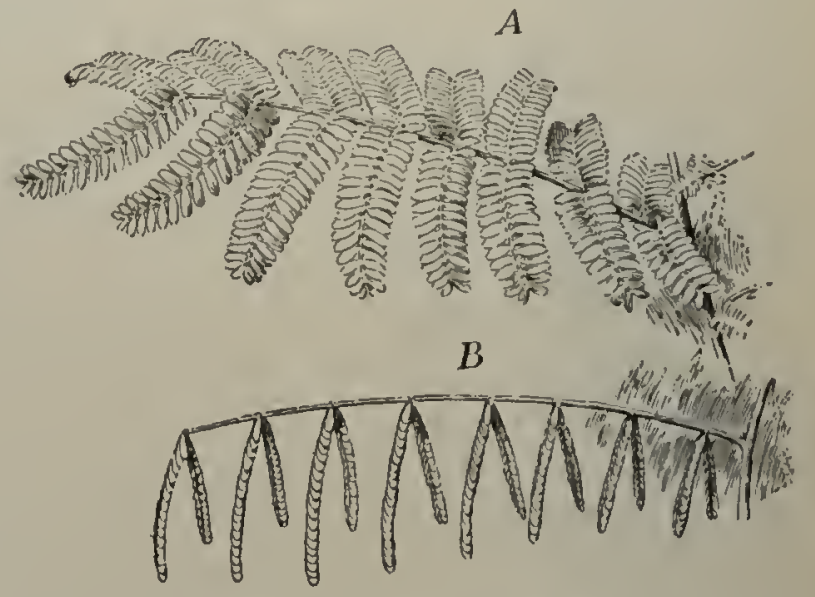

Fifi. 108. A leaf of acacia circle in from one $A$, as seen by day; $B$, the same leaf at night. $-\lambda$ fter to three or more Darwin minutes. The motion is jerky, like that of the second hand of a watch, and gives onc a vivid impression of the plant as a living thing. 
A good many plants of the pea family have leaflets which are sensitive to the touch. The best-known species is the common sensitive plant of the florists, ${ }^{1}$ the leaflets of which close and drop, like those of Fig. 108, and the leafstalks droop when the plant is touched or jarred. Some of our common wild plants of the same family ${ }^{2}$ have leaves which promptly show irritability

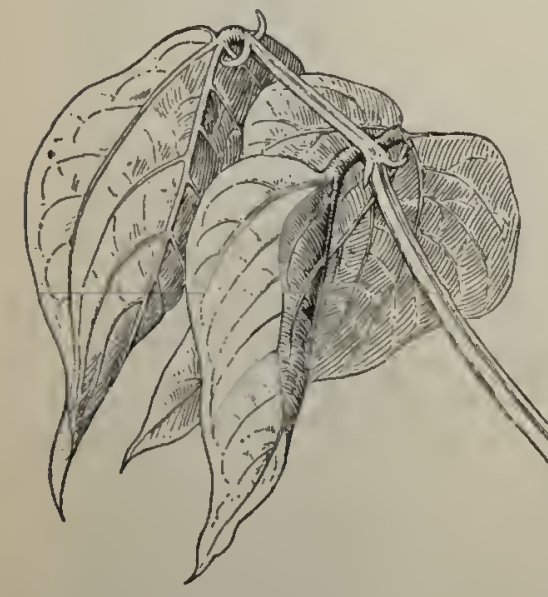

FiG. 109. Compound leaf of bean with pulvinus

The pulvinus shows as an enlargement in the figure about three-eighths inch long, at the base of the petiole. - After Sachs when touched, and one species is locally known as "shame vine," from this peculiarity.

116. Structure of the parts which cause leaf motions. In a great number of cases the daily movements of leaves are produced by special organs at the bases of the leafstalks. These cushion-like organs, called pulvini (Fig. 109), are composed mainly of parenchymatous tissue, which contains much water. It is impossible fully to explain in simple language the way in which the cells of the pulvini act, but in a general way it may be said that changes in the light to which the plant is exposed cause rather prompt changes in the amount of water in the cells in onc portion or other of the pulvinus. If the cells on one side are filled fuller of water than usual, that side of the pulvinus will be expanded and makc the leafstalk bend toward the opposite side. The promptness of these movements is no doubt in considerable measure due to the fact that in the pulvini, as in many other parts of plants, the protoplasm of adjacent cells is connecter. Delicate threarls of protoplasm extend through the cell walls, making the whole tissue a living

1 Mimosa pudica.

${ }^{2}$ Species of Cassia and Desmanthus. 
web, so that any suitable stimulus or excitant which acts on one part of the organ will soon affect the whole organ.

117. Vertically placed leaves. Many leaves, like those of the olive (Fig. 111), always keep their principal surfaces nearly
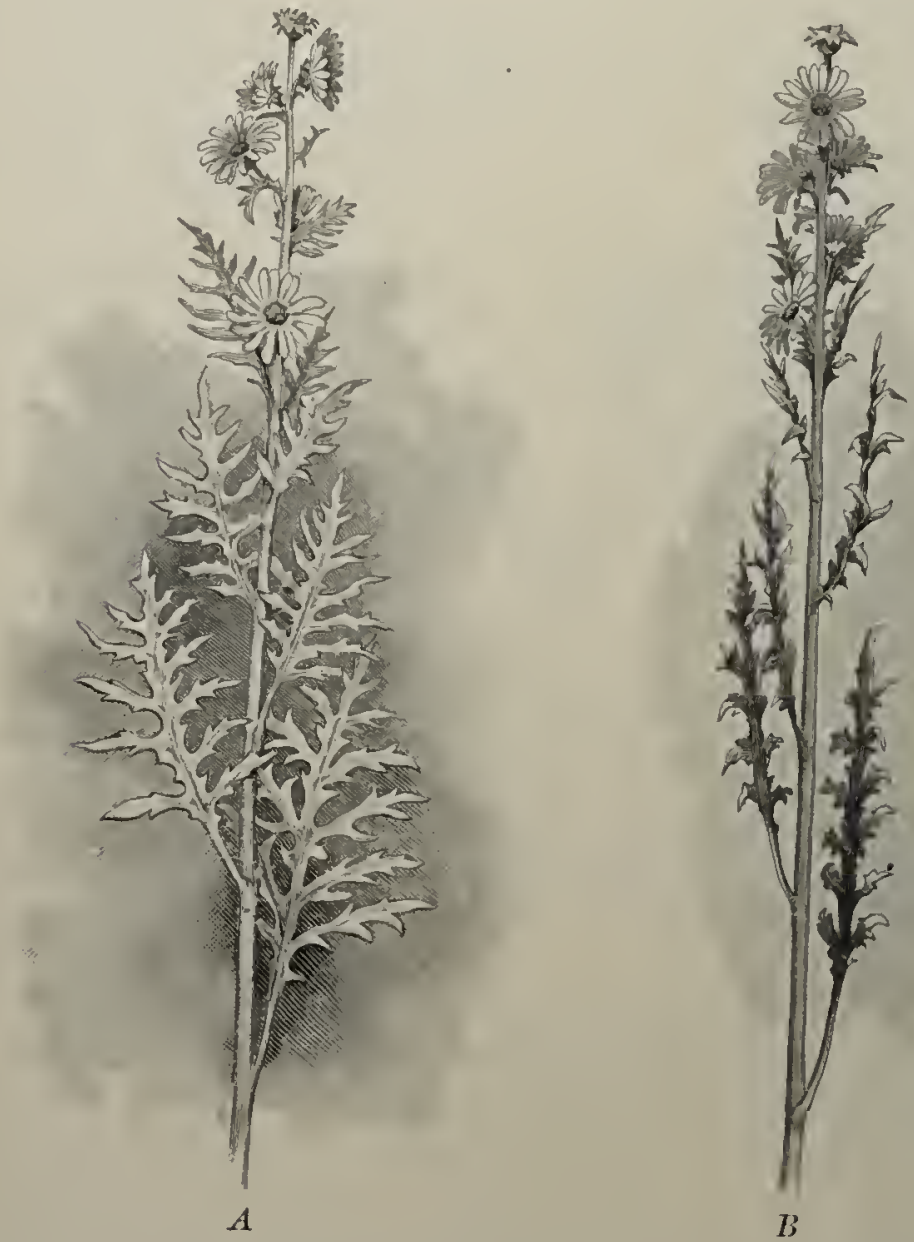

Fig. 110. Leaves standing nearly vertical in compass plant (Silphium laciniatum)

$A$, view from east or west; $B$, from north or south. - After Kerner

vertical. Thus they receive the morning and evening sun upon their faces, and the noonday sun (which is so intense as to injure them when received full on the surface) upon their edges. 
This adjustment is most perfect in the compass plant of the prairies of the Mississippi basin. Its leaves stand nearly upright, many with their edges just about north and south (Fig. 110), so that the rays of the midsummer sum will, during every bright day, strike the leaf surfaces nearly at right angles during a considerable portion of the forenoon and aftermoon, while at midday only the edge of each leaf is exposed to the sun.

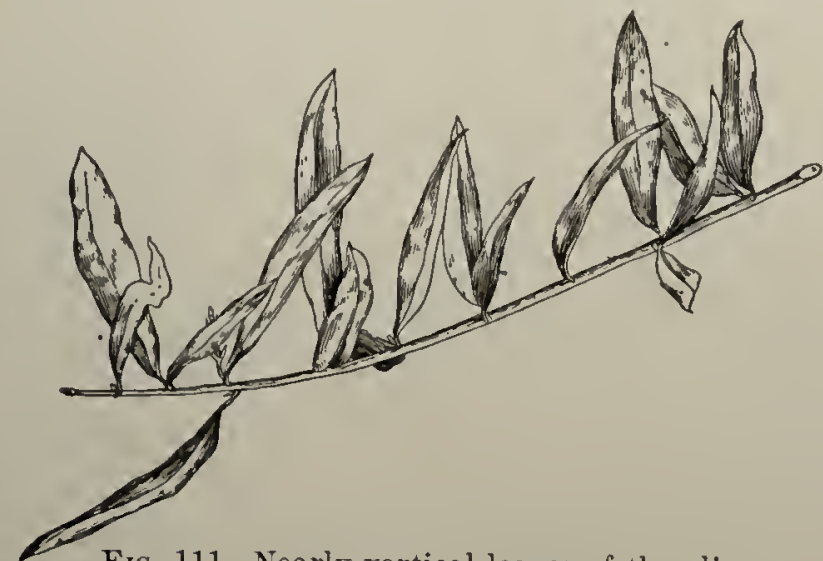

FIG. 111. Nearly vertical leaves of the olive

118. Heliotropic movements. The whole plant above ground usually bends toward the quarter from which most light comes.

Any set of flowering plants growing close to a wall, or of house plants in a window, generally offers many illustrations of this principle. Movements caused by light are called heliotropie movements (from two words meaning turning toward light).

119. Positive and negative heliotropic movements; how produced. Plants may bend either toward or away from the strongest light. In the former case they are said to show positive heliotropism, in the latter negative heliotropism. In both cases the movement is produced by unequal growth, brought about by the stimulus of unequal lighting of different sides of the stem. A plant if placed on a revolving table before a window and slowly turned during the hours of daylight grows upright, like a plant out of doors. This is because it is not left with a one-sided illumination long enough to produce any bending. 


\section{CHAPTER XII}

\section{MINUTE STRUCTURE OF LEAVES; FUNCTIONS OF LEAVES*}

120. Outline of leaf structure. Most foliage leares of seed plants contain a rather complicated system of fibro-vascular bundles forming the veins (Sec. 105), which, taken together, constitute a framework by which the leaf is supported and strengthened. Over and around these veins lies a mass of green pulpy material, the spongy parenchyma. The whole leaf is covered by an epidermis. Frequently, especially in soft and rather thick leaves, such as those of the garden live-forever, the epidermis can be readily peeled off as a thin, transparent skin.

The epidermis and the spongy parenchyma decay far more readily than the woody framework, and so skeleton leaves may often be found on the ground in the spring, showing plainly the arrangement of the veins of the leaf.

121. Details of a leaf section. The relative positions and the detailed structure of the parts mentioned in Sec. 120 are best understood by reference to the magnified cross section of a typical foliage leaf.

In the ordinary leaf (Fig. 112) a section shows at the upper surface a layer of transparent cells of the epidermis $e$. Beneath this lies a layer of elongated cells $p$, of a green color, standing at right angles to the epidermis. These are called palisade cells, from a fancied resemblance of their shape and relative position to palisades. Under this layer the leaf interior is filled with an irregularly grouped mass of green cells known as the spongy parenchyma $s p$, throughout which occur numerous air spaces $a$,

* 'To тиl: Isstructor : $\Lambda$ s the present chapter takes up its topics in considerable detail, it is suggested that it may be found expedient, if time is limited, to omit Secs. 129, 130, 132, 134, 139 (table), 145-147. 
and in which is an occasional fibro-vascular bundle $b$. The palisade layer or layers and the spongy parenchyma arc together known as mesophyll (meaning middle of leaf).

The lower surface of the leaf is covered by a layer of colorless epidermal cells $e^{\prime}$, differing somewhat in size and shape from those of the upper epidermis.

The lower epidermis is pierced by many openings or stomata $s$. Each stoma opens into an air chamber. The nper epidermis

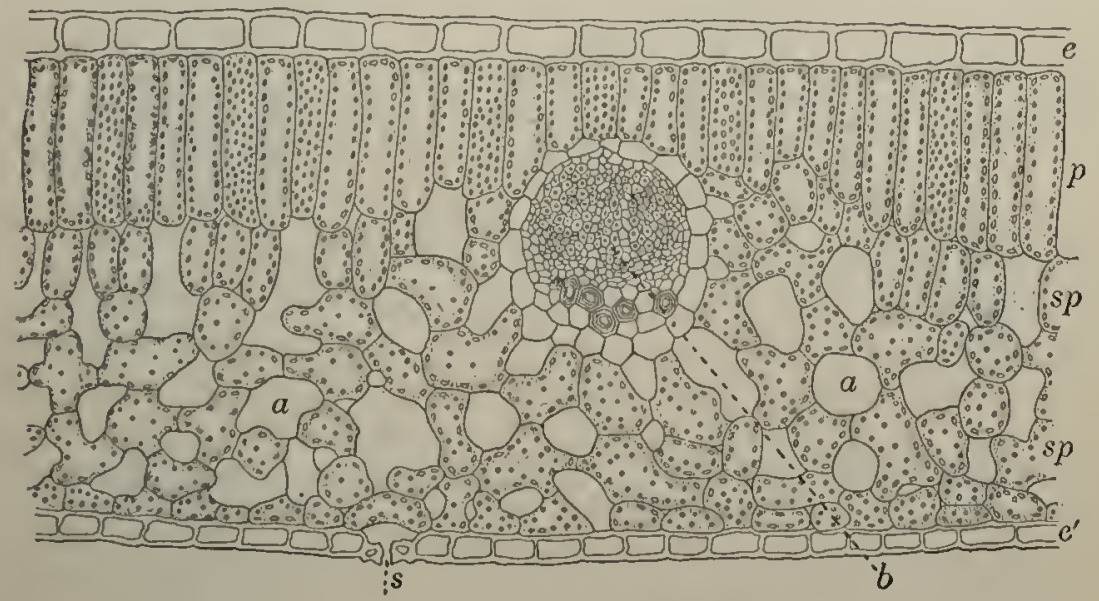

Fig. 112. Cross section of privet leaf

$e$ upper epidermis; $p$, palisade cells; $s p$, spongy parenchyma; $a$, air spaces; $b$, fibro-vascular bundle; $e^{\prime}$, lower epidermis; $s$, stoma. Much magnified.Modified after Giesenhagen

of this leaf contains far less stomata than the lower one, and this is true of most leaves, - often the upper surface contains none.

122. Uses of the parts above mentioned. It will be most convenient to discuss the uses of the parts of the leaf in detail a little later, but it will make matters simpler to state at once that the epidermis serves as a mechanical protection to the parts beneath and prevents excessive evaporation; that the palisade cells hold large quantities of the green coloring matter of the leaf in a position where it can receive enough but not too much sunlight; and that the cells of the spongy parenchyma share the 
work of the palisade cells, besides evaporating much water. The stomata admit air to the interior of the leaf, where the air spaces serve to store and to distribute it ; they allow oxygen and carbon dioxide gas to escape; and, above all, they regulate the evaporation of water from the plant.

123. The epidermis. The cells of the epidermis are very generally filled with water. Their form and the thickness and material of their walls depend largely on the kind of soil and

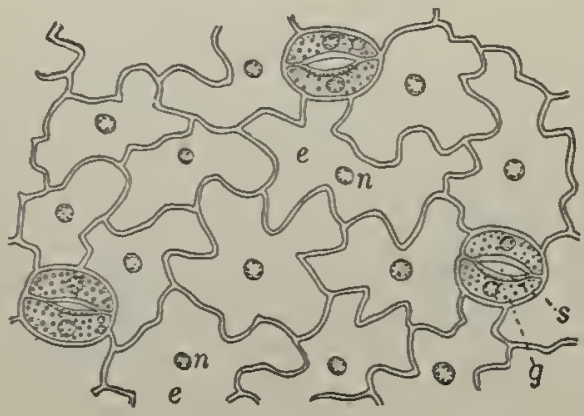

FIG. 113. surface view of the epidermis of a buttercup leaf 1

$e$, cells of epidermis; $n$, nuclei of epidermal cells; $g$, guard cell of stoma; $s$, stoma. Mnch magnified. - After Giesenhagen

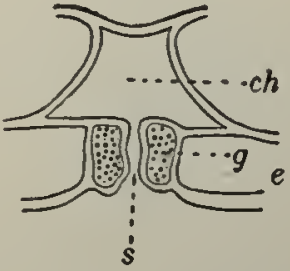

FiG. 114. Section through stoma of a buttercup leaf, at right angles to epidermis

$e$, epidermal cells; $g$, guard cell of stoma; $s$, stoma ; ch, air chamber. Nuch magnified.-After Bonnier and Sablon

climate to which the plant is adapted. In most herbs the epidermal cells form only a single layer and are not greatly thickened.

The stomata are not mere holes in the epidermis, but have a somewhat complicated structure. Each stoma consists of two kidney-shaped guard cells inclosing a slit-like opening into the leaf (Fig. 113).

When the stoma is viewed in a section at right angles to the surface of the leaf (Fig. 114) it appears as a narrow passage communicating with an air chamber inside the epidermis.

The number of stomata in a square inch of leaf surface is very great. An apple leaf contains about 24,000 and a black

1 Fig. 113 is from Ranunculus Ficaria; Figs. 114-118 from R. acris. 
walnut leaf about 300,000 per square inch of the lower epidermis.

124. The mesophyll; chloroplasts ; chlorophyll. The mesophyll appears to the naked eye of a un iform green, but under the microscope its cells are seen to contain many green

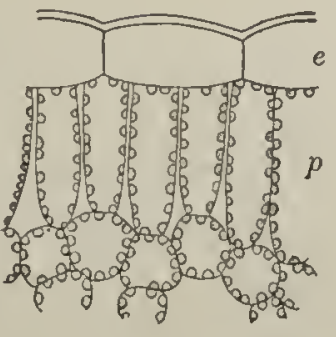

A

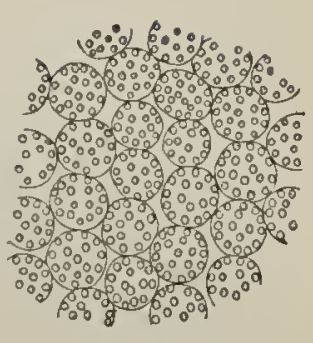

L

Frg. 115. Upper epidermis and palisade cells of a buttereup leaf

$A$, sectiou perpendicular to upper surface; $B$, exterior view of upper surface with palisade cells seen through epidermis ; e, epidermis ; $p$, palisade cells. Much magnified. - After Bonnier and Sablon structures called chlorophyll bodies or chloroplasts ("chlorophyll" meaning leaf green and "chloroplast" meaning molded out of green material). The color of the leaf, as well as that of green stems and other parts of the plant body, is due to these. A

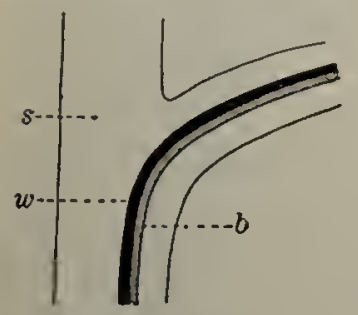

Fig. 116. Passage of a fibro-vaseular bundle from stem to leaf of a butterenp (diagrammatic)

$x$, stem: $x$, wooly part of bundle; $b$. sieve cells of bundle-After Boninier and Sablon chloroplast is usually, in seed plants and in the higher spore plants, of an ellipsoidal form or lens-shaped and somew hat translucent. Its color is due to a green substance, soluble in alcohol but not in water, known as chlorophyll.

125. Woody tissue in leaves. The veins of leaves consist of fibro-vascular bundles containing wood fibers and vessels much like those of the stem of the plant. Indeed, these bundles in the leaf are continuous with

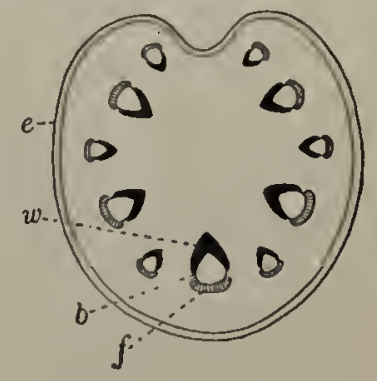

Fig.117. Diagram of distribution of fibrovasenlar bundles in the leafstalk of a butteren! $e$, epidermis; $w$, woody part of bundle; $b$, sieve cells of bundle; $f$, fibrous layer on outer part of bundle. Magnified.After Bonnier and Sablon 
those of the stem and consist merely of portions of the latter which pass outward and upward from the stem into the leaf under the name of leaf traces.

The manner in which fibro-vascular bundles pass from the stem through the petiole into the leaf and are there distributed can readily be gathered from an examination of Figs. 116-118. Their wood cells and vessels serve to carry water into the leaf, while their sieve cells carry plant food from its place of manufacture in the blade of the leaf down into the stem.

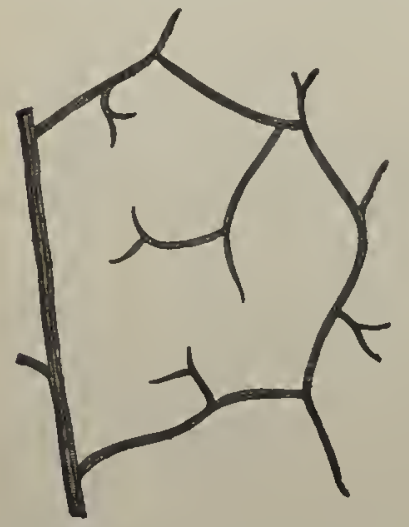

Fir. 118. Part of the fibrovascular skeleton of a buttercup leaf

Much magnified. - After Bonnier and Sablon

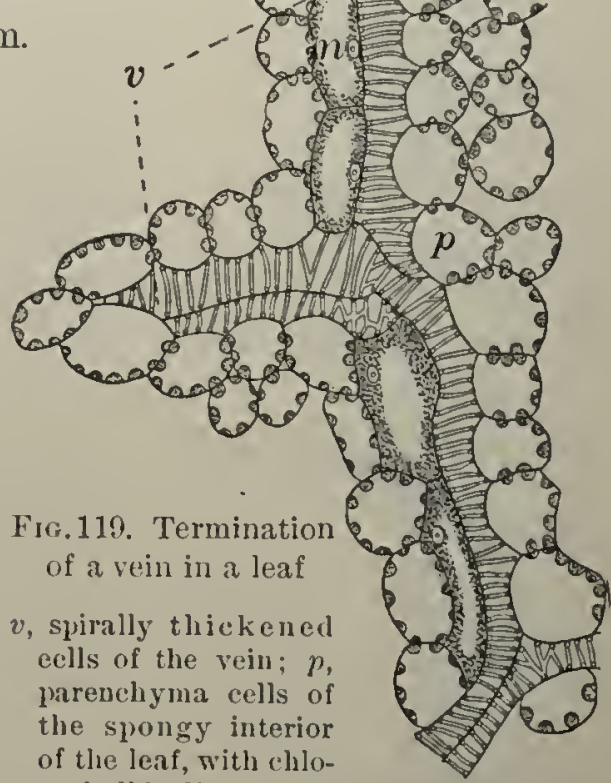

rophyll bodies; $n$, nueleated cells. $x$ alout 345 diameters

126. Nutrition. The series of processes by which the plant (1) takes up the raw materials to form its food, (2) unites these into foods, and finally (3) constructs tissue from these foods, or (4) stores thein, constitutes nutrition.

A good deal of that portion of nutrition included under (1) is carried on by the roots. But all kinds of nutritive work are carried on in green leaves, and the portion numbered (2) is a specialty of green plant cells, particularly of those in leaves. 
127. The work of leaves. A leaf has four principal functions:

1. Photosynthesis.

2. Respiration.
3. Assimilation.

4. Transpiration.

128. Photosynthesis. All green leaves, when in hcalthy condition, at suitable tcmpcratures and with sufficient illumination can producc carbohydrates (starch or sugars) from carbon dioxide and water.

This process is of the greatest importance, since directly or indirectly all plants and animals depend upon it for their food supply. The manufacture by the plant of carbohydrates from the raw materials is known as photosynthesis (from two words neaning light and putting together). It is often called fixation of carbon or assimilation of carbon. Photosynthesis is performed by the chloroplasts, especially in the palisade cells, and goes on imperfectly or not at all in plants or parts of plants, as in certain parasites and other forms, in which no chlorophyll exists (Chapters XxI, Xxx).

129. Chemical formula for photosynthesis. The details of the photosynthetic process are not wholly known, and it is not at all likely that in starch-producing plants starch is the first substance formed from carbon dioxide and water, but it is one of the early products of the action of the chloroplasts and is the easiest to detect by chemical tests applied to the leaf. In some plants, as the onion, the products of photosynthesis are all stored in the form of sugar.

If the chloroplast produced starch as the direct result of combining carbon dioxide and water, the chemical equation for the process would in its simplest form be ${ }^{1}$ :

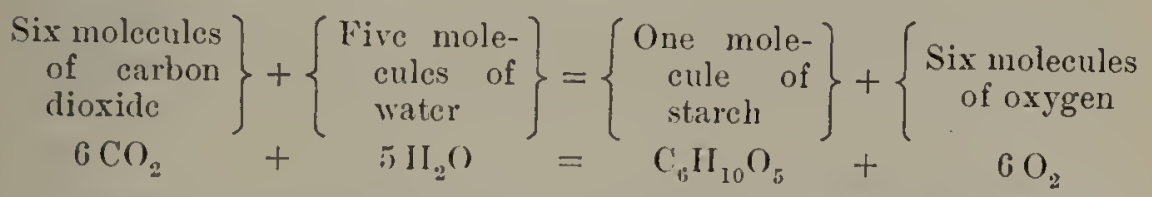

${ }^{1}$ Really some multiple of $\mathrm{C}_{6} \mathrm{H}_{10} \mathrm{O}_{5}$ probably more nearly expresses the composition of starch than the simple formula given. It is certain that the photosynthetic process is much more complicated than a merc combination of carbon dioxide with water to form either starch or sugar. 
If glucose (grape sugar) were the first product, the simplest equation would be:

$$
6 \mathrm{CO}_{2}+6 \mathrm{H}_{2} \mathrm{O}=\mathrm{C}_{6} \mathrm{H}_{12} \mathrm{O}_{6} \text { (one molecule of glucose) }+6 \mathrm{O}_{2} \cdot{ }^{1}
$$

It should be noticed that each of the processes above formulated results in the disappearance of six molecules of carbon lioxide and the production of six molecules of oxygen as a waste product.

These facts, namely, that in the green parts of plants exposed to sunshine carbon lioxicle is consumed and oxygen liberated, form the foundation of our knowledge of pliotosynthesis. The first step in the study of the subject was taken by Joseph Priestley in 1771, by his discovering that air in which candles had been burned until they went out could be restored to something like its original condition by leaving in it for some time vigorous leafy sprigs of mint.

130. External conditions for photosynthesis. Plotosynthesis can only occur:

1. When the plant is supplied with air containing carbon dioxide.

2. When the temperature is neither too high nor too low.

3. When the illumination is snflicient.

Ordinary air contains about one thirty-third of one rer cent of its bulk of carbon dioxide. An increase of this amount nj' to four per cent, aplarently often, for a consideralle time, increases photosynthesis, but a larger proportion usually at length proves injurious to the health of the plant.

Some arctic and alpine plants can perform the work of making carbohydrates at tempcratıres as low as the freezing point of water, but plants of warmer climates require a ligher tenperature. The rate of photosynthesis usually increases with rise of temperature up to about $77^{\circ} \mathrm{F} .\left(25^{\circ} \mathrm{C}\right.$.), after which it decreases.

Photosynthesis nay go on very feebly, even in comparative darkness, but the light of the interior of ordinary roous is

1 See I'eirce, Ilant Physiology, pP. 58-66. 
insuffieient for the vigorous growth of most seed plants exeepting those which, in a wild condition, flomrish in the shade. The rate of photosyuthesis for inost of the higher plants increases with the illumination up to a light intensity equal to that of full sunlight.

131. Conditions for formation of chlorophyll; its mode of action. Chlorophyll is usually produced only in plants grown in the light. Seedlings which have leen sprouted in total darkness almost always have a white or very pale yellow color, and blanehed eclery affords a familiar example of the ajpearance of leaves grown in comparative darkness. Mieroscopical examination of thoroughly blanehed plants shows them to be destitute of any decidedly green chloroplasts, and aleohol fails to extract from them the green ellorophyll solution which is readily obtained from ordinary leaves.

Iron must be present in the soil in order to enable the plant to form ellorophyll, and plants developed in water enltures absolutely free from iron remain yellow and grow feebly.

Chlorophyll appens to act ly intercepting a considerable portion of the light rays which strike the leaf, thus compelling them to expend their encrgy on the chloroplasts and so to produee photosynthesis. If light traverses a substanee with great ease, as it does pure dry air, for example, comparatively litlle effeet is produeed. On the other liand, when it strikes a substanee which readily alsorbs it, henting or chemieal effects or both are produced, as is evident when a rough sheet of iron, a sensitized photographie dry plate, or bluc-print paper is exposed to sunliglit. Chloropliyll eamnot itself do the work of photosynthesis, but it eauses the light rays to act on the ehloroplasts so that their protoplasm carrics on the manufacture of carbohydrates from the raw inaterials.

132. Rate of starch making. The amount of stareh manufaetured daily by a given area of foliage must depend on the kind of lenves, the ternperature of the air, the intensity of the sunlight, and some otler conditions. Sunflower leaves and 
pumpkin or squash leaves produce starch at about the same rate. In a summer day fifteen hours long they can make nearly three quarters of an ounce for each square yard of leaf surface. A full-grown squash leaf has an area of about one and one-eighth square feet, and a plant may bear as many as a hundred of them. The entire plant would then produce nearly nine and a lialf ounces of starch per day.

Another way to emphasize the amount of work done by the leaves is to consider how much air would be needed to supply the carbon in a given weight of wood; for all this carbon has probably been derived from carbohydrates made in the lenves (or other green parts) by photosynthesis. If the wood of a tree after drying weighs 11,000 pounds and is half carbon, the latter would weigh 5500 pounds. Taking the carbon dioxide contents of the air at $\frac{3}{10,000}$, there would be not quite $27,000,000$ cubic yards of air needed to furnish the carbon of such a tree. ${ }^{1}$

The enormous amounts of carbon dioxide annually removed from the air by the growth of plants are continually being replaced by the respiration of animals, the decay of animal and vegetable material, and by the burning of fuel. From the burning of coal alone it is estimated that nearly 3,000,000 million pounds of carbon dioxide are every year returned to the atmosphere.

133. Respiration. Plants cannot carry on their life processes without consuming oxygen and giving off carbon dioxide and water. This oxygen consumption is the respiration of plants. Like animals, plants are dependent on the union of oxygen with oxidizable substances in their tissues for the energy with which they do the rork of assimilation, growth, and reproduction,in other words perform their life processes.

How oxygen can be made to combine with the carbon- and hydrogen-containing compounds in the plant at moderate temperatures is a problem which plant plysiologists have not yet fully solved; but the union does constantly go on, and as a

1 Taken with slight alterations from Peirce, Plant Physiology, p. 44. 


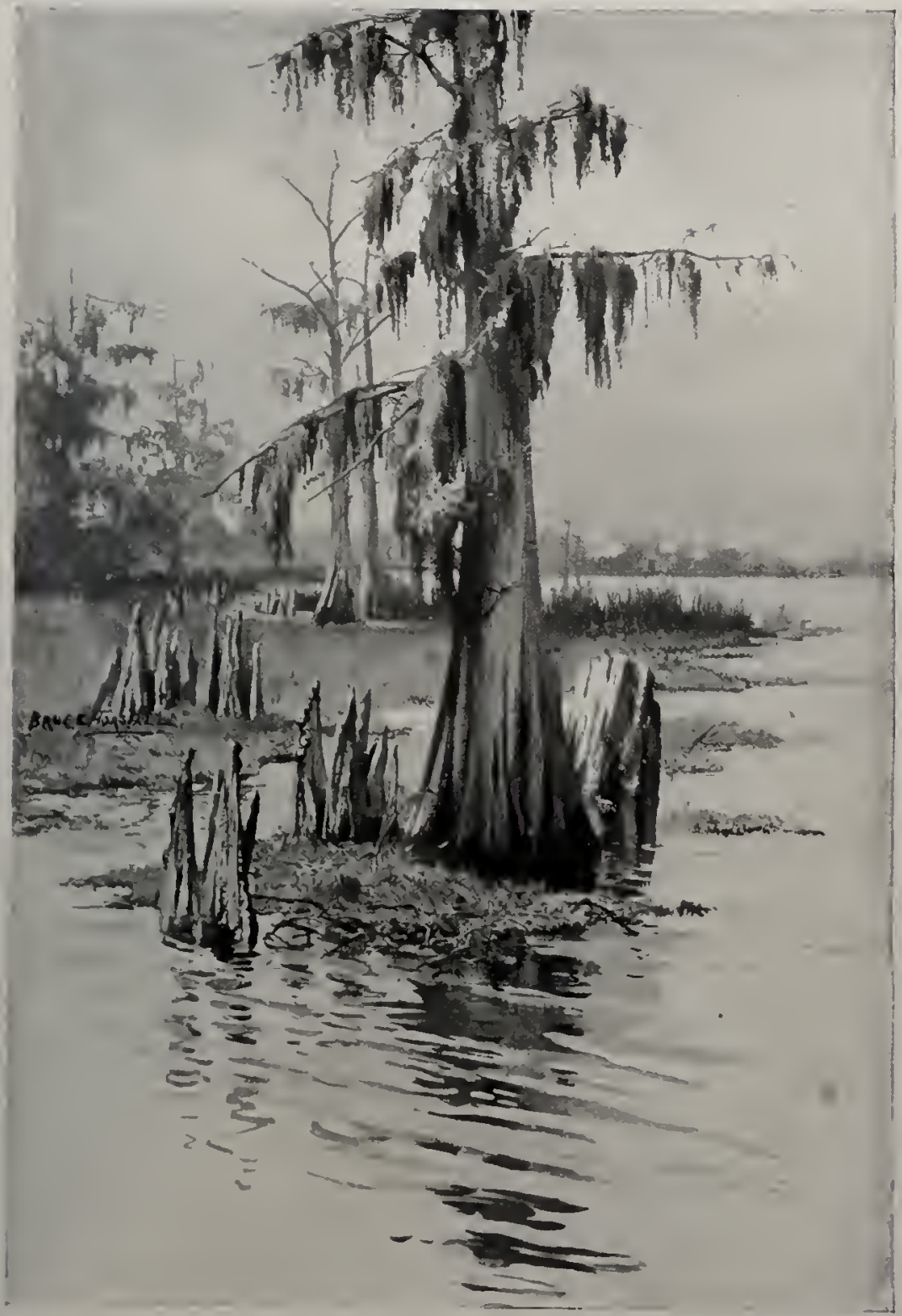

I'LATE III. A eypress swamp, the trees draped with Spanish moss (Tillandsia)

Modified, after 11. J. Webber 

result of the combination, water and carbon dioxide are continually excreted (see note, page 5:36).

The amount of oxygen absorbed and of carbon dioxide given off is, however, so trifling compared with the amount of each gas passing in the opposite direction, while starch making is going on in sunlight at temperatures most favorable for photosynthesis, that under such circumstances it is difficult to observe the occurrence of respiration.

When the illumination is very feeble, from $\frac{1}{1} \frac{1}{0}$ to $\frac{1}{4} \overline{0}$ that of bright, diffuse daylight, the manufacture of carbon dioxide by respiration and its consumption by photosynthesis are equal.

At high temperatures, such as $104^{\circ}$ F. $\left(40^{\circ} \mathrm{C}\right.$.), respiration may produce carbon dioxide more rupidly than photosynthesis can consume it, even with brilliant illumination.

In ordinary leafy plants the leaves, through their

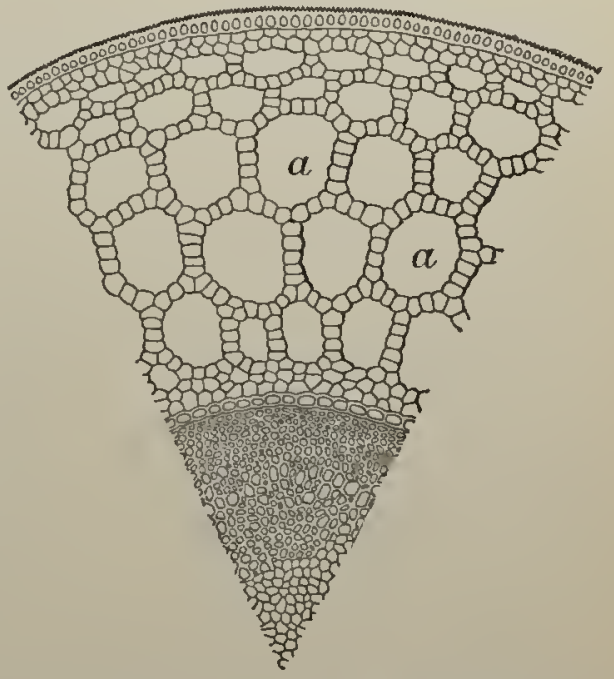

FIG. 120. Cross section of stem of marestail (Hippuris), with air passages a

After Baillon stomata, are the principal organs for absorption of air, but much air passes into the plant through the lenticels of the bark.

In partly submerged aquatics especial provisions are found for carrying the air absorbed by the leaves down to the submerged parts. This is accomplished in pond lilies by ventilating tubes which traverse the leafstalks lengthwise. In many cases such channels run up and down the sten (Fig. 120). In the American cypress (Taxodium) the "knees," which rise from the roots, as shown in Plate III, are thought to be for use in respiration, obtaining oxygen from the air and carrying it into the roots beneath the water. 
134. Resting condition and diminished respiration. The whole plant body or parts of it may pass into a resting condition, in which growth is suspended and few manifestations of life are discerniblc. Familiar examples of this inactive condition are leafless trees in winter, and rootstocks, tubers, and bulbs during the winter of ordinary temperate climates or the rainless summer of southern California and the Mediterranean coast region. Seeds and many kinds of resting spores afford extreme instances of the possibility of a suspension of activity for years, followed by prompt growth when suitable conditions are supplied. In general, a moderately low temperature and dryncss favor the resting state. During the resting period respiration is greatly diminished, so much so in the case of thoroughly dry seeds as to be almost or quite imperceptible.

When resting protoplasm is placed in circumstances which enable it to begin active respiration, growth and development soon appear. Thus twigs of lilac or other shrubs will flower after a time, when placed in water and brought into a warm room in winter.

In many cases, as with most seeds, the period of repose is essential for growth. Potato tubers will not sprout as soon as they are mature: some varietics need only two montlis and others four or five months of rest.

135. Assimilation. By most American plant physiologists ${ }^{1}$ the word assimilation is used as a name for the series of changes by which the plant transforms absorbed or manufactured food into the materials of its own tissues.

The transformation of starch or sugar into substances, like cellulose, which consist of the same elements (carbon, hydrogen, and oxygen) differently combined, is a rclatively simple matter; but the manufacture from carbohydrates of such very complex nitrogenous substances as the proteids and living protoplasm is a most complicated process, and inperfectly understood.

1 European botanists of ten inelude in the term assimilation both photosynthesis and the proeesses discussed in this seetion. 


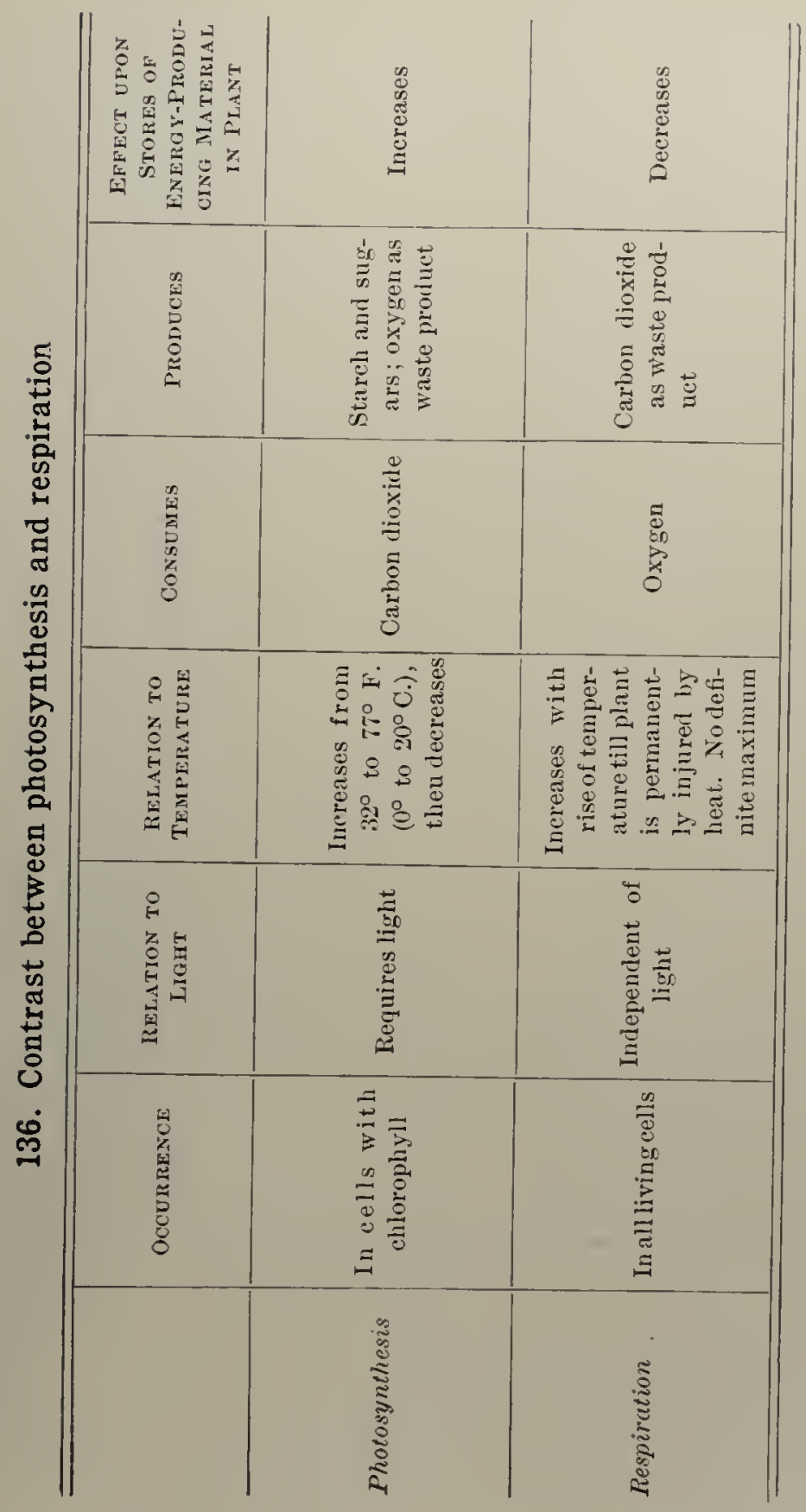


Probably diastase or some other ferment in the green parts of the plant transforms the newly made stareh into sugar, and some of this is apparently combined on the spot with nitrogen, sulphur, and phosphorus. These elements are derived from nitrates, sulphates, and phosphates, taken up in a dissolved eondition by the roots of the plant and transported to the leaves. The details of the process are not understood, but the result of the combination of the sugars or similar substances with suitable (very minute) proportions of nitrogen, sulphur, and phosphorus is to form eomplex nitrogen eompounds. These are not precisely of the same composition as the living protoplasm of plant cells or as the reserve proteids stored in seeds (Sees. 8, 12), stems (See. 66), and other parts of plants, but are readily ehanged into protoplasm or proteid foods as necessity may demand.

Assimilation is by no means confined to leaves; indeed, most of it, as above suggested, must take place in other parts of the plant. For instance, the manufaeture of the immense amounts of cellulose, of cork, and of the compound (lignin) eharacteristie of wood fiber, which go to make up the main bulk of a large tree, must be carried on in the roots, trunk, and branches of the tree.

137. Metabolism. It is convenient to have a single word to express all the ehemical elianges whieh are controlled by the living protoplasts. Sueh a word is metabolism. It embraces all the nutritive proeesses mentioned in See. 126 , as well as respiration and the ehemieal ehanges concerned in the exeretion of waste materials.

There are two principal types of inctabolic proeesses, - constructive metabolism (sueh as photosynthesis), which unites simpler eompounds into more complex ones, and dcstructive metabolism (such as respiration), which breaks up eomplex substances into simpler ones.

Digcstize metabolism, performed by means of various ferments, begins, as already mentioned, in the seed during germination and is carried on in most parts of the higher plants during all aetive periods of their lives. It is especially energetie in removing 


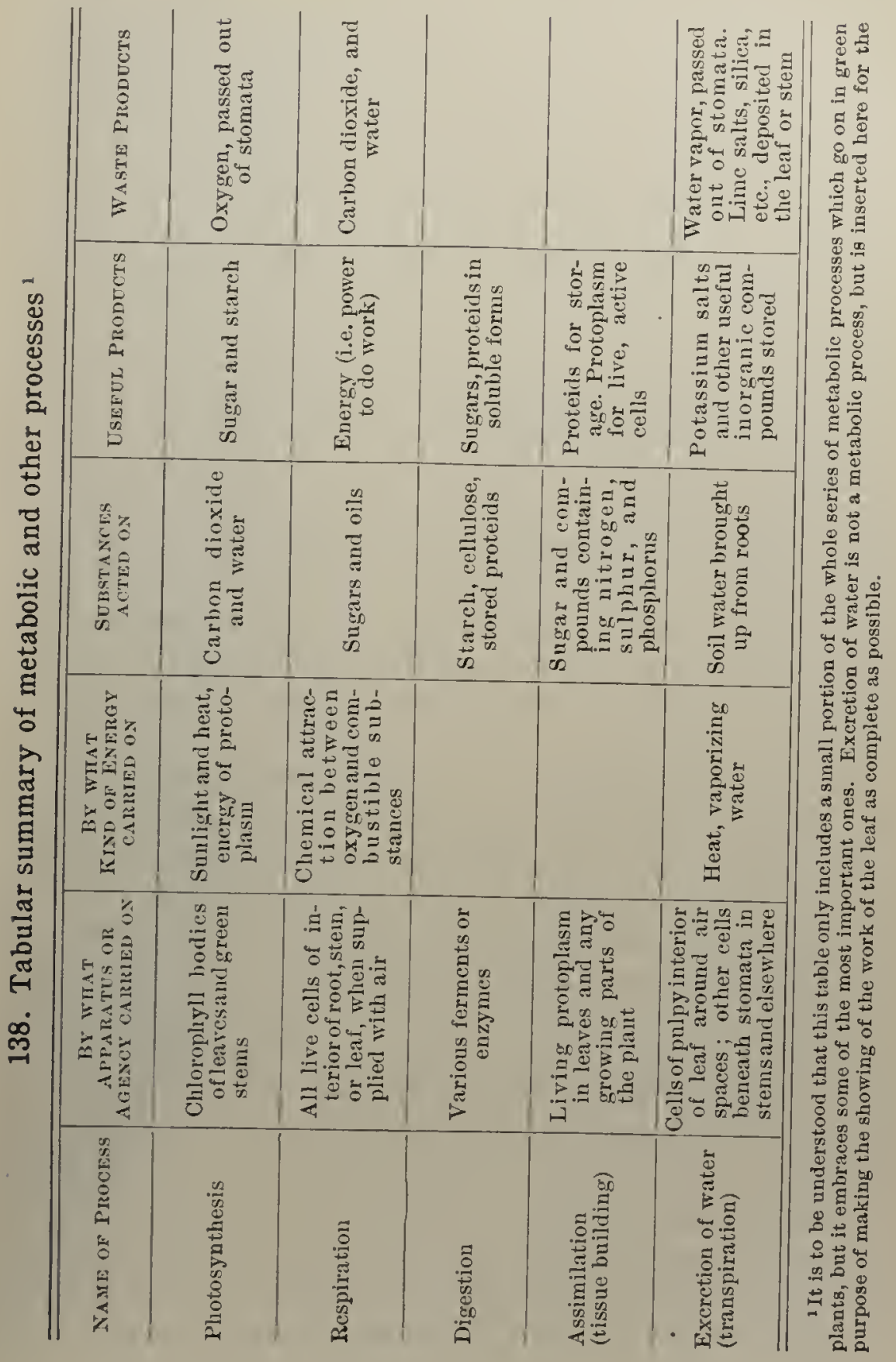


the newly formed starch from the green cells of leaves for use in other parts of the plant body. Much of this food (carried about in the form of a solution of sugar) is used for building material, as suggested in Sec. 135 ; but a good deal of it is often transported to parenchyma cells of the stem and the roots, where it is changed back into starch for storage. This change is accomplished by small structures known as leucoplasts in the cells. Each leucoplast may cause a deposit, upon some part of its outer surface, of successive layers which finally develop into a complete stareh grain. How the leucoplast is able to bring about the change from sugar to starch is unknown.

139. Transpiration. The process of giving off water in the form of vapor from the stomata of plants is called transpiration. It is not a mere drying up, such as occurs when a pile of seaweeds or a split stick of cord wood is exposed to dry air, but is an important function of the leaves of most seed plants and of the ligher spore plants. In such forms as the cactuses (Fig. 50), which are practically leafless, transpiration is performed by the epidermis of the stem.

As ahready mentioned (Sec. 36), ordinary terrestrial seed plants are, during the active periods of their lives, continually absorbing water through the roots. This water brings with it dissolved salts from the soil, many of which are used in the tissueforming work of the plant body. Some of the water, but only an insignificant portion of the whole amount, is needed for 'photosynthesis, and a good deal of it is useful in carrying the 2 soluble plant fools, such as sugars, to the growing parts; but

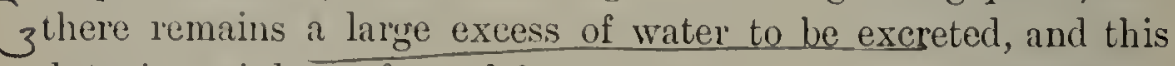
duty is mainly performed by the mesophyll, and its amount is regulated by the epidermis of the leaves. The air within the intercellular spaces of the mesophyll is surrounded by thinwalled cells filled with watery protoplasm, and it must therefore be nearly or quite saturated with moisture. When allowed to esaape from the leaf this air rapidly carries off quantities of watery vapor. 
140. Uses of the epidermis. ${ }^{1}$ The epidermis, by its toughness, tends to prevent mechanical injuries to the leaf. After the change of the outer portions of its cell walls into a corky substance it greatly diminishes evaporation from the general surface. This process of becoming filled witl cork material, suberin (or a substance of similar properties known as cutin), is essential to the safety of leaves or of young stems which have to withstand heat and dryness. The corky or cutinized cell wall is waterproof, while ordinary cellulose allows water to soak tlirough it with ease. Merely examining sections of the various kinds of epidermis will not give nearly as good an idea of their properties as can be obtained by studying. during severe droughts the behavior of plants which have strongly cutinized surfaces and of those which have not, or by exposing thin-leaved plants and thick leatl-

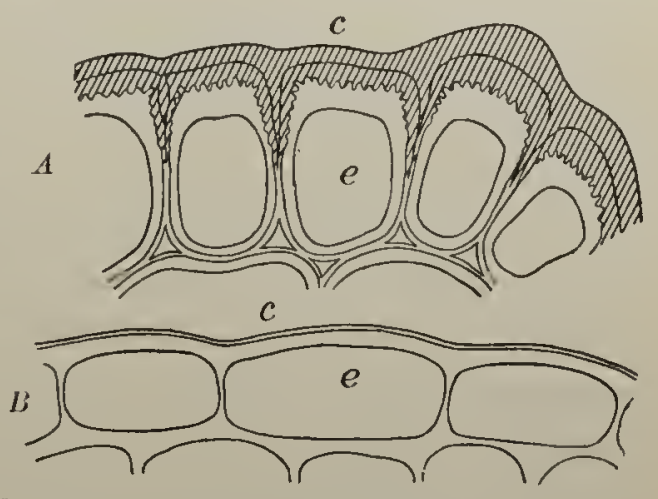

FIG. 121. Unequal development of cuticle by epidermis cells

$A$, epidermis of butcher's broom (Ruscus); $B$, epidermis of sunflower; c, cuticle; $e$, epidermis cells. - After Frank and Tschirel ery-leared ones to a very dry atmosphcre without watering. Fig. 121, however, may convey sone notion of the difference between the two kinds of structure.

In $A$ the shaded part is all cutinized; it consists of the thick cuticle proper and, beneath this, cutinized layers of cell wall, under which is a heavy layer of cellulose. In $B$ the cuticle is thin, and the outer portion of the cell walls consists wholly of cellulose.

In most cases, as in the india rubber tree, the external epidermal cells (and often two or three layers of cells beneath these) are filled with water, and thus serve as rescrvoirs from

${ }^{1}$ See Kemer and Oliver, Natural IIistory of Plants, Vol. I, pp. 273-362. 
which the other parts of the leaf and the stem are at times supplied (see Fig. 359).

In many cases, noticeably in the cabbage, the epidermis is covered with a waxy coating, which doubtless increases the power of the leaf to retain needed moisture, and which certainly prevents rain or dew from covering the leaf surfaces, especially the lower surfaces, so as to hinder the operation of the stomata. Many common plants, like the meadow rue and the nasturtium, possess this power to shed water to such a degree that the under surface of the leaf is hardly wet at all when inmersed in water. The air bubbles on such leaves give them a silvery appearance when held under water.

141. Operation of the stomata. The stomata serve to admit air to the interior of the leaf and to allow moisture in the form of vapor to pass out of it. They do this not in a passive way, as so many mere holes in the epidermis might, but to a considerable extent they regulate the rapidity of transpiration, opening more widely in damp weather and in sunlight, and closing in very dry weather. The opening is caused by each of the guard cells bending into a more kidney-like form than usual, and the closing by a diminution of tuxpger and straightening out of the guard cells.

The details of the mechanical explanation of stoma movements are complicated, and it is difficult fully to account for their irritability in response to light, heat, and moisture stimuli. and to variations in the amount of salts in the water absorbed by the roots.

142. Location of the stomata. The under side of the leaf, free from palisade cells, abounding in intercellular spaces, and pretty well protected from becoming covered with rain or dew, is especially adapted for the working of the stomata, and accordingly we usually find them in much greater numbers on the lower surface. On the other hand, stomata occur only on the upper surface of the leaves of porsl lilies, which lie flat on the water. In those leares which stand with their edges 
nearly rertical, the stomata are distributed somewhat equally on both surfaces. Stomata occur in the epidermis of young stems, being replaced later by the lenticels.

The health of the plant depends largely on the proper working condition of the stomata, and one reason why plants in cities often fail to thrive is that the stomata become choked with dust and soot. If the stomata were to become filled with water, thein activity would cease until they were freed from it; hence many plants have their leaves, especially the under surface, protected by a coating of wax which sheds water.

143. Hairs on leaves. Many kinds of leaves are more or less hairy or downy, as those of the mullein, the "mullein pink," many cinquefoils, and other common plants. In some instances this hairiness may be a protection against suails or other small leaf-eating animals, but in other cases it seems to be pretty clear that the woolliness (so often confined to the under surface) is to lessen the loss of water through the stomata. The Labrador tea is an excellent example of a plant with a densely woolly coating on the lower surface of the leaf. The leaves, too, are partly rolled up like those of the crowberry (Fig. 361), but less completely, with the upper surface outward, so as to give the lower surface a sort of deeply grooved form, and on the lower surface all of the stomata are placed. This plant, like some other's with the same characteristics, ranges far north into regions where the temperature, even during summer, often falls so low that absorption of water by the roots ceases, since it has been shown that this nearly stops a little above the freezing point of water. Exposed to cold, dry winds, the plant would then often be killed by complete drying if it were not for the protection afforded by the woolly, channeled under surfaces of the leaves.

144. Total amount of transpiration. In order to prevent wilting, the rise of sap during the life of the leaf must have kept pace with the evaporation from its surface. The total amount of water that travels through the roots, stems, and leaves of most seed plants during their lifetime is large, relative 
to the weight of the plant itself. During 173 days of growth a corn plant has been found to give off nearly 31 pounds of water. During 140 days of growth a sunflower plant gave off about 145 pounds. A grass plant lias been found to give off its own weight of water every twenty-four hours in hot, dry summer weather. 'This would makc about $6 \frac{1}{2}$ tons per acre every twentyfour hours for an ordinary grass field, or rather over 2200 pounds of water from a field $50 \times 150$ feet, - that is, from a tract not larger than a goou-sized city lot. Calculations based on observations made by the Austrian forest experiment stations showed that a birch tree with 200,000 leaves, standing in open ground, transpired on hot summer days from 700 to 900 pounds, while at other times the amount of transpiration was probably not more than 18 to 20 pounds. ${ }^{1}$

145. Accumulation of mineral matter in the leaf. Just as a deposit of salt is found in the bottom of a seasidc pool of salt water which has been dried up by the sun, so old leaves are found to be loaded with mineral matter left behind as the sap drawn up from the roots is evaporated through the stomata. A bonfire of leaves makes a surprisingly largc heap of ashes. An abundant constituent of the ashes of burnt leaves is silica, a substance chemically the same as sand. This the plant is forced to absorb along with the potash, compounds of phosphorus, and other useful substances contained in the soil water; but siuce the silica is of hardly any value to most plants, it often accumulates in the leaf as so much refuse. Lime is much more useful to the plant than silica, but a far larger quantity of it is absorbed than is needed; hence it, too, accumulates in the leaf.

146. The fall of the leaf. In the tropies trees retain most of their leaves the year round; a leaf occasionally falls, but no considerable portion of them drops at any one season. ${ }^{2}$ The same

${ }^{1}$ See B. E. Fernow's discussion in Report of Dirision of Forestry of United States Department of $\Delta$ griculture, 1889 ; also the article, "Water as a Factor in the Growtl of I'lants," by B. T. Galloway and Albert F. Woods, YearBook of United States Departinent of Agriculture, 1894.

${ }^{2}$ Except where there is a severe dry season. 
statement holds true in regard to our cone-bcaring evergreen trees, such as pincs, spruces, and the like. But the impossibility of absorbing soil water when the ground is at or near the freezing temperature would cause the death, by drying up, of trees witl hroad leaf surfaces in a northern winter. And in countries where there is much snowfall, most broad-leafed trees could only escape injury to their branches from overloading with snow, by eneountering winter storms in as close-rcefed a condition as possible. For sueh reasons our common shrubs and forest trees (except the eone-bearing, narrow-leafed ones already mentioned) are mostly dcciduous, - that is, they shed their leaves at the approach of winter. 'There are, however, in the eastern United States a few species of broad-leafed evergreen trees and large shrubs, such as the live oak, some Rhododendrons, the mountain laurel ( $K a l m i a$ ), and the hollies. Along the Paeific coast there are many more forms, including five fairly common species of evergreen oaks, the beautiful Arbutus, and the manzanitas (Arctostaphylos).

Looking somewhat closely into the matter of dcciduousness of the trees and shrubs of temperate climates (not including the coniferous species), one finds that they may be classed as follows :

I. Leaves simultaneously deciduous. . 4 , winter deciduous

\} B, summer deciduous

C, leaves some of them lasting two years $9 \mathbb{P}^{\circ}$

II. Leaves not simultaneously decidnous (evergreen) . more

D, leaves lasting nore than onc year but less than two

The only one of the four subdivisions which shows fairly eonstant leafage at all scasons is the one designated as $C$. Leaves of the subdivision $D$ often fall when about fifteen months old, so that the tree is unusually leafy during the thrce months when the new leaves are developing to their full size, but before the old ones begin to fall. It is a noteworthy fact that in many species of broad-leafed evergreens, for example the ilex oak, the 
oleander, and Smilax cespera, the leaves do not attain their maximum power of transpiration as soon as they are fully grown. Such a leaf transpires nore when fifteen months old than when three months old.

The fall of the lcaf is preceded by important changes in the contents of its cells. Much of the sugary and protoplasmic contents of the leaf disappear's before it falls. These valuable materials have been absorbed by the branches and roots, to be used again the following spring.

The separation of the leaf from the twig is accomplished by the formation of a layer of cork cells across the base of the petiole in such a way that the latter finally breaks off across the surface of the layer. A waterproof scar is thus already formed before the removal of the leaf, and there is no waste of sap dripping from the wound where the leafstalk has been removed, and no ehance for fungi to attack the bark or wood and cause it to decay. In compound leaves each leaflet may become separated from the petiole, as is notably the case with the horse-chestnut leaf (Fig. 99). In wooly monocotyledons, such as palms, the leafstalks do not commonly break squarely off at the base, but wither and leave projecting stumps on the stem.

The brilliant coloration, yellow, scarlet, deep red, and purple, of autuinn leaves is popularly but wrongly supposed to be due to the action of frost. It depends merely on the changes in the chlorophyll grains and the liquid cell contents that accompany the withdrawal of the proteid material from the tissues of the leaf. The chlorophyll turns into a yellow, insoluble substance after the valuable materials which accompany it have been taken away, and the cell sap at the same time may turn red. Frost perhaps hastens the break-up of the chlorophyll, but individual trees often show bright colors long before the first frost, and in very warm autumms most of the changes in the foliage may come about before there has been any frost. 


\section{CHAPTER XIII}

\section{THE FLOWER OF THE HIGHER SEED PLANTS}

147. F1oral organs. The parts of a complete bisexual flower of the higher seed plants (angiosperms) are sepals, petals, stamens, and pistils (Fig. 122). The sepals, taken together, constitute the ealyx; the petals, taken together, constitute the

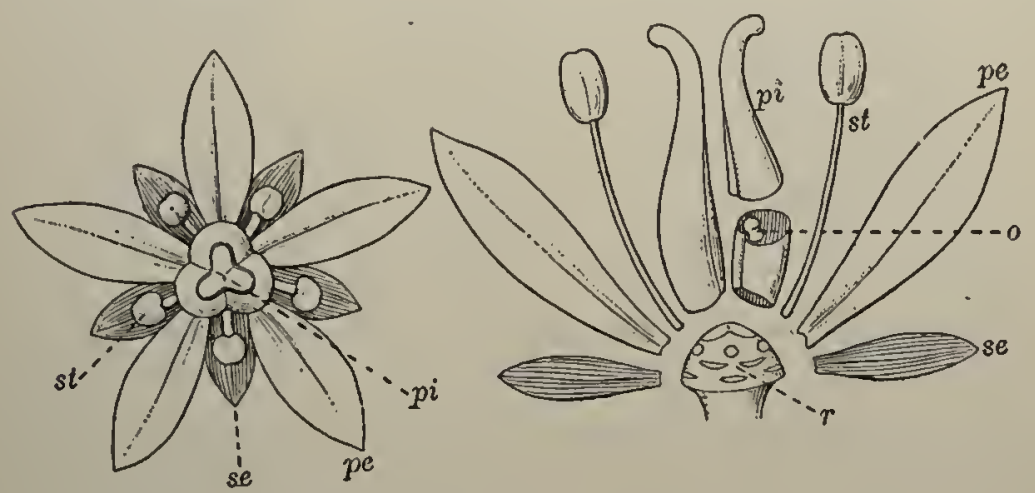

Fig. 122. Face view and dissection of an angiospermous flower $r$, receptacle; se, sepal; pe, petal ; st, stamen ; pi, pistil ; o, ovule

eorolla. The calyx and corolla are collectively known as the floral envelopes, or perianth.

Many angiospermous flowers eonsist of five eircles, or whorls, two of which belong to the perianth, two to the stamens, and one to the pistils. The parts of euch eirele alternate in position with those of the preeeling or following one, and all the members of euch eirele are alike (Fig. 122).

148. Suppression and multiplication of circles. Any circle, or part of a circle, may be suppressed. If one set of parts of the perianth is lacking it is assumed to be the corolla (Fig. 123). ${ }^{1}$

1 For otler instances of suppression of varions sets, see Bergen, Flora of the Northern States (Figs. 4, 10, 11, 12, 14, 15, 23). 
A whorl of stamens is frequently suppressed, so that only one circle is present in the flower (Fig. 128).

Multiplication of whorls is particularly frequent among the stamens, but other whorls may also show it (see Figs. 149, 150).

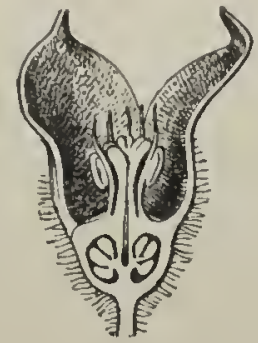

Fig. 123. Flower of

(Europeaul) wild ginger, with calyx but no petals

After Wossidlo
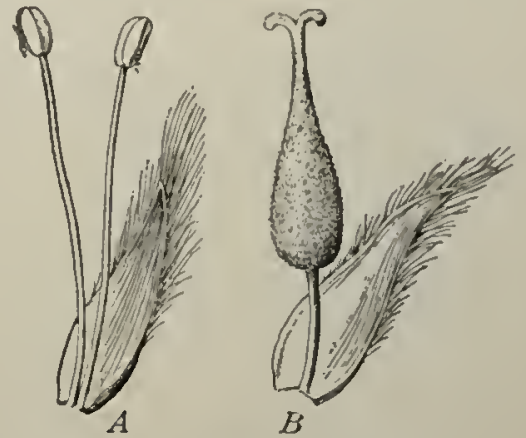

Fic. 124. Flowers of willow

$A$, staminate flower; $B$, pistillate Hower. Magnified.-After Decaisne

149. Unisexual flowers. The stamens and pistils may be produced in separate flowers, which are unisexual (often called imperfect) flowers. In the very simple unisexual flowers of the willow (Fig. 124) each flower of the catkin (Fig. 143) consists merely of a pistil or a group of (usually two) stamens springing

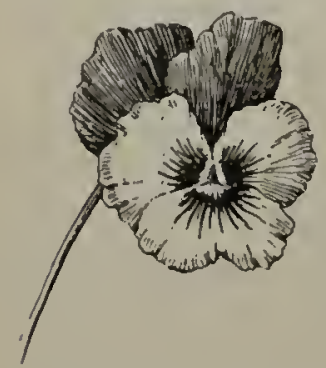

Fic. 125. Isilaterally symmetrical flower of pansy from the axil of a sinall bract.

Staminate and pistillate flowers may be borne on different plants, as they are in the willow, or they may be borne on the same plant, as in the hickory and the liazel among trees, or in the castor-oil plant, Indian corn, and the begonias. When staminate and pistillate flowers are borne on separate plants, such a plant is said to be dicecious, that is of two households; when both kinds of flower appear on the same individual, the plant is said to be monecious, that is of one household. 
150. Symmetry of the flower. Most angiosperms have symmetrical flowers. The simplest are those whose parts are arranged as in Figs. 122, 128, and 149, having radial symmetry. ${ }^{1}$
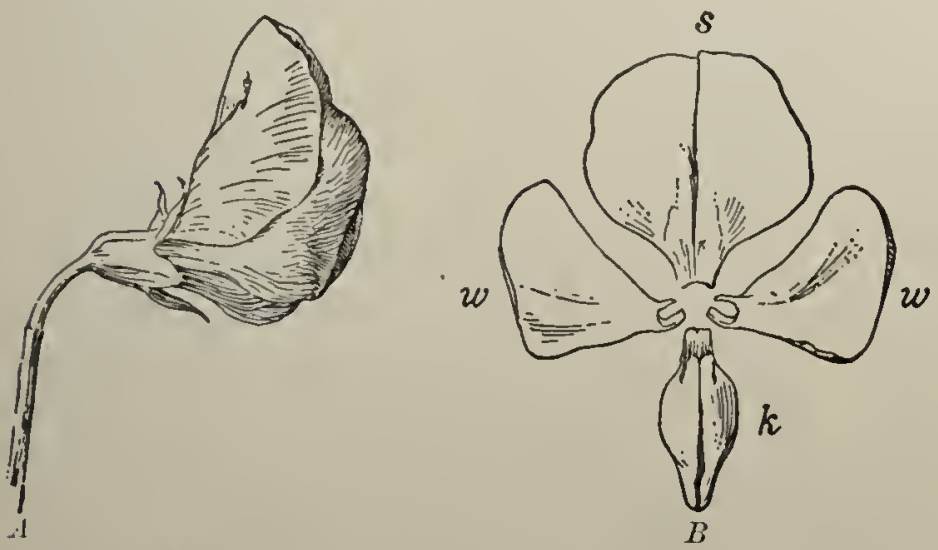

Fig, 126. Bilaterally symmetrical flower of sweet pea

$A$, side view; $B$, front view, dissected; $s$, standard; $w, w$, wings; $k$, keel

A higher type of flower is that which shows bilateral symmetry, as in Figs. 125 and 126.

If the drawing of such a flower were folded along the axis of symmetry, one half of the drawing would cover and correspond with the otlier half. Some flowers are wholly irregular, showing no sort of symmetry.

151. The receptacle. The parts of the flower are borne on a variously formed expansion of the flower stalk known as the receptacle. Usually, as in Fig. 122, this is only a slight enlargement of the flower stalk, but in the rose (Fig. 127), the pond lily (Fig. 137), the magnolia, the Calycanthus, and a good many other familiar flowers it is large and conspicuous.

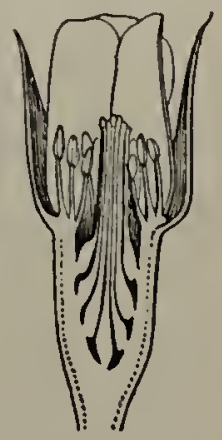

FIG. 127. A rose

Lougitudinal section After Decaisne

1. Such flowers are also called actinomorphic, meaning ray-formed.

2 'These are ealled zygomorphic tlowers (from Greek worls signifying yoke and form). In wany floras these are described as irregular flowers. 
152. The perianth. In dicotyledonous plants the sepals, or divisions of the calyx, are commonly green and somewhat leaflike. The petals in showy flowers are of many colors, ranging all the way from violet to red. Either whorl of the perianth may be found to have assumed some very peculiar form, to carry out the purpose of the flower, as is briefly cxplained in Chapter xxxiI.

Among the lower families of angiosperms the parts of the perianth arc frequently all distinct, as shown in Figs. 122 and

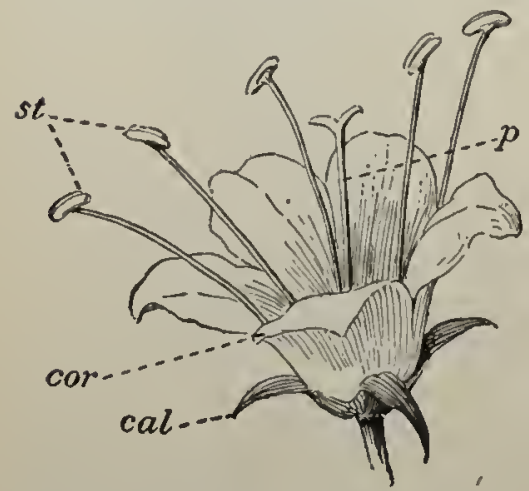

Fig. 128. Flower of Hydrophyllum cal, lole of calyx; cor, lobe of corolla; st, stamens; $p$, pistil. Modified. - After Lindley

134. Among the higher familics the nembers of the perianth are often borne upon a tubular or cuplike outgrowth from the receptacle (Fig. 136, B), so that the sepals or petals, or both, appear to have grown together more or less completely. ${ }^{1}$

When the calyx or the corolla is borne upon a tubular, bowlshaped, or other extension of the receptacle, there arc often divisions, teeth, or lobes at the rim of the tube (Figs. 128, 144, Appendix) showing how many scpals or petals the flower possesscs. Special names are given to a large number of forms of the sympetalous corolla, and these are of much use in accurate descriptions of sced plants. A few of these are illustrated in Chapter Xxxil and in the Appendix.

1 When the parts of the perianth are distinet the calyx is said to be chorisepalous and the corolla ehoripetalous; other terms are polysepalous and polypetalous. When the receptacle forms a cup-like or tubular outgrow th so that the teeth or lobes of this alone are sepals or petals, the flower is sairl to be synsepalous or sympetalous; other terms are gamosepalous or gamopetalous. Choris means apart, poly means many, syn ineans together, gainns means marriage. Botanists have until recently used such expressions as "sepals united into a tube," etc., but these are incorreet. 
153. Form of the stamen; union of stamens. Stamens are of many specialized forms, to adapt them to their functions in flowers of various shapes, but many are of the shape shown in Fig. 129. Such a stamen consists of an expanded part, the anther, borne on a stalk called the filament. Anthers are often nearly or quite sessile (seated, i.e. destitute of filaments). Inside the anther is the powdery or pasty substance called pollen (Fig. 153).

Stamens may be wholly unconnected with each other, or distinct, as shown in Figs. 122, 124 , and 128 , or they may be really or apparently more or less united to each other.

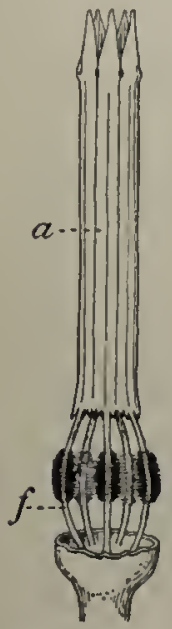

Fir. 130. Stamens of a thistle, with anthers united into a ring

$a$, united anthers; $f$, filaments, bearded oll the sides. - After Baillon
In Fig. 130 the stamens have arisen separately, but finally become joined together by their anthers (as is always the case in the family Compositce).

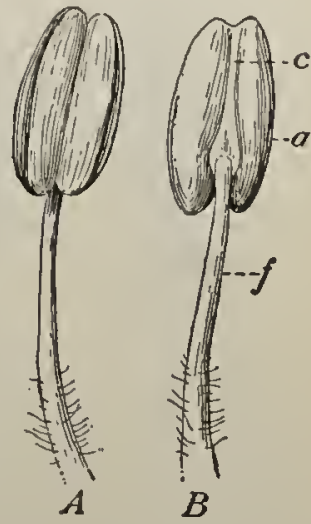

Fic. 129. Parts of a stamen

$A$, front; $B$, back; $\alpha$, anther; $c$, eonnective; $f$, filament.After Strasburger

In other cases the stamens appear united when they are not really so, because they are borne on a ring or tube of tissue, as already explained in connection with the perianth (Sec. 152).

Without regard to whether the union is real or apparent, stamens which occur in a single group (the filaments appearing joined) are said to be monadelphous (Fig. 131), in two groups, diadelphous (Fig. 132), in many groups, polyadelphous (the terms meaning one brotherhood, two brotherhoods, many brotherhoods).

154. The carpel. The simplest form of the organ which bears the structures called ovules, that are to mature into seeds, is known as the carpel. 
In the lowest of the two great groups of seed plants, the gymnosperms (meaning naked sceds), to which the pines, spruces, cedars, and the like belong, the ovules arc

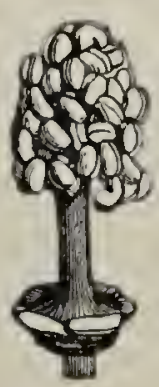

Fig. 131. Monadelphous stamens of mallow i cu which contains the ovules and is formed by the carpcls of the angiospcrms. This is a morc general term than carpel, for it applies to organs com-

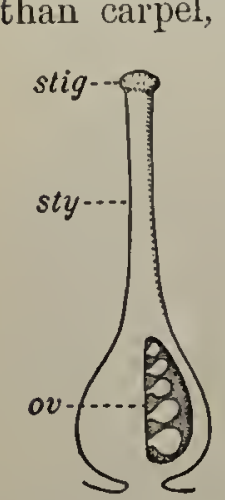

fig. 183. l'arts of the pistil borne exposed on the surface of the carpels, which usually have the form of scales. But in the higher group of seed plants, the angiosperms (meaning secds in a vesscl), the carpcls constitute a part of cases or chambers in which the orules are formed and which are generally quitc closed.

155. The pistil. The term pistil (Latin for pestle) is applied to the closed structure which contains the

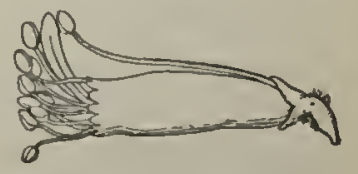
posed of one or of sereral carpels. If a pistil is of one

FIG. 132. Diadelphons stamens of sweet pea carpel it is said to be simple, if of two or more carpels it is compound.

The pistil often consists of an cnlarged, hollow portion containing orules and known as the ovary, ${ }^{1}$ a stalk-like style, and a knob or ridged expansion called the stigma (Fig. 133). Not infrequently the style is wanting and the stigma is sessile (seated) on the orary.

A flower may contain sercral or many carpcls ov, ovary; sty, style; stig, stigma in the form of simple pistils separate from one another, as in the stonecrop and the buttcreup (Figs. 134, 161). When screral carpels form a compound pistil the manner and extent of the union is various.

1 The term ovary is an unfortunate one, since it would seein to mean the organ which bears egrgs. Those who wish to avoid the use of the term may substitnte the worl ovulary, proposed by Professor Charles k. Barnes, or may simply say ovule case. 
The union generally forms the ovary, although this is sometimes developed in large part as a cup-like or tubular growth from the stem under the carpels. Sometimes the union is so complete
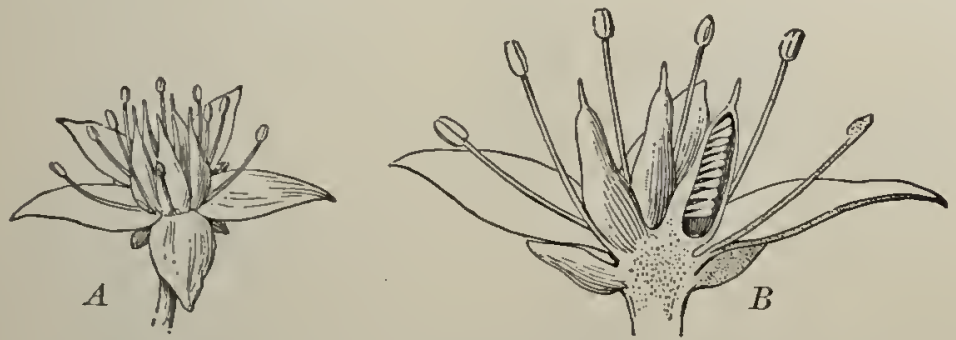

FIG. 134. Flower of stonecrop

$A$, entire flower; $B$, vertical section. - After Decaisne

that the compound pistil has only one style and one stigma; but frequently the styles remain separate, or the styles may be united and the stigmas separate, or at least lobed so as to show of how many carpels the pistil is made up (Figs. 123, 124). Even when there is no external sign to indicate the compound nature of the pistil, it can usually be recognized from a study of a cross section of the ovary.

156. Locules of the ovary; placentas. Compound ovaries very commonly consist of a number of separate chambers known as locules. ${ }^{1}$ Fig. $135, B$, shows a three-loculed ovary seen in cross section. The ovules are not borne indiscriminately by any part of the lining of the ovary. In one-loculed pistils they frequently grow in a line running along one side of the ovary, as in the pea pod (Fig. 343). Tlie ovule-bearing line is
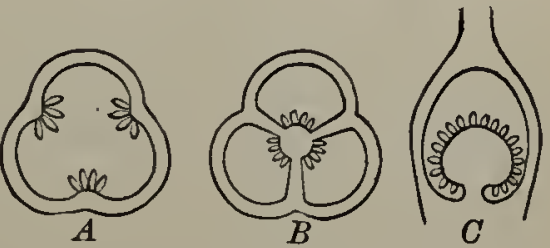

Fig. 135. Principal types of placenta $A$, parietal placenta; $B$, central placenta; $C$, free central placenta; $A$ and $B$, transverse sections; $C$, longitudinal section. - After Strasburger called a placenta; in compound pistils there are commonly as many placentas as there are separate carpels joined to make the

1 Often (less correctly) called cells. 
pistil. Placentas on the wall of the ovary, like those in Fig. 135, $A$, are called parictal placentas; those which occur as at $I B$

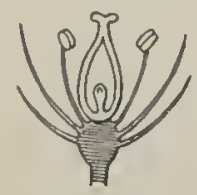

$A$

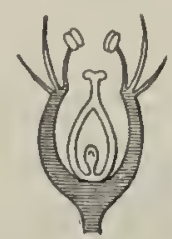

$B$

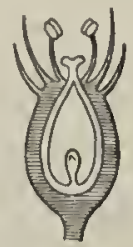

$C$
Fig. 136. Insertion of the floral organs

$A$, hypogynous, all the other parts on the reeeptacle, beneath the pistil ; $l$, perigynous, petals and stamens apparently growing out of the ealyx, around the pistil ; $C$, epigynous, all the other parts appearing to grow out of the pistil. After Strasburger are said to be axial; and those which, like the form represented in $C$, consist of a column rising from the bottom of the ovary are called free contral placentas.

157. Superior, half-inferior, and inferior ovaries. When, as in the diagrammatic flower of Fig. 122, the receptacle is rounded or club-shaped, and the floral organs arise from it in successive sets, the flower is said to be hypogynous (from two Greek words here applied to mean under the pistil), and the ovaries are said to be superior (Fig. 136, A).

When the receptacle is concave, or when it grows up about the pistil, carrying the other floral parts with it, so that the pistil is inserted on the same level with the stamens or lower, but not at all united with the receptacle, the flower is said to be perigynous (meaning around the pistil) and the ovary is half inferior (Fig. 136, B).

When the ovary is united with the receptacle the flower is said to be epigynous (meaning upon the pistil), or the ovary is inferior (Fig. 136, C).

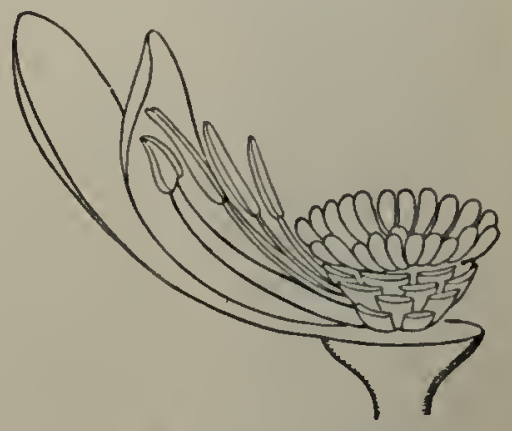

FIG. 137. White water lily

The inner petals and the stamens growing from the ovary. - After Deeaisne

158. Floral diagrams. Sections (real or imaginary) through the flower lengthwise, like those of Fig. 136, help greatly in giving an accurate idea of the relative position of the floral 
organs. Equally important in this way are cross sections, which may be recorded in diagrams like those of Fig. 138.1 In constructing such diagrams it will often be necessary to suppose some of the parts of the flower to be raised or lowered from their true position, so as to bring them into such rela-

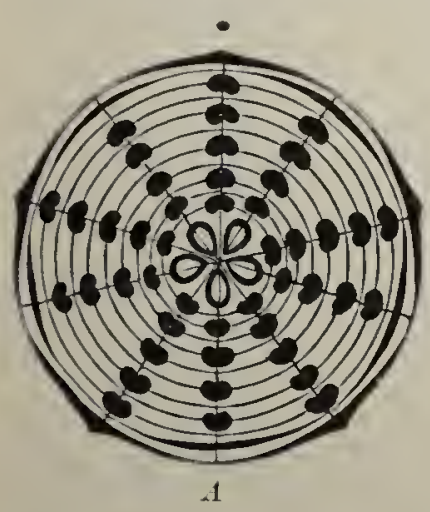
tions that all could be cut by a single section. This would, for instance, be necessary in making a diagram for the

FIG. 138. Diagram of cross sections of flowers

$A$, columbine; $B$, heath family; $C$, Iris family. In each diagram the dot alongside the main portion indicates a cross section of the stem of the plant. In $B$ every other stamen is more lightly shaded, because some plants of the heath family have five and some ten stamens. - After Sachs

cross section of the flower of the white water lily, of which a partial view of one side is shown in Fig. 137.

It is found convenient, in diagrams of cross sections, to distinguish the sepals from the petals by representing the former with midribs. The diagrammatic symbol for a stamen stands for a cross section of the anther, and that for the pistil is a section of the ovary. If any part is lacking in the flower (as in the case of flowers which have some antherless filaments), the missing or abortive organ may be indicated by a dot. In the diagram of the Iris family (Fig. 138, C) the three dots inside the flower indicate the position of a second circle of stamens, found in most flowers of monocotyledons but not in this family.

1 For floral diagrams see Le Maout and Decaisne, Traité Général de Botanique, or Eichler, Bliithendiagramme. 


\section{CHAPTER XIV}

\section{INFLORESCENCE}

159. Definition of inflorescence and flower cluster. The manner in which flowers are arranged on the stem is known as inflorescence. ${ }^{1}$ Not infrequently the flowering shoot bears only a single flower, but very generally among seed plants these shoots are grouped into definite systems, which are called flower clusters.

160. Advantage of grouping flowers. Flowers when clustered, as in Figs. 140-143, on special nearly leafless shoots are much more conspicuous than they would be if scattered along

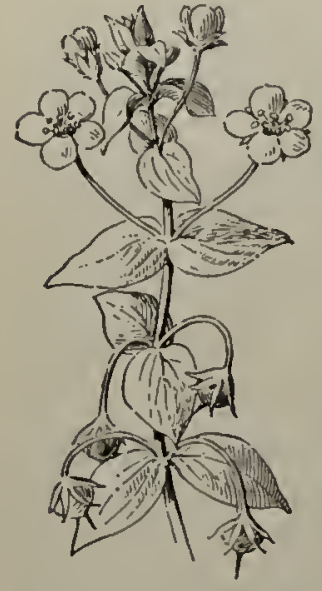

Fin. 139. Axillary and solitary flowers of pimpernel ordinary leafy branches and partly hidden by the leaves. This is a decided advantage in securing many visits from insects which carry pollen from plant to plant (Chapter XXXI) and leads to a more abundant production of seed.

161. Regular positions for flower buds. Flower buds, like leaf buds, occur regularly either in the axils of leaves or at the cud of the stem or branch, and are therefore either axillary or terminal (Sec. 168).

162. Axillary and solitary flowers ; indeterminate inflorescence. The simplest possible arrangement for flowers which arise from the axils of lcaves is to have a single flower spring from each leaf axil. Fig. 139 shows how this plan appears in a plant with opposite leaves. As long as the

${ }^{x}$ Sometimes (but less correctly) the word infloresccnce is uscd to mean flower cluster. 
stem continues to grow the production of new leaves may be followed by that of new flowers. Since there is no definite limit to the number of flowers which may appear in this way, the mode of flowering just described (with many others of the same general character) is known as indeterminate inflorescence.

163. The raceme and related forms. If the leaves along the stem were to become

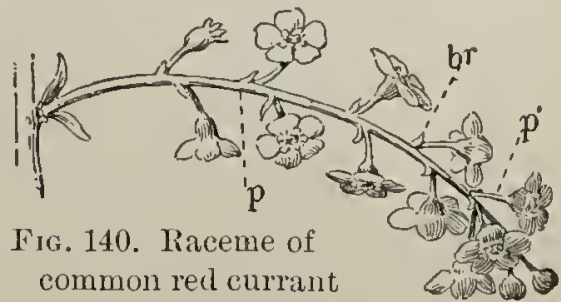

$p$, peduncle; $p^{\prime}$, pedicel; $b r$, bract very much dwarfed and the flowers brought closer together, as they frequently are, a kind of flower cluster like that of the currant (Fig. 140) or the lily of the valley would result. Such an inflorescence is called a racene; the main flower stalk is known as the peduncle; the little individual flower

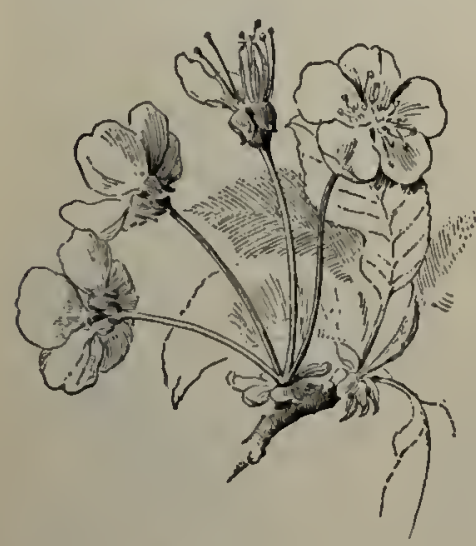

Fig. 141. Simple unbel of cherry stalks are pedicels, and the small, more or less scale-like leaves of the peduncle are bracts.

Frequently the lower pedicels of a cluster on the general plan of the raceme are longer than the upper ones and make a somewhat flat-topped cluster, like that of the hawthorn, the elder, the sheep laurel, or the trumpet creeper. This is called a corymb.

In many cases, for example the parsnip, the sweet cicely, the ginseng, and the cherry, a group of pedicels of nearly equal length spring from about the same point. This produces a fower cluster called the umbel (Fig. 141).

164. Sessile flowers and flower clusters. Often the pedicels are wanting, or the flowers are sessile, and then a modification of the raceme is produced which is called a spike, like that of 


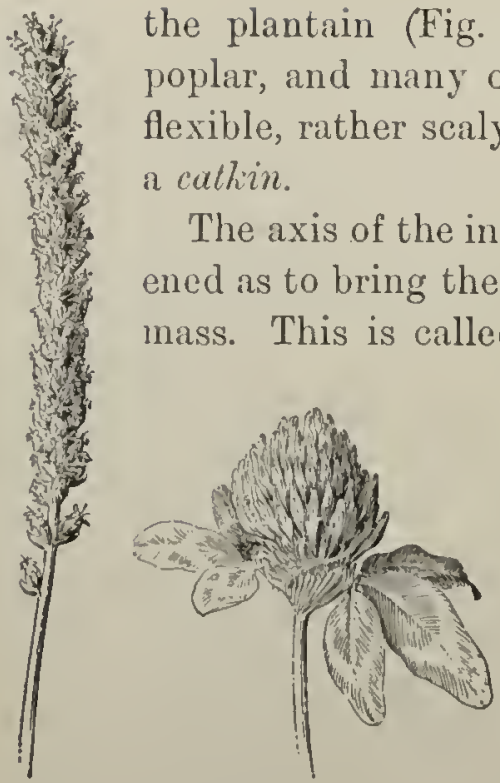

Fig. 142. Spike of plantain and head of red clover

base of the head usually occurs a circle of bracts known as the involuere. The same name is given to a set of bracts which often surround the bases of the pedicels in an umbel.

165. The composite head. The plants of one large group - of which the dandelion, the daisy, the thistle, and the sunflower are well-known members — bear their flowers in close involucrate heads on a common receptacle. The whole cluster looks so much like a single flower that it is nsually taken for one by non-botanical people. In many of the largest and most showy heads, like that of the sunflower and the daisy, there are two kinds of flowers, - the ray flowers, around the margin, and the tubular dish flowers of the interior of the head (Fig. 144). The early botanists supposed the whole flower cluster to be a single compound flower.

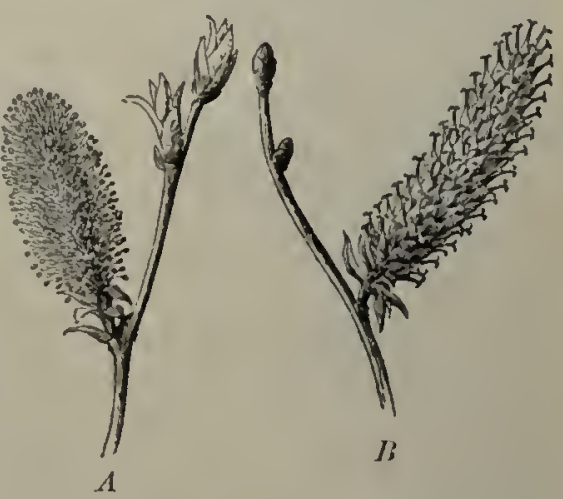

Fug. 143. Catkins of willow $A$, staminate flowers; $B$, pistillate flowers This belief gave rise to the name of one family of plants, Composito, - that is, plants with compound flowers. In such 

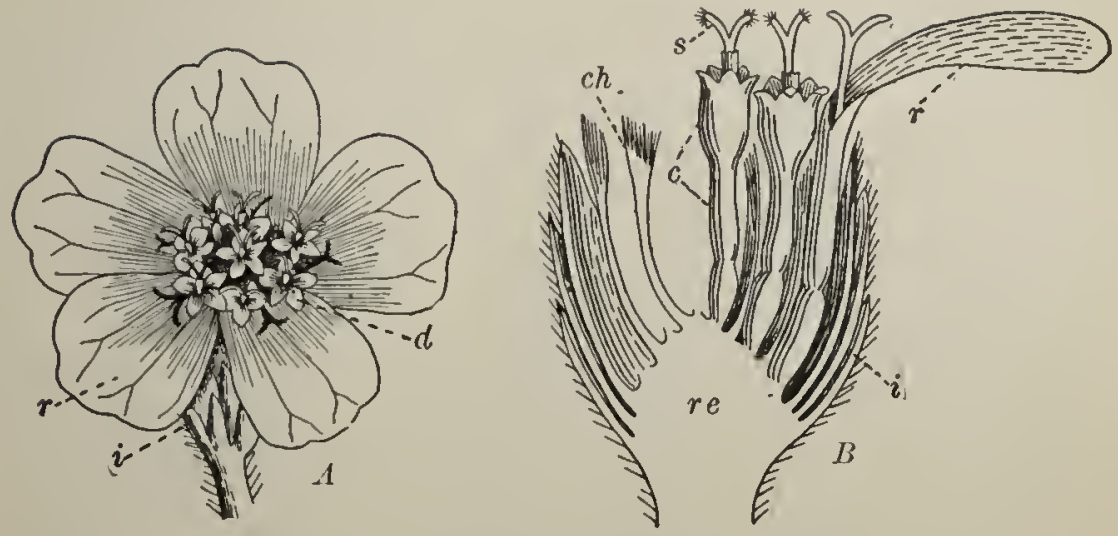

FIG. 144. Head of yarrow

$A$, top view (magnified); $B$, lengthwise section (magnified); re, receptacle; $i$, involuere; $r$, lay tlowers; $d$, disk flowers; $c$, corolla; $s$, stigma ; ch, ehaff, or bracts of receptacle

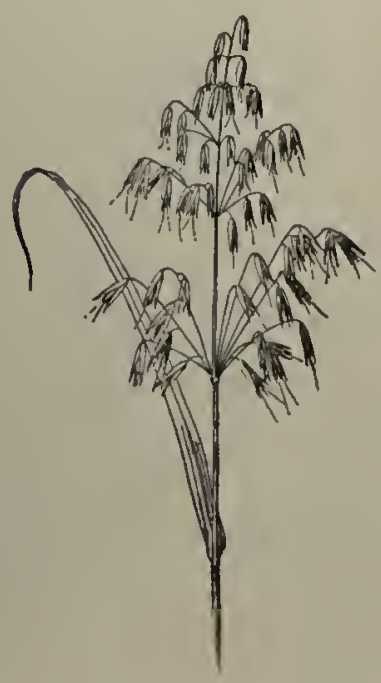

F'1(i. 14is

Panicle of oat

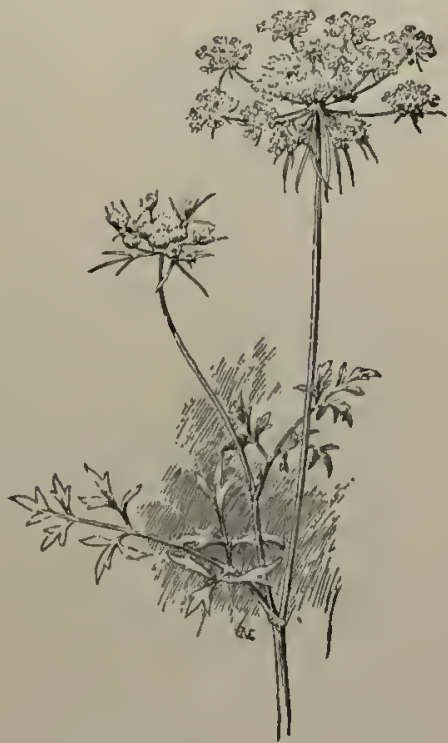

Fig. 146. Compound umbel of carrot

heads as those of the tansy, the thistle, the cudweed, and the everlasting, there are no ray flowers, and in others, like those of the dandelion and the chicory, all the flowers are ray flowers. 
166. Compound flower clusters. If the pedicels of a raceme branch, they may produce a compound raceme, or panicle, like that of the oat (Fig. 145). ${ }^{2}$ Other forms of compound racemes have received other names.

An umbel may become compound by the branching of its flower stalks (Fig. 146), each of which then bears a little umbel, called an umbellet.

167. Inflorescence diagrams. The plan of inflorescence may readily be indicated by diagrams like those of Fig. 147.
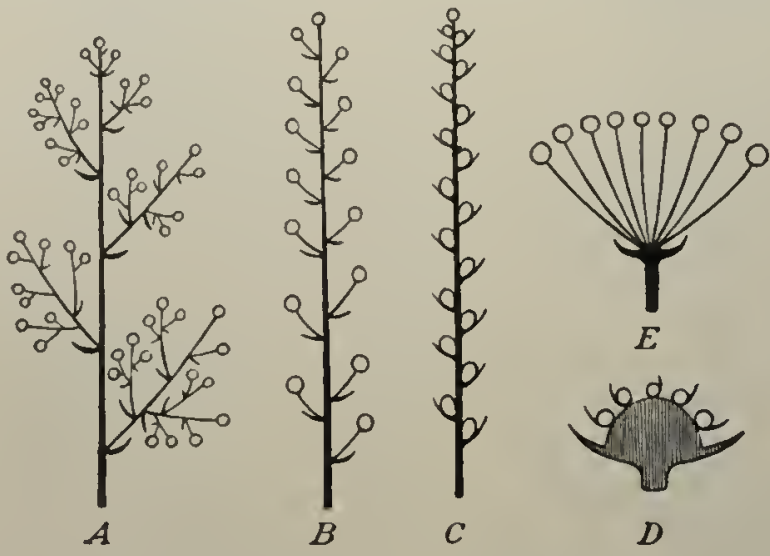

FıG. 147. Diagrams of inflorescence

$A$, panicle; $B$, raceme ; $C$, spike $D$, head; $E$, umbel

168. Terminal flowers; determinate inflorescence. The terminal bud of a stem may be a flower bud. In this case the direct growth of the stem is stopped or determined by the appearance of the flower; hence such plants are said to have a determinate inflorescence. The simplest possible case of this kind is that in which the stem bears but one flower at its summit.

169. The cyme. Very often flowers appear from lateral (axillary) buds, below the terminal flower, and thus give rise to a flower cluster called a cyme. This may have only three flowers, and in that case would look very much like a three-flowered

1 Panicles may also be formed by compound cymes (see Sec. 169). 
umbel. But in the indeterminate inflorescence, such as the raceme, corymb, and umbel, the order of flowering is from below upward, or from the outside of the cluster inward, because the lowest or the outermost flowers are the oldest, while in determinate forms of inflorescence the central flower is the oldest,

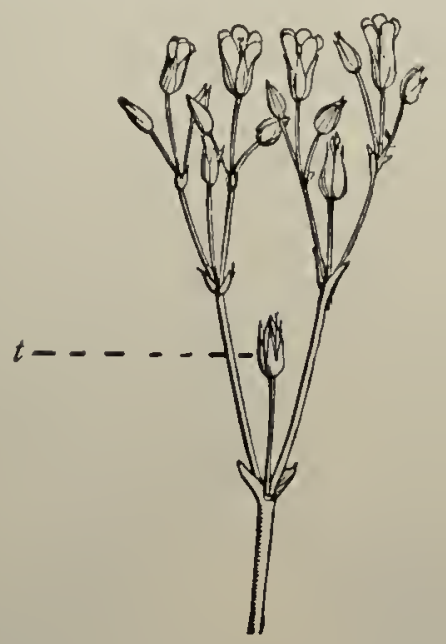

FIG. 148. Compound cyme of mouse-ear chickweed

$t$, the terminal (oldest) flower

and therefore the order of blossoming is from the center outwards. Cymes are very commonly compoumd, like those of the elder and of many plants of the pink family, such as the sweet william and the mouse-ear chickweed (Fig. 148). They may also, as already mentioned, be panicled, thus making a cluster much like Fig. 147, A. 


\section{CHAPTER XV}

\section{ORIGIN AND STRUCTURE OF FLORAL ORGANS ; POLLINATION AND FERTILIZATION}

170. The flower a shortened and greatly modified branch. In Chapter Ix the leaf bud was explained as being an undeveloped braneh, which in its growth would develop into a real braneh (or a prolongation of the main stem). Now, since flower buds appear regularly either in the axils of leaves or as terminal
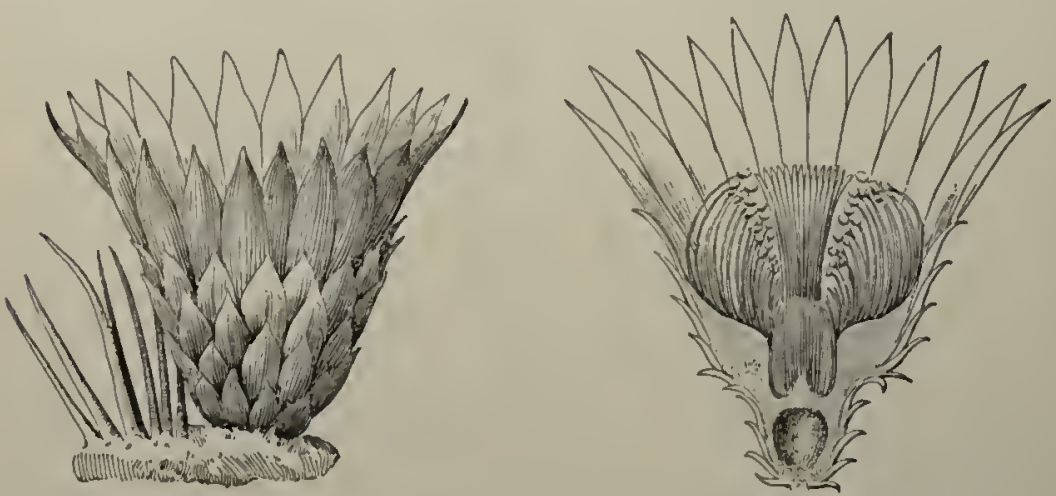

FIG. 149. Transition from bracts to sepals in a cactus flower

buds, there is reason to regard them as of a nature similar to leaf buds. This wonld imply that the reeptaele corresponds to the axis of the buds shown in Fig. 85, and that at least some of the parts of the flower correspond to leaves. There is plenty of evidenee that this is really true. Sepals frequently look very much like leaves, and in many eaetuses the braets about the flower are so sepal-like that it is impossible to tell where the braets end and the sepals begin (Fig. 149). The same thing is true of sepals and petals in such flowers as the white water lily. In this flower there is also a remarkable series, ranging all the 
way from petals tipped with a bit of anther, through stamens with a broad petal-like filament, to regular stamens, as is shown in Fig. $150, A, B, C, D$. The same thing is shown in many double roses. In completely double flowers the stamens and pistils are transformed into petals by cultivation. In the flowers of the cultivated double cherry the pistils oceasionally take the form of small leaves, and some roses turn wholly into green leaves.

Summing up, then, we know that flowers are altered and shortened branches, (1) because flower buds have, as regards

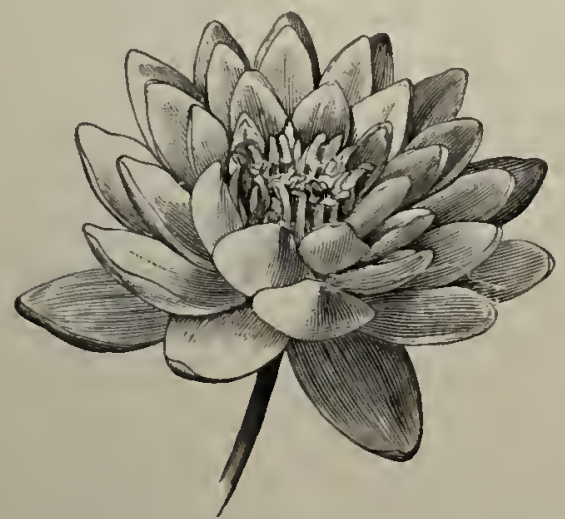

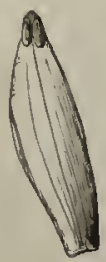

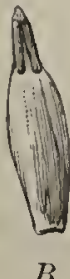

A

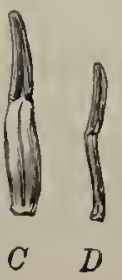

Fig. 150. Transitions from petals to stamens in white water lily $A, B, C, D$, various steps between petal and stamen. - After Brown position, the same kind of origin as leaf buds; (2) beeause all the intermediate steps are found between bracts on the one hand and stamens on the other.

171. Development of the anther. If the development of an anther is followed throughout, it will be found at an early stage to contain, usually, four regions, where rapid cell division is going on, which become organized into pollen sacs. These eavities (Fig. 151) are filled with pollen grains and finally merge into two pollen chambers which, in the commonest type of anther, split open lengthwise to allow the eseape of the pollen.

172. Relation of stamens and carpels to structures in the lower plants. The exact significance of the stamens and carpels as organs of the plant body set apart for the purpose of 
reproduction can only be understood by means of a study of certain forms in the fern group, or pteridophytes; for these

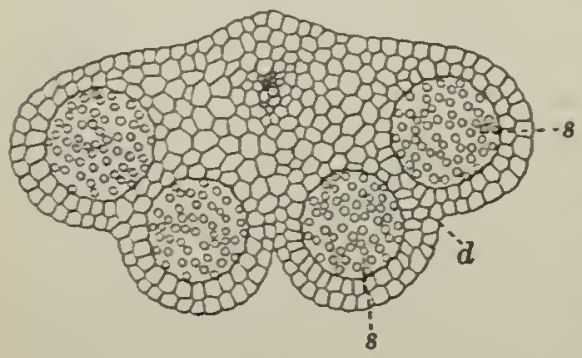

FIG. 151. Cross section of anther of mint

$\varepsilon$, pollen sacs, with grains of pollen; $d$, groove along which the anther will split open. Somerrhat magnified. After Bonnier and Sablon structures had their origin in connection with the derelopment, from simpler conditions among the fern group, of the habit of producing seeds. The subject is treated at some length in Part II, Chapters $x x^{\prime}$ to $\mathrm{XXX}$ inclusive.

\section{The anther and its} contents. Some of the shapes of anthers may be learned from Figs. 129, 130, and 152.1 The shape of the anther and the way in which it opeus depend largely upon the manner in which the pollen is to be discharged and how it is carried from flower to flower. The commonest method is that in which the anther cells split lengthwise, as in Fig. 152, A. A few anthers open by trapdoor-like ralves, as in $P$, and a larger number by little holes at the top, as in $C$.

The pollen in many plants with inconspicuous flowers (as the evergreen cone-bearing trees, the grasses, rushes, and sedges) is a fine, dry powder. In plants with showy flowers it is often somewhat stichy or pasty: The forms of pollen grains are $e x-$
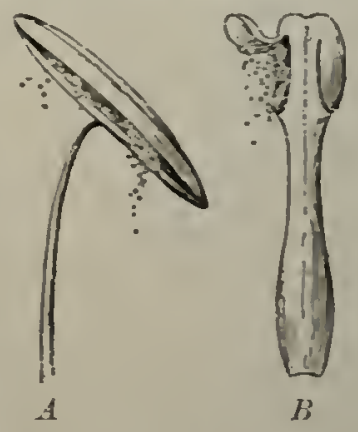

FIG. 152. Modes of discharging pollen

$A$, by longitudinal slits in the anther cells (amaryllis); $B$, by uplifting ralves (barberry): $C$, by a pore at the top of each anther lobe (night. shade). - After Baillon tremely various. Fig. 153 will serve to furnish exanples of some of the shapes which the grains assume; $c$ in that figure is perhaps as common a form as any. Each pollen grain

1 See Kerner and Oliver, Natural History of Plants, Vol. II, pp. 86-05. 
consists mainly of a single cell, and is covered by a moderately thick outer wall and a thin inner one. Its contents are thickish protoplasm, full of little opaque particles and usually containing

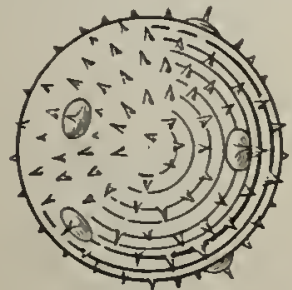

a

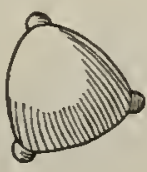

$b$

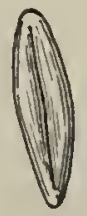

c

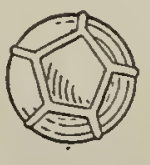

$d$

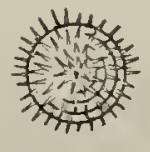

$e$

FIG. 153. Pollen grains

$a$, pumpkin; $b$, enchanter's nightshade; $c$, Aluuca; $d$, pink; e, hibiscus. Very greatly magnified. - After Kerner

grains of starch and small drops of oil. During the germination of a pollen grain the outer coat bursts at some point, forced outward by the pressure of a tube formed from the tough inner coat. Sometimes, as in Fig. 153, b, there are knobs or other indications of the places at which the outer coat is most easily ruptured. After the tube has pushed its way out it continues to elongate rather rapidly.

174. Microscopical structure of the stigma and style. Under a moderate power of the microscope the stigma is seen to consist of cells set irregularly over the surface, and secreting a viscid liquid to which the pollen grains adhere (Fig. 15t). Peneath these superficial cells is spongy parenchyma, which runs down through the style, if there is

one, to the orary. In some pistils the Magnified. - After Faguet pollen tube proceeds through the cell walls, which it softens by means of a substance which it exudes for that purpose. In other cases (Fig. 155) there is a canal or passage along which the pollen tube travels on its way to the ovule.

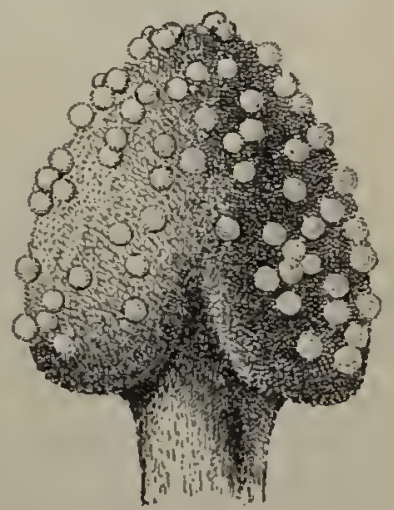

Eve. 154. Stigma of thorn apple (Datura), with pollen 
175. Pollination. The transference of pollen from anthers to stigmas is ealled pollination. In the case of plants with dry, dust-like pollen this is generally due to the action of the wind. Moist, sticky pollen is generally carried by some kind of animal, usually by insects. The subject of pollination is so important,

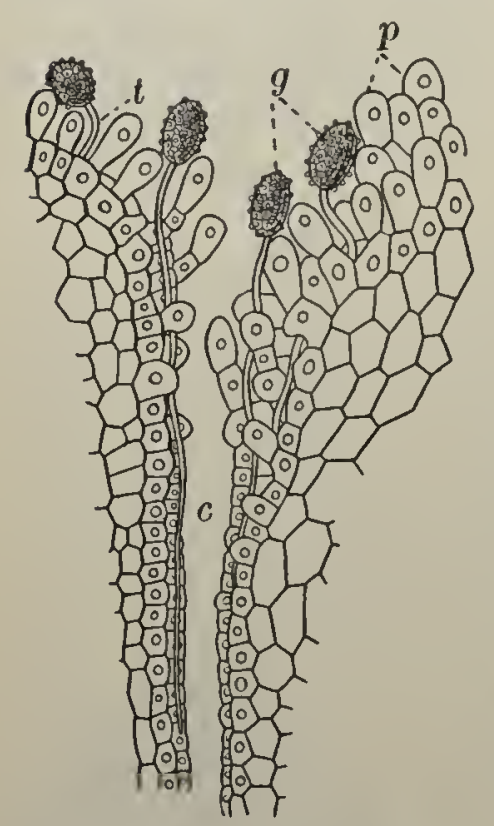

Fia. 155. Pollen grains producing tubes, on stigma of a lily $g$, pollen grains; $t$, pollen tubes; $p$, papille of stigma; $c$, eanal or passage running toward ovary. II uch magnified.After Dodel-Port especially in relation to the visits of insects, that it needs a chapter by itself (see Chapter xxxil).

176. Fertilization. By fertilization in seed plants the botanist means the union of a male sexual nucleus from a pollen grain with the female nueleus of the egg cell at the apex of the embryo sac (Fig. 157). This process gives rise to a cell which contains protoplasm derived from the pollen tube and from the egg cell. In wany plants the pollen, in order best to secure fertilization, must come from another plant of the same kind, and not from the individual which bears the orules to be fertilized.

Pollen tubes (Fig. 156) begin to form soon after pollen grains lodge on the stigma. The time required for the process to begin varies in different kinds of plants, requiring in many cases twenty-four hours or more. The length of time needed for the pollen tube to make its way through the style to the ovary depends upon the length of the style and other conditions. In the crocus, which has a style several inches long, the descent takes from one to three days.

Finally the tube penetrates the opening at the apex of the ovule (Fig. 157, $m$ ), called the micropyle (meaning little gate), and transfers a male nucleus into the egg cell. 
177. Nature of the fertilizing process. The necessary feature of the process of fertilization is the union of the essential contents of two cells, especially the nuclci, to form a ncw one from which the future plant is to spring. This kind of union also occurs in all the lower plants (Chapters XX-XXXI), resulting in the formation of a spore capable of growing into a complete plant like that which
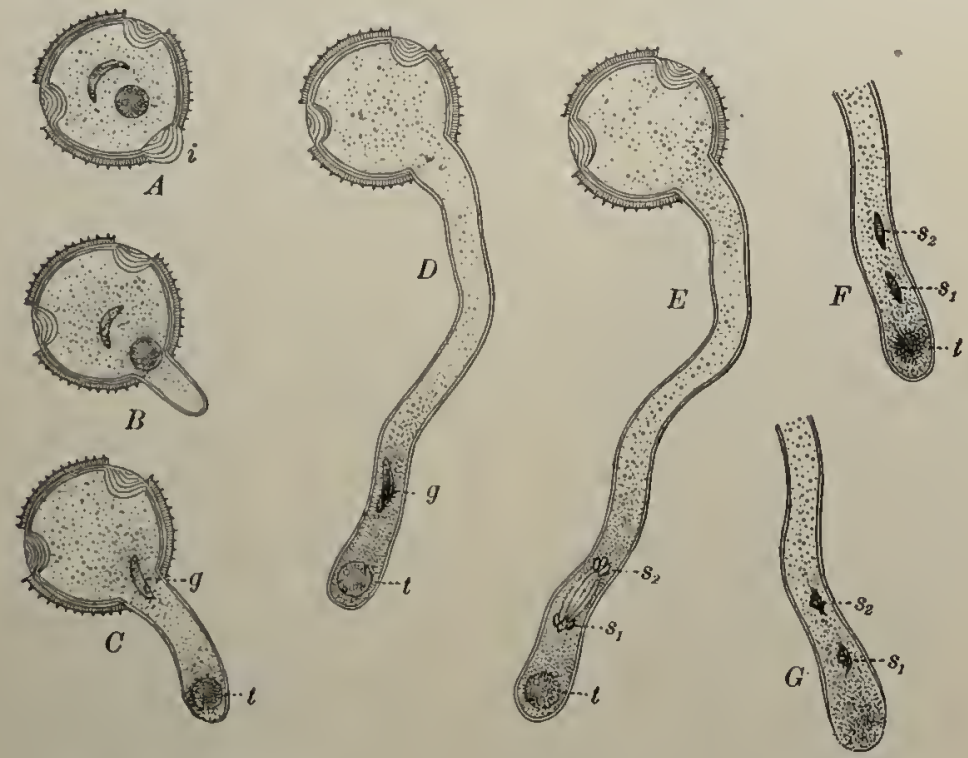

Fig. 156. Germination of the pollen grain of an angiosperm

$A$, inner coat of the pollen grain distended by osmosis from contact with the moist stigma, and protruding shightly at the point $i ; E$, the pollen tube beginning to form; $C$, the pollen tube more elongated, with the tube nucleus $t$ at its tip, the generative cell. $g$ having begun to enter the tubc; $D$, the pollen tube still farther elongated; $E$, the division of the nucleus of the generative cell to form the two sperm nuelei $s_{1}$ and $s_{2} ; F^{\prime}$, the sperm cells $s_{1}$ and $s_{2}$ fully formed, and the tube nucleus $t$ breaking down; $G$, the tube nucleus has disappeared, aud the sperm cells are about to be discharged near the tip of the pollen tube. Somewhat diagrammatic and much magnified. - After Bonnier and Sablon

produced it. It is a sexual act and can be studied much better in some of the algie, mosses, and ferns than in seed plants.

178. Development of the embryo. After fertilization the eggr cell finally develops the embryo of the future seed. This formation of the embryo is always a complicated process and varies much in different groups of seed plants. Briefly stated, 
the process in angiosperms is as follows. The egr cell (Fïg. $158, A)$ some time after fertilization forms a transverse partition

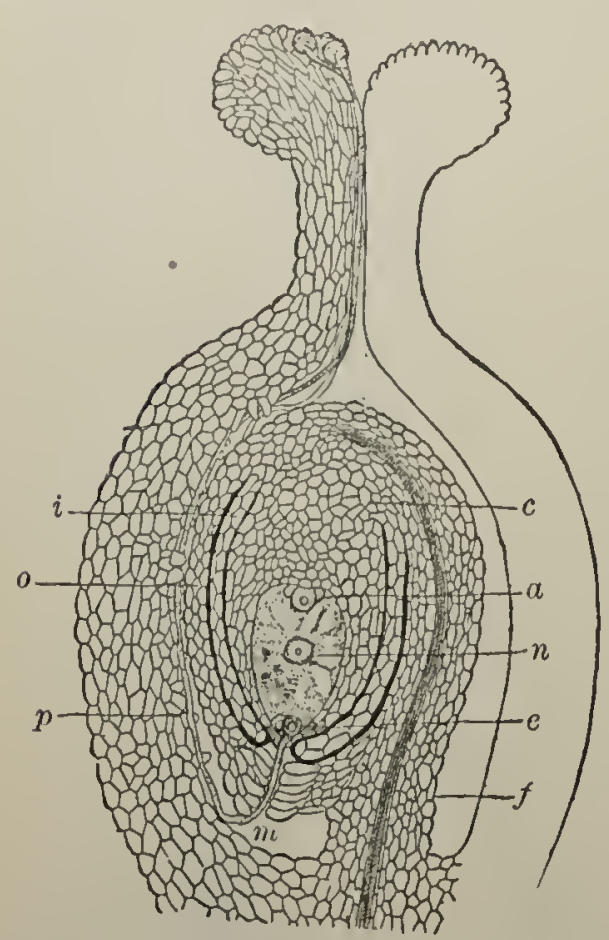

Fig. 157. Diagrammatic representation of fertilization of an ovule

$i$, inner coating of ovule; $o$, outer coating of ovule; $p$, pollen tube proceeding from one of the pollen grains on the stigma; $c$, the place where the two coats of the ovule blend. (The kind of ovnle here slown is inverted, its opening in being at the bottom, and the stalk $f$ adhering along one side of the ovule.) $a$ to $e$, embryo sac, full of protoplasm; $a$, so-ralled autipolal cells of embryo sic; $n$, central nucleus of the embryo sac; $e$, nucleated cells, one of which, the egg eell, receives the inale nuelers of the pollen tube; $f$, funienlus or stalk of ovnle; $m$, micropyle or opening into the ovile. - After Interssen more of them than they do ovules. The ratio, lowever, varies greatly. In the night-blooming cereus there are about 250,000

and is thus divided into two cells, one of which (Fig. 158, $B, s)$ is to form the slender suspensor of the embryo (which serves various purposes, such as forcing the embryo into the nutritive tissue of the seed, absorbing food from the wall of the ovary, or storing food for the growing embryo) and the other (e) is to form the embryo itself. These cells in turn subdivide, as shown in $C, D$, and $E$. The whole pearshaped body in parts $P-E$ is called the pro-embryo, and this continues to grow and its cells to subdivide until its structure becomes lighlyly complex. Finally it contains many sharply defined regions which gradually develop into the several organs of the full-rrown embryo.

179. Number of pollen grains to each ovule. Only one pollen grain is necessary to fertilize each ovule, but so many pollen grains are lost

144 STRUCTURE OF FLORAL ORGANS; FERTHIYATION (1)

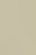


NUMBER OF POLLEN GRAINS TO EACH OVULE 145 pollen grains for 30,000 ovules, or rather more than 8 to 1 ; in the common garden wistaria there are about 7000 pollen grains to every ovule, and in Indian corn, the cone-bearing evergreens, and a multitude of other plants, there are many

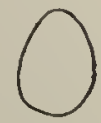

A

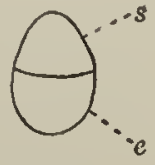

b)
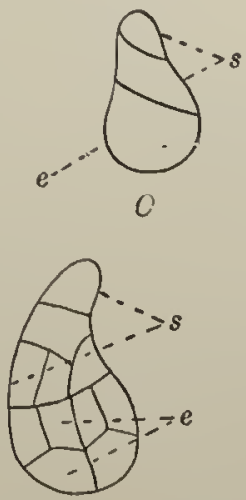

E

Fig. 158. First stages in the development of the egg cell of tho European ivy (Hedera Ifelix)

$A$, egg cell. $l i: s$, cell which will form the suspensor; e, cell which will form the embryo. $C$, showing first subdivision of the suspensor-forming cell; $D$, showing subdivision of the embryo-forming cell; $F$, showing subdivision of both regions, slightly more advaneed. - After Bounier and Sablon

times more than 7000 to 1 . These differences depend upon the mode in which the pollen is carried from the stamens to the pistil. Plants which are pollinated by the wind must produce far more pollen, to allow for inevitable waste, than those which are self-pollinated, or pollinated by insects (Chapter xxxil). 


\section{CHAPTER XVI}

\section{THE FRUIT ${ }^{1}$}

180. What constitutes a fruit. It is not easy to make a short and simple definition of what botanists mean by the term fruit. It has very little to do with the popular use of the word. Briefly stated, the definition may be given as follows: The fruit of a sced plant consists of the matured ovary and contents, together with any intimutely connected parts. Botanically speak-

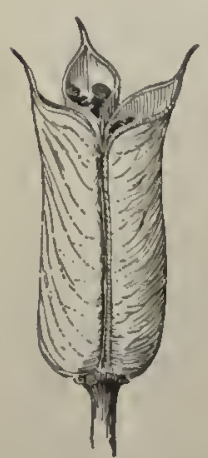

Fig. 159. Group of follicles and a single follicle of the monkshood

After Faguet ing, the bur of beggar's ticks (Fig. 344), the three-cornered grain of buckwheat, and such true grains as wheat and oats are as wuch fruits as is an apple or a peach.

181. Classes of fruits. Fruits may be divided into four classes as follows: (a) unipistillary fruits, those which result from the ripening of a single pistil; (b) aggregate fruits, those which result from the ripening of a cluster of carpels of one flower, massed together; $(c)$ aecessory fruits, those in which the main bulk of the fruit consists of something else besides the carpels, - e.g. calyx or receptacle, - arlded to a simple or an aggregate fruit; (d) multiple or collective fruits, those which result from the combination of the ripened pistils of two or more flowers into one mass.

182. Forms of unipistillary fruits: the capsule. This is a dry fruit, splitting open (dehiseing) to allow the seeds to escape. Capsules of simple pistils may either open along one line, as

1 Sec Gray. Structural Botany, chap. vii, also Kerner and Oliver, Natural Uistory of Plants, Vol. II, pp. 227-438. 
in the follicles of monkshood (Fig. 159), or along two lines, as in the lcyumes of the pea (Fig. 343). Many capsules result from the ripening of compound pistils, as the poppy, Datura, or jimson weed (Fig. 343), and crocus (Fig. 166, I, B).

The schizocarp. This is a dry fruit, breaking into pieces which do not split open, the name meaning breaking fruit (Figs. 160, 166, IT).

The akene, grain, and nut. These are dry fruits which never split open (indehiscent fruits).

Under the general name akene are grouped several types of fruits.

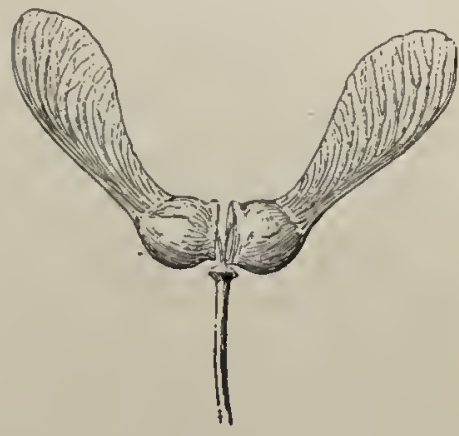

Fig. 160. Schizocarp of maple After Faguet Many, like those of Fig. 161, are small one-seeded carpels. Another large group, the fruits of the family Composita, has akenes which result from the ripening of an inferior ovary, frequently crowned by the limb of the calyx (Fig. 166, III).

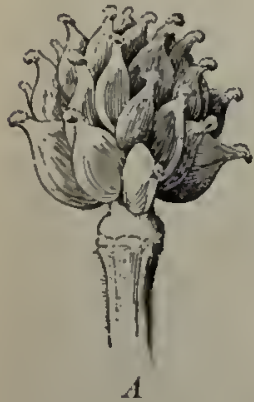

Fic. 161. Akenes of a buttercup

$A$, head of akenes; $B$, section of a

single akene (magnilied); $a$, seed

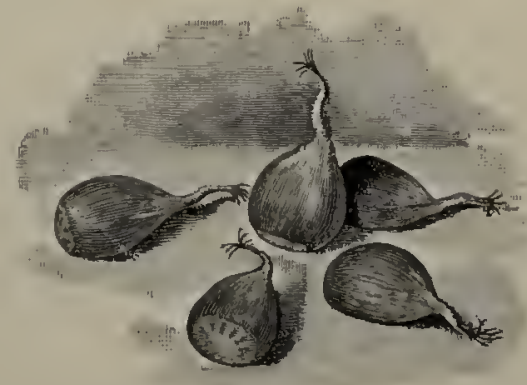

Fig. 162. Chestunts

Grains, such as corn, wheat, oats, barley, rice, and so on, have the interior of the ovary completely filled by the seed, and the seed coats and the wall of the ovary are firmly united, as shown in Fig. 3. Naturally, therefore, they are popularly supposed to be seeds and are always so called by non-botanical people. 
A nut (Fig. 162) is larger than an akene, usually has a liarder shell, and commonly eontains a seed which springs from

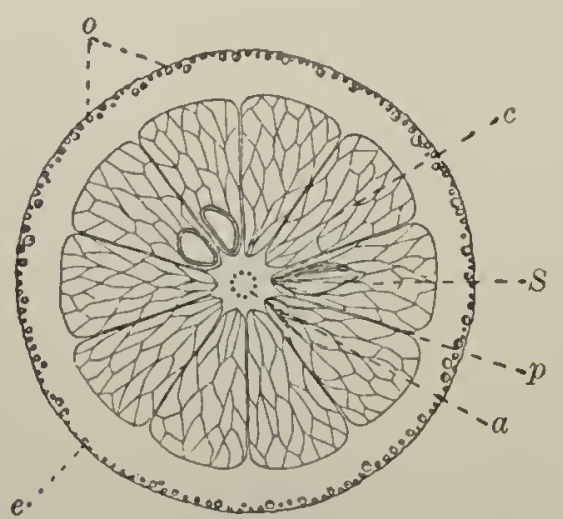

Fig. 163. Crosis section of an orange

$\alpha$, axis of fruit, with dots showing cut-off ends of fibro-vas'ular bundles ; $p$, partition between cells of ovary; $S$, seed; c, locule of ovary tilled with a pulp composed of irregular saes full of juiee; $o$, oil reservoirs near onter surface of rind; $e$, corky layer of epidermis. After Deeaisne a single orule in one locule of a eompound ovary, which develops at the expense of all the other ovules. The ehestnut bur is a kind of involucre, and so is the acorn eup. The name nut is often ineorreetly applied in popular language ; for example, the "Brazil nut" is really a large seed with a very hard testa.

183. The berry. This is a generally fleshy fruit, which usually does not split open. Such berries as the tomato, grape, and persimmon result from the ripening of a supsrior ovary. Those of the gooseberry, eurrant, and many others result from half-inferior or inferior ovaries, and therefore a considerable part of the bulk of the fruit is receptacle. The leatheryskimned fruit of the orange family is a true berry.

The fruit of the apple, pear, and quince is ealled a pome. It eonsists of a several-loculed ovary, the seeds and the tough membrane surrounding them in the eore,inclosed by a fleshy edible portion which makes up the main bulk of

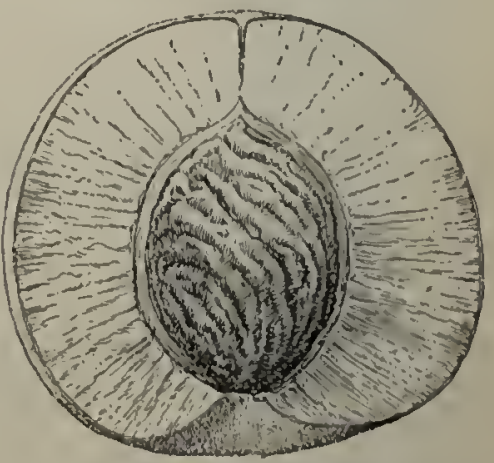

F16. 164. J'ench. Longitudinal section of clrupe

After Decaisne the fruit. In the apple and the pear much of the frut is receptacle. 
In the squash, pumpkin, and cucumber the ripened ovary, together with the receptacle, makes up a peculiar fruit (with a firm outer rind) known as the pepo. The relative bulk of the greatly enlarged hollow receptacle and of the ovary in such fruits is not always the same.

The drupc. This fruit is often fleshy, and usually does not split open. The pericarp, or wall of the ripened ovary (meaning round about and fruil), consists of an outer fleshy (or fibrous or leathery) layer, the cxocarp, and an inner, somewhat hard or stony layer, the endocarp. In common language the endocarp with its contained seed is called a "stone"; hence drupes are
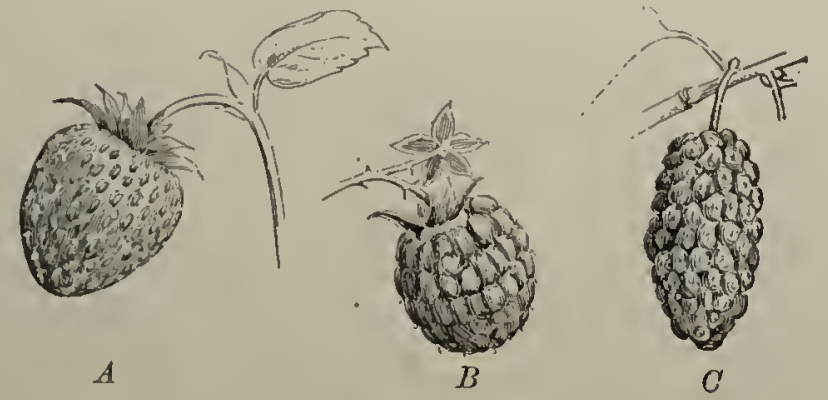

F1G. 165

A, strawberry ; 13 , raspberry ; $C$, innlberry.-After Faguet

often known as stone firuits. Most drupes, as in the case of the peach (Fig. 164), cherry, plum, cocoannt, and walnut, are onestoned and une-seeded.

184. Aggregate fruits. The raspluerry (Fig. 165, $B$ ), blackberry, and similar fruits consist of many carpels, each of which ripens into a part of a compound mass which, for a time at least, clings (1) the receptacle. The whole is called an agyregate fruit.

185. Accessory fruits. Notinfrequently, as in the strawberry (Fig. 165, A), the main bulk of the so-called "fruit" consists rather of the receptacle than of the ripened ovary or its appendages. Such a comhination is called an acecssory fruit.

186. Multiple fruits. The fruits of two or more flowers may blend into a single mass, known as a multiple fruit. Perhaps 
the best-known edible examples of multiple fruits are the mulberry (Fig. 165, C) and the pineapple. The last-named fruit is an excellent instance of the seedless condition which often results from long-continued cultivation.
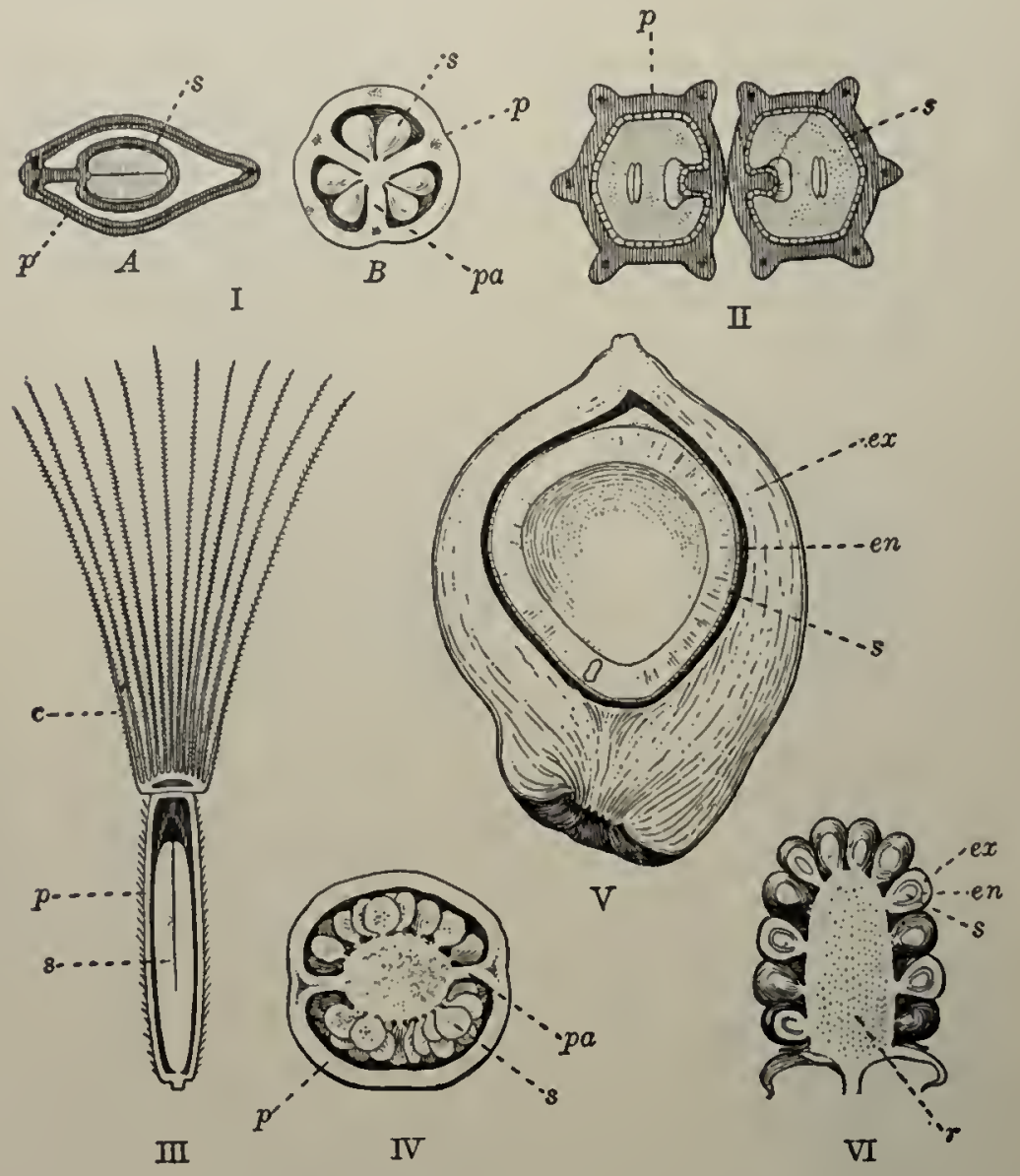

FIG. 166. Comparative sections of fruits

I, eapsule: $A$, unilocular liquoriee pod, cross seetion (maguified); $R$, triloeular erocus pod, eross section (magnified). II, schizocarp, double fruit of poison hemlock (Conium), cross section (magnified); III, akene of arniea, longitudinal section (magnified); IV, berry of pepper (Capsicum), eross seetion (redueed) ; V, drupe of eocoanut, longitudinal section (reduced); VI, aggregate and aecessory fruit of blackberry, longitudinal section (reduced). - I-IV, after Schmidt; $V$, after Deeaisue; VI, (modified) after Gray

$c$, limb of ealyx; en, endocarp; ex, exocarp; $p$, pericarp; $p a$, partition between locules; $r$, receptacle; s, seed 


\section{Phrti II}

\section{THE MORPHOLOGY, EVOLUTION, AND CLASSIFICATION OF PLANTS}

\section{CHAPTER XVII}

\section{THE PRINCIPLES OF MORPHOLOGY, EVOLUTION, AND CLASSIFICATION}

187. Morphology. Morphology treats of the form and structure of a plant or animal. 'The lowest organisms have a simple morphology, but the higher plants and animals are made up of many parts or organs, and consequently their morphology is very complex. Organs are structures set apart or developed for a definite kind of work. Thus the roots of a plant are organs usually employed to attach the plant to the ground in order that it may absorb soil moistnre.

One department of morphology (comparative morphology) deals with the various forms or lisgnises which the same sort of organ may take in different kinds of plants, and compares these structures with one another. For example, the foliage leaf is a well-rlefined organ which can be recognized at a glance; but it requires some study to understand that the seales on the bud and around an onion, and also some forms of spines and tendrils are morphologrically leaves, that is are leaves variously modified. Becanse all of these structures are related to one another they are ealled homoloyous, and morphology studies the homologies, or relationships, of organs. Comparative morphology is one of the most interesting subjects of biological study, since it furnishes 
the basis for the established belief in the evolution or derelopment of the higher plants and animals from simpler forms.

188. Classification. The classifications of animals and plants are attempts to express the actual kinships, or what among human beings are called blood relationships, which are believed to exist among them. To illustrate the principles of elassification let us consider the position of the pines among plants. All of the pines have for their fruit a sealy eone whose seeds are borne noked at the base of each seale and mature the seeond year. The leaves are needle-shaped, evergreen, and clustered. Any tree which has all the eharacteristies above given is a pine.

The spruces, hemloeks, firs, and larches agree with the pines in many respeets, but all of them mature their seeds the first year, and their folinge is different. The American eypress has " globular woody cone and deciduous leaves in two rows. The arbor vitæe and the juniper have awl-shaped or seale-like leaves, not in elusters.

All of these cone-bearing trees are distinct kinds, but they are grouped together because the seeds are borne nated on the scales of the cones. This peculiarity separates the group from a much larger assemblage of seed plants in which the seeds are borne inclosed in seed eases, pods, or other types of fruit. Finally, all of the seed-bearing plants are separated from the spore-bearing groups by the possession of methods of reproduetion which develop seeds.

Thus the pines find their place in the elassification of plants through clearly marked characters which define several different groups. 'These characters are (1) the presence of the seed, (2) the faet that the seeds are exposed or naked, (3) the derelopment of the seeds in a eone type of fruit, and finally (4) some peculiarities of the eone, and the eharacter of the foliage. The proeess of elassifieation leads from an assemblage of more than one hundred thousand linds of plants (the seed plants), througlt suceessively smaller divisions, to the relatively small group of the pines, with hardly more than seventy known kinds. 
189. Nomenclature. It was long ago found convenient to give Latin names to the kinds of animals and plants and to their various natural groups. These names constitute the nomenelature of botany and zoölogy. Each kind of plant or animal is termed a specics. A group of closely related species constitutes a genus (plural, genera). Every species is given a name that consists of two parts. There is the specific name, which defines the species, and the generic name, which includes the more immediate relatives. The specific name follows the generic, just as the first name of a man follows his family name or his surname in a directory. Furthermore, an abbreviation of the name of the botanist who first described the species follows the combination of generic and specific names. Thus the name of the pitch pine is written Pinus rigida Mill., this species having been described by a botanist named Miller. This universally adopted system of designating species by two names, known as the binomial system of nomenclature, was perfected by the famous Swedish naturalist Linneus, and the edition of his Species Plantarum, which is the basis of all botanical classification, bears the date 1753 .

Closely related genera are grouped into families, whose names generally terminate in the ending - acew, and families are brought together into orders, whose names are written with the uniform mding -ales. Orders are further assembled into elasses, and the classes into subdivisions, or more frequently into divisions, of the plant kingdom. Applying this system of classification, we have all the species of pines in the genus Pinus, in the fantily Pinacee, in the order Coniferales, in the class Coniferce, in the subdivision Gymnosperme of that highest division of the plant kingdom, the Spermatophyta.

190. Organic evolution. In the times of Linnæus, who lived in the eighteenth century, alnost all naturalists believed that the species or kinds of animals and plants had never changed in their characters during their long history on the earth. They believed that new kinds conld only arise by special acts of creation. This doctrine of special creation gave way to the present 


\section{MORPHOLOGY, EVOLUTION, AND CLASSIFICATION}

belief in organic evolution, or the theory of descent, chiefly through the work of Charles Darwin, whose famous book, The Origin of Spceies, appeared in 1859. The theories of organic evolution hold that all the existing species of animals and plants have bcen derived or evolved through the geological ages from the simplest forms of life in the begimning. These theorics also hold that the kinds now on the earth are subject to change, and that very many of them are in process of developing new specics. There are varying opinions as to the causes which bring about changes in species, and there are several schools of evolutionists whose theories are the subject of constant discussion and investigation.' But all botanists and zoölogists believe in the main principles of organic evolution; and the theory is the framework of biology. Indeed, the theory of organic evolution is as important to biology as the atomic theory is to cliemistry and as the doctrine of the conservation of energy is to physics.

191. An outline of the classification of plants. There will be given for reference at this point a classified arrangement of the most important of the larger groups of plants. It is quite impossible to develop a classification very far in the compass of this book, but this outline will serve to indicate the field covered in the succeding chapters. ${ }^{2}$ The thallophytes are especially dificult to classify, for the groups are not as clcarly understood as those of the higher plants, and there are complex relationships, especially betwcen the algie and the fungi. The relationships among the green algie are also not wcll understood, and the arrangemcnt prescnted here is largely one of convenience in the present state of our knowledge of this puzzling assemblage of forms. Classifications are, of coursc, subject to constant modification, as groups receive more careful study, and authors differ widely in their systems.

1 See Chapter $x \times x u x$, Variation, Mutation, and Origin of Species.

2 For the most recent and detailed classification of plants the reader is referred to Eugler, Syllabus der I'flanzenfamilien, 1907, or to Engler and Prantl, Die Natürlichen Pflanzenfamilien. 


\section{AN OUTLINE OF THE CLASSIFICATION OF PLANTS}

Division I. Thallophyta, the thallus plants, or thallophytes.

Series of the Alge.

Class I. Cyanophycece, the blue-green algæ.

II. Chlorophycere, the green algx.

Order 1. Protococcales, the one-celled green algæ.

2. Confervales, the confervas and sea lettuce.

3. Conjugalcs, the pond scums

4. Diatomales, the diatoms.

5. Siphonales, the siphon algæ.

6. Charales, the stoneworts.

III. Phoophycex, the brown algæ.

IV. Rhodophycex, the red algæ.

Series of tile Fungi.

Class V. Schizomycetes, the bacteria.

VI. Saccharomycetes, the yeasts.

VII. Phycomycetes, the alga-like fungi.

VIII. Ascomycetes, the sac fungi.

IX. Basidiomycctes, the basidia fungi.

Divisios II. Bryophyta, the liverworts and mosses, or bryophytes.

Class I. Hepaticu, the liverworts.

Order 1. Ricciales, the Riccia forms.

2. Marchantiales, the Marchantia forms.

3. Jungermanniales, the Jungermannia forms, or leafy liverworts.

4. Anthocerotales, the Anthoceros forms.

II. Musci, the mosses.

Order 1. Sphagnalcs, the peat mosses.

2. Bryales, the common mosses.

Division III. Pteridophyta, the ferns and their allies, or pteridopliytes.

Cuass I. Filicinew, the true ferns.

II. Equisetinea, the horsetails.

III. Lycopodinca, the club mosses.

Divisiox IV. Spermatophyta, the seed plants, or spermatophytes.

Surivisiox I. Gymnospcrme, the gymnosperms.

II. Angiosperma, the angiosperms. 1

Cuass I. Monocotylcdonece, the monocotyledons.

II. Dicotyledonere, the dieotylcdons.

1 The realer should note that in this elassification the angiosperms contain only two out of sixtcen elasses of somewhat equivalent value. 


\section{CHAPTER XVIII}

\section{THE LOWEST ORGANISMS AND THE CELL AS THE LIFE UNIT}

192. The process of evolution. The ligher complex animals and plants are readily distinguished from one another, but the differences become less apparent in the lower, simpler forms. There are indeed groups of uncertain position, some authors placing them among the plants and some among the animals.

The animal and plant kingdoms, in the process of evolution, followed a tree-like method of development. The forms and groups split up into divergent lines which constantly gave off, and are still giving off, new shoots. Thus from a number of trunks in the beginning there have been derived a multitude of smaller branches, and from these in turn have arisen countless twigs. It is impossible to construct accurately these genealogical trees, because the species now living occupy the position of buds on the strueture, some relatively low down and some at the highest points, but all at the ends of their respective lines of development. The forms which represented the lowest and intermediate stages of development are almost all extinet, - that is, have long ago died out on the earth, _ and we can only judge of their structure by the fragmentary remains which are left as fossils, or by comparative studies on the structure and development of living species, which frequently give us suggestions of what took place in the long process of organic evolution.

193. The simplest living unit a cell. The living material of organisms, that is the part which possesses life, is called protoplasm. Protoplasm is not a simple substance, but, on the contrary, is the most involver mixture of the most complex suhstances which the chemist knows. These belong to the group 
called protcids, a familiar example of which is the white of egg (albumen). Very little is known of the exact chemical structure of the numerous protcids. Their molecules are very complex, for they contain a large number of elements of remarkably varied chemical properties, - carbon, nitrogen, oxygen, hydrogen, sulphur, and in some cases phosphorus. But besides the proteids and many other organic compounds (substances usually formed only in association with life processes, as, for example, the sugars, starch, and fats), protoplasm also contains certain necessary inorganic substances, such as salts of sodium, potassium, calcium, magnesium, and iron, and in addition to these a very large amount of water.

Although we know very little about the chemical nature of protoplasm, certain remarkable structural peculiarities have been recognized for a long time. Protoplasm always exists in the form of units which are called cells. The simplest organisms consist of solitary units, and are consequently termed onc-celled (unicellular). The higher organisms are made up of aggregates of cells, and are termed many-celled (multicellular).

The cells in many-celled organisms have each a separate individuality, but they are usually set apart for particular kinds of work and depend upon one another for mutual assistance. The many-celled organism has been tcrmed a ccll republic, because all the cells, as individuals, work for the common good of the community, and by a system of helpful division of labor benefit one another.

There is a large group of one-celled microscopic animals called the Protozoa. 'This constitutes the lowest division of the animal kingdom, and is quite distinct from the groups of nany-celled animals, although the latter are believed to have been derived from it. There are likewise numerous onc-celled plants, but they are related to the higher many-celled forms by very conplete and interesting connecting links, so that botanists do not make a group of onc-celled plants, and can readily understand the evolution of the many-celled forms from the single-celled. 
It is much easier to understand the structure of the plant cell hy comparing it with one of the simplest of the one-celled animals; so at this proint there will be given a bricf account of one of the best-known protoroans, the Amaba.

194. The Amœba. * 'The Amoba under the inicroscope appears as a minute, irregularly shaped body of a jelly-like consistency. Its form when active constantly changes. A finger-like exteusion

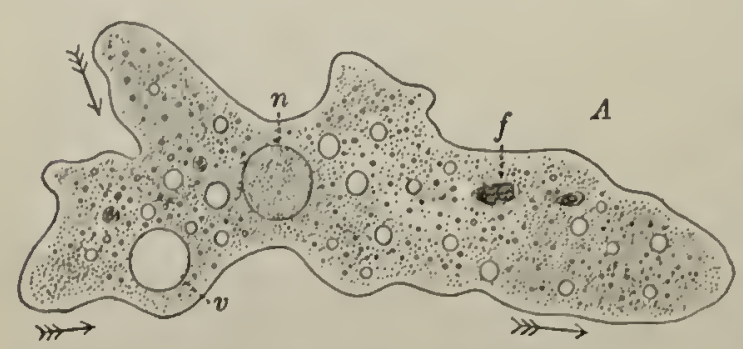

or process is thrust out from one side (Fig. 167, A) and the so inewliat granular protoplasm flows into this from neighboring regions. Other

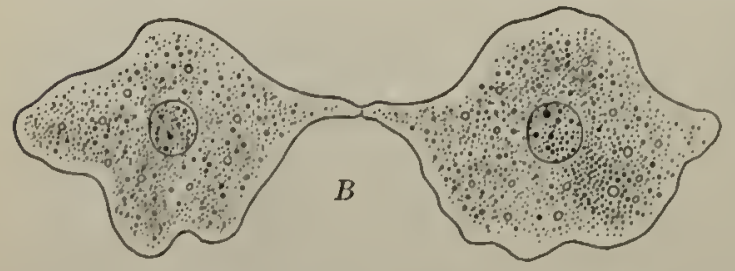

I'sc. 167. 'The Amoba

$A$, an individual moving in the direction of the arrows; $n$, murleus; $v$, pulsating vacuole; $f$, foor body. $J 3$, the process of cell division by constriction, a nucleus in each half. $-B$, after Jordan, Kellogg, and IIeath

ture terined the muclens, which is known th processes are successivcly withdrawn, so that the protoplasm actually moves or flows slowly forward in to the newly formed lobe, and thus the Amoba glides along. There is present in the protoplasm a denser protoplasmic structure termed the nucleus, which is known to be the center of very important activities in the cell. The protoplasm also contains numerous small gramules, and frequently large food particles, and there are also globules, called vacuolcs, of a watery fluid, which appear and disappear in the thicker substance. Such is the structure of a typical cell, which nay be defined as a small mass of protoplasm containing a nuclcus.

*'I'n tw: Isstructor: If material of Amcba is available, its study will furnish an excellent introduetion or accompaniment to laboratory work on the plant cell. 
The Amocba feeds upon smaller organisms. These may be drawn in at any point on the surface of the cell, whose protoplasm simply flows around the bodies and thus takes them into the interior. The oxygen gas held in the water which bathes the Ameba is also absorbed all over its surface. Food materials which cannot be digested, togcther with the waste products, arc left bchind by the protoplasm as it moves from place to place.

When the Amoba reaches a certain size there takes place the interesting event called cell division. The cell divides, by a process of constriction (Fig. 167, B), into similar halves, which separate from one another as two independent daughter Amcebce. Previous to the division of the cell there has been a division of the nucleus, so that each daughter Amceba is provided with a daugliter nucleus, and therefore has exactly the same structure as the parent cell, but is, of course, only about half as large. Ccll division is the method of cell reproduction. It is interesting to notc that in this process of reproduction there has been no loss of protoplasm, no death of any region of the parent Ameba, but from the division of onc have come two. There is, therefore, no death from old age in one-celled organisms. They are being killed constantly, of course, by adverse conditions, or eaten by other animals. These are the accidents of life. However, the Amaba and other one-celled animals and plants need never die of old age; that is, there is nothing in the constitution of such an organism to prevent its living forever.

195. The plant cell. The plant cell generally differs from the animal cell in two important respects.

First. The protoplasm is inclosed in a little box-like chamber with transparent walls. The substance of the walls is called cellulose, - a compound belonging to the great group of the starches and sugars (carbolydrates). Sucl an envelope is termed a cell wall, and is peculiar to plants. Indeed, the term eells, as used in biology, was first applied to the chambers inclosed by cell walls, which may be seen in thin scetions of cork, pith, and other plant structures. 
Second. The protoplasm of green portions of plants will be found to contain grcen bodies called chromatophores (meaning color bearers). Chromatophores have a great variety of forms in different plants and are sometimes very complex and beautiful, - as the spiral band in the cells of the pond scum, Spirogyra
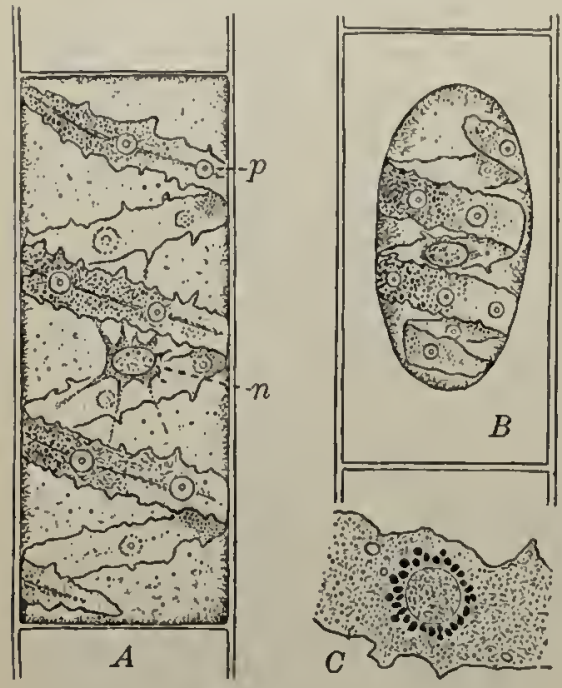

Fig. 168. Cell structure of the pond scum (Spirogyra)

$A$, living cell, showing spiral band-like chromatophore with pyrenoids $p$, and centrally placed uncleus $n$; $B$, living cell after treatment with "a salt solution, the protoplasm contracted away from the cell wall; $C$, pyrenoid stained with iodine and very greatly magnified (about 1000 dimueters), a circle of starch grains around the pyrenoid

(Fig. 168, A). The green coloring matter in a chromatophore is called chlorophyll (meaning leaf green). Green chromatophores are called chloroplasts when small and numerous in a cell. Chloroplasts are charaeteristic of the cells in plants above the thallophytes, and may be readily studicd in the leaves of mosses (Fig. 169, $A$ ), ferns, and seed plants. Chromatophores are sometimes colored brown or red, as in the cells of the brown and the red alga. Chromatophores are peculiar to plants, never being found in typical animal cells.

The protoplasm of the plant cell always lies directly under the cell wall, sonetimes eompletely filling the cavity, but more frequently forming a lining which surrounds one or more spaces, or vacuoles, which contain a watery fluid called cell sap. The relation of the protoplasm to the cell wall is easily understood when the protoplasm is made to contract from the wall by the withdrawal of the watery cell sap from the vacuoles. Thus if a filament of a pout scum or a portion of a moss leaf be placed in an aqueous solution of common salt ( 5 or 10 per cent), the cell sap is drawn 
out of the vacuole (osmotically) and the bounding layer of protoplasm shrinks away from the wall (Figs. 168, $B ; 169, B$ ). The force that keeps the layer of protoplasm against the cell wall is called cell turgor.

The mass of protoplasm inclosed by the cell wall is called the protoplast, and always contains at least one nucleus. Some plant cells have many nuclci. The position of the nucleus is somewhat variable. In the cell of the pond scum (Fig. 168, A, n) it is situated in the middle region and held in place by delicate strands of protoplasm which run out to the protoplasmic layer under the cell wall, but the nucleus frequently lies just under the wall, as in the moss leaf (Fig. $169, A, n)$. The chromatophores are generally found in the outer layer of protoplasm under the cell

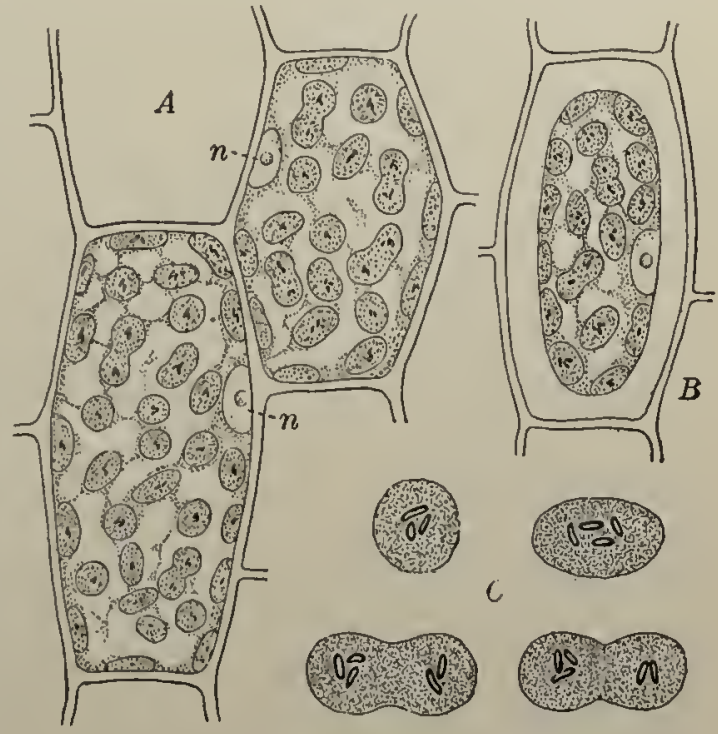

Fig. 169. Cell structure of the moss leaf (Funaria)

$A$, two living cells from a leaf, showing the numerous chloroplasts and the position of the nucleus $n$ in the layer of protoplasm under the cell wall; $B$, living cell after treatment with a salt solution, the protoplast contractcd away from the cell wall; $C$, stages illustrating the division of the plastids, starch grains shown in their interiors

wall. There are also many granules in the protoplasm, some of them minute globules of oils and fats and others of a proteid character. Many of these are food products in the cell. Finally, thc central portion of the cell generally contains a single vacuole filled with cell sap.

It is clear that the protoplast of the plant ccll corresponds to the entire Amoba or any other animal ccll. The ccll wall is a 
formation outside of the protoplast and is not a living part of the plant cell. Many lower plants form reproductive cells (zoöspores, gametes, etc.), which for some time are without a cellulose wall, and in this condition are motile and behave like animal cells. However, the cell walls and the chromatophores are respousible for the most conspicuous differences between plants and animals, as is noted in Sec. 202.

196. Photosynthesis. ${ }^{1}$ Chromatophores and chloroplasts in the presence of sunlight are able to manufacture from water and the simple gas carbon dioxide certain eomplex organic foods of which starch is generally the first visible product. This process is called photosynthesis, which signifies a putting together by light. The ehemical formula for carbon dioxide is $\mathrm{CO}_{2}$, for water $\mathrm{H}_{2} \mathrm{O}$, and for starch $\mathrm{C}_{6} \mathrm{H}_{10} \mathrm{O}_{5}$. The chemistry of the manufacture of starch cannot be truthfully shown by a simple equation, for starch is not formed directly from carbon dioxide and water, but by several steps through invisible substances that have not been isolated and therefore have never been studied. The chemical processes in these steps are not well understood. The final results may be roughly expressed as follows :

$$
6 \mathrm{CO}_{2}+5 \mathrm{H}_{2} \mathrm{O}=\mathrm{C}_{6} \mathrm{H}_{10} \mathrm{O}_{5}+6 \mathrm{O}_{2} \text {. }
$$

This shows why free oxygen is formed during the processes of photosynthesis. In some plants starch is never manufaetured, but instead sugars, which are substances closely related to starch, some of them having the formula $\mathrm{C}_{6} \mathrm{H}_{12} \mathrm{O}_{6}$. The sugars are in solution and invisible. Oil is formed in some plants, as in the green felt (Vaucheria), diatoms, ete., in place of starch as the first visible produet of photosynthesis.

Many chromatophores have well-defined denser regions called pyrenoids, which are the centers of starch formation, as is well illustrated in the pond scum (Fig. 168, C). Chloroplasts

1 The subject of photosynthesis is treated in greater detail in connection with the structure and functions of leaves (Chapter $x i s$ ), especially in Secs. $127-132$. 
frequently contain starch grains, as may be readily shown in the cells of the moss leaf (Fig. 169, C) when colored (stained) with iodine. Photosynthesis is only found in plants containing chlorophyll or other pigments of a similar physiological nature. The sun furnishes the energy in the form of light for the building up of the simplest food products, and the plant cell is the main factory which supplies the food of the world.

197. The food of plants; assimilation. All plants with chlorophyll can manufacture their own food by the processes of photosynthesis. Moreover, it is manufactured directly within the protoplasm of the cell and does not have to be absorbed from without, as in the case of the animal cell (see account of Amoba, Sec. 194).

As we have already noted, starch is generally the first visible product of this process of food manufacture (photosynthesis). Starch and the related substances, sugars, are the primary foods of green plants, and the most important, but they are merely the starting point for a complex series of processes through which the highly organized proteids of the protoplasm are derived. There are some plants which lack chlorophyll, as the fungi and certain plant parasites, and they, like the animals, depend upon food absorbed from without the body. The food of plants is broken down and recombined in various ways to form the protoplasm, as it is in animals, and the breaking down of some of the substances sets free energy in the form of plant heat (corresponding to animal heat), as is easily proved in the germination of seeds (see Sec. 5). So the processes of food absorption, or assimilation, in plants are essentially the same as in animals, but the manufacture of food (photosynthesis) is an entirely different process and peculiar to plants.

198. The food cycle. There is a circulation of certain elements (especially carbon, nitrogen, sulphur, and phosphorus) through the bodies of plants and animals which may be called the food cycle (see diagram, Fig. 207). It begins in the plant cell with the manufacture of starch, and related substances 
(earbohydrates) by photosynthesis. This makes carbon, obtained from the earbon dioxide of the air, available in these primary foods. Nitrogen is obtained from the nitrates dissolved in water and drawn up through the roots, and sulphur and phosphorus in a similar manner from sulphates and pliosphates. The proteids of protoplasm are built up from these elements, with the addition of hydrogen and oxygen. Plants are able to form some very complex organic substances, but animals are able to carry the building-up process still farther, for the lighest forms of proteids known are found in their substance.

There is, however, a turning point in the building-up activities when complex compounds begin to break down into simpler substances. Some of these are the daily waste products of an animal or plant. The most striking plienomena are those which occur during the processes of decay, which begin at once with the death of an organism. Decay is the process by which highly complex organie compounds are broken down into successively simpler substances. The final steps return the elements carbon, nitrogen, sulphur, and phosphorus to the earth and air in very simple forms available again for the constructive work of green plants. The processes of decay are due to the growth and activities of bacteria and other fungi, and the subject is treated at some length in Sec. 252.

199. Cell division, growth, and reproduction. Assimilation increases the amount of protoplasm, and this results in growth and reproduction through cell and nuclear division. Cell division in plants, as in animals, is preceded by nuelear division, after whieh a cell wall is formed between the daughter protoplasts. The nueleus in the resting condition contains granular material called chromatin, which may be readily colored (stained) by certain dyes. Generally there are also present one or more globular bodies called nuclcoles (Fig. 170, A). Chromatin is a proteid and is believed to be the essential substance of the nucleus and necessary for the life of the cell, because protoplasm will not live if deprived of nuclei. Just previous to nuclear 
division the chromatin beeomes organized into a number of hodies called chromosomes, each of which splits, and the halves are distributed in two sets to the daughter nuclei. The distribution of the chromosomes is effected by an interesting apparatus ealled a spindle (Fig. 170, B'), whieh consists of delicate fibers (spindle fibers) formed in the early stages of nuclear. division. The two sets of daughter ehromosomes (Fig. 170, C) collect at the poles of the spindle to organize the daughter nuelei, whieh then pass into the resting condition (Fig. 170,D), and a eell wall is formed between, that divides the original

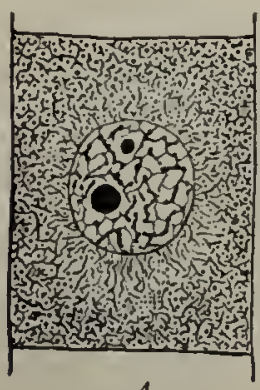

A

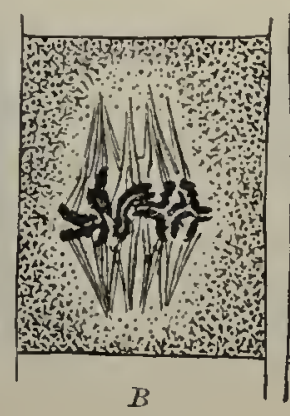

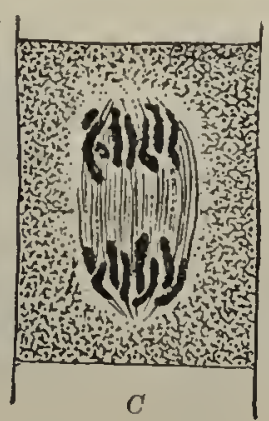

C

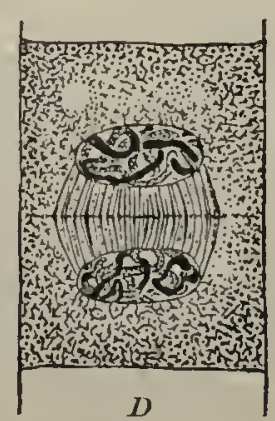

$D$

Fic. 170. Stages in nuclear and cell division from the root tip of an onion $A$, resting nucleus with the chromatin in the form of a network and two meleoles; $B$, a spindle with the divided chromosomes gathered in the middle region and about to separate into two groups of daughter chromosomes; $C$, the two sets of daughter chromosomes at the poles of the spindle; $D$, formation of the new wall
between the daughter nuclei

cell into two daughter eells. It is a remarkable fact that the number of chromosomes in the nucleus is fixed for different plants, - a point which we shall have oecasion to eonsider in other eonneetions.

Chromatophores and chloroplasts reproduce themselves by fission, or splitting, plainly illustrated in the cells of the moss leaf (Fig. 169, C), and are thus passch on with each cell division.

200. The cell theory of organization. The process of growth and development of a many-celled organism is through continuous cell multiplieation. Development generally begins with a eell, whieh both in animals and in plants is called the egy. 
The egg is a female sexual element which normally cannot develop into a new organism until a male sexual cell, called the sperm, has united with it. This union is called fertilization, and the fertilized egg is a sexually formed cell because it results

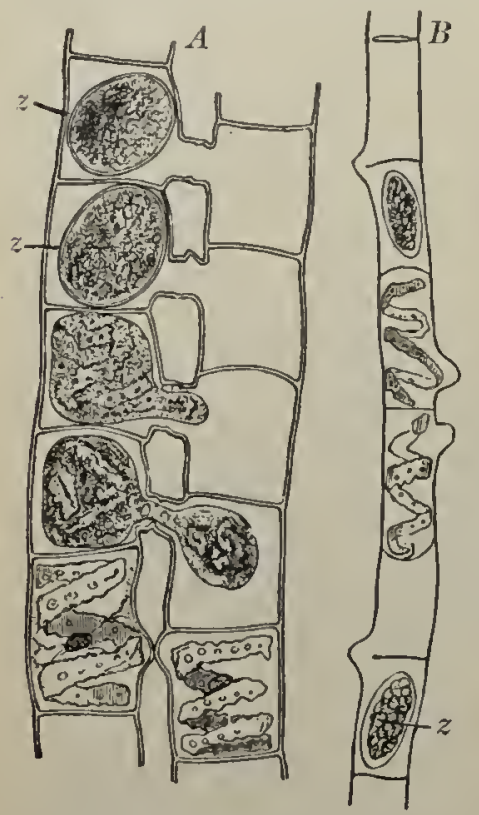

Frg. 171. The union of the gametes in Spirogyra

$A$, two filaments of Spirogyra quinina, side by side, showing stages in the union of the cells (gametes) to form the zygospores; $B$, another specics (S. longata), in which the cell unions occur between adjacent gametes in the same filament. After Schenck from the fusion of two sexual cells, the egg and sperm. The fertilized egg is termed an oüspore (meaning an egg spore), when there is a resting period before its further derelopment, or germination. A sexual cell, such as the egg or sper'm, is called a gamete. The protoplasmic union of egg and sperm is very complete, for the two nuclei come together in the center of the egg and fuse to for'm a large nucleus which has, of course, about twice as much of that important nuclear substance, chromatin, as the single nucleus of either egrg or sperm.

Frequently there are present in plants other forms of reproductive cells called spores, which are not formed sexually but are simply special cells which can develop at once into new plants.

The union of gametes to give sexually formed cells is especially well illustrated in the fruiting ${ }^{1}$ of the pond scum (Spirogyra). In most species the cells of filaments lying side ly side put forth short processes which fuse in pairs, thus presenting a characteristic ladder-like arrangement (Fig. 171, A). The contents of one cell then pass over and

1 The terms fruit and fructification will be used in Part II in an untechnical sense to designate various forms of reproductive organs and processes. 
unite with that of the other, giving a large fusion protoplast which develops a hcavy protective wall and is a sexually formed spore. It is called a zygospore (meaning yoked spore) because the gametes are similar, like the halves of a yokc. This cell union is the same in all essentials, including the final fusion of the two nuclei, as the fertilization of the egg, except that the two sexual cells, or gametes, are not different in form as are eggs and sperms (examine illustrations of Volvox (Fig. 178), Edogonium (Fig. 182), Fucus (Fig. 199), etc.). The fruiting of Spirogyra is a relatively simplc illustration of a sexual process, for the gametes are similar and have never become differentiated into eggs and sperms.

Development proceeds through continued cell divisions, which lead to growth and a gradual specialization or setting apart of certain cells for particular kinds of work in the body. This specialization of cells results in the various forms of cell structures, or tissucs, of the mature organism. So the life history is a succession of eell divisions, and the reproduction of the species is a return to a one-celled eondition through the reproductive eells (gametes and spores). The animal and plant body dics, but the stream of life flows on through the reproductive cells. This is the outline of the cell theory of organization, which perhaps ranks next to the theory of organic evolution as one of the fundamental principles of biological science.

201. Properties peculiar to living matter. We have noted that the chemical composition and reactions of protoplasm are exceedingly eomplex, but nevertheless there are no reasons for supposing that they are outside of chemical and physical laws. However, protoplasm has properties whieh distinguish it from lifeless matter (see also Secs. 45-47).

Protoplasm has the power of growth and repair. This means that protoplasm ean manufacture living substanee out of the lifeless and add the same to itself. It can replaee with new and fresh living matter the waste material which is used up or discarded during the life processes. 
Protoplasm has the power of reproduction. Reproduction accompanies growth and depends upon cell division. Of course the surface area of a cell cannot increase in the same ratio as its bulk. The surface is the region of the cell through which some of the most important life processes of assimilation and respiration take place, and a certain amount of cell surface is necessary for a given bulk of protoplasm. Therefore the cell divides when, after a period of growth, the bulk of protoplasm becomes proportionally too great for the amount of surface area. The sum total of the surfaces of the daughter cells is materially increased by their division, while the combined bulk of their protoplasm remains the same as before.

A living being is like a machine in that it requires fuel to generate its energy or power of doing work, but the organism has the peculiar ability of making its own repairs, of increasing in size, and of detaching from itself portions which can in their turn attain the structure and efficiency of the parent. The process of life is continuous, although the material of protoplasm is constantly changing, - that is, substances are constantly going into the organism and substances are going out. It may be compared to a whirlpool in a river: the form and action of the whirlpool is constant, although the water which enters and leaves remains for only a short time in circular movement.

Protoplasm always comes from preëxisting protoplasm. This means that protoplasm, so far as we know, never springs into existence from inorganic material. It is never formed de novo. There have been naturalists and philosophers who believed that life might arise spontaneously under favorable conditions in suitable nutrient solutions. They cited such illustrations as the swarming microscopic life which appears in extracts or infusions of animal and vegetable matter as examples of spontaneous gencration. These theories were overthrown chiefly by the work of Pasteur and Tyndall, who showed that life never appears in these extracts and infusions provided proper care is taken to kill all organisms that may be in them, together 
with all spores or other reproductive cells, and then to prevent the entranee of any more germs. An experiment in this line can be performed by heating an extract in a flask, closed by a plug of eotton, until all germs have been killed. Such a solution then will not even produee the bacterial growths that cause deeomposition, for the eotton plug prevents the entrance of any dust. It is now established that all organisms at present on the earth are generated only by their like; that life only comes from life, and protoplasm from preëxisting protoplasm.

202. The distinctions between animals and plants. Plants in general are distinguished from animals by two important peculiarities.

First. The presence of ehlorophyll, or equivalent pigments, enables the plant to manufacture its own food by photosynthesis in the interior of its own eells. Animals require foods already manufaetured by other animals or plants, and this food is absorbed from without the eell.

Second. Plants, when growing, are generally stationary, with a firm, widely expanded, rigid structure, while animals are more rounded, eompact, and yielding. These differences are deterinined by the faet that the protoplasts of plants are inelosed in cellulose compartments. The cell wall gives to plant structure a degree of stiffness which greatly limits or almost prevents movement, but the individual protoplasts of plants have all the eliaracteristics of life in common with animal eells, sensation, movement, and the powers of growth, repair, and inultiplieation.

203. Some organisms of doubtful position. Several groups of lowly organisms liave charncters which are in part plant-like and in part animal-like. We shall eonsider briefly only one of these groups, the flagellates.

${ }^{1}$ Another large group of doubtful position is the slime molds, or Myxomycetes, more frequently included among plants than among animals, but too special for this account. See Macbride, The North Americun Slime Moulds, 1899. 
204. The flagellates. 1 The flagellates (Flagcllata) are aquatic, motile forms, either one-celled or consisting of colonies of cells held together in a common gelatinous secretion. The individual
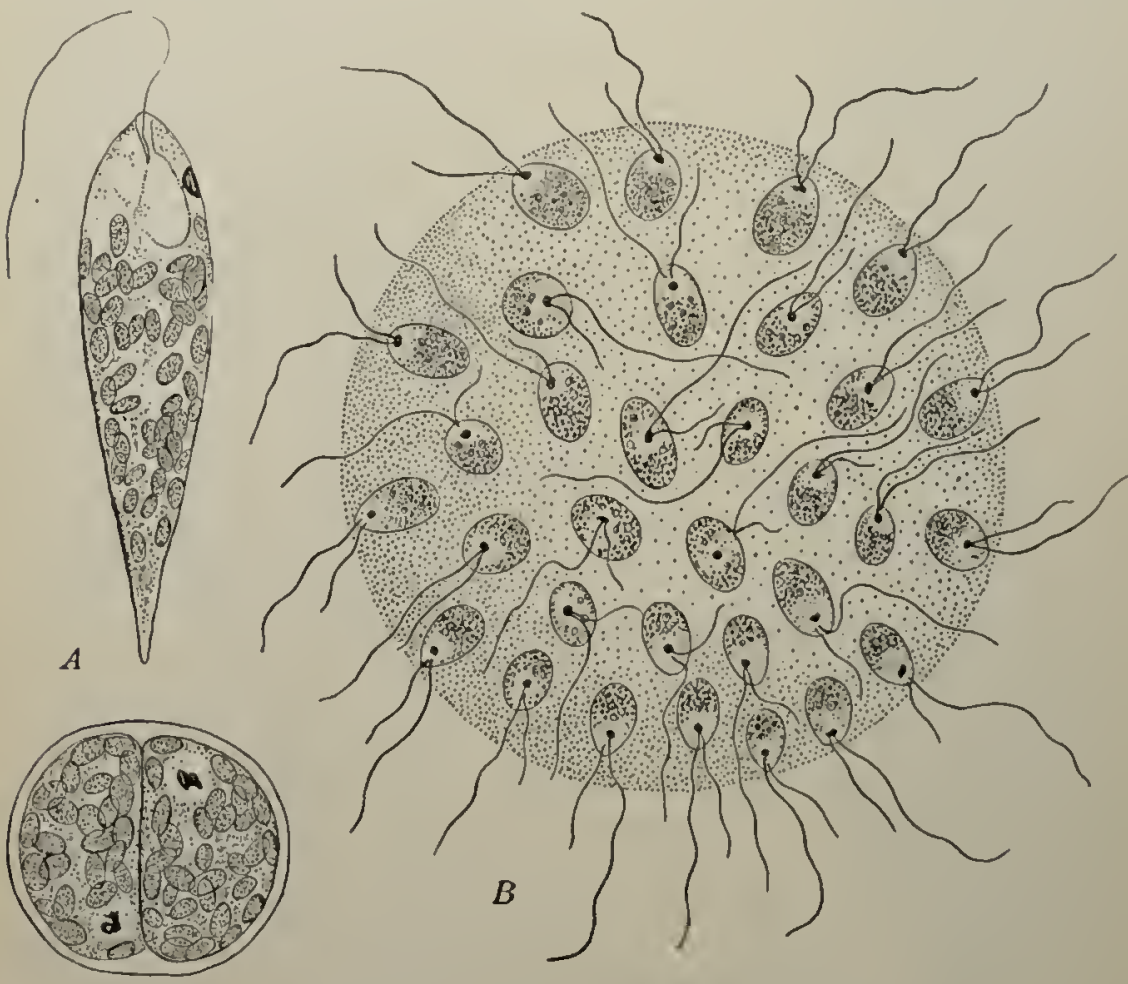

Fig. 172. Two flagellate forms

A, Euglena, the motile cell shown above, with its eilium and pigment spot at the forwarl end, the proeess of reproduction by simple division while in a resting condition being illustrated below; $B$, Uroglena Americana, a large eolonial dlagellate. $-B$, adipted after Moore

cells are provided with one, two, or sometines more delicate hair-like appendages called cilia (singular, cilium, meaning an eyelash), which move rapidly in the water and are organs of locomotion. Some forms have chromatophores and can therefore manufacture their own food, while others are colorless and take their food in animal fashion through a funnel-like depression into

1 The best account of the flagellates will be found in Engler and Prantl, Die Natürlichen Pflanzenfamilien. 
the interior of the cell. A bright red pigment spot, frequently found in each cell, is regarded as a structure sensitive to light, for these organisms generally move towards the source of bright illumination. The flagellates are-helieved to be related to the lowest green plants, the alga, and some groups of algæ are thought to have been derived from them.

Euglena (Fig. 172, $A$ ) is a common flagellate found in stagnant pools. The cells are generally green, but some of the species and related forms are colorless, having adopted the habit of living exclusively on organic food substances in the drainage water which they frequent. Euglena graeilis becomes quite colorless when cultivated in solutions of sugar away from the light, uhus suggesting the way in which colorless plants, such as the fungi, may have arisen from ehlorophyll-bearing ancestors under an environment whieh supplied an abundance of organic food.

Uroglenc (Fig. 172, B) is a colonial flagellate which frequently appears during the summer months in reservoirs and gives a fishy, oily taste and odor to the water, making it unfit for use. The taste and odor are cansed by globules of oil that are set free by the rupture of the delicate cells when the water is carried through pipes. This is one of the organisms which can easily be destroyed by treating reservoirs with copper sulphate.

1 See papers by Moore and Kellerman, United States Department of A griculture, Bureau of I'lant Industry, Bulletin 64,1904 ; also Bulletin 76 , 1905. 


\section{CHAP̈TER XIX}

\section{THE THALLOPHYTES}

205. The thallophytes. The division Thallophyta (meaning thallus plants) contains the lowest forms in the plant kingdom. A thallus is a simple vegetative body, without stems, leaves, or roots, in the usual sense. The groups of the thallophytes fall naturally into two series known as algæ and fungi.

The alge. The alge contain chlorophyll or other pigments which can do the work of photosynthesis.

The fungi. The fungi have no chlorophyll, and must therefore obtain their food either as parasites from the tissues of living plants or animals, called their hosts, or they may live as saprophytes (meaning decay plants) upon the produets of deeay.

'The fungi are believed to have been derived from alga which lost their color and gave up the processes of photosynthesis because they happened to be placed under conditions favorable to a life of saprophytism or parasitism. A perfect classification of the thallophytes should show the relationships of the fungi to the algæ, but these are so little understood that it seems best for the present to treat the two groups separately.

The thallus is not really the distinguishing character of the thallophytes, for some higher plants, as the liverworts, have thalloid plant bodies, and some of the algie have a stem and leaf structure as complex as that of the mosses. The thalloplytes are separated from the next higher group, the bryophytes (iverworts and mosses), by the absenee of a peculiar type of life. history characterized by certain complicated reproductive organs. These peculiarities cannot be understool until the liverworts and mosses have been studied, so a full definition of the thallophytes will be deferred until the end of Chapter xxiv. 


\section{CHAPTER XX}

\section{THE ALGE, THE LOWEST GREEN PLANTS}

206. The algæ.* For the present we may think of the thallophytes as the immense assemblage of plants below the liverworts, mosses, ferns, and seed plants. In number of species and divergent evolutionary lines the group is much the largest of the four divisions of the plant kingdom (Thallophyta, Bryoplyyta, Pteridophyta, and Spermatophyta).

The algie are thallophytes whose plant bodies are eolored because the eells eontain ehromatophores. Almost all of the fresh-water forms are green, but the majority of the marine alga, or seaweeds, are either brown or of beautiful shades of red. The green color is, of eourse, due to ehlorophyll, while the brown and red tints are eaused by other piginents. The algre are divided into four elasses as follows:

Class I. The blue-green algac, or Cyanophycece.

Class II. The green algx, or Chlorophycece.

Class III. The brown algæ, or Pliceplyycex.

Class IV. The red algæ, or Rhorlophycere.

It might appear from the above that the alge are elassified by their color, but this is not true. These four groups are defined by peeuliarities of eell strueture, life history, and methods of reproduction which ean only be understood through a study of types in the laboratory, and the summaries of these charaeter's

* To tur Ixstrictor : 'This chapter describes many more types than it would be desimble to present in a general conrse. 'The instructor should make selections according to the material available (which varies greatly in different seetions of the country), and the time at the disposal of the class. A brief diseussion of the best and most available types, and the reasons why they are desirable for laboratory work will be found in the laboratory manual of the anthors. 
must follow the accounts of the groups. However, it is an interesting fact that representative algæ of these four classes can generally be picked out at a glance by their color alone.

\section{CLASS I. THE BLUE-GREEN ALGA;, OR CYANOPHYCEAE}

207. The blue-green algæ. The simplest types of plants are found among the blue-green algre and in that related group of
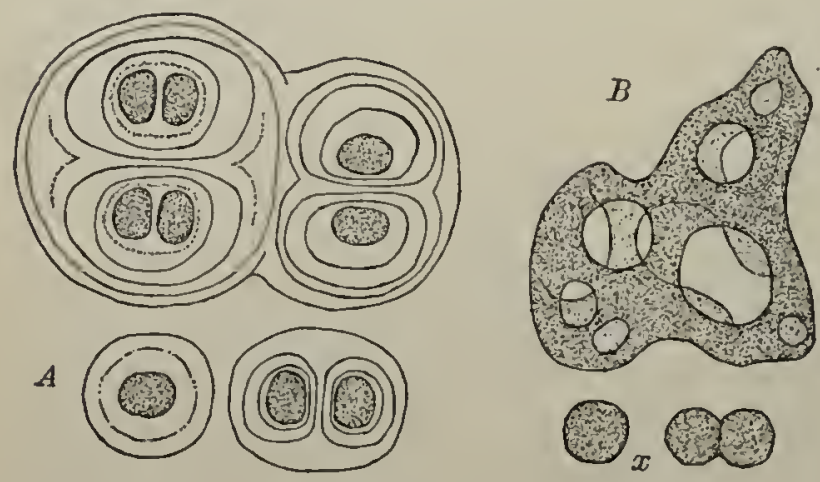

Fig. 173. One-celled blue-green alga and their cell colonies

$A$, Glococapsa, solitary cell and small groups held together

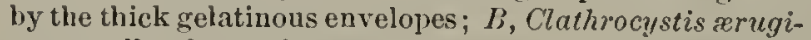
nosa, cell colony of many hundreds of protoplasts imbedded in a jelly-like substance; 2 , single cells illustrating division by fission the fungi called the bacteria. Some of these planis are the most primitive forms of life now present on the earth.

208. The onecelled bluegreen algæ. These forms may develop as slimy growths on the surface of stones, woodwork, and other objects, but certain types float freely in the water in small groups, or sometimes in large cell colonies. The following types are representative.

Glococapsa ${ }^{1}$ (Fig. 173,A) consists of cells with peculiar soft walls which form concentric envelopes around the groups of protoplasts. It is evident that the wall of each protoplast persists for a long time after every cell division, so tlat groups of

${ }^{1}$ Chrö̈coccus is an excellent substitute for Glococapsa, and is not uncommon in stagnant pools and on wet clay banks. Its cells are solitary and lack the gelatinous envelopes of Glococapsa. 
daughter, granddaughter, and even great-granddaughter cells may remain inclosed in the envelope of the original mother cell, which becomes very mueh swollen and jelly-like. The outer walls of the groups of eells finally beeome changed to a soft mucilage, so that the groups of Glococapsa cells form at times slimy, dark green patches over damp earth, roeks, and logs. The individual protoplasts have an exceedingly simple strueture, for the coloring matter is uniformly distributed through the cells and no nucleus ean be seen.

Clathrocystis and Colospharium are free, floating cell colonies, often forming greenish scums during the summer months on the surface of park ponds, reservoirs, and other small bodies of water. The colonies of Colosphorium are spherical, while those of Clathrocystis (Fig. 173, B) beeome irregular in shape through the development of holes, so that the structure is somewhat, net-like.

209. The filamentous blue-green algæ. These frequently form felted or tufted growths or gelatinous expansions of considerable size. There are a number of complex branching types, but the following are good examples of the assemblage.

Oscillatoria is the most interesting type of the Cyanophycce if only one form ean be sturlied. The filaments are generally made up of flattened disk-shaped cells, placed face to face within an exeeedingly delicate sheath, much like a roll of coins wrapped in paper. Cell division takes plaee in all portions of the filament, and several stages are illustrated in Fig. 174, A. Growth is therefore not eonfined to the tip or any other special region of the plant. New filaments arise by the breaking apart of the older ones, generally at some point where one or more eells have died (Fig. 174, $A, d$ ). The end eells of filaments or fragments of filaments are always rounded, illustrating beautifully the phenomenon of cell turgor or pressure from within the protoplast upon the cell membrane. The cell strueture of Oscillatoria is very typical of the blue-green alga. The blue-green pigment gives color to the entire outer region of the protoplast, which 
may be considered a diffused chromatophore. There is no nueleus in the usual sense of the term, although the eentral region of the cell has a different structure from the unter and probably eontains chromatin. The small granules arranged along the eross walls are believed to be food produets built up by the activities of the blue-green pigment in sunlight (photosynthesis). Oscillato-

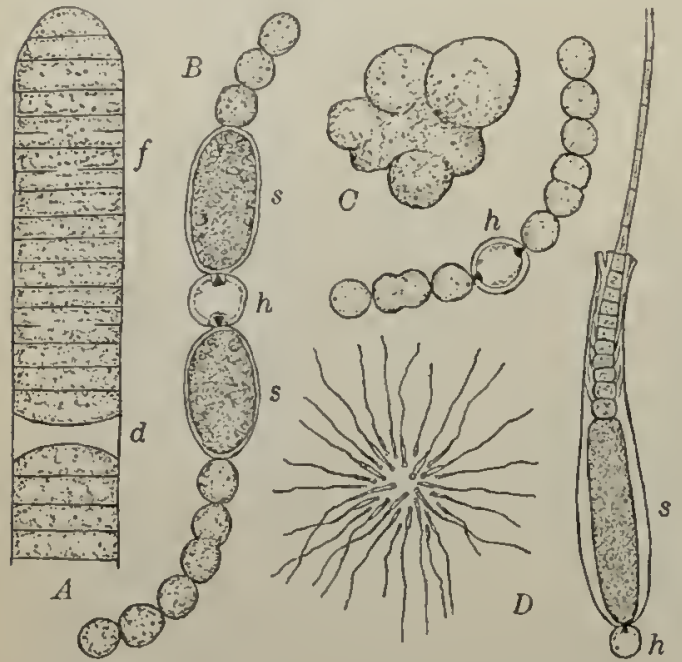

Frg. 174. Filamentous blue-green algre

A, Oscillatoria; $d$, dead cell, inrlicating a point where the filament might break apart; $f$, stages of cell fission; $l$, Anabæna; h, heterocyst; $s$, resting cells; $C$, Nostoc, liabit sketch of a colony and the details of a single filament; $h$, heterocyst; $D$, Glæotrichia, portion of a colony and the base of a single filament in detail; $h$, heterocyst; $s$, resting cell

ria takes its name from the remarkable movements of the filaments, whose free ends swing baek and forth describing a circle or an ellipse, while the filaments may glide slowly forward. The eause of this movement is not understood. Oscillatoria is found in greatest abundanee in open drains, ditches, or pools, where the water is foul with deeaying organic matter. There it may form thick felts on the bottom, or rise to the surface in slimy masses beeause of the bubbles of gas, largely oxygen, formed during the proeesses of photosynthesis and lield within the tangle of filaments.

Anabena and Nostoc are closely related genera. The filaments are ehains of round or elliptieal cells. Besides the bluegreen vegetative cells there are present at intervals eurious eells termed heterocysts (meaning other cells), which are generally larger than the vegetative eells, lighter in color, and often empty of protoplasm. Their function is not elearly understood. The 
filaments may break apart on either side of the heterocyst, setting free elains of eells which grow into new filaments. Certain vegetative eells in $A$ nabcenc increase greatly in size and become densely filled with protoplasm and food material and surrounded by a thick proteetive wall (Fig. 174, B, s). Sueh eells are called rcsting cells, or spores, and they are able to live through seasons of drought or a winter's cold and with the return of favorable eonditions to germinate and form new filaments. The filaments of Anabcena are held in a soft slime, but those of Nostoc are surrounded by a stiff jelly, so that the mass of much-coiled ehains of eells has a firm boundary. Consequently, Nostoc eolonies (Fig. 174, C) may liave a spherieal form and beeome as large as marbles. The slimy or jelly-like substance of Ancubcence and Nostoc is a modifieation of the delicate sheath around the filaments and eorresponds to the envelopes about the eells of Gloocapse.

Glceotrichia (Fig. 174, D) sometimes develops in sueh quantities in ponds and lakes during the summer as to form a brilliant green seum on the surfaee of the water. The filaments liave a radiate arrangement in a soft, gelatinous substance and end in long hairs, and a very large resting eell may be formed at the base of eaeh filament adjaeent to the terminal heteroeyst.

210. Life habits of the blue-green algæ. The Cyanophycea have some peculiar life habits of ecological interest. They are generally found in warmish waters, both fresh and salt, and many of the forms prefer those whieh are foul with deeaying organie matter. Thus open drains and reeking pools of stagnant water present luxuriant growths of these alga. It is probable that the plants aetually use for food eertain of the organie substanees in sueh waters. Some of the most eonspieuous green seums on ponds and small lakes are composed of certain of these algre (Colosphcorium, Clathrocystis, Anabona, and Glootrichia, ete.). Such seums may be ealled water blooms, after the German term Wasserblüthe. The coloration of the Red Sea is due to an 
extcnsive water bloom caused by a filamentous blue-green alga (Trichodesmium) which at times fills the water, and whose color, a reddish brown, gives then a peculiar tint to the sea.

Some forms (Anabana, Clathrocystis, and certain species of Oscillatoria) are frequently responsible for the fouling of water supplies which take on what is called the "pigpen odor," and are otherwise unfit for public use. All of these blue-green algæ, together with the flagellate Uroglena, can be killed by treating the reservoir or other body of water with copper sulphate (see Sec. 204), a perfectly safe and inexpensive remedy for contaminated water supplies.

Perhaps the most remarkable display of the blue-green algæ is in the waters of certain hot springs, as in Yellowstone National Park. It is doubtful whether any algæ except the Cyanophycce can live in water warmer than $100^{\circ} \mathrm{F} .\left(40^{\circ} \mathrm{C}\right.$.), but some of the blue-grecn algæe grow luxuriantly in hot springs at $137^{\circ}-145^{\circ} \mathrm{F}$. $\left(58^{\circ}-63^{\circ} \mathrm{C}\right.$.). It is probable that their simple cell structure makes possible a greater power of resistance to these extraordinary life conditions.

211. Summary of the blue-green algæ. The Cyanophycce are distinguished from other groups of algre by the simplicity of their ccll structure, the absence of sexual reproduction, and the presence of a blue-green pigment uniformly diffused through the outer region of the cells. The method of growth by rapid divisions or splitting of the cells throughout the entire plant body is a very characteristic feature of the group, and the blue-green algæ are sometimes called the "fission alga" (Schizophycea).

The blue-green algæ agree with the bacteria, or "fission fungi" (Schizomycetes), in their simplicity of cell structure and methods of reproduction, but the bacteria are of course generally without, pigment. It is quite clear that the Cyanophycece and the Schizomycctes are closely related, and some authors place them together in a separate division of the plant kingdom below the Thallophyta, named the Schizophyta, or " fission plants." 
CLASS II. THE GREEN ALGA, OR CHLOROPHYCEA

212. The green algæ. The green algæ comprise a large and varied assemblage of groups, many of which are widely different from one another. Some forms of the Chlorophyeece are believed to stand rather close to what was the main line of ascent from the algæ to the liverworts and mosses. Consequently the class has an important place in an account of the evolution of the plant kingdom. The green algæ illustrate better than any other group the origin and evolution of sexual processes in plants. Since the more familiar algal growths of fresh water are green alge, a more extended treatment of the Chlorophycea will be given than of the less familiar groups of the Cyanophycce, Pheophycece, and Rhodophycece, and the following six orders will be considered together with a "Summary of the Green Algæ."

Order 1. The one-celled green algæ, or Protococcales.

Order 2. The confervas, or Confervales.

Order 3. 'The pond scums and desmids, or Conjugales.

Order 4. The diatoms, or Diatomales.

Order 5. The siphon algx, or Siphonales.

Order 6. The stoneworts, or Charales.

\section{Order 1. The One-celled Green Alga, or Protococcales}

213. The one-celled green algæ. This order contains almost all of the one-celled green algæe excepting the large but very special groups of the desmids and diatoms. We can only describe briefly five types.

214. Pleurococcus. Plcurococcus (family Pleurococcacec) forms the green coating or stain that is very common on the north sides of trce trunks, fcnces, and stone walls. The cells (Fig. 175) may be solitary, but they usually remain associated in small groups for some time after the cell divisions. The protoplast contains generally a single chromatophore of irregular shape whieh, as a rule, fills the greater part of the cell. The chromatophore is, however, variable in size and may or may not have 
a pyrenoid (Sec.196). The nucleus can sometimes be seen in the center of the cell. The cells are exceedingly resistant to cold and drought, but under very severe conditions they protect themselves by forming a heavy cell wall, thus becoming resting

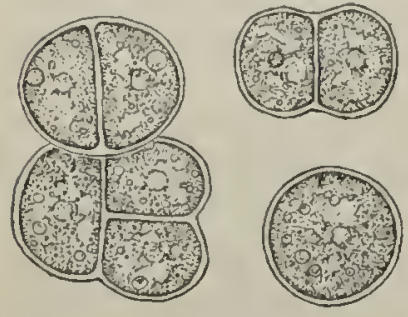

Fig. 175. Pleurococcus vulgaris, a one-celled green alga

Several cells illustrating the method of cell division and their association in small groups cells. Sometimes the contents of a cell break up into several daughter protoplasts, but as a rule the only method of reproduction is by simple cell division. Other forms of one-celled algx, with more complicated methods of reproduction (by zoöspores and gametes), are frequently found associated with Plcurococcus, but should be carefully distinguished from this simple alga.

Plcurococcus may seem almost as simple as the one-celled blue-green alga Gloocapsa, but its cell structure with a chromatophore and well-defined nucleus is far in advance of the Cyanophycee.

215. Sphærella and Volvox.* These forms are representatives of one of the luost interesting families of the green algre, the Volvox family (Volvocacca). The lowest members are onecelled and resemble the flagellates (Sec. 204), but the higher forms are cell colonies of remarkable structure and life listories. The regetative cells are motile, being always provided with two

* To tue Instructor: It is rather diffieult to obtain material of the Volvox fauily, and it cannot be depended upon for type study. 'Therefore laboratury work on the reproduetive proeesses in the algæ can mueh better be arranged with such types as Ulothrix, or Ulva, or some form of the Chatophoracea, or Cladophora, EEdogonium, or Vaucheria and Fucus. But the Volvocacea and Flagellata are so important to a conception of certain primitive eonditions of algal life that they should be diseussed in any extencled general eourse. The faet that zooblogists have found Volvox and its relatives of interest should not deter botanists from making use of their own.

1 For a detailed aeeount of the Folvocacere see Goebel, Outlines of Classi. fication and Special Morphology of Plants, and Engler and Prantl, Die Natürlichen Pflanzenfamilien. 
hair-like cilia, whose incessant whipping of the water carries the organisin along. There is also a red pigment spot at the ciliated end of the cell (Fig. 176, $A, p$ ). This free-swimming, ciliated cell is of a type strikingly different from Plcurococcus, but it is believed to represent very mearly the ancestral condition of many groups of algie.

Spharclla lacustris (Ifomatococcus pluvialis) is found freely swimming in rock pools and sometimes in troughs and basins,

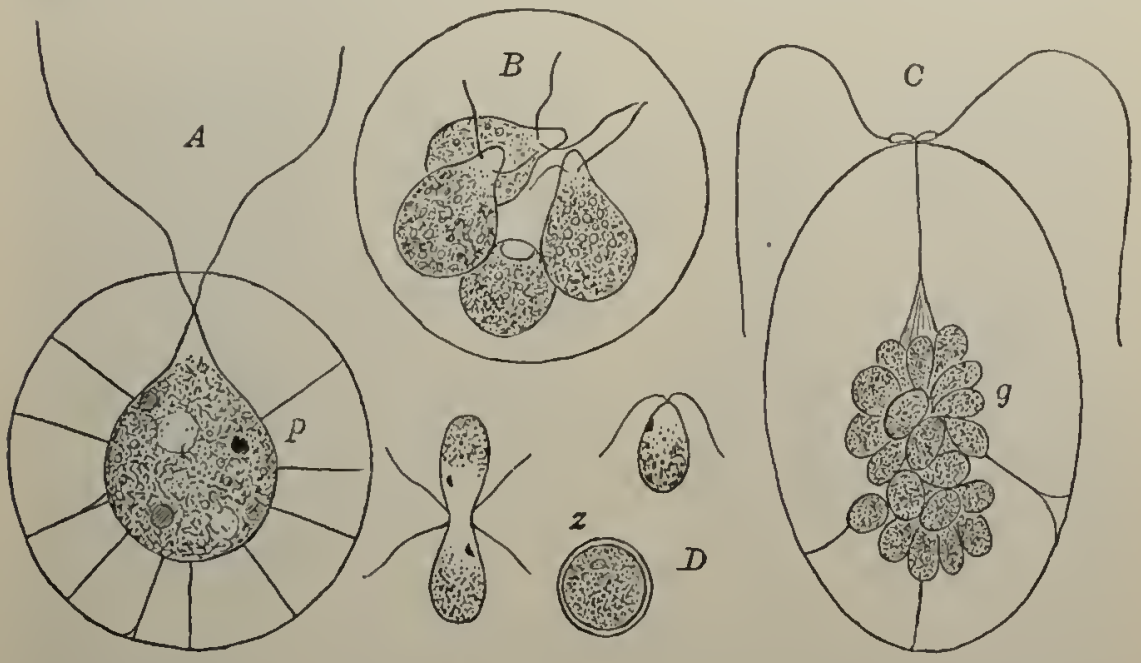

FI: 17i. Spharella

A, l;, Spharella lacustris: a single cell in detail and a group of daugliter protoplasts within the pareut cell. C, D, Spharella Bïtschlii: numerons small sexual elements or gametes are shown in the parent cell $C$, anl $D$ illustrates their fusion in pairs to give the sexually formed cell or zygospore $z$. $-l$, after Schenck; $C, D$, after Blochmann

and is frequently so abundant as to color the water a bright green. The organism multiplies very rapidly, for the larger individuals (Fig. 176, A) form 2-16 daughter cells (Fig. 176, B), which eseape from the mother-cell membrane, swim away, and after a period of growth form in their turn a new set of daughter cells. The free-swimming cells come to rest at times, becoming thick-walled resting cells, which are colored red by a peculiar pignent. These resting cells carry the plant over 
unfavorable seasons and are sometimes developed so numerously as to cover the bottom of pools and rock hollows with a red deposit. The phenomenon called "red snow" is duc to deposits of the resting cells of Spharellu nivclis on fields of snow and ice.

Some species of Spharella (Fig. 176,C) develop a much greater number of daughter elements, 32 to 64 , which are much smaller

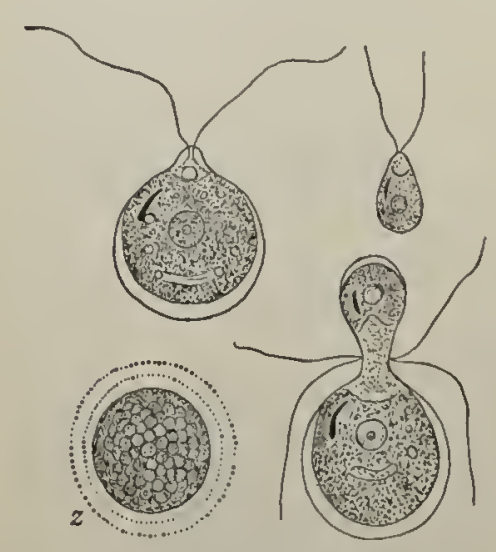

Fis. 177. Chlamydomonas Braunii

Chlamydomonas is not uneommon in the same sort of situations as Sphrrella. It may be distinguished from the latter by the absenee of a thick gelatinous envelope around the eells. Some of the forms show important advanees over Spharella in their sexual processes, for the gametes may be of two sizes, large female and small male cells, as shown above. $z$, the zygospore. - After Goroschankin

than those just described, but lave the same structure. These smaller cells swini about freely for a short time, and then come together in pairs and completely fuse with one another, beginning at the ciliated cnds (Fig. 176,D). A cell fusion of this character is a sexual act (Sec. 200) and the cells which unite arc gametes. The scxually formed fusion cell or zygospore of Spharella soon settles down on some surface and, losing its four cilia, remains quict for several days or weeks, finally developing within itself several motile cells of the usual type.

Volvox (Fig. 178, A) is a colonial form consisting of many hundreds of cells (sometimes more than twenty thousand) imbedded in a gelatinous substance in the form of a splere, with the pairs of cilia pointing outwards. These remarkable organisms, as large as pin heads, roll slowly through the water of quiet pools and ponds, sometimes gathering in great numbers in open sunlit portions, free from water weeds and algal growths. Daughter colonies (Fig. 178, $A, d$ ) are formed from ccrtain cells which after a period of growth develop a large number of motile cells like the parent. These small cells 
become arranged to form a daughter colony which swims around in the interior of the mother colony. Sometimes several of the daughter colonies may be developed, and they finally escape by the rupture of the parent structure. The sexual cells, or gametes, are of two sorts: (1) large female cells, which are called eggs because they are without cilia and consequently never motile, and (2) small male cells, or sperms, of peculiar form, with two cilia, and consequently very actirely motile. The eggs
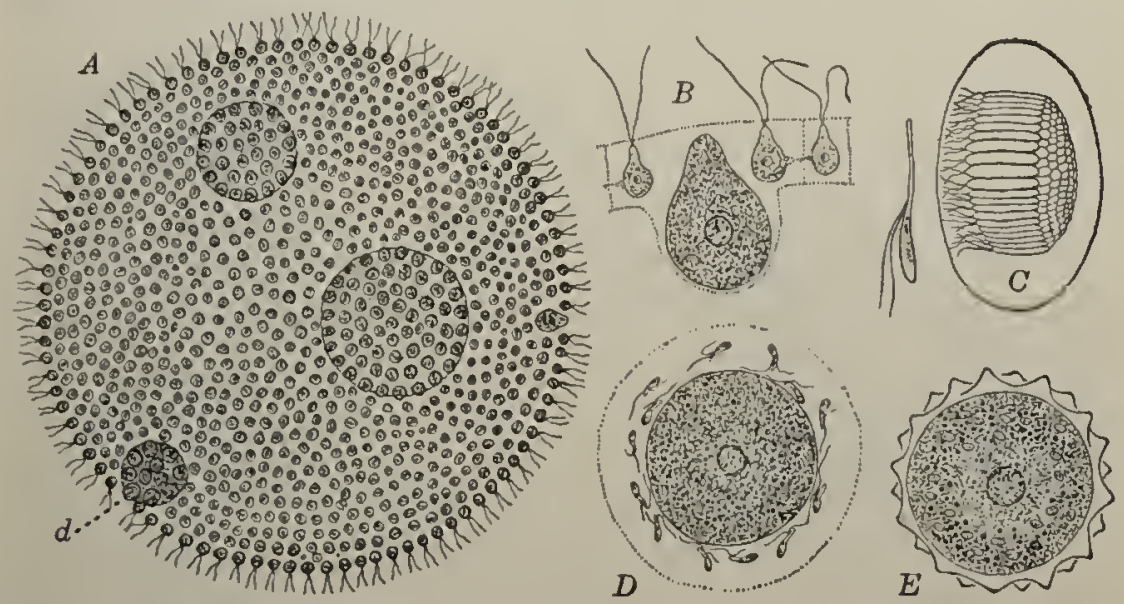

Fig. 178. Volvox globator, a colonial form of the Volvocacen

$A$, mature eolony, with four daughter colonies developing in its interior; $B$, seetion of the edge of the colony, showing three vegetative eells and a developing egg; $C$, a packet of sperms within the parent cell and a single sperm very much magnified at the side; $I$ ), an egg surroundel by a swarm of sperms; $E$, an oüspre with heavy proteetive wall. $-C$, after Cohu.

(Fig.178, B, D), formed by the enlargement of vegetative cells, escape into the interior of the colony as naked spherical protoplasts. The sperms (Fig. 178, C) are developer in great numbers within enlarged vegetative cells. They are also set free within the parent colony and gather about the eggs in swarms (Fig. 178,D). Finally, a single sperm fuses with each egg, which is then said to be fertilized. The fertilized egg immediately forms a cell wall about itself and passes tlirough a period of rest as an oöspore (Sec. 200). 
Volvox thus presents a great advance over Sphcerella, Chlamydomonus, and other one-celled members of the Volvocacee, in the highly developed sexual process as well as in the

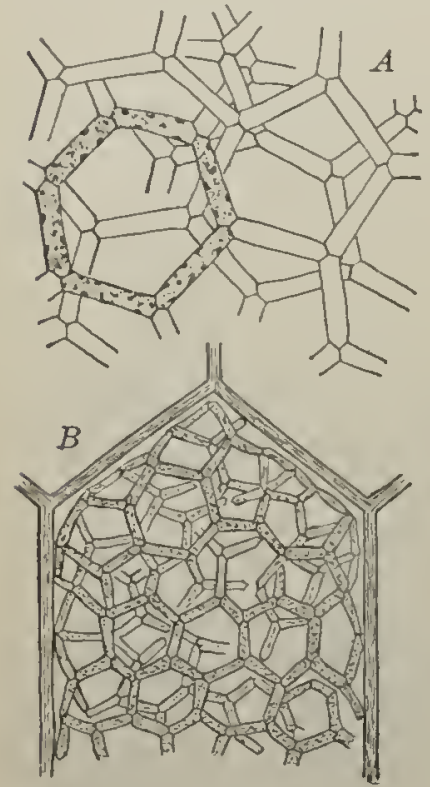

Fig. 179. The water net (IIydrodictyon)

This is a remarkable form of the Protococcales, whosecells form the meshes of a net-like cell colony, $A$. New nets are formed in the interior of large cells, $B$, whieh develop an immense number of zoöspores that never escape from the nother cell, but join with one another to form daughter nets, which are set free by the breaking down of the mothercell wall complex cell colony. There is, however, a series of genera (Gonium, Pundorina, Eudorina, Plcodorina, etc.) in the family, illustrating intermediate conditions between these extreme forms, which makes it clear that Volvox stands at the head of a remarkable line of development in the algie. It may be considered the climax type of a side line of evolution, - that is, a branch which departs widely from the main line of ascent.

\section{Order 2. The Confervas, or CONFERVALES}

216. The confervas. The Confervales comprise many rery common filamentous algæ and also such membranous forms as the sea lettuce. The algæ which seem to be nearest to the main line of ascent to the liverworts and mosses are found in this group. Some of the types illustrate especially well the principal forms of sexual reproduction in the algæ and various types of life histories.

217. Ulothrix. This conferroid alga (family Ulothricaeece) is abundant on stones and rocks along the shores of the great lakes, in quieter waters at the seaside, and frequently grows in stone fountains or on stonework around park ponds. The filaments are unbranched, and each consists of a row of similar 
cells. Each cell contaius a single chromatophore with pyrenoids, which has the form of a wide band, or girdle, just under the cell wall, and generally surrounds the nucleus in the middle region of the cell ( $\mathrm{Fig}$. 180, $A, B$ ). The filaments are attached at one end (Fig. 180,A), and the growth by cell division takes place throughout the entire length and is not confined to the
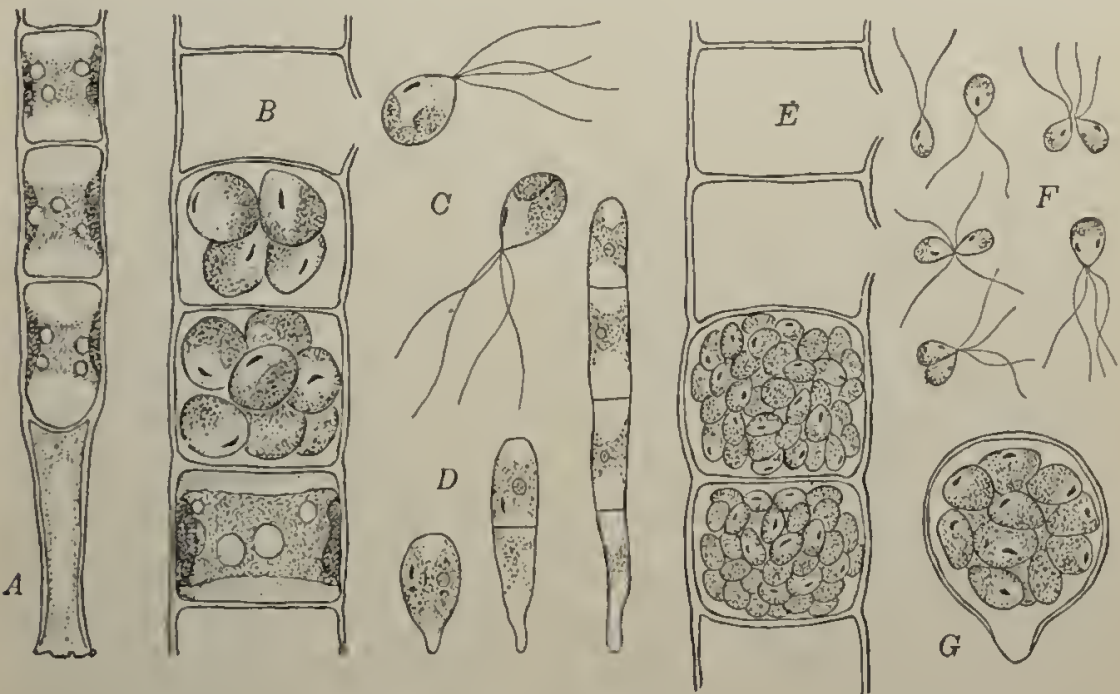

Fig. 180. Ulothrix zonata

$A$, base of filament, showing its attachment and eells containing band-shaped chromatophores with pyrenoids; $B$, portion of a filament about fifty eells above the base, showing a vegetative cell below and two eells which have formed 4 and 8 zoösplores respectively; $C$, the zoöspores, each with a pigment spot aud four cilia; $U$, stages in the germination of the zoöspore; $E$, portion of a filament illustrating the formation of gametes, 64 in each eell; $F$, the zanetes, showing pigment spot and two cilia, and stages in their fusion to form a four-ciliatezygospore with two pigment spots; $G$, germination of the zygospore, which develops a umbler of zö̈spores. $-G$, after Dodel

tip as in some algie. The cells in the upper portions of older filaments (Fig. 180, I3) develop a type of reproductive cell very common among the algæ, called the zoöspore (meaning animal spore) because of its animal-like habit of swimming about.

Zoöspores are naked ciliated protoplasts formed within parent cells called sporangice. They swim rapilly through the water, and each generally contains a red pigment spot. Zoüspores are 
attracted by light and collect at the illuminated side of a vessel, forming a green cloud in the water. Because of these habits, and their rapid darting to and fro in the water, they are often called swarm spores.

The zoöspores of Ulothrix are developed most numerously at night and are set free from the parent filaments chiefly during the morning hours. Sometimes the entire protoplast slips out as a single large zoöspore, but more often 2,4 , or 8 zoöspores are formed in each parent cell (Fig. 180, B). They are roundish or pear-shaped (Fig. 180,C), with four cilia at the pointed end, and each contains a red pigment spot, chromatophore, and nucleus. The zoöspores thus resemble the organisms called flagellates (Sec. 204), and like them swim freely around in the water by the lashing movements of their cilia. But the zoöspores have a relatively short free-swimming period, for after perhaps an hour or more they attach themselves by the ciliated ends to various objects and grow into new Ulothrix filaments (Fig. 1S0, D).

At times a much greater number of zoöspores may be developed in the parent cells, - perhaps 32 or 64 , or even more than a hundred (Fig. 180, E). These have generally only two cilia and are much smaller than the four-ciliate zoöspores, but otherwise have the same structure. They swim very actively for a short time, and then come together in pairs in the water and fuse with one another (Fig. $180, F$ ). This cell union is a sexual process (see Sec. 200), and the small two-ciliate zoöspores are therefore sexual elements and are called gametes. The result of this fusion is a sexually formed cell called a zygospore (meaning a yoked spore), because the two gametes are similar, like the halves of a yoke, and not different in form, as the sperm and egg (see Fig. 178, Volvox). This simple type of sexual reproduction is termed isogamy, becausc the gametes have the same form, or morphology. The zygospore, of course, corresponds to the fertilized egg, or oöspore, characteristic of higher plants.

The zygospore of Ulothrix swims about for a short time with its four cilia, and may only be distinguished from the large 
four-ciliate asexual zoöspores by its two pigment spots. It finally comes to rest and remains quiet for many weeks or several months, but slowly increases in size. Finally, the zygospore develops several zoöspores (Fig. 180,G), which escape from the cell, swim off, and develop new Ulothrix plants.

218. The sea lettuces. The sea lettuces include Ulva and its relatives (family Ulvacee), and are very common along the seacoast, forming green fringes on the rocks and wharves near low watermark. The thallus is a thin green membrane (Fig. $181, A)$ instead of a filament as in Ulothrix. Zoöspores and gametes (Fig. $181, B, C$ ) are developed in the cells along the edge of the membranes. Their structure, methods of formation, and habits are essentially the same as in Ulothrix, and the sea lettuces are equally good for the study of these points, and they are sometimes more available than UTothrix for those living at or near the seacoast.

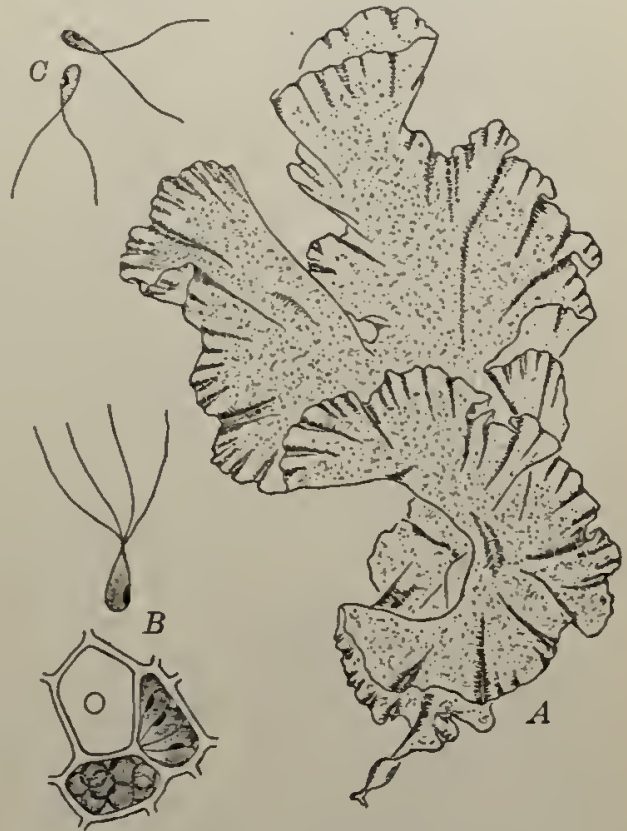

Fig. 181. The sea lettuce (Ulva)

$A$, habit sketeh ; $B$, cells forming four-ciliate zoöspores; C', two-ciliate gametes.-Adapted after Thuret

219. The origin of sex in plants. Ulothrix, Ulva, and some other types show clearly that the simplest forms of gametes in plants are closely related to zoöspores, for they are developed in the same way and liave a similar structure. Indeed, the gametes of these lower plants frequently germinate directly like zoöspores, thus showing that the sexual habit of fusing with one another is not firmly fixed. However, the plants that 
develop from such gametes are generally smaller and weaker than those which come from the usual zoöspores. For these reasons it scems evident that the gametes of plants arose from zoöspores, or motile cells similar to zoöspores, which, adopting the halits of fusing in pairs, becane sexual cells. Such types as Ulothrix and Ulec have an especial interest because they illustrate the general conditions which must have been present with the origin of sex in any gromp of plants.

220. Edogonium. Aidogonium (fanily Gidogoniacce) is one of the best illustrations in the green algie of the higher sexual condition where the gametes becone differentiated and specialized as eggs and sperms.

The species are unbranched, filamentous, fresh-water forms, attached by a disk-like development from the lowest cell (Fig. 182, A) called a holdfast. The cells have large chromatophores of irregular form, containing pyrenoids. There are sets of curious lines called caps across the ends of many of the cells (Fig. 182, B, c), - structures peculiar to this fannily, - which result from a method of cell division too complicated to be described here. Zoöspores are developed singly in the cells, and are large protoplasts with a circle of cilia at a colorless end (Fig. 182, D). After swimning about for a short tine the zoöspores settle down on the ciliated end, develop the holdfasts, and grow at once into new filaments.

The sexual cells, or gametes, of Oidogonium are cgys and sperms. The eggs are developed singly in enlarged cells, which are the female sexual organs (Fig. 182, $P$ ) and are called ö̈gonia (singular, ö̈gonium). The entire protoplast of the oögonium becones the egrg ( Iig. 182, B, c), which remains within the oögonium as a naked, notionless cell, without cilia, and is riclily supplied with chromatophores and food material. The sperms are developed in pairs in short, disk-shaped cells, which are found in small groups, forming the male sexual organ, or

1. See Goebel, Outlines of Classification and Special Morphology of Plants, 1.. 44. 
antheridium (Fig. 182, b, a). The sperms, frequently ealled antherozoids by botanists, are siuall, almost colorless protoplasts, with a cirele of cilia at one end (Fig. 182, C) like the zoöspore. They are in sharp contrast to the eggs, being actively motile, eiliated, and with very mueh redueed ehromatophore and food contents.

A cleft, or pore (Fig. $182, B, e)$, is formed in the oögonium so that the sperms may enter, and one of them, fusing with the egg, fortilizes it. The egg after fertilization develops a heavy wall (Fig. $182, B, 0$ ) and hecomes an oöspore (meaning an egg spore). The oöspores, thus proteeted, ean live through drought ol winter's eold and so survive seasons of the year impossible for vegetative growth. Din the return of favorable conditions they germinate, each oöspme

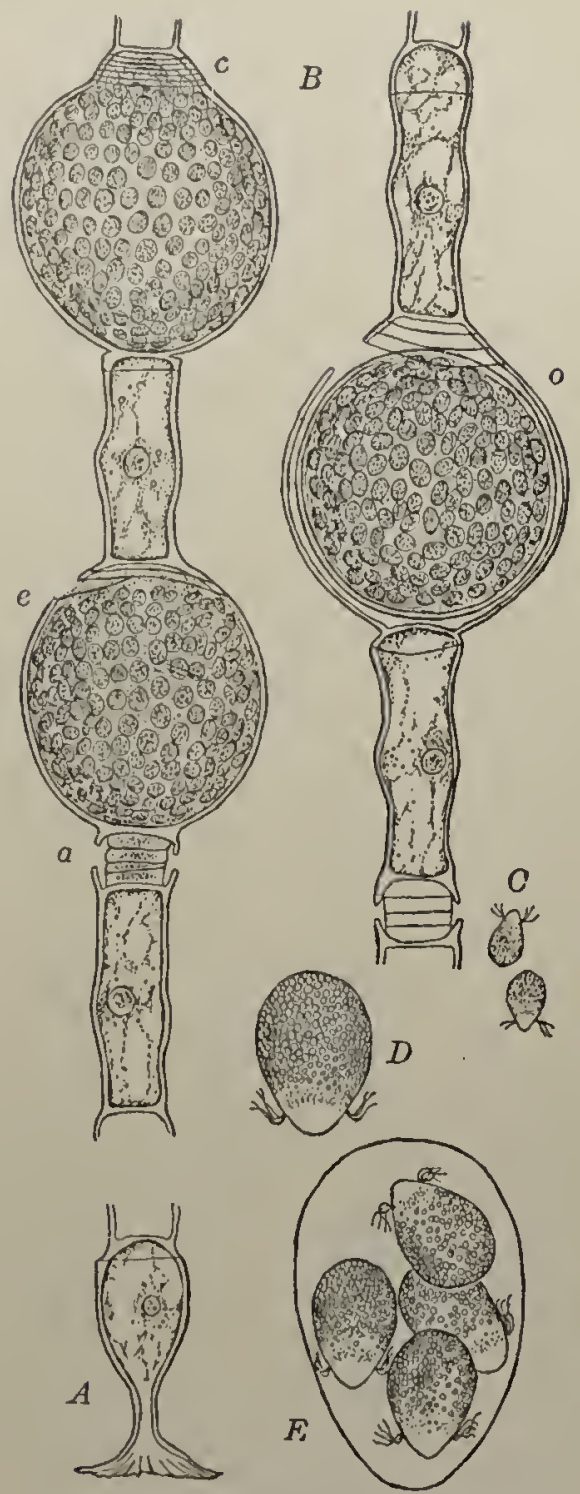

F'เ:. 182. Gidogoninm nodulosum

A, luse of filament showing holdfast; $B$, filaments with oügonia and antherilia; $e$, an ege rearly for fertilization, showing the cleft for the entrance of the sperm; 0 , the thick-walled ouspore; $u_{1}$ antharilium, composed of four cells; $c$, caps; $C$, sperms, showing crown of cilia; $J$, zoüspore; F. germination of the nöspore, produeing four zoüspores. - (,$I), E$, after Juranyi 
giving rise to four large zoöspores (Fig. $1 \dot{8} 2, E$ ), which develop at once into Gidogonium plants.

Both eggs and sperms are believed to have been derived from simpler ancestral types of ciliated gametes, similar in structure to one another and to the zoöspore. These ancestral sexual conditions must lave been those of isogamy, somewhat as is at present illustrated in Ulothrix. The originally similar ciliated gametes varied in size. The smaller reduced their chromatophore and food contents because they were formed in large numbers but retained their cilia and thus became the small active sperms. The larger gametes accumulated rich supplies of food, became sluggish, finally lost their cilia and swimming habits, and at last were retained within and protected by the oögonia, thus becoming large nonmotile eggs.

It is clear that the plant gains very much by differentiating and specializing its gametes as eggs and sperms, for the eggs are protected and richly supplied with protoplasm and food, while the sperms are developed very numerously and are well adapted to swim actively about in the water, where they are attracted to the eggs by substances secreted by its protoplasm. The higher sexual condition, as in EEdogonium,

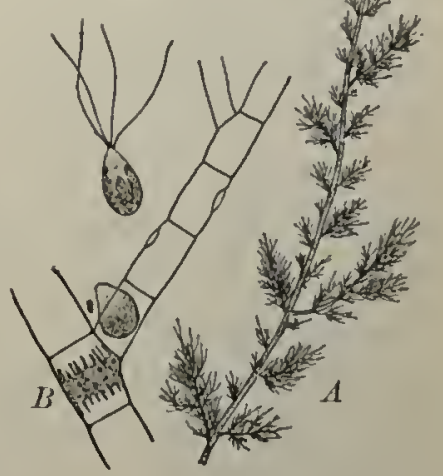

Fı. 183. Draparnaldia, one of the Chatophoracea

$A$, labit sketclı ; $B$, side branch, discharging large four-ciliate zoöspores formed singly in the cells where the gametes are eggs and sperms, is called heterogamy because the gametes are dissimilar, in contrast to isogamy (see account of Ulothrix, Sec. 217).

221. The Chætophoraceæ.* The members of this family, inclnding such common genera as Stigeoclonium, Draparnaldia

* To tue Isstructor : It loes not seem to be generally known that forms of the Chatophoracea are almost equally good types for the study of zoöspores as Ulothrix and may be realily substituted for that form. Stigeoclonium 
(Fig. 183), and Chatophora, are more complex than Ulothrix, for they consist of branching filaments of peculiar forms. However, the cell structure, life histories, methods of reproduction, and low sexual conditions (isogany) of these types all show relationships to the Ulothricacea. They are of especial interest as leading up from the level of Ulothrix to the lighest form of the Confervalcs, the genus Colcochate.

222. Coleochæte. Colcochatc (family Colcochatacea) contains a number of species which live in fresh water, attached to the stems and leaves of water weeds, and they frequently appear on the sides of aquaria. Some of the forms are circular flat plates or cushions of cells that really consist of systems of filaments radiating out from a center. Large, two-ciliate zoöspores are formed singly in the cells. The fcmale organ, oügonium, is a large, flask-shaped cell with a long neck (Fig. $185 \mathrm{~A}, \mathrm{o}$ ). Its protoplasm forms a single spherical egg which ncarly fills the lower swollen portion of the ooggonium, and the neck finally opens above to allow the entrance of the sperms. The malc organs, antheridia (Fig. 185, $A, a$ ), arc small

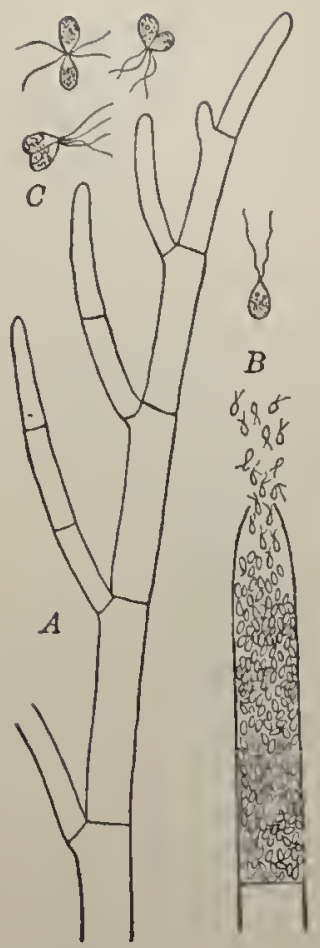

Fig. 184. Cladophora

This large, much-branched, filamentous alga, $A$, has many speeies common in both fresh and salt water. Zoöspores, $B$, are formed generally in terminal sporangia, and there are gametes which fuse in pairs, $C$, as in Ulothrix. The older cells eontain large numbers of nuclei, and this form, with certain relatives (funily Cladophoracere), occinpy a position somewhat intermediate between the Confervales and siphonales cells, gencrally in groups, each of which develops a two-ciliate sperm.

anl Iraparnaldia are common on stones in clear brooks and in springs. Cladophora (Fig. 181) is also a good type for laboratory study and very common. 
The fertilized egg becomes an oöspore within the oögonium and is further protected by a cellular envelope (Fig. 185, B) developed from short filaments which grow up around the structure (Fig. 185, A, f), making a conspicuous fructification.

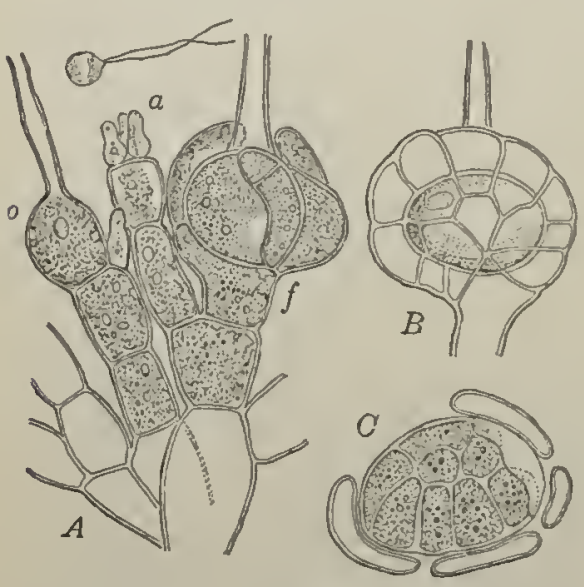

Fig. 185. Coleochate pulvinata

$A$, filaments witlı an ö̈gonium $o$, antheridium $\alpha$, and a sperm above; $f$, fertilized egg in its oögonium becoming surrounded by short filaments from the cell below; $B$, oöspore completely inclosed in a cellular envelope derived from filaments such as are shawn in $A, f ; C$, germination of oöspore, each cell in the interior develops a zoöspore. - After Pringsheim The oöspore germinates the following spring, forming within itself a small group of cells (Fig. 185, C), each of which gives rise to a zoöspore. The decay and rupturing of the fructification allows the zoöspores to escape and start new Coleochwe plante at the beginning of each season. The fructification of $\mathrm{C}^{\mathrm{O}}$ leochate serves to multiply the number of zoüspores produced by the oöspore, which is clearly an adrantage.

Colcoehcete stands at the head of one of the best-defined lines of evolution in the algæe, a line which starts at the lowly level of the Ulothricaece anil runs upwards through the Chotophorucece. Authors have generally regarded these forms as leading almost directly to the bryophytes, with Coleo. checte just a little below the liverworts; but, as we shall see later, there are serious difficulties in the way of this view. ${ }^{1}$ Nevertheless, these forms are perhaps nearer than any other living alga to the theoretical main line of ascent.

1 The fruetification of Coleochute has been regarded as similar to the soealled fruit or sporophyte of the liverworts, but, as explained in Sec. 396 , there is strong evilence against this interpretation. The one-cellerl sexual organs of Coleochate are also very different from the many-cellerl sexunl organs of the bryophytes, and this is also evidence agrainst the existence of in close relationship between the groups (see see. 297). 


\section{Ordik 3. ThF Poxid Scums and Desmids, OR Conjugales}

223. The pond scums and desmids. The pond scums and desmids (order Conjugales) are remarkable for the beauty and symmetry of their cell structure, and especially for their large and complicated chromatophores. There are no motile stages in their life histories, and the sexual processes consist in the union or conjugation of similur nonmotile gametes (isogany). These character's distinguish the group sharply from all other algæ, but
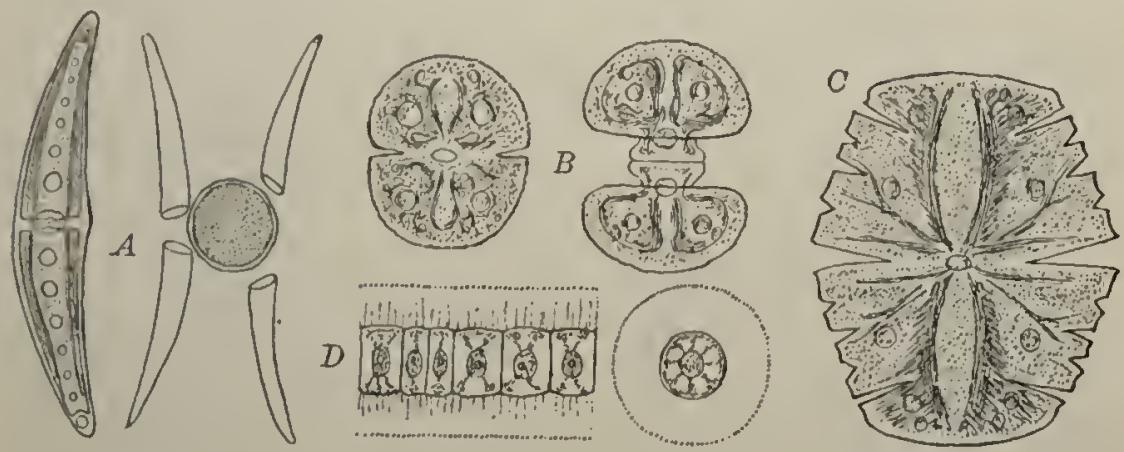

Fr: 186. Deswids

$A$, Closterium, a regretative cell at the left and a zygospore at the right between the halves of two empty cells whose contents have fused; $B$, Cosmarium; the desmir at the right lias just divided and is forming two new parts between the old halves of the parent cell. C, Micrasterias, a very elaborate form in its outline and markings; $J, H_{y}$ alotheca, a common filamentous desmid; the appearance of the cells in face view is sliown at the right

make the relationships of the forms very uncertain. These plants live only in fresh water and seek the sumsline, being abundant in clear, shallow pools. The desmids live chiefly along the margin and on the bottom, while the pond scums frequently form growths upon the surface of the water, which appear frothy because of the bubbles of gas (largely oxygen) held among the filaments. The filaments are very slippery to the touch on account of a slimy excretion from the cells.

224. The desmids. There are about one thousand species in this large group whose forms are generally one-celled, although some desmids are filamentous (Fig. $186, D$ ). Each cell has two 
parts, which duplicate one another even in the details of protoplasmic strueture, and the nucleus lies in the middle region, with the chromatophores arranged symmetrieally in the halves.
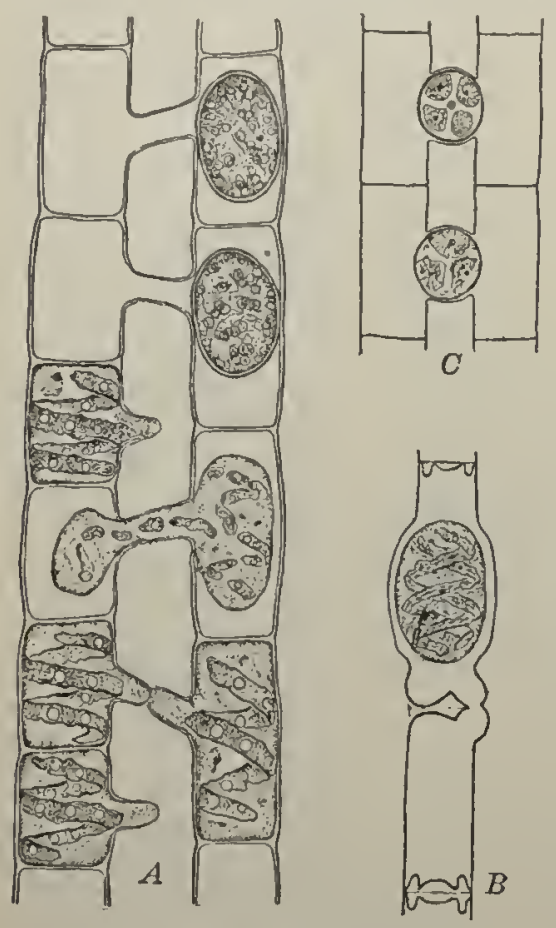

Fig. 187. Pond scums

A, Spirogyra, illustrating stages in tho conjugation between cells of different filaments, two zygospores sliown ahove; sinee the eells in the filament on tho left are shorter than those on the right, some of them must lie left ont in the pairing of the gametes. $B$, the eonjugation between arljacent cells of the same filament in Spirosyra qualtratu; C'Zygnema (Zygogonizm) pectinatum, sliowing zygospores formed in the conjugating tubes between two filaments
The desmids multiply rapidly by cell division, each daughter eell taking one half of the old eell wall and adding to it a reproduetion of the other half (Fig. $186, B)$. The gametes are naked protoplasts, which eseape by the breaking apart of the halves of the cells and fuse in pairs, forming thick-walled zygospores (Fig. 186, A). In some common forms (Closterium and Cosmarium) the zygospore on germinating produees two desmids.

225. The pond scums. Some of the eommonest and most beautiful of filamentous green algæ, sueh as Spirogyra and $Z$ yynema, belong here. The complex ehromatophores with their sharply differentiated pyrenoids give an especial interest to the cells and help to distinguish the genera. Thus the chromatophores of Spirogyra are spiral bands (Figs. 168, 187); Zygnicnua has two star-shaped chromatophores, and Mougeotia has a broad, thin band in the eenter of the eell. The method of sexual reproduetion is very elanacteristie, but exeeptional among the algx. Generally the eells of different filaments unite or eonjugate with one another by the 
fusion of processes, one put out from each gamete (Fig. 18.7, A). The gamete protoplast of one of the cells in the pair then passes over into the other, or in certain forms the two protoplasts unite more or less midway between the two cells (Fig. 187, C). In some species, however, there is a eonjugation between adjacent cells of the same filament (Fig. 187, B), the eontents of one eell entering the other. The fusion of the two gamete protoplasts results in a zygospore, which develops a heavy wall about itself as in the desmids and, as a resting spore, earries the plant over unfavorable seasons. On germination each zygospore puts forth a filament, which grows by repeated eell divisions all along its length.

\section{Order 4. The Diatoms, or Diatomales}

226. The diatoms. The diatoms (order Diatomales) comprise a remarkable group of onc-celled plants, containing several thousand speeies, everywhere present in both fresh and salt water. They compose the greater part of the floating mieroscopie life, called the plankton, of the ocean and lakes, and are the most important souree of food for some of the smaller animal forms, and through them for the fish life. The eell walls are filled with the mineral siliea and consist of two parts, ealled valves, which fit together something like the halves of a pill box (Fig. 188, $A$ ). Diatom cells liave a great variety of forms, elliptical and eircular, wedge-shaped and triangular, eylindrical and rhomboidal (see Fig. 188). The cells are solitary in many forms, but in others are arranged in filaments, or borne at the ends of gelatinous stalks, or held in filamentous sheaths or jelly-like masses. Many of the diatoms, and especially the boat-shaped forms, glide to and fro in the water. The cells eontain chromatophores which are generally eolored brown (although certain species are green), but in spite of this color the most natural position of the diatoms seems to be among the green algæ, with possible distant relationships to the desmids. 
The diatoms resemble the desmids in the similar halves of the cell and in the development of a peculiar type of spore called an auxospore, which probably corresponds to a zygospore. Some
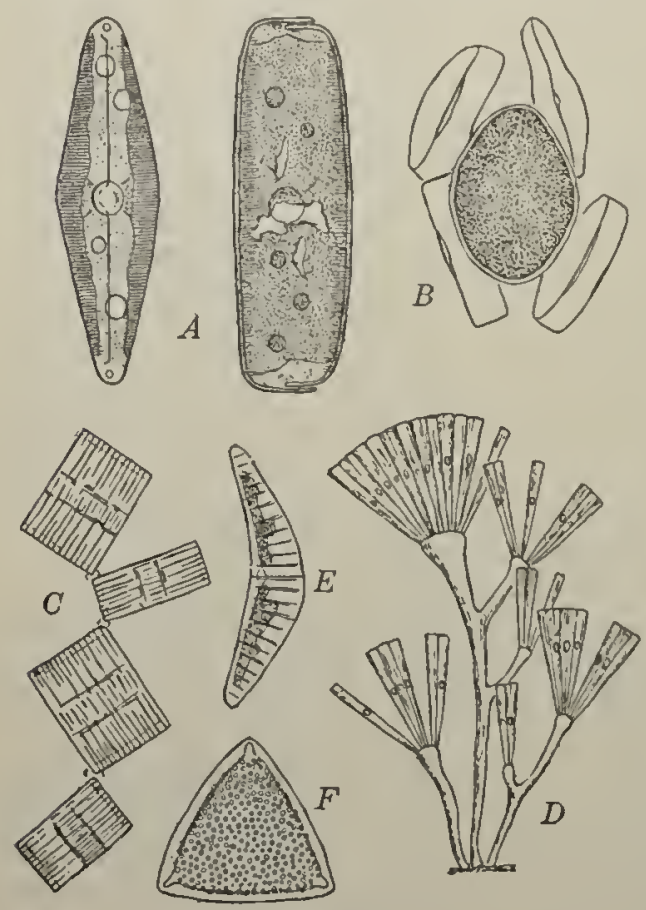

Fir. 188. Diatoms

A, Navicula, the boat diatom, the side view at the right showing the two overlappiug shells or valves; $B$, Acnanthes, an auxospore with the four empty shells of the two diatoms whose contents united to proluce this sexwally formed spore similar to the zygospore of the desmids (see Closterium (Fig. 186, A); C, Tabellaria, groups of cells nuited with one another to form a zigzag filament; $I$, licmophora, groups of cells borne on gelatinous stalks; F, Epithemia; $F$, Triceratium. $-B$, after West auxospores are formed by the fusion of two gamete protoplasts which leave the diatom shells at one sicle (Fig. 1SS, B), and these are true zygospores very similar to those of the desmids (Fig. 186, A). Other auxospores are developed without protoplasmic fusions and are lrobably examples of sexual degeneration; that is, cells which were originally gametes now develop lirectly into auxospores. The auxospores are resting spores and appear to be formed after long periods of vegetative cell divisions to stimulate or rejurenate the protoplasm for further activities.

The shells of diatoms, heing composed of silica, resist solution in water and are constantly being deposited at the bottom of seas, lakes, ponds, and marshes, sometimes in such quantities as to form so-called siliceons or diatomaceous earths. There are some geological deposits (Tertiary) of diatomaceuus earth many feet in thickness, as that at Richmond, Virginia. Some of these 
earths have so large a proportion of hard diatom shells as to be valuable as polishing powders, and they are also used as the absorbent of nitroglycerin in the manufacture of dynamite.

\section{Order 5. The Siphon Alga, or Siphonales}

227. The siphon algæ. The siphon algæe (order Siphonales) differ from all other groups of algie in the striking peculiarity that the protoplasm, with thousands of nuclei, is not separated into compartments or cells, but is all contained within a common filament or other cell cavity. Such a many-nucleate structure is called a conocytc (meaning a vessel in common). The siphon algæe are chiefly marine, and many large and complicated forms are found in the warmer seas (Caulerpa, Udotca, etc.). Some of these are heavily incrusted with lime (Acctabularia, Penicillus, Halimeda, etc.). Two-ciliate zoöspores and gametes are developed by certain types in cells cut off from the ends of the filaments. The gametes fuse in pairs on thcir escape into the water, forming zygospores. All of the siphon algie are isogamous, when sexual at all, except the green felt, Vauchcria, which stands quitc alone as the only heterogamous type in the group.

228. Vaucheria. Vauchcria, the green felt, is a very common alga, forming mats of coarse filaments on the muddy bottom of shallow pools and ditches. Some species are terrestrial and may often be found as thread-like growths over the damp earth of flowerpots in greenhouses. The filaments are long and sparingly branched, and are, of course, continuous tubes without cross walls except whcre reproductive organs are developed. Immense numbers of small, disk-shaped chloroplasts (Fig. 189, F') are present in the layer of protoplasm under the cell wall, and the very small nuclei lie anong them. The protoplasm contains numerous globules of oil, which in this plant takes the place of starch as the first visible product of photosynthesis.

The zoöspores of Vauchcria are very large, many-nucleate and many-ciliate structures, visible to the naked eye. They are 
developed singly in terminal cells (sporangia), which are cut off at the ends of the filaments by the formation of a cross wall (Fig. 189, A). The protoplasm in the sporangium contains hundreds of nuclei from the beginning, and pairs of eilia are formed all over the surface of the protoplast opposite them

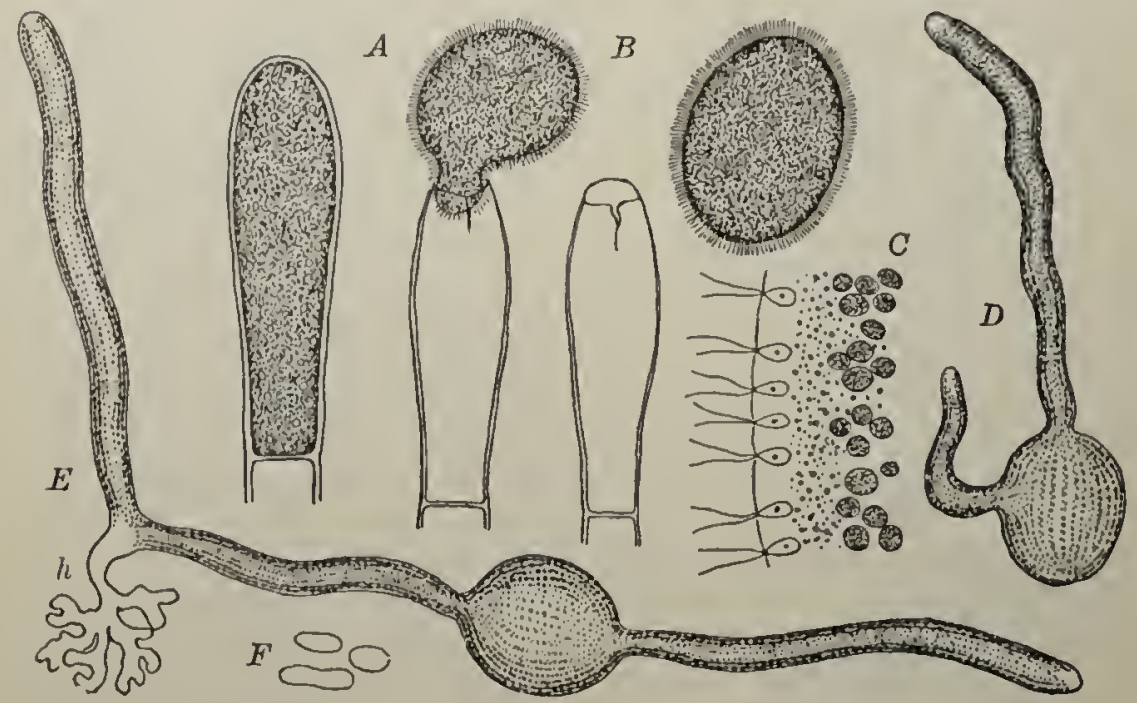

Fig. 189. Asexual reproduction of the green felt (Vaucheria)

$A$, formation and discharge of the linge, many-ciliate zoöspore from the terminal sporangium; $l$, , the zoöspore showing the ciliated surface; $C$. section through the surface of the zoöspore showing the pairs of cilia above the nuelei and the layer of plasticls beneatl ; $D$, germination of zoöspore; $F$, young plant of Iaucheria, the two filaments having arisen at opposite ends of the zoöspore, one having leveloped an organ of attachuent or holdfast $h ; k$, a group of plastils, the lower in process of division. $-A, B$, after Güt $\%$; after Strasburger; $D, E$, after Sacls

(Fig. 189,C). The entire mass of protoplasm then slips out from the end of the sporangium (Fig. 189, $B$ ) and swims slowly away, but soon comes to rest and puts forth one or more filamerits (Fig. 189, $I$ ). The nuclei and pairs of cilia in this interesting zoöspore of Vaucherie unquestionably represent the twociliate zoöspores characteristic of most of the Siphonales and the green algæ in general. The protoplasmie divisions neeessary to eut out the numerous zoöspores in a sporangium are 
suppressed in Vaueheria, so that the entire mass of protoplasm remains together as a many-nucleate and many-ciliate unit, which is really a protoplast or cell in spite of its complicated structure. Some authors have regarded this zoöspore as a compound structure,- that is, a mass of small, two-ciliate zoöspores,
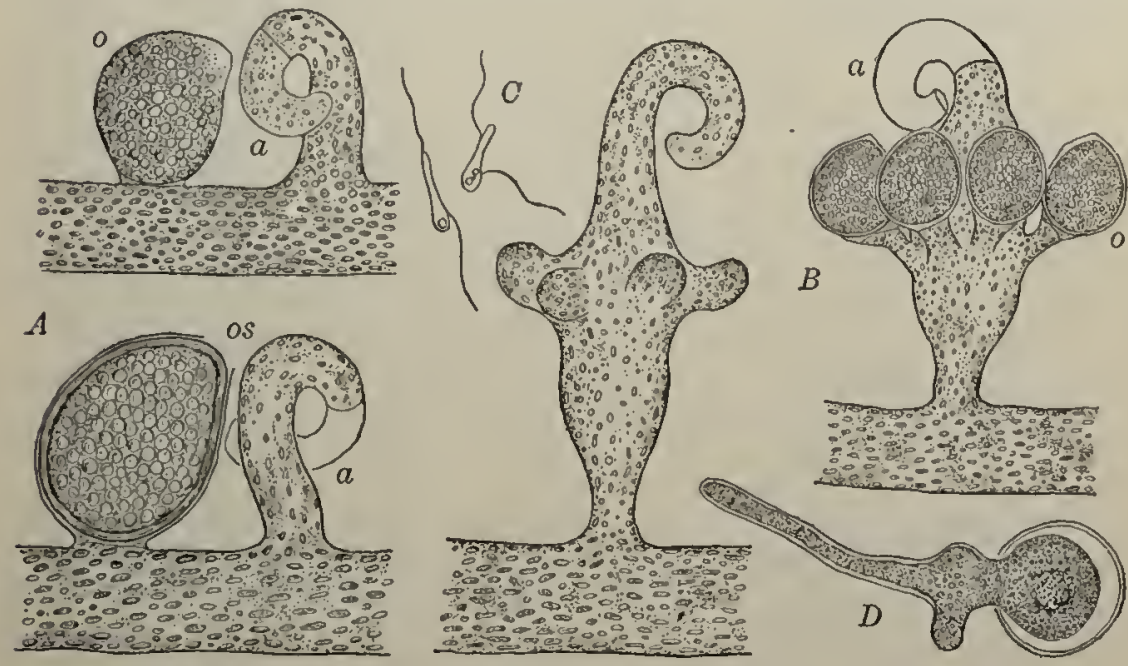

Fig. 190. Sexual reproduction of the green felt (Vaucheria)

$A$, Vaucheria sessilis ; 0 , oögonium ; $\alpha$, antheridium; os, the thick-walled oöspore, and beside it an cmpty antheridium; $B$, Vaucheria geminata, a short lateral branch developing a cluster of ö̈gonia and a later stage with mature oögonia 0 and empty antheridium $a ; C$, sperms; $D$, germinating oöspore.- $C$, after Woronin ; $D$, after Sachs

— but it is more correct to consider it a large, undivided, manynucleate protoplast.

The sexual organs of Vaueheria are oögonia and antheridia, sometimes found side by side, as in Vaucheria sessilis (Figr. $190, A)$, and sometimes in groups on special side branches, as in Vaucheria geminata (Fig. 190, B). The ooggonium is a large oval cell separated from the parent filament by a wall, and each develops a single egg (Fig. 190, $A, B, o$ ). The young oögonium contains numerous nuclei, but all of these degenerate except one, which lies near the center of the cell and becomes the single nucleus of the egg. The antheridium is a cell formed 


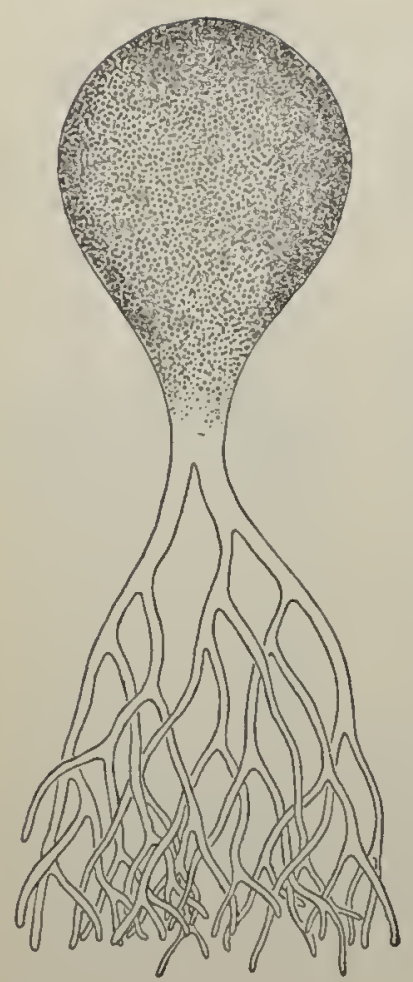

Fig. 191. Botrydium and Protosiphon

These forms of the siphon alga are almost indistinguishable in the regetative condition. The plants are little green globes, som ew hat larger than pin heads, attached to the surface of mud and wet earth by a branching system of filaments (rhizoids). "These single cenocy tic cells are therefore differentiater into a green part above ground, exposed to the air and sunliglit, and a colorless underground portion in contart with moisture. A single cell may thus slow the same relation of parts as a complex plaut with aierial stems and leaves and a subterranean root system. at the end of a branch, which is generally bent like a crook (Fig. 190, $A, B, a$ ), and discharges a very large number of small, two-ciliate sperms (Fig. 190, C). The sperms enter the oögonium through a pore in the beak-like extension at one side, and one of them, fusing with the egg, fertilizes it. The fertilized egg surrounds itself at once with a heary wall, becoming an oöspore (Fig. 190, A, os), which is a resting spore in this form, as in Volvox, Edogonium, Coleorhate, etc.

Vaueheria has been made the subject of some interesting experimental studies on the conditions which determine the formation of zoöspores and sexual organs respectively. Zoöspores are generally developed at once, following some marked change in the external conditions, as in the character of the water, or an increase in light exposure, or a rise in temperature. Sexual organs are formed when plants are cultivated in a 2-5 per cent solution of cane sugar at a fairly high temperature $\left(50^{\circ}-68^{\circ} \mathrm{F}\right.$; $10^{\circ}-20^{\circ} \mathrm{C}$ ), and in the presence of light. The conditions in Vaucheria probably illustrate very well the kinds of influences which cause an alga to begin its various forms of fructifications, but very few algæ have been studied in detail.

229. The cœnocyte. The large, manynucleate structures called ccnoeytes, so well illustrated by the siphon algæ 
and such fungi as the molds (Sec. 261) and water molds (sec. 262), are peculiar to plants. The question may be asked, Why are coenocytes considered single cells, and not a conpound structure made up of a mited mass of protoplasts represented by the numerous nuclei? It is known that the nuclei do not occupy fixed positions in the coenocytes, as if they represented the cells of a compound structure. On the contrary, they shift with the movements of the protoplasm which lehaves as a unit, like a gigantic protoplast growing in different directions in obedience to various stimuli, and carrying on the usual cell activities. For these reasons the conocyte must be regarded as a many-nucleate cell and not a compound structure or mass of protoplasts.

\section{Order 6. The Stoneworts, or Charales}

230. The stoneworts. ${ }^{*}$ The stoneworts (order Charales) are the most complex of the green algæ. The plant body (Fig. 192, A) consists of long, jointed stems, which bear circles of lateral branches at the joints. The sexual organs (Fig. 192, $B, C, D$ ) are borne on these branches, but are too complicated for consideration here. Many of the Charales are heavily incrusted with lime, which peculiarity gives them their popular name of stoneworts. They sometimes grow in great masses attached to the bottom of ponds and shallow lakes.

Some forms of stoneworts (Nitella), which are free from incrusting lime, frequently illustrate very beautifully the movements of protoplasm in the large cells (internodes) which lie

* To tre Ixstructor: The Charales is sucli a highly special group that it is hardly wise to give it much attention in a general course, especially if time and material is available for a more thorougl stuly of the Confervales. Nevertheluss, material of the stoneworts is frequently ensily ontained, especially in the Middle West, where it is diflicult to do justice to the brown and red alge, and it might be substituted for certain work in those groups. (one of the best accounts of the Charales will be found in Goebel, Oullines of Clressification and Special Morphology of Plants. 


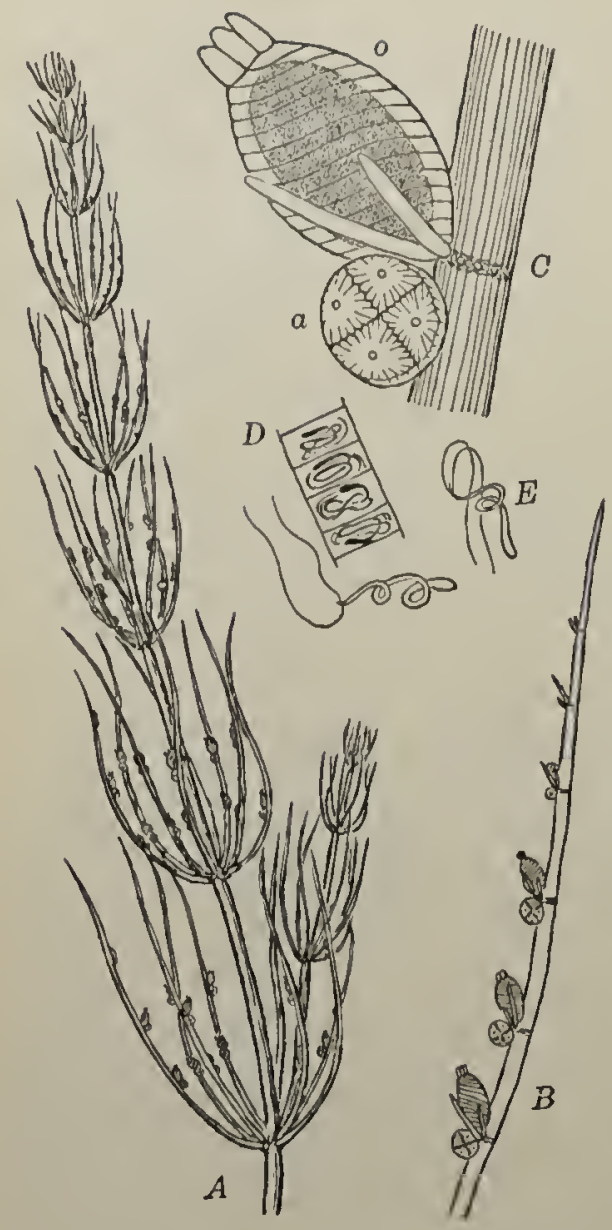

F1G. 192. The stonewort (Chara)

$A$, portion of plant showing eircles of lateral branches at the joints (nodes); $B, a$ lateral branch bearing the sexual organs; $C$, the sexual organs; o, oögonjum, with spirally wound filaments encircling the egr and forming a erown above; $a$, the antheridium, composed of eiglit flattened cells (shields), inelosing the antheridial filaments; $D$, portion of an antheridial fila. ment, each eell developing a singlo sperm; $E$, two-ciliato sperms

between the eireles of lateral branches. The protoplasm passes in two streams in opposite direetions somewhat diagonally around the eell. The edges of the stream form a line of stationary protoplasm (free from elloroplasts), beeause the movements of the eurrents, which may be seen on either side of the line, neutralize one another.

The Charales stand entirely by themselves at the end of a line of aseent wliose developmental history is a mystery. They are very far above most of the green algæ in the complexity of the plant body and sexual organs, which are not, however, like those of the liverworts and mosses. The antheridium of the stoneworts is a very puzzling strueture but the oögonium is easily understood. The jointed stems with eireles of lateral branches are, of eourse, mueh more eomplicated than the typieal thallus, but the simple life history, with no trace of an alternation of generations, makes it neessary to include the stoneworts among the thallophytes. 


\section{Summary of the Green Alga}

231. Summary of the green algæ. The green algæe eomprise a number of well-defined groups which are evidently widely separated from one another. The most conspieuous of these are the Volvocaeece, the desmids and pond scums, the diatoms, the siphon algax, and the stoneworts. They constitute independent evolutionary lines of varying importance, but each one elearly developing in ways peculiar to itself and quite apart from the theoretical main line of aseent to the liverworts and mosses (Bryophyta). A discussion of the origin of these groups and their possible relationships to one another would be much too eomplicated for the present account. The forms of the green algæ which seem to be nearest to the main line of ascent are in certain related families (Ulothricacce, Chotophoracce, and Colcochetacces), but it is very doubtful if any of them are directly on the nain line, and there are $n$ living algae known which show elearly the origin of the bryophytes.

Almost all of the green algae at some stage in their life history form zoöspores or motile gametes (the sperm being motile in heterogamous forms). These ciliate cells point elearly to an aneestry of the green algx from groups comprising onecelled motile organisms something like the flagellates (See. 204) and lower forms of the Volvocacew (Sec. 215). The formation of the zoöspore and the motile gamete is considered to be a return in the life listory, for a short time, to the primitive one-celled conditions from which the various lines of the green alge are believed to have arisen. The notile conditions which necupy praetically all of the life history of the flagellates and Volvocacece become reduced to a short reproductive period in most of the green algre. The most important forward steps in the evolution of the green alge cane with the introduction of long vegetative periods in the life histories when the protoplasts remained quiet and formed many-celled plant bodies (conocytic siphon alga excepted) of various structure. All the 
possibilities of development into such complex attached organisms as the higher spore plants and sced plants were determined by those changes in the habits of algæ by which the motile periods in the life history becane reproductive stages, and the quicscent conditions came to be the conspicuous part of the life history as the vegetative plant body was gradually developed.

232. Summary of the reproductive organs and processes of the green algæ. Zoöspores, also called swarm spores, are ciliate asexual cells (gencrally two- or four-ciliate), and are developed as a rule numerously (in some forms singly, or in twos, fours, etc.). in a mother cell called a sporangium, or zoösporangium.

Gametes are sexual cells. The simplest forms are ciliate and have the same form and structure (morphology) as the zoöspores, to which they are related. These in the process of sexual evolution became differentiated into egys and sperms. Gametes are developed in cells called gametangia.

Eggs are never ciliated, and are consequently nonmotile. They are generally large cells, with abundant chromatophores and food material. Fggs are formed in cells called oögonia.

Sperms, frequently called antherozoids by botanists, are always ciliated in the green algre and are very actively motile. They are smaller than zoöspores and colorless, or almost colorless. Sperms are developed in cells called antheridia, or a group of such cells is frequently termed an antheridium.

Isogamy is the sexual condition in which the gametes are sinilar in form and structure; that is, they have the same morphology. They may differ in size. The sexually formed cell is called a zygospore.

Heterogamy is the sexual condition in which the gametes are different in form and structure, as the sperm and egg, and therefore have a different morpholory. They are always very unlike in size, but this does not make heterogamy, because morphology does not deal with size but with form. The egg is fertilizcd by the fusion and entrance of a sperm and thus becomes a fertitized egg, or, if it develops a protective cell wall, an öspore. 


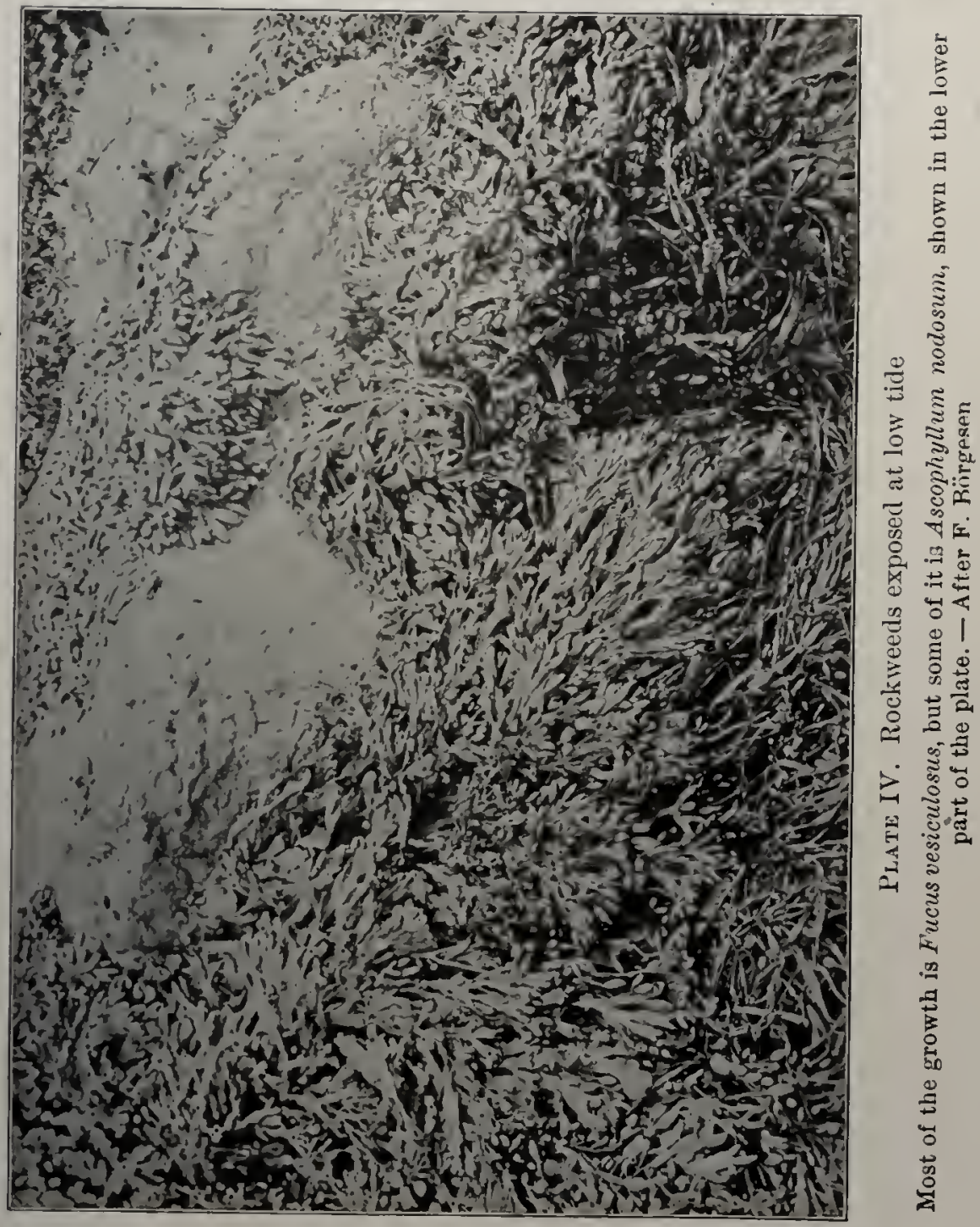



CLASS IH. THE BROWN ALGE, OR PHAEOPHYCEA

233. The brown algx. The Phoophycce comprise a very large assemblage of marine algæ, or seaweeds, called the brown alge because their chromatophores are colored brown instead of green. The brown pigment, however, performs the same sort of work (photosynthesis) as the chlorophyll of the green algx. The brown algæ can generally be recognized at a glance by their color, but the group is really separated from all other classes of alge by certain peculiarities of structure, or morphology. The plant bodies in most of the forms are very much larger and more complex than those of any green algæ and frequently liave a degree of differentiation quite above that of the typical thallus. Indeed, some of the higher brown algæ have well-defined stems fastened to the rocks by remarkable holdfasts, resembling clusters of roots, and bearing expanded leaflike structures of complex and striking forms. Certain types develop swollen bladders, which contain considerable oxygen, given off from the tissues, and serve to float parts of the plant in the water. Besides the complexity of the plant body the brown algæe are also distinguished by peculiarities of the reproductive organs that can only be understood through a study of types. Iodine is obtained from the ash of certain kelps and rockweeds. These larger brown algæ are also gathered from the rocks and beaches by the peasantry of certain European countries and by farmers on the Ncw England coast and spread over farm lands to fertilize the soil.

234. Life habits. The brown algæ are nost luxuriant in the - colder waters of the oceans, where they form extensive growths along the coasts. Some of the larger forms, as Fucus and Ascophyllum, are known as rockweeds because they cover the rocks between low and higl tide marks with heavy fringes of brown vegetation (I'late IV). Other forms, known as the kelps, or devil's aprons, grow below or just at low watermark and sometimes form large beds attached to the rocks. These larger types 
can withstand the beating of the heaviest surf because of their firm texture and strong lioldfasts, and some of them grow on the most exposed points and reefs. There are, however, many smaller brown algre, membranous and cord-like forms, and some

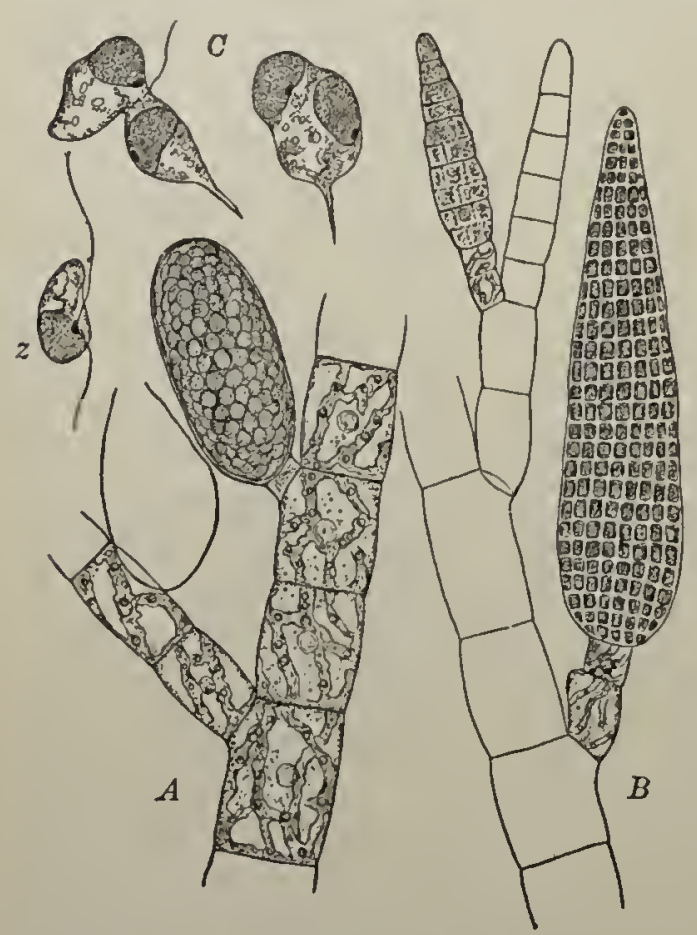

Fig. 193. A filamentous brown alga (Ectocarpus siliculosus)

$A$, unilocular sporaugia, one containing zoöspores, the other empty ; a zoöspore, $z$, shown at the left; $B$, pluriloenlar sporangia, the larger mature, the smaller still showing the outlines of the original cells in the branch from which it arose; $C$, the union of the gametes fo form the zygospore; note that the chromatophores with the pigment spots remain separate. $-C$, after Oltmanns

delicate filamentous types (Ectocarpus) which are as simple as many green algæ and grow generally in rather quiet waters.

We can only illustrate the brown algæ by representatives of three orders, - the Ectocarpus group, the kelps, and the rockweeds.

\section{Ectocarpus.} 'This alga (order Ectocarpales) is a branching filamentous type which forms tufts attaclied to the larger algre, eelgrass, and to the woodwork of wharves. Its chief interest for us lies in the reproductive organs, which are of two sorts, and illustrate. very well the reproductive processes of the lower brown algie. The asexual organs are one-celled sporangia (Fig. 193, A), which develop large numbers of kidney-shaped zoöspores, each with a pair of cilia attached at the side (Fig. 193, $A, z$ ). Because the zoöspores are all developel in a single cell, the sporangia are called unilocular 
sporangia, to distinguish them from the sexual organs, but the structure is clearly the same as that of the one-celled sporangium of the green algæ.

The sexual organs are developed from side branches, most of whose cells divide repeatedly until an immense number of small compartments are formed. The filament thus becomes trausformed into a complicated many-celled organ (Fig. 193, B) made up almost wholly of small cubical cells, each of which develops a single two-ciliate gamete similar to a zoöspore, or, perhaps, two or three of these motile elements. Because the gametes are developed in small compartments, the organ has been termed a plurilocular sporangium. It is clear that this many-celled organ is a very different sort of structure from the one-celled reproductive organs. It marks an important advance in the evolution of reproductive structures in plants and suggests the many-celled sexual organs characteristic of the bryophytes and pteridophytes.

The gametes are known to fuse in pairs (Fig. 193, C), as in many simple green alga, and since they have a similar structure, the sexually formed cell is

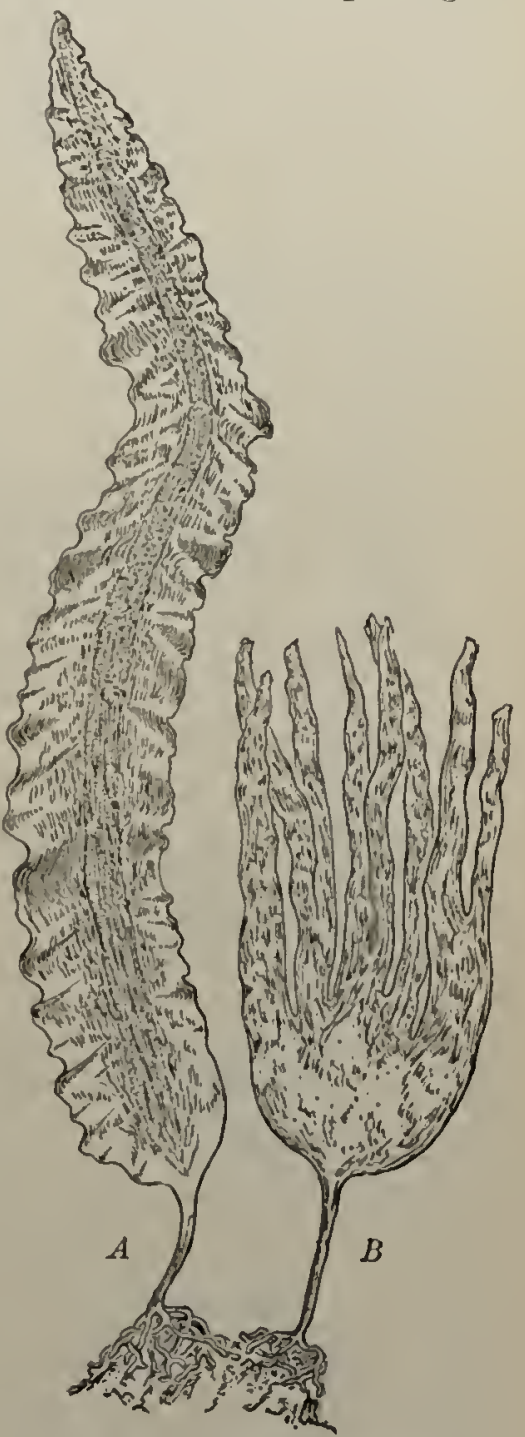

FIG. 194. Kelps from the North Atlantic

$A$, the simple type of Laminaria, some of whose species grow to be thirty or more feet long; $B$, the digitate type (Laminaria digitala), which is never very long, but is broarl at the base 
a zygospore and the sexual eondition is that of isogamy. It is interesting to note that these motile eells sometimes germinate without eonjugation, just like the zoöspores which they resemble, - a faet which shows that sexuality has not becone very firmly established in the simplest of the brown algie and illustrates, as in Ulothric (See. 217), the general conditions which are to be expected with the origin of sex in any group of plants.

236. The kelps. The kelps (order Laminariales), also known as the devil's aprons, are the largest types of the brown algie. Those of the North Atlantic eoast have eomparatively simple

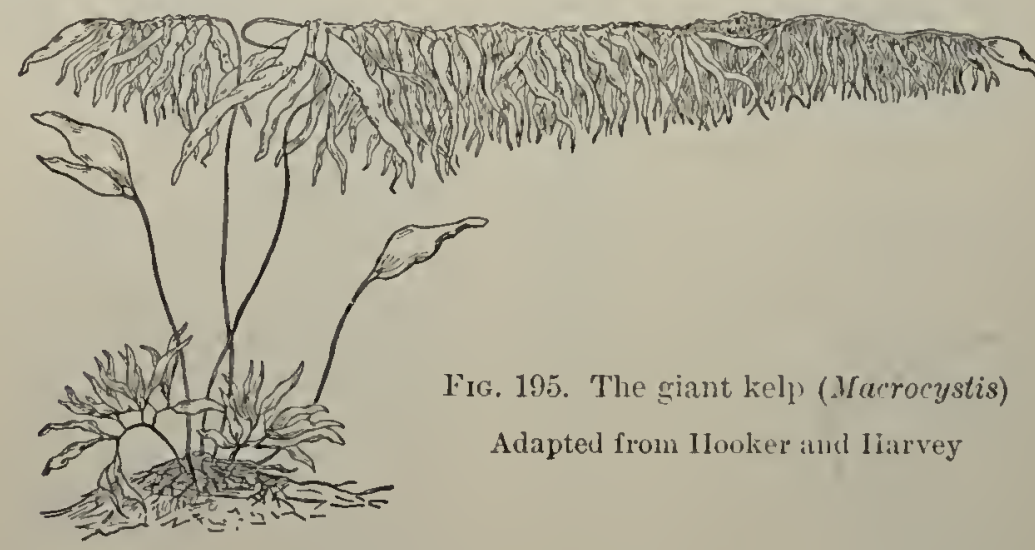

forms (Fig. 194). There is always a stalk (stipe) attaehed to the roeks by a holdfast consisting of a eluster of strong outgrowths, and the stalk bears a long, leaf-like expansion called the blate. The blades of some kelps are divided lengthwise into segments, as in Laminaria digituta (Fig. 194, Is).

Certain kelps of the Pacific coast are much more eomplex, consisting of numerous large, leaf-like blades variously arranged on different forms of stems. Some of the stcins attain great lengths. Thus the giant kelp (Hacrocystis, Jig. 195) is known on the California eoast, where it grows in large beds, to reach a length of one hundred and fifty feet. The sea otter's cabbage (Nereocystis, Fig. 196) frecuently has a stem more than one hundred feet long, which is enlarged above into a 
hollow float that rests on the surface of the water and hears a number of strap-shapel leaves. The sea palm (Iostelsia, Fig. 197) is another remarkable form, with a thick, strong stalk about a foot high, which bears a crown of small leaves and somewhat resembles a palm tree in miniature. Macrocystis and

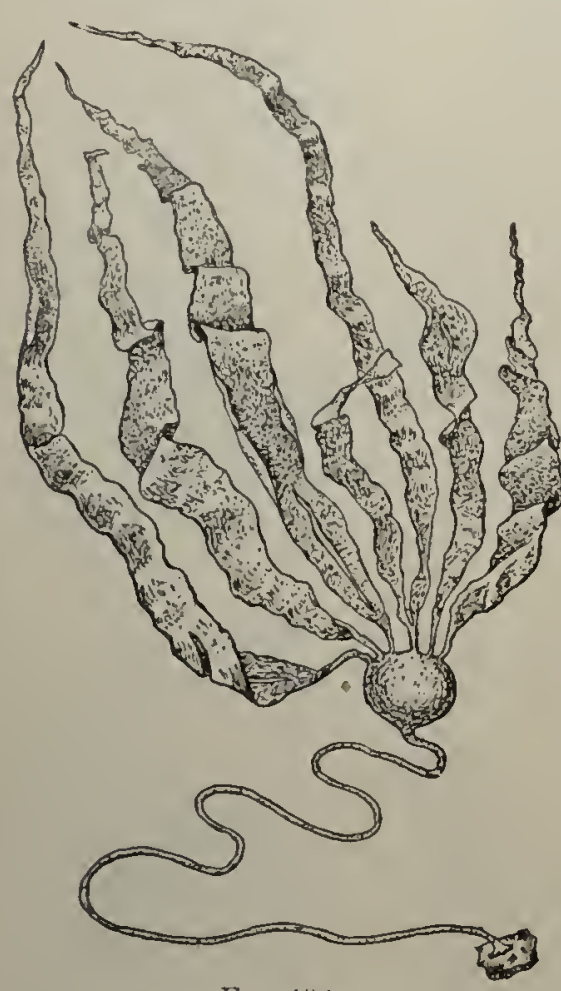

Fig. $19 \mathrm{H}$

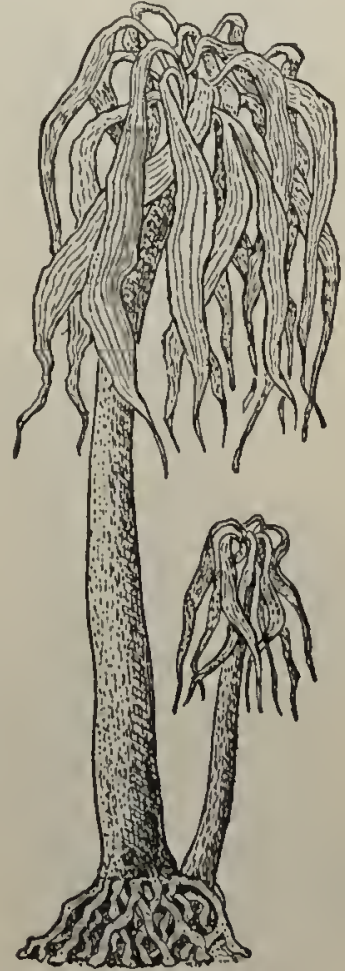

FIG. 197

Fig. 196. 'The sea otter's cabbage (Nereocystis)

Adapted from Postels and Ruprecht

Fix. 197. 'The sea palm (Postelsia)

Nereocystis grow in deep water, but the sea palms are found on the rocks, where the surf breaks so heavily that the tough elastic stems are bent over at right angles by the force of every wave. The kelps reach their most luxuriant development in cooler waters of the globe, as, for example, along coasts bathed by relatively cold ocean currents. 
The kelps reproduce by zoöspores developed in one-cellcd sporangia that arc formed in large patches upon the blades. A conjugation of these zoöspores in pairs has been reported,

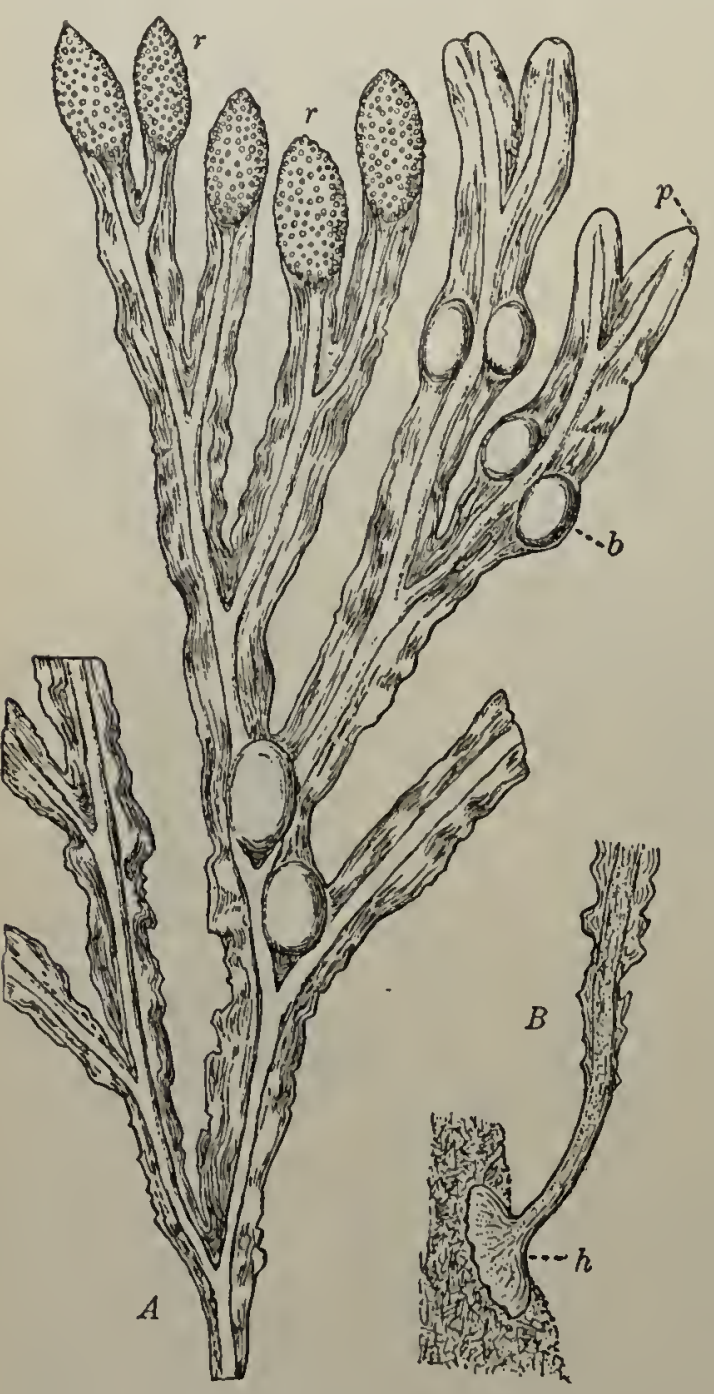

Fis. 198. A rockweed (Fucus vesiculosus)

$A$, habit sketch, showing the forking of the branches ;

$b$, air bladders; $r$, swollen fruiting tips (recentacles), with the sunken cavities (conceptacles) which contain the sexual organs; $r$, pit at a growing point. $B$, base of a plant; $h$, holdfast indicating a method of sexual reproduction.

237. The rockweeds. The rockweeds (order Fucales) are the highest forms of the brown algie, both in vegetative structure and because of the complex sexual conditions (heterogamy), with characteristic eggs and sperms.

The commonest genus is Fucus (Fig. 198), which is very widely distributed in the colder seas and forms the bulk of the algal vegetation between tide marks (Plate IV). The plant body of Fucus forks very regularly (dichotomous branching), and the growth is from a region of cells situated in a pit at the end of each branch (Fig. $198, p)$.

The sexual organs arise from the sides 


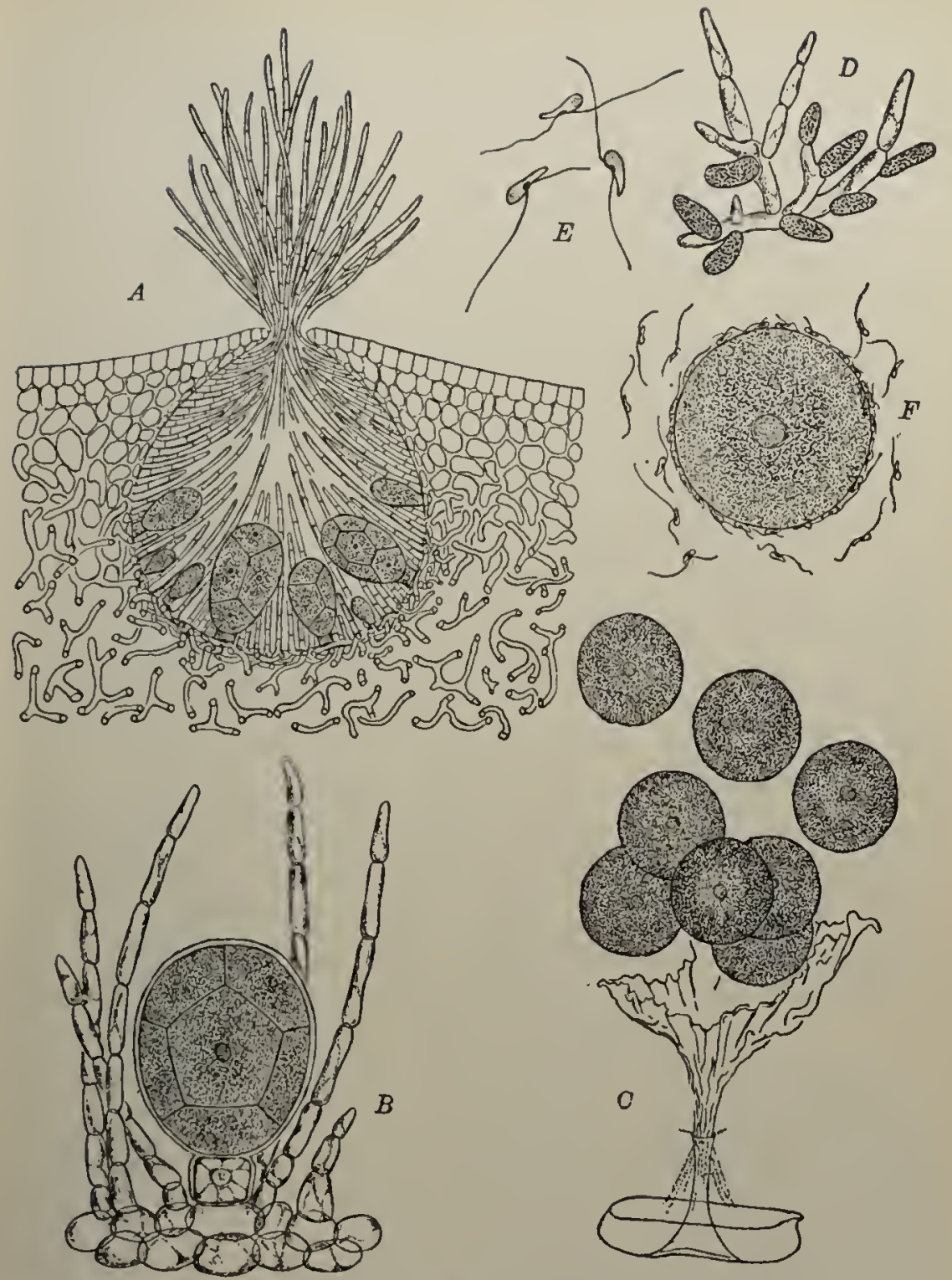

Fic. 199. The sexual organs of a rockweed (Fucus vesiculosus)

$A$, section of a female conceptacle with oügonia, showing the hairs which project throngh the opening of the conceptacle into the water, and the loose network of filaments in the interior of the plant; $B$, inature oïgonium containing eight eggs; $C$, the discharge of the eggs from an oögonimn; $I$ ), a group of antherilia on the branching filaments which grow in tnfts over the sides and bottom of the male conceptacles; $E$, sperms very highly magnified, showing elongatel form and the two cilia at the side; $F$, an egg lying free in the water and surrounded by sperms. $-B, C, D, E, F$, after Thuret 
and bottom of small cavities, called conceptacles (Fig. 199, A), which are developed in swollen tips of older branches termed receptacles (Fig. 198, r). Some species of Fucus (as $F$. cdentatus) have both male and female organs in the same conceptacle, but in other species they are formed in different conceptacles, and even upon different plants, as in $F$. vesiculosus. The fcmale organ is a large cell, or oögonium (Fig. 199, $B, C$ ), which in Fucus develops eight eggs. The male organs, antheridia, are also single cells (Fig. 199, D), but they are gencrally borne in densc clusters upon branching stalks, and each produces more than a hundred

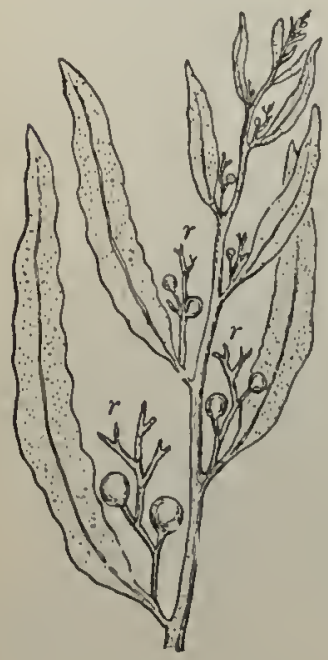

Fig. 200. Sargassum Filipendula

Tipof plant showing leaflike lateral branches, the stalked, berry-like, hollow floats, and the fruting brauches, or receptacles, $r$ very sinall sperms with two cilia at the side (Fig. 199, E). The eggs and sperms are forced out of the conceptacles by the swclling of mucilage that is devcloped within the structure, aided by the contraction of the tissue when the plants are exposed at low tide to the drying action of the air.

The eggs are fertilized in the sca water outside of the conceptacles. The sperms gather around an egg in great numbers (Fig. 199, $F$ ), making it revolve, and finally onc enters. The male nuclcus passes rapidly to the center of the egg and in a few minutes begins to fusc with the female nucleus. The striking differences in size and structure between the large egg and minute sperm make the sexual process of Fucus one of the best illustrations of heterogamy in the plant kingdom. Such fertilized eggs as are fortunate enough to find favorable resting places begin to germinate within twenty-four hours, and develop directly into young Fucus plants.

238. Sargassum. Sargassum (Fig. 200) is onc of the Ficalcs that deserves spccial mention for the complexity of its plant body, which bears three forms of lateral structures: (1) thin. 
leaf-like branches which resemble foliage, (2) berry-like floats, and (3) small reproductive branches, or receptacles (Fig. 200, r). Some species of Sargassum, when torn away from their attachment to rocks, are able to vegetate in the open sea, where they are called gulf wccd, but they are not known to fruit in the free floating condition. Certain ocean currents carry and accumulate immense quantities of this floating gulf weed in great eddies in the ocean, forming the Sargasso seas.

239. Summary of the brown algæ. The Phecophycew stand entirely apart from the green alge as a side line of plant evolution. There is much evidence that it is a group of very ancient origin, probably arising from an ancestry of motile organisms (somewhat like the flagellates) just as did the green alge in early geological ages. The brown algæ have developed in their own peculiar ways the largest and most complex forms of plant bodies in the thallophytes, and also some very high types of sexual reproduction. It is clear, however, that these have no relation to higher plants, bryophytes and pteridophytes, and are also entirely independent of other groups of algæ. Thus heterogamy in the brown alga has bcen developed entirely independently of heterogamy in the green alga, illustrating very well how similar results may be worked out through different evolutionary lines independently of one another.

\section{CIASS IV. THE RED ALGE, OR RHODOPIIYCEXE}

240. The red algæ.* The Rhodophycece include the most bcautiful of the marine alga, for many of the forms are exquisitely colored in clcar shades of red, and are extremcly delicate in structure. Other forms are brownish red or purplish, and ecrtain ty'pes are greenish. The pigment is held in chromatophores,

* To tur Isstrictor: In a hrief course where only one type can be studied in the laboratory, Nemalion or Batrachospermum is preferable, followed by a study of the life habits of the group and demonstrations of herbarium material. 
and performs the photosynthetie work of the plant. Although the red algx can generally be distinguished by their color, the fundamental charaeters of the group are based on the strueture of the sexual organs and eertain eomplieations in the life histories which will be explained in the aecounts of Vemalion and Polysiphonia. The plant body of the red algre

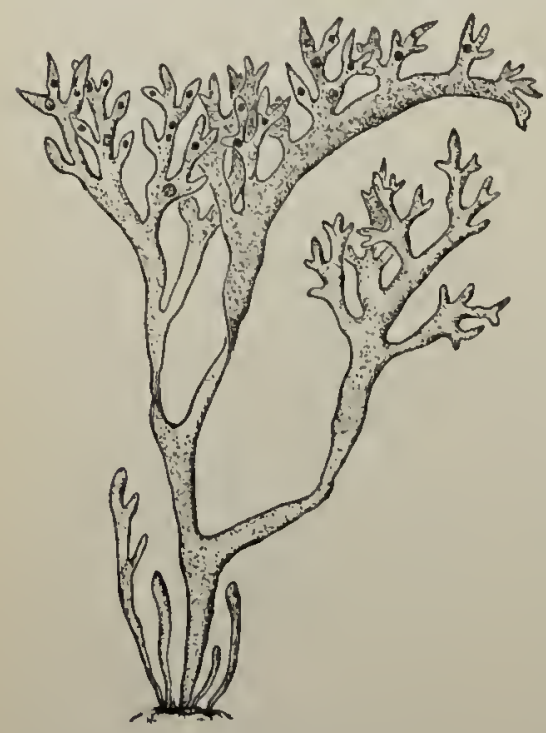

FIG. 201. The Irish moss (Chondrus crispus)

About one half natural size; the shaded spots are sexually formed fruits, or cystocarps ranges from filamentous types of great delieaey (as Callithamnion) to such coarse forms as the Irish moss (Chondrus) and the dulse (Rhodymenia). It is a remarkable faet that tìe large types are really ecri $\mathrm{r}_{\mathrm{r}}$ osed of complieated systems of filaments so closely assoeiated, liowever, as to give the appearanee of a eell tissue. Adjaeent eells in the same filament are usually conneeted by strands of protoplasm, a striking feature of the group. Some of the red algre, as the Irish moss and the dulse, are eaten, and a number of them are used as relishes by the natives of the Hawaiian Islands, China, and Japan. Certain forms have an eeonomie value for gelatin, whieh is obtained from their tissues; thus agar-agar eomes from the stems of a red alga (Gracilaria) whieh grows in the seas of the Orient.

241. Life habits. The life habits of the red alga are in striking eontrast to those of the brown. They prefer warmer waters, and the best displays are on suel eoasts as the Mediterranean, the islands of the West Indies, southern California, and Australia. They generally flourish in deeper waters than the green and brown algre, and form the greater part of the seaweed growth 
below the fringe of green and brown which is frequently quite conspicuous on rocks near low-water mark. Some of the forms are found at depths of two hundred feet or more, the depth limit varying with the clearness of the water. Most of the red alga seem to prefer shaded situations among the rocks, and it is probable that their characteristic color is associated with these
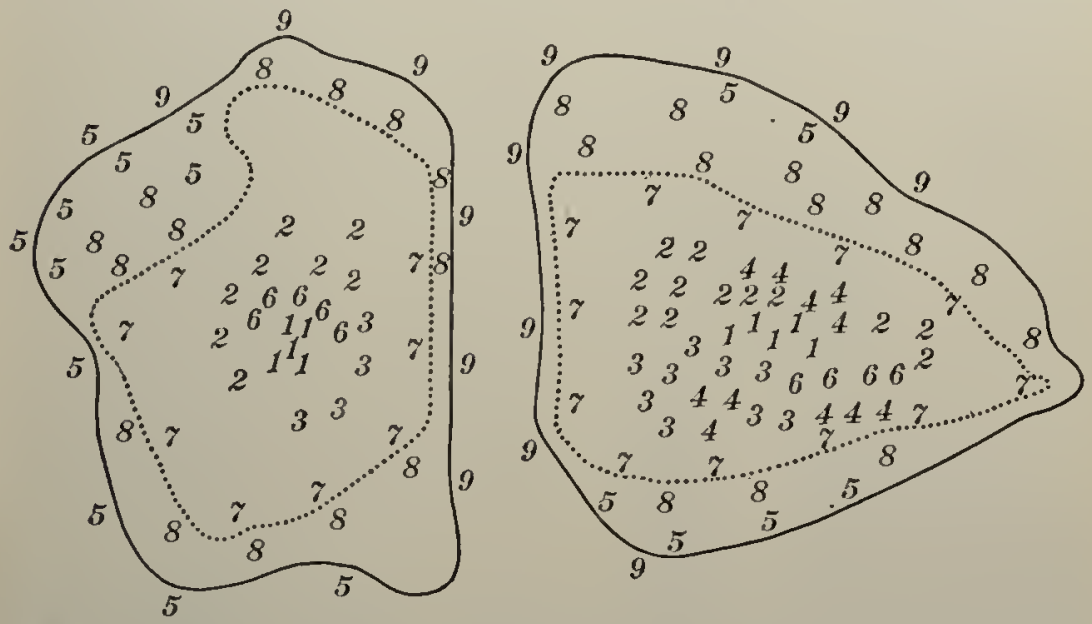

Fig. 202. The distribution of conspicuous algre on two rocks of Spindle Ledge, Woods Hole, Massachusetts, in September, 1905

The dotted line is low-water mark, and the rocks are completely eovered at higl tide. Blue-green alga: 1, Calothrix scopularum, on the highest part of the roek. Green alga: 2, Ulva lactuca var. rigida (sea lettuec); 3 , Enteromorpha prolifera (sea lettuee); both forms grow well above low-water mark. Brown alga: 4, Kucusvesiculosus (roekweed), in patehes, but not plentiful in the summer; 5, Chordaria flagelliformis (shoestrings), heavy growths, well below low-water mark. Red algx: 6, Nemalion multifidum, on the higher parts of the roek; 7, C'eramium rubrum, a well-marked fringe at low-water mark; 8, Polysiphonia violacea, a well-marked fringe just lolow low-water mark; 9, Chondrus crispus (Irish moss), large patehes from one to three feet below low-water mark

peculiar subdued light relations, so different from those of other algæ. Some types are incrusted with lime and form the curious growths on locks called corcllines.

242. The distribution of algæ on rocks. Many seaweeds are only found in certain situations upon rocks, where they grow in patches and fringes, and frequently exhibit a sort of zonation somewhat similar to the distribution of plant life around the 
margins of ponds and lakes. Fig. 202 presents a diagram of such distribution on two isolated rocks. It will be seen that there is a clear zone of a red alga (Polysiphonic ) just below low-water mark, another zone (Ceramium) at or a little above this mark, while the Irish moss grows at some depth. The sea lettuces and rockweed are well above low-water mark, as is also Nemalion, which is exceptional in its habits for a red alga. On the northerly New England coast and beyond there are usually two distinct zones on the rocks, - one well above low-water mark, composed chiefly of rockweeds, and the other near this point, but below, and made up mostly of Irish moss with other red algæ, including the dulse.

243. Nemalion. Nemation illustrates excellently the structure of the sexual organs and the sexually formed fructification of the red algæ, called the cystocarp (meaning a fruit cavity). The plant body is a rather soft, cord-like, branching structure, composed of an immense number of filanents held together by a stiff gelatinous substance around the cells. There is a central axis of delicate threads, while the outer regions consist of short filaments pointing outward. The cells of the outer filaments contain each a single chromatophore, and the vegetative actirities (photosynthesis) as well as the reproductive take plaee in this region of the plant.

The male organs, or antheridia, consist of clusters of small cells at the surface of the plant (Fig. 203, A), each of which develops a single sperm, spherical in form and without eitia, and consequently nonmotilc. The female organ (Fig. 203, B') is rleveloped at the end of a short branch and consists of a cell which bears a long, hair-like extension called the trichogyne (meaning female hair), which is the receptive organ for the sperms. The sperms are applied to the trichogynes largely by the contact of male plants with the female as they are washed about by the movements of the water. When a sperm fuses with the trichogyne its nucleus (male) passes down into the swollen base of the female cell and unites there with a female nucleus. The 
trichogyne then withers above the fertilized female cell. The female cell is called the carpogonium, but it corresponds exactly to an oügonium, and indeed resembles very closely the oögonium of some species of Colcochate (Sec. 222). Its peculiar form, with a receptive organ, the trichogyne, is undoubtedly associated with the nonmotile habits of the sperms. The red algxe are clearly heterogamous in their methods of sexual reproduction.

The female coll, or carpogonium, after fertilization, gives risc to a dense cluster of short filaments, called fertile filaments, which all together form a globular fructification called the cystocarp (Fig. 203, D). The terminal cells of the fertile filaments become spores, termed curpospores, which develop new Nemalion plants. The cystocarp is clearly a ncw type of fructification in the algre. It is a structure which begins with the fertilization of the carpogonium and cnds with the formation of carpospores, and thus stands as a phase in the life history inserted between two generations of the sexual plants.

244. B a t a c hos perm u m. Batrachospermum is one of the few fresh-water forms of the red alga, and is also an exceptional type for its color, which is

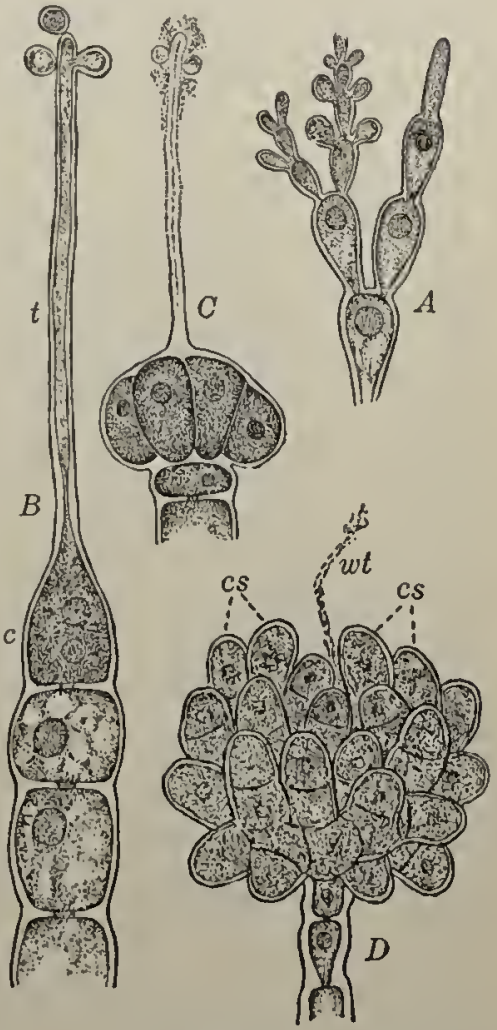

Fic. 203. Nemalion multifidum

$A$, antheridia, consisting of groups of small cells, each of which develops a single sperm; the vegetative branch at the right illustrates the method of terminal growtl and the protoplasmie eonneetions between the eells. $l ;$, the female cell, or carpogonium, $c$, with its trichogyne, $t$, to which are attaehed three sperms. $C$, early stage in the development of the cystoearp; the triclogyne above lias begun to witler. $D$, mature eystoearp eomposed of fertile filaments which levelop the carpospores cs terminally; $w t$, withered trichogyne 
generally some shade of green. The sexual organs and cystocarps are enough like those of Nemalion to make il as good a form to illustrate the sexual processes and life listory of the red algæ as the latter type, and it is sometimes more available for inland classes. Batrachospermum grows in clear brooks and is generally found in its best condition in late winter and early spring.

245. Polysiphonia. Polysiphonia illustrates some further complexities in the life history of the red algre which are not present in Nemalion and Batrachospermum. The filaments of these beautiful plants consist of rows of cells, called siphons, connected with one another in an elaborate manner. There is a central siphon, around which are arranged a circle of outer siphons variable in number for different species.

The sexual organs are found on separate plants. The male organs, antheridia, are modified branches (Fig. 204, A) that develop an outer covering of small cells which form the sperms (Fig. 204, B). The female organ is found on a small branch (Fig. 204,C) and consists of a carpogonium, with its trichogyue, accompanied by a number of vegetative cells which later take part in the development of the cystocarp. The fusion of a sperm with the trichogyne fertilizes the carpogonium as in Nemalion. There are two sets of activities concerned with the development of the cystocarp: (1) there are some remarkable cell unions between the fertilized carpogonium and neighboring cells (auxiliary cells) for nutritive purposes, and then the development of carpospores from the large fusion cell which is formed; (2) accompanying this activity there is the development of an urnshaped envelope (Fig. 204,D), from some of the vegetative cells around the carpogonium, and this is clearly a protective structure to contain the carpospores. The first set of activities corresponds to the development of the simple cystocarp of Nemalion. The second set forms the additional urn-shaped protective case. The cystocarp of Polysiphonia is therefole a system of two tissues, one derived from the fertilized carpogonium, and the other from the vegetative cells of the parent plant. 
Besides the sexual plants (male and female) there is an asexual condition in Polysiphonia called the tetrasporic plant. Tetrasporic plants are individuals which develop asexual spores, called tetraspores because they are formed in groups of four, termed tetrads, in mother cells (Fig. 204, $L, F$ ). The tetraspore mother cells arise from the central siphon near the ends of the branches.
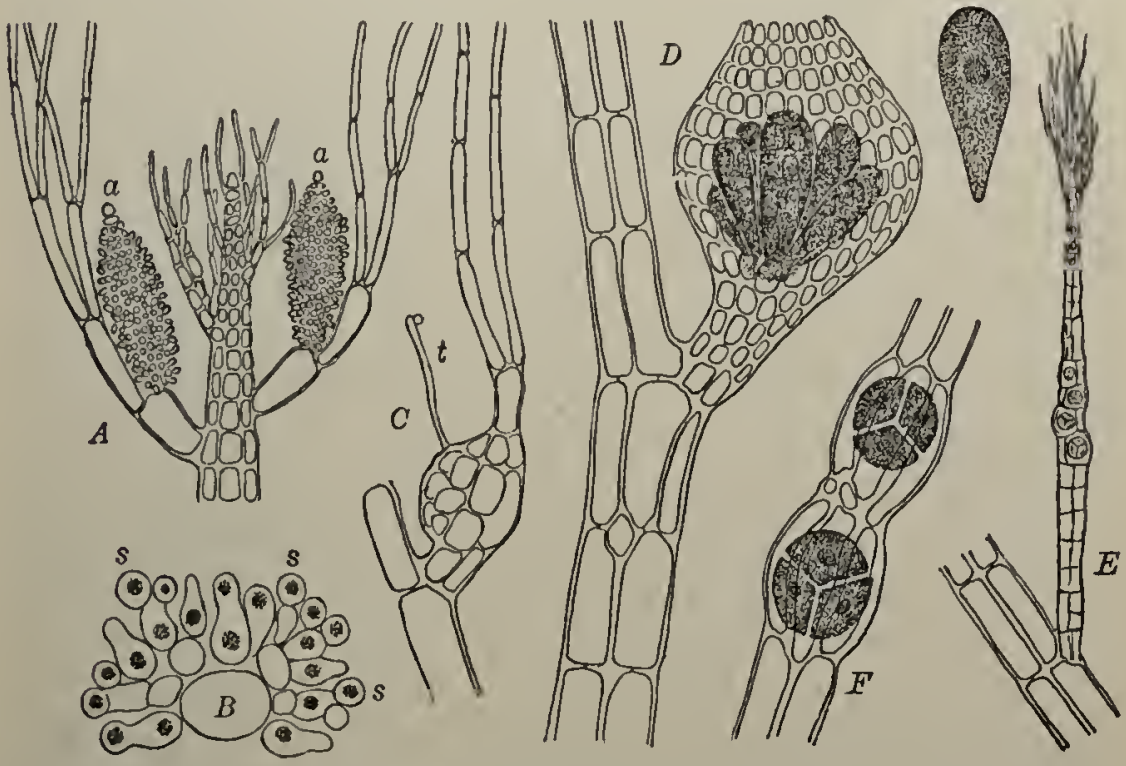

FIs. 204. Polysiphonia violacea

$A$, tip of filament slowing two antheridia, $a ; B$, cross section of a portion of an antheridium illustrating the development of the sperms at the ends of the very numerous short branelies; $C$, a procarp with the projecting trieliogyne $t$, from the female cell (carpogonium), whieh is hidden by the surrounding sterile eells; $D$, mature cystomarp with the urn-shaped envelope inelosing the eluster of curpospores, a single spore slown at the right; $E$, a short luranch from a tetrasporic plant; $F$, two groups of tetraspores from a branel similar to $E$; note the peculiar arrangement of the tetraspores in a group of four, or tetrad

It has been shown experimentally in cultures of certain of the red algie (including l'olysiphonia) that tetrasporic plants are developed from carpospores and that the tetraspores give rise to sexual plants. So there is an alternation of sexual and tetrasporic plants in the life history of Polysiphonia. 
246. Summary of the red algæ. It is quite eertain that the red algæ have had their origin from a very much higher level than the green or brown algie because of the eomplicated sexual organs and life histories and the absence of motile stages represented by the zoöspores and motile gametes of those groups. The red algie resemble Coleochcete (Sec. 222) in a number of features, and it is possible that this type may be rather close to the starting point of the group. The peculiar structure of the fcmale sexual organ (carpogonium), which is really an oögonium with a receptive organ (trichogyne), is undoubtedly associated with the loss of motility on the part of the sperms. But the most remarkable peculiarity is the development from the fertilized carpogonium of a tissue which produces carpospores. This structure (from the fertilized carpogonium to the carpospores) is a new plase in the life history of algre, and together with protective envelopes, when present, constitutes the cystocarp.

As has been noted, the asexual tetrasporic plants found in most species of the red alge arise from the carpospores, and the sexual plants in these types are developed from the tetraspores. The structure developing from the fertilized carpogonium and ending with the carpospore, together with the tetrasporie plant, when present, therefore forms an asexual phase in the life history, alternating with the sexual plants. Such asexual phases are ealled sporophytes (meaning spore-bearing plants), to distinguish them from the sexual plants, called gametophytes (meaning gamete-bearing plants), and their following one after another in a life history constitutes an alternation of generations. Such an altcrnation of generations is found in very few groups of the thallophytes, but it is characteristic of the life histories of all higher groups begiming with the liverworts and mosses (Sec. 285). Its significance is discussed in Chapter XXvI. 


\section{CHAPTER XXI}

\section{SUMMARY OF THE LIFE HISTORIES AND EVOLUTION OF THE ALGE}

247. The life histories of the algæ. The life history of a plant is the succession of stages leading from one generation to another and of eourse includes the reproductive periods. Reproduction may be as simple a process as the breaking off of portions from the parent plant, called vegetative reproduction. Almost all groups of plants have developed some forms of vegetative reproduction. The detached portions may be merely fragments, as in Oseillatoria (See. 209), or much more complicated, as certain bud-like struetures in some of the brown and red algæ. Methods of vegetative reproduction give very simple life histories, which are merely a succession of similar forms such as may be represented by the formula

$$
P-P-P-P \text {, etc., }
$$

$P$ standing for the plant type.

The commonest methods of reproduction in the algæ are through the special cells called spores, which may be asexual in character or formed sexually. The commonest form of spore reproduction in the algæ is through the zoöspore. When there is no sexual process in the life history, but some method of asexual spore reproduetion, the formula of the life history becomes

$$
P-\operatorname{asex.} s_{.}-P-\operatorname{asex.} s .-P, \text { etc., }
$$

asex. s. standing for asexual spore.

The development of sex in a plant eomplicates at onee the life history. Gametes are formed, which unite to give sexually formed cells or spores. These spores may develop directly into plants like the parents, as in Spharella and Volvox, Spirogyra, 
Vaueheria, Chara, and Fucus, or they may form zoöspores, which swim off and grow at once into plants like the parents, as in Edogonium, Ulothrix, and Coleochetc, the latter type developing the zoöspores somewhat indirectly through a group of cells. But in all these forms the essentials of the life history are expressed by the formula

$$
P<{ }_{g}^{g}>\operatorname{sex} . \text { s. }-P<{ }_{g}^{g}>\operatorname{scx} . \text { s. }-P \text {, etc., }
$$

$y$ and sex. s. standing for gamete and sexually formed spore, respectively.

It must always be remembered that the algxe with sexual methods of reproduction frequently have also asexual zoöspores or other forms of asexual reproduction, which may produce a number of successive generations between the development of sexual plants. This happens very frequently among the green algre (as in Ulothrix, Edogonium, Coleochate, and Vaucheria) and in the lower brown algie (as Eetoearpus). The life history formula of the sexual algæ may then be variously broken by the introduction of successive generations developed asexually.

In the red algie the sexually formed cell corresponding to an oöspore does not give rise at once to a generation like the parent plant, but an asexual generation is inserted between successive sexual plants, alternating with them. This asexual phase may be represented only by the tissue which produces the carpospores, as in Nemulion, or it may be represented by this structure plus a tetrasporic plant, as in Polysiphonia. There is, then, in the red alga an alternation of generations, an asexual pliase, or sporophyte, alternating with the sexual plant, or gametophyte. This is the most complex type of life history in the algie and may be expressed by the formula

$$
\begin{aligned}
& G<\begin{array}{l}
g \\
g
\end{array}-S\left(\begin{array}{l}
\text { cystocarp and } \\
\text { tetrasporic plant, } \\
\text { when present }
\end{array}\right)-a s c x . s \cdot\left(\begin{array}{l}
\text { carpospore and } \\
\text { tetraspore, } \\
\text { when present }
\end{array}\right) \\
& -G<_{g}^{g}>-S-\operatorname{asex.s.}-G \text {, etc.. }
\end{aligned}
$$


$G$ and $S$ standing for the gametophyte and sporophyte generations, respectively. It will appear later that the higher plants have essentially the same life history formula as this.

248. The evolution of sex. The account of the algæ has given material for a brief discussion of the origin and evolution of sex. It has been shown that the simplest forms of sexual cells, or gametes, have essentially the same structure and origin as the zoöspores. These conditions are illustrated by Spharella, Ulothrix, Ulva, and Cladophora. The difference between the gamete and zoöspore is chiefly one of size. The gametes are smaller because they are generally formed more numerously in their mother cells. Gametes sometimes are able to germinate like zoöspores, but such gametes are apt to develop small and weak plants, and as a rule they must fuse with one another in pairs in order to live. It seems clear that sex arose with the development of a type of zoöspore smaller and apparently weaker in its power of vegetative growth than the normal zoöspore. These smaller zoöspores formed the labit of fusing in pairs, and this habit, finally becoming fixed in the plant's life history, developed into a method of sexual reproduction.

After the establishment of sex in a group of plants, further developments will tend to modify the form of the gametes, the process finally ending in their differentiation into eggs and

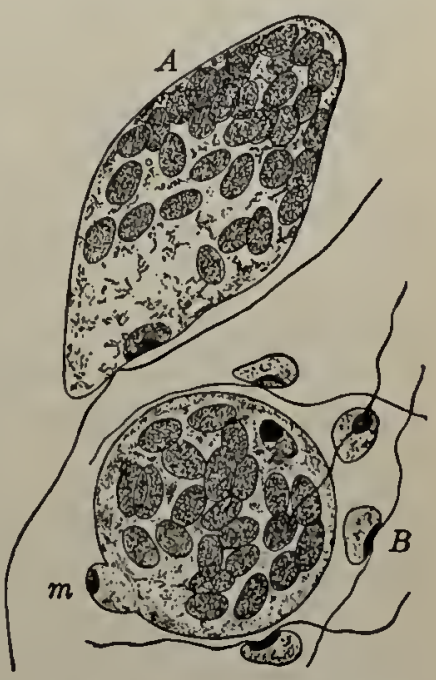

Fig. 205. Cutleria multifida

$A$, the large female gamete; $B$, the same at rest and surrounded by small male gametes, one of which, $m$, is shown in the act of fusion sperms. The simplest gametes are so similar in form and size that they cannot be distinguished as male and female, but a number of algæe have gametes which are different in size, although similar in structure, or morpliology. This condition 


\section{$22 t$ LIFE HISTORIES AND EVOLUTION OF THE ALGA}

has been noted in species of Chlamydomonas (Fig. 177), and some other green algæ (as the siphon alga Bryopsis) sliow it, while among the brown algie certain species of Eetocarpus and Cutleria (Fig. 205) furnish especially good illustrations. The larger gamete is female and often has a relatively short motile period, being fertilized when at rest by the smaller male gamete, thus rescmbling an egg (Fig. 205, B). These are transitional conditions leading towards the highest types of gametes, - the egror and sperm. The term isogamy (similar gametes) is applied to sexual conditions when the gametes are similar in form,that is, have the same strueture, or morphology, even though they may be very different in size. The sexually formed cell is called a zygospore.

Heterogamy (dissimilar gametes) is the sexual condition in which the gametes are unlike in form, - that is, have a different strueture, or morphology, one being the larger nonmotile egg, and the other the small, specialized, motile sperm. The sexually formed cell is called an oöspore, or the egg is said to be fertilized after the union with the sperm. Several eggs may be formed in the mother cell, or oögonium, as in Fueus, but they are generally developed singly. This latter condition is the result of evolutionary processes by which all of the protoplasm and nutritive material in the oögonium is preserved for a singlc egg, thus giving it all the energy and power of growth possible. The sperms, on the contrary, are frequently devcloped in very grcat numbers in their parent cells, and are consequently sinall, and must die quickly if they are unable to fertilize cggs.

It is very important to note that the principles affecting the evolution of sex are always at work and have undoubtedly operated separately in various groups of plants. Thus heterogamy has developed independently in the lines of the green algre, ending in Volvox, Eclogonium, Coleoehote, Vaueheria, and Chara, and in the rockweeds (Fucales) as wcll. Heterogamy is the highest point of sexual evolution, but plants above the thallophytes sliow some important advances in their methods 
of protecting the egg. It will appear later that the eggs of liverworts, mosses, aud ferns are retained in special, protective, cellular structures called archegonia, which are the femalo-reproduetive organs. The presence of this organ is one of the important cliaracters of these groups (bryophytes and pteridophytes), and its absence is one of the peculiarities of the thallophytes.

249. The evolution of the algæ. The evolution of the algæe is the result of many factors which affect their life habits and life histories. Sexual processes have been the chief factors modifying life histories, for they are always a stimulus to development, and have been the starting points for some of the most important complications in the life histories and developments of groups. The most conspicuous illustration of this principle appears in the red algæe, where an asexual generation follows the sexual process, and similar conditions are present in a peculiar group of the brown alga represented-by Dictyota.

One of the most clearly marked evolutionary principles illustrated in the algx is the tendency to establish fixed or attached forms and to limit the motile stages in the life history to the reproductive cells (zoöspores or gametes). Some of the lower algæ are motile throughout almost all of their life histories, as in the Volvocacece (Sec. 215) and that group of uncertain relationships, the flagellates (Sec. 204). But the motile stages become merely reproductive phases in the higher forms. Thus the appearance of zoöspores and motile gametes in the life histories of higher types of algæ is believed to represent a return for a short time to the motile conditions and habits of their ancestors.

The establishment of attached plant bodies opened immense possibilities of plant development, and resulted at once in a great variety of structures. The first of these were simple forms of thalli, such as filaments, membranes, and plates of cells. But later the plant structures became more complex, developing holdfasts and stems, which bore leaf-like lateral structures, evidently differentiated to give a large exposure to sunlight, and for the work of photosyuthesis. Thus types of plant bodies 
arose which were more complex than the thallus, since they showed three regions, — stems, leaf-like blades, and holdfasts. It will be seen later that stems, blades, and holdfasts of the highest algæ do not correspond to the stems, leaves, and roots of fern and seed plant, which developed very much later through a complicated history. But this differentiation of the plant body in the thallophytes is, at least, a response to the same sort of influences as guided the development of the higher plants. These influences were in part the evident advantages to a plant of being fastened to a suitable attachment, from which it can grow and present as much surface as possible to the sunlight.

In conclusion, one should think of the algx as comprising a large number of divergent lines, whose relationships are sometimes so distant that one cannot make even a good guess as to the evolutionary history. The stoneworts (Charalcs) constitute perhaps the best illustration of such an isolated group. Very few of the algx now living are near the theoretical main line of ascent to the liverworts and mosses. The algre should be thought of as spreading out in many directions, each group developing in its own particular line of evolution, adjusting itself as best it may to its particular sort of life. Some possible relationships have been suggested in the accounts of the various groups, but the subject is too complex to be given detailed consideration here. 


\section{CHAPTER XXII}

\section{THE FUNGI AND THEIR RELATION TO FERMENTATION AND DISEASE}

250. The fungi.* The fungi are thallophytes whose plant bodies have no chlorophyll or other coloring matter capable of doing the work of photosynthesis. Consequently fungi are unable to manufacture the primary foods of plants, such as starch, and are absolutely dependent upon organic substances obtained from animals and plants. Fungi must therefore live either as parasites upon living plants or animals, called their hosts, or as saprophytes (meaning decay plants) upon dead organic matter or the products of decay. Fungi are frequently spoken of as colorless plants, because they have no chlorophyll, but many forms are brilliantly colored by special pigments.

The fungi have undoubtedly been derived from the algæ, not from a single group of the algæ, however, but from several widely separated groups. Consequently the classes of the fungi have not developed one from another, but in most cases are believed to be either of entirely independent origin or of very rcmote relationship through ancient forms of algæ no longer living. The chief peculiarities of the structures and life histories of fungi are largely the results of their adaptations to lives of parasitism or saprophytism. One of the results of these adaptations has bcen the development of a much greater number of species than is found in the algæ.

* To the Instructor : $\Delta$ s in the account of the algre, this chapter describes more forms than should be given in a general course. Many of them must be omitted or merely discussed in the class. 'They have been included in order to provide a range of material for selection adaptable to various sections of the country and the different conditions under which the subject must be presented. 
We shall consider five classes in the series of the fungi among the thallophytes (see Outline of Classification, p. 155).

Class V. The bacteria, or Schizomyceles.

Class VI. The yeasts, or Saccharomyceles.

Class VII. The alga-like fungi, or Phycomycetes.

Class VIII. The sac fungi, or Ascomyceles.

Class IX. The basidia fungi, or Basidiomyceles.

\section{CLASS V. THE BACTERIA, OR SCHIZOMYYCETES}

251. The bacteria. The bacteria are the smallest living beings known. The single cells of many species are less than one ten thousandth of an inch in diameter, and some are very much smaller still. Most of the bacteria are one-celled. Some types are spherical or oval, somc are straight or slightly bent rods, and some are spirally twisted forms of various lengths (Fig. 206). Certain species are provided with numerous cilia and are actively motile. The cells may be loosely joined together in chains or collected in jelly-like masses or colonies, which are sometimes brightly colored, yellow, red, blue, or grcen. Some of the bacteria are filamentous and made up of rows of cclls. The cells are very simple in structure, since they do not have a clearly defined nucleus, and in this important respect they resemble the blue-green algæ, from which they arc believed to have been derived (Sec. 211).

The cells of the bacteria multiply by simply splitting apart, which gives them their name of Schizomyeetes, or fission fungi. Thesc cell divisions, under favorable conditions, take place in some forms as frequently as once evcry half hour, and the desccndants from a single individual nay number many millions in a few days. The bacteria are only limited in thcir remarkable powers of multiplication by lack of food or other unfavorable conditions. Many bacteria have the power of developing thickwalled resting cells, or spores, within the parent cell, which can survive a temperaturc above the boiling point of water and also 


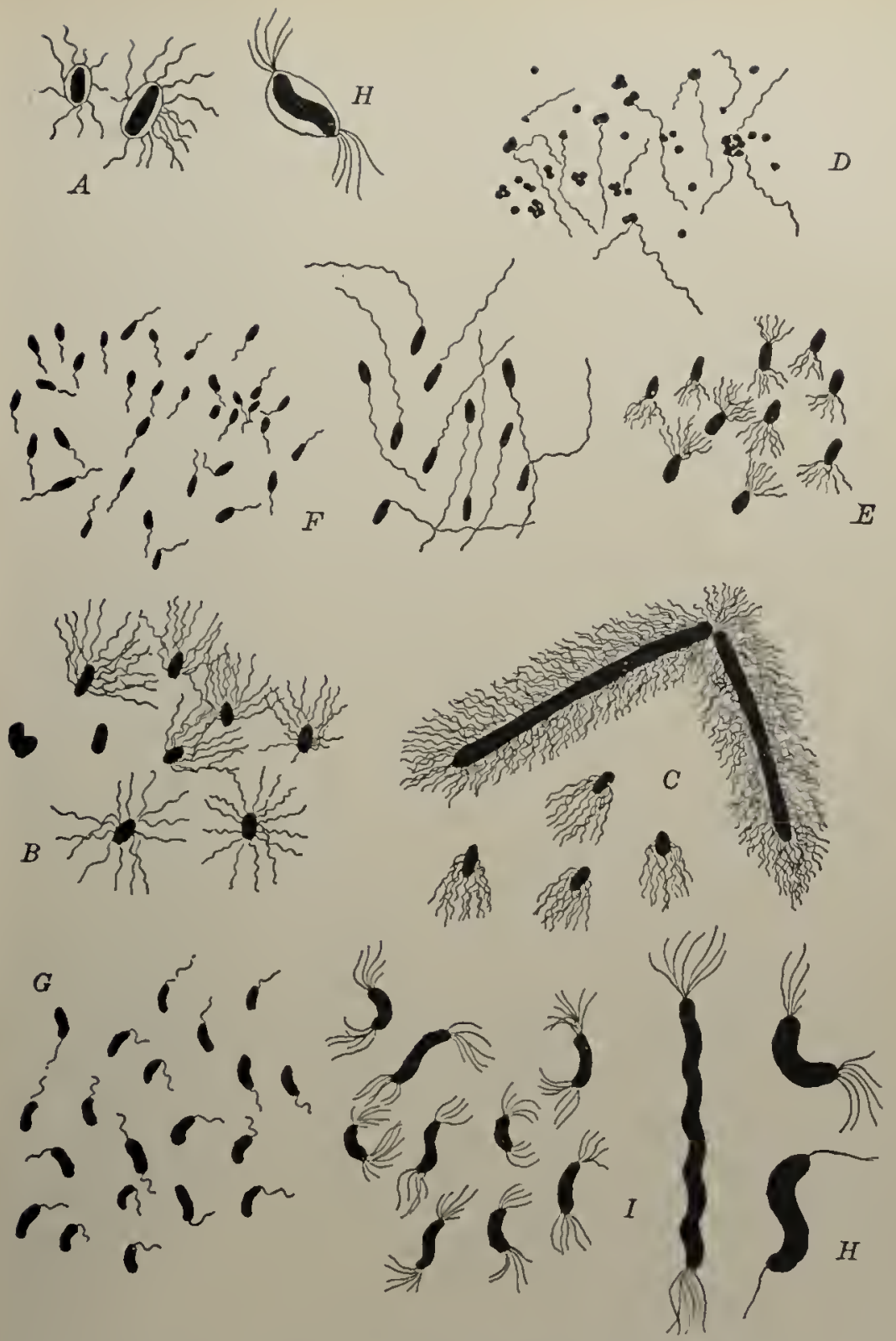

Frc. 206. Groups of bacteria stained to show their cilia

A, Bacillus subtilis, an organison of decay characteristic of hay infusions; $B$, Bacillus typhi, the germ of typhoid fever; C; Jacillus vulgaris, single eells and filaments; $n$, Planococcus eitreus, which forms yellow (onlonies on various substrata; E, I'seudomonas syncyanea, which turis milk blue; $F$, other species of Pseudomonas; $G$, Mierospira eomma, the germ of Asiatic eholera; II, Spirillum undula, in water eontaining deeaying fish, algæ, etc.; $I$, another speeies of Spirillum. - After Migula 
below freezing, and are able to live for very long periods. But other forms, as the Bacillus of typhoid fever (Fig. 206, B), may be certainly killed within a few minutes by boiling the water in which they live. Certain bacteria, as the species which produce lockjaw and cause butter to become rancid, will live without air, and are even injured by contact with free oxygen. They obtain the oxygen necessary for respiration from compounds, such as the carbohydrates, which contain it.

The bacteria are present almost everywhere, floating in the air on particles of dust, in the water, in the soil, and always living within and upon the bodies of animals. Thus the bactelia are ready to grow and multiply wherever they find favorable conditions, but these are exceedingly various for the different species. Some forms are restricted to a parasitic life on particular hosts, as certain animals or plants, or man. Other types are connected with special chemical reactions, as in the processes of decay, fermentation, nitrification, etc. Many bacteria are indispensable to life on the earth, and of the greatest service to man. Many forms are harmless, but of no special value to man. Some cause dangerous contagious diseases.

252. Decay. Decay is the destruction or decomposition of highly complex organic compounds, such as the proteids, fats, sugars, and cell walls of plants, by which they are broken down into successively simpler substances, and finally into fluids and gases, some of which are very ill smelling. The products of decomposition form various chemical combinations, and are finally used again in the constructive processes of life. The bacteria and other fungi are the chief agents of decay, and if it were not for them the world would soon be filled with organic waste products, together with the dead bodies of animals and plants of no value as food. Thus all the chemical elements capable of sustaining life would long ago have been used up and life on the earth would have ceased. The bacteria are therefore chiefly responsible for a circulation of elements (see diagram, Fig. 207), from the highly complex organic compounds of 
animals and plants back to the simpler substances from which green plants manufacture their food and build up protoplasin.

Food may be kept indefinitely when under conditions that hinder the growth of bacteria, as in cold storage. The exclusion of all bacteria from hermetically sealed tinned foods, in which all germs have been previously killed by heat, is the chief principle in the success of the canning industry. The agreeable flavors of high-grade butter and certain cheeses, as well as the gamy taste of meat, are largely due to bacteria, and really indicate the first stages in the process of decay, although usually not at all harmful or distasteful. Not infrequently, however, incipient putrefaction forms certain organic poisons, called ptomaines, in nitrogenous foods, and these may give rise to distressing symptoms, or even prove fatal to the consumer.

253. Fermentation. Decay may take place in two very different classes of substances: (1) the carbohydrates, such as cellulose, starch, sugar, etc., and (2) the proteids or nitrogenous substances that make up protoplasm, flesh, and many food products. The breaking down of the carbolydrates is called fermentation, and many othcr fungi besides the bacteria arc concerned with the process. Yeasts, for example, are the most important organisms in the fermentation of sugar, and the decay of cell walls in timber is chiefly due to some of the higher fungi.

The best-known types of fermentation are the alcoholic and the acid. Alcoholic fermentation involres the change of sugars to alcohols, accompanied by the formation of large quantities of carbon dioxide, and will be considercd more espccially in the account of the ycasts. Acid fermentation is the transformation of sugars and alcohols into organic acids, and bacteria play the most important part in this process. Thus the change of cider to vinegar is one of sugars and alcohols into acetic acid, and the souring of milk is the formation of lactic acid from milk sugar. Botl processes are caused by bacteria. There arc a number of stages in the processes of fermentation. For example, cellulose is first changed into some kind of sugar, and this 
later into alcohols and organic acids. The last stages result in the formation of the gas carbon dioxide $\left(\mathrm{CO}_{2}\right)$ and sometimes marsh gas $\left(\mathrm{CH}_{4}\right)$, which, when mixed with hydrogen phosphide, becomes the "will-o'-the-wisp" of swamps.

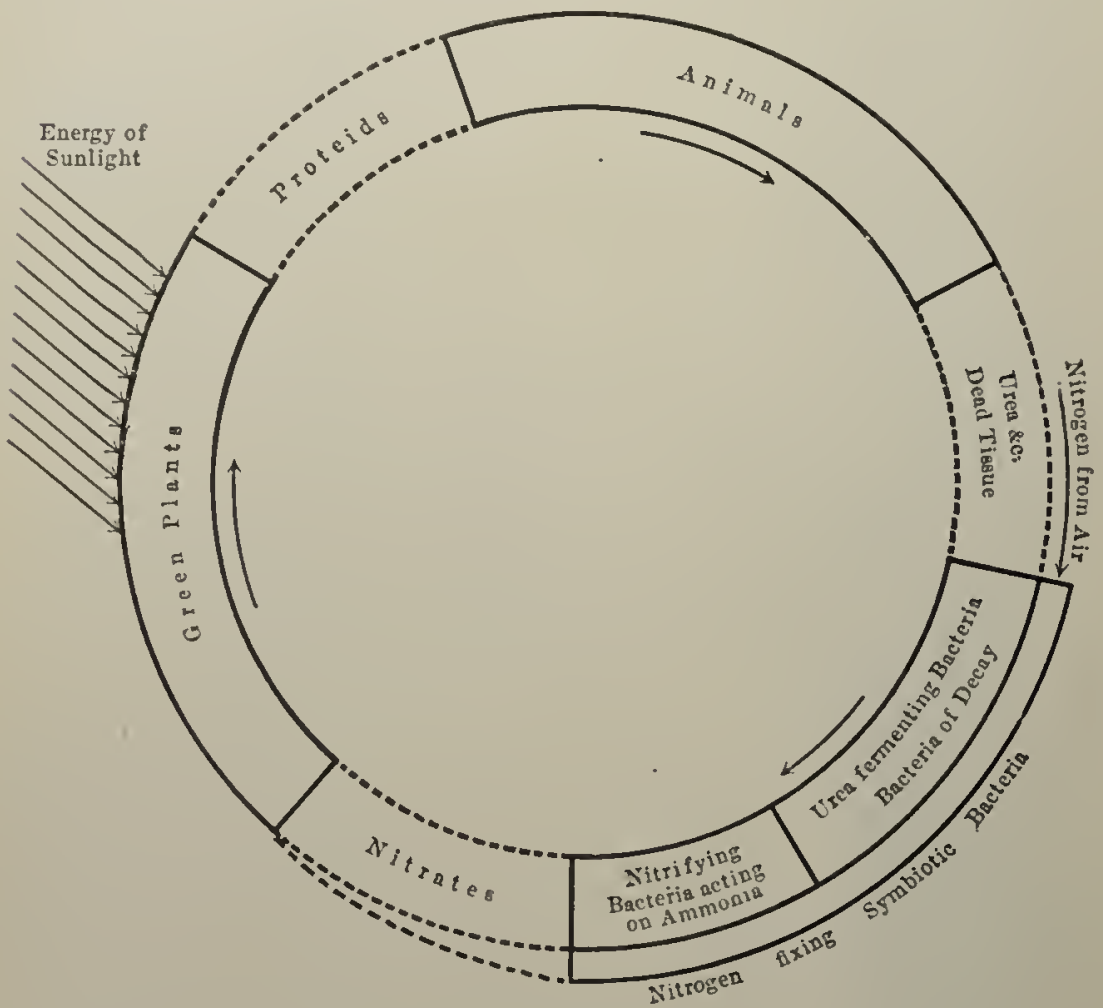

Fig. 207. Diagram illustrating the circulation of nitrogen

Nitrogen is taken by green plants from the nitrates, and through energy derived from the sunlight the proteids are formed. Animals earry the proeess of proteid manufaeture somewhat farther. The nitrogen of the proteids is then returned, through the decay of waste products (urea, ete.) and dead tissues, to simpler substances, aud finally to ammonia, whieh is worked over into nitrates by the nitrifying bacteria. Free nitrogen is brought into the eirele by the nitrogen-fixing symbiotie bacteria

Some important forms of fermentation have no connection with living organisms, but are due to special substances called unorganized fcrments, or cnzymes (Sec. 10). Such a ferment is diastase, whicl converts starch to sugar. 
254. Nitrification. The decay of proteid matter involves, first, the change of the insoluble proteids into soluble substances called peptones, - a similar process to that of digestion in the stomach. This liquefaction is due to the secretion of special ferments by certain bacteria. 'Then follow further' complicated changes until the nitrogenous substances are broken down, and ammonia $\left(\mathrm{NH}_{3}\right)$, a relatively simple compound, is formed, together with various organic acids and other compounds. Two forms of bacteria which are abundant in almost all soils coöperate to transform the ammonia first into nitrous acid, and then into nitric acid, the latter forming at once nitrates, or salts of nitric acid. The nitrates are the chief source of the nitrogen supply of green plants. The process by which the ammonia of decay becomes available through the nitrates for plant use instead of passing into the air is called nitrification.

255. The circulation of nitrogen. There is a circulation of nitrogen in nature, which is indicated in the diagram (Fig. 207). This circulation starts with the nitrates, which are taken up in solution by the cells of green plants, - in the higher plants, of course, through the root system. The nitrogen in the nitrates is combined with carbon compounds obtained from the carbohydrate food manufactured by the processes of photosynthesis. Hydrogen, oxygen, sulphur, and often phosphorus also enter into the resultant substances, which are proteids. The energy which makes possible this building up of the complex proteids comes from the sunlight, as is indicated in the diagram. Animals are able to carry the building-up processes somewhat higher, obtaining their cnergy from food which comes directly or indirectly from plants. Then the breaking-down process begins through the decay of nitrogenous waste products and of dead matter, and this is accomplished as described in the previous sections through the activitics of fungi and chiefly the bacteria. Finally, simple ammonia is produced, and this, by the process of nitrification, enters into the formation of nitrates, and the nitrogen is then available again for green plants. 
256. The fixation of free nitrogen. One of the most important relations of bacteria to agriculture and to plant life generally lies in the ability of some species to put the free nitrogen of the air into chemical compounds that are available for absorption by green plants growing in barren soil. When crops are taken off the land through a series of years the supply of nitrates

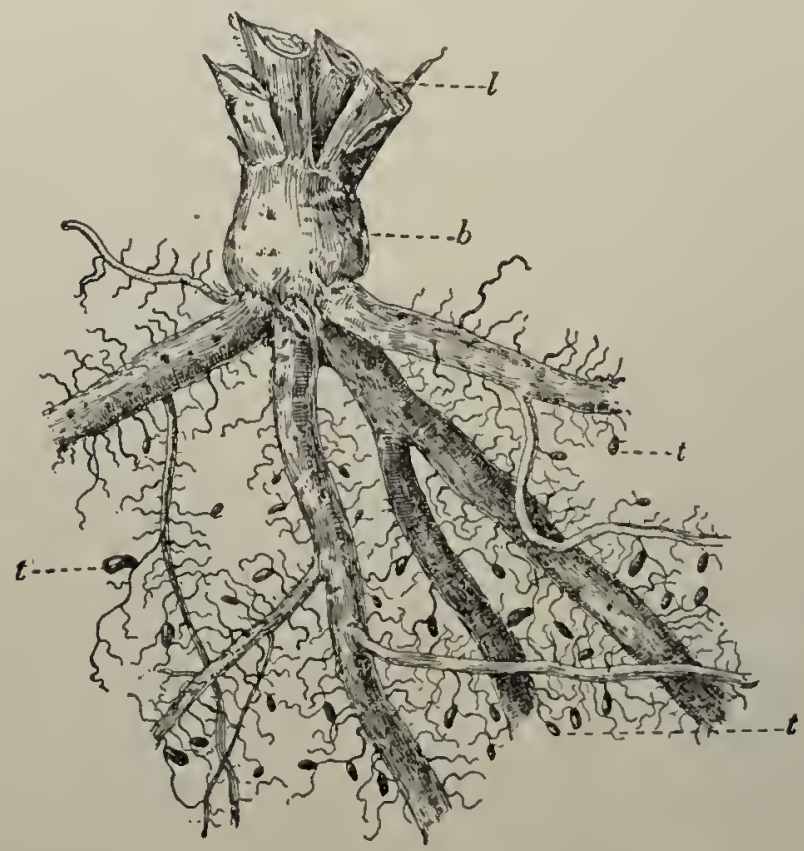

FIG. 208. Tubercles on the roots of red clover

$l$, section of ascending branches; $b$, enlarged base of stem; $t$, root tubcrcles containing bacteria

is largely used up and the soil becomes impoverished or exhausted. The uitrogen may be brought back to such soil by fertilizers, but this is expensive. The restoration of nitrogen to barren land has been one of the most serious problems of agrieulture. There is one of the bacteria (Pseudomonas radicicola), which lives on the roots of members of the legume, or pea family, including such forms as the clover, alfalfa, and soy bean, and develops swollen regions called root tubercles (Fig. 208). This remarkable organism is able to take the free nitrogen from 
the air and pass it through complicated chemical changes to the clover and alfalfa. Consequently these crops can be grown on worn-out soil or in waste land that is deficient in nitrates. Indeed, soils may now be inoculated with fluid cultures of these "nitrogen-fixing bacteria," so that the organisms will immediately establish root tubercles on the seedlings of these legumes, when sown, or the seeds themselves may be soaked in cultures insuring the application of the bacteria. ${ }^{1}$ 'Therefore, when a soil becomes barren of nitrogen through successive crops of wheat, for example, the nitrogen may be largcly restored by planting clover or alfalfa and plowing the crops under. Barren soil may also be inoculatcd more certainly by distributing over it earth from an old clover field.

The "nitrogen-fixing bacteria" make available the almost inexhaustible supply of free nitrogen in the air which cannot be absorbed by green plants and which consequently has been of no service to agriculture. As indicated in the diagram (Fig. 207), free nitrogen is constantly being brought into the nitrogen circle through the bacteria which form root tubercles (symbiotic bacteria), and this helps to make up the loss of nitrogen from the nitrogen circle, which comes in various ways, as by fire or the cscape of ammonia into the air.

257. The germ diseases. Therc is a class of contagious, and in somc cascs very dangcrous, diseases caused by certain bacteria which are frequently called microbes, or gcrms. The most serious are diphtheria, typhoid fever, tuberculosis (consumption), cholera, leprosy, bubonic plague, pneumonia, influenza or grippe, and whooping cough. Some other germ diseases, such as malaria, tropical dyscntery, and possibly smallpox, are caused by lowly organisms which are not, however, bactcria. The germ diseases are duc to the parasitic development of the organism within the

1 See MIoore, "Soil Inoculation for Legumes," United States Department of Agriculture, Bureau of Plant Industry, Bulletin $\gamma 1,1905$, and Wood, "Inoculation of Soil with Nitrogen-Fixing Bacteria," Bulletin 72, Part IV, 1905. 
liuman or other host. They are contagious because the germs can be easily passed directly or indirectly in various ways from the ill person to those around him.

The active substances which affect the patient are known in all eases to be certain poisons called toxins, which are, for the most part, secretions, less often decomposition products, accompanying the growth of the lacteria. These poisons become distributed by the blood and cause the fevers. The body resists the effects of the toxins to the best of its ability, and in some cases substances are formed called antitoxins, which neutralize the poisons. The injection into the human body of an antitoxin, obtained from the blood of a horse treated with the toxin of diphtheria, is the chief principle in the "antitoxin " treatment of this very serious disease. Recovery from a germ disease generally renders the person safe, or immune from further attack for a long time, because the body has developed resistant powers to the poisons and growth of that particular germ. The virulent poisons, called ptomaines, are usually the result of bacterial growths in foods that have not been properly kept.

Inflammation of wounds is caused by germs, and the formation of pus is in large part the gathering of white blood corpuscles which feed on the germs as they multiply in the infected tissues. The whole practice of modern surgery is based on absolute cleanliness in the treatment of wounds to prevent the entrance of bacteria during operations.

There are some serious bacterial diseases of plants, as the pear and apple blight, cucumber and melon wilt, black rot of cabbage, wet rot of potatoes, and hyacinth blight, and probably peach yellows is also of this class.

258. Public health. The matter of public health and hygiene calls for constant attention on the part of physicians and health officers to the possible sources of germ diseases. For example, contaminated water and impure milk are the commonest means of infection for typhoid ferer, and epidemics of this disease are frequently traced to these sources. We 
cannot emphasize these points better than by studying the history of a typical typhoid epidemic, taking as our illustration. the well-known outbreak in 1885, in Plymouth, Pennsylvania, a town of about eighty-five hundred inhabitants. Typhoid fever appeared in the spring with such violence that from fifty to two hundred cases developed daily, until about eleven hundred persons werc stricken (about one eighth of the population), more than one hundred of whom died. The disease appeared only in persons who drank the hydrant water from certain town reservoirs, and those who used private wclls escaped. On investigation the following facts were established. During the winter a case of typhoid fever, contracted in Philadelphia, had been cared for in a house which stood close to a stream that flowed into the town reservoirs. During the illness intestinal discharges from the patient had been thrown out upon the snow within a few feet of this stream. During late March and early A pril the snow melted and there were frequent rains that washed the germ-laden material into the stream, which carried it into the reservoirs. The first cases of typhoid fever in the cpidemic appeared within two or three weeks (the period of incubation in typhoid fever) after the infected water had been distributed through the town. Thus the entire epidemic was duc to the carelessness or ignorance of attendants who did not safely dispose of the germ-filled wastes from a typhoid patient. The terrible outbrcaks of cholera are usually due to infection of water supplics. The germs of tuherculosis are very widely distributed by means of the dried sputum of diseased persons, hence the importance of rules against spitting in public places. The common diseases incident to the association of children in school, such as diphtheria, scarlet fever, measles, and mumps, makc necessary the strict isolation of all cases until there is no possible danger of contagion. As the sources of germ infection are reluced or stamped out, the possibilities of germ diseases become at once lessened. The healthy liuman body is wonderfully resistant, and the problem of public health is largely the 
practical one of combating germs. So important are the bacteria in disease and hygiene that a science has developed, called bacteriology, with elaborate methods of its own to which speciatists give their entire attention.

CLASS VI. THE YEASTS, OR SACCHAROMYCETES

259. The yeasts. The yeasts are much larger than the bacteria, and have a more complex cell structure, for there is present a clearly defined nucleus. The cells reproduce in a peculiar manner called budding, and the yeasts are frequently termed budding fungi. Small extensions arc put forth from the

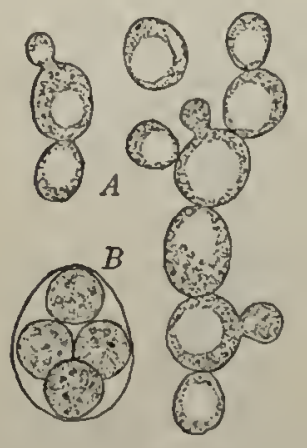

Fıg. 200, Yeast (Saccharomyces cerevisice)

$A$, vegetative cells, slrow-

ing methor of budding; li, spore formation cells (Fig. 209, A), which, after increasing in sizc, become cut off from the parent structure. The parent and daughter cells frequently remain attached in short chains or clusters. The relationships of the yeasts are very obscurc, but there are reasons for believing them to be degenerate conditions derived from some types of higher fungi whose spores arc known at times to pass into ycast-like forms when cultivated in sugary solutions.

Yeasts arc chiefly interesting as the agents of alcoholic fermentation by which sugar dissolved in water is changed into alcohol and the gas carbon dioxide. The alcoholic nature of wincs, beers, ales, and hard cider is due to the fermentation of grape juice, wort, or swect cider, all of which contain sugar, and the froth and bubbles of gas which escape from the fermenting fluid is carbon dioxide. The ycasts are distributed very widely, and they are surc to be introduced by dust into any sugar solution that is not sealed up. Thercfore weak sugar solutions ferment spontancously if left exposed, althougl it is the practice in the manufacture of bcers and some wines to use special kinds 
of $y$ zasts that are cultivated for the purpose. The ycasts that are distributed indiscriminatcly by the air are called wild yeasts, to distinguish them from those which are cultivated for the purposes of brewing and bread making. The wild yeasts somctimes become established in cheeses and other dairy products, and also in breweries, where they set up fermentations that render the food or drink unfit for use.

The raising of bread results from the fermentation by yeast of sugar that is present in the dough. ${ }^{1}$ The cavities, or holes, in the dough are formed by bubbles of carbon dioxide which, with the small percentage of alcohol developed, is driven off in the baking. Compressed yeast is made in certain distilleries from cultures in large vats, whose yeast scum is removed and pressed into the yeast eakes that are sold for domestic use.

\section{CLASS VII. THE ALGA-LIKE FUNGI, OR PII YCOMYCETES}

260. The alga-like fungi. The Phycomycetcs (meaning algafungi) eomprise a large number of forms which resemble the algæ in their structure and methods of rcproduction. Some of them are one-celled and microscopic, but others are very conspicuous mold forms, and certain types are destructive parasites that cause some very serious plant diseases. The intcresting fungus (Empusa) which kills the house flies, that are frequently found attached by their mouth parts to window panes and woodwork, is in a special group of this assemblage. We shall only be able to eonsider representatives of the following three orders of this interesting class of the fungi: (1) the molds, (2) the watcr molds, and (3) the blights and rots.

261. The molds. The molds (order Mueorales) form very cxtcnsive and conspicuous shining cobwcb-like growths (Fig. 210) through and upon the matcrial of manure heaps and other

1 See the paper by Helen W. Atwater, "Bread and the Principles of Bread Making," United States Department of Agrieulture, Furmer's IBulletin 112, 1800. 
masses of decaying matter. It is desirable tliat the term mold should be restricted to fungi of this group.

The bread mold (Rhizopus nigricans) illustrates well the characters of the group. An extensive growth may always bo obtained on bread by placing it in air saturated with moisture, as under a bell jar set in a dish of water. The vegetative body consists of large branched filaments which generally appear

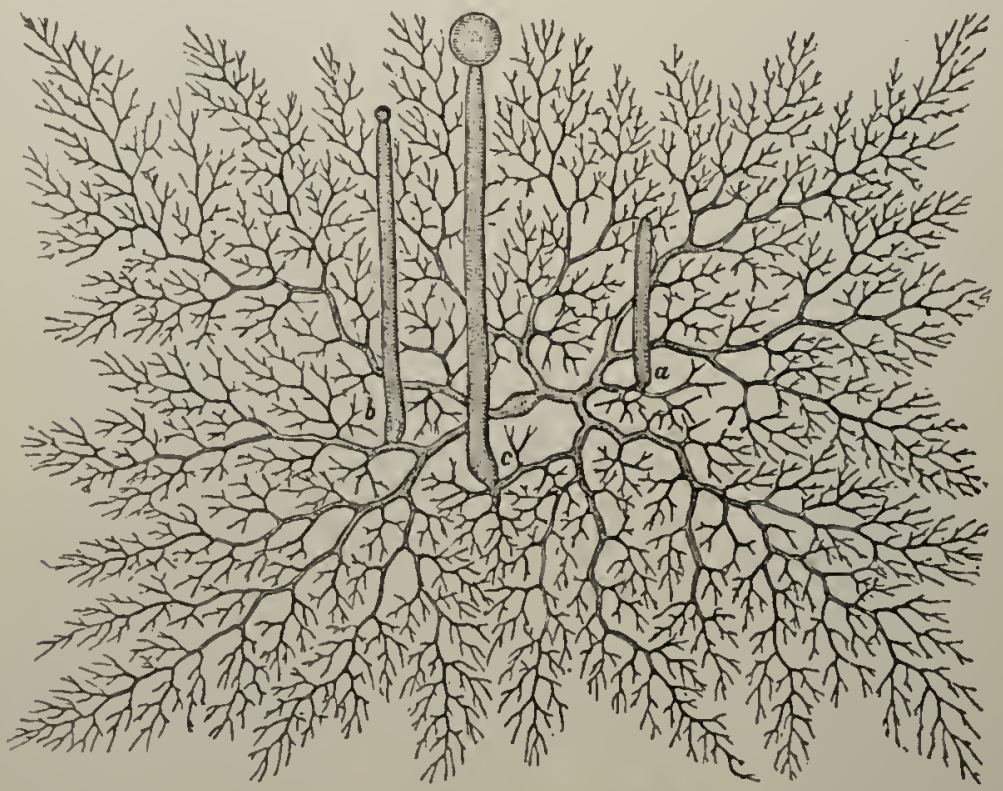

Fig. 210. The mycelium of a mold (Mucor Mucedo) developed from a single spore

$a, b$, and $e$, erect branches whieh are to bear the sporangia, showing three stages of development. - After Brefeld

glistening white because they are covered with minute drops of moisture. The individual filament of a fungus is called a hypho (meaning a web), and a mass of hyphæ is termed a mycclium. The hyphre of the bread mold resemble the filaments of Vaucheria (Sec. 228) in having no cross partitions, the filaments being a single cliamber from end to end, and consequently a conocyte (Sec. 229). The multinucleate protoplasm forms a layer under the wall of the hypha and contains 
minute globules of a fatty nature. The bread mold is an excellent example of a saprophytic fungus. The hyphie grow all through the porous substance of the moist bread and absorb fluids containing products of the bread's incipient decay. The material over which a saprophytic fungus grows and upon which it lives is called'its substratum.

The fructifications of the bread mold are very characteristic. Numerous erect branches arise, several in a group, from creeping hyphre that develop clusters of short, root-like filaments at these points (Fig. 211). The end of each erect branch then gradually

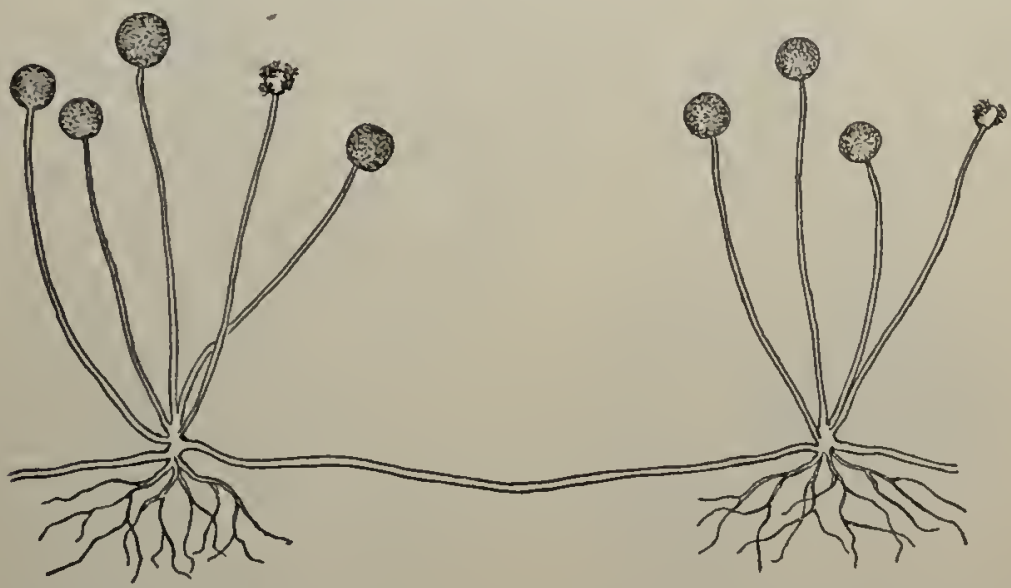

FIG. 211. Growth habit of the bread mold (Rhizopus nigricans)

Sketch showing two groups of erect hyphre bearing sporangia, with root-like clusters of filaments at their bases

enlarges and becomes separated from the stalk below by a domeshaped eross wall ealled the columclla (Fig. 212, A). The terminal cell becomes a spore case, or sporangium, and develops a multitude of smoke-colored spores, which make the spore eases appear as blaek lieads upon the upright stalks (Fig. 212, B). The spores are distributed by the breaking of the sporangium wall, exposing the dome-shaped columella which remains at the end of the stalks after the dispersal of the spores (Fig. 212,D).

The molds have a remarkable method of sexual reproduction, which is, however, rarely found in the bread nold (Rhizopus), 
but is not uncommon in other gencra, as Mucor and Sporodinia. Two slort branches from the mycelium bccome applied to one another, end to end (Fig. 213,A). The tip of eacli then becomes cut off as a sexual cell, or gamete (Fig. 213, B,C), peculiar in having very many nuclei, and consequently called a conogamete. The two gametes finally fuse, and a large zygospore (Fig. 213, $I$ ) with heavy black walls is formed between
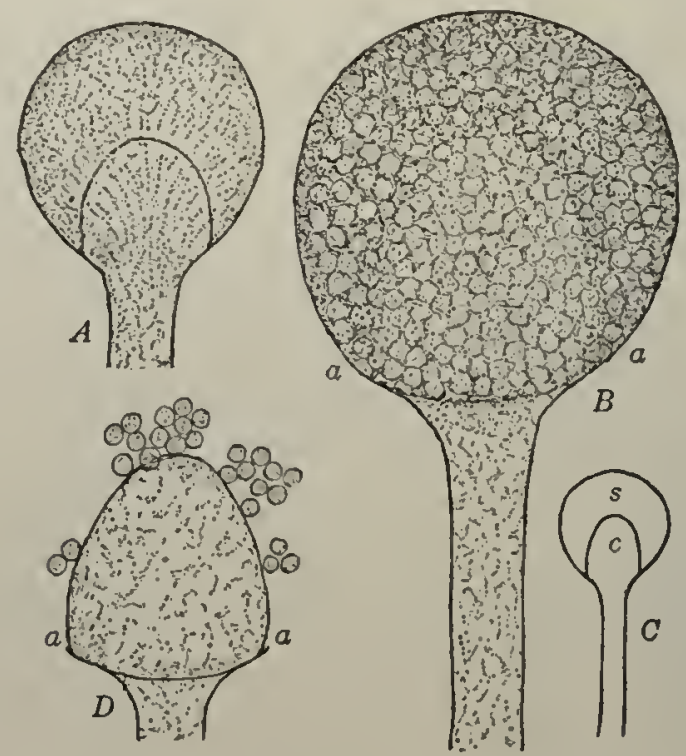

Fig. 212. The sporangium of the bread mold (Rhizopus nigricans)

$A$, young sporangium, showing domc-shaped cross wall (columclla) shortly after its formation; $B$, mature sporangium, the columella being hidden by the spores; $C$, diagram of a lengthwisc section of a sporangium; $s$, spore cavity ; $c$, columclla. $D$, columella after the rupturing of the sporangium wall, which was attached along the line $a$ corresponding to similar line in $b$; clusters of spores still clinging to the columella

the filaments. It is probable that the sexual uuclei from the two gametes fuse in pairs within the zygospore.

262. The water molds. The water molds (order Saprulegniales) are very renarkable aquatic fungi which grow on the dead bodies of insects when immersed in pond or ditch water (Fig. 214, A). Certain species attack the gills and mouths of young 
fishes in hatcheries and may be very destruetive. The conocytic hyphæ live in the tissues of the animal, and filaments grow out from them freely into the water, where they develop the reproductive organs.

Zoöspores are formed numerously in terminal club-shaped sporangia and arc discharged into the water (Fig. 214, $C, D$ ). They are two-ciliate and constitute the method of rapid multiplication, swimming about in the water, seeking a favorable substratum on which to settle down.

The sexual organs are male and female. Globular oögonia are formed at the ends of certain hyphæ, and each develops a number of eggs (Fig. 214, F). The male organs arc dclieate anthcridial filaments which arise below the oögonia or from neighboring hyphr. These apply thenselves to the oögonia and send delieatc tubes (conjugntion tubes) into the interior, which in somc forms are said to unite with the cggs. How-

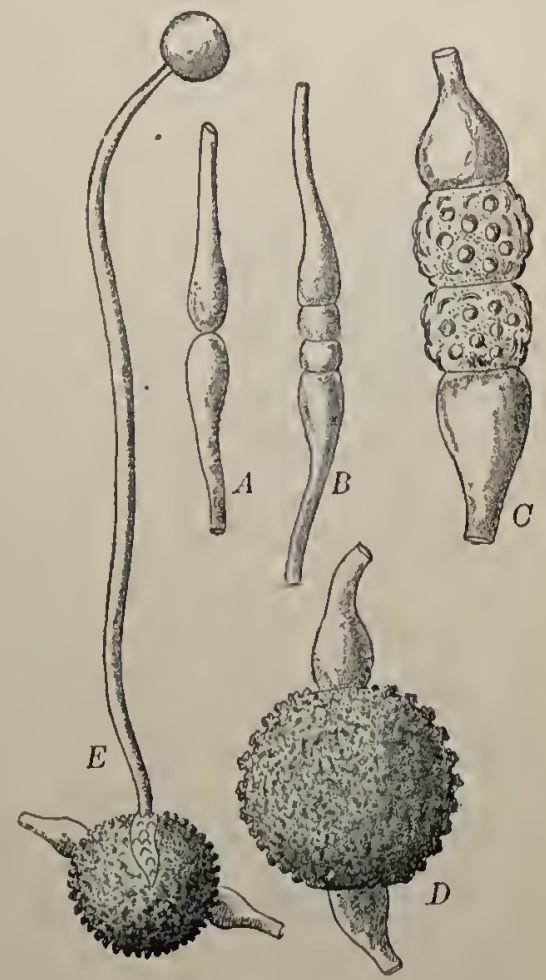

Fis. 213. Formation of zygospores in a mold (Mucor Mucedo)

$A$, two hypha in contact, end to end $J$, the terminal gametes; $C$, later stage, the gametes fusing; $D$, a ripe zygospore; $k$, germination of a zygospore, the filament forming at sporangium at once in this ease. - After Brefelcl

ever, it is known that the antheridial filaments in many of the water molds perform no function, and indeed are not even present in some types. In such cases the eggs mature into oöspores without fertilization. The water molds furnish, then, cxcellent illustrations of the degeneration of a sexual process, a phenomenon found in other groups of fungi. 
The suppression of a sexual act is termed by botanists apogamy (meaning without marriage), or sometimes parthenogenesis, when the egg itself develops without fertilization. Apogamy is found in many groups of plants, - in the algæ and fungi, among the ferns, and even in the seed plants.

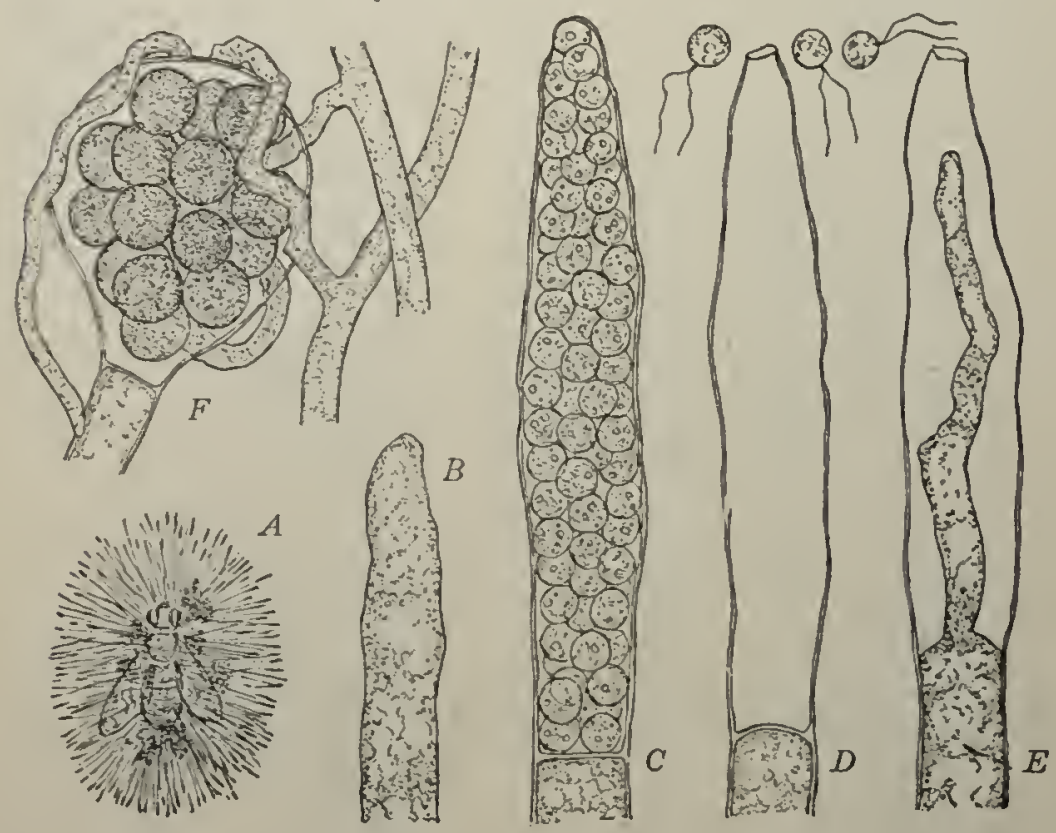

FIG. 214. A water mold (Saprolegnia mixta)

A, halit sketeh of the myeelium around a fly; sporangia being formel at the tips of the longest hyphat and sexual organs nearer the body of the insect; 1 , tip of hypha: (", terminal sporangium filled with zoöspores; 1$)$, empty sprorangium with a group of zoispores near the opening; $E$, empty sporanginm with the lypha continuing its growth inside; $F$, an oögonium containing many eggs and with three antheridial filaments applied to it

263. The blights. The blights (order Peronosporales) are parasitic fungi which cause some very destructive plant diseases. Some of them are also called "downy mildews," but it would be better if the term mildew were reserved for a peculiar group of sac fungi (Sec. 266). The hyphr form extensive growths in the tissues of the hosts. The asexual fructifications appear on the surface, but the scxually formed oöspores are developed within 
the host. The type most available for study is the blister blight (Albugo), but the potato blight, or rot, and the grapevine blight (downy mildew) are, for economic reasons, the most important forms in the group.

The blister blight. The blister blight (Albugo) grows on the shepherd's purse (Cupsella) and not infrequently on the radish, appearing as white blisters on the leaves and stems (Fig. 215). The blisters are formed by the asexual fructifications, which consist of masses of spores called conidia that are developed in chains from the ends of hyphie just underneath the epidermis (Fig. 216, A, $B$ ). Conidia are air spores of fungi, - that is, spores formed singly or in chains at the ends of special branches and scattered in

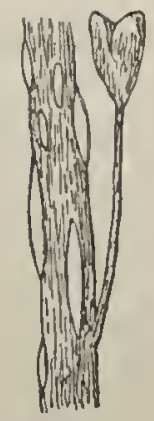

Fig. 215

'The blister blight (Albugo candida)

Blisters containing conidia on the stem of the shepherd's purse (Capsella) the air. Those of Albugo are distributed by the wind after the breaking of the blisters, and germinate in moisture, developing
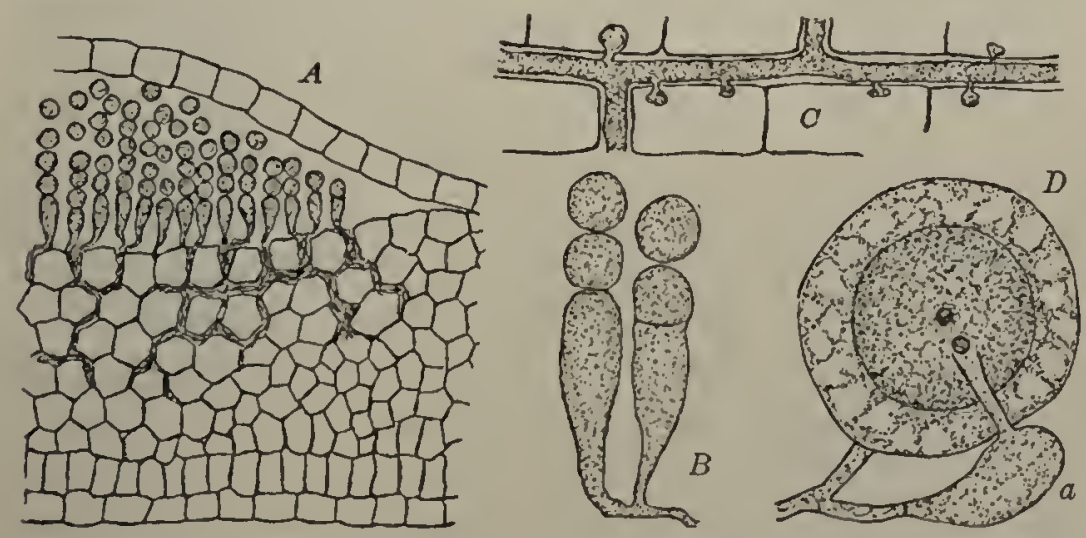

F1G. 216. Reprorluctive organs of the blister blight (Albugo candida)

A, section through the edge of a blister on a leaf; the air spores, or conidia, are formed in chains under the epidermis from the swollen tips of fungal filanents growing between the eells of the leaf; $l$, tips of two filaments, showing development of the eonid ia serially; $C$, a filament slowing sueker-like struetmes (haustoria) which enter the eells of the host; $I$, the sexual organs; the male cell, or antheridiun, a, has just discharged its nucleus through a beak-like process into the single egg within the oögonium 
several two-ciliate zoöspores. If the conidium has germinated on the proper host after a rain or heary dew, the zoöspores swim over the moist surface, and finally coming to rest they

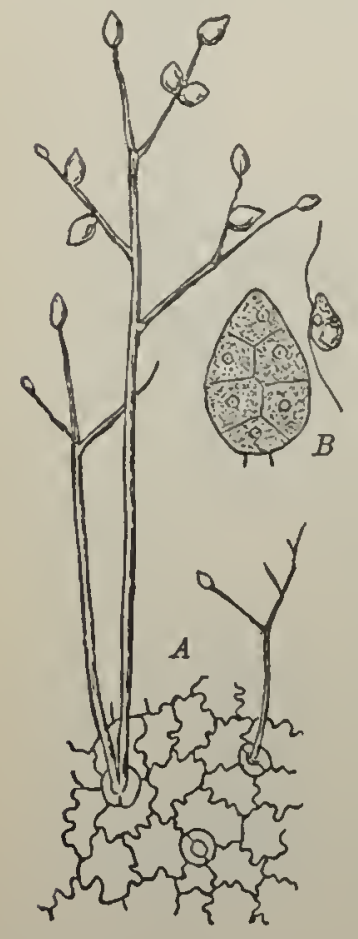

F1G. 217. Conidial fruetifieation of the potato blight (Phytophthora infestans)

$A$, the air spores (conidia) formed on long filaments which grow out from the interior of the potato leaf through the stomata; $B$, the development of zoüspores in a eonidium; a single zoöspore is shown at the right. - After Sehenck put forth delicate germ tubes that penetrate the epidermis of the host through one of the stomata. The sexual organs are generally found in portions of the leaves and stems which become much swollen and colored reddish or purplish. The large oögonium forms a single egg and is accompanied by a single antheridial filament which develops from the hypha below (Fig. 216, D). The antheridial filament puts forth a tube-like process which enters the oögonium and discharges one or more nuclei into the egg, fertilizing it. The fertilized egg develops heavy walls, becoming an oöspore, which rests during the winter, and on germinating in the spring produces a large number of zoöspores that infect new hosts.

The potato blight, or rot. The potato blight (Phytophthora infestans) has a different type of conidial fructification from Albugo. The hypha emerge from the leaves through the stomata (Fig. 217, A), and conidia are formed freely in the air in immense quantitie. These air spores are distributed by the wind, and germinating in moisture develop zoöspores (Fig. $217, B 3)$, which infect new losts, as in Albugo. Cloudy, wet, and windy seasons are naturally especially favorable to the sprcad of the potato blight. The green parts of a blighted potato plant wither, and the potatoes either cannot be formed, or rot in the ground. The 
disease is carried over from one year to the next in diseased potatoes that are planted. The potato blight came originally from South America (perhaps l'eru) and first appeared in Europe in 1845, probably introduced from North America. The disease spread very rapidly, causing local famines in various countries, notably in Ireland. It is now, however, largely held in check by spraying the plants with Bordeaux mixture, which contains copper and is poisonous to the fungus.

The grapevine blight, or downy mildew. This form (Plasmopara viticola) develops conidia on hyphæ outside of the host plant, as in the potato blight, the conidia on germination developing zoöspores. The discase had its origin in America, but our vines are not generally very seriously injured by it. However, when it was accidentally introduced into Europe it proved a terrible menace to the vine-growing industries there. The European varieties of grapes are largely grafted upon American stocks because the latter resist the attacks of the very destructive insect pest called Phylloxera. But the American grapevine blight was for a time more injurious than the insect, until means were discovered of keeping it in check hy spraying the vines with Bordeaux mixture.

The interesting genus Pythium, which causes the "damping off " of seedlings, and is sometimes very destructive in greenhouses, is related to the lights.

264. Summary of the alga-like fungi. The chief points of resemblance of the Phycomycctcs to certain algre lie in the conocytic structure of the fungal filaments and the development of \%öspores in terminal sporangia. The sexual organs are likewise similar to those of alga in that they are developed terminally, but there are important modifications because motile sperms are not generally formed. However, motile sperms are known for one type (Monoblcpharis). 'The conidia are plainly modified sporangia, which becone detached from the parent filaments and are distributed as special reproductive spores. The algre which most resemble the larger filamentous Phyeomycetes 
are such forms as Vauchcria (Sec. 228), and other types of the Siphonules, and some authors believe that the molds, water molds, and blights have been derived from that general region of tlie algæ.

\section{('LASS VIII. THE SAC FUNGI, OR ASCOMYCETES}

265. The sac fungi. The sac fungi are distinguished by a peculiar type of reproduction, through spores which are developed, generally eight in number, in a special unicellular organ.

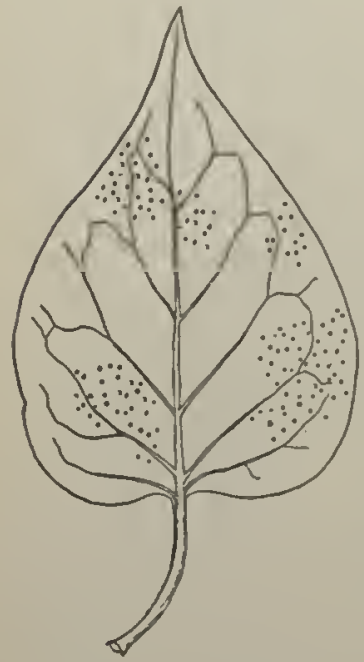

Fic. 218, Sac fruits (ascocarps) of the lilac mildew (Jicrosphwra Alni) on the surface of a lilac leaf called an ascus (plural, asci), which means a sac. The asci are produced sometimes in very great numbers in a fructification termed an ascoearp, or sac fruit, which is a structure of importance. The filaments, or hyphr, of the sac fungi are clivided by cross walls into cells, and are never long coenocytes, as in the alga-like fungi ( $P h y$ comycctes). The Ascomycetcs is one of the two la rgest groups of the fungi, comprising more than fifteen thousand species. We can only describe a few forms from the following groups: (1) the nildews, (2) the cup fungi, and (3) the knot and wart fungi.

266. The mildews. The true mildews (order Perisporiales) are a very clearly defined group of fungi, and it is desirable that the term mildcw be restricted to them. They are mostly external parasites, very cominon on the leares of many seed plants, such as wheat, lilae, Virginia creeper, grapes, verbena, cherry, oak, willow, etc. The hyphr form a cobweb-like growth (mycelium) over the leaves, and put forth sucker-like processes called haustorin, which enter the epilerunal cells of the host. There is a method of rapid multiplieation during the summer months by air spores, or ecnidia, 
which are formed in chains from the ends of erect hyphre (Fig. $219, A$ ) and give the leaves a powdery appearance. But the most important fructifications are the sac fruits (ascocarps), which appear later in the season as black dots on the leares. They can be most conveniently studied in the lilac mildew.

The lilac mildcw. This type (Microsphara Alni) forms white blotches on the leaves of the lilac, especially over somewhat

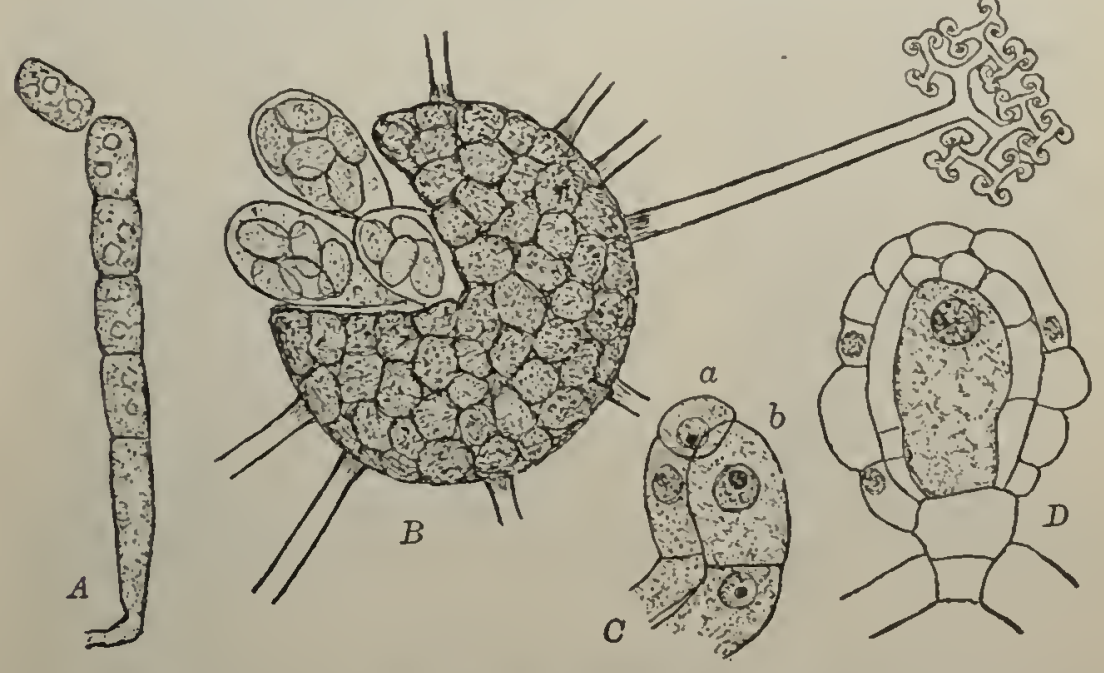

FIG. 219. Reproductive organs of the mildews

$A, B$, the lilac mildew (Microsphxra Alni) : A, a chain of air spores (conidia) formed from the tip of an erect filament; $l$, a sac fruit (ascocarp) cracked open, witl, two spore saes (asci) protruding, one of the appendares shown in detail. $C, D$ (Podosphara): $C$, the sexull organs, $-a$ the antheridium, $b$ the female gamete or ascogonium; $I$, the development of the cellular envelope of the sac fruit around the fertilized female gamete. - $C, D$, after Harpee.

shaded portions of the plant. The sac fruits are found in the autumn as black globular bodies made up of filaments so closely united that they form a cellular mass (Fig. $219, B$ ), in the interior of which are developed the spore sacs (asci). The sac fruit of Microsphare lias several radiating appendages with peculiar tips. It is developed as the result of a sexual process involving the fusion of two sexual cells, or gametes (Fig. 219,C). The asci are formed at the ends of hyphic that arise from the 
fertilized female cell, while the wall of the ascocarp is formed from neighboring filaments (Fig. 219, D). The ascocarp thus resembles in its development the sexually formed fructification (cystocarp) of certain red algæ such as Polysiphonia (Sec. 245). The ascocarp, like the cystocarp, is a system of two tissues, one derived from the fertilized female gamete (called an ascogonium) and the other from the vegetative cells of the parent plant. The phase in the life history beginning with the fertilized ascogonium and ending with the production of ascospores is an asexual or sporophyte generation alternating with the sexual

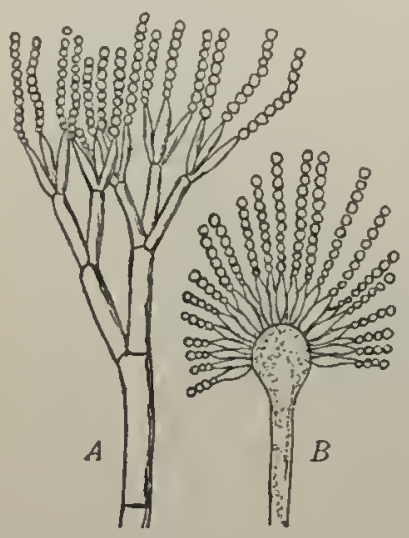

Fig. 220. Green and yellow mildews

$A$, the green mildew (Penicil(ium) ; $B$, the yellow mildew (Aspergillus)

generation or gametophyte, as in the red algie (Sec. 246). The wall of the sac fruit is clearly a protective structure for the sacs, each of which generally develops six spores in the lilac mildew, although eight nuclei are present in the sac.

The green and yellow mildews. These are very common saprophytes on bread, cheese, shoes, clothing, and other substances that mildew or "mold" in dampness. They are easily distinguished by their colors and the structure of the conidial fructifications. The green mildew is Penicillium (Fig. 220, A), which is believed to give the peculiar flavor to Roquefort checse. The yellow mildew is Aspergillus (Fig. 220, B). Their ascocarps are rather uncommon, especially those of Pcnicillium.

267. The cup fungi. Most of the conspicuous forms in this very large assemblage belong to the order Pezizules. The sac fruits are saucer-, cup-, or funnel-shaped (Fig. 221, A, B), frcquently colored yellow, orange, red, brown, or bluish, and in some forms are threc or more inches in diameter. The cup fungi are almost all saprophytes, and are found on rotten logs and earth in 
damp woods, forming very striking and beautiful growths. The chief peculiarity of the ascocarps is the fact that the entire inner surface of the cup is a fruiting surface, consisting of immense numbers of asci, arranged upright and all parallel with one another, among delicate sterile filaments (Fig. 221, C). The
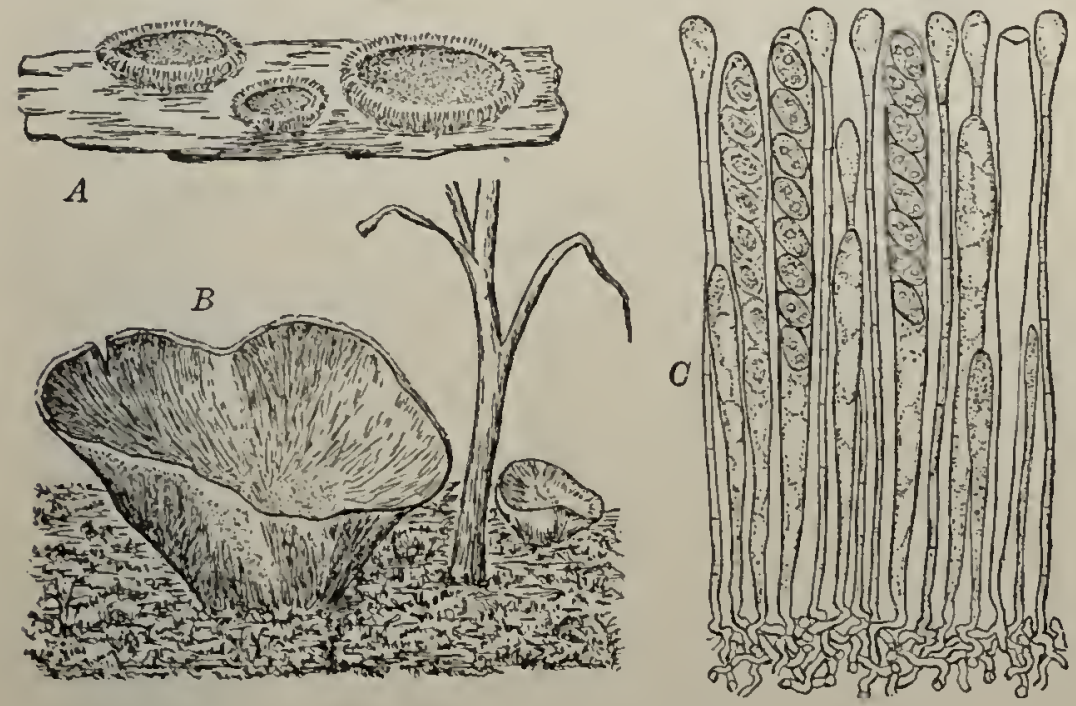

Frg. 221. Cup fungi

A, Lachnea, a small hairy form frequently growing on wood; $B$, Peziza, a large form growing on eartli; $C$, section through the fruiting surface of a Peziza type, showing asci in various stages of development among delicate sterile filaments (paraphyses)

asci are thus exposed, imbedded in a fruiting surface, and are not inclosed in a case, as in the mildews.

The sac fruits of some cup fungi (notably Pyronema) are known to be developed as the result of a sexual process, but there is probably a great deal of sexual degeneration in this group of the funvi, as in the water molds (Sec. 262).

The morel. Some very striking large forms are closely related to the cup fungi. Anong them is the morel (Morchella), much prized as one of the best of the edible fungi (Fig. 222), and some other curiously shaped types (Helvella, Mitrula, Geoglossum, ete.). 


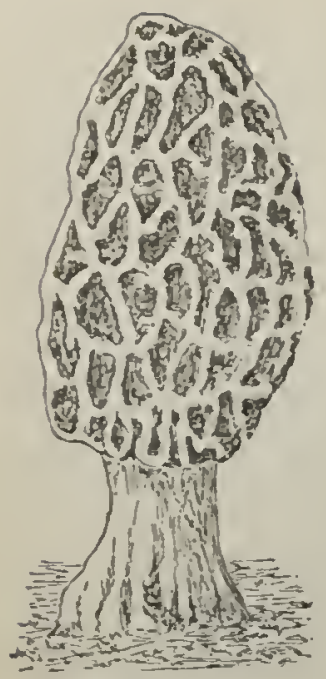

Fig. 2:2:2 The morel

(Morchella), an edible sac fungons

The conroluted upper portion is an exposed fruiting surface

The fruiting surface of the ascocarps is sometimes very extensive, and is thrown up into irregular lobes and ridges.

268. The knot and wart fungi. This large group contains forms with peculiar hard black or brown wart and scab-like fructifications, which are found on the bark of trees. Most of the species are saprophytic, but some, as the black knot (Fig. 223), on the plum and cherry, are very destructive parasites. The outer parts of the sac fruits contain immense numbers of small carities (perithecia) that are lined with asci. Tery little is known of the development of such complex sac fruits, but it is probable that many of these fungi are sexually degenerate, as are some of the cup fungi. Xylaria, with its large finger-like fructifications, belongs to this group.

269. Other sac fungi. Several exceptional sac fungi deserve special mention.

Eryot. Ergot grains (Fig. 224, A) are hard black structures found in heads of barley, rye, wheat, and certain grasses, notably the wild rice. They are really the mummified and distorted ovaries, or grains whose tissues lave become filled and destroyed by the mycelium of the fungus (Clariceps). The ergot represents a sort of resting stage in

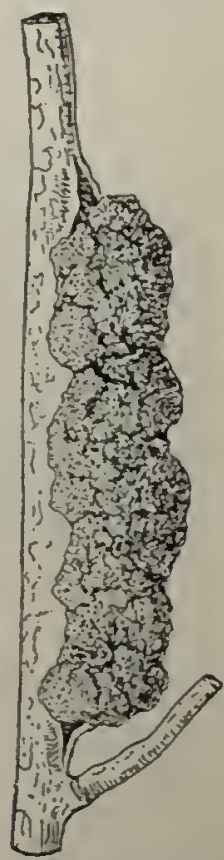

FIG. 22?. The black kuot (Plourightia) on a branch of the cherry

The branches become distorted, and long cracks are formed, greatly impairing the strength of the trees the life listory of the fungus, and from it are developred in the spring purplisl stalks bearing the sac fruits (Fig. 22t, B). 
The eaterpillar and grub fungi. These extraordinary parasites (Cordyeeps) grow in the borkes of certain caterpillars and other

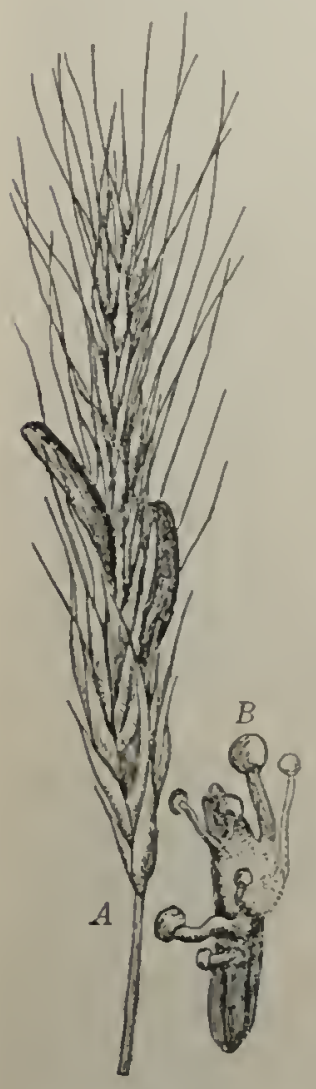

Fir. 224. The ermot (Claviceps)

1. ergot graius on a heal of barley; $B$, small sac fruits (asrocarps) developing from an ergot grain. - $B$, after Tulasne

larre, and in their pupe. The body carity of the insect becomes filled with the mycelium, and generally mummified, after which a longstalked sac fruit grows out from between certain segments (Fig. 225).

The truffles. The truffles are very remarkable sac fruits, sometimes as large as potatoes, developerl underground on mycelium that is generally associated with the roots of certain trees. The commonest truftle on the rnarket (Tuber brumale) comes from the region of Perigord, in central France, and is the most prized of all the edible fungi. It grows under certain kinds of oak trees, and is found by logs and swine that are trained to discover its location, and which detect the fungus by a characteristic odor. The association of the mycelium of the truffle with the roots of the oak tree is an excellent example of what is called a mycorrhiza, and is discussed in Sec. 278 .

The spot fungi and rots. The spot diseases of plants Caterpillar fungus are unmerous, and mostly (Cordyceps) growing out of the larva of the May beetle, which lives underground upon the leares and fruit. Many of them are ca used by sac fungi, as the strawberry-leaf spot (Fipherella), black spots on grasses aud clover

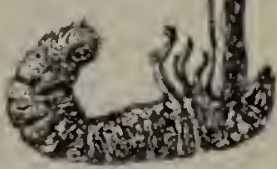

Fig. 225
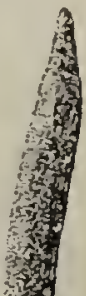
most destructive rots are sac fungi, though frequently associated with some kind of conidial fructification rather than with the sac fruit. Among them are the bitter rot of apples (Glomerella), brown rot of peaches and plums (Selcrotinia), and pluın pockets (Exoascus).

270. The imperfect fungi. Some other spot diseases and rots are caused by fungi which are known only through conidial or other types of asexual fructification. More species of these forms have been described than of all the sac fungi together, and they are assembled in a group called the Fungi imperfecti. Some of them are very important economically, causing such diseases as the potato scab (Oöspora), tar spots (anthracnosc) on beans (Colletotrichum), black rot of tomato (Macrosporium), and black rot of apples (Spharopsis). Most of the imperfcct fungi, however, are saprophytes, and play an important part with other saprophytic fungi in bringing about the decay of regetable débris.

271. The lichens. The lichens deserve special consideration as a very remarkable group. They are not single plants, but composite organisms made up of algæ which are contained in an enveloping mesh of fungal filaments. The algal cells showing through the fungal layers frequently give the lichen a greenish color, but other pigments may be present, and some lichens have brilliant yellow, orange, brownish, and reddish tints. Lichens liave a great variety of forms. Some grow closely pressed against rocks and tree trunks (crustaccous, Plate $V, A$ ), some are leaf-like (foliose, Fig. 226), and some are inuch branched (fruticose, Fig. 227).

The fructification of a lichen is most commonly a sauceror cup-shaped structure. The inner surface is a fruiting layer (Plate $\mathrm{V}, B$ ), and contains numerous eight-spored sacs, or asci (Plate V, D), showing clearly that the fungi concerned in the lichen are sac fungi, or Ascomycctes. The fructifications are therefore sac fruits, or ascocarps, and these are known in some forms to develop as the result of a sexual process. Most of the 


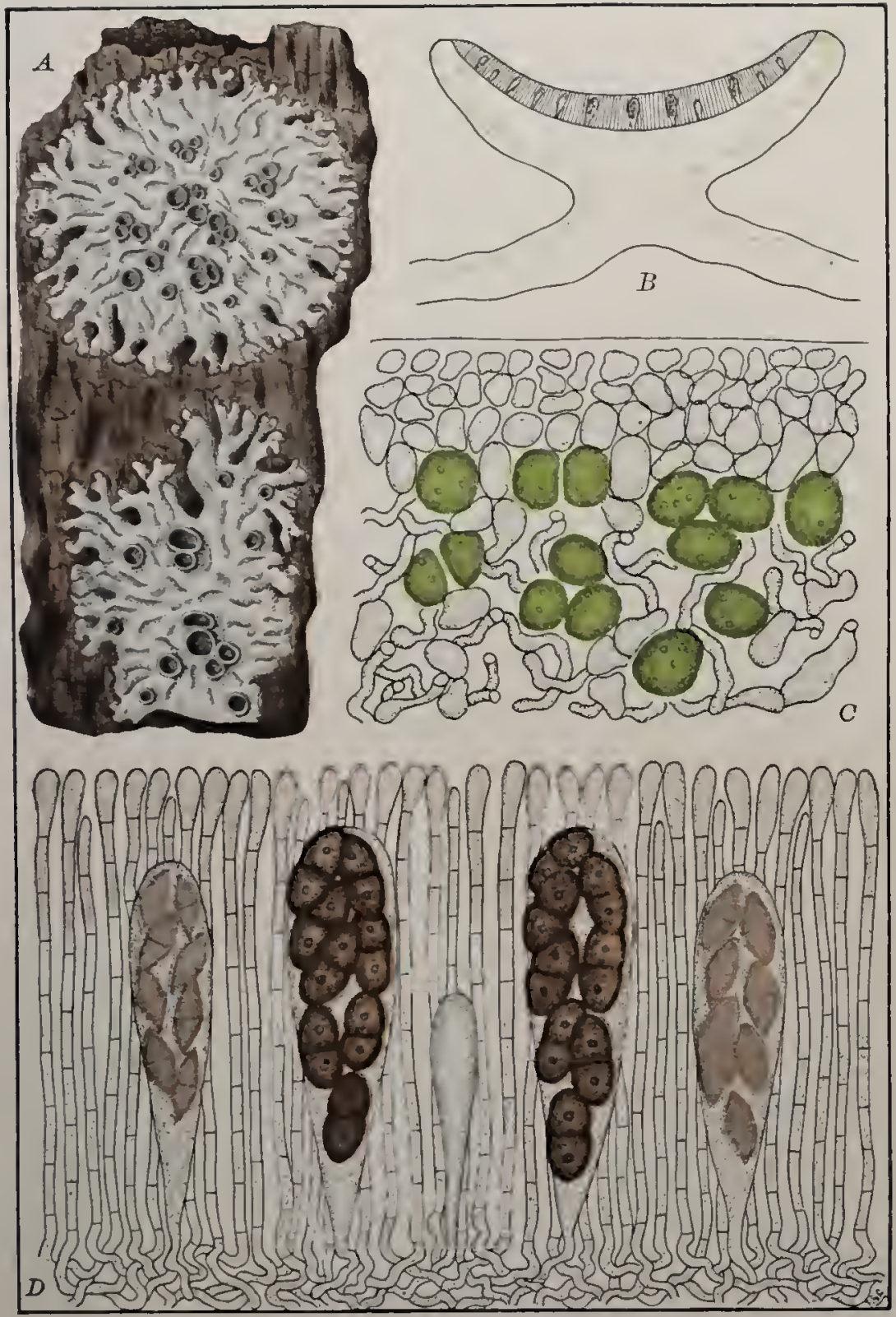

I'LAт: V. A Common 'T'ree I ichen (Physria stellaris)

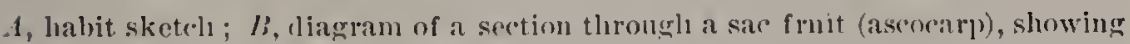
the fruiting surfare and layer of aleral rells; $C$, section slowwing a group of al lyil colls (Pleurococcus), lichl in the notwork of fumsal filanents; $l$, section of the fruiting surface, slowiner silcs (asci) in stages of developument among the sterile filaments (parapliyses) 
lichens have sae fruits closely resembling those of the cup fungi. There is one small group of tropical lichens whose fungal portions are basidia fungi, or Basidiomycctes, and not Ascomycctes.

The algal portious of a lichen may be scattered, but in some types they are arranged in definite layers. The linds of alga differ in various lichens. Some of them are unicellular green forms, evidently of the genus Plourococcus (Plate V, C). Most of the species belong to the blue-green algæ, one-celled forms being commonest, though some complicated filamentous types, such as Nostoc, are found in certain lichens. One curious lichen, which grows on the leaves of the coffee plant, contains a species of Colcochectc (Sec. 222).

The development of the present clear understanding of the composite, or fungal and algal nature of lichens makes one of the most interesting chapters in the history of botanical science. First came the recognition of the colorless portion of the lichen as fungal and the colored elements as algal in character. Then these portions were separated and cultivated independently of one another, which proved that they remained respectively algæ and fungi; for example, the lichen spore never developed into algal cells, but only into fungal filaments. Finally, lichens were created by bringing germinating spores in contact with wild algie of a suitable kind, and these lichens liave in some cases lived for many months, finally developing typical lichen sac fruits (ascocarps), thus completing the life history.

The lichens are perhaps cliefly interesting for the relations which the algre and fungi bear to one another. When two organisms live in intimate pliysiological association, so that both receive some benefit from the partnership, the condition is called symbiosis (meaning a living together). The mycorrhiza relationship (See.278) is an excellent illustration of symbiosis. It is not easy to analyze critically the relationships between the algie and fungi in a lichen association, but some points seem clear. 
First. The fungi are absolutely dependent upon the algæ for their organic food (such as the carbohydrates), which, of course, the algie are able to manufacture in the manner characteristic of green plants (photosynthesis). The relation of the fungus to the alga is then in all essentials that of a parasite to its host.

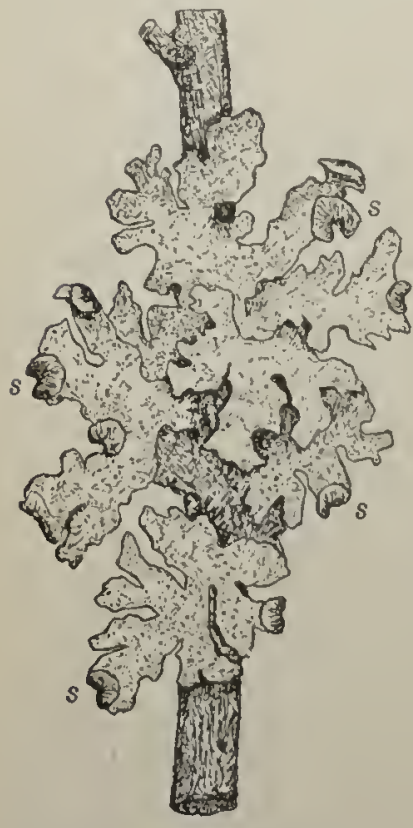

Fig. 226. A leaf-like, or foliose, lichen (Cetraria) $s$, sac fruits

Second. The algae receive a certain sort of protection in the lichen thallus. Thus they have fixed positions on exposed rocks, cliffs, trees, and other objects where they could harlly grow otherwise, or at least not in the same luxuriance. The substance of the lichen also retains moisture, so that the algal cells are not so subject to drought.

It is wrll known that many of the lowly algce would grow in situations frequented by lichens if left alone, and it is evident that the lichens arise because fungus spores fall among the algre, and geminating produce hyphe which live parasitically upon them as hosts. The algre are then, in a sensc, slaves of the fungi. They are not killed, for that would be of no advantage to the fungus, which requires them to manufacture its organic foods. The term sluvery perhaps best expresscs the rclation of the algre to the fungi in the lichens.

Life habits of the liehens. Lichens are found on rocks, cliffs, branches and trunks of trees, and on the ground, when the latter cannot support green vergetation, either because it is too barren, or is exposed to unfavorable climatic conditions. They are most luxuriant in temperate and sub-aretic regions, especially where there is much rain. They form the bulk of the vegetation on the tops of mountains and in the aretics, where grass and other alpine seed plants cannot grow. They are abundant 
along storm-swept seaeoasts. Some forms actually eover large areas, as the reindeer moss (Cladonia rangiferina, Fig. 227, A), whieh in extrene northern eountries furnishes an important source of food for herbivorous animals, as the reindeer. Since the lichens are the first plants to grow on exposed rocks, they form there the first soil, mingled with decayed vegetable matter (humus), which may furnish a foothold for higher plants, such as the mosses and grasses, that are eonstantly trying to establish themselves in the territory of the lichens.

Some uses of lichons. Some liehens (Roccclla) yield beautiful purple, blue, and erimson dyes called oreliil and eudbear, much used in former centuries in Italy, and later in other parts of Europe. Orelil when prepared with soda or potash yields the dye litmus, employed in the manufacture of litmus paper.

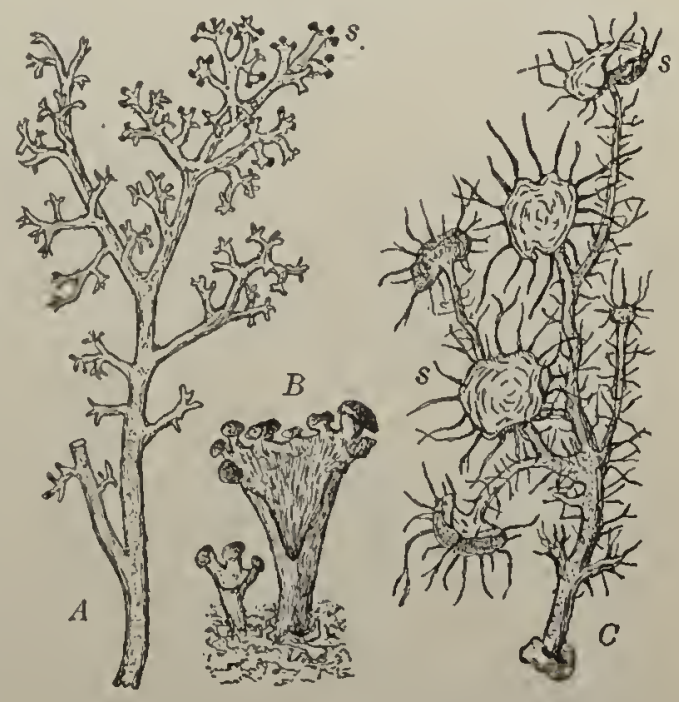

Frg. 227. Some branching, or fruticose, lichens

$A$, the reindeer moss (Cladonia rangiferina); I3, Cladonia cornucopioides; C, Usneabarbata; $s$, sac fruits

Other liehens, as Iecland moss (Cetraria), are ground up and mixed with wheat and nuade into eakes.

272. Summary of the sac fungi. The most remarkable feature of the life history of the Ascomycetes is the position of the aseoearp as a sporophytic phase following the sexual proeess and alternating with sexual plants, or gametophytes. The ascocarp holds a place in the life history similar to that of the eystoearp in the red algie (See. 246). There are numerous types of asexual spores (such as conidia) in the Ascomycetcs, whieh 
cannot be described here but greatly complicate the classification of the forms. Some authors believe that the sac fungi hold rela. tions to the red algæ, and, indeed, have been derived from them.

\section{CLASS IX. THE BASIDIA FUNGI, OR BASIDIOMYCETES}

273. The basidia fungi. The Basidiomyectes come next to the Ascomycetes in number of known species, which is about fourtecn thousand. The group takes its name from a peculiar type of reproductive organ called a basidium (mcaning a small pedestal). The basidium (Fig. 238) is a somewhat swollen terminal cell of a filament, or hypha, from which are developed a group of four spores on delicate stalks called sterigmata. The hyphre of the basidia fungi are divided into cells, as in the sac fungi.

The basidium is a very characteristic structure of the higher forms of the Basidiomycetes. However, therc are some types, as the smuts and rusts, in which the basidium is represented by a peculiar phase in the life history (the promycelium), which does not at first thought secm to resemble the basidium. These points can only be made clcar after a study of representative types, and they will be referred to latel in the summary of the basidia fungi (Scc. 279). This peculiarity is the basis of a classification of the basidia fungi into two series: (1) the Protobasidiomyectes, which are preliminary to (2) the Eubasidiomyectes, or typical basidia fungi. The representatives that can be considered here will accordingly be grouped as follows:

Series I. The simpler basidia fungi, or Protobasiliomycetes.

1. The smuts, or Ustilaginales.

2. The rusts, or Uredinales.

Serres II. The typical basidia fungi, or Eubasidiomycetes.

3. The coral fungi, the pore fungi, the tooth fungi, the gill fungi, collectively called IIymenomycetes, and divided into several orders.

4. The puffballs, the earth stars, the nest fungi, the carrion fungi, collectively called Gastromycetes, and divided into several orders. 
Series I. The Simpler Basidia Fungi, or ProtobasidiomyCETES

274. The smuts. The smuts (order Ustilaginales) are parasites which have the peculiar habit of attacking the floral parts, and especially the ovaries, of various members of the grass family. The hyphæ fill these parts with a dense mycelium, destroying the tissue of the host. Finally, most of the cells in the mycelium take on heavy walls and become. resting cells, or winter spores, which form the black powdery mass so characteristic of the smut fructification. These resting cells survive the winter and germinate in the spring. Each cell then puts forth a short filament called the promycelium (Fig. 228, A), upon which are developed a number of small spring spores called sporictia, and these in some cases germinate upon the sprouting host plants, as in oats, putting forth filaments that enter the host and develop a mycelium within, which may not be noticed until the fructifications appear in the floral organs. It is important to note that the sporidia multiply rapidly by budding (Fig. 228, $B$ ), especially under favorable conditions, as in heavily manured soils,

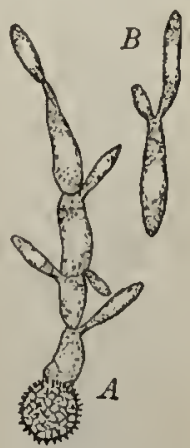

Fig. 228. Promycelium of the corn smut (Ustilago Maydis)

$A$, with spring spores (sporidia) attached ; B, spring spores budding like yeast cells. - A f ter Brefeld and these buds, or conidia, will infect like the sporidia. These habits of budding led to the theory that the yeasts have been derived from the smuts.

Various smuts. The corn smut is, perhaps, the most conspicuous form and very destructive. The infection in the corn is local; that is, the spore masses are formed close to the point of entrance of the fungus. Any tender growing region is subject to infection. The corn smut can only be held in check by burning the spore masses as soon as discovered and by avoiding the use of manure, which gives favorable nutrition for the 
germination of the spores. The smuts of oats and wheat often cause enormous loss in these crops. The best preventive measures seem to be, treatment of the grains with solutions of copper sulphate, or formalin, or steeping them in lot water for a short time

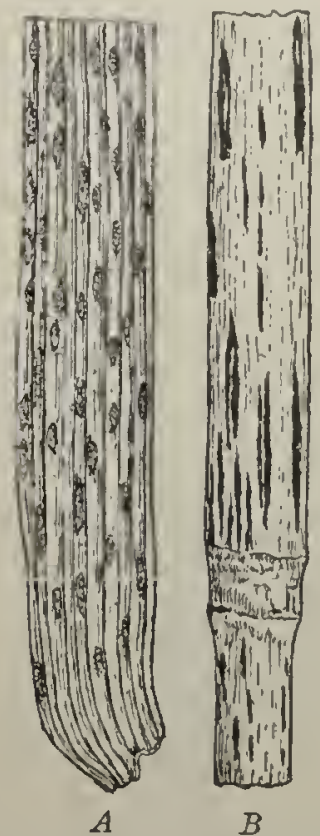

FIG. 229. The wheat rust (Puccinia graminis)

$A$, spots of the red rust on a wheat leaf, composed of the summer spores (uredospores); li, spots of the blaek rust on wheat straw, composed of the winter spores (teleutospores) before planting, which kills the smut spores without injuring the grain..

275. The rusts. The rusts (order Uredinales) cause some of the most

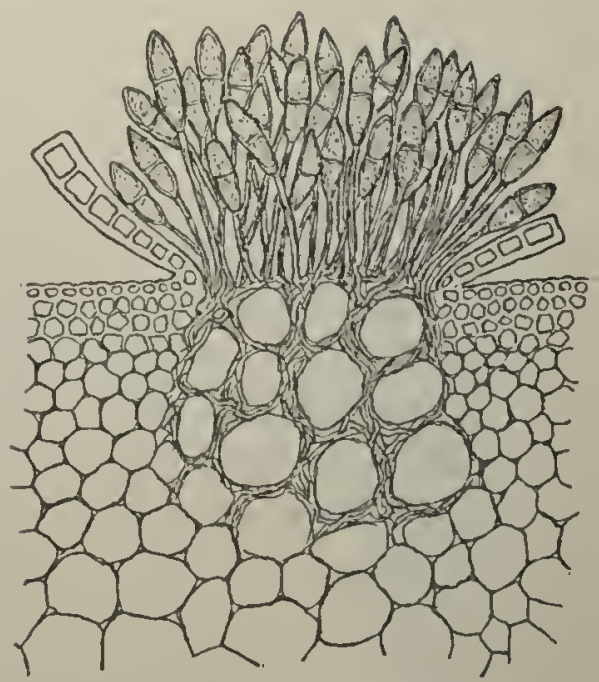

Fig. 230. The winter spores (teleutospores) of the wheat rust (Puccinia graminis)

Section throngh a spot of the blaek rust on oats, the epilermis of the leaf being thrown baek and the two-celled teleutospores raised aloove the surface on stalks; note the web of fungal filaments (hyphe) around the very much enlarged (hypertrophied) cells of the host under the spot

disastrous diseases of such grains as wheat, oats, barley, and rye. They are all parasites, forming yellow or black spots on

1 See Swingle, "The Prevention of Stinking Smut of Wheat and Loose Smut of Oats," United States Department of Agriculture, Farmer's Bulletin $250,1900$. 
the leaves and stems of their hosts. The most complicated life histories in the fungi are found in this group, for many species require two different hosts to complete their life cycle and form a number of different reproductive spores during their development. These peculiarities are best illustrated by the rust of wheat.

The wheat rust. The wheat rust (Puccinia graminis) appears on wheat, oats, and other grains and grasses, first as red or yellow streaks or spots upon the leaves and stems (Fig. 229, A). The host is greatly weakened and consequently matures only a small yield of grain. Towards the end of the season black streaks (Fig. 229, $B$ ) are formed in addition to the red-rust spots, and these indicate the development of resting cells, or winter spores, which are peculiar two-celled structures in Puccinia (Fig. 230). The winter spores, called teleutospores, germinate in the spring, and each cell gives rise to a short filament, the promycelium, usually consisting of four cells (Fig. 231), from which are generally developed four spring spores, or sporidia. The winter spores, promycelium, and spring spores probably correspond to the same stages in the life history of a smut.

Wherever the barberry is common, as in Europe and New England, the spring spores (sporidia) infect these plants and produce on their leaves peculiar fructifications called cluster cups, or acidia (Fig. 232, A, B), in

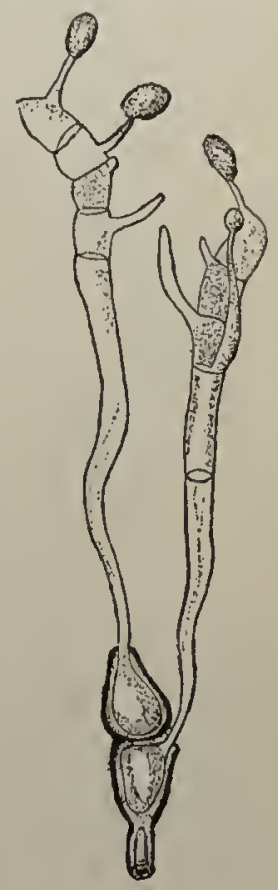

Fig. 231. Promyce lium of the wheat rust (Puccinia graminis)

After Tulasne which are developed cliains of cluster-cup spores, or acidiospores (Fig. 232, C). There is considerable evidence to prove that the cluster cups represent the remains of what was once a sexual phase in the life listory of the rust, but which is now much modified, and indeed entirely suppressed in some forms. 
Curious structures called spermogonia (Fig. 232, C) frequently accompany the cluster cups and are believed to be the remains of male sexual organs now no longer functional. They develop immense numbers of minute cells, termed spermatia, which may at one time have been functional sperms, but apparently serve no useful purpose now:

The recidiospores are distributed by the wind and germinate upon young wheat, putting forth tubes which enter the host
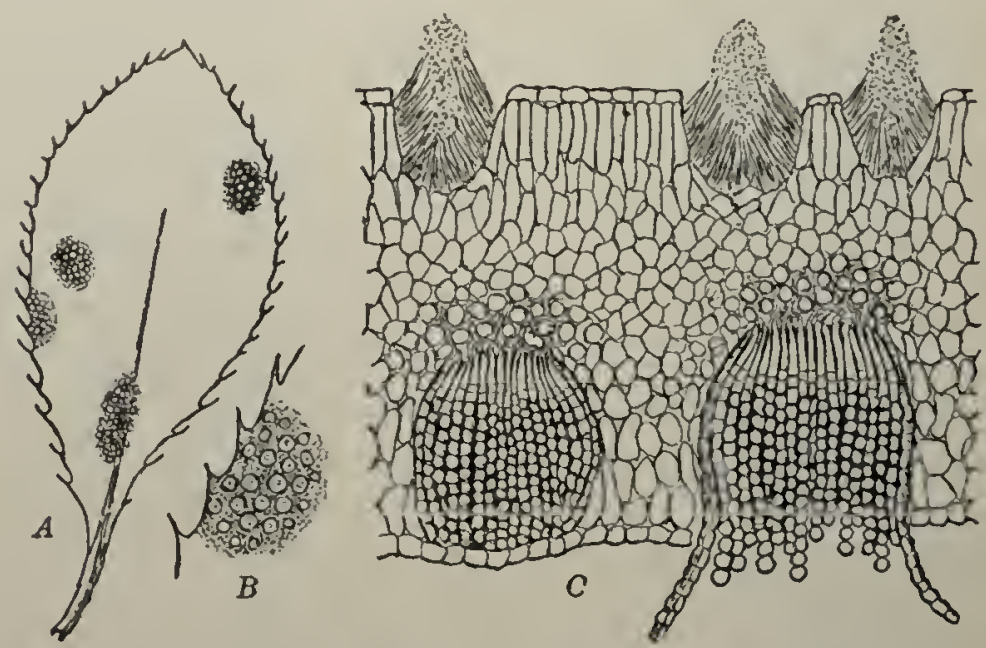

Fig. 232. Cluster cups (æcidia) on barberry leaves

$A$, habit sketch showing groups of cluster cups on a leaf; $B$, a group enlarged; C', section througl a leaf showing cluster cups on the lower surface, with the chains of recidiospores and the male organs (spermogonia) on the upper surface. The latter develop immense numbers of minute cells which probably represent sperms, but are now functionless

through the stomata. The infected wheat then develops a number of crops of one-celled summer spores called uredospores (Fig. 233). The first crops of summer spores are widely scattered in high winds and infect more wheat, thus spreading the disease very rapidly. The spots of uredospores are reddish or yellowish, and this is the stage known as the red rust of wheat. Finally, at the end of the season, the black spots of teleutospores appear, and the rust's life history is completed. 
This long life history, which is thoroughly known in Europe, becomes much shortened in the Middle West, California, and Australia, where there is no barberry, by the omission from it of that host. In these regions the uredospores (summer spores) may survive the winter or dry season, or be carried over from summer to summer through the winter wheat and germinate directly upon the new developing wheat of the following year, so that the reproduction of the rust is by a succession of the uredospores.

There is no method known of killing the wheat rust on the living host; but it has been found that certain varieties of wheat, as the macaroni wheats, are far more resistant to the rust than others. There is some hope that varieties may be bred by crossing our wheats with macaroni wheat that will be largely immune to this disease, which annually causes losses of many million dollars in the United States alone. ${ }^{1}$

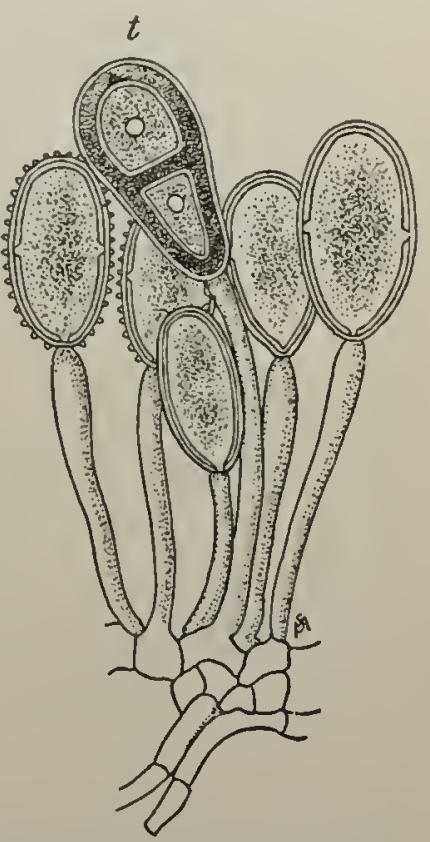

Fig. 293. The summer spores (uredospores) from the red rust of wheat

A single two-celled teleutospore, $t$, happens to be presentamong them. - After De Bary of Pucciniu graminis, and also several other species of Puccinia which attack various grains, grasses, and other plants. One of these ( $P$.asparagi) sometimes causes great damage to asparagus.

Other rusts. The group of the rusts is very large, the genera being distinguished chiefly by the structure of the teleutospores

1 For a disenssion of the rusts and rust problems of the United States, see papers of Carleton from the publieations of the United States Department of A grieulture, "Cereal Rusts of the United States," Division of Vegetable Physiology and Pathology, Bulletin 16,1899; "Macaroni Wheats," Bureau of P'lant Industry, Bulletin 3, 1901; "Investigations of Rust," Bureau of I'lant Industry, Bulletin 68, 1904. 
and the different types of life histories affecting various hosts; but many of the forms liave $n$ economic importance, being found on such plants as the violet, May apple, cocklebur, asters, golden-rods, members of the pea family, etc. However, there are destructive rusts on the roses (Phragmidium), clovers (Uromyces), blackberries (Ceoma), etc. An interesting type is the rust (Gymnosporangium) which causes the distortions called cedar apples on the junipers, and the much-branched stunted growths called witches' brooms. This rust has a cluster-cup stage (once named Rostclia) on the hawthorn and apple.

\section{Series II. The Typical Basidia Fungi, or Eubasidiomycetes}

276. The Hymenomycetes. This group, which may be considered a sub-class of the Basidiomycetes, comprises all of the

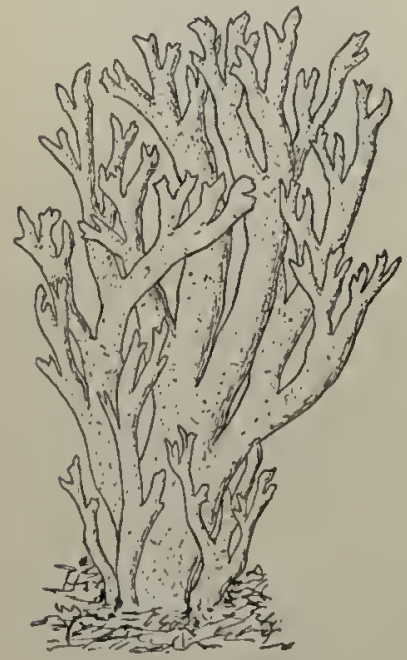

FIG. 234. A coral fungus (Clavaria) higher basidia fungi whose spores are developed on a fruiting surface, called an hymenium (meaning a membrane), which is exposed. This condition is thus contrasted with that in the Gastromycetes (puffballs, etc.), where the spores are developed within a case. The types of fructification are exceedingly various in this group, which includes the pore, the tooth, and the gill fungi in the various forms of toadstools and brackets. But there are also some simpler types, as the coral fungus ( $\mathrm{Cla}$ varia), with irregular branches (Fig. 234), and also sone expanded forms.

The pore fungi. The pore fungi (family Polyporceece) have eommonly the shape of lorackets and grow on the trunks of trees, although some are large, fleshy toadstools, as Boletus (Fig. 235). The lymenium lines the cavities of the numerons pores which are found on the under surfaces. 
Many of the pore fungi are peremnial, increasing in size from

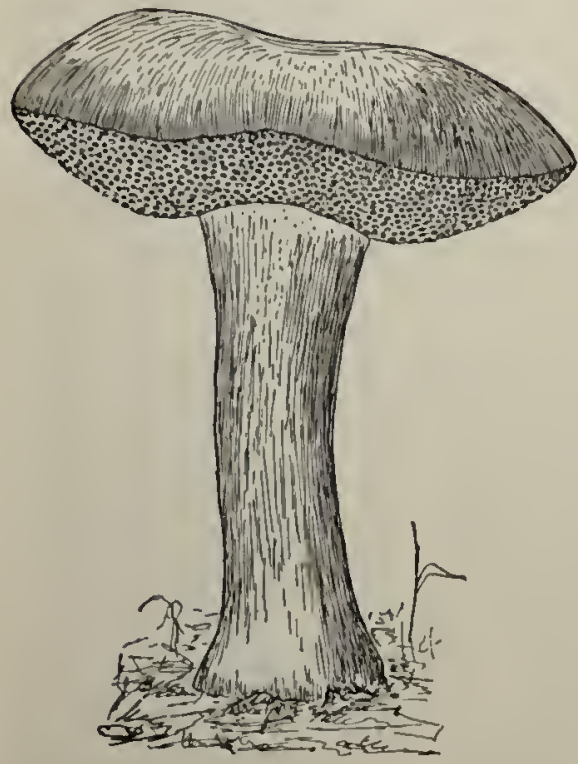

FIG. 235. A pore-bearing toadstool (Boletus) year to year by adding new layers of growth outside of the old. The bracket or toadstool is merely the fructification which receives its nourishment from an extensive mycelium growing in the wood, and -under the bark of trees, or in the soil. Many of the pore fungi are very destructive parasites, greatly injuring and sometimes killing forest trees. They may cause great injury to growing timber. Most of the pore fungi are, however, saprophytic in their manner of life.

The tooth fungi. The tootl fungi (family Hydnace $)$ ) are less common than the pore and gill fungi. Some of them liave bracket forms, and some are toadstools (Fig. 236). The fruiting surface is distributed over tooth or spine-like processes.

The gill fungi. The gill fungi (family Agaricucea) include most of the toadstool and mushroom forms (Fig. 237). A toadstool consists of Fif. 236. A tooth fungus (IIydnum)

ISee von Schrenk, "The Deeay of 'limber and Methods of Preventing It," United States Department of Agrienlture, Bureau of Plant Industry, Bulletin 14, 1902. 
a stalk (stipe), which in some genera arises from a cup (volva) and is expanded above into the cap (pileus). The under surface

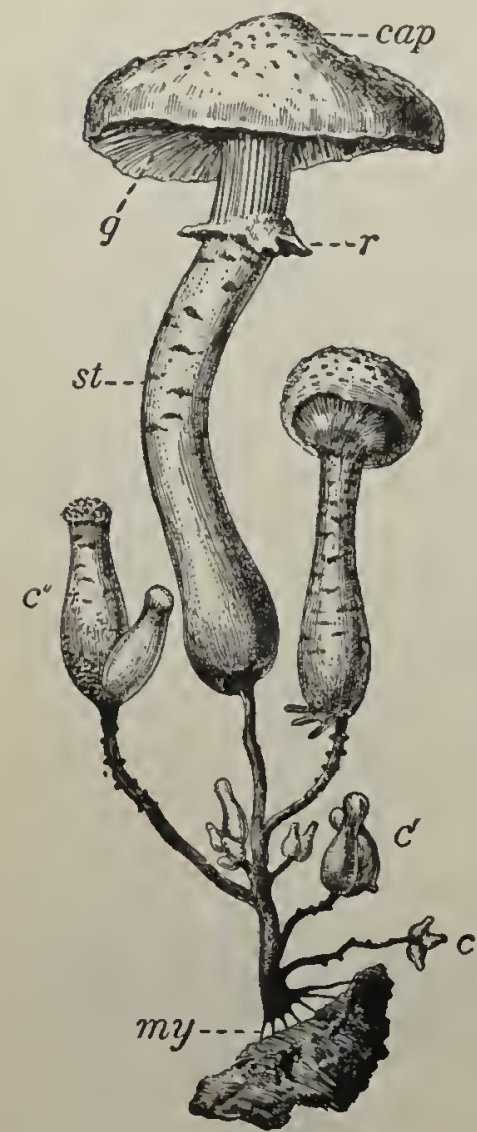

FIG. 237. A group of mushrooms (Armillaria mellea)

my, mycelial attachment ; $c, c^{\prime}, c^{\prime \prime}$, young stages ealled buttons; mature mushroom with expanded cap (pileus) shown above; st, stem (stipe); $g$, gills; $r$, ring. After Hartig, through Beunet and Murlay of the cap bears many thin plates which hang down in a radiating arrangement and are called gills. The gills illustrate very well the structure and position of the basidia on a fruiting surface, or hymenium, and cross sections are shown in Fig. 238. It will be seen that the basidia are the swollen terminal cells of a compact mesh of hyphæ, and that each bears a group of fcur spores on short stalks or sterigmata.

The toadstool is really a fructification. It is attaclied to an extensive mass of mycelium, which is the vegetative portion of the plant. This mycelium generally lives saprophytically in the soil, frequently around buried roots of trees, but there are some parasitic gill fungi (Plate VI) which cause the decay and final death of valuable timber. The toadstool develops from an accumulation of hyphæ in small structures called buttons (Fig. 237, c, $c^{\prime}, c^{\prime \prime}$ ). The cap region with the gills and stalk become differentiated within the button, and finally break out from the surrounding envelope, volva, and in some species expand in a few hours to their full size, - a "mushroom growth." The remains of the envelope are found in some forms as scales on the top of the cap (see mature mushroom 
of Fig. 237) and in a ring attached to the stalk below the gills (Fig. 237, r), while in certain types (Amanita, etc.) there is a large cup (rolva) at the base of the plant out of which the stalk rises.

It is rather general popular usage to apply the term mushroom to all toadstools and other fleshy fungi which are edible. There are no general rules for distinguishing the edible from the non-edible fungi which do not have exceptions; but the collector may readily learn the cliaracters of the most poisonous species, and likewise become acquainted with a number of choice forms which are easily recognized. ${ }^{1}$ It is a good principle, however, to rest satisfied witl a knowledge of a few absolutely safe mushrooms and not to experiment with those that are not fully known. The most poisonous species of the gill fungi are in the genus Amanita and have generally large cups, rings, and white spores, and may be readily recognized when carefully examined. However, the very poisonous Amanita muscaria, "fly agaric," has no cup. The commonest mushroom of the market
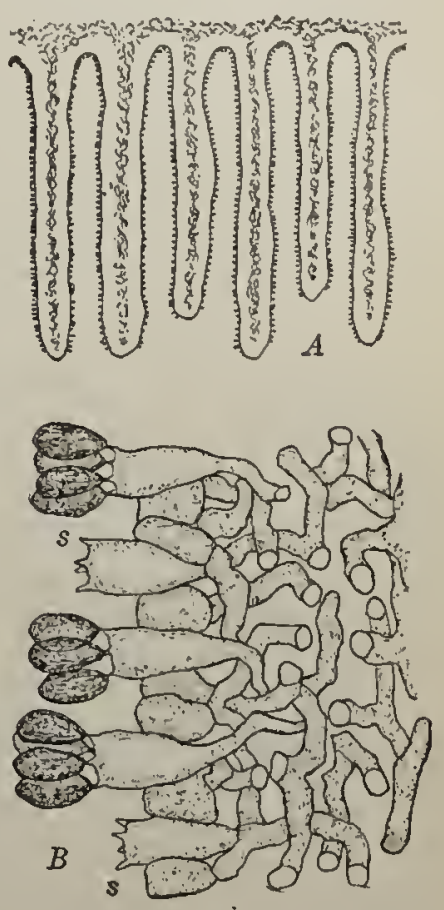

Fig. 238. Gills of mushroom (Coprinus comatus)

$A$, eross section of gills showing fruiting surfaee (hymenium); $B$, portion of fruiting surface illustrating three basidia with spores and two from which the spores have fallen off, showing the spore-bearing stalks (sterigmata) $s$

(Agaricus campcstris) is a form extensively cultivated, but which also grows in the fields. These mushrooms are raised in cellars and caves, in specially prepared, heavily manured beds, which are planted with masses of mycelium called

1 See Farlow, "Some Edible and Poisonous Fungi," United States Department of $\Lambda$ griculture, Division of Vegetable Pluysiology and Patloology, Bulletin 15, 1898. 
spawn.1 Some species of Boletus are edible, and they, with the morels (Sec. 267) and truffles (Sec. 269), are sold in the European markets with edible gill fungi.

277. The Gastromycetes. This group, in contrast with the Hymenomyectes, includes forms in which the basidia line the interior of chambers, or cavities, in the fructifications and are consequently inclosed until the fructification matures. Here

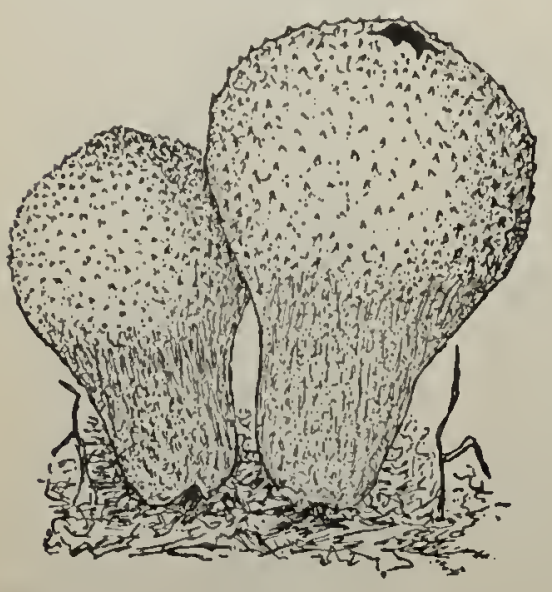

Fic. 239. A puffball (Lycoperdon) are found the puffballs, earth stars, nest fungi, and carrion fungi.

The puffballs. These are the fructifications (Fig. 239) of an extensive underground saprophytic mycelium, as in the toadstools and mushrooms. The young puffball has a white flesh made up of hyphre and filled with small irregular cavities lined with tle fruiting surface (hymenium). The spores when ripe lie freely as a brown powder in the dried-up fibrous tissue inclosed in an onter parchment-like envelope. The spores may be discharged through a special opening at the top or scattered by the irregular rupture and decay of the puffball. Young puffballs are generally edible, and there is one extraordinary species (Iyeoperdon giganteum) which grows to be a foot or more in diameter and is much prized as a delicacy.

The earth stars. The earth stars (Geaster, Fig. 240) are modified forms of puffballs. The envelope is rery thick, and the outer portion splits lengthwise into segments which, when wet. curve back from above and raise the fructifications from the ground. In dry weather the segments are usually rolled up

ISee Duggar, "The Prineiples of Mushroon Growing and Ifushroom Spawn Making," United States Department of Agriculture, Bureau of Plant Industry, Bulletin 85, 1905. 
tightly around the fructifications. These movements of the segments in certain species when alternatcly wet and dry sometimes

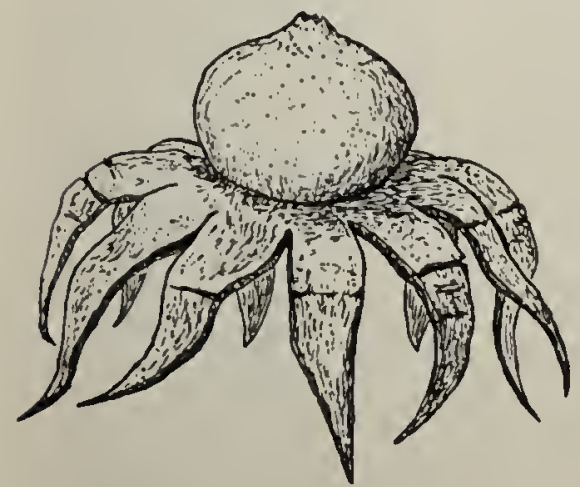

Fig. 240. An earth star (Geaster) tear the earth stars loose from the ground so that they may roll about, thus assisting in the distribution of the spores. The puffballs and earth stars are in the same order (Lycoperdales).

The nest fungi. These beautiful little forms (order Nidulariales) grow on the earth and decaying wood and when open resemble a nest filled with eggs (Fig. 241). The egg-like structures are portions of the interior of the fructification, and each contains a clramber filled with spores.

The carrion fungi. These very malodorous fungi (order Phallales) grow in rich humus and mulchings. They are complicated stalked types first formed within a large globular structure which remains around the base of the stalk as a cup. The top of the stalk wears a dark-colored, sticky mass of spores, that has the odor of carrion and attracts carrion flies, which probably assist in the distribution of the spores.

278. Mycorrhiza. Mycorrhiza (meaning fungus-infected roots) is a remarkable association of the mycelium of certain fungi with the The section at the right shows the egy-like roots of many seed plants,
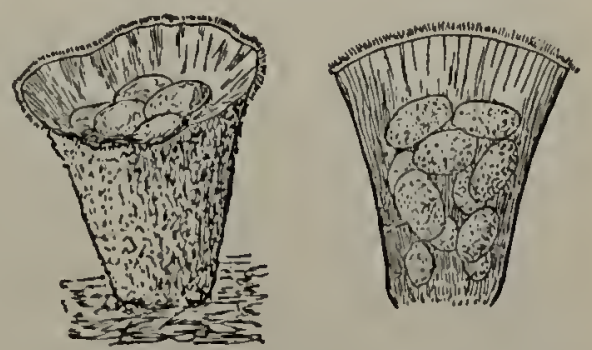
notably trees. The fungal filaments surround the roots witl a web (Fig. 242) and enter the outer regions of the root tissue, probably living somewliat parasitically upon the plant as a host. They are in close contact with the soil around the roots, 
and are believed to be of great assistance to them in their work in the following way. It is necessary for the roots, of course, to establish a close relation to the moisture of the soil in order to obtain water for the green parts of the plant above ground. The surface of the older portions is without root hairs and is surrounded by a hard outer layer which cannot come into very close contact with the minute moist soil particles. But it is thought that the fungal filaments act as root hairs, and perhaps through them the root can absorb a much greater quantity of

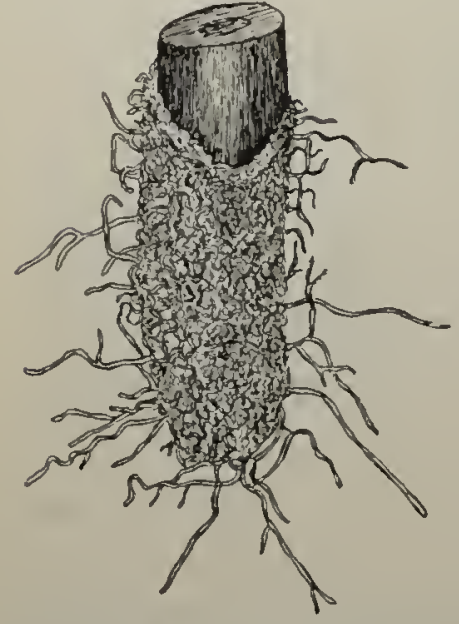

Fig.242. Mycorrhiza surrounding the tip of a beech root

After Pfeffer water and can well afford to give them what nourishment they require in exchange for such valuable services. It is probable that most trees and many others of the larger plants have formed this partnership with the fungi. The kinds of fungi concerned with mycorrhizas are not well understood, but some of them are known to be the mycelia of toadstools and puffballs. The sac fungi also furnish notable examples in the truffles (Sec. 269). The mycorrhiza relationship is an excellent illustration of symbiosis (which means a living together), for two organisms exist here in intimate physiological association and both apparently receive benefit from the partncrship.

279. Summary of the basidia fungi. The relationships between the different groups of the Basidiomycetes cannot be discussed further than to state that the promycelium of smuts and rusts, with its sporidia, is bclieved to correspond to the basidium with its four spores. There are two small groups called the jelly fungi (orders Aurieularales and Tremellales), including the rather common Jew's-ear fungus, whose basidia becone divided into four parts. In the Jew's-ear fungus the basidium 


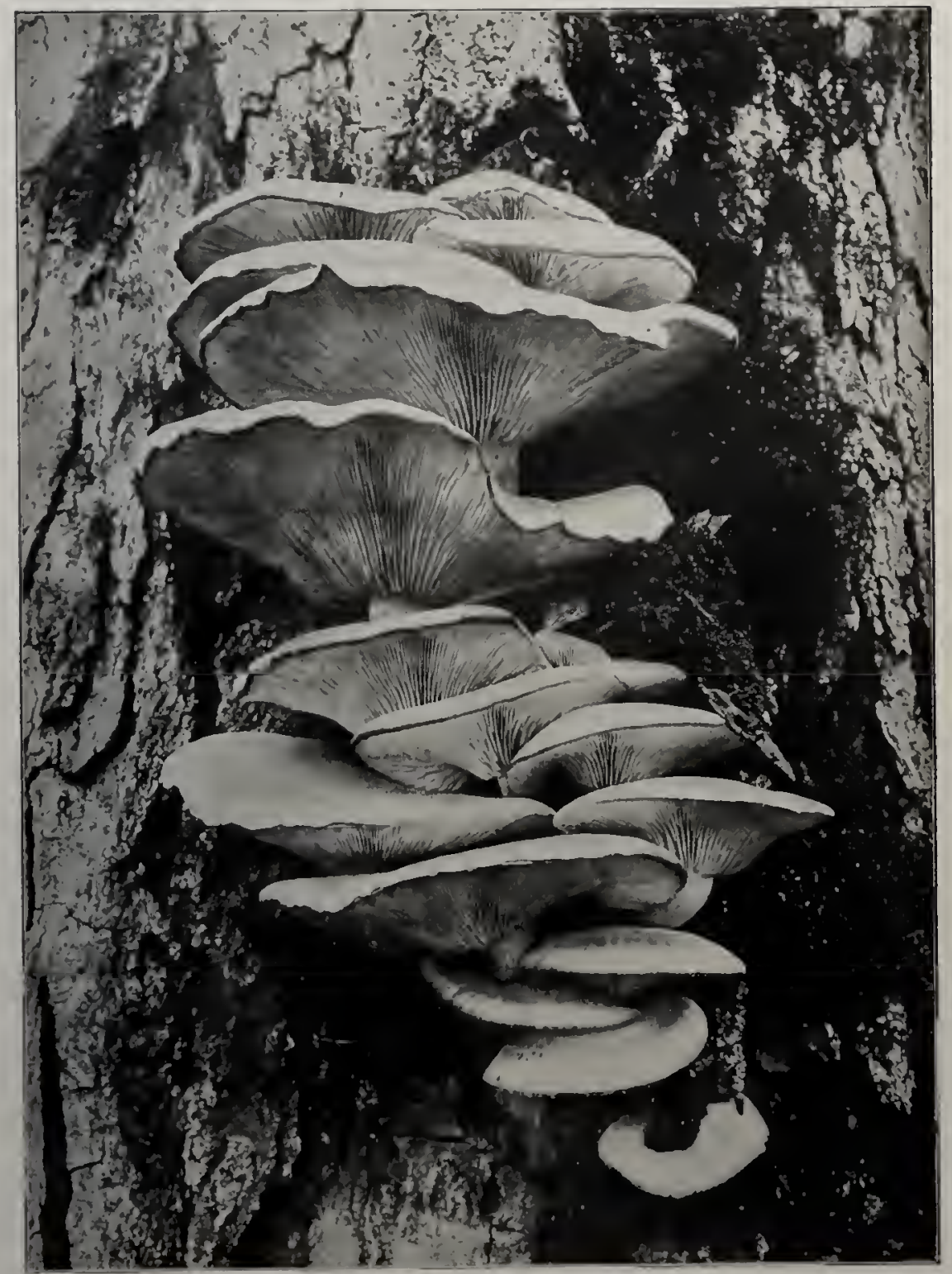

PLATE VI. A wound parasite (Pleurotus ulmarius) on the trunk of a maple tree 

is indeed a four-celled filament resembling the promycelium of a rust, each cell developing a spore at one side on a stcrigmata. The winter spores, or teleutospores, of the smuts and rusts are considered to be special resting cells of the fungi, developed to carry these parasitic forms over unfavorable seasons of cold or drought when the host plants are not alive. There is thus a brcak in the life history at the point where the basidium should normally appear. The germination of these spores continues the life history with the immediate development of a structure (the promycelium) which corresponds to a basidium with its spores.

The higher basidia fungi have apparently lost all trace of sexual organs, but the cluster-cup stage in the rusts is believed to indicate the remains of a modified sexual generation in their life historics. 'The evidence for this view rests chiefly upon the beliarior of the nuclei throughout the life history of the rust and is too complicatcd for trcatment here. The basidia fungi are therefore chiefly, if not wholly, apogamous. The origin and evolution of the Basidiomycetes is a problem as yet unsolved, which cannot be here considered. The basidia fungi are, however, by far the most wonderfully varied and specialized assemblage of the fungi. 


\section{CHAPTER XXIII}

\section{SUMMARY OF THE LIFE HISTORIES AND EVOLUTION OF THE FUNGI}

280. The life histories of the fungi. To understand the types of life histories in the different groups of the fungi one must bear in mind the life histories of the most nearly related groups of algæ (Sec. 247), for those of the fungi are based, of course, on the life histories of their algal ancestors. But there have been some very important modifications as the result of the parasitic and saprophytic modes of life of the fungi, and especially because the highest groups of fungi present much sexual degeneration, or apogamy, which of course in some respects simplifies the life histories.

The life history of the bacteria is essentially as simple as that of the blue-green algæ. The alga-like fungi (Phycomyetes) is a group, however, whose highest members (the molds, water molds, and blights) have reproductive organs with many points of similarity to the siphon algæ, and more especially to Vaueheria (Sec. 228). The sexually formed spores generally develop directly into plants like the parents, ${ }^{1}$ so that the formula for the life history is

$$
P-<_{g}^{g}>\operatorname{sex} . \text { s. }-P<_{g}^{g}>\operatorname{sex} . \text { s. }-P, \text { etc. }
$$

the abbreviations $g$ and sex. $s$. standing for gamete and sexually formed spore, respectively. There is often extensive reproduction through various types of asexual spores between successive sexual generations. And indeed sexual organs may only be formed at rare intervals, as in the bread mold, or they may

1 They form zoïspores, however, in some of the blights. 
not be functional so that a condition of apogamy is present, as in the water molds.

The life histories of the sac fungi (Ascomycetcs) are especially interesting in relation to those of the red algæ (Sec. 246). It is known in regard to a number of types that the sac fruits (ascocarps) develop as the result of a sexual process, corresponding in this respect to the cystocarps. The ascospores are formed at the end of the ascocarp phase of the life history just as the carpospores are formed at the end of the cystocarp phase in the red algæ. Both ascocarps and cystocarps are, then, new generations developed between and alternating with the sexual plants. T'hey are sporophytes alternating with gametophytes. The formula for the life history of a sac fungus with functional sexual organs is then

$$
\begin{aligned}
G< & g \\
g & >-S \text { (ascocarp) - asex. s. (ascospore) } \\
& -G<g \\
& -G>-S-\text { asex. s. }-G \text {, etc., }
\end{aligned}
$$

$G$ and $S$ standing for gametophyte and sporophyte, respectively, and asex. s. for asexual spore.

It must always be remembered, however, that the sac fungi have a great variety of methods of asexual reproduction through conidia, etc. Consequently sexual organs may be formed only occasionally, as in the green mildew (Penicillium). There is also probably much apogamy in the group, so that the sac fruits are apogamously developed.

The basidia fungi present the remains of an alternation of generations in the rusts somewhat similar to that of the sac fungi. The cluster cups are believed to be the beginning of a phase that formerly followed a sexual process just as do the ascocarps and cystocarps. However, the male organs (spermogonia) of the rusts are no longer functional, and the cluster cups must be considered as developing apogamousy, although there js noy a complicated history substituted for the original sexual 
process. The cluster-cup stage is omitted entirely in some of the rusts and in all of the smuts, and there are likewise no traces of it in the higher basidia fungi (Eubasidiomycetes). Sexual degeneration in these forms, then, has apparently been carried so far that the sexual organs have disappeared entirely from the life histories.

281. The origin and evolution of the fungi. The study of the evolution of the fungi must be taken up for each of the larger classes separately, for there is every probability that each has had an independent origin from widely separated groups of the algre. The bacteria have probably been derived from the blue-green algæ. The higher alga-like fungi (molds, water molds, and blights) apparently show relationships to the siphon algæ. Some authors believe that the sac fungi have come from the red algæ. The origin of the basidia fungi is very much in doubt and that of the yeasts also, although it is generally held that the latter are degenerate forms from some of the higher fungi. The evolution of the fungal forms in each group becomes very complicated, because the fungi have such wonderfully varied habits resulting from their parasitic and saprophytic ways of living. In fact, these life habits have produced the greatest variety of structures and adaptations known in any group of spore plants. Still more remarkable, perhaps, is the widespread tendency towards sexual degeneration, which is also believed to be associated with the parasitic and saprophytic life habits. 


\section{CHAPTER XXIV}

\section{THE BRYOPHYTES AND THE ESTABLISHMENT OF ALTER- NATION OF GENERATIONS}

282. The bryophytes.* 'The division Bryophyta (meaning moss plants) is the next great group of plants above the division Thallophyta (Chapter XIX), and includes two classes: (1) the liverworts, or Hepatica, and (2) the mosses, or Musci. It is not best to define these classes until the structure and life histories of types from each group have been studied. Furthermore, it is impossible fully to understand the cliaracters of the bryophytes and thallophytes except when compared with one another. Accordingly these matters have been reserved for the final section of this chapter under the heading Summary of the Bryophytes and Thallophytes (Secs. $300,301)$.

However, the bryophytes differ from the thallophytes in two very important respects which may be briefly stated at once, for they must be thoroughly comprehended in order to understand the life histories of the liverworts and mosses. They can only be nade clear when illustrated through labora-

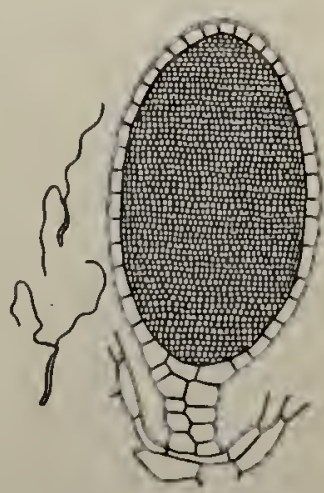

Fig. 243. The antheridium of a liverwort (Marchantia)

Antheridium in seetion, showing the outer eapsule and the mass of small eells within, in which are developed the minute two-ciliate sperms sliown at the left. - After Saehs tory studies. These two differences are (1) in the sexual organs, which are many-colled, and (2) in the appcarance of a new stage in the life cycle called the sporophyte.

* To the Isstructor: The introduction to this chapter assumes that the life history of a liverwort or moss has been studied in the laboratory. 
283. The sexual organs. The sexual organs of the bryophytes are many-colled. They are male and female and each consists

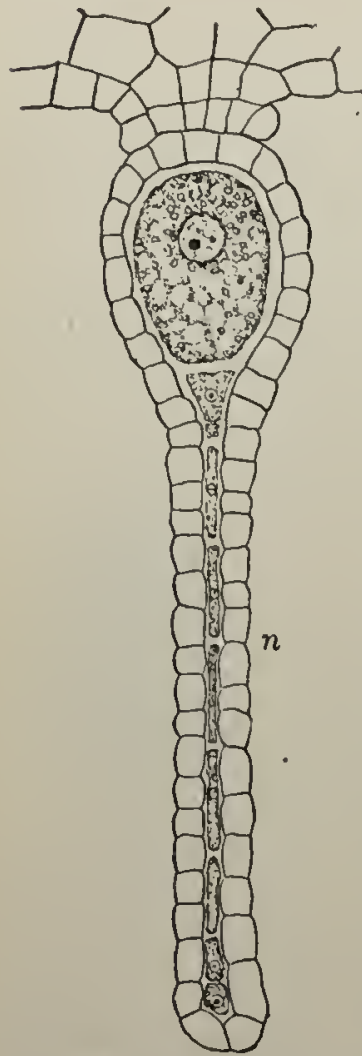

Fig. 244. 'The a rehegonium of a liver.wort (Marchantia)

The archegonia in this genus hang down from a special receptacle (Fig. 251). The large egg is shiown in the swollen base of the archegonium, while the neck $n$ contains a row of canal cells which break down into mucilage as the archegonium matures. of a cellular case, or capsule, in which are formed the respective gametes, which are sperms and eggs. It will be remembcred that the sexual organs of the thallophytes are, with very few exceptions, one-celled. The conspicuous exceptions are the plurilocular sexual organs of the lower brown alga (see Ectocarpus, Sec. 235 ) and the antheridium of the stoneworts (Sec. 230).

The spcrm-producing organ, or anthcridium. The antheridium (Fig. 243) is a stalked, oval or elliptical structure, wit! an outer cellular envelope inclosing a dense mass of very small cubical cells in which are developed the sperms. The sperms are minute elongated or slightly coiled protoplasts, with a pair of cilia at one end. The mature antheridia only discharge their sperms when wet, as after heavy rains or dews, and the sperms then swim about in the moisture. At these timcs the plants are practically leading an aquatic life like their algal ancestors, and the development of motile sperms in these land plants shows clearly that they must have come from forms with aquatic life habits.

The egg-producing organ, or archegonium. The female organ is called an archegonium. It is flask-shaped (Fig. 244), and the outer cellular envelope incloses at maturity a row of cells. The cell situated in the enlarged portion of the archegonium 
(venter) Lecomes the single egrg, while the others in the neck region (Fig. 24t, $)$, called cancl cells, break down and their substance becomes changed into mucilage. The archegonia, like the antheridia, open only when wet, the cclls at the tip separating so as to give a clear passage for the entrance of the sperms into the neck. The sperms are attracted to the opening by certain substances such as sugar contained in the liquefying mucilage. The sperms swim down the neck, and one of them, fusing with the egg, fertilizes it. There is much evidence that the canal cclls are degenerate gamctes, and that the archegonium came from a type of sexual organ that originally produced a number of gametes, as loes the antheridium.

284. The sporophyte. The term sporophyte has appeared before in the accounts of the red alge (Sec. 246) and sac fungi (Secs. 266, 272) where ccrtain peculiar fructifications (cystocarps and ascocarps), following the sexual process, alternated with the sexual plants. The sporophytes of the liverworts and mosses have a similar position in the life history, and are likewise borne on the parent plants and frequently called their "fruits."

The sporophyte of the liverworts and mosses develops at once from the fertilized egg, which never becomes a resting spore (oöspore), as in the algie. The form is various in different groups. Most of the nosses have long, stalked sporophytes (Figs. 261, 265), which end in swollen spore cases. The liverworts generally have much smaller sporophytes, some of which have no stalk at all and consist of the spore casc alone. If the sporophyte is small it may remain inclosed in the base of the archegonimn, which becomes much enlarged. But the stalked sporophytes cither burst out of the archegonim, or frequently, as in the common mosses, tear it off and carry it upwards as a cap-like structure (Fig. 265, B, cal) called the ealyptra (meaning a veil). The sponophytes always remain attached to the parent plant, and finally develop spores asexually in the sporc cases. The spores are formed in groups of four, called tetrads, within spore mother cells (Figs. $245, B, s ; 258, B$ ). These asexual 
spores have heavy walls aud can survive the winter, frequently protected by the spore case. It will be remembered that in the algat the sexually formed spore is generally the protected resting spore.

285. Alternation of generations. There are thus two pliases in the life history of a liverwort or moss. First, there is the plant which bcars the sexual organs, and this is called the gametophyte (meaning a gamete-bearing plant) ; second, there is the structure which arises from the fertilized egg and ends its history by developing asexual spores, and for this reason it is called a sporophyte (meaning a spore-bearing plant). 'The gametophyte is developed from the spore, and the sporophyte from the fertilized egg. So there is a regular alteruation of these two phases in the life history, the gametophyte producing sexual cells, or gametes, and the sporophyte prodncing asexual spores. The two phases are regarded as separate generations because each has its origin from a distinct kind of reproductive cell (erg or spore). The ganetophyte is of course a sexual generation and the sporophyte an asexual one. Their following one after the other makes an alternation of generations, - a phrase which from now on will be frequently used, because it siguifies the most remarkable feature in the evolution of all plants above the thallophytes. The simple sporophytes of ancient bryophytes gave rise to the feru plants and through them to the large and complicated seed plants.

A life history which consists of an alternation of sporophyte and gametophyte, as in the liverworts and mosses, may be expressed by the formula

$$
\begin{aligned}
\text { Gametophyte }<\text { sperm } & >- \text { Sporophyte }- \text { asexual spore } \\
& \text { - Gumetophyte, etc. }
\end{aligned}
$$

This in an abbreviated form becornes

$$
G<_{e}^{s}>-S-s p-G<_{e}^{s}>-S-s p-G, \text { ete. }
$$


One must bear in mind these general characters of the bryophytes, as the liverworts and mosses are separately taken up and their characters finally summarized by treating the subjects under the four heads:

Class I. 'T'he liverworts, or Hepatice

Class II. The mosses, or Musci.

The origin and evolution of the bryophytes.

Summary of the bryophytes and thallophytes.

\section{CLASS I. 'THE IJVERWORTS, OR HEPAT'CAE}

286. The liverworts. The liverworts grow most luxuriantly in moist and sliaded situations, some forms on the ground, some on rocks, and some on trees. There are also certain aquatie liverworts which float on the surface of the water, and a few very simple ones which are entirely submerged like the alge. 'Thus, although most of the types have the land habit, some show very clearly adaptations for the aquatic life of their ancestors anong the algae. The creeping liabits of the liverworts probably indieate the way in which land plints arose and beeame estallished first along the margins of streams, ponds, and marshes where algal growths emerged from the water or were left stranded on the wet earth. These first land liverworts naturally clung close to the wet earth in the beginning, until the development of root-like systems of filaments (rhizoids), which could gather moisture, permitted them to develop upright stems as in the mosses. The forms of the liverworts are various, as will appear in the following brief account of the four orders.

287. The Riccia group. The simplest liverworts (order Ricciales) have a flat plant body (gametophyte), some forms floating on the surface of the water and others subnerged, while certain types grow close to moist earth. The plant body is a true thallus (Fig. 245, A), and indeed is much simpler than the plant hodies of many thallopliytes among the brown and red alge. The lower surface of the thallus bears numerous filanents, 
called rhizoids (from their resemblance to roots), and delicate membrane-like fringes, which draw up water from the soil like
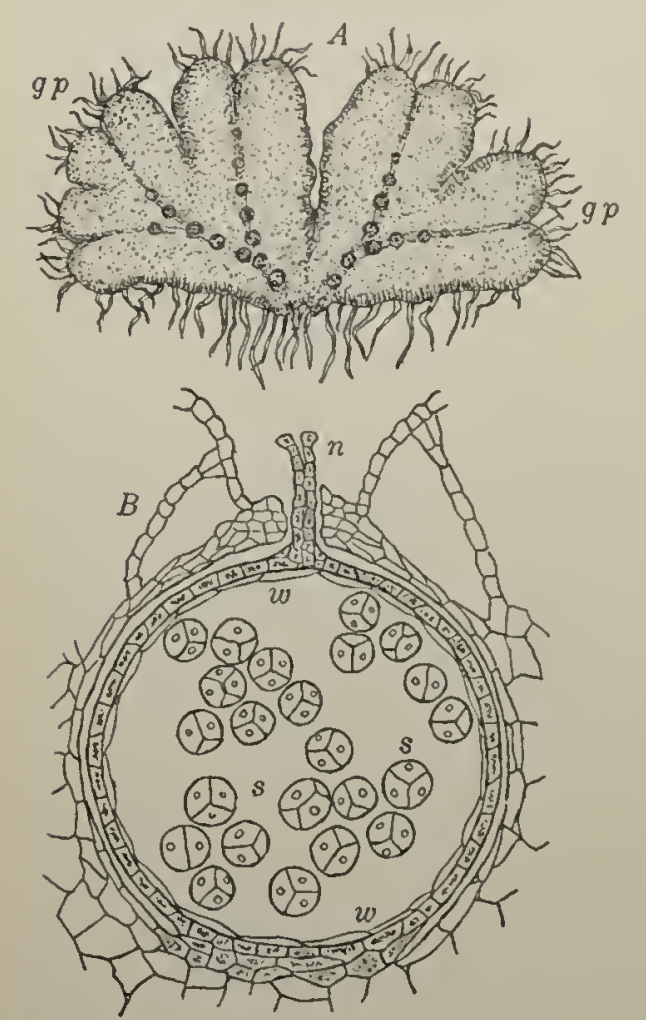

F1G. 245. A floating liverwort (Ricciocarpus) and its sporophyte

$A$, habit sketch of the sexual plant (gametophyte) viewed from above, showing the position of the sporophytes in lines back of the growing points $g p . \quad B$, section of a sporophyte contained within the parent archegonium, whose neck $n$ is still present: $s$, spores in groups of four (tetrads) within the spore mother cells; $w$, remains of the wall of the sporophyte root hairs if the plant has the land labit. The thallus grows from a number of points (Fig. 245, $1, g p$ ) situated in notches at the ends of lobes which fork in pairs and finally split apart, so that the plants multiply very rapidly during the vegetative season. The sexual organs are borne on the upper surface of this gametophyte, and the sporophyte is a simple globular case (Fig. 245, B), filled with spores, which remains inclosed in the base of the archegonium, so that the spores are not set free until the decay of the plant.*

288. The Marchantia group. This large group (order Marchantiales) is well represented by tlie common liverwort (Marchantia polymorpha), which grows on the ground in noist situations. The ribbon-like thallus of species of Marchantia (Fig. 246) forks regularly, but one of the branches is

*'To тик Ixiтитстов: These points are admirably illustrated in the large floating form (Ricciocarpus natans), which is not uncommon and is an excellent type for laboratory study, al though Marchantia is the form most generally used. 
almost always larger and stronger than the other. The lower surface bears numerous filaments and fringes which are formed in front of the growing points, protecting them, and later become distributed along the lower surface. The upper surface is marked by diamond-shaped areas (Fig. 247, A) which show the position of eurious large air chambers (Fig. $\left.247, J^{\prime}\right)$ that contain very $f r$, female reeptacle; $c$, eups produeing buds. numerous filaments whose

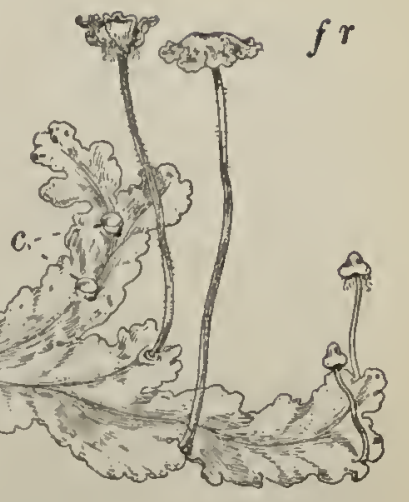

Fici. 246. A Mrarchentia form (Marchantic disjuncta) cells have well-developed chloroplasts. These filaments perform
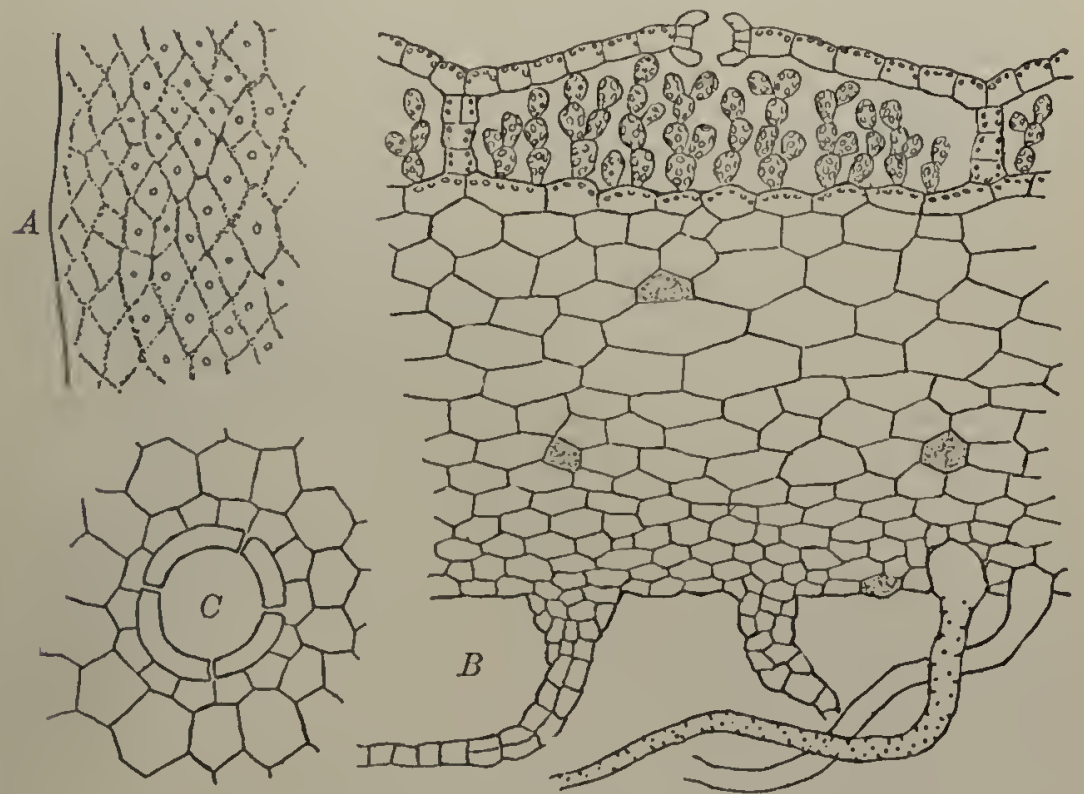

Fig. 247. Structure of the thallus of Marchantia

$A$, surfare of thallus, the dlinmoul-shazper a reas marking air chambers; B, a section throngh the midulle region of the thallus showing air chambers al,ove, filled with branching green filaments, and the fringes and root-like hairs (rhizoids) on the lower surface; $C$, surface view of the pore which opens into an air chamber 


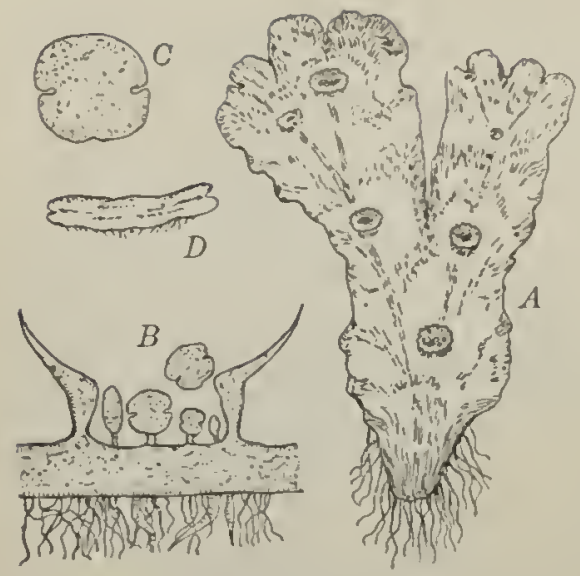

Fir. 248. The cups and buds of Marchantia

$A$, cup-bearing plant; $B$, section of a cup showing the buds arising from its bottom; $C$, a bud slowing the two growing points; $D$, young plant developing from the bud the greater part of the chloroplyyll work (photosynthesis) of the plant, and the chambers are dereloped as protective structures around them. Each chamber is open abore to the air by a circular pore (Fig. $247, C)$, which can be easily seen in the center of each diamond-shaped area. This specialization of the upper surface of the Marchantia plant to a light relation gives it a general resemblance to the cell structure of leaves in seed plants and ferns.

Some individuals of Marchuntia (Fig. 248, A) will usually be found bearing cups (cupules) which contain numerous green bodies. These are many-celled reproductive organs, called buds (gemmæ), which develop from the bottom of the cup (Fig. 248, B). Each bud has two notches at opposite sides (Fig. 248, C), which become two growing points when the structure falls on its side upon damp earth and begins to grow (Fig. 248,D). This is a characteristic and very successful method of rapid asexual multiplication in Marchantia.

The sexual organs of Marchantia are developed

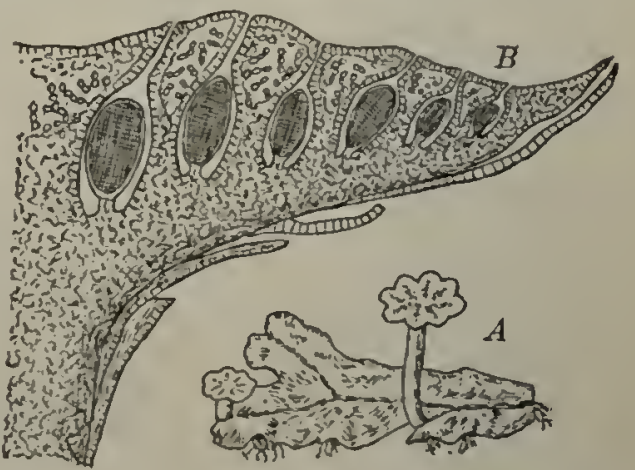

F1:. 24?. The male plant of Marchantia $A$, male plant bearing antheridial receptacles; $B$, lengthwise section of a receptaele (semidiagrammatic), showing a row of sunken. antheridia upon the upper surface; the roungest lie just back of the notches in the receptacle, which are the growing points; air ehambers are also shown on the upper surface 


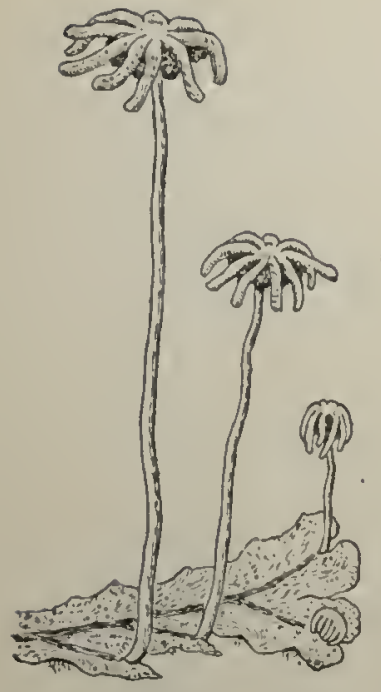

Fic. 250. Female plant of Iarchantia

Showing the umbrella-like arehegonial receptacles in various stages of development

on stalked, umbrella-like receptacles, which are really much-modified branches of the thallus. They bear either antheridia or archegonia, and the two sexual organs are not found together on the same plant. The antheridial receptacle (Fig. 249. $A)$ is shorter than the archegonial, and the top is a flattened disk with a lobed or scalloped margin. The antheridia (Figs. 243, 249, I) lie in cavitics or pits along radiating lines

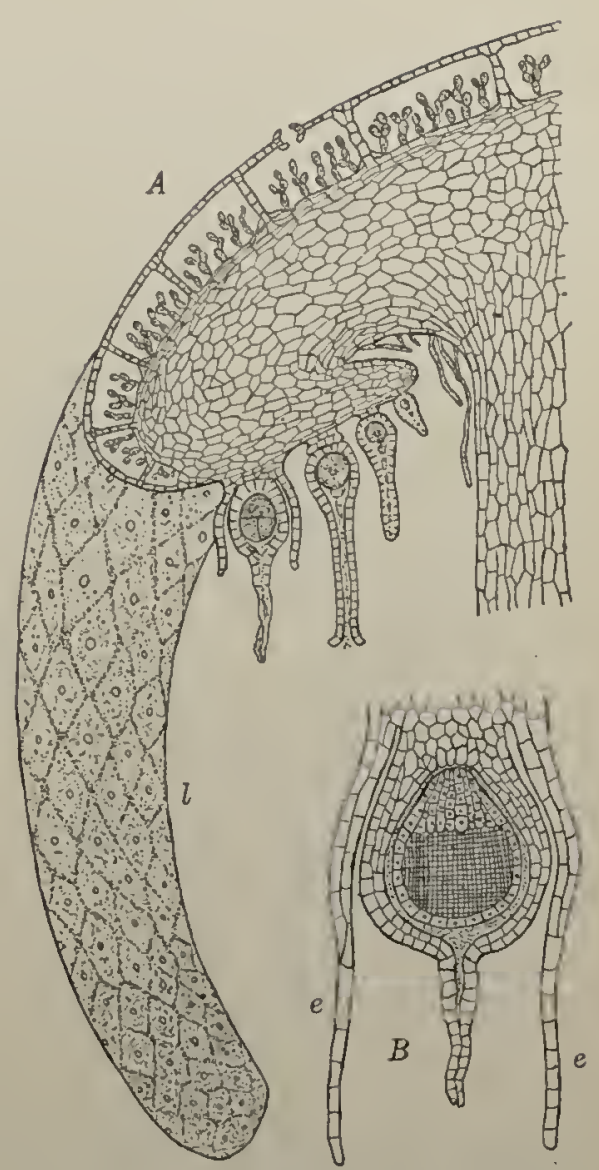

Fig. 251. The female receptacle of Marchantia

A, portion of a lengthwise seetion of a young receptacle (semi-cliagrammatic), showing a row of arehegonia hanging down from the lower surface, the youngest being nearest the stalk: air ehambers are present on the upper surface; $l$, one of the finger-like lobes back of the section, the diamond-shaped areas indicating ail chambers. $l$, a young sporophyte within the parent archegonium: the region which is to become the spore case is indicated by the corss lines, and the small foot is attached to the base of the archegonimm; $e$, a special envelope developed arouml the archegonia of Murchuntice 
on the upper surface of the receptacle, and the youngest antheridia are found nearest the notches which mark the position of the growing points along the edge of the disk. The archegonial receptacle (Fig. 250) is larger than the antheridial, and the top is bent back into several long, finger-like projections like the ribs of an umbrella. Numerous archegonia are formed in lines (Fig. 251, A) on the under side between the lobes, and are protected by singular fringes. The youngest archegronia are formed

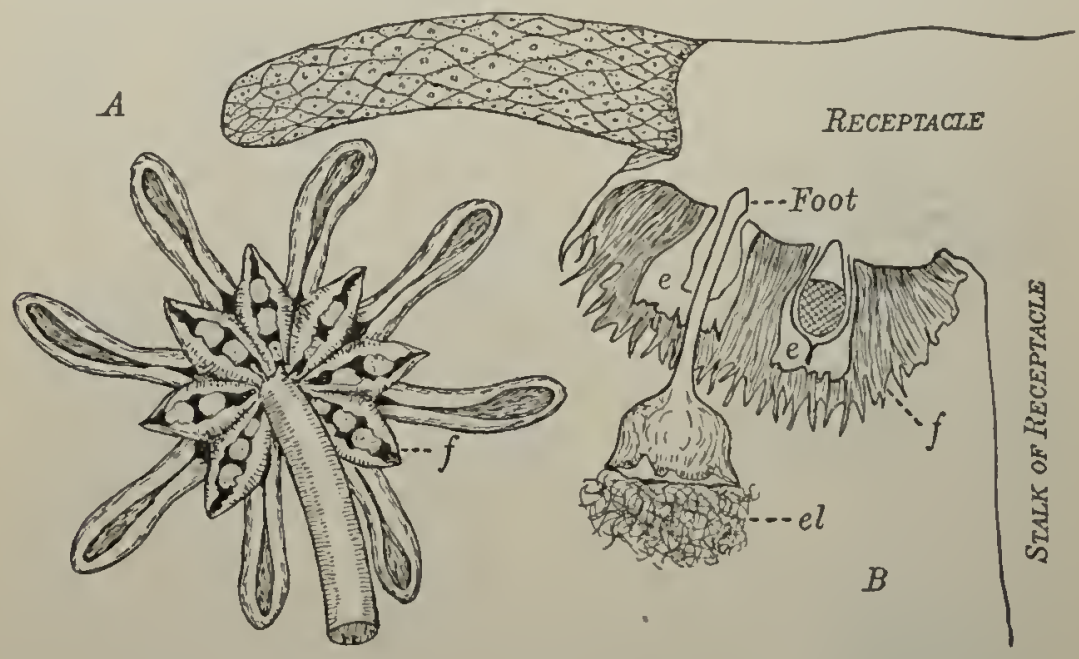

Fig. 252. Sporophytes and receptacles of Marchantia

$A$, lower view of an old female receptacle, showing the sporophytes in rows hetween the fringes $f$, like peas in a porl. $B$, section of a receptacle (diagrammatic), showing a mature sporophytc anchored ly its foot and projecting beyond the fringe $f$ : the spore case is open, cxposing the mass of elaters $e l$; a young sporophyte is slown at the right still inelosed within the archegonimn (calyptra); e, special cnvelopes around the archegonia and sporoplytes

nearest the stalk, so that the older ones lie farther ont,-an arrangement exactly opposite from that of the antheridia. This is explained by the fact that the growing points which lie between the lobes grow downward and underneath towards the stalk. The edge of the disk is thus bent back on itself, and the lower surface is really an extension of the upper surface.

A number of arcliegonia may be fertilized in Marchantia, and their eggs then develop sporophytes in radiating rows on the 
lower surface of the receptacle (Fig. 252,A) between the fringes. The sporophyte is more complex than in the Riccia types. The lower part (Figs. $252, B ; 253, A$ ) becomes a small organ of attachment to the gametophyte, called the foot, through which it obtains water with food in solution. The upper part becomes a spore case, developing numerous spores, and among them spirally marked filaments, termed elaters (Fig. 253, B), which are stiff and elastic and help to distribute the spores. The elaters are developed from cells in the young spore case. The spore case is carried beyond the fringe of the receptacle (Fig. $252, B)$ by the elongation of the region above the foot, which forms a stalk. The presence of a foot and stalk in addition to the spore case marks a decided advance over the simple sporophytes of the Riccia types, which consist of the spore case alone.

It is very important to note that the, sporophyte has this close attachment to the gametophyte and is dependent upon it for water and food in solution, because it shows that the sporophyte of the liverworts really lives in large part like a parasite upon the gametophyte as a host.

289. The Jungermannia group. This assemblage (order Jungcrmannialcs) is

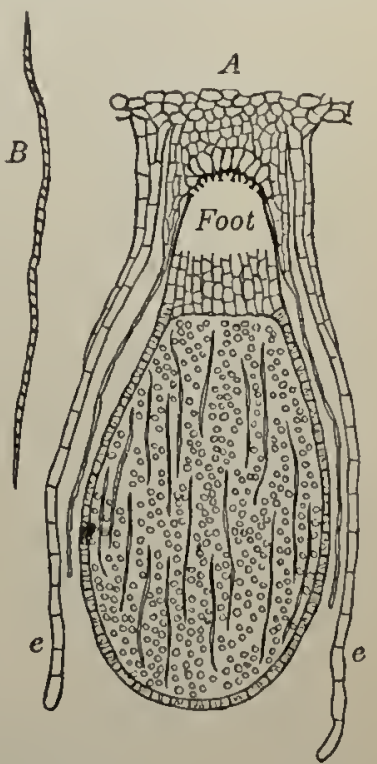

Fig. 253. The sporophyte of Marchantia

$A$, longitudinal section of sporophyte showing spore case and foot attached to the base of the archegonium: $e$, a special envelope. $B$, an elater very much the largest group of the liverworts and contains more than three thousand species. They are known as the leafy liverworts because most of them have long stems, with delicate, moss-like leaves. 'The leafy liverworts are frequently mistaken for mosses, since they are common on tree trunks and in shaded situations. But they have a creeping habit, and there are two crowded rows of large leaves (Fig. $254, A$ ), one on each side of 

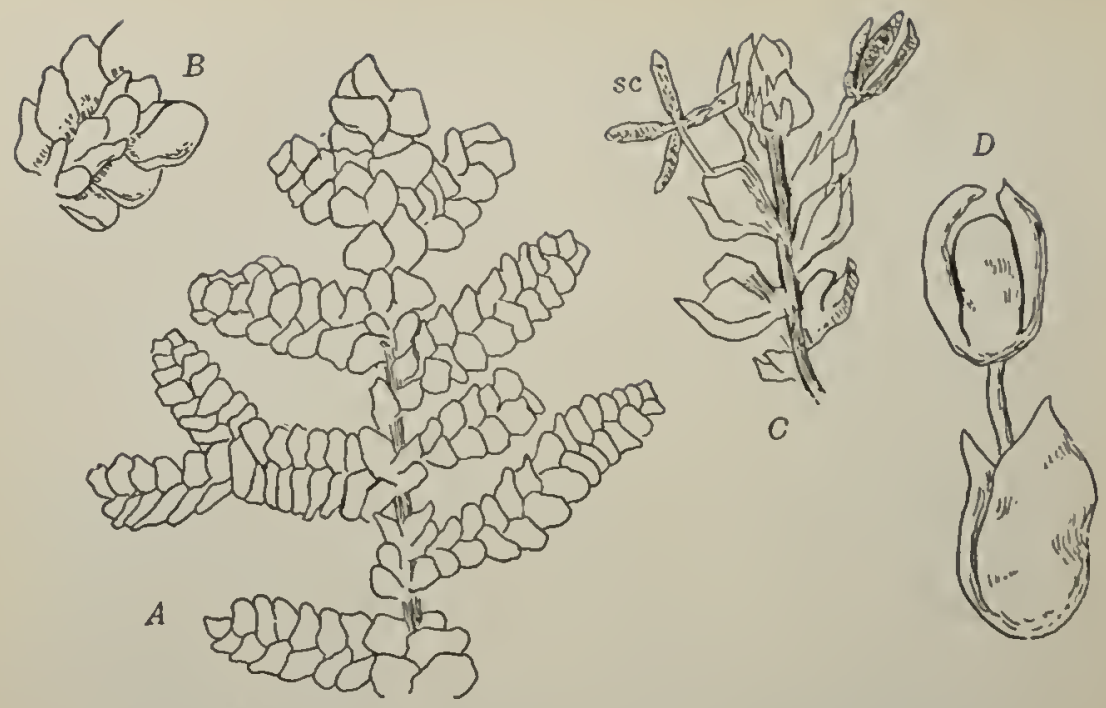

FIG. 254. The female plant of a leafy liverwort (Porella)

$A$, habit sketch of the upper surface, with the two rows of leaves at the sides; $B$, a portion of lower surface, showing the third row of small leaves (amphigastria); $C$, the stalked sporophytes with open spore eases $s c$; $D$, a sporopliyte with the spore case split lengthwise into four parts. - After Campbell

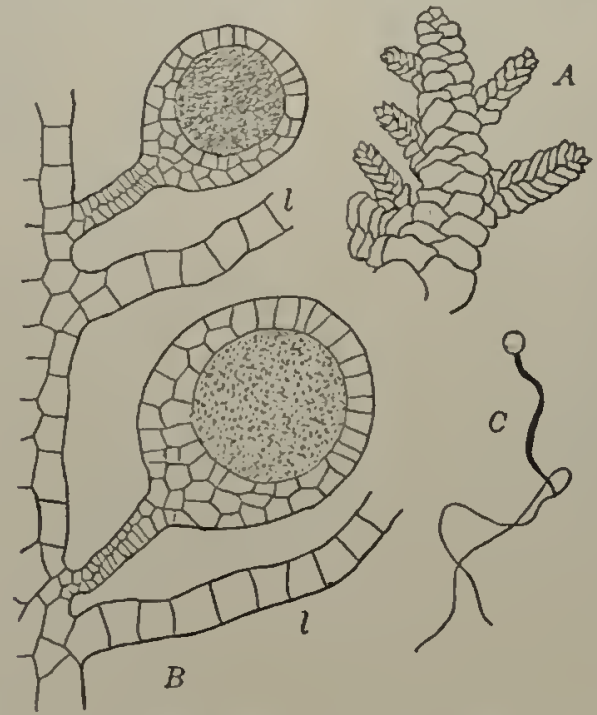

Fig. 255. 'The antheridia of a leafy liverwort (Porella)

$A$, portion of male plant, illustrating the small antheridial branches at the side; Ii, section of all antherilial branch, showing two antherilia situated just above the attachment of the leaves $l$; $C$, the much-elongated sperm, with the two cilia at one end aul the remains of the parent cell at the other. $-C$, after Camplell 
the stem, and a third row of small norlified leaves on the lower surface (Fig. $25 t$, li). The stems of nosses, on the contrary, are almost always mulight, and the leares are arranged radially, 30 that the stem has no nlyer or lower surface.

The antheridia of the leafy liverworts are borne singly along the stem at the bases of the lateral leaves (Fig. $25 \overline{5}, B$ ) on certain branches which are frequently much smaller than the vegetative shoots (Fig. 25\%, A). The archegonia are developed in clusters at the ends of branches.

The sporophyte (Fig. $256, A$ ) has a stalk which elongates rapidly just before the spores are rearly to be shed, so that the spore case is raised above the gametophyte (Fig. 25t, C), as in the mosses. However, the spore case is much less complex than that of the mosses, being a simple capsule that splits length-

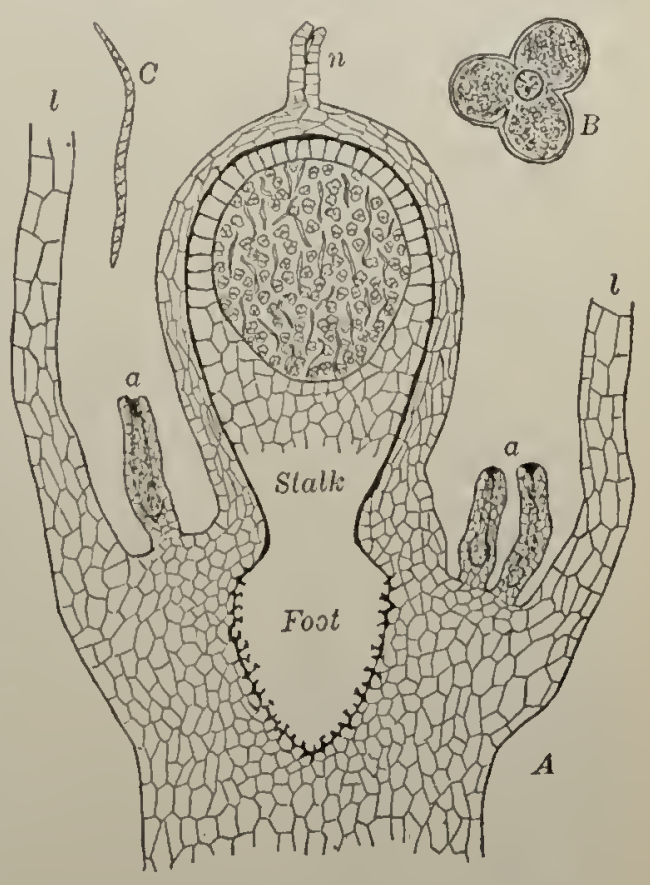

Fig. 250. The sporophyte of a leafy - liverwort (Porella)

$A$, section of a sporoplyyte still contained within the parent archegonium, whose neek $n$ is shown alove, the foot deeply sunken in the tissue of the rametophyte: $a$, arehegronia of the terminal group, which were not fertilizen; $l$, leaf-like envelopes. $B$, the four-lobed spore mother orll, which develops four spores (tetriul). (C, an elater

wise into four parts at maturity (Fig. $25 t, D)$. There are spirally thickened filaments, or elaters (Fig. 256, $C^{\prime}$ ), anong the spores, as in Mrerchantir, and these structures are not found in the mosses. The foot of the sporophyte (Fig. 256, A) is always well developed in the leafy liverworts.*

* To tur INstricton : Gool material of the leafy liverworts frequently furnishes better subjects for type study of the liverworts than Marchuntiu. 
290. The Anthoceros group. These types (order Anthoccrotales) are considered the lighest of the liverworts because of their more complicated sporophytes. The gametophytes are thalloid (Fig. 257), somewliat irregular in outline, and more simple in structure than those of Marchantia. The sporoplytes are an inch or more in lieight, and grow up from the gametophyte like blades of grass. The upper portion splits lengthwise into halves at maturity.

The spores of Anthoceros do not all mature at once, as in other liverworts, but new spores are formed at the base of the sporo-

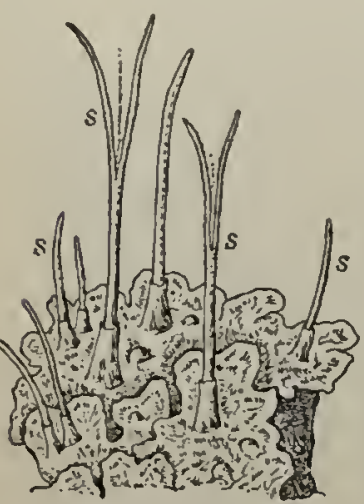

FIG. 257. Habit sketch of Anthoceros

The thalloid sexual plants (gametophytes), with the sporoplytes $s$ in various stages of development

plyte as the older mature (Fig. 25S, $A$ ), and there is a continuous elongation of the structure during the summer frnm a basal region of growth. The cells conposing the wall of this long sporophrte contain large single chromatophores (Fig. $258, E)$, and there are breathing pores, or stomata (singular, stoma, meaning a moutlı), on the surface (Fig. 258, D), which lead into intercellular spaces in the green tissue beneath. Consequently the sporophyte is able to manufacture its own food by photosynthesis, as any green plant may do. But it depends upon the gametophyte for its supply of water, which is absorbed through a large bulbous foot (Fig. 258, A) that is deeply inbedded in the thallus of the gametophyte.

If the base of this sporophyte could establish a root-like structure growing in the soil, it might live independently of the parent gametophyte, for it has chlorophyll-bearing tissues in communication with the air through stomata, just as in the ferus and seed plants. And it has also the power of indefinite growth from its basal region (Fig. 258, A), limited only by the length of the summer season. These peculiarities of the sporophyte of Anthoceros are very suggestive of the way in 
which higher plants must have arisen from forms somewhat like the liverworts, a subject which we shall consider later in our account of the ferns (Sec. 331). Of all the bryophytes, this seems to be the genus which most closely approaches the higher plants. This account of plant evolution is now well started towards the higher conditions of plant development, namely, those of the ferns and seed plants whose sporophyte generations are independent plants with roots, stems, and leaves, and which comprise the most independent and successful regetation on the earth.

\section{CLASS II. THE MOSSES, OR IIUSCI}

291. The mosses. The mosses are very much more numerous than the liverworts. Some of the common kinds grow in extensive carpets on hillsides and in forests, becoming important factors in the plant

$A$, longitudinal seetion (semi-diagrammatie) through the base of the sporophyte, showing the large foot imbedded in the tissue of the gametoplyyte, the region of growtli, and the spore-produeing tissue which forms a eylinder in the eenter of the stalk; $B$, a group (tetrad) of four spores (three shown) in a spore motlier cell; $C$, spores; $D$, a stoma viewerl from the surface; $F$, seetion through a stoma, showing cells with large single chromatoplores under the surfaee layer (epidermis)

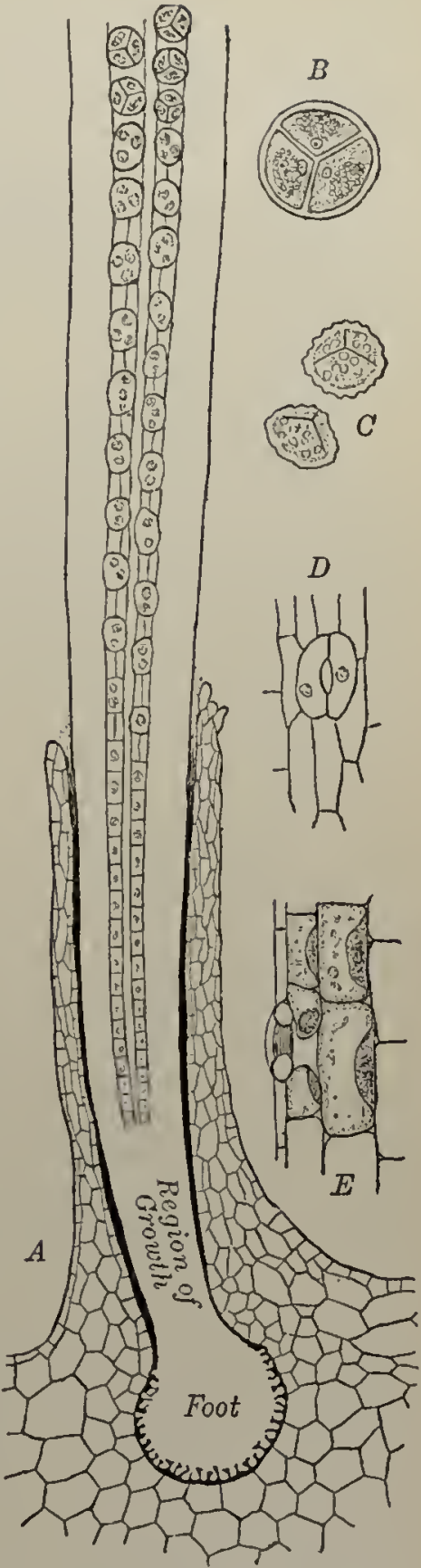

Fig. 258. The sporopliyte of Anthoceros 
formations of many regions. The peat mosses are the chief inhabitants of ccrtain kinds of bogs and pond margins. The mosses

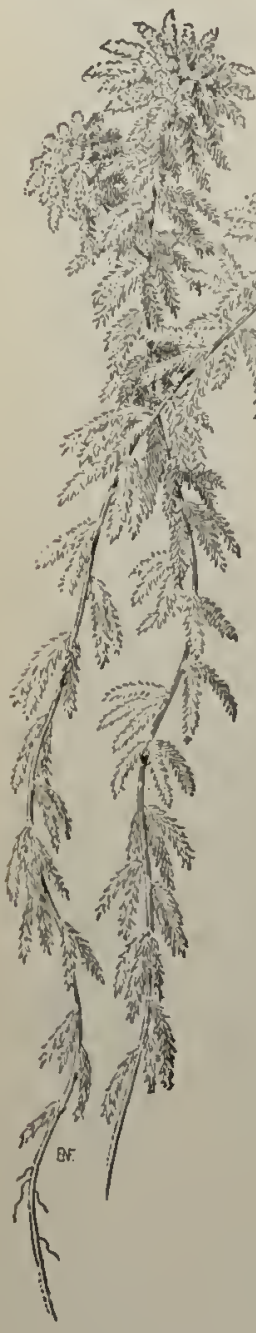

FIG. 259

The peat moss

(Sphagnum) thercfore constitute a group of considerable importance in the plant population of the earth, while the liverworts are for the most part confined to rather special life habits and, with the exception of the leafy liverworts, are not rich in species or numerous in individuals. Almost all of the mosses fall into two groups, which may be called the peat mosses and the common mosses.

292. The peat mosses. The peat mosses (order Spliagnales) are very remarkable for thcir structure and life habits. There is only a single genus, Sphagnum, with about two hundred and fifty species. The plants (gametophytes) have long stems, with delicate, lcafy branches, some of which grow downward and soak up water, while the rest form a dense cluster at the top (Fig. 259). The peculiar structure of these noosses allows them to absorb and hold water like a sponge, for which reason they are used by gardeners for packing around plants and flowers. The dricd moss is somctimes used for bcdding in stables.

The sexual organs (antheridia and archegonia) are formed very early in the spring or in the late winter, and the fertilization of the cgg leads at once to the development of a sporophyte. The sporophytes are large, smooth capsulcs (Fig. $260, A)$, which appcal to have stalks, but these are really special developments of the gametophytes. The spore case is attached to the top of the stalk by a large foot and opens by a cover (Fig. 260, B, e), which falls off. The spores on germination produce small flat ccll plates, out of which the lcafy 
peat mosses arise from special buds. These cell plates suggest the simple thalloid gametophytes of the liverworts, and the leafy structure is perhaps a special development from them.

The peat mosses live in bogs and swamps and are especially common in northerly regions and in the momtains, where they
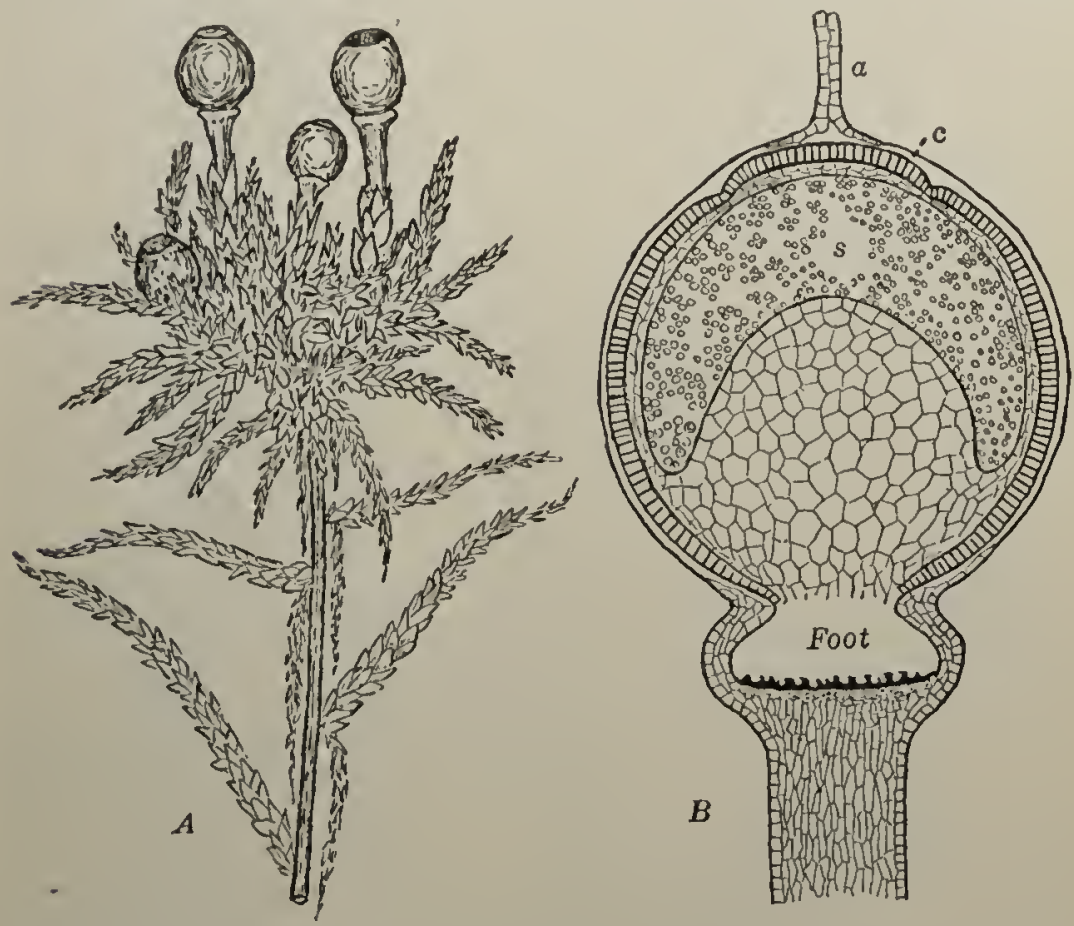

Fic. 260. The sporophyte of the peat moss (Sphaynum)

$A$, group of the sporoplyytes on stalks, whieh are really growths from the gametophyte. $I$, longitulinal seetion througl a sporophyte, showing the large font imbedled in the top of the stalk: $a$, the remains of the parent archegonium, with the neek still present; $s$, spore chamber; $c$, cover

grow over wet rocks, sometimes covering large areas. They' frequently accompany certain sedges and shrubs that grow inward from the margins of ponds over the surface of the water, which finally becomes covered with a mat of floating vegetation. Such growths produce soft or quaking bogs, for the surface is not firm enough to hold any large animal which might walk upon it. Quaking bogs become firmer as the lower 
parts of the plants die and form a deposit below, called peut. These deposits may grow to be many feet in thickness, and finally bccome so firm that they can be cut out in blocks. Such blocks when dried are used for fuel, especially in Ireland and in parts of Germany. There are regions of the northern United States, Canada, Europe, and Asia, where the peat-forming plants cover immense territories, and there are innumerable bogs filled with deposits of peat which may sometime become important sources of fucl supply.

Peat bogs are generally poorly drained or not drained at all, and the water often becomes rich in certain toxic organic substances that result from the partial decomposition of the regetation. The accumulation of these substances renders the water unfit for the growth of bactcria, and is largely responsible for the preservation from decay not ouly of the remains of the peat mosses but of other plants with them. It is said that whalers and other ships from the New England coast, when starting on long voyages, preferred to take their supplies of drinking water from peat bogs because of its keeping qualities. Oceasionally the bones of extinct animals, such as the mammoth and mastodon, are found in peat, since these gigantic creatures becamc mired in the soft bogs of former periods.

As a soft or quaking bog becomes firmer, grasses may appear and some characteristic orehids (Calopogon; Pogonia, Arethusu, Cypripedium, etc.), the insectivorous plants Sarraccnia (Fig. 311) and Drosera (Fig. 312), such heaths as the swamp cranberry; swamp blueberry, swamp azalea, and Labrador tea, and ccrtain trecs, as the lareh or tamarack (Larix), black spruce (Piceu), arbor vite (Thuya), white eedar (Chamacyparis), alders, and the red maple. These plants and others, in various combinations with the peat mosses, form very characteristic associations, and furnish some of the best illustrations of what the ecologist calls plant formations. The northeastern United States and Canada are full of examples of this interesting feature in the natural history of the Sphagnum swamp. 
293. Common mosses.* The common mosses (order Bryales) are familiar because of the occurrence of numerous species with conspicuous upright stems, which develop the longstalked sporophytes with characteristic terminal spore cases (Figs. 261, 265). It is a very large group, containing over eight thousand species, and is by far the most numcrous assemblage in the bryophytes. These mosses grow in the greatest variety of situations, - in swamps and bogs, in the water of streams, in moist and shaded woods, in open fields, and on relatively dry hillsides and rocks. They perform an important scrvice to plant life in holdingback much of the rainfall, a 110 wing it to sink into the earth

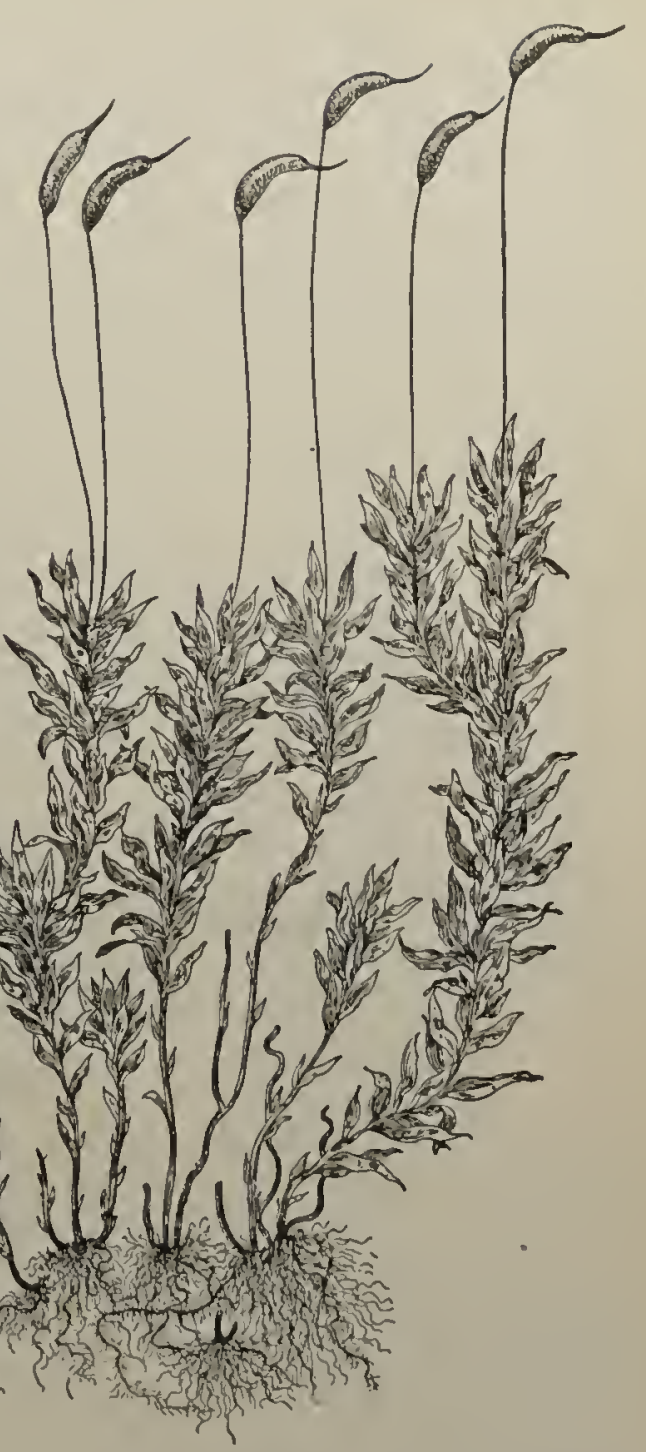

Fir. 261. A common moss (Catharinea undulata)

Showing the branching leafy moss plants (gametophytes) attached to the root-like mass of protonemal filaments and bearing sporophytes. - After Sachs

* To tur Ixtrrictor: In a short course it is best to present the life history of bryopliytes through a somewhat detailed study of one of the common mosses, followed by general studies of a variety of forms of mosses and liverworts. 
insteut of ruming rajidly off in flools. The lichens and mosses are annmer the first plants to appear on barren soil or exposed rocks and cliffs, and are also the plant pioneers that push their way up mountains and into the arctic regions where no other vegetation ean live.

294. The life history of a moss. 'The life history of the common mosses is more complex than that of a liverwort. The moss spore does not develop, directly into the leafy moss plant. It

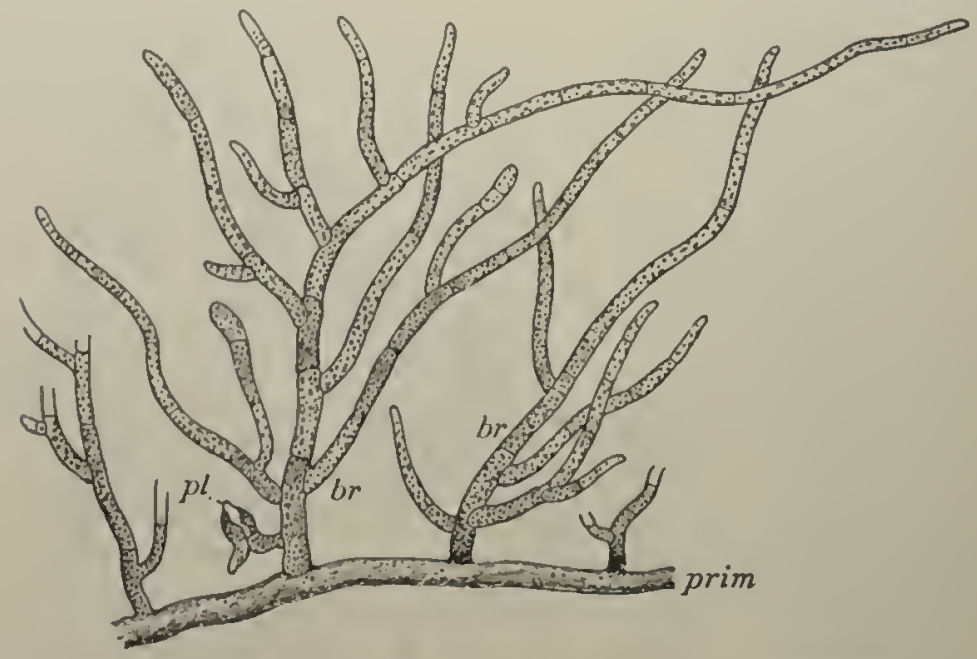

Fur. 262. 'The protonema of a common moss (Funaria)

prim, primary shoot; $b r$, branches from primary shoot; $p l$, young moss plant or bud. - After Suchs

proluces a preliminary filanentous growth, called the protonema (meaning preliminary threal), which sometimes forms an extensive network over the ground, rescmbling at first sight such terrestrial algae as certain species of Vuncheria. The protonemal filanents (Fig. 262), however, consist of cells placed end to end (they are never conorytio); they have generally oblique cross walls and contain numerous disk-shaped chloroplasts. There are no alge known which the protonema resembles in detail, and yet this phase in the life history suggests what may have been the life habits of ancestors of the mosses. C'ertain eells of 
the protoncma cliange their methods of cell division and develop small buds (Fig. 262, $p l$ ) which grow into the leafy moss plants (Fig. 263). One moss spore may give rise to a great quantity of protonema, which by means of the numerous buds will form a large group or even a turf of moss plants. Therefore the protoncma is a very effective mean's of establishing the large carpets of moss vegctation. The leafy moss plant develops the sexual organs in clusters at the top of the stem and has further peculiaritics of structure which will be described later. The protonema togethcr with the leafy moss plant constitute the sexual or gametophyte phase of the life history.

The fertilization of an egg in an archegonium starts at once the development of the sporophyte, often called the moss fruit. The fertilized egg gives rise to a manycelled structure (Fig. 264, $A$ ), which establishes a growing point above and a foot attachment to the gametophyte bolow. This young sporophyte is contained at first entircly within the parent archegonium, which cnlarges with its development (lig. 264, $B, a$ ). But finally the growth of the

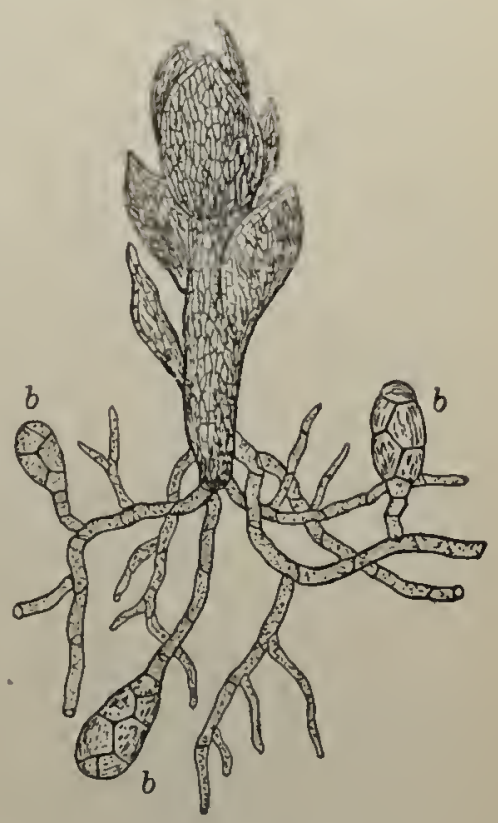

Fri. 263. A young plant of a common moss (Webera)

Showing its attachment to the protonemal filaments which bear reproductive buds $b$

sporophyte is so rapid that the archegonium is torn away at its basc and borne upwards on the clongating stalk of the sporophyte. The remmant of the archegonium then covers the tip of the stalk like a cap (Fig. 265, B, cal) and is called the calyptra (meaning a veil), which nust scrve a useful purpose, protecting the delicate growing tip of the sporophytc. Finally, the tip of the sporophyte enlarges and becomes the complex sjore case 


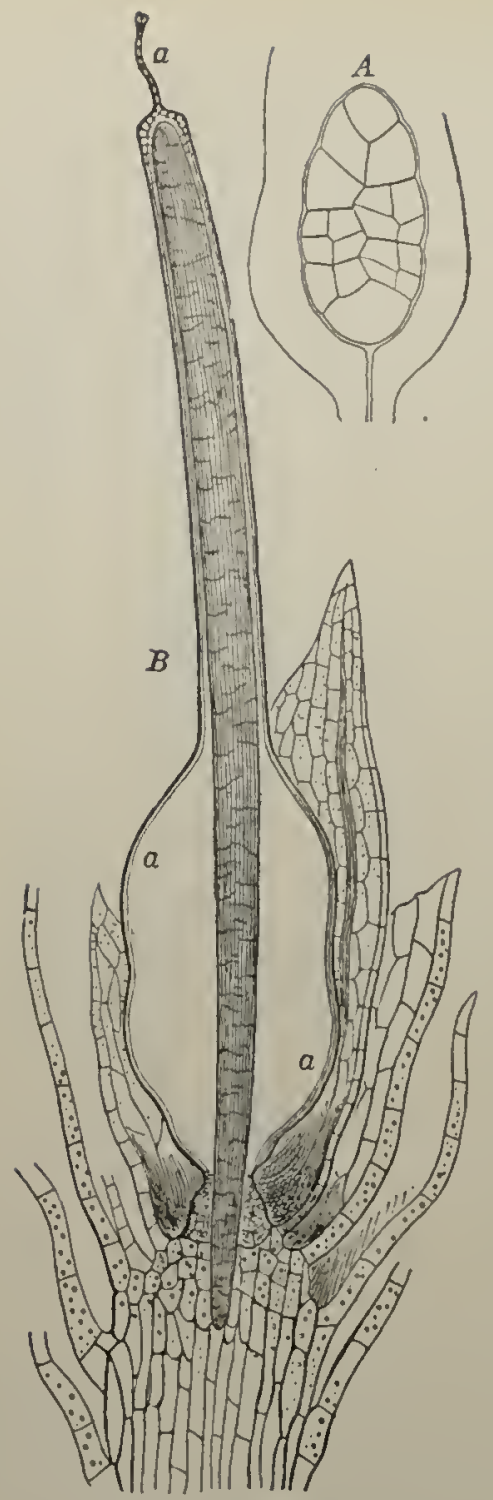

Fir: 264. Developing sporopliytes of a common moss (Funaria)

$A$, very young stage, showing the early cell divisions of the egg; $B$, older sporophyte just before the archegoniun $a$ is torn away from the gametophyte and carried upward as the calsptra. The base of the sporophyte has now grown down into the tip of the lea fy moss plant (gametophyte) and is firmly anchored to it. - After Sachs

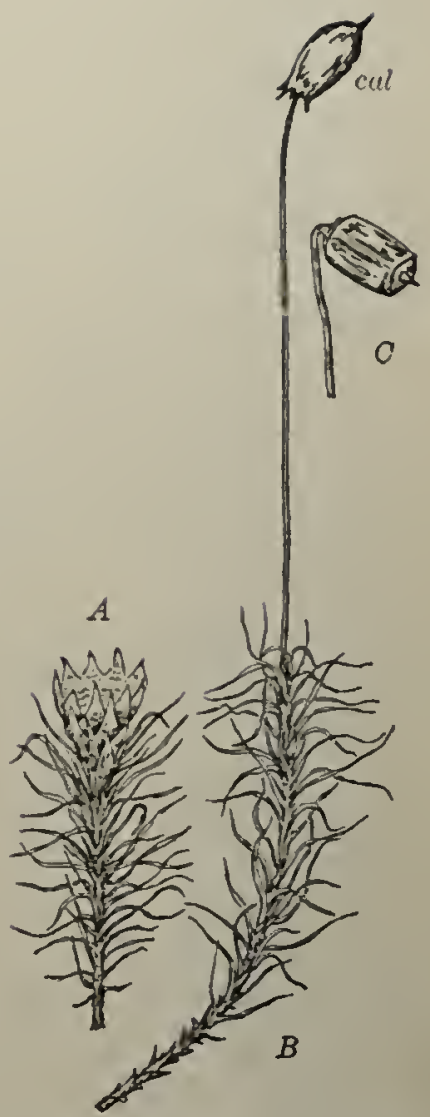

Fig, 265. A common moss (Polytrichum commune)

$A$, male plant, showing cup-like tip containing the antheridia. $B$, female plant with the sporophyte: cal, cap, or calyptra, over the developing spore case. $C$, a mature spore case with the calyptra removed 
(Fig. 265, C). The development of the asexual spores in the spore case ends the life history of the moss plant, which may be formulated as follows:

Gametophyte $\left(\begin{array}{c}\text { protonema and } \\ \text { leafy moss plant }\end{array}\right)<$ sperm $>$ eyg $>$ Sporophyte

- asexual spore - Gametophyte, etc.

This in abbreviated form becomes

$$
G<_{e}^{s}>-S-s p-G<_{e}^{s}>-S-s p-G \text {, etc. }
$$

This formula is identical with the general life-history formula presented for the bryophytes in Sec. 285 , and it is clear that gametophyte and sporophyte alternate with one another.

295. The leafy moss plant. 'The leafy moss plant is, of course, the conspicuous part of the gametophyte phase of the life history. It consists of an upright stem, branching in some forms, with the leaves almost always distributed spirally. The symmetry of the plant is therefore radial instead of having an upper and a lower side (dorsiventral) as in the leafy liverworts. The leares consist for the most part of simple plates of cells, which in some forms can become dry and still retain their vitality, freshening up with the next rain. ${ }^{1}$ The moss plant is fastence to the cartl by filaments of protonema (Fig. 263), which grow out from the base of the stem and form a dense network underneath the moss plants (Fig. 261). This protonena hecones brown with age and serves as a system of root-like filaments, or rhizoids, hy which the moss plant obtains water from the soil. The growth of the stem normally ends with the production of a terminal group of sexual organs, botl of which (antheridia and archegonia) are found on the same plant in some species and on different plants (male and female) in others. Male plants are generally smaller than the female ones

1 The cells of the moss 'eaf are excellent subjects for study and have been described in Sec. 195 and illustrated in Fig. 169. 
and more easily distinguished (Fig. 265, A) bccause the orange or reddish-brown clusters of antheridia lie exposed at the tip of the stem and are sometimes surrounded by a circle or rosette of modified or colored leaves. Female plants are larger, and the archegonia are hidden by enveloping leaves, which must be picked off to expose these sexual organs. The antheridia (Fig. 266, $a$ ) and archegonia (Fig. 26S, A) are

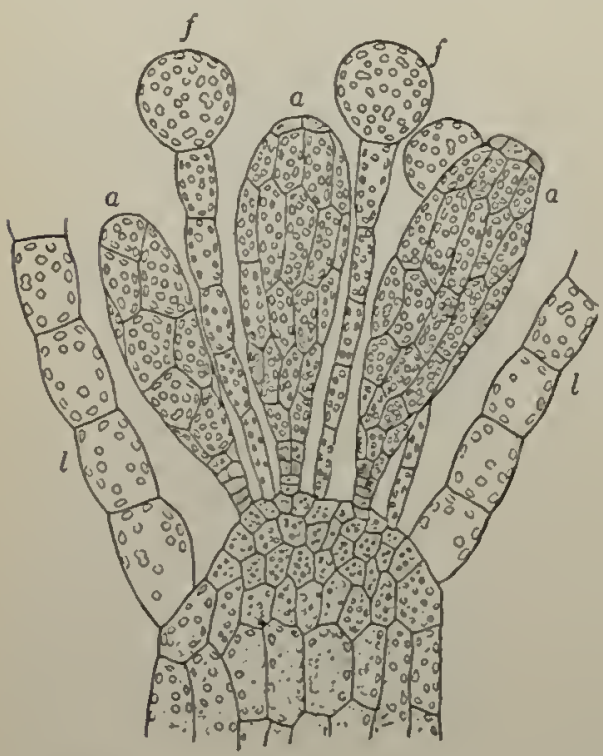

FIG. 260. Section through the tip of the male plant of a moss (Funaria)

$a$, antheridium; $f$, sterile filament, or paraphysis; $l$, leaf

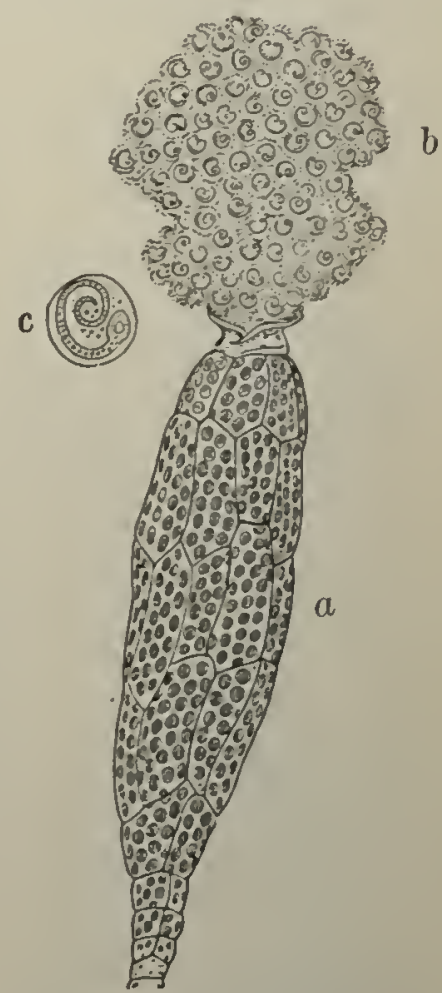

Fif. 26iT. The antheridiun of a common moss (Funaria)

$a$, antheridium; $b$, escaping sperms; $c$, a single sperin in its parent cell. - After Sachs

sometimes numerous in the clusters and lie anrong hair-lite structures (paraphyses).

The mature antheridia and arehegonia open ouly when wet by the swelling and separation of a group of cells at their tips. The sperms (Fig. 267, $)$ ) are discharged, then, after rains or heary dews, so that the moss at that time is practically living an 
aquatic life. The arehegonia (Fig. 268, fi) have very long necks, and the relatively small egrg lies at the bottom as in a flask. The sperins are attracted to the mouth of the open archegonium by substances in the mucilage within the neck, one of which at least is sugar. They swim down the neck to the ragg, and one of them fortili\%es it.

296. The sporophyte of the moss. The sponopliytes of some of the eommon mosses are the inost complex found among the bryoblytes, with the possible exeeption of those of Anthoceros. 'There is generally a long stalk which beass a large spore cise (Fig. 269, A). 'Tho? strueture of the spore cuse is very elaborate. A cover (opereulum) is formed at the end, which falls off so that the spores maty escape from within. In many mosses the eover is loosened and thrown off by an interesting mechanism, which is sometimes very highly developerl. There nuay be a circle of cells with thickenerl and otherwise molified rell walls, forming a well-rlefinerl ring (Fig. 269, $A, r$ ) aromm the spone (ense underneath the cover. 'These rells rhange their form when wed, sonnetinnes swelling greatly (lïg.

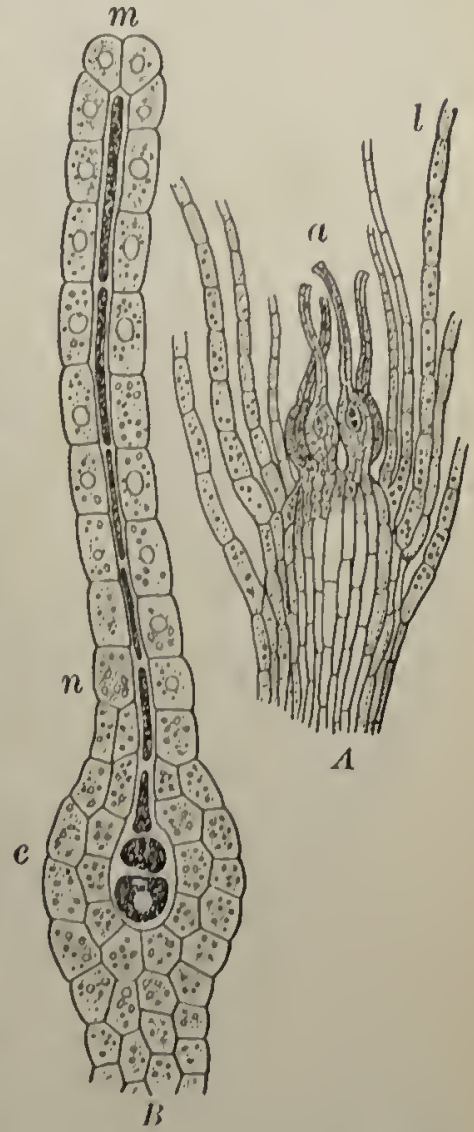

Frre. 2ris. Seretion through thes tip of a fomale plant of a moss (Funuria)

A, gronpof atrehegronla a: l, leas. B, an archegonium in detall, showjug anlarged bissal portion o with

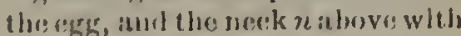
its row of catnat erells: $m$, moulh. - Aftrer Simbles

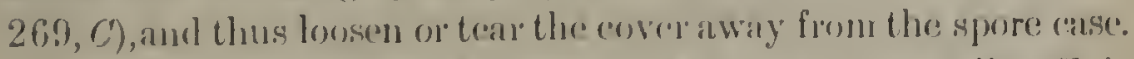

Tha rim of the ripening formed when the cover falls off is surromeded by a circle of pointed triangular structures conled 
teeth (Fig. 269, B,t), which meet at the eenter of the opening when folded inwards. The number of teeth is fixed for different mosses. Inder the circle of teeth various mosses have another circle of much more delicate segments (Fig. 269, I;,s)

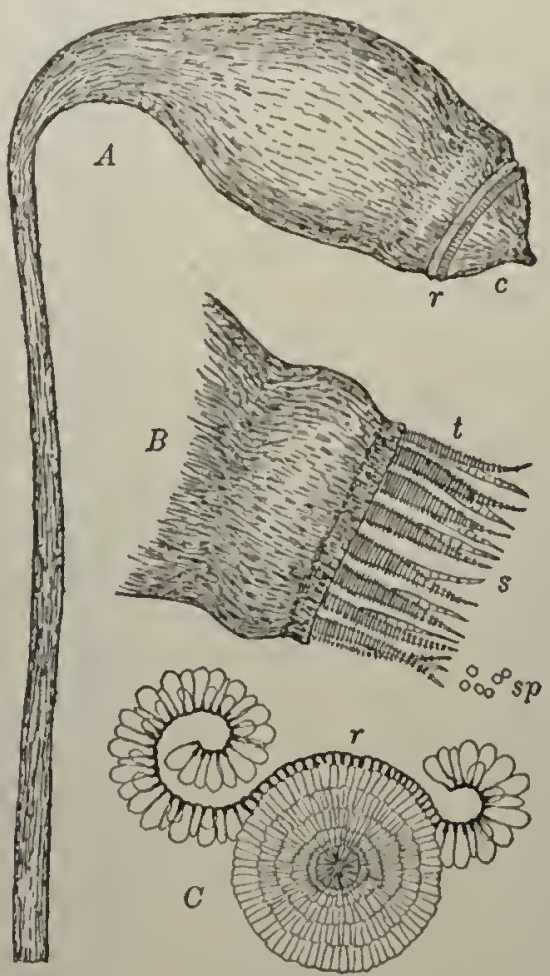

Fici. 240. The spore case of a common moss (Bryum)

$A$, the elosed spore cise: $c$, the eover (operculum); $r$, the ring. $B$, the rim of an open spore case, showing the onter circle of teeth $t$, inside of which is indieaterl the inner circle of delicate segments $s$ : $s p$, spores. $C$, the cover after remaining for a ininte in water: the rells of the ring $r$ have alsorbed the water and havo swollen so tlat tho ring has broken anl enrled baekwarls on two sides

of the same number and general forn. The teeth are sensitive to moisture, eurling inwards and outwards with changes in the amount of vapor in the air, and hy these movements they probably help in some types to empty the ease of its spores, retaining them in wet weather and letting them fall out in dry. 
The lower portion of the spore case has stomata (Fig. 270, D), and there is much chlorophyll-bearing tissue in the moss fruit that is caprable of doing the work of photosynthesis just as in Anthoceros. But this sporophyte is, of course, dependent upon the gametophyte for its supply of water, which is taken up through the pointed foot of the stalk that is deeply sunken in the top of the leafy moss plant (Fig. 264,B). The spores

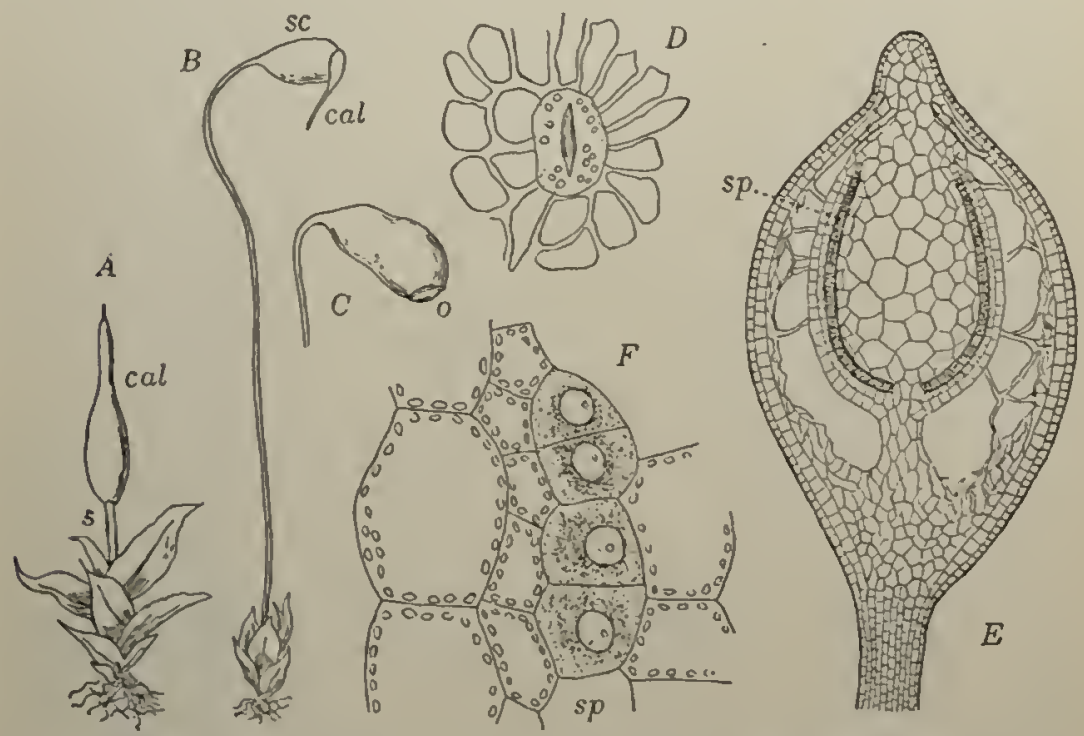

Fig. 270. The sporophyte of a common moss (Funaria)

A, young sporoplyte s attached to the leafy moss plant anil covered by the calyptra cal. l;, sporophyte with mature spore case sc and calyptra cal at the tip. $C$, spore case with calyptra removell: 0 , the cover (opereulum). I, a stoma from the surfare of the spore case. $H$, section of young spore case, showing the cylindrical central region of spore-producing tissue sp. $F$, the spore-producing tissue in detail. - Adapted after Camplell

are developed in groups of four (tetrads) within spore mother cells (Fig. 270, $F, s p$ ), which form a barrel-shaped tissue (Fig. $270, E, s p)$ within the spore case.

In spite of the immense numbers of species in the Bryales, the order is clearly separated from other groups of bryophytes as a side line of plant evolution, and its families and genera are distinguished by relatively minor differences. 
THE ORIGIN AND ETOLUTION OF THE BRYOPHYTES

297. The origin of the bryophytes. The origin of the bryophytes is a mystery. They have of course arisen from the alga, but there are no living algre that resemble the bryophytes at all closely. Colcochate ${ }^{1}$ and the stoneworts (Charales) are the tyjes most frequently consiclered in relation to the mosses. But the sexual organs of Colcochate are one-celled, and the female organ of Chara bears only a superficial resemblance to an arehegonium, while its antheridium is totally unlike any other male organ. There must have been formerly some group of the algre, probably in the Chlorophycce, distinguished by having many-eelled sexual organs from which the antheridium and arehegoniun of the bryophytes arose; for these complex sexual organs, together with the characteristic sporophyte generation, constitute the ehief advance of the bryophytes over the alga.

298. The evolution of the bryophytes. The evolution of the bryophytes is elearly related to the change from the aquatic habits of the algre to the land habit. Living upon the land exposes the plant to the drying effeets of the air and demands at onee inportant struetural adaptations, that is to say the plant inust either develop a firm cell structure so that drying up will not injure the tissues seriously, or else it must maintain a constant connection with water through the surfaces of filaments (rhizoids) which are direetly in eontact with moisture. Many of the mosses and leafy liverworts have solved the problem in the first way and may beeome quite dry without serious injury. The Riccice and Marchantice forms and Anthoccros, on the other hand, are clearly adapted to the seeond altemative and die at once if removed from water or moist earth. The creeping habit aud thallus strueture of the simpler liverworts, while of advantage

1 'The fruetification of Colcochate has freyuently heen compared to a simple type of sporophyte. somewhat like those found in the Ricria gloup of the liverworts. Recent investigations, however, indieate that this emmlarison is not justifierl, and that the fructifieation, is not sporophytic at all. See See. 336 on the origin of the sporophyte. 
in some situations, do not constitute so effective a plant body as a leafy stem with an erect habit, which secures a much greater exposure to air and light. Accordingly the appearance of leafy stems marked a great advance over the thallus structure. This new form of bryophyte plant body reached its highest development when the stem became erect with the leaves arranged spirally, as in the mosses, so as to give a radial symmetry.

It is quite safe to say that the adoption of the land habit was the chief cause of the rapid adrance of the bryophytes orer the algre. The advance in vegetative structure is generally most marked in the gametophyte pliase of the life history, although the sporophytes of such types as Anthoeeros and certain mosses are clearly higher than the gametophytes. It may be noted in this connection that the next great forward step in the evolution of plants came in the fern group, or. pteridophytes, when the sporophyte generation adopted the land habit and became independent of the gametophyte. Horrever, this subject will be taken up in the next chapter.

\section{SUMMARY OF THE BRYOPHYTES AND THALLOPH Y'TES}

299. Bryophytes and thallophytes compared. It is possible at this point to make clear the fundamental reasons for the separation of the spore plants, so far studied, into the two great divisions of the plant kingdom called the Thallophyta and Bryophyta. It will be seen that the bryophytes have a set of very clearly defined characters, while the thallophytes are distinguished largely by the absence of these.

300. Summary of the bryophytes. The sexual organs are many-eelled structures differentiated into female organs (archegonia) and male organs (antheridia). The fertilized egg develops at once into an asexual generation, or sporophyte, which prodnces asexual spores in groups of four, or tetrads, within certain cells called spore mother cells. The sporophyte, often called 
the fruit, alternates with the sexual generation, or gamctophyte, and is always attaehed to it and dependent upon it for water and, at least in large part, for certain foods. The asexual spores produced by the sporophyte are of a new type not found in the thallophytes.

The two classes of the Bryophyta are distinguished by the following characters:

Cless I. The liverworts, or Hepatice. This class is characterized by relatively simple sporophytes (Anthoceros excepted). The gametophytes are thalloid except in the leafy liverworts, and have distinct upper and lower surfaces (dorsiventral symmetry).

Class II. The mosses, or Musci. These have relatively complex sporophytes, whose spore cases open by covers, and the rim of the spore case is frequently fringed by a cirele of teeth. The gametophytes have erect leafy stems, and the leaves are generally arranged spirally (radial symmetry').

301. Summary of the thallophytes. The sexual organs are alnost always one-eellal structures. The chief exceptions are the so-called plurilocular sporangia of the brown alge (Sec. 235) and the peculiar antheridium of the stoneworts (Sec. 230). There is no organ in the thallophytes resembling the archegonium in structure or development. There is no alternation of sexual generations with asexual in most of the thallophytes. However, in the red algee (Rhodophyece) and the sae fungi (Aseomycetes) the fertilized female cell produees peculiar fructifications called eystocarps and ascocarps, which develop asexual spores and constitute phases in the life history, alternating with the sexual plants. These phases are sporophytes, and there is a true alternation of generations in the red algye and sac fungi, but theso structures are peculiar and are believed to be independent developments in these two remarkable groups and not related to the sporophytes of the bryophytes. None of the thallophytes have sexual plants resembling in detail those of the liverworts or mosses. The plant body is generally a thallus, though the variety 
of form is very great, but the highest types in the brown and red algae are differentiated into stems, leaf-like structures, and holdfasts. The cell structure of the thallophytes is generally much simpler than that in the plant bodies of the bryophytes, which owe their complexities of cell structure chiefly to the varied conditions introduced by the land labit; for the land habit requires the plant to protect itself from drying up, in the air. This, in general, means that a land plant must obtain water from the soil through some kind of organs adapted for that purpose (rhizoids or roots). And, as a rule, a land plant soon differentiates a protective layer of cells (epidermis), which helps to hold the water within its tissues. These structures are either entirely absent or present in greatly reduced form in aquatic plants, and for these reasons the cell structure of the aquatic thallophytes is generally very much simpler than that of the bryophytes.

Nevertheless, the thallophytes have developed some complicated organs with highly differentiated tissues, as in the kelps, rockweeds, red algæ, sac fungi, and the higher basidia fungi, such as the toadstools and mushrooms, puffballs, nest fungi, and carrion fungi. Thesc complexitics are, however, very special in character and not related to the structure of higher groups of plants. 
CHAPTER XXV

\section{THE PTERIDOPHYTES AND THE APPEARANCE OF HETEROSPORY}

302. The pteridophytes.* The division Pteridophyta (meaning fern plants) comprises three classes: (1) the ferns, or Filicinece, (2) the horsetails, or Equisetinece, and (3) the club mosses, or Lycopodinece. Representatives of these groups are generally somewhat familiar to all, and no one would think of grouping them with the liverworts and mosses. The differences become more conspicuous after a study of the life histories of pteridophytes, which shows that the large fern plant with its roots, stem, and leaves is really an asexual generation, or sporophyte, and that the gametophyte is represented by a small, compraratively insignificant sexual generation. This condition, so different from anything in the bryophytes and thallophytes, marks one of the great forward steps in the progress of plant evolution. It leads towards the seed plants, for these highest forms with their varied and complex structures are sporophytes, whose gametophyte generations are so much reduced that they can only be recognized by careful study of the processes of seed formation.

303. The advances in plant evolution up to the pteridophytes. It is well to summarize at this point the contributions of the thallophytes and bryophytes to the progress of plant erolution.

1. The alge. The chief contributions of the algae to plant evolution were four in number: (1) the attached many-celled plant body arose from the single-celled condition of the lowest

* To tie Isstrector: The introduction to this chapter assumes that the life history of some fern has been studied in the laboratory. 
alga and soon became established as the vegetative period in the plant's life history; (2) as a result of this, the motile stages (zoöspores) became set apart as reproductive phases in the life histories, such reproductive motile stages, with other reproductive cells, being called spores; (3) certain of the reproductive cells became sexual in character, and these gametes at first similar (isogamy) were later differentiated into eggs and sperms (heterogany); (4) alternation of generations developed in the red algre and sac fungi, but probably. independently of the same phenomenon in the bryophytes.

2. The fungi. The fungi as special and peculiar offshoots from the alga have of course contributed nothing to the main evolutionary line running up to the higher plants.

3. The liverworts and mosses. The chief advances of the liverworts and mosses over the algae were three in number: (1) many-celled sexual organs (antheridia and archegonia) took the place of the one-celled reproductive organs of the algre; (2) an alternation of generations (gametoplyte with sporoplyte) became well established, together with the origin of a new type of asexual spore developed in groups of four (tetrads) by the sporophyte; (3) there was a general advance in the cell structure of the plant bodies because of adaptations to the more complex conditions of the land habit.

The sporophyte of the bryopliytes is always attached to the ganetophyte, and except in Anthoceros and some mosses it is not as complex as the gametophyte. In the pteridophytes, however, the conditions are reversed. The sporophyte is the large, conspicuous phase in the life history, and as it develops it becomes entirely independent of the gametophyte, while the latter'appear's relatively insignificant, although it holds, of course, a necessary place in the life history. The appearance in the pteridophytes of the sporophyte as an independent plant was the most important advance in plant evolution at this time, for the regetative activities griadually became shifted, at first ehiefly and finally wholly, from the sexual to the asexual generation. 


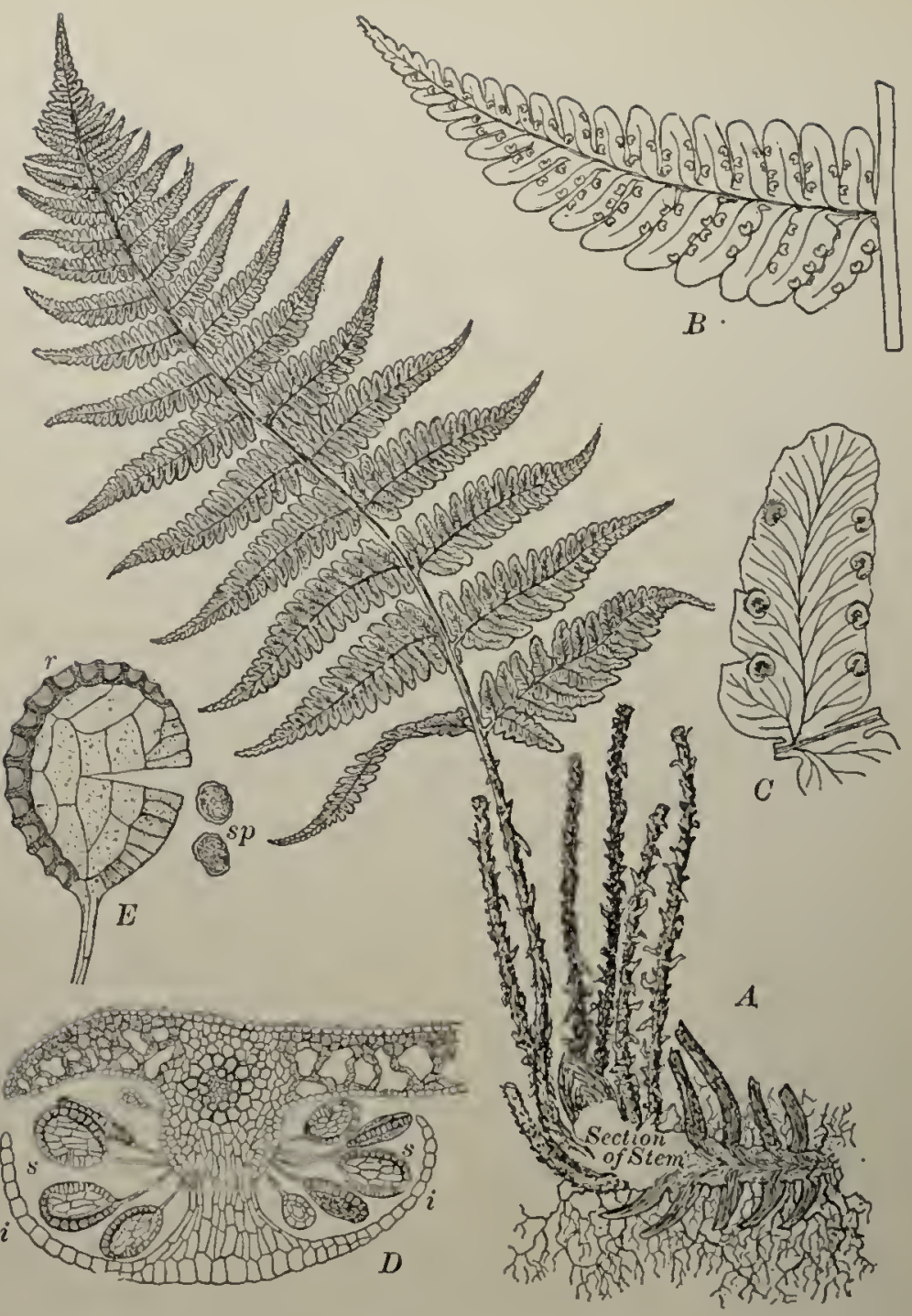

FIG. 271. A fern (Aspidium maryinale)

$A$, seetion of the creeping stem, or rontstock, showing the arrangement of the living fronds aromin the tip, and the dead stems of last year's fronds farther back. $B$, a leatlet of the frond riewed from below to show the position of the sori. $C$, details of the sori and veining on a portion of a leaflet. $D$, section of a sorns: $i$, indnsium; s, sporangia. $E$, a spore ease or sporangium, showing the opening from which the spores $(s p)$ have been diseliarged; $r$, ring 
The material of this chapter will be treated under the following headings:

Class I. The ferns, or Filicinew.

Class II. The horsetails, or Evquisetinece.

Class III. The club mosses, or Lycopodinece.

Fossil flants and coal.

The origin and evolution of the pteridophytes.

Summary of the pteridophytes and their advances over the bryophytes.

\section{CLASS I. THE FERNS, OR FIIICINEAE}

304. The ferns. The ferns are a very large assemblage of more than four thousand species, and most of them can be recognized at a glance $b y$ the characteristic forms of their leaves, called fronds, and by their habits of growth. They are widely distributed, but reach their greatest luxuriance in the tropics, where they present some very striking displays. Thus the tree ferns have stems thinty or forty feet high, with a crown of fronds often fifteen or more fect in length. The stems of some of the tree ferns are covered by a sheath of fibrous roots (as in Dicksonia, Plate VII), and in other types the bases of the old and withered fronds

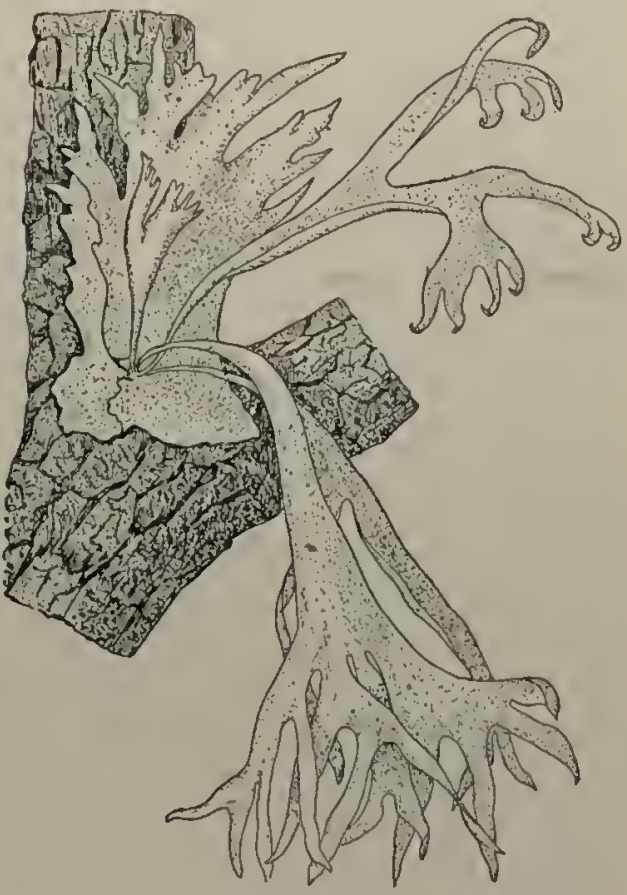

Fig. 272. 'The stag-hom fern (Platycerium Willinki)

form a similar investment. There are also in the tropics certain small delicate ferns

A tropical epiphytic fern with two forms of leaves, one of which grows clnsely against the bark of trees and gathers and holds moisture and humus. - After Goebel 
called filny ferns, whose stems and fronds are as delicate as mosses. Some peculiar types, as the stag-horn fern (Platyeerium, Figs. 272, 364), grow over the surface of tropical trees and are zonsequently called epiphytes (meaning upon a plant). These have certain flattened leares (Fig. 272) closely pressed against the surface to which the plants are attached, where they gather and hold

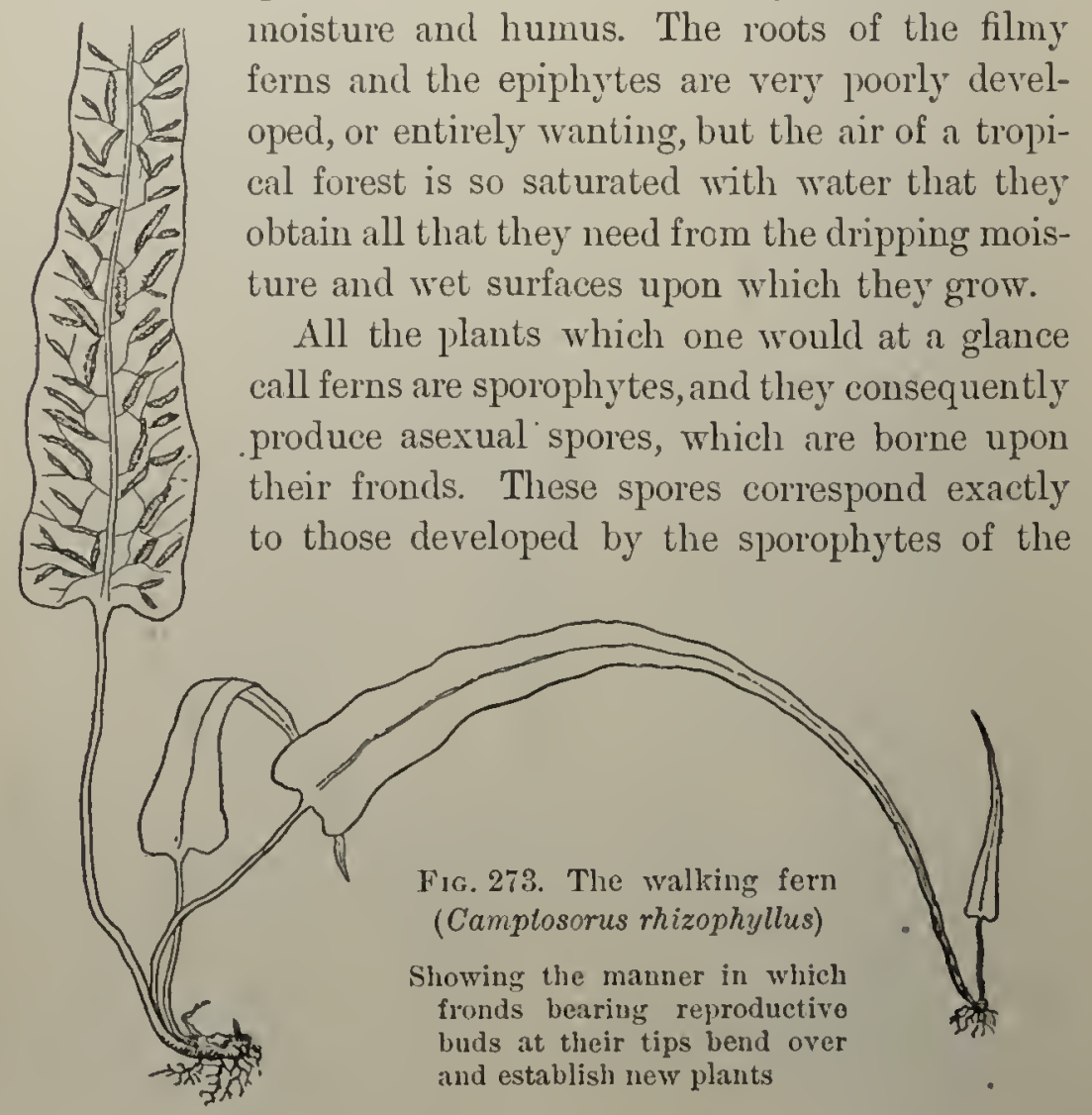

liverworts and mosses, and they give rise to a small sexual generation, the gametophyte. The life history of a pteridophyte can be most casily studied from one of the common ferns familiar to us in the woods, greenhouses, and gardens. ${ }^{1}$

1 The moonwort and adder's-tongue (Sec. 315) illustrate more primitive conditions in the pteridophytes than the common ferns, but are not generally available for type studies. 


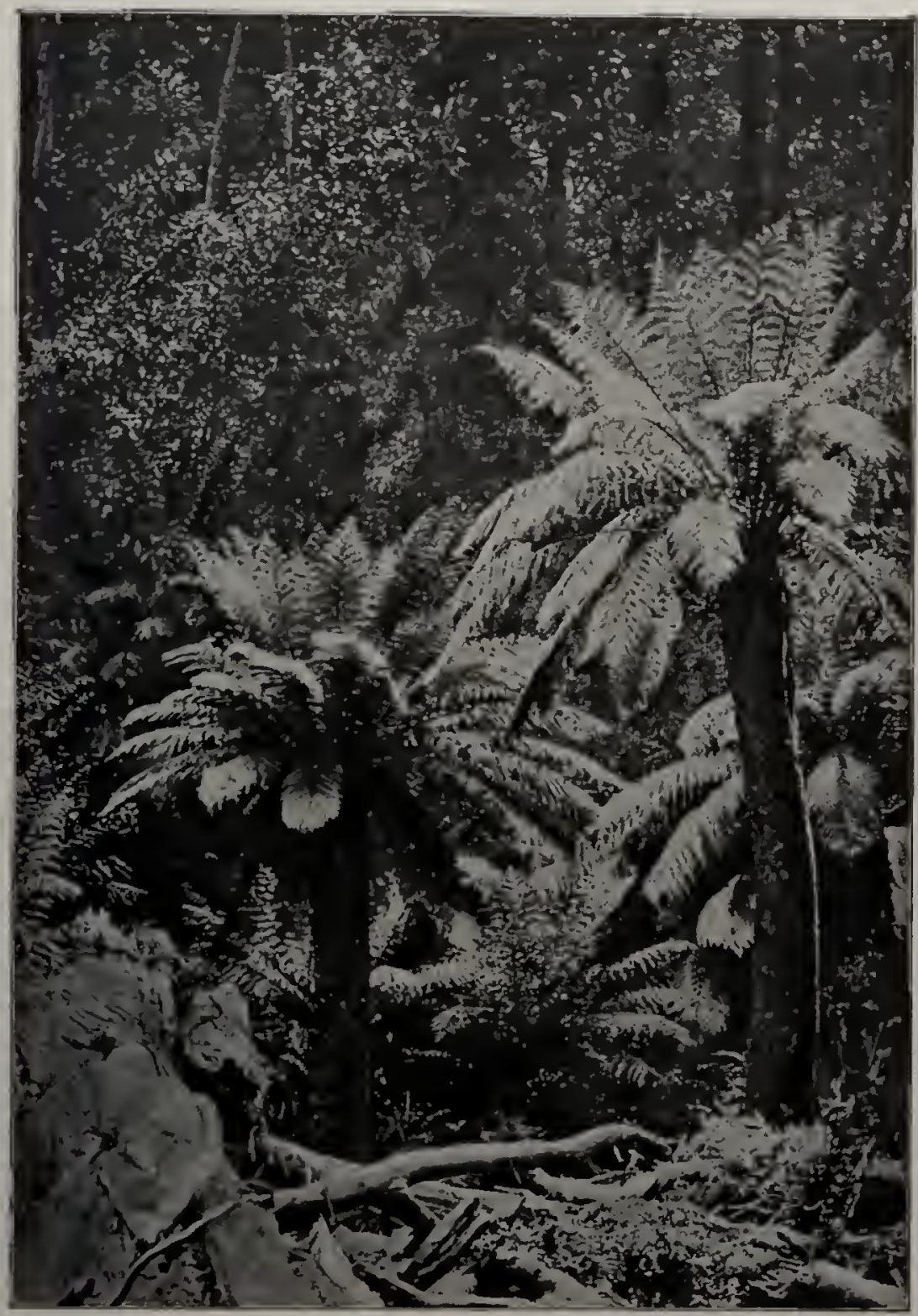

Plate VII. Tree ferns (Dicksonia antarctica) from Tasmania

These tree ferns grow to be 30 to 40 feet high, with fronds 8 to 12 feet long, and the trunks, densely covered with sunall roots, may become 3 feet thiek. - After a photograph in the Ilarvard Museum 

305. The common ferns. The common ferus (order Filicales) completely outclass all other orders of pteridophytes in number of species and mass of vegetation. The forms are exceedingly various. The stems may be short and close to the ground, or upright trunks, as in the tree ferns. But many types have creeping stems, frequently, wholly buried in the earth as underground stems, or rootstocks, well illustrated by the common brake, or bracken fern (Pteris aquitina). Some ferns have peculiar methods of reproduction by buds that are formed on the leaves, as in the bladder fern (Cystopteris bulbifera), or the walking fern (Camptosorus) shown in Fig. 273.

The fronds or leaves arise from the tip of the stem and form clusters or crowns around the top of upright structures, but are generally somewhat scattered along the creeping stems. Most fronds are much cut or divided (compound) after regular and various patterns (Fig. 271). They are developed very slowly in some genera, remaining rolled up in the bud for several inonths. However, when fully formed and in the proper season they unroll comparatively quickly from the base in a very cliaracteristic manner until the apex finally appears above.

The cell structure of the leaves, stems, and roots is very much more coinplex than the cell structure in the bryophytes and recalls at once the tissues of the seed plants (see Part I, Chapters vil and XII). The plant body has a system of tissues, called fibro-vascular bundles (Fig. 274), whose parts are much modified for two important functions. One tissue is composed of large cells (Fig. 274, $t$ ) empty of protoplasm and with heavy thickened walls marked with curious pits. These elements, called tracheids, compose the woody part of the fibro-vascular bundle termed the xylem, and their purpose is to conduct water from the roots to parts of the plant above ground. But they are also very important for the strength that they give to stems and leaves. Another tissue is composed chiefly of cells, called sieve tubes (Fig. 274, st), which contain much protoplasm and food material and make up a softer region of the bundle termed 
bast or phloëm. The bast regions are known to be paths for the distribution of food material in the plant. The structure of the fern frond is essentially similar to that of the leaf of a seed plant. There are stomata on the lower surface and chlorophyllbearing tissues underneath the outer cell membrane, or epidermis. The fibro-vascular bundles run out into the green expanded portions of the leaves as forking veins, which do not, however,

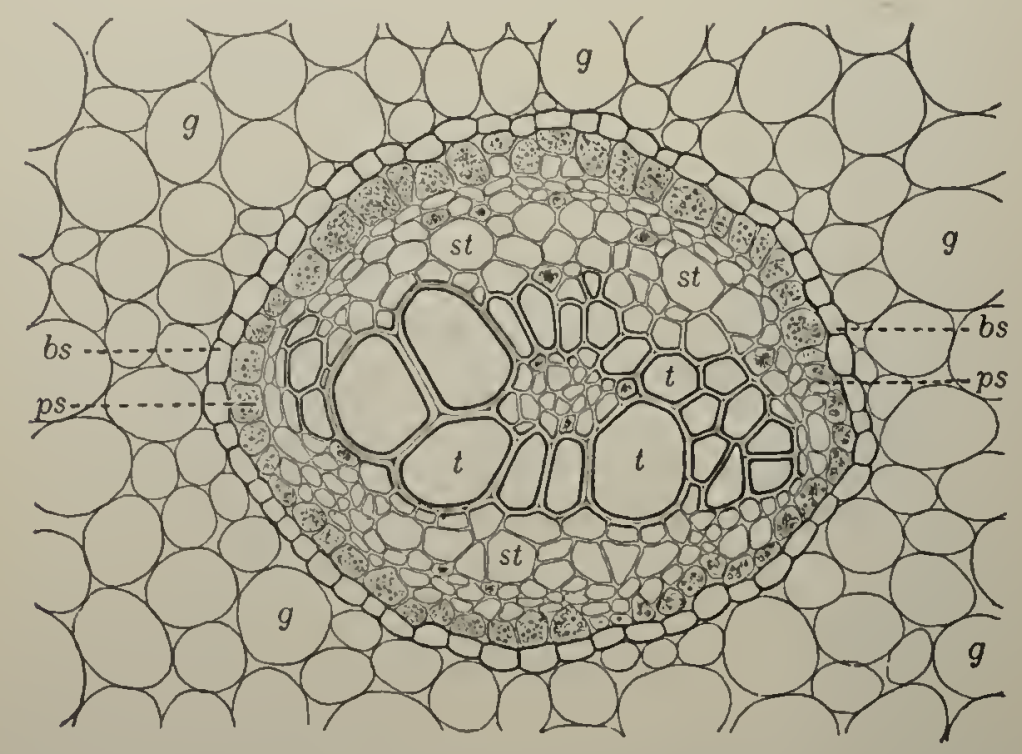

Fig. 274. Fibro-vascular bundle from the underground stem, or rootstock, of the common brake (Pteris aquilina)

$g$, ground tissue, or parenchyma; $b s$, bundle sheath; $p s$, bast, or phloëm, sheath surrounding the sieve tubes (st) and bast fibers which compose the bast, or phlocm; $t$, large, thick-walled cells called tracheids, which with smaller celis in the center make up the wood, or xylem

generally unite to form the close network so characteristic of dicotyledonous seed plants.

As stated above, the fibro-vascular bundles greatly strengthen the tissues of the leaves and stems, for they form a sort of skeleton in the plant. They are frequently assisted in their strengthening functions, especially in the stem, by regions of rigid tissue, which may be variously situated, sometimes under 
the epidermis and sometimes forming broad strands in the interior. This rigid tissue (selerenchyma) is composed of elongated cells with rery heavy, much-thickened walls, which are often yellowish in color. This tissue is developed from the thin-walled cells (parenchyma), called the ground tissue, that compose the greater part of the interior of the stems.

306. Spore formation. The sporopliyte nature of the fern plant becomes clear at the time of fructification. Certain ones or sometimes all of the fern fronds as they grow older develop spore cases, or sporangia. These are variously situated on the fronds, sometimes appearing as clusters or spots, called sori (singular, sorus, meaning a heap), on the under surface and sometimes in lines along the under edge. A sorus may be naked, but it is frequently protected by a membranous outgrowth, or indusium, from the surface of the frond (Fig. 271, D, i).

The sporangia are stalked and somewhat flattened manycelled cases, each of which develops from a single surface cell of the frond. There are sixteen spore mother cells in the interior of the spore case, each of which gives rise to a group of four spores (tetrad). The method of spore formation, four spores in each mother cell, is thus identical with that of the bryophytes.

The sporangium of many common ferns is composed of thinwalled cells exeept along the edge, where there is a line with much-thickened walls, which extends from the stalk about two thirds around on the outside (Fig. 275, A). This line of cells is called the rinf, and as the sporangium ripens and becomes dry, the ring is forcibly held like a bent spring. Finally, the delicate cells at the side of the spore case opposite the ring are umable to stand the strain and are torn apart so that the ring straightens somewhat and a wide rent is made in the side of the sporangium (Fig. $275,13, C$ ). The spores are thrown out violently through the rent for a considerable distance. This is the structure of the spore case in the fanily Polypodiacee, for the several families of the Filicules have sporangia which differ from one another in form and in the structure and position of the ring. 
307. Fronds, vegetative leaves, and spore leaves' (sporo. phylls). Must fronds are regetative, that is, perform chlorophyll work (photosynthesis) during the early part of the season and develop sporangia later. However, some types, as the royal and cinnamon ferns (Osmunda) and the sensitive and ostrich ferns (Onoclca), devote the whole of certain leaves or portions of them entirely to the work of spore production. The blades of these fronds or portions of fronds never become expanded, but remain somewhat rolled up, forming pod-like structures in which the sporangia are developed (Fig. 276). Other fronds on these
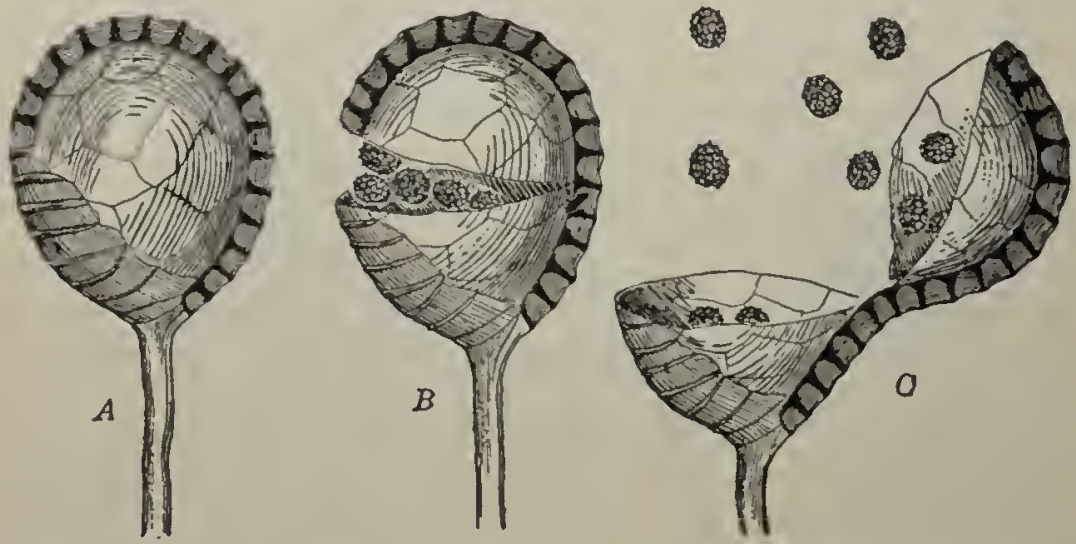

FIG. 275. The sporangium of a common fern (Aspidium Filix-mas) $A$, closed sporangium; $B$, sporangium opening; $C$, fully opened and discharging the spores. - After Kerner

ferns are devoted entirely to vegetative activities and never derelop sporangia. There is thus in some ferms a division of labor among the fronds, certain of them becoming strictly vegetative leaves, while others are spore leaves, called sporophylls.

There is a constant tendency in the pteridophytes to give all the work of spore production to the specialized spore leaves (sporophylls), which means that all the other fronds on the plant become entirely devoted to vegetative activities and may then be called vegetative leaves or simply leaves in the sense in which this term is generally used in the seed plants. This differentiation of the frond into leaves and sporophylls reaches 
a high point of development in the horsetails and club mosses, and becomes even more conspicuous in the seed plants, as will appear later.

308. The gametophyte of the fern. The fein spore germinates readily on moist surfaces and puts forth a delicate filament, consisting of a row of cells (Fig. $277, A$ ). Several oblique ccll walls at the end of this filament cut out a triangular apical cell (Fig. 277, $B, x$ ), which becomes the growing point. The final development is usually a small, delicate, heart-shaped, thalluslike body resembling a small livcrwort, but only one cell in thickness, except in the middle region. The apical cell (Fig. 277, $C, x)$ generally becomes situated in a deep notch at the forward end (Fig. 277, D) because of the greater cell growth on either side. The back part of the structure becomes fastened to the earth by uunerous delicate filaments or rhizoids which act like root hairs. This structure develops the sexual organs of the fern and is consequently the gametophyte generation in the life history. It is called the prothullium because it precedes the fern plant (sporophyte).

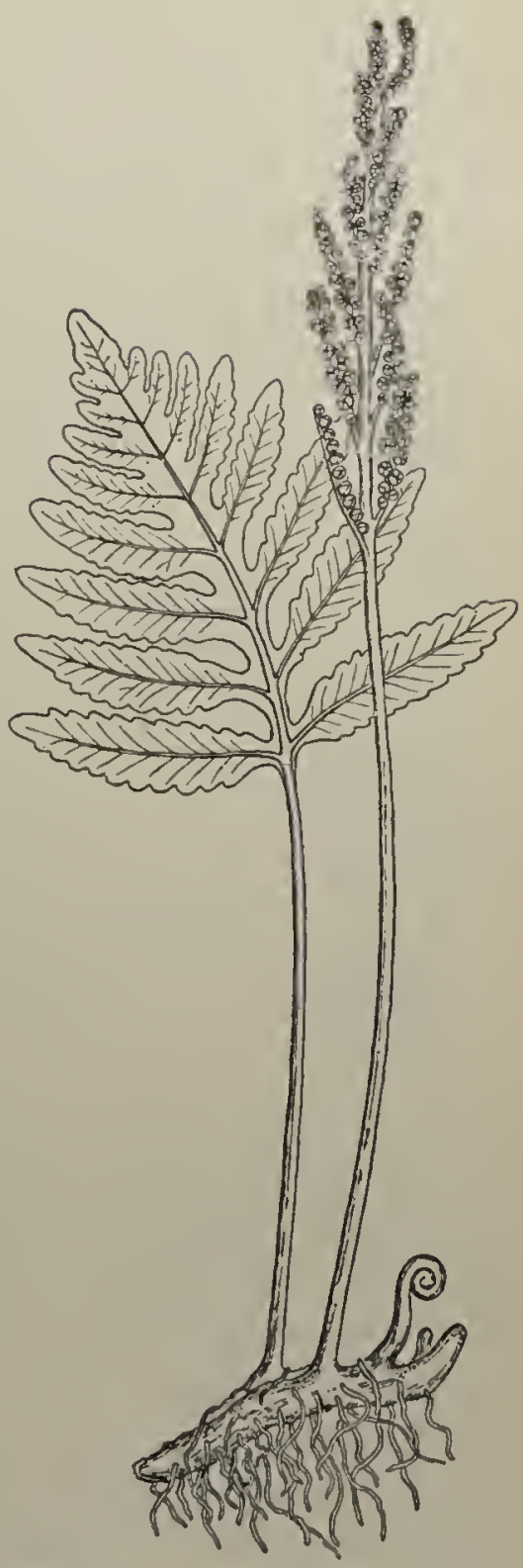

Fra. 276, 'The sensitive fern (Onoclea sensibilis)

Showing vegetative leaf and spore leaf (sporophyll) rising from the creeping rootstock 
Both sexual organs (antheridia and archegonia) are found on the same prothallium if it is well dereloped. But when prothallia are crowded or grown under other unfarorable conditions they remain small and stunted and become irregular in form (Fig. 278, A). Such dwarf gametophytes only develop antheridia.

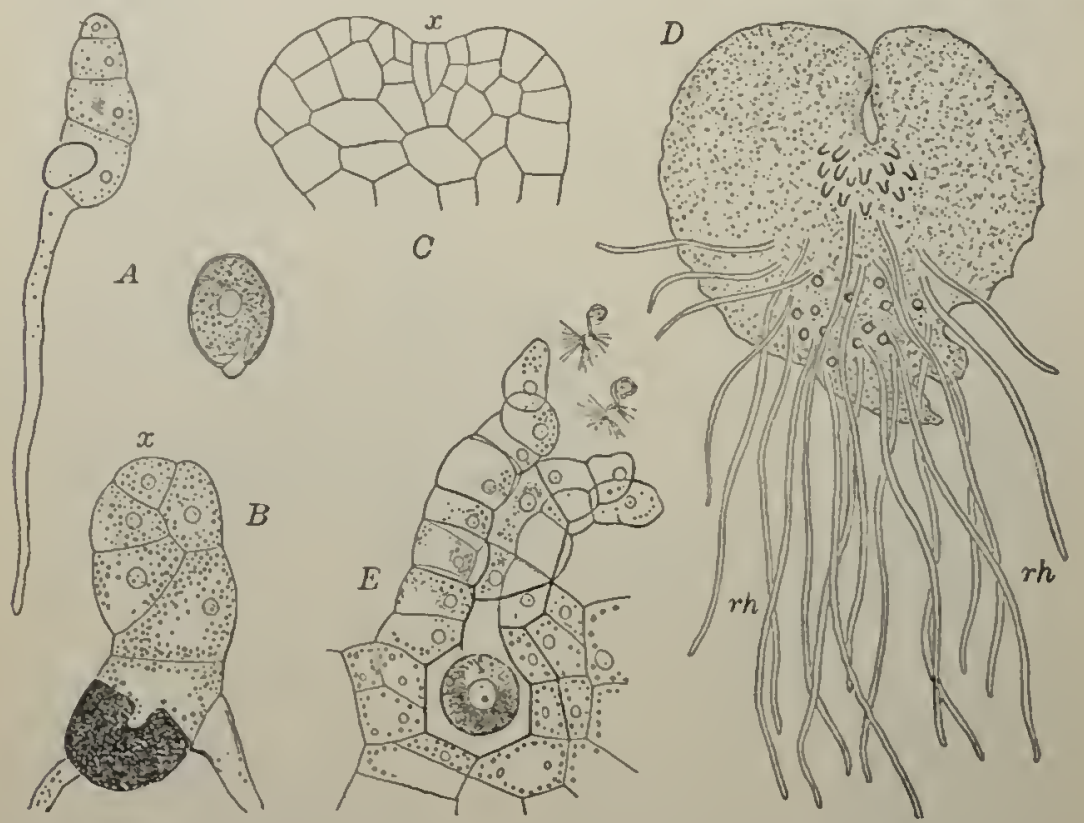

Fis. 27\%. The fern prothallium and archegonium

$A$, stages in the germination of the spore. $I$, young prothallium, showing first appearance of wellyed-shaped, apical cell $2 . C$, tip of prothallium beginning to take on the heart-sliaped form: $x$, apical cell. I), mature prothallium, showing gronp of archegronia on the cushion just back of the notch, and antheridia further back: $r h$, rhizoids. $F$, an open archegonimm with egg reads for fertilization, and two sperms near the entrance of the neck. $-A, B, C$, $b$, after Camplell; $D$, after Schenck

On well-nourished prothallia the antheridia are formed first on the elge and lower surface of the back portions. The archegonia are developed last when the prothallium is quite large, and are only found on the thickened region, called the custion, lirectly back of the notch, or growing joint.

The antheridir. The antheridia (Fig. 278, $B, C$ ) are very much smaller than those of the bryophytes. They develop from a 
siugle cell which projects above the surface of the prothallium. There arc only three cells forming the capsule of this structure, - a cover cell above, a ring-shaped cell in the middle, and a funmel-shaped, basal cell. These three cells inclose at first a large central protoplast, from which is developed a group of one hundred or more small cubical cells that produce the sperms, as in the bryophytes. These sperms are, however, very different in form from the two-ciliate sperms of the liverworts and mosses and many algre. Each consists of a spirally coiled band (Fig. 27S, D), whose narrowerpointed end is covered with numerous cilia, making it a many-ciliate sperm.

The archegonia. 'The archegonia of the ferns are also much smaller than those of the bryopluytes and simpler in structure. The short neck alone projects above the surface of the prothallium (Fig. 277, E) and generally bends hackwarl, probably because the forwarl part of the prothallium is not directly on the earth, but rises at an angle. The cgrg lies beneath the surface of the prothallium, so that the base

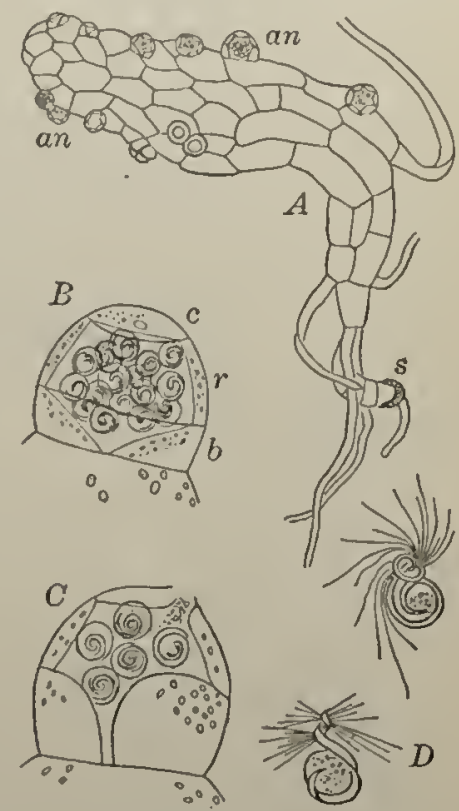

Fis: 278. The anthericlium and sperms of a ferm (Onoclea)

$A$, small prothallium with many intherilia $a n: s$, old spore wall. l;, autherilium, showiug cover cell $c$, ring cell $r$, and basal cell $b$, inclosing the sperm mother cells. $C$, antherillum opening. J), sperins. - After Campbell of the archegonium may he described as sunken. 'There are only two or three canal cells (Sec. 283) in this arehegonium.

The eggs are fertilized under exactly the same conditions as in the bryophytes (See. 283). When the prothallia are wet the sexual organs open, and the sperins swin over the moist surfaces and are attracted to the necks of the archegonia hy substances secreterl within, onc of which at least is malic acid. The 
sperms swim down the neck to the egg, and one of them fertilizes it. The fern plant then, like the liverwort and moss, practically returns to the aquatic life of the algæ at the time when the sexual cells are functional.

309. The development of the sporophyte. The early stages in the development of the fern sporophyte as in the bryophytes

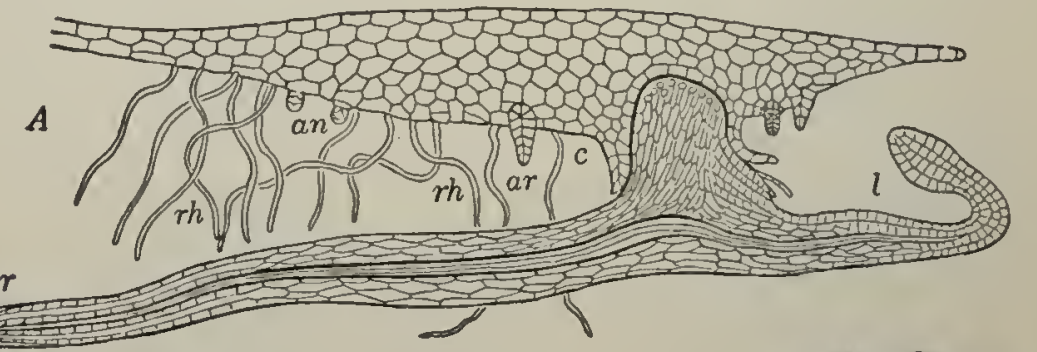

Fig. 279. Development of the sporophyte of a fern

$A$, section of prothallium with a young sporophyte: $c$, thickened region, or cushion, in which is imbedded the foot; $l$, first leaf ; $r$, root; $a r$, unfertilized archegonia; $a n$, old antheridia; $r h$, rhizoids. $B$, an old prothallium with young fern sporophyte attached, whose first leaf $l$ has grown up through the notch at the forward end of the prothallium, while the root $r$ has entered the earth: $r h$, rhizoids. - A fter Sachs

are passed entirely within the tissue of the prothallium, surrounded by the remains of the archegonium. The fertilized egg cell divides, and there are formed four regions in the embryo

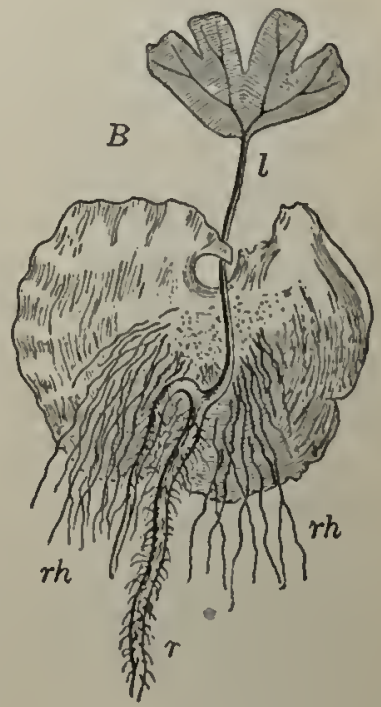
fern : (1) a stem region, (2) the first leaf, (3) the first root, and (4) an organ of attachment to the gametophyte called the foot. The leaf and root soon break out of the archegonium, the first growing upward and the second into the earth (Fig. 279, $A, B$ ). 'The stem grows more slowly. The young fern all this time obtains nourishment from the prothallium through the foot after exactly the same method as in the bryophytes. However, when 
the root and leaf are well established the sporophyte becomes independent of the gametophyte, which gradually dies within a few weeks or months. It is the development of root, stem, and leaf on the part of the sporophyte, giving it complete independence, which marks the greatest advance of the pteridophytes over the bryophytes.

310. Summary of the life history of a fern. The alternation of generations in the fern is much more apparent than in the liverworts and mosses because both gamétophyte and sporophyte are independent plants. The two groups (bryophytes and pteridophytes) are in striking contrast in the relative importance of the two generations. The gametophytes of the bryophytes are relatively large, long-lived, and complex organisms (with sterns and leaves in the mosses and leafy liverworts), while the sporophytes are simple and so dependent upon the gametophyte that they were for many years called its fruit. The gametophytes of the pteridophytes, on the contrary, are small, shortlived, and simple, while the sporophytes are very large and complex (possessing stem, roots, leaves, and a vascular system) and, except in their earliest stages of development, completely independent of the gametophytes.

The life history of a fern may be formulated as follows:

$$
\begin{aligned}
\text { Gametophyte (prothallium) } & <{ }_{\text {egg }}>\text { sperm }>\text { Sporophyte (fern plant) } \\
& \text { - asexual spores - Gametophyte, etc. }
\end{aligned}
$$

This in abbreviated form becomes

$$
G<_{e}^{s}>-S-s p-G<_{e}^{s}>-S-s p-G, \text { etc. }
$$

and is the same life-history formula as that of the bryophytes (Sec. 285).

311. Apogamy and apospory in the ferns. There are some irregularities in the life histories of certain ferns which are not uncommon in greenhouses and under cultivation (species of Pteris, Aspidium, Athyrium, Nephrodium, etc.). Prothallia 
sometime fail to develop arehegonia or the arehegonia do not function, but the sporophyte generation arises as a bud-like ontgrowth from the prothallium. In other cases the egg may develop without fertilization (parthenogenesis). Such suppressions of sexuality with the development of a succeeding generation asexually are called apogamy. The phenomenon has been noted before in the water molds (Sec. 262) and other fungi, and it is found in varions groups throughout the plant kingdom.

Apospory is the suppression of the process of spore formation and the development of a gametophyte generation directly from the sporophyte. It is found in many of the ferns, which are also apogamous, and is shown by the presence of prothallia, which

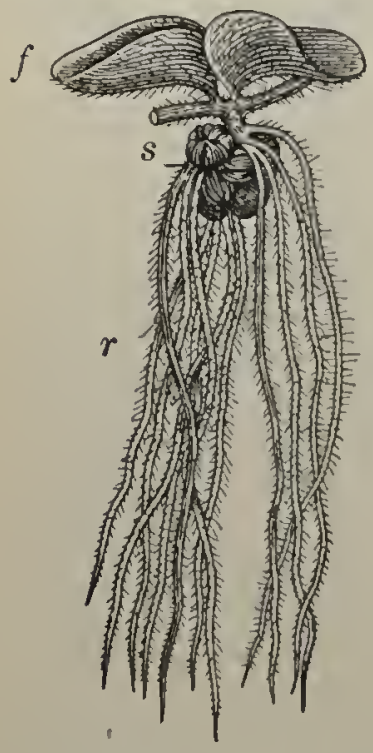

Fic. 280. 1 water fern

(Salvinic)

$f$, floating leaves; $r$, highly modified leaf acting as a root; $s$, spore fruits. After Pringsheim are direct outgrowths from the fern frond in the place of the sporangia, or sometimes at the tips. Apospory is also found in certain mosses where protonema may develop directly from portions of the stalk and spore cases of the sporophytes.

Apogamy and apospory are both short cuts in the life histories, which are believed to be due to some unusual life conditions that interfere with the regular developnent of gametes and spores in the normal life histories, established during the evolution of plant groups.

312. The water ferns. The water ferus (order Iydropterales) include four interesting genera (Marsilia, Pilularia, Salvinia, and Azolla), each of which is remarkable for some peculiarity of structure. Salvinia (Fig. 2S0) and Azolla are floating aquatics, and Marsilia and I'ilularia are either aquatic or grow in very wet places. These habits give the common nane of water ferns to the group. They are important illustrations of the condition called heterospory, 
whieh is briefly described in Sec. 214 and diseussed in some detail in Chapter xxvir. The Hydropterales are believed to have been derived from the Filicales, and the development of heterospory is the most important advance over that group. We ean only eonsider the rather widely distributed type Marsilia.

313. Marsilia." Marsitia, the elover leaf fern, or pepperwort, is easily recognized from the form of the leaf (Fig. $281, A)$. The leaves arise from a ereeping stem which in eertain species, as $M$. quadrifolia, grow over the mud in shallow water along the margins of ponds and streams, but often come out of the water upon muddy banks. Other speeies, as $M$. vestita, grow almost entirely on inuddy banks or in wet meadows.

The spores of Marsilia are developed in bean-shaped

* 'To rill Ixstructor: If only one heterosporous pteridophyte can be stuclied in the laboratory, it is nuch better that the type lie Selaginella. For this reason the ac-

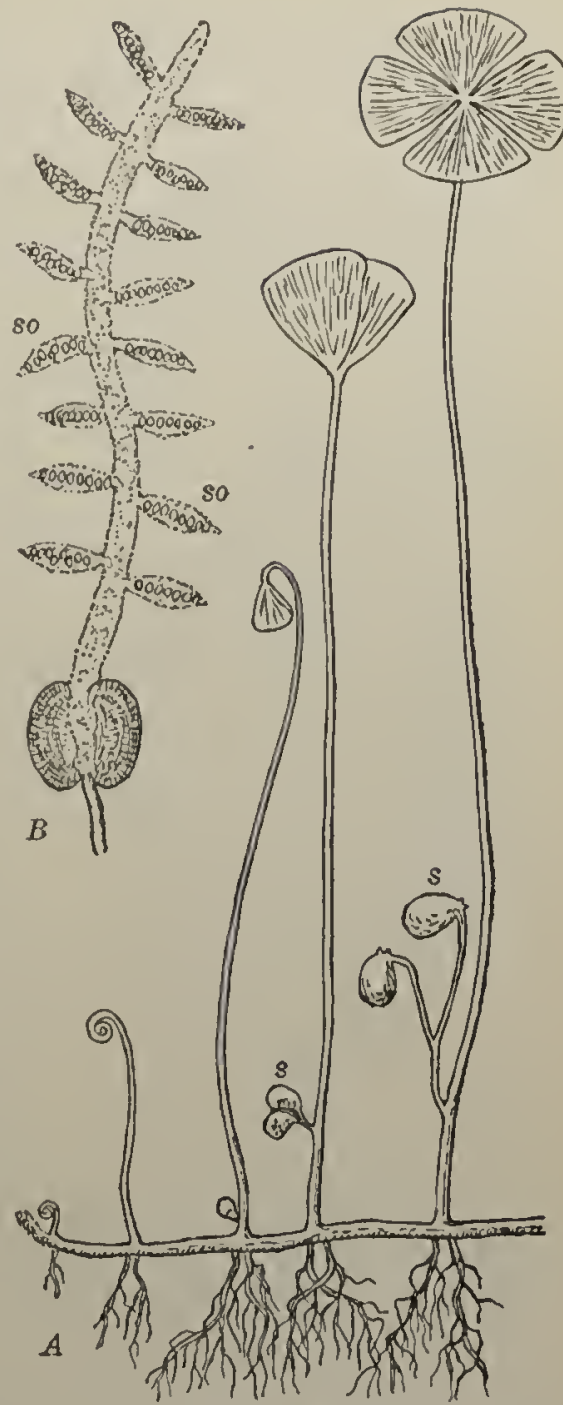

FIG. 281. Marsilia

A, creeping stem of Marsilic quarlrifolia, showing a series of leaves in various stages of development: $\varepsilon$, spore fruits (sporoearps). $B$, a spore fluit of M. vestita, whieh lias opened in water aurl extrurlel il gelatinous, wolm-like structure bearing sori so count of Marsilia has bren marle slort. The life-history formula is, of course, the same as that of Selaginclla, which is fully treated in see. 326. 
spore fruits, or sporocarps, borne in groups on short stalks. These spore fruits (Fig. 281, $A, s$ ) are really modified portions of

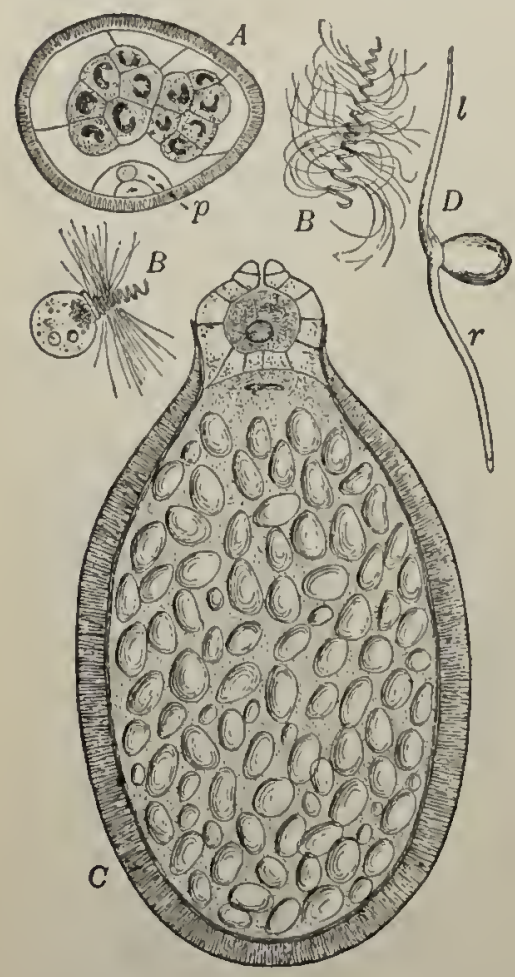

Fig. 282. Gametophytes of Marsilia vestita

$A$, male gametophyte within microspore: $p$, prothallial cells; two groups of sperm mother eells shown within. $B$, sperms. $C$, female gametophyte consisting of a single arehegonium at one end of the megaspore, which is filled with starclı grains. $D$, a week-old embryo (slightly magnified) still attaehed to the megaspore: $l$, first leaf; $r$, root. $-A, B$, after Campbell leaves, which are excellent illustrations of very highly developed sporophylls, much more specialized than the spore leaves of such ferms as Onoclca and Osmunda.

The spore fruits burst open when soaked in water through the swelling of mucilage within, and the contents come out as a gelatinous, worm-like structure bearing large groups (sori) of spores along the sides (Fig. 281, $\boldsymbol{B}$, so). The spores are developed in essentially the same manner as in the common ferns (Filicales), but the tissues of the sporangia are so much modified that the resemblances can only be followed through a detailed developinental study. The spores are set free by the softening of the gelatinous material, and they begin to germinate at once in the water. They are of two sizes, large and small, and are consequently called meguspores and microspores. This condition is termed heterospory.

The inegaspores are full of starch grains, which furnish the food for the development in a few hours of a small female gametophyte. This gametophyte (Fig. 282,C) consists of a single archegonium at one end of the spore. Although the cells are somewhat greenish, it is perfectly 
elear that the food of this much-reduced prothallium is furnished chiefly by the sporophyte by means of the megaspore. The gametophyte of Marsilia has therefore degenerated from the independent condition in the common ferns and is now no longer self-supporting, but is dependent upon food stored by the sporophyte, a relation which is exactly the reverse of that in the bryophytes.

The microspore develops a very small male gametophyte even more quickly than the megaspore develops the female one. This structure consists of a lens-shaped sterile cell called the prothallial cell (Fig. 282, $A, p$ ), together with a group of cells which probably represent a single much-reduced antheridium. The sperms are formed within this group. They are remarkable, long, coiled bands covered with cilia (Fig. 282, B), and are among the largest sperms in the pteridophytes.

The young sporophyte develops within the archegonium, following essentially the same listory as that of the common ferns, and is consequently attached to the megaspore (Fig. 282, D). But there is an important peculiarity in its relation to food supply. This sporophyte makes use of considerable food that remains in the megaspore after the development of the female gametophyte. The Marsilia plant, therefore, actually provides for the next sporophyte generation by storing food in the megaspore. This provision is strikingly similar, as will appear later, to the eonditions in the seed where the embryo (young sporophyte) is nourished by food stored in the seed by the sporophyte of the preeeding generation.

Marsilia illustrates exceptionally well three important principles in the evolution of pteridophytes and seed plants, namely: (1) the establishment of heterospory, resulting in the separation of male and female ganetophytes, (2) the reduction or degeneration of the gametophytes, which become dependent upon food stored in the microspores and megaspores, and (3) provision in the megaspore for the nourishment of the embryo of the succeeding sporophyte generation. 
314. Heterospory. Heterospory (meaning dissimilar spores) arose in the pteriduphytes with the establishment of two sizes of spores, - megaspores and microspores. Pteridophytes having these are called heterosporous, and those with spores of the same size, as in the common ferus (Filicales), are called homosporous
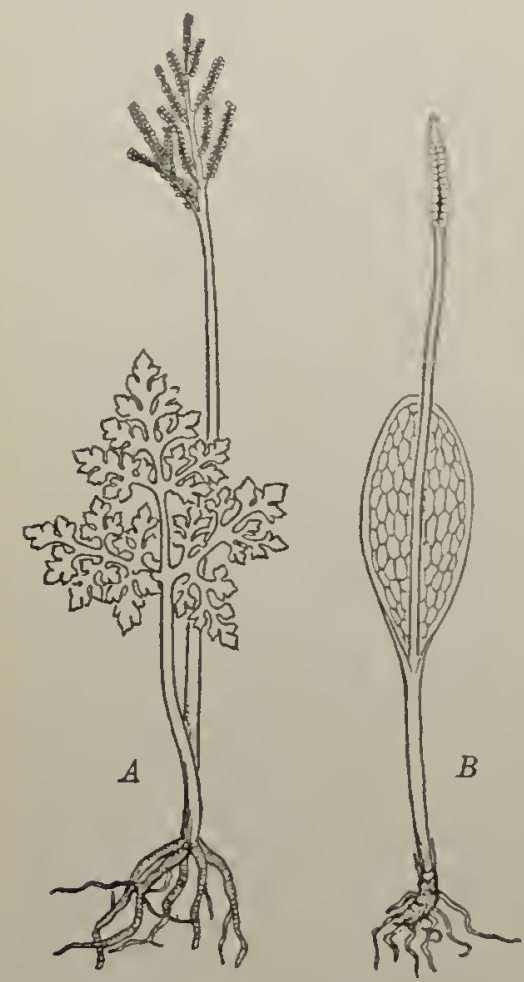

FIG. 28:. 'The moonwort and adder's-tongue

$A$, the moonwort (Botrychium terna-

tum $; L$, the allder's-tongue (Ophioglossum vulgatum) (meaning similar spores). With heterospory came also a differentiation of the gametophytes into male and female structures, the first developing from the microspores and the second developing from the megaspores.

315. The moonwort and adder's-tongue. The moonwort (Botrychium, Fig. 283, $A$ ) and the adder's-tougue (Ophioglossum, Fig. $283, B$ ) are in the same group (order Ophioglossalcs) and illustrate certain primitive conditions in the pteridophytes. These forms do not have external sporangia, as in the Filicules, but the spores are developed in smiken regions along peculiar stalks. Such sunken sporangia are much more primitive in strueture than those which develop upon thie surface of the plant, for they resemble more closely the conditions in the bryophytes where the spore mother cells are found in the interior of the plant. The spore-bearing stalks are accompanied lyy sterile blades devoted to the regetative activities, so that these leares illustrate the same sort of division of labor as is found in the royal fern (Osmunda reyalis). The gametophytes are underground, tuberous bodies generally, destitute of chlorophyll and 
saprophytic in their life habits, being associated with certain fungi which form a mycorrhizal partnership (Sec. 27S) with them.

\section{CLASS II. THE HORSETAILS, OR EQUISETINEA}

316. The horsetails. The lorsetails, or scouring rushes, are all comprised in the genus Equisetum, which contains abont 10 living sprecies, the sole modern representatives of the order Equisetales and the class Equisetinece. These plants are the remnants of what was a very extensive flora in an early geolugical period, called the Carboniferons Age, when the largest deposits of coal were formed. The ancient relatives of Equisctum (Plate V'III, 2), together with the club mosses, were then trees and formed the forests in those times. The horsetails live now nnder what seem to be rather severe conditions in bare or sancly soils that are unfavorable for the growth of trees, herbs, and grasses. They illustrate very well the way in which an ancient group is sometimes able to avoid total extinction by withdrawing as far as possible from competition witl the recent floras, and thus hold its own by means of peculiar life habits and adjustments to special conditions.

The most striking feature of the morphology of Equisetum is the total absence of foliage suitable for vegetative activities (photosynthesis). The foliage is represented by sheaths (Fig. 284, A, $B$ ), which are found at the joints of the hollow stem. The prints on these slieatlis are the tips of small leaves more or less mnited below. The vegetative functions are performed by the green stems. These are fluted, that is, they have numerons ridges which run lengthwise, and the depressions between the ridges contain stomata, which lie above the chlorophyll-bening tissues (Fig. 2St, $F, e$ ). The epridermis contains deposits of silica, which is the chief substance in glass, and conseruently the stems feel rough. They are sometimes used for scouring or polishing metal; hence the origin of one of the common names, "scouring rush." 


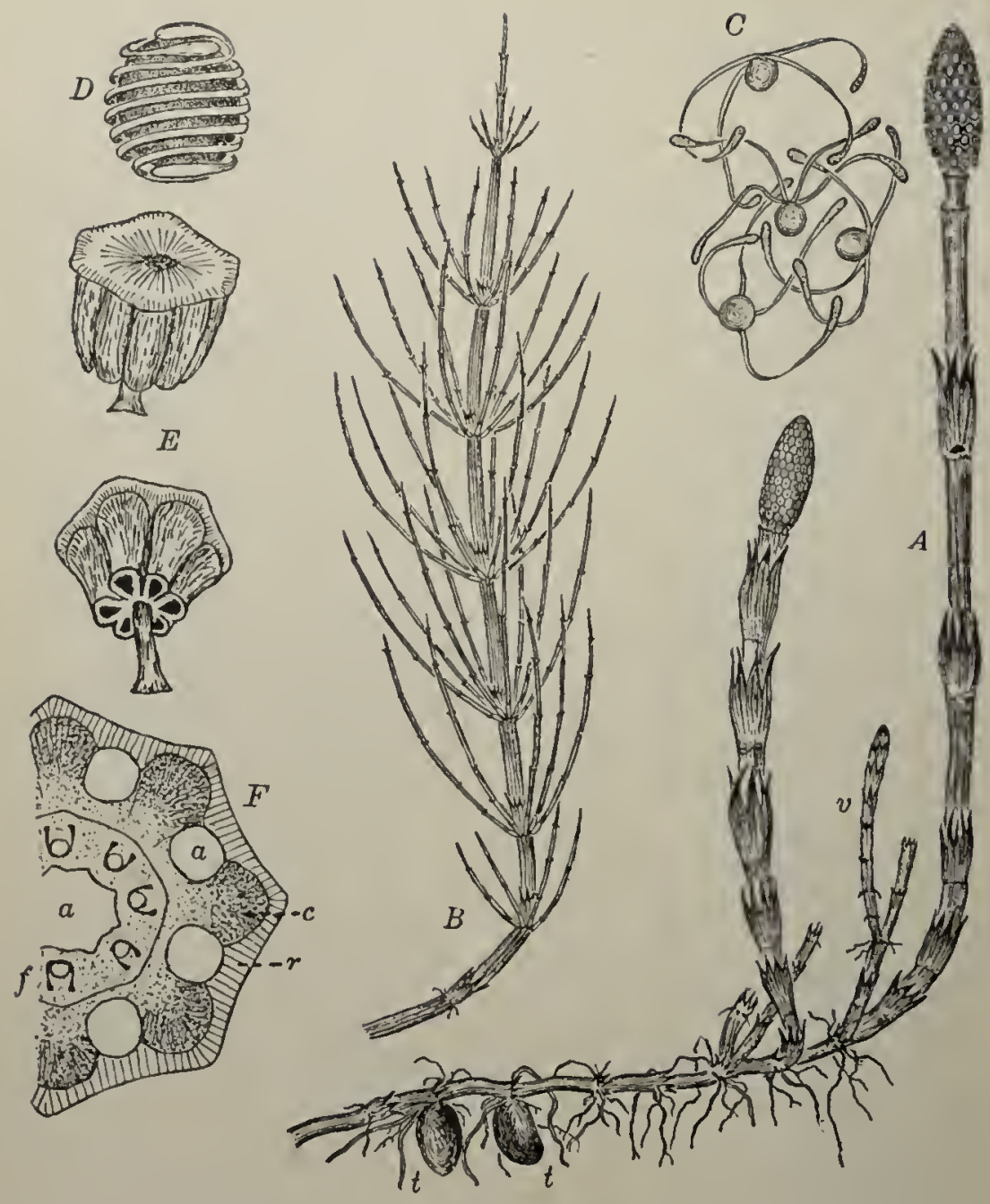

Fig. 284. $\Lambda$ horsetail (Equisetum arvense)

$A$, fertile stems, bearing eones rising from the creeping rootstoek: $t$, tuberous bodies; $v$, young vegetative stem below ground and realy to grow into the mature structure shown in $B$. $I$, regetative stem as it appears perhaps three weeks after the fertile stems have shed their spores and died. $C$, a group of spores with their elaters expanded. $D$, a spore with the elaters eoiled around it. $E$, two views of the spore leaves (sporophylls), showing the group of sporangia. $F$, portion of a seetion of the stem: $a$, air spaees: $c$, chloroplyyll-bearing tissues: $r$, rigitl outer tissues; $f$, fibro-vasenlar bundle around suall air space. $-A, B, C, D$, after Sehenek 
The stems are generally of two forms. There are green aërial stems above ground, unbranchę in some species, but quite bushy in others by the development of circles of side branches at the joints (Fig. 284, B). The aërial stems arise from crecping underground stems, or rootstocks, which have the same jointed structure and sheaths of degenerate leaves, but are not green and often not hollow. The underground stems live from year to year and grow rapidly through the soil, frequently establishing large beds of horsetails, as, for example, along railroad tracks and the margins of sandy pools and ponds.

The stem has large, central air cavities, running from joint to joint, and also a number of smaller air canals, alternating with the fibro-vascular bundles (Fig. 2S4, $F, a)$. It is strengthened by thick-walled cells, forming a rigid tissue (Fig. 284, $F, r$ ) under the epidermis, and is consequently well protected from the danger of drying up. These peculiarities, together with the reduced leaf surface, are characters which the horsetails have in common with many desert plants (xerophytes), and they permit them to live when necessary under very severe drought conditions.

The fructification of Equisctum is a cone (Fig. 284, A) developed at the tip of the stem, and it is composed of scale-like spore leaves (sporophylls), which fit closely together and develop spores in sporangia upon their under surfaces (Fig. 284, E). These cones are generally found on ordinary green stems. However, in some species, as $E$. arrense, the stems which first appear above ground are pale in color and are devoted entirely to the development of the cones and die after the spores are shed, while the green vegetative stems appear later.

317. The cone of Equisetum. A cone, or strobilus, is a compact group of spore leaves (sporophylls) distributed around the tip of a stem and distinct from the rest of the plant. It takes its compact form becnuse the sporophylls are closely set together and frequently so much modified that their structure is not apparent at a glance. Each sporophyll in Equisetum consists of a short stalk attached to the side of the stem and bearing an 
angled shield-shaped top (Fig. 284, E). A group of sporangia hang down all around the stalk from the lower surface of the shield, and each develops from a group of cells instead of from a single cell, as in the common ferms (Filicalcs). The shields separate from one another when the cone matures, and the ripe spores escape through rents in the sporangia and sift out between

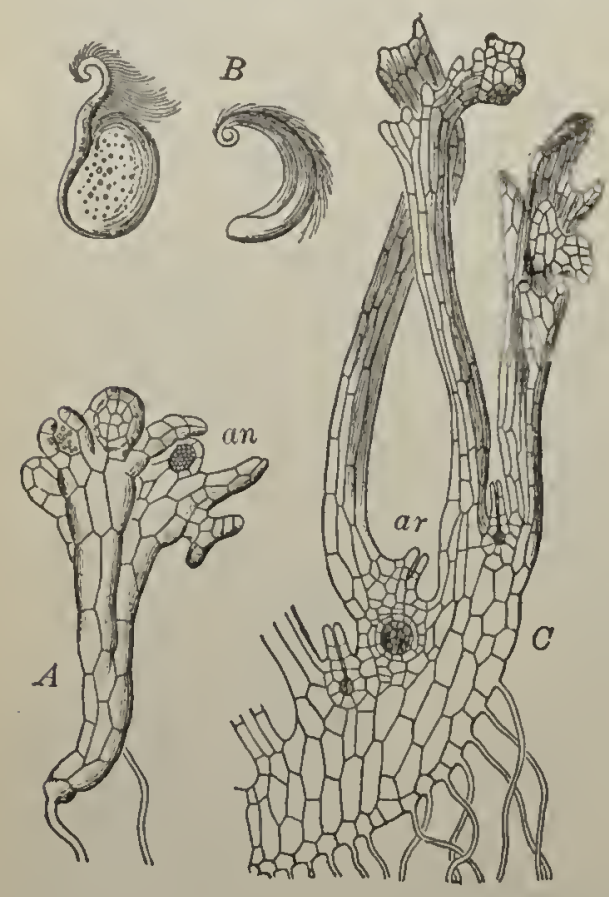

Fig. 285. Gametopliytes of Equisetum

$A$, male prothallinm: an, anthericlium.

b, sperms. $C$, female prothallium: $a r$, archegonium. $-A, C$, after Hofmeister; B, after Schacht the shields. The spores are formed in groups of four (tetrads) in the spore mother cells.

Each spore (Fig. 284, C,D) bears four filaments developed from an outer layer of the spore wall, which splits into bands that separate from one another, but remain attached to the spore at one point. The filaments coil around it when moist, but loosen and spread out when dry. These movements must assist the escape of the spores from the sporangia. The filaments also serve as wings in the distribution of the spores by the wind, and they become entangled with one another so that groups cling together and are carried away and germinate in clusters. The spores are of the same size, and therefore Equisctum is homosporous.

318. The gametophytes of Equisetum. The spores only retain their vitality for a few days. They produce green gametoplyytes somewhat like fern prothallia, but very irregular in form (Fig. 285, $A, C$ ), the larger with long lobes, at the bases of which 
are situated the sexual organs. The prothallia are normally diocious, that is, male and female in sex, but since the spores are distributed in groups, antheridial plants are likely to develop in the same cluster with the arehegonial. The sexual organs are sunken in the tissues of the gametoplytes. The sperms are coiled, many-ciliate protoplasts (Fig. 285, B') resembling those of the common ferms.

The carly stages in the developinent of the young Equisctum sporopliyte from the fertilized egg are the same as those of the common ferus. 'This together with the similar ganetophytes and sperms is believed to indicate a distant relationship between the Equisetinew and Filicinere, even though the mature sporophytes of the two groups appear so different in structure.

\section{CLASS III. THE CLUB MOSSES, OR LYCOPODINEAE}

319. The club mosses. The Lyeopodinece take their common name of club mosses from the moss-like appearance of the stems, which in most forms are covered with small leaves (Figs. 286, $289, A)$, and the fructification, which is generally a club-shaped cone developed at the end of the stem (Figs. $287, \boldsymbol{A} ; 289, \boldsymbol{A}$ ). Isoctes (Fig. 291) is, however, in these particulars a conspicuous exception. But the club mosses are very much larger than any of the true mosses $(1 /$ Lesc 2 ), and are of course sporoplytes, like the horsetails and ferns, while the true mosses are gametophytes. Like the lorsetails, they are the remmants of a very ancient group which formed forests in the Carboniferous Age (Ilate V1II, 3, 4); also, they have been able to persist only by alapting themselves to life conditions where they do not cncomber keen competition with grasses and herbs. Almost all if the Lycopodinece are contaned in three geurra: Iycopodium (alout 100 species), Selayinella (about 500 speeies), and Isoctes (si)me 60 species). But in addition there are sereral remarkable types (Phylloglossum, I'silotum, Tmesipteris) which are tropical or sub-tropical and cannot be described here. 
320. Lycopodium. Lycopodium includes the larger club mosses, frequently called lycopods, and are distinguished by having needle-like leaves arranged spirally on the stem (Fig. 286) and similar spores (homosporous). The stems are of two forms: (1) creeping stems, close to the ground and frequently buried

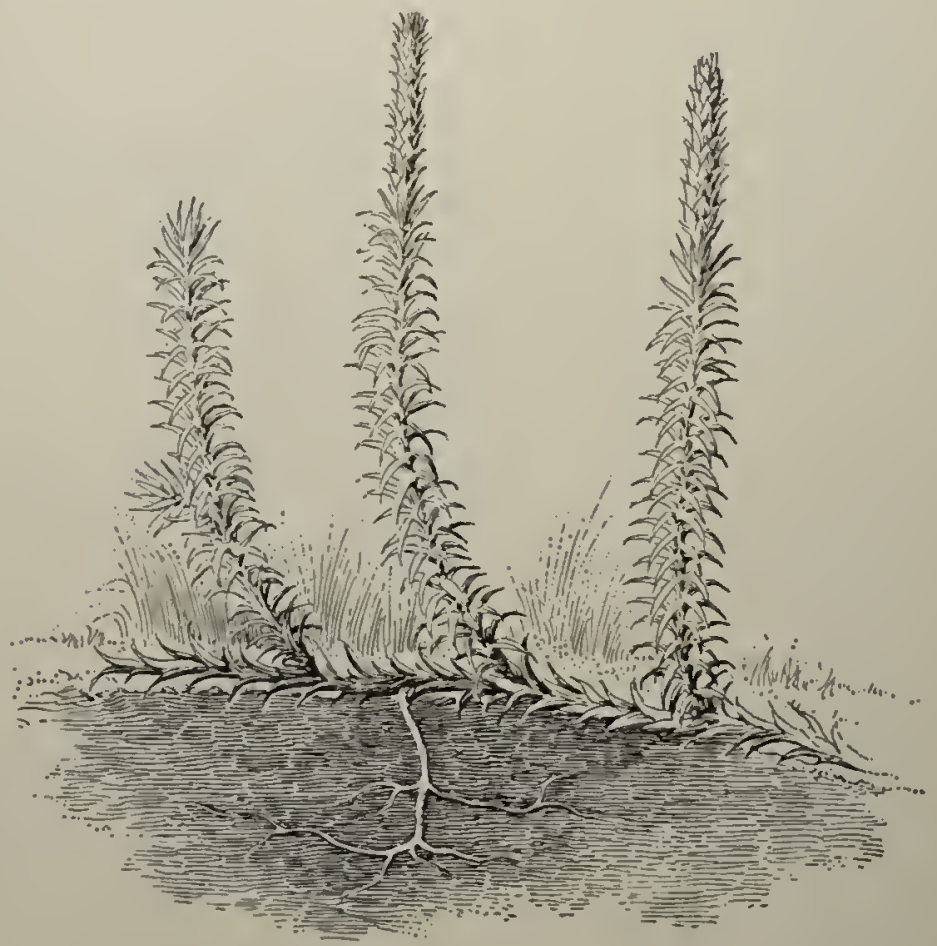

Fia. 286. A club moss (Lycopodium annotinum)

Modified after Kerner

under leaves and other forest débris, and (2) upright stems, very much branched in some species and bearing the cones like clubs at their ends. Some of the larger species are very common in the northern woods, the long, crecping stems often growing thickly orer the ground. The stem is generally quite woody in structure, and the leaves are cvergreen. They are much used . in holiday decoration, and certain species are in danger of extinction, since the club mosses reproduce very slowly. 
321. The cone of Lycopodium. In some species of Jycopodium, as $J_{\text {. }}$ Scluyo, the spore leaves (sporophylls) have the same form and grouping as the vegetative leaves so that there is no cone distinct from the rest of the stem. Put most of the forms lave very clearly defined cones, which are sometimes laised on long stalks, as in $L$. complanatum. The sporophylls are grenerally seale-like and closely set (Fig. 287, A, B'). Each spore leaf bears a single, large, sac-like sporangium ( Fig. 287, C) at its base, which develops from a group of cells. The spores (Fig. $287, D$ ) are formed in groups of four (tetrars) in the spore mother cells. They are very minute and are produced in such immense numbers that they are collected in quantity as the lycopodium powder of apothecary shops, used in dusting pills to keep them from sticking together as well as for other purposes. This powder is also employed in the manufacture of fireworks umler the name of vegretable sulphur.

\section{The gametophytes of} Lycopodium. The gametophytes

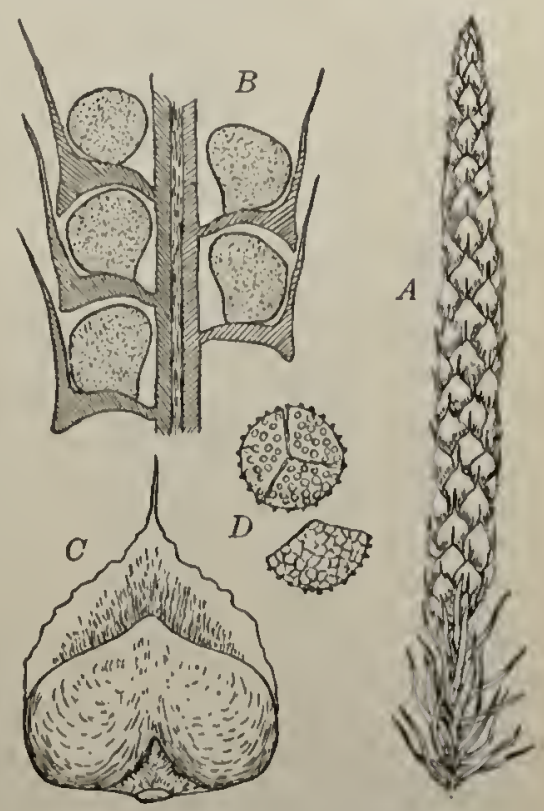

lis; 287. 'The eone of a club moss (Lycopodium annotinum)

$A$, the cone, showing overlapping spornphylls; $I$, diagram of a longitudinal section, illustrating tho form and position of the sporopliyls and spon rangia; $C$, the inner face of a sporophyll, showing the large sporangimm; $I)$, two views of spores from a group of four (tetrad) of the club mosses in our northern woods must be uncommon, if they are developed at all, for they have never been found. It is probable that thesporophytes reproduce chiefly or perhaps entirely by vegetative branching of their stems and in some forms by curious buds. The gametophytes of some tropical lycopods are however known and have been studied. They are small, tuberous 
bodies (Fig. 288) generally subterranean and practically desti-

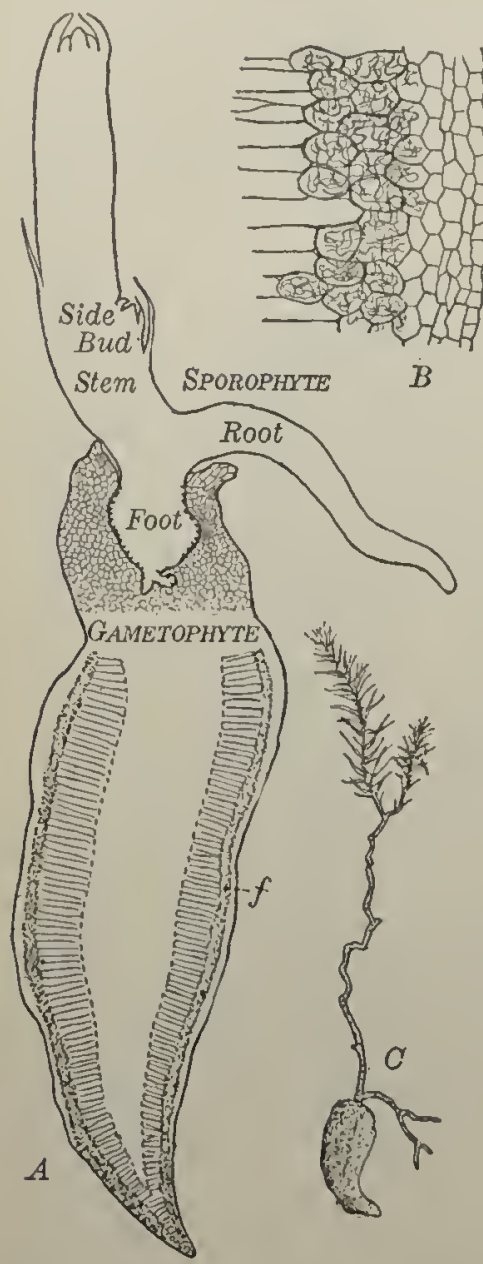

Fra. 288. Gametophytes and young sporophytes of a club moss (Lycopodium complanatum)

$A$, gametophyte with young sporophyte: $f$, tissue fillerl with the filaments of a fungus situated just outsile a layer of palisale cells. $B$, the fungus-infected tissue. $C$, a youug club moss still attached to the subterraneau gametophyte. - $A, B$, from material of Bruchmann prepared by Miss Lyon; $C$, after Bruchmann tute of chlorophyll, like those of the moonwort and adder's-tongue. They are therefore saprophytic, and associated with them are fungal filaments to form a mycorrhizal relation (Sec. 27S). The sexual organs are sunken structures. The sperms are two-ciliate.

The embryo sporophyte remains attached to the gametophyte by a large foot (Fig. 2SS) for a long time after the stem and root are developed, and must obtain much nourishment from the gametophyte, as in the case of the ferms.

323. Selaginella. Selaginella is readily distinguished from Lyeopodium. The leaves in most species are arranged in four rows, two rows of smaller lcaves ou the upper surface and two rows of larger leaves somewhat at the sides (Fig. 289, A). The cones also have four rows of spore leaves (sporophylls) and are consequently foulangled. The spores are of two sizes, and the type is perhaps the best illustration of heterospory in the pteridophytes. Forms of Seluginella are frequently called "little club mosses," for many of them are much more delicate than the lycopods. But some tropical species, frequently cultivated in 
greenhouses, are large, much-branched, and bushy plants, very graceful and decorative. Some forms grow in dry situations on sand and locks, in Mexico and the Southwest. One species (S. lepidophylla) is frequently sold in the North under the name

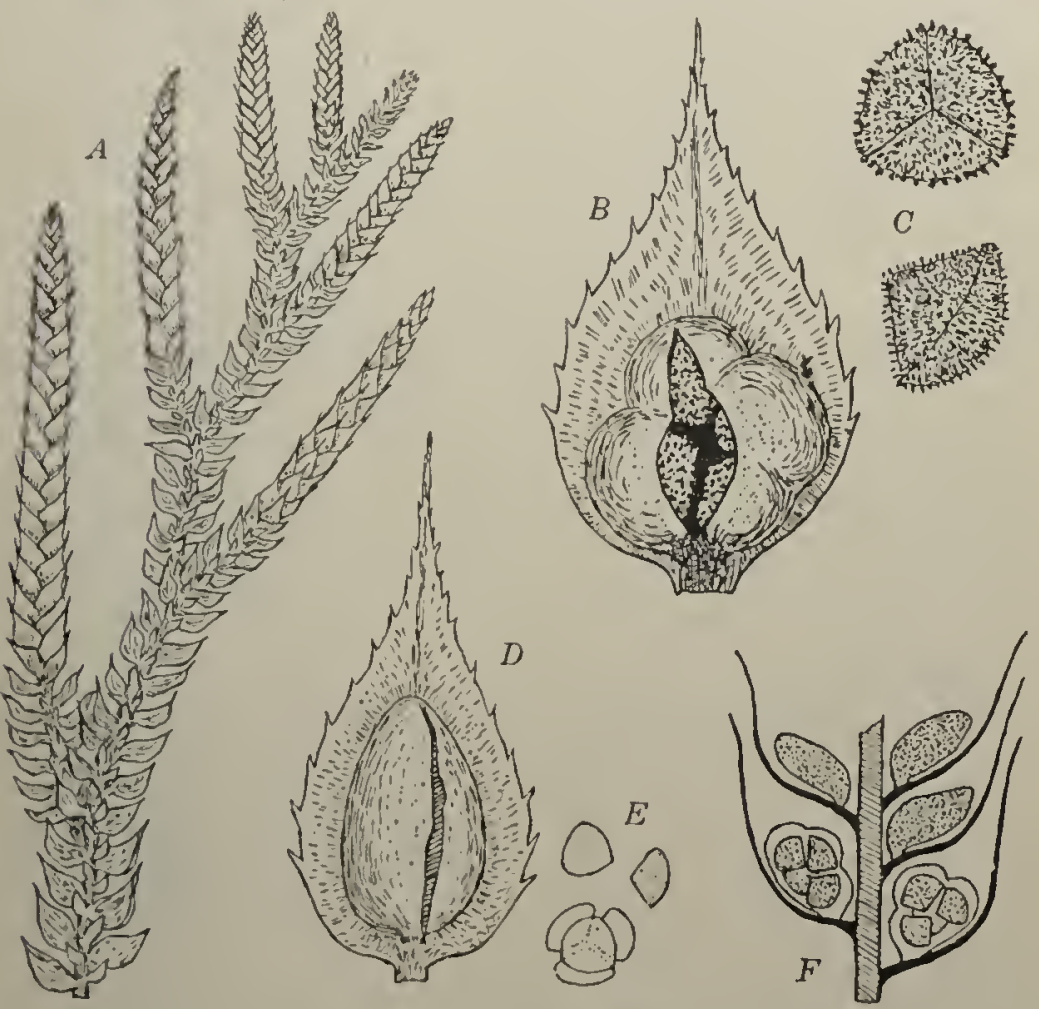

Fig. 289. Selaginella Martensii

$A$, branch bearing cones and showing the leaf arrangements; $B$, inner face of a megasporoplyyll, showing the large megasporangium containing a group of four megaspores (tetrad); ( , two view's of megaspores; $l$ ), inner face of microsporophyll, showing microsporangium; $F$, microspores; $F$, diagram of a longitudinal section of cone ilhstrating position of microsporophylls and megasporophylls and their microsporangia and megasporangia

of "resurrection moss." This plant protects itself during drought by rolling up the branches to form a compact ball. When moistened the branches spread out and become fresh and green. ${ }^{1}$

1 A botanist states that the plants sold in the Xorth will absorb moisture and unroll, but are generally "dead" beyond reeorery. 
324. The cones of Selaginella. The cones of Selaginella are not as large as those of Iycopolium, but they are much inore eomplex in structure. The sporangia are of two sorts, both developing singly from a group of eells on the stem just above the origin of the spore leaves and later becoming attached to their bases. The sporangia near the lower part of the cone (Fig. 289, B) produce from one to eight very large nnegaspores, and frequently a group of four (tetrad). The sporangia higher up on the cones (Fig. $289, D$ ) are smaller and develop a great number of minute microspores, also in tetrads. Selaginella has, then, different sporangia for the two forms of spores, nicrospores and megaspores, which are accordingly called mierosporangia and megasporangia. Furthermore, these sporangia are borne upon different spore leaves, which are consequently termed microsporophylls and megasporophylls. It is important to note that the few megaspores which mature are nourished and grow at the expense of neighboring spore mother eells which beeonte disorganized.

325. The gametophytes of Selaginella. The microspore develops a redueed and degenernte male gametophyte, as in Marsilia (See. 313). There is a small sterile cell (prothallial eell) and two groups of sperm cells in a very simple cellular strueture probably representing an antheridiun (Fig. 290, A). The sperins are two-ciliate (Fig. 290, B).

The inegaspore develops a female gametophyte which is larger than that of Marsilia, but it is the same sort of a reduced strueture, dependent upon food stored by the sporophyte within the megaspore. This ganetophyte at maturity fills the megaspore, and bursting through the spore wall it fresents an exposed surface upon which severnl sumken arehegonia are developed (Fig. $290, C)$. The female gametophyte actually begins its development before the inegaspore has attained its full size in the megasporangium. It is thus parasitic upon the sporophyte during its early history, a habit whieh is miversal in the seed plants, but among the pteridophytes it is only found in Selayinella. 
There are some other life habits of Sclaginclla wonderfully suggestive of the way in which seeds and the seed habit arose. It is known in sone species, as $S$. rupestris, that the microspores are thrown out from the sporangia on the upper part of the eone and sift down like pollen grains anong the megaspores

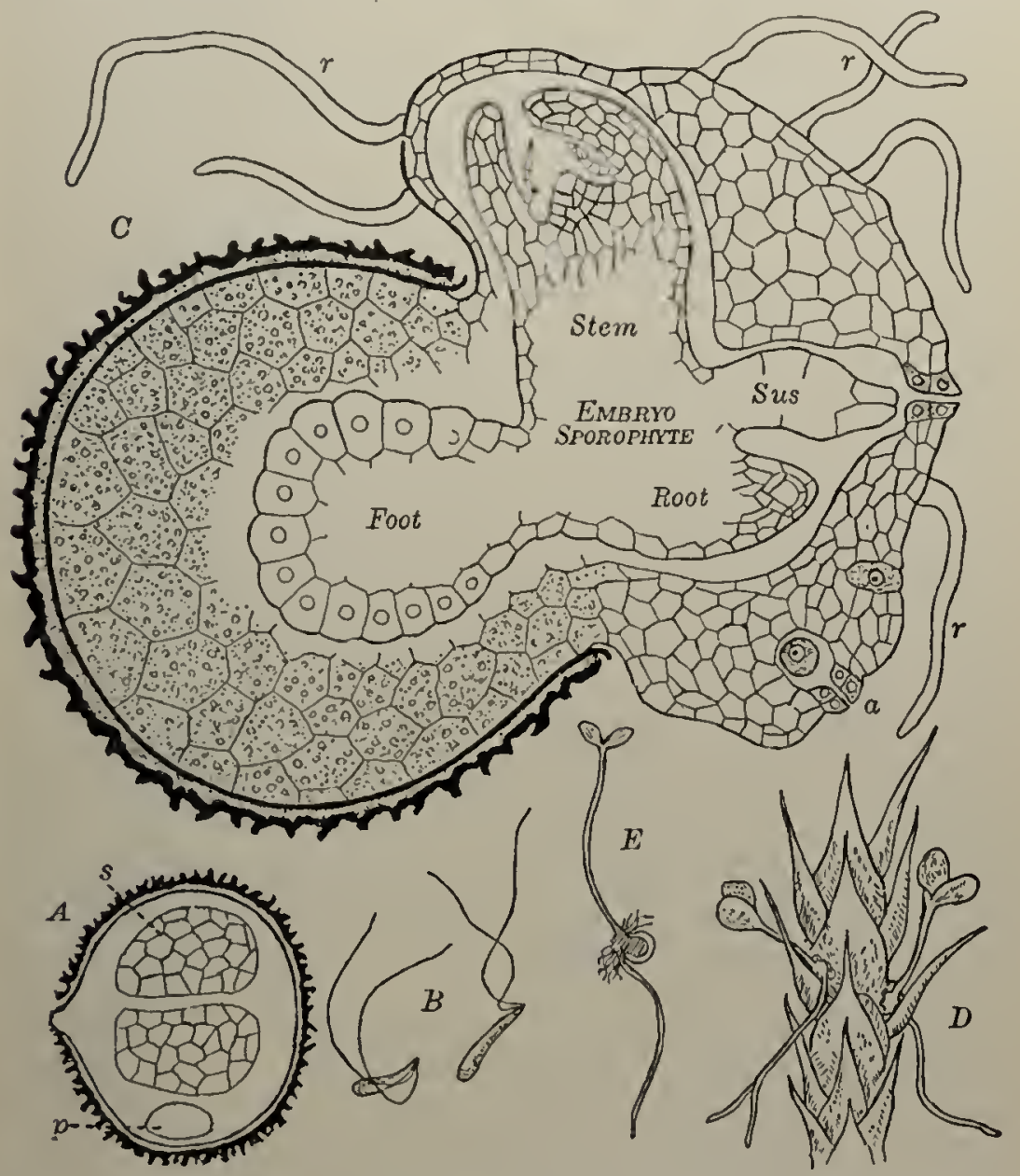

Fis. 290. The gametophytes and embryo of Selaginella

A, male gametophyte contained within the microspore: $p$, persistent nucleus of prothallial cell; $s$, two groups of sperm mother cells. 13 , two-ciliate sperms. $C$, female gametophyte containing an embryo sporophyte: a, archegoniun; $r$, rhizoids. I), young sporophytes held by the spore leaves of the enne. $F$, a young sporophyte still attached to the megaspore. $-B$, after Belajeff; $A, C$, $D$, adinted after notes and sketehes of Miss Lyon 
into the split megasporangia below. The sperms are formed and set free in the moisture of such situations, and the eggs of the gametophytes may be fertilized while the inegaspores are still retained within the megasporangium. The young sporophytes as they develop are thus actually held by the sporophylls of the parent sporophyte (Fig. 290, D) until they reach a considerable size and fall off. These habits should be noted and this paragraph read again after the life history of the seed plant is thoroughly understood.

The development of the young sporophytes of Selaginella and also of Lyeopodium has features resembling those of the seed plants. The early divisions of the egr establish a strueture called the suspensor (Fig. 290, C, Sus), which carries the developing embryo down into the midst of the tissue of the gametophyte, where it can draw nourishment from all of the cells around it. A large foot is developed (Fig. 290) which absorbs food from that portion of the gametophyte which lies in the megaspore, so that the culbryo sporophyte is aetually nourished with food stored in the megaspore by the sporophyte of the previous generation.

326. Life history of Selaginella. Selaginella is an execllent type with which to illustrate the life listory of a heterosporous pteridoplyte. Since two forms of spores, microspores and megaspores, are present, there are two forms of ganetophytes, male and female, and this feature complicates the relatively simple life-history formulie of bryophytes and homosporous pteridophytes (Sees. 285, 310).

The life history of Selayinella is as follows:

$$
\begin{aligned}
& \text { Sporophyte }<\text { microspore - Mule Gametophyte - sperm } \\
& \text { meyaspore - Female Gametophyte - eyy }
\end{aligned}>
$$

This in abbreviated form becomes

$$
S<\begin{aligned}
& m i s p-M G-s \\
& m e s p-F e G-e
\end{aligned}>-S \text {, ete., }
$$


which when carefully studied is essentially the same as the general life-history formula of bryophytes and pteridophytes (Secs. 285, 310), namely,

$$
G<_{e}^{s}>-s-s p-G<_{e}^{s}>-S-s p-G, \text { etc. }
$$

The differences lie in the fact, above mentioned, that there are two forms of spores, microspores and megaspores, which develop, respectively, male and female gametophytes, a complication which was introduced with heterospory and which is present, as will appear later, in the life histories of seed plants (Scc. 356).

327. Summary of Selaginella. Selaginella is the highest of the pteridophytes and the most important because of the evolutionary principles which it illustrates, leading up to the seed habit. The first three of these principles are also illustrated by Marsilia and Isoctes, but the fourth and fifth are new. They are (1) the establishment of heterospory resulting in the separation of male and female gametophytes; (2) the reduction or degeneration of the gametophyte, which becomcs dependent upon food stored in the microspores and megaspores; (3) provision in the megaspore for the nourishnent of the embryo of the succeeding sporophyte generation; (4) the early parasitic relation of the female gametophyte within the megasporangium upon the slorophyte; (5) the occasional habit of devcloping the young sporophyte while the megaspore is still retained within its prarcht megasporangium.

328. Isoetes. The species of Isoetes are known as quillworts. Their position among the pteridophytes is a matter of dispute, and some botanists place them with the ferns (Filicinece), but the anatony of the sporophytes is more like that of the club mosses than any other group. They have a peculiar rush-like habit of growth, the long leaves arising in clusters around a short stem (Fig. 291, A). Some forms are aquatic, growing on inul at the bottom of ponds, while others are usually found out of water. 
Isoetes is heterosporous, and the spores are developed in sunken sporangia at the bases of spore leaves (Fig. 291, $B, s$ ). The spore leaves are differentiated so that only the outermost develop megaspores and are eonsequently megasporophylls, while the

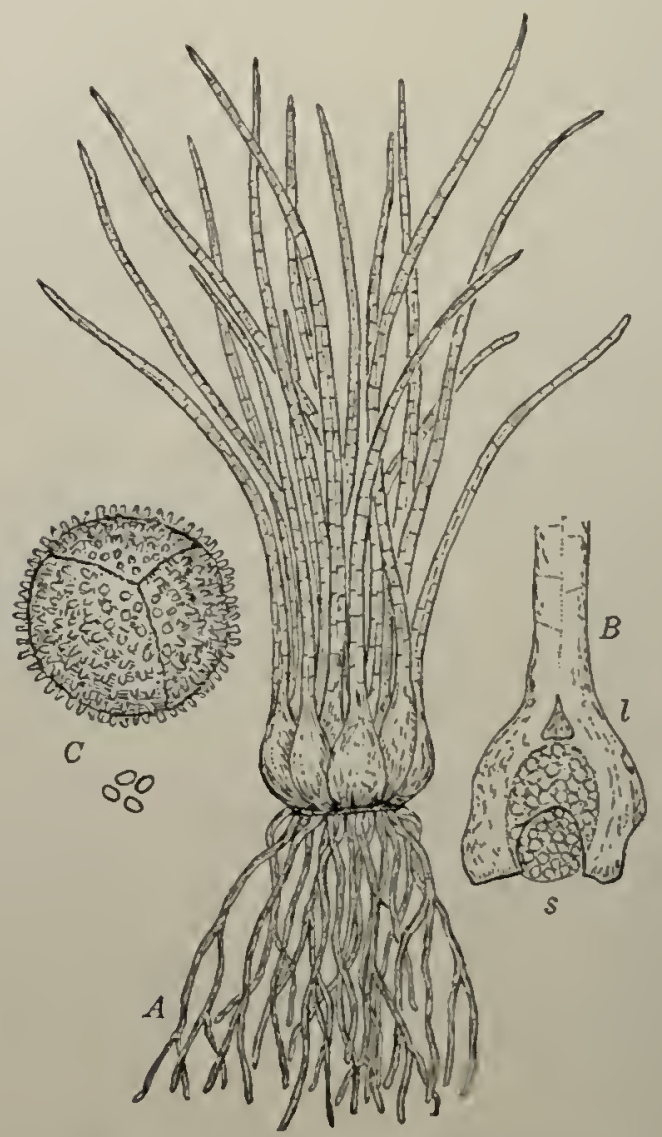

Fig. 291. The quillwort (Isoctes echinospora)

$A$, habit sketch. $B$, base of megasporophyll, slowing inner surface: s, sporangium, containing the large megaspores; $l$, ligule. $C$, a group of microspores below, and a large megaspore above, showing comparative size

innermost are microsporophylls, producing only microspores. Male and female gametophytes are developed slowly in the microspores and megaspores, respeetively, and are reduced or degenerate sexual plants (Fig. 292, A,C), almost as simple as 
those of Marsitia. Having no chlorophyll, they depend upon food stored in the megaspore, as in Marsilic and Selayinella. The young sporophyte also makes use of food in the megaspore as in these other two heterosporous pteridophytes above mentioned. The sperms (Fig. 292, B) are somewhat coiled and many-ciliate, resembling in this respect those of the Filiciner. The life-history formula is the same as that of Selaginella (Sec. 326).

\section{FOSSIL PLANTS AND COAL}

329. Fossil plants. Plant remains are not generally preserved as fossils, partly because they do not often have hard parts, such as the shells and bones of animals, and partly because the larger forms grow on land where they are subject to rapid decay. So the record of plant life in former geological ages is poor as coinpared with that of animal life. However, there are some very wonderful deposits of plant renains forming the hard and soft coal beds, which deserve brief mention here, since
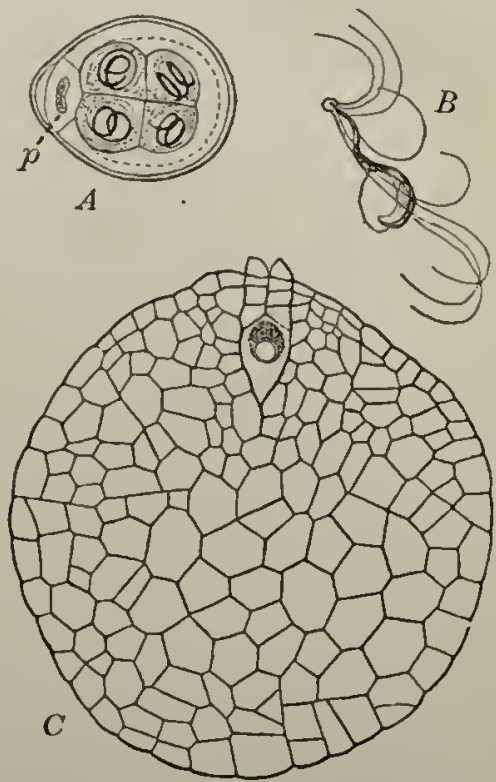

FIG. 292. Gametophytes of the quillwort (Isoetes)

$A$, male gametoplyyte within the mierospore: $p$, prothallial eell; four sperm mother cells shown within the reduced in theridium. $B$, sperm. $C$, section of female gametophyte removed from megaspore, showing sunken archegonium. $A$, $C$, Isoetes echinospora. $-A, C$, after Camplell; $B$, after Belajeff most of the plants composing them are fossil pteridophytes.

During the Devonian and Carboniferous Ages the most conspicuous vegetation was represented by tree fems and relatives of the horsetails and club mosses, together with certain very primitive gymnosperms. These plants reached the height of trees and formed forests on the land and in the unarshes (see Plate VIII). The Calamitcs (Plate VIII, 2) were gigantic 
horsetails, so nearly like the living forms of Equisetum that we can readily picture their appearance along the margins of swanps and streams. Curiously some of the Calamites were heterosporous, although all of the living types of the Equisetinece are homosporous. The ancint representatives of the club nnosses (Plate VIII, 3, 4) were among the largest plants of those times, reaching the height of one hundred feet or more. Some of them were true lyeopods, and others, as Lepidodendron and Sigillaria, were evidently close relatives of the club nosses. Their large trunks were covered with leaves, which fell off, leaving curious, diamond-shaped scars that are very conspicuous on the fossil stems. The earliest seed plants arose in these ages, but they were far outnumbered by the pteridophytes. They were gymmosperms of the group Cordaitea (Plate VIII, 5), but with very little resemblance to any living forms. The fructifications of sonc of these primitive forms, somewhat intermediate between . spermatophytes and ptcridophytes, are occasionally so well preserved that we can learn something of the structure of the gametophytes developed by the spores. It is possible that we shall later know much more about the origin of the seed plants and the seed habit from the study of these fossils.

After the Carboniferous Age the tree ferns, horsetails, and club mosses became less abundant, and gymnosperms, like the cycads and conifers, increased in numbers and became the dominant forest types. There was an age of cycads in a later period (Jurassic), when the earth was covered with these plants as far north as Creenland and the climate must have been tropieal from pole to pole. We know rery little about the carlicst forms of angiosperms. They do not appear abundantly as fossils nintil a later period (Cretaceous), after the age of cycads (Jurassic), although they doubtless liad their origin inuch earlier, for many insects were present which must have had the habit of fceding on pollen or nectar.

It is clear that the horsetails and club mosses of the present time are merely the remmants of this ancient flora once dominant 


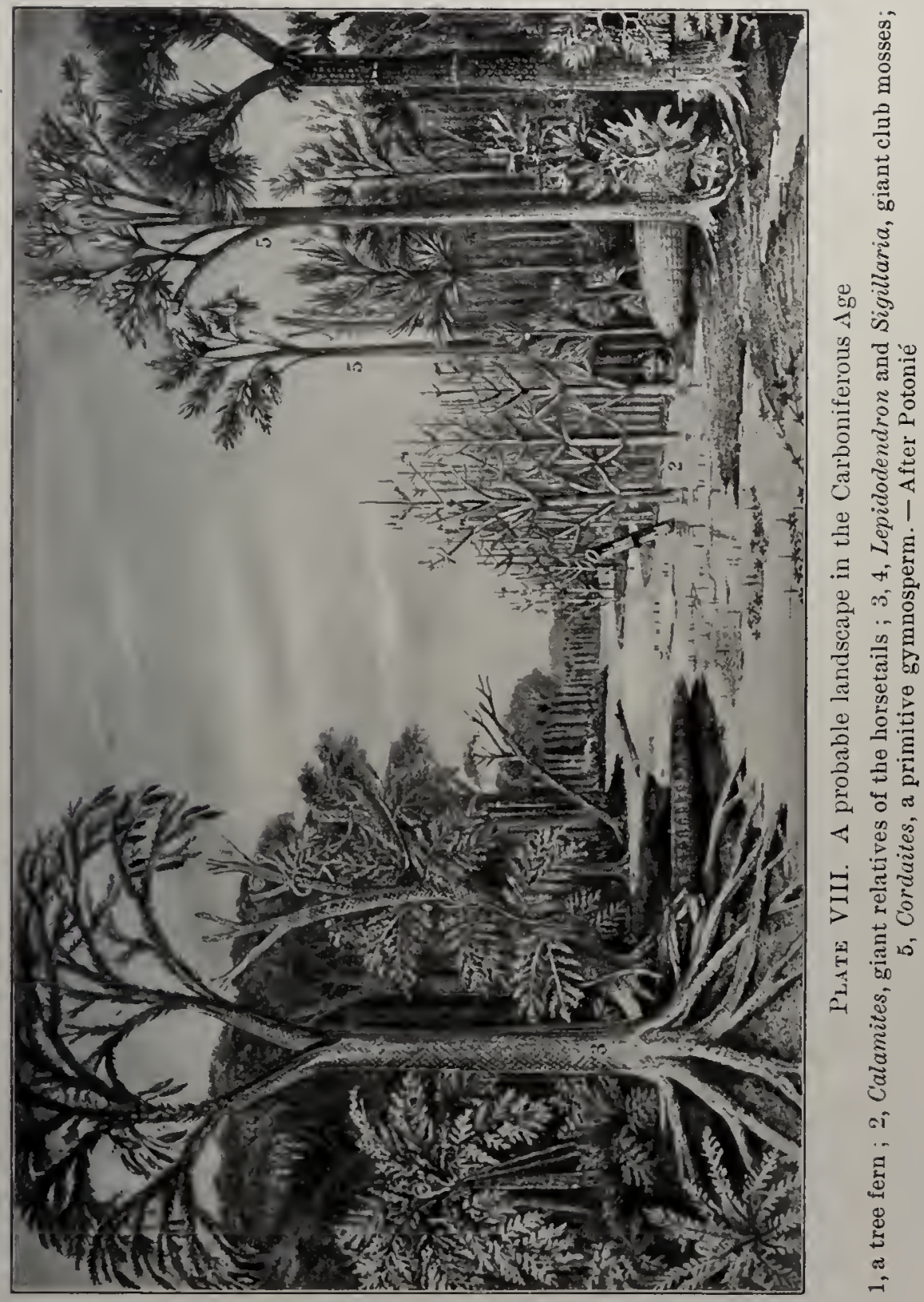



and perhaps as luxuriant as the tropical forests of to-day. They have survived by adjusting themselves to very different life conditions from those of Carboniferous times, and by adopting life habits which remove them as far as possible from competition with the prevailing vegetation forms of to-day (trees, grasses, lierbs, etc.). The degenerate, saprophytic gametophytes of Lycopodium illustrate well how far such changes of life habits may extend.

330. Coal. Coal was formed during a number of periods in the earth's history, but the most extensive deposits were laid down during the Carboniferous Age (frequently called the coal age), forming the so-called coal measures. The luxuriant pteridophyte vegetation of tree ferns, horsetails, and club mosses formed deposits in swamps over immense areas, probably in much the same way as peat is being formed to-day. Such plant deposits from time to time became covered with sediment by the sinking of the land. And since the land alternately rose and sank, successive layers or beds of plant remains were laid down. These remains became finally buried under heavy deposits of sediment, which pressed them into compact beds of the carbonaceous matter called cocl.

Coal is of two sorts: (1) soft or bituminous coal, which is hardly more than lialf pure carbon, the rest being composed of a variety of carbon compounds, and (2) hard or anthracite coal, which may be 90 per cent pure carbon. Hard coal represents a greater degree of change than soft coal, the oils and other products having been driven off under pressure by the heat of the earth. The coal beds vary in thickness from small layers of only a few inches to deposits a hundred feet deep. Those of the United States cover several hundred thousand square miles, of which jerhaps fifty thousand square miles are being worked. Vast as are these coal beds in the United States, there are deposits in other lands, as in China, of even greater extent. The coal supply of China is estimated as enough to last the world seven hundred years. The total deposits of pteridophyte vegetation were very 
much thicker than the coal beds which they formed, for it lias been estimated that it took about five feet of plant remains to make one foot of coal.

It is interesting to think of the part which the pteridoplyte flora of the Carboniferous Age plays in the present life and economic activities of the world, giving us a fuel whose carbon was taken ages ago from the air, which was then much more heavily charged with carbon dioxide than is the atmosphere of to-day.

\section{THE ORIGIN AND EVOLUTION OF THE PTERIDOPHYTES}

331. The origin of the pteridophytes. The pteridophytes undoubtedly arose from a bryophyte ancestry, when the sporophyte generation, in some forms having a structure capable of doing chlorophyll work, developed a root system and vascular tissues, and taking the land habit became independent of the gametophyte. This was one of the most important forward steps in the evolution of the higher plants, for it gave the sporophyte complete freedom to live and grow to its maximum size. It marked a turning point in plant evolution, for after that the sporoplyte becane the most complex and conspicuous phase of the life history, and the gametophyte grew less prominent, until finally in the seed plants the sexual generation becomes actually dependent or parasitic upon the asexual generation, a relationship which is exactly the reverse of that between the gametophyte and sporophyte in the liverworts and mosses. These very importanit results in the evolution of plants are summarized in Chapter XxIx, The Evolution of the Sporophyte and Degeneration of the Gametophyte.

There are no bryophytes that show clearly how the root system arose, but we can easily understand that so complex a sporophyte as that of Anthoceros (which has chlorophyll-bearing tissues with stomata, and a long, indefinite period of growtli) would at once become an independent plant, if it could develop 
a rocit system. For this reason, Anthoceros (Scc. 290) is generally considered the form among the bryophytes most closely approaching the pteridophytes in its structure and possibilities of development.

332. The evolution of the pteridophytes. After the sporophyte becamc independent of the gametophyte, the next important advance was the development of the lateral spore-bearing and vegetative organs called fronds. Then came the differentiation of the fronds into vegetative leaves, given up cutirely to chlorophyll work (photosynthesis), and spore leaves, or sporophylls, devoted chiefly or wholly to spore production. With this also eame the massing of the sporophylls in cones, which was really the beginning of the struetures called flowers in the sced plants.

Finally, the condition of heterospory was attained independently in several groups of the pteridophytes, as the water ferms, Selaginella, and Isoetes. Heterospory soon led to very significant changes in the structure and behavior of the gametophyte generations. They bccame differentiated in sex, the microspores producing male prothalli, and the megaspores female ones. Furthermore, the gamctophytes became greatly reduced, finally depending wholly, or almost wholly, on food stored in the spores. The food in the female gametophyte also came to contribute to the development of the embryo sporophyte, which was thus furnished with food by the sporophyte of the previous generation. At last, in the highest form, Selaginella, the female gametophyte, begins its development while still retained within the megaspore, a condition approximating very closely to the secd habit.

\section{SUMMARY OF THE PTERIDOPHYTES ANI) ITHEL ADVANCES OVER THE IRYOPHYTES}

333. Summary of the pteridophytes. The chicf characters of the pteridophytes and their arlvances over the bryophytes are:

1. The development of a lcafy shoot and root system with vascular tissues in the sporophyte gencration, rendering it 
independent of the gametoplyte, giving it the land habit, allowing it to attain a large size, and making it by far the most conspicuous phase in the life history.

2. The development and differentiation of fronds into regctative leaves and sporophylls, and the grouping of the latter into cones.

3. The derelopment of heterospory, which differentiated the gametoplytes as male and female in scx.

4. The degeneration of the gametophytes (in heterosporous forms) so that they finally became dependent upon food supplied by the sporophyte in the spore. In Sclaginella the female gametophyte even begins its development at the expense of neighboring cells in the megnsporangium. These conditions are an exact reversal of the relations between the generations which exist in the bryophytes.

The three classes of the Pteridophyta are readily distin. guished by the following characters:

Class I. The ferns, or Filicinec. Fronds large and few in number; those bcaring spores generally similar to the strictly regetative leaves and not grouped in cones.

Class II. The horsetails, or Equisetiner. Leaves reduced to mere scales, forming sheaths around jointed stems, which have many peculiarities of structure; sporophylls of peculiar form, each bearing several sporangia, and grouped in a characteristic cone.

Class III. The club mosses, or Iycopodinea. Vegctative leaves, small and very numcrous (except in Isoetes), covering the stem; sporophylls generally grouped in cones, each bearing a singlc sporangium; gamctoplyytcs much degenerate, especially in the heterosporous Selaginella and Isoetes; sperms two-ciliate (except in Isoctes) and not spiral, and many-ciliate as in the Filicinece and Equisetinew. 


\section{CHAPTER XXVI}

\section{ALTERNATION OF GENERATIONS}

334. The protoplasmic basis of an alternation of generations.* The history of the alternation of generations in plants has now been traced from the relatively simple beginnings in the thallophytes, as illustrated by the life histories of the red alga (Sec. 246) and sac fungi (Sec. 266) through the more clearly defined conditions in the liverworts and mosses, and also through the ferns, horsetails, and club mosses. It is clear that in the latter groups and the pteridophytes the asexual, or sporophyte. generation had become much the more complex of the two, and that the sexual generation, or gametophyte, had begun to degenerate. This degeneration is carried much further in the seed plants, as will be described in Chapter XxviI, and summarized in Chapter xxix.

It is now time to try to determine some of the reasons for the establishment of a sporophyte generation following the gametophyte one, or the basis in the protoplasm itself of the alternation of sexual and ascxual generations. The basis undoubtedly rests on the effects of the sexual process upon the nature of the protoplasm in the succeeding generation. The union of gametes is so grent a physiological stimulus that the sexually formed cell (generally a fertilized egg) is given the possibilities of a development different from that of either parent plant or gametophyte; for the protoplasm of a fertilized egg is not the same as that of either gamete which enterer into its formation. It is a mixture of protoplasms and therefore inust be different from the protoplasm of the parent plants, and this difference is the basis for

* To tиe Isstructor : In a brief course or with immature students this chapter should be omitted. 
the peculiarities of the generation which arises from a sexually formed cell.

Protoplasm has so far proved much too complex for an analysis into the structures which determine its qualities and possibilities of development; that is, we do not know why the egg of a fem develops into a ferm and that of a elub moss into a club moss; both are eells with a general similarity of eell structure. But the possibilities of fern and club moss are nevertheless present in the respeetive eggrs, and the one could not possibly be made to produce the other plant. It is generally believed that the charncteristics of eggs are deternined by the structure of their protoplasm, represented perhaps by means of the invisible molecules and groups of molecules in its chemical and physical composition. The structures that are assumed to give distinct character or possibilities of development to protoplasm are called rudiments.

It is doubtful whether we shall ever be able to distinguish the rudiments, but there are some larger structures in the cell which with care can be followed through the cell divisions from generation to generation. The most interesting of these are the chromosomes, which are very characteristic structures most clearly scen during the processes of nuclear division (See. 199). The substance of the chromosomes, called chromatin, is the most important material in the nucleus. Chromatin can be deeply colored or stamed in thin sections of tissue after speeial methods of treatment. It is present in the resting nucleus, generally in the form of an irregular network. The chromosomes are formed from the chromatin and appear during the carly stages of nuclear division. Each chromosome then divides into halves, and the two sets of daughter chromosomes are distributed with each nuclear division.

It is an important fact that the number of cliromosomes for the nuclei of each plant is fixed, and the number is usually not very large. Thus the gametoplytes of a red alga (Polysiphonia, Sec. 245) have about 20 ehromosomes, but those of 
the liverwort (Anthoceros, Sec. 290) have only 4 and the fern (Osmunda) 12. The most important feature of the process of fertilization is the union of the two gamete nuclei, that of the sperm with that of the egg. These nuclei have an equal number of chromosomes in the same species (the number characteristic of the gametophyte), and the egg and sperm are therefore equivalent in their nuclear structure, whatever may be the differences in their size. This nuclear fusion doubles the number of chromosomes, and the fertilized egg begins the development of the sporophyte (when present) with twice as many chromosomes as the gametophytes which produced the eggs and sperms.

The double number of chromosomes appears in all of the nuclear divisions throughout the development of the sporophyte up to the time of spore formation. Thus the sporophyte phases of Polysiphonia have about 40 chromosomes, the sporophyte of Anthoccros 8, and Osmunda 24. The lilies have 24 chromosomes, and the gametophytc phase only 12 . The chromosomes have been counted in more than fifty different kinds of plants, mostly seed plants, and it is established that sporophytes have normally double the number of chromosomes of their respective gametophytes.

Spore formation at the end of the sporophyte generation is a very significant period in the life history, for at this time the double number of chromosomes is reduced by half. The spores have then the original number of the gametophyte. The reduction of the chromosomes is effected by processes too complicated to be described here, but the formation of the asexual spores in groups of four, called tetrads (see Figs. 204, 245, 258, 289, 298, $302,304)$, is rather charactcristic of the phenomenon. There are thus fundamental reasons for the identical methods of spore formation in the bryophytes and pteridophytes, and, as will appear later, for the methods of pollen formation and the embryo sac in the seed plants. For the same reasons, groups of four spores, (tetraspores), are developed at the end of the sporoplyte generation in the red algax. 
The chromosomes are generally believed to be the actual bearers of the qualities (represented perhaps by rudiments) which are inherited, that is, passcd on from onc generation to the next. The chief reasons for this view are thcir importance as the essential structures of the nucleus, their regular behavior throughout the cell divisions, and the evidence that thcy never lose their identity completely, even in the resting nucleus, but remain perhaps as the only permanent organs in the ccll.

335. The life-history formula, showing the chromosome count. The life-history formula which has bcen employed for the bryophytcs and pteridophytes becomes much more interesting when considered in reference to the chromosome count. The formula has been :

Gametophyte $<$ sperm $>$ egg Sporophyte - asexual spore

- Gametophyte, etc.

Representing the gametophyte number of clromosomes by $x$ and the sporophytc number by $2 x$, these may accompany the formula as follows:

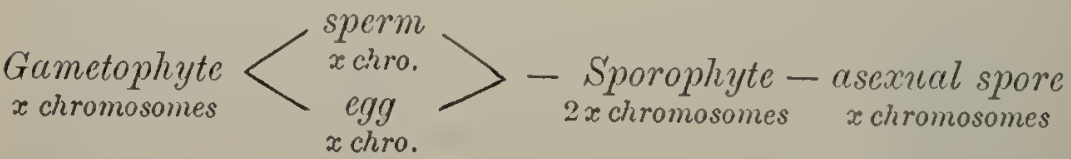

- Gametophyte, ctc.
$x$ chromosomes

Examining this formula, it is clear that there are two pcriods when the number of chromosomes changes abruptly: (1) at fertilization, when the number is doubled, and (2) at spore formation, when the number is reduced. The fertilized egg derelops into the sporophyte becausc its protoplasm has different qualities from that of the gametophytc. The asexual spore devclnps into the gametophyte because its qualities have becomc again the samc as those of the former gamctophytc generation. Sporc formation, then, in bryophytes and pteridophytes is a return of the plant in its life history to the conditions of ancestral gametophytes. 
336. The origin of the sporophyte. It seems clear that the sporophyte lad its origin through the stimulus of the union of gametes, and especially the union of gamete nuclei, to give a fusion nueleus with double the number of chromosonics characteristic of the gametophytes. It is probable that there is a reduction of this number in many thallophytes before or during the germination of the zygospore or oöspore, so that there is no opportunity for a sporophyte gemeration. This condition has been reported for Colcochote (Sec. 222), and it is probably also true of Edogonium, Spirogyra, the desmids, Vaucheria, Ulothrix, and other types.

The sporophyte arose when nuclear divisions appeared with the double number of chromosomes, thus postponing the time of chromosome reduction to a later period in the life history, which became generally characterized by the formation of ascxual spores in tetrads. Sporophytes undoubtedly appeared thus in sereral groups of plants entirely independently of one another, as illustrated in the divergent lines of development of the red algie, the sac fungi, the Dictyotacce (a small group of the brown alga), and the bryophytes leading up to the pteridopliytes and spermatophytes.

337. Summary. The alteruation of generations in plants takes on added interest when considered in rclation to the beliavior of the chromosomes, for the importance of the two eritical stages in the life history - (1) fertilization, and (2) spore formation - beeomes at once apparent. Fertilization doubles the number of chromosomes in the egg and gives it the possibilities of the sporophyte's development. Spore formation reduees the double number of ehromosones by half and brings the plant's protoplasin back to the condition where it may develop the ganctoplyytc. The two proecsses follow one another as the life listory is repeated again and again with machine-like regularity, and therc is undoubtedly a cliemical and physical basis for the life history. And, as before stated, it is generally believed tlrat the ehromosomes hold the rudiments that determine in a broad 
way the programme of development, the double number defining the sporophyte generation.

It must not be supposed, however, that the life history unfolds entirely through the operation of forces within the organism, as a watch runs on the strength of the wound-up mainspring. While the organism is truly a machine, it is a machine which is constantly influenced by forces from without which modify its complex adjustments, and, above all, it is a self-perpetuating machine which makes its own repairs.

There are two prominent theories respecting the manner in which an organism develop̣s from an egg or other reproductive cell. The first, called preformation, assumes that the characters of the adult are preformed or represented in miniature by rudiments or other structures in the protoplasm. Development is, therefore, something like the unfolding of a bud, and the results are determined by conditions within the organism. The second theory, termed epigenesis, is not willing to grant such a complicated architecture to protoplasm, but holds that development is guided chiefly by conditions without the organism. It is probable that the correct interpretation lies between the two extreme views, that the cell does have a complicated structure far beyond our present possibilitics of knowledge, but that the processes of development are largely guided and controlled by outer influences. 


\section{CHAPTER XXVII}

\section{HETEROSPORY}

338. Heterospory.* Heterospory arose in the pteridophytes with the establishment of two sizes of spores, called megaspores (large spores) and mierospores (small spores). Heterospory and the independence of the sporophyte are the chief contributions of the pteridophytes to the progress of plant evolution. The establishment of megaspores and microspores was merely the beginning of a number of far-reaching developments in plants, all of which are really parts of the general principle of heterospory. They all reach their highest degrees of specialization in the seed plants, as will be described in the next chapter and summarized in Chapter XxIx, but most of them are clearly illustrated in the pteridophytes.

These developments resulting from heterospory are:

1. The gametophytes became differentiated in sex so that the megaspore always develops a female gametophyte and the microspore a male gametophyte.

2. The sporangia assumed two forms: megasporangia devoted to the production of megaspores and mierosporangia devoted to the production of microspores, as illustrated by Marsilia, Isoetes, Selaginella, and, as will appear in the next chapter, the seed plants.

3. The spore leaves, or sporophylls, were differentiated into megasporophylls and mierosporophylls which develop, respectivcly, megasporangia and microsporangia, as illustrated by Isoetes, Selaginella, and the seed plants; the sporophylls of Marsilia bear botl forms of sporangia.

* To the Isstructor: In a brief course or with immature students this chapter should be omitted. 
4. A tendency was developed to reduce the number of megaspores by sacrificing many of the cells which might be fertile so that relatively few megaspores are formed, but these are very large and richly supplied with food material, as illustrated by Selaginella and the seed plants. This principle is clearly similar to that by which plants have found it advantageous to produce a limited number of large eggs well stocked with food, even at the sacrifice of cells which may have bcen originally gametes, such as the canal cells in the archegonium.

5. The gametophytes degenerated, as self-supporting green plants, to a condition in which they lost their chlorophyll and became dependent upon food stored in the megaspores and microspores and even live somewhat parasitically upon the sporophytes, as is illustrated in the early stages in the development of the female gametophyte of Selaginella and in the gametoplytes (pollen tube and embryo sac) of the seed plants.

There is another important advance in plant cvolution which is closely related to heterospory, but may be treated to better advantage in the account of the origin of the seed habit (Sec. 367). This advance arose in the seed plants when the megaspore became retained within the megasporangium (a portion of the ovule), so that the female gametopliyte (embryo sac) developed like a parasite upon the parent sporophyte, and the male gametophyte (pollen tube) was required to grow down to the female gametophytc somewhat parasitically through the tissues of the ovule to bring about the fertilization of the egg cell.

339. Sexual characteristics given to the megaspore and microspore by means of heterospory. The megaspore and micruspore are of course asexual spores because they are formed by an asexual plant, the sporophyte. They are simply specialized forms of the similar spores prescnt in the liverworts, mosses, the common ferms, horsetails, and lycopods, as shown by their similar origin in tetrads at the end of the sporophyte generation.

But when the microspore and megaspore became clearly differentiated through heterospory from the earlier conditions of 
homospory they took on certain characteristics of sex. This does not mean that the mierospores and megaspores became gametes, for their spore nuelei have never beeome sexual nuelei in any group of plants. But microspore and megaspore did assume sexual characters to this extent that they always give rise, respcctircly, to male and female gametophytes.

Furthermore, the degeneration of the gametophytes steadily reduced the number of the nuclear divisions between the germination of these spores and the formation of the gametes until the gamcte nuclei have been brought very close indeed to the spore nuclei. An examination of the figures of the male gametophytes of Marsitia (Fig. 282, A), Selaginella (Fig. 290, A), and Isoctes (Fig. 292, A) will show that there can hardly be more than from six to ten nuclear divisions in these types before the sperms are developed. There are em a fewer nuclear divisions in some groups of seed plants where the degeneration of the gametophyte is carried much further than in the pteridophytes. Some forms of angiosperms present but a single division of the spore nucleus before the female gamete nuclei are formed, as in the embryo sac of the lily (Sec. 360, note), and there are only two nuclear divisions in the male gametophytes (pollen grain and tube) of the angiosperms.

This gradual transference of sexual characteristics to portions of the asexual generation, accompanying the reduction of the sexual generation, is one of the most interesting results of the crolution of the sporophyte and degeneration of the gametophyte (summarized in Chapter XxIx), for it makes clear many puzzling conditions in the seed plants. Thus it shows why the pollen grain (which is a microspore) is really funetionally a male reproductive structure and the stamen a male organ; and why the carpels and pistil are funetionally female organs, even though they have had their origin on asexual plants (sporophytes). 


\section{CHAPTER XXVIII}

\section{THE SPERMATOPHYTES AND THE SEED HABIT}

340. The spermatophytes.* The division Spermatophyta (meaning seed plants) contains not only the groups frequently called "flowering plants" but also other groups which do not have flowers in the popular sense of the word, for the reproductive organs are borne in cones or clusters which are not at all showy, but rather inconspicuous. These are, however, flowers in the scientific sense, as arc also the cones of the horsetails and club mosses. The spermatophytes have also bcen called phanerogams, or phonogams (ulcaning evident marriagc), to distinguish them from all the lower groups of plants which were called cryptogams (meaning hidden marriage). However, this separation was made before the sexual processes of the lower plants were undcrstood, for as a matter of fact they arc much more evident than the complicated ones in the seed plants. The seed is a more significant structure in the group than the flower, so the name spcrmatophytes has in recent years come into general favor.

The seed plant, like the forn, is a sporophyte. There is a gametophyte generation in the life history which is, however, so much reduced in structure that it can only be understood by a carcful study of the reproductive processes in seed formation. It is the main purpose of this chapter to make clear the position of the gametophyte gencration in the life history, together with the origin and crolution of the flower. The structure and physiology of the sporophyte are considered in Part I,

* To the Ixstrector: The introduction to this chapter assumes that the life history of some seed plant, as the pine or lily, has been studied in the laboratory. 
and only brief reference will be made to thcse features, which are treated thcre in detail and should follow this account if they have not alrcady bcen studied.

341. The seed. The importance of the seed in the development of plant and also of animal life can hardly be exaggerated. For the plant it furnishes one of the surest means of reproduction not only because of protective structures, means of dispersal, long vitality, etc. (sce Chapter rxxir), but also because the embryo plant is carried so far forward in its development that it is able to take root and establish itself at once. And further to aid the embryo, the seed is a storage organ of the most eondensed forms of food matcrial found in plants. In this respect, also, the seed has proved a most important influence in shaping the habits and in a large measure the evolution of somc forms of animal life; for the highest groups of animals live to a very great extent directly or indirectly upon food stored in seeds and certain fruits, finding there some of the richest and most nutritious proteid and carbohydrate foods. The animal life of the Carboniferous Age (coal age) and the periods immediately following eomprised animals of great bulk of body, but of low nervous organization. They browsed on the vegetation like the hay and grass-eating animals (herbivora) of to-day, and like them their bodily structure and nervous system were adapted to such life habits. But, later, groups arose with digestive organs adapted to richer foods, and this dict became associated with varied life halits, which led to much higher types of nervous organization and bodily strueturc.

342. The morphology of the seed. The morphology of the secd can only be understood when the spermatophytes are studied in relation to the pteridophytes. The secd plant is a heterosporous sporophyte. The pollen grain is a mierospore. The inegaspores of the sced plant are never shed. They are retained in the megasporangium and never even lie freely as independent cells, but arc always in close physiological relation to the tissue of the megasporangium. The cell which is the 
equivalent of the megaspore, or megaspore mother cell, is called the cmbryo sae. The megasporangium, termed the nueellus, with the embryo sac is contained within one or two protective envelopes, called integuments, and this group of structures constitutes the ovule. There is developed within the cmbryo sac a much-reduced female gametophyte which lives entirely on foods supplied by the sporophyte. The ovulc at maturity then consists of the embryo sac (megaspore or inegaspore mother cell) with the femalc gametophyte, the nucellus (megasporangium), and the integuments.

The femalc gametophytes are quite different in the two great subdivisions of seed plants (gymnosperms and angiosperms). In the first group (gymnosperms) several archegonia are generally formed, each containing a single large egg. In the second group (angiosperms) the female gametophyte is very much reduced and only one egg is formed. The fertilization of an cgg leads at once to the development of an embryo sporophyte within the embryo sac. The embryo sporophyte of the second generation is thus nourished through the ovule by the parent sporophyte of the first.

The seed is a ripened ovule, that is, an ovule containing an embryo sporophyte so far along in its development that the seed may safely be separated from the parent plant. Morphologically, the seed is composed of tissues representing three gencrations: (1) the integuments and nucellus are of the parent sporophyte; (2) the embryo sac contains morc or less tissue of gametophytc origin called endosperm ${ }^{1}$; (3) an cmbryo sporopliyte of the next generation lies within the embryo sac.

343. Pollination and fertilization. The retention of the megaspore (embryo sac) within the megasporangium (nucellus) so that the femalc gametophyte is contained in the tissues of the sporophyte has resulted in modifications of the structure and

1 'The endosperm of the angiosperm seed has special peenliaritics involved with the fertilization of the egg and development of the embryo, as explained in Sees. 302 and 363. 
life habits of the male gametophyte quite as remarkable as those of the female. These peculiarities are concerned with two distinct processes necessary to insure the development of seeds, namely, pollination and fertilization.

The pollen grain is a microspore developed in groups of four (tetrads) in pollen mother cells in essentially the same manner as the spores are developed in all bryophytes and pteridophytes (Fig. 302, B). The pollen grain forms a very much reduced male gametophyte, which is represented by the protoplasmic contents of the pollen grain and pollen tube. It would be useless for the male gametophyte to form and discharge sperms which could not possibly reach the embryo sac imbedded in the nucellus of the ovule. So the sperm-forming habits of the pteridophytes, bryophytes, and the algie are generally given up, although curiously they still persist, as will be described later, in the cycads and Ginkgo (Sec. 348). The sperms are represented by two spern muclei developed by each male gametophyte and discharged from the tip of the pollen tube.

The pollen tube is an outgrowth from the pollen grain. Its purpose is to carry the sperm nuclei to the embryo sac, where one of the two may unite with the egg nucleus and fertilize the egg. In one of the two subdivisions of seed plants called the gymnosperms (menning naked seeds) the pollen grains are applied directly to the ovules, and the pollen tube need only grow through the tissne of the nucellus (megasporangium) to reach the embryo sac. In the other large group called the angiosperms (meaning seeds inclosed in a vessel) the pollen tubes must penetrate a case (the pistil) which contains the ovules before they can reach the ovules themselves. There is a special receptive surface, called the stigma, upon this structure, where the pollen grains find moisture and other conditions favorable for their germination.

Pollination is the application of the pollen to the ovule or to the stigma. This application is effected in various ways: sometimes by the wind, sometimes by other chance processes, but many 
plants have developed elaborate devices to insure pollination, as through the visits of insects to flowers (see Chapter xxxII).

Fcrtitization is effected when the pollen tube pierces the embryo sac and onc of its two sperm nuclei fuses with the egg nucleus.

When one considers the extraordinary modifications of the male gametophytes of the seed plants, the process of pollination and the development of the pollen tube seem quite as remarkable as the retention of the female gametophyte in the megasporangium. They are both cssential features of the seed habit.

344. The flower. The term flower in the popular sense generally means some showy structure such as is only found in certain groups of the angiosperms. The flower in the scientific sense consists of a group of spore leaves, or sporopinylls, with or without surrounding envelopes, which may or may not be showy. It lias been defined as "a shoot beset with sporophylls." Since the seed plants are heterosporous, the spore leaves are either microsporophylls, called stamens (producing pollen), or they are megasporophylls, called carpels (producing embryo sacs in the ovules). The stamens and carpels of the gymnosperins are generally grouped in cones which resemble the cones of the horsetails and club mosses. But the carpels of the angiosperms form, often with adjacent tissue, closed cases called pistils.

It should be noted that the cones of the horsetails and club mosses are as truly flowers in the scientific sense as the cones of the gymnosperms, and also that certain groups of angiosperms (grasses, sedges, and most trees) have flowers which are not showy.

The material of this chapter will be treated under the following headings :

Subdivision I. The gymnosperms, or Gymnospermee.

Subdivision II. The angiosperms, or Angiosperme.

The origin of seed plants and the seed habit.

The evolution of the flower.

The classifieation of the angiosperms.

Summary of the sperinatophytes and their relationships to the pteridophytes. 


\section{SUBDIVISION I. THE GYMNOSPERMS, OR GYMNOSPERMAE}

345. The gymnosperms. The gymnosperms (meaning naked seeds) are distinguished from the angiosperms because their seeds are borne exposed on the carpels. They comprise not only the familiar cone-bearing trees, or conifers, generally with needle-shaped leaves, such as the pines, spruces, firs, hemlocks, larches, cedars, etc., but also the large-leaved cycads, the straggling, shrubby Ephedras, the climbing Gnetums, and that interesting Japanese tree Ginkgo. The gymnosperms contain the most ancient groups of living seed plants, and the fossil remains of primitive types are found in the Carboniferous Age and even earlier periods, with those of the giant horsetails and club mosses (see Cordaites, Plate VIII). The study of ancient gymnosperms, together with a fossil group, Pteridospermw, intermediate between the pteridophytes and spermatophytes, may throw much light on the origin of the seed and seed habit.

The living groups of the gymnosperms comprise in all less than 450 species, of which more than 300 are conifers and about 80 are cycads. With the exception of the conifers, these groups are hardly more than remnants of the ancient gymnosperm floras. But the conifers are a very successful group, which still forns extensive forests in some temperate regions and covers mountain sides and certain large rather barren areas, although such forests are being rapidly cut off for timber. Of the smaller groups the cycads are mostly tropical, the Ephedras are chivfly desert plants, and the Gnetums tropical vines with large-veined leaves. Iike the horsetails and club mosses, the Ephedras liave for the most part developed peculiar life habits under unfavorable conditions, and so have been able to avoid total extinction by withlrawing as far as possible from competition with the more recent floras.

This account can only consider the two largest groups, the cycads and the conifers. 


\section{The CrCads}

346. The cycads. The cycads (order Cycadales) have thick stems which rarely branch and are generally rather short, resembling immense tubers partly buried in the ground (Fig. 293, A).

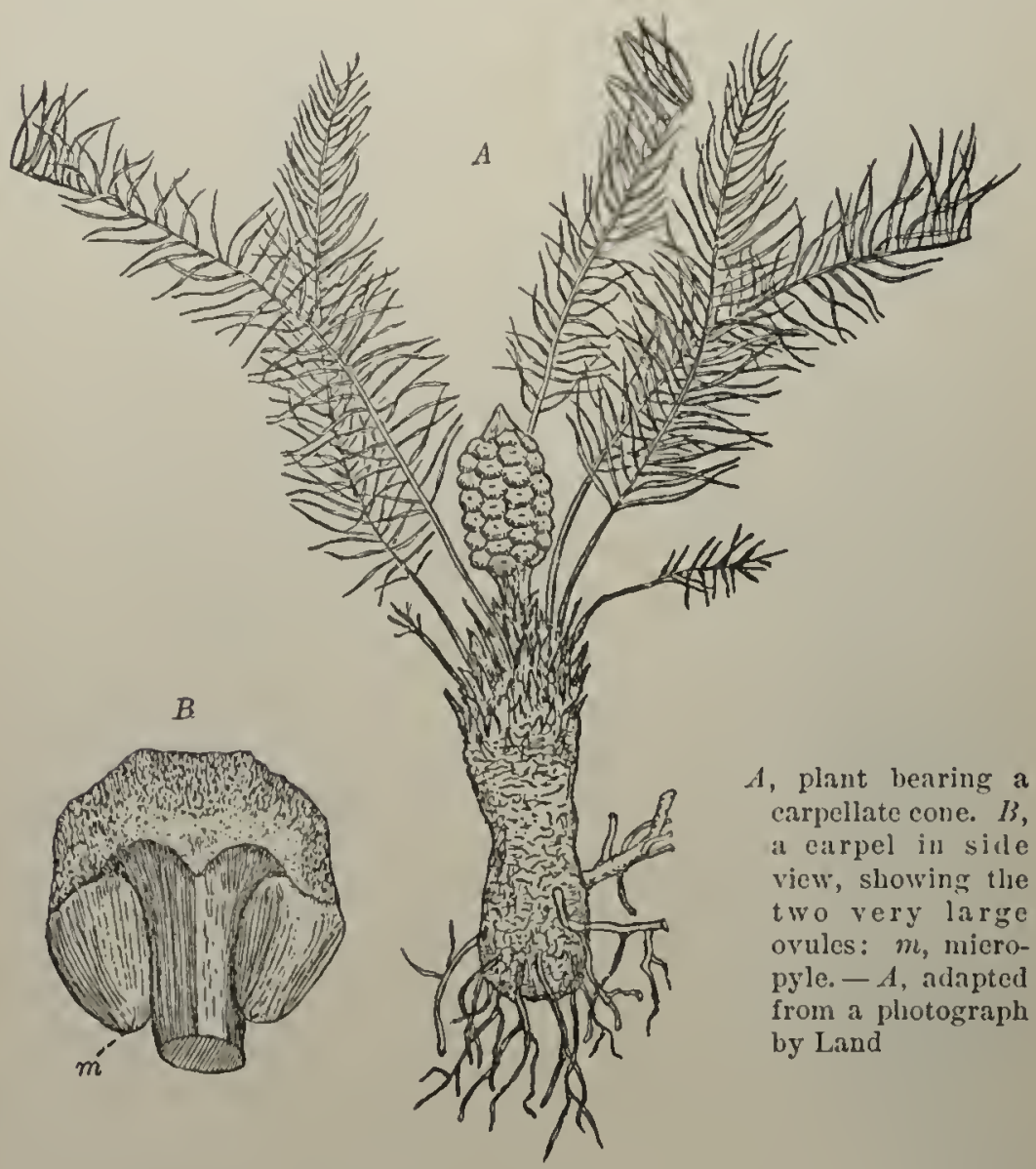

Fi(. 293. A cycad (Zamia)

Some of the cycads have, however, stems which rise like columms ten to forty feet high. The compound leaves, like immense stiff feathers, form a crown at the top of the stem so that the general habit of the cycads is somewhat like that of the tree 
ferns and palms. One form (Cycas revoluta), incorrcetly called the sago palm (since it is not a palm), is valuable for the sago of commeree which is obtained from the stem.

347. The cones of the cycads. Some of the cycads bear cones composel either of carpels (megasporophylls), or stamens (microsporophylls) which resemble large scales. Carpellate and staminate cones are always borne on separate plants. In other types, however, as Cyeas revoluta, the carpels, especially, have more nearly the appearance of regetative leaves (Fig. 294 ), and form rosettes at the top of the stems. Cyeas revoluta is frequently grown in park conservatories, and occasionally produces these rosettes of hairy, orange-colored carpels, which bear a series of orules as large as plums on either side. Wrell-differentiated cones are present in Zamia (Fig. 293, $A$ ), which is quite common in southern Florida. The carpel (Fig. 293, B), in this genus, bears two ovules and the stamen, a group of pollen saes (Fig. 295, A). The ovule (Fig. 295, D) has a thick integument surrounding the large nucellus, in

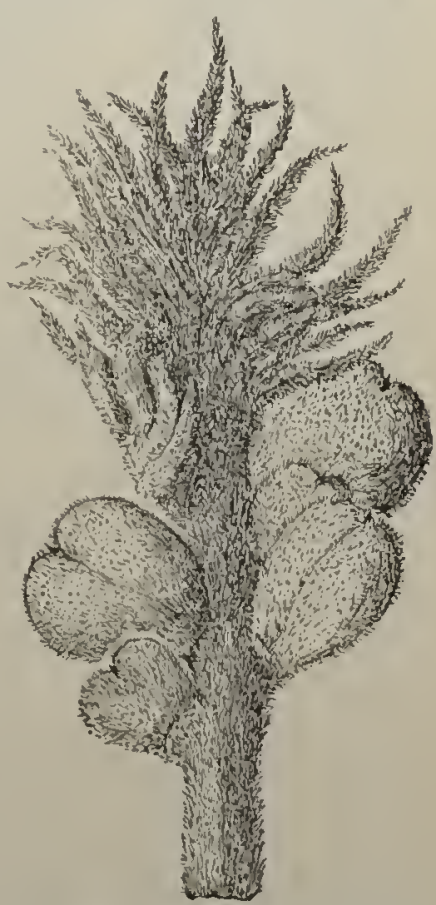

Fig. 294. Carpel of Cycas revoluta bearing five ovules which lies the embryo sac containing the female gametophyte. The pollen grains of Zamia enter the opening called the mieropyle (meaning little gate), where the integument fails entirely to inclose the nucellus, and so come to lie in a small cavity

* To THF INstructor: It ought to be possible to obtain Zamia in quantities for advanced elasses. The type is most admirable for the stully of the gametoplytes of gymuosperms. The best account of these is given by Webber, United States Department of Agriculture, Bureau of l'lant Industry, Bulletin :, 1901. 
termed the pollen chamber (Fig. 295, D, $p$ ). The pollen grains germinate in the pollen chamber, forming male gametopliytes, whose development disorganizes much of the tissue at the tip
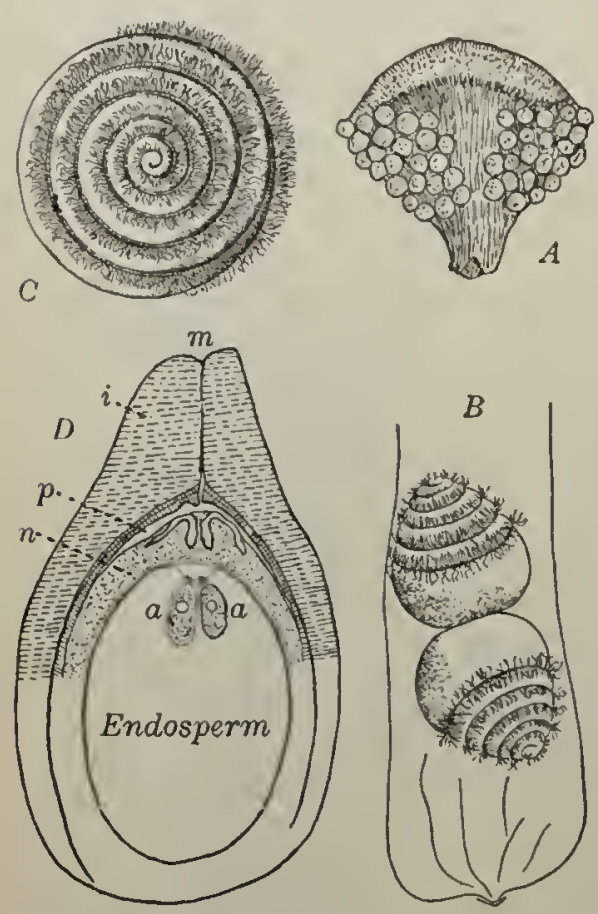

Fia. 295. The sperms and ovule of a cycad (Zamia)

$A$, lower surface of a stamen, witl numerous pollen saes in two groups. $B$, the two large top-shaperl motile sperms at the end of the pollen tube ready to be discharged above the archegonia. $C$, a sperm viewed from the end, showing the spiral band which bears the cilia. $D$, diagram of a seetion of an ovile after pollination: $m$, mieropyle; $i$, integument; $p$, pollen chamber; $n$, nueellus eontaining developing pollen tubes; $a$, archegonia, with large eggs inbedded in the endosperm (female gametophyte). $-B, C$, after Webber of the nueellus, so that the pollen grain end of the male gametophytes finally lang down just above the entbryo sae.

\section{The gametophytes} of the cycads. The embryo sac of the cycads is said to develop from one of a group of four eells in the interior of the nucellus. Sueh a group is undoubtedly a tetrad, and exeh of the four cells eorresponds to a megaspore, but only one produces a female gametophyte, and thus beeomes an embryo sae.

The nucleus of the embryo sac (megaspore nueleus) gives rise to a great many hundred nuclei, and the amount of protoplasm inereases very greatly until the embryo sac oecupies the larger part of the interior of the nueellus in this large ovule. The nuelei at first lie freely in the protoplasm, but, later, walls are formed and the embryo sae beeomes filled with a delieate tissue, called the endosperm (Fig. 295, D), which eorresponds to the vegetative part of a prothallium in a fern. Several arehegonia are developed at 
the micropylar end of the endosperm (Fig. 295, D, a). These are very much reduced in stmeture, the neek being represented probably by two small cells ant the very large eggs lying imbedded in the cells of the endosperm.

The male gametoplyte consists of the protoplasm with several nuelei contained in the pollen grain and tube. Some of the nuclei near the pollen grain ent of the tube lie within deliente cell walls. One of these cells termed the generative cell develops two sperm mother cells which becone organized into two very large motile sperms (Fig. 295, $B, C$ ), each with a spiral band or line bearing hundreds of cilia. The two sperins finally begin to move around in the fluid of the pollen tube and are discharged from the end nearest the pollen grain (which now hangs down over the embryo sac) into the fluid within the cavity formed from the disorganized tissue at the tip of the nucellus. The pollen tube in the cycads grows off to one side in the nucellus and seems to be a sort of absorbing organ, so that it does not carry the sperms to the embryo sac as the sperm nuclei are carried in most seed plants.

The motile sperms are set free in the fluid above the embryo sac, whose female gametophyte at that time bears mature archegonia. They have been observed swimming about for many minutes in sections of the living ovules, and probably have a long motile period in the ovule. One of them is finally able to enter the neck of an arehegonium, and fusing with an egg fertilizes it.

The finding of motile sperms in the cycads and in Ginkgo ${ }^{1}$ by two Japanese botanists in 1896-1897 proved two of the inost interesting botanical discoveries of the past decade. It is very remarkable that the sperin-forming habits of the bryophytes and pteridophytes should have persisted so long after the seed habit became establisherl in a group. The free swimming of these motile sperms is actually a return, such as occurs in the liryophytes and pteridophytes, for a short time in the life history of the cycad to the aquatic halits of an algal ancestry of ages ago.

1 A beautiful Japanese tree, not uncommon under cultivation. 


\section{The Conifers}

349. The conifers. This group (order Coniferales) has representatives distributed all orer the earth, some of them forming the most extensive forests and having the greatest value as timber trees. There are not many more than 300 species of conifers, of which the pines (Pinus) have 70 ; Podocarpus (growing in South America and easteru Asia), 40 ; the junipers (Juniperus), 30; certain cedars (Cupressus), 20; the firs (Abics), 20 ; and the spruces (Pieca), 12. Others have few species and a very limited distribution. Such a form is the giant redwood of California (Sequoia gigantea), which is found only in a few scattered groves in the Sierra Nevada Mountains (Fig. 33).

350. The form and foliage of the conifers. The form and foliage of the conifer's is generally very characteristic. The trees have, as a rule, a single central stem wlich rises vertically from the ground, and the side branches spread out horizontally from this shaft so that the trees are very symmetrical and taper to a point like a cone. The foliage, as a rule, consists of scaleor needle-shaped leaves, which usually remain on the trees for a number of years so that most of the trees are evergreen. But there are some exceptions to the rule, as the larch or tamarack (Larix), which sheds its needles every year.

The needle leaves can endure severe cold, fierce heat, and drought. This is made possible by their very compact structure (Fig. 296), which presents a minimum of surface exposure and the protective layer of thick-walled cells under the heary epidermis. The chlorophyll-bearing tissue is closely packed in the pine leaf and consists of cells with peculiar infolding walls. Some species of pine have needles with one fibro-vascular bundle, e.g. the white pine; others have two bundles, e.g. the Scotch and the Austrian pine. The buds, leaves, and stems contain much resin and turpentine, which render them unpalatable to grazing animals and cover them with a film which sheds water and protects the plant both from the winter's cold and the summer's 
drought. Resins and turpentines are also very effective in protecting young conifers from the attacks of parasitic fungi, especially when the trees are wounded.

Certain pines furnish the resin and turpentine of commerce. Incisions are made through the bark, penetrating the wood. A thick liquid oozes out which is a mixture of resins and oil of turpentine. This liquid is then distilled, driving off the fluid oil of turpentine which is collected. The resin remains behind

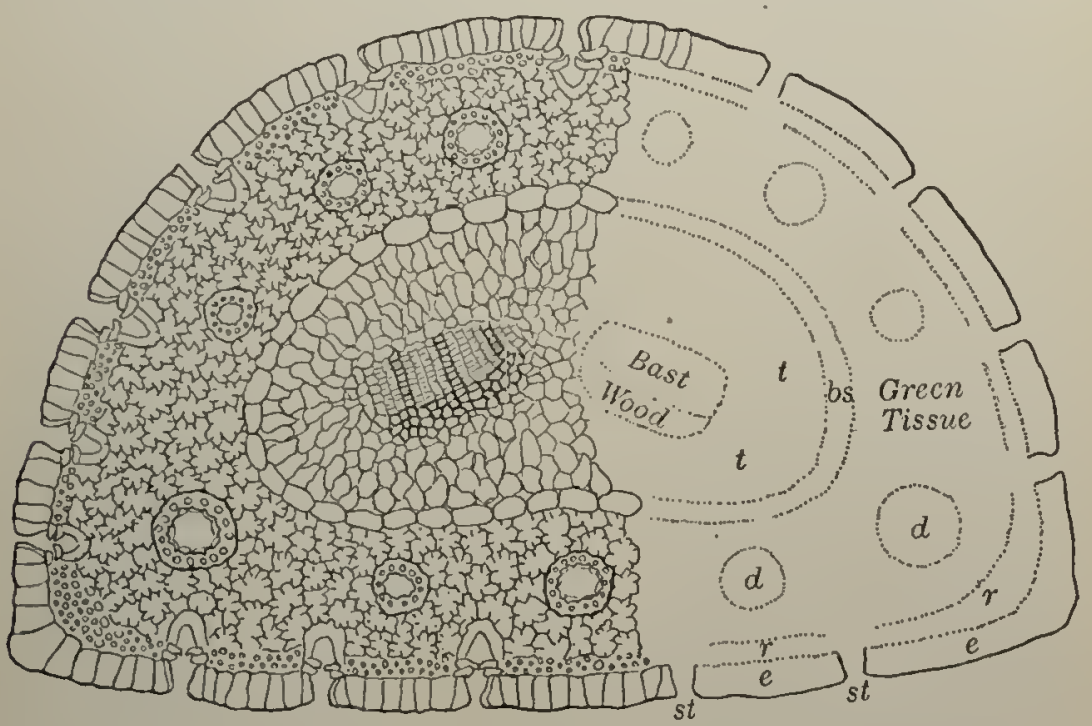

Fig. 296. Structure of a pine needle (Pinus Laricio)

The eompact green tissne, or mesophyll, with resin ducts $d$, surrounds an area containing two fibro-vascular bundles, which lie in a peculiar region of transfusion tissue $t$, boumled by the bunile sheath $b s$. Outsille of the green tissne are thick-walled cells forming a rigid tissue $r$, and around the whole is the lieary cpidermis $e$ with lengthwise grooves containing the stomata st

in the still, and when cool is no longer semi-fluid, but becomes quite hard and brittle. The timber value of certain conifers is much greatcr than that of most other kinds of trees because the wood is soft, splits legularly, is easily worked, and also because the tree trunks are so straight. The problems of forestry (see Chapter Xl1) are largely concernal with the preservation of the pine forcsts, which are being cut off with little regard to the future. 
351. The tissues of the pine stem. The pine is an excellent subject for the study of stem structure and growth in a timber tree. There are five principal regions in the stem: (1) the pith,

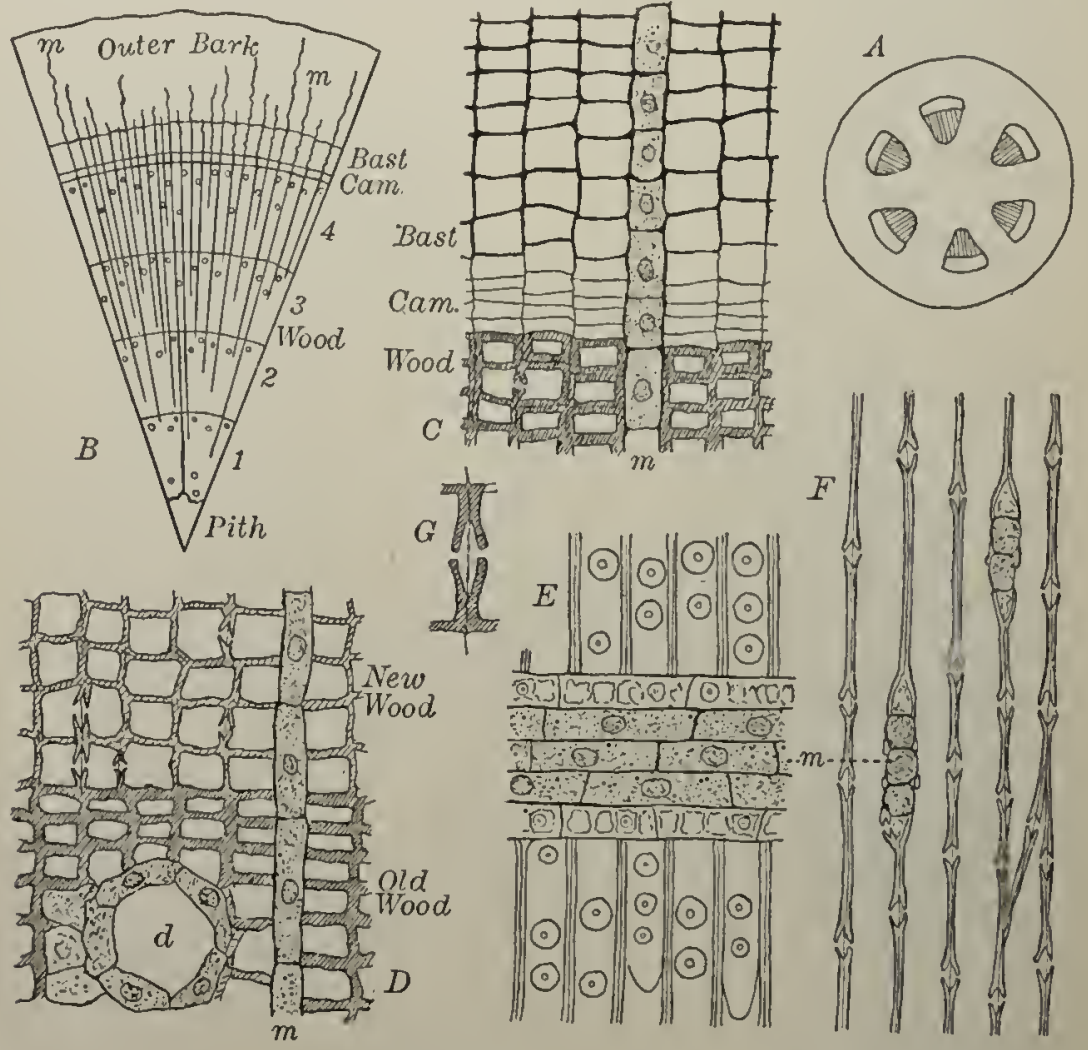

Fra. 297. Structure of the stem of the Scotch pine (Pinus sylvestris)

$A$, diagram of the arrangement of the fibro-vaseular bundles at a growing point: the shided parts are wood. 3, diagram of the position of the principal tissues shown in a cross seetion of a four-year-old stenr. $C$, eross sertion of a region of eanbinm Cam, with adjaeent wood and hast. D, cross section of wond at au annual ring: $d$, resin duet. $F$, radial section of woor. $F$, longitudinal section of wood. $G$, seetion of bordered pit. Medullary rays $m$ appear in nost of the figures

(2) the wood, (3) the cambium, (4) the bast, and (5) the outer bark (see Fig. 297, B).

The pith oecupies the very center of the stem, and is the remains of the undifferentiated primitive tissue present at its 
growing point before the fibro-vascular bundles and bark are formed. It practically disappears as the stem grows older and the wood increases by a number of years of annual growth.

The wood, or xylem, comprises by far the greater part of older stems, becoming proportionally greater as each annual ring is added. It is composed' of very much elongated cells, called trucheids, with firm, somewhat yellowish, thick walls. Cell walls of this character are said to be lignified. These cells contain pits (Fig. 297, $E, F, G$ ) surrounded by a circle and termed bordered pits, the circle being a feature charncteristic of this group of plants. There are resin ducts among the wood cells, and also peculiar plates of cells called medullary rays which extend through the cambium and bast into the outer wood. The medullary rays have the form of thin knife blades penetrating the wood for various distances.

The cambium is a cylinder of thin-walled cells just outside of the wood, and is the most active region of growth in the stem. This cylinder (Fig. 297, C) is only two or three cells wide, and the cells are continually dividing by walls parallel to the surface (tangentially) during the season of growtl. The daughter cells on the inside of the cambium become firm wood cells by the thickening of their walls together with certain clianges (lignification) that give them firmness; they also become empty of protoplasm. The daughter cells on the outside of the cambium form the bast, remaining soft and containing protoplasm and much food material. The cambium thus adds cells to the wood on the inside and the bast on the outside. 'The wood is deposited in annual rings during the season of growth, and these are sharply distinguished from one another because the wood cells formed at the beginming of one season are larger than those formed in the latter part of the previous season (Fig. 297, D).

The bast is difficult to study chiefly because the cells are under severe pressure from the growing cambium on the inside ancl the restraining bark on the outside, and the cell arrangements are frequently distorted. 
The outer bart is developed from the primitive or ground tissue which lay outside of the circles of rood and bast when these circles were first formed by the union of the primary fibro-rascular bundles (Fig. 297, A), as described in Sec. 79. There is much actively growing tissue in the bark, but the outer
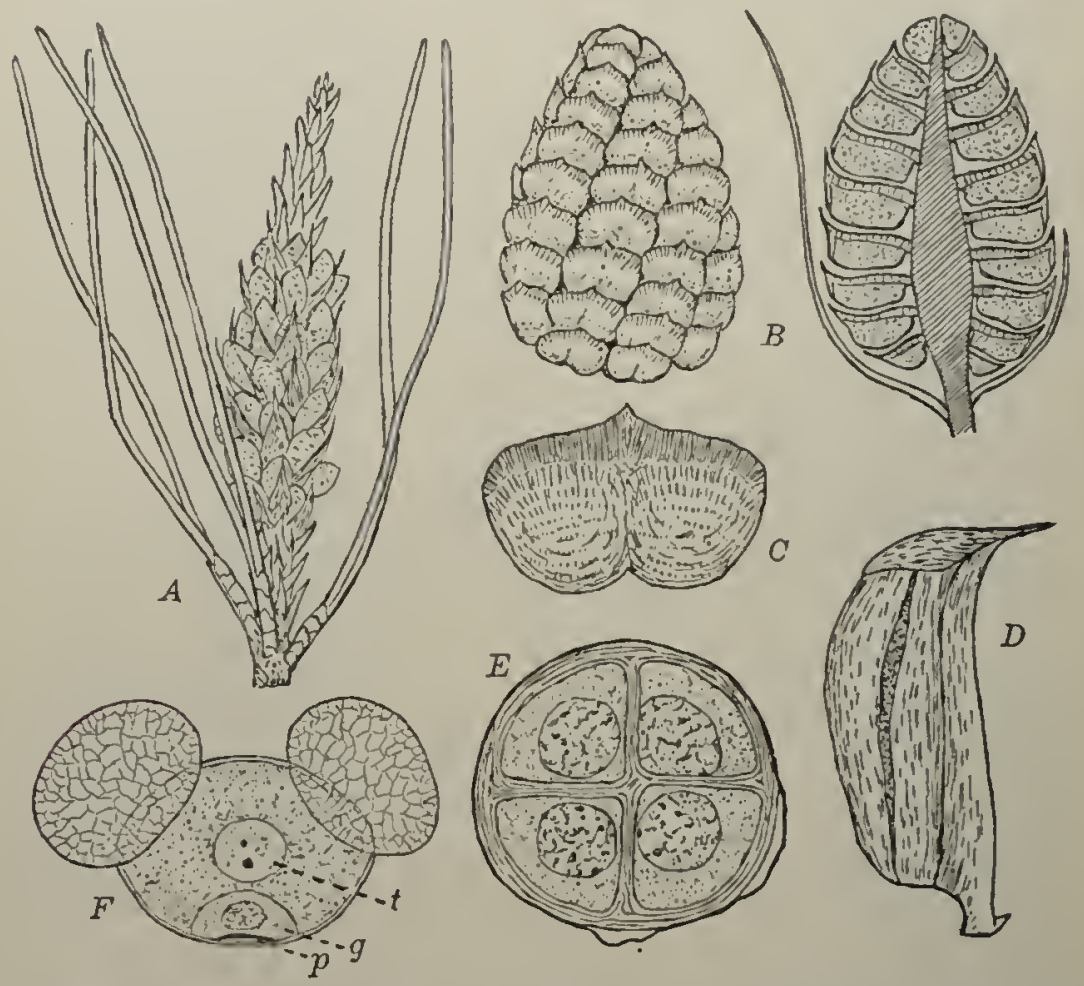

Fia. 248. The stiminate cone, stamen, and pollen of the Scotch pine (Pinus sylvestris)

A, young growth, with staminate cones about two weeks after the opening of the terminal bud. I, details of cone. C, end riew of stamen. $D$, side view of stamen. $E$, pollen mother cell developing four pollen grains in a tetrad. $F$, pollen grain showing the trio wings: $p$, prothallial eell; $g$, generative cell; $t$, tube nueleus. $-E$, after Miss Ferguson

regions become quite dead, and crack under the pressure of the growing cambium, thus forming scales. The cracks are healed by the living tissue of the bark. The bast is generally so closely attached to the outer bark that it peels off with it, and therefore 
is a sort of inner bark and must be included in any account of this region of the stem.

The functions of these tissues are discussed in Part I, Chapter vili.

352. The cones of the pine. The cones of the pine, as in all conifers, are of two sorts: (1) staminate, when made up of stamens (microsporophylls), and (2) earpellate, when composed of earpels (megasporophylls).

The staminate eone. The staminate cones are developed in clusters on the young growth that appears late in the spring with the opening of the terminal buds (Fig. 298, A). Each cone consists of a large number of stamens closely packed together and arranged somewhat spirally around the central axis (Fig. 298, B). The stamen bears two pollen sacs (Fig. 298, $C, D$ ), within which the pollen grains are developed. The pollen grains are formed in groups of four, or tetrads (Fig. 298, $E$ ), just like the spores of the bryophytes and pteridophytes, and their further history shows them to correspond exactly to the microspores. ${ }^{1}$ The pollen sac is then a microsporangium, and the stamen a microsporophyll. The pollen sacs develop from a group or region of cells as in the horsetails, lycopods, and Selaginella, and not from a single surface cell as in the common ferns.

The pollen grains are produced in enormous quantities, and being set free by the splitting of the pollen sacs, they are scattered as fine yellow dust by the wind. Sometimes pollen is carried from pine forests by the wind for many miles, falling as so-called showers of sulphur. The pollen grains are especially adapted for distribution by the wind, for the outer layer of the cell wall is swollen on two sides to form outstanding wings (Fig. 298, F).

1 This relationship is further established by the count of the chromosomes in the Scotch pine (Pinus sylvestris), which shows that the pollen grain has 12. while certain tissues of the pine sporophyte have 24. Pollen formation is then the period of chromosome reduction when the sporophyte generation passes over to the gametophyte, as explained in Secs. 334 and 395.5 . Similar chromosome reduction undoubtedly takes place with the formation of the eubryo sac in the nucellus. 


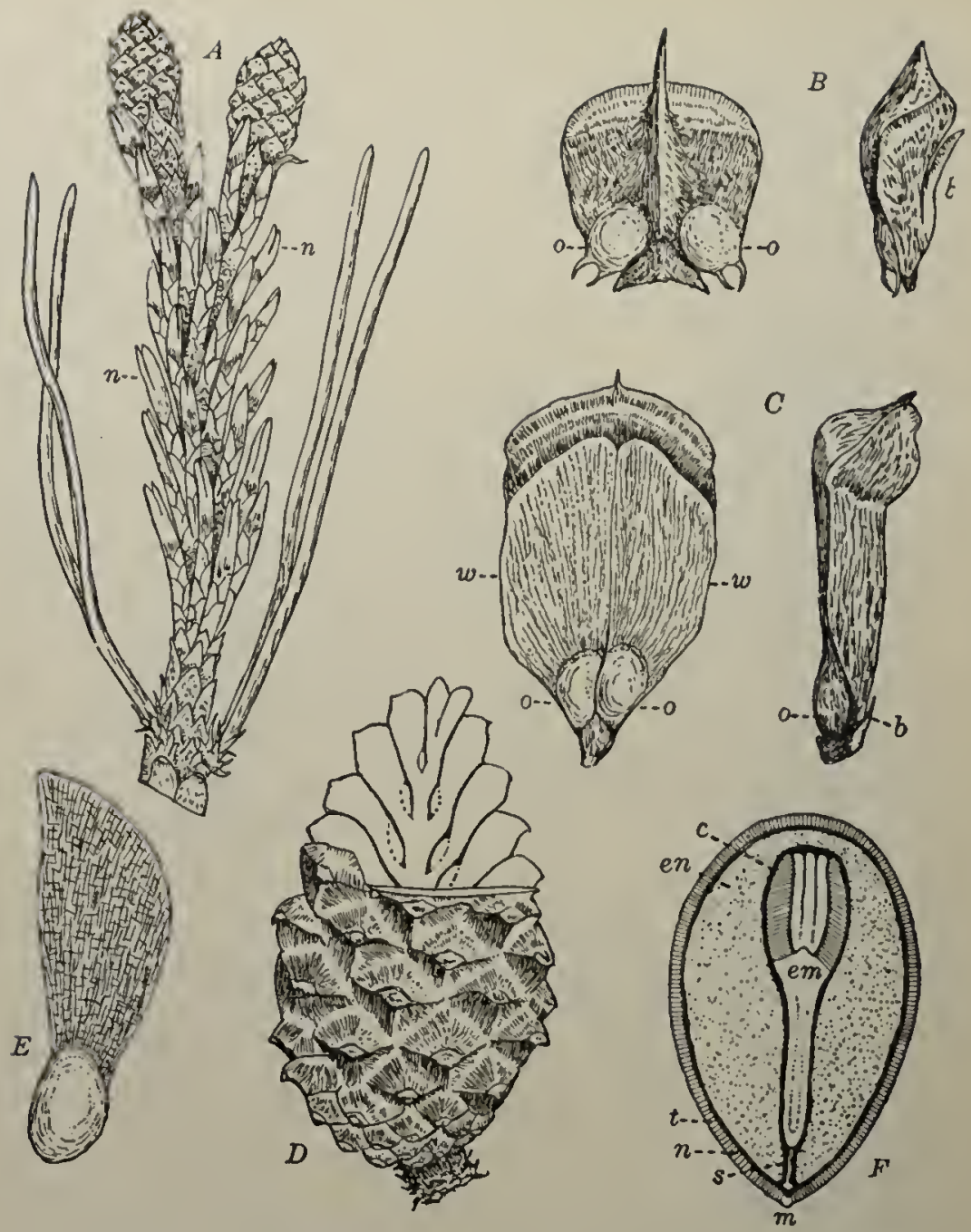

Fig. 299. Carpellate eone, carpels, and seed of the Seotelı pine (Pinus sylvestris)

$A$, yonng growth with earpelate enes, about three weeks after the opening of the terminal bud: $n$, young pine needles. $l$, inner and side view of a cone scale at the time of pollination as shown in $A: b$, braet; 0 , ovules. $C$, inner and side view of scales from a mature cone as shown in $I$ ): $b$, bract; 0 , fertilized ovnles now rapidly maturing into winged seeds; $w$, the developing wings. D), a mature eone. $E$, a matnre winged seml. $F$, section of mature seed: $t$, hard seel coat, or testa, developed from the integnment of the ovule (see Fig. 300 , $A, i) ; n$, a membranons seed coat which is the remains of the nucellus (see Fig. $300, A, n) ; e n$, endosperm or tissue of the female ganetoplyte (see Fig. : $A)$; em, embryo with group of cotyledons $c$ and the suspensor $s$; micropylar end of seed 
The carpellate cone. The carpellate cones have a complex strueture that camnot here be described in detail. They are borne singly or in groups of two or three at the ends of the new growth in the spring (Fig. 299, A) simultaneously with the staminate cones. Each cone is composed of scales arranged somewhat spirally. Each scale (Fig. 299, B) is believed to be a group of three fused carpels (the point representing a sterile carpel between two fertile ones). The scale bears a pair of ovulcs below on the inner face, near the place where it is attached to the axis of the cone.

The ovule has a large nucellus, surrounded by an integument, whieh bears two appendages looking like a pair of horns in miniature (Fig. 299, $B, 0$ ). The embryo sac which develops in the center of the nueellus is one of a group of four cells, or tetrad, which shows its relationship to a spore (megaspore) and to the pollen grain. The other three cells of the tetrad fail to develop, so that all the strength of the ovule is given to this single functional megnspore which produces the female gametophyte. The ovule is an outgrowth from the surface of the carpel, its nucellus ( $\mathrm{Fig} .300 \mathrm{~A}, n$ ) corresponds to a megasporangium, and the integuments (Fig. 300, $A$, $i$ ) are probably protective investments. The integuments do not completely inclose the nuccllus, but there is left a small opening at the tip (Fig. $300, A, m$ ) called the micropyle.

353. Pollination in the pine. The young carpellate cones are upriglit when they first appear, and the scales are slightly separated from one another. When the pollen is shed in elouds from the stamens some of the grains are carried by the wind to the carpellate cones and sift in between the scales, collecting in little drifts near the ovules. This is the process of pollination. At this time there are globules of moisture between the two hornlike appendages of the ovules, and the pollen grains are caught by these. The fluid gradually dries up, drawing the pollen grains toward the micropyle, and finally into a cavity called the pollen chamber (Fig. 300, $A, p c$ ), whieh lies just above the nucellus. 
Meanwhile the scales of the cone close together and the cone bends over until it hangs downward. This is a curious behavior, although there is evident advantage to the plant, for the cone is now in a better position to protect the ovules from rain or dust which might enter between the scales if the cones remained upright.
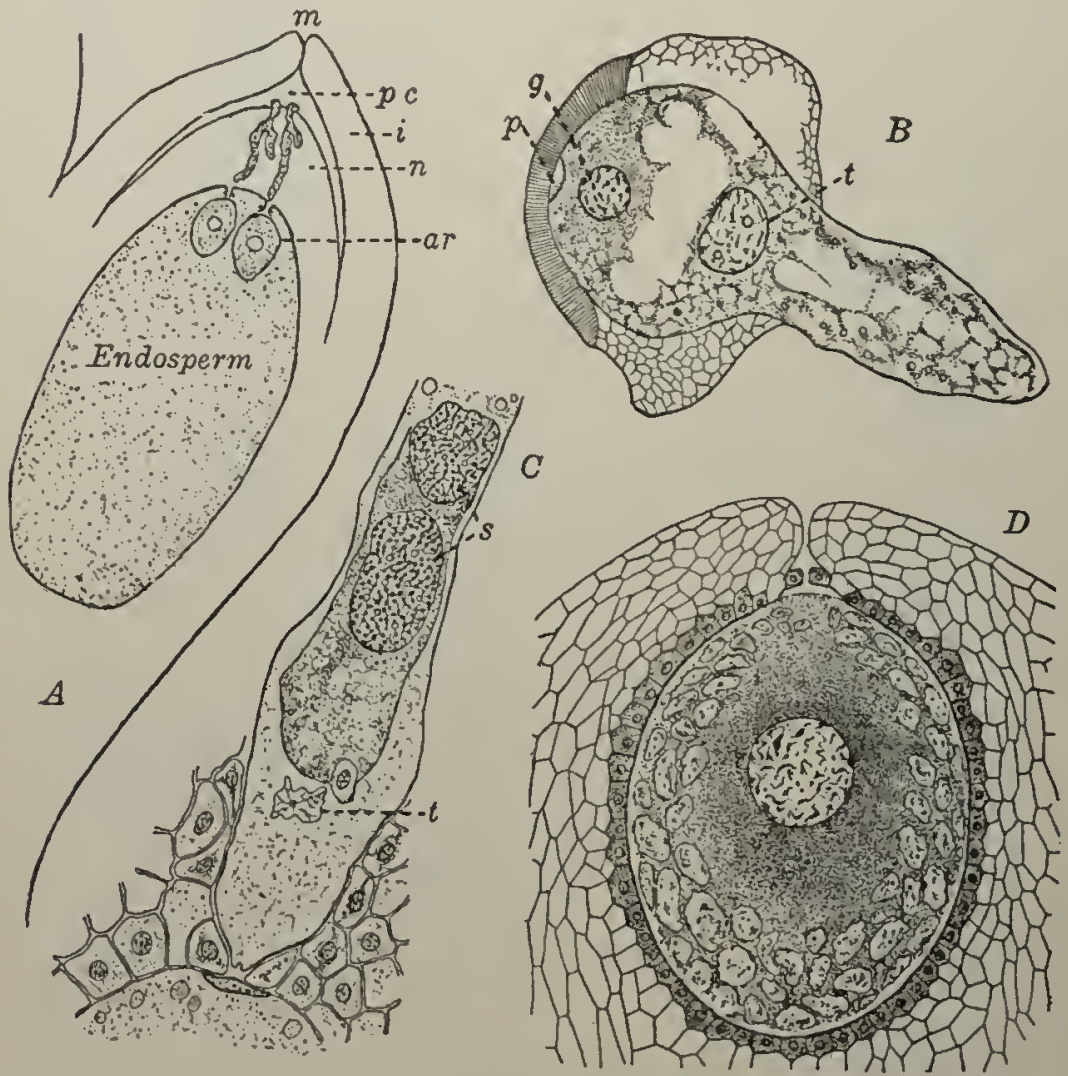

Fra. 300. The gametopliytes of the pine

1, liatram of a section of a year-old ovnle: cmbryo sae with mature arehegouia ar imberded in the tissue of the enclosperm (female ganctophyte); pollen tubes (male gametophytes) growing down through the tissue of the nuecllus $n ; p c$, pollen cliamber; $m$, micropyle; $i$, integument. $B$, germinating pollen grain, showing young male gametopluyte: $t$, tube nuclens; $g$, generative uucleus; $p$, prothiallial cell. $C$, tip of pollen tube applied to the egg: $t$, tube nucleus; $s$, the two sperm nuclei. $D$, a mature arehegonium sunken in the tissue of the endosperm, showing the large egres surrouuded by a jacket of cells rich in protoplasm: two neck cells of the arehegouium showu just above the egg. $-B, C$, after Miss Ferguson 
354. The gametophytes of the pine. The pine, likie all seed plants, is of comrse heterosporous because it has microspores (pollen grains) and megaspores (embryo sacs); so there are two gametophytes, male and female.

The male gametophyte. The male gametophyte, as in most, if not ali, seed plants, begins to develop before the pollen is shed. There are thrce nuclear divisions which cut off two small cells, called prothallial eells, of which traces may sometimes be found against the wall of the pollen grain (Figs. 29s, $k, p ; 300, B, p$ ). The third division leaves the pollen grain with a mucleus (the tube nucleus) in the central region and a small lens-shaped cell (the generative cell) at one side (Fig. 298. $F, g$ ). This is the condition when the pollen is shed.

Shortly after pollination the pollen tubes begin to develop in the pollen chamber (Fig. 300, $A, p e$ ), but their development is very slow until the following spring. Then the large tube nucleus passes to the tip of the tube, which grows rapidly towards the center of the nucellus (disorganizing the surrounding tissue as it does so), where the female gametophyte lies within the embryo sac. The generative cell now divides into a stalk and body cell which pass into the tube. The body cell forms two sperm nuclei a few weeks later. Four nuclei are then finally present at the end of the pollen tube (two sperm nuclei, the tube nucleus, and that of the stalk cell). The pollen tube has now reached the cmbryo sac and is ready to discharge its contents into one of the eggs developed by the gametophyte (Fig. 300, D).

The female gametophyte. The embryo sac (megaspore) is a one-nucleate cell at about the time of pollination. This nucleus gives rise by repeated divisions to a large number of nuclei that lie at first freely in the protoplasm as the embryo sac gradually increases in size. Later, cell walls are formed around the free nuclei, and the entire embryo sac becomes filled with a delicate tissue called the endosperm (Fig. 300,A), which corresponds to the vegctative portion of a prothallium. It takes almost a full 
year for the female ganetophyte to reach this stage of development, when it occupies the greater part of the nucellus. In the spring following the pollination of the cone, the endosperm forms a group of several arehegonia at its mieropylar end. Each archegonium (Fig. 300, D) consists of a much-reduced neck region, generally composed of four eells, and the very large egg which lies imbedded in the endosperm, whose cells fornis an investment around it called the jucket. The egg is filled with dense protoplasm and contains much food material supplied through the eells of the jacket.

This is the condition of the female gametophyte thirteen months after. pollination. At about this time the pollen tube reaches the embryo sac and entering it passes between the neck cells of an archegonium, where its tip fuses with the egg membrane. 'The contents at the end of the pollen tube are diseharged into the egg, ineluding not only the two sperm nuclei, but also the tube nucleus and that of the stalk cell. One of the sperm nuclei noves towards the egg nucleus, which lies near the center of the egg, and fusing with it completes the act of fertilization. The other three nuclei break down and soon disappear.

355. The development of the embryo in the pine. Fertilization takes place, as described above, a litile more than a year after pollination. The cone during this time has increased greatly in size, but is generally hardly a third as large as the mature seed-bearing cone.

The fertilized egg soon begins to develop the pine embryo. This is a complicated history, which cannot be described here in detail. The embryo is however formed at the end of a structure called the suspensor (Fig. 299, $F, s$ ), whose development carries the embryo into the center of the endosperm, where it lies in a favorable situation for its nourishment. The cmbryo (Fig. 299, $r, \mathrm{~cm}$ ) is straight, and the stem part is surrounded by a cirele of seed leaves called eotyledons. 'The pine seedling is shown in Fig. 12. 
Meanwhile the integument becomes firmer and funally forms the hard, protective seed coat, or testa (Fig. 299, F, t). Arljacent tissue of the cone scale above the ovule develops a nembranous wing (Fig. 299, C, w), which separates from the scale of the conc with the ovule as a part of the seed. These changes take place during the summer, and the cone is not fully mature (Fig. 299, $D)$ and the seeds ripe until the following autumn, which is therefore more than a year after the cones are pollinated. Then the scales of the cone, now quite woody in texture, separate, and the seeds are shaken out and, since they are winged (Fig. 299, E), may be carried for a considerable distance by the wind.

356. The life history of a gymnosperm. The life history of a gymnosperm, beginning with the sporophyte (for the gametophyte phases are now so inconspicuous that they only appear during the process of seed formation), may be formulated as follows :

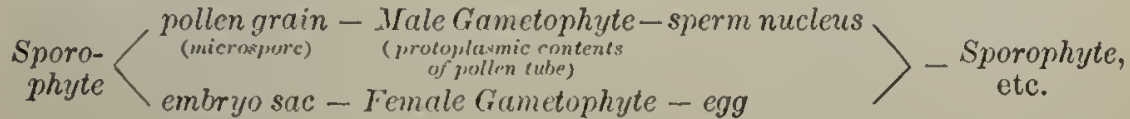

$$
\begin{aligned}
& \underset{\text { (megouspore) }}{\text { (protiphumic contents }} \\
& \text { of embryos sar) }
\end{aligned}
$$

This in abbreviated form becones

$$
\begin{aligned}
& S<P-M G-s \\
& e s-F e G-e
\end{aligned}>-S, \text { etc. }
$$

This formula should be compared with that of some heterosporous pteridophyte, as Selaginella (Sec. 326), to make clear the relationships. When carefully studied it will be found to be merely an elaborated form of the simple formula of alternation of generations.

$$
G<_{e}^{s}>-S-s p-G<_{e}^{s}>-S-s p-G \text {, etc. }
$$

The peculiarities of the life history of a gymnosperm are due to heterospory (and this is true of all seed plants), by means of which two sexual plants, male and female, have been differentiated, and the fact that both gametophytes live wholly or almost wholly as parasites upon the sporophyte. 


\section{SUMDIVISION II. THE ANGIOSPERMS, OR ANGIOSPERMIE}

357. The angiosperms. The angiosperms (meaning seeds in a vessel) are distingruished by the fact that the ovules are developed in a closed case (ovule case or ovary) formed by the carpels, sometimes alone but often together with adjacent tissue of the stem. This immense assemblage of plants, with more than 120,000 species, forms the greater part of the earth's vegetation and includes the most successful groups, dominating most of the land floras. It is a much more varied assemblage than the gymnosperms, and successful in every vegetation form (herb, shrub, or tree). The angiosperms adapt themselves to all sorts of life conditions, some of them being aquatics, others covering the meadows, prairies, and heaths, certain groups entering the deserts, and the trees forming forests generally accompanied by undergrowths of sluubs. They occupy the highest points of plant evolution, but along a great many very divergent lines, for some of the culminating groups are the grasses, the hardwood trees, the composite groups, the orchids, etc.

The general structure of the angiosperms, including the roots, stems, leaves, flowers, and fruits, together with many principles of plant physiology best illustrated in this group, have been described in Part I. This account will consider chiefly the life history, with especial reference to the gametophyte generations and significance of the flower.

358. The angiosperm flower. The essential structures of the angiosperm flower (Fig. 301), as of the gymnosperms, are the stamens (inicrosporophylls) and the carpels (megasporophylls); but in addition to these some accessory parts are generally present, which are either modified leaves of the plant, or sometimes stamens and carpels that have become sterile. These accessory parts constitute the perianth (Fig. 301, p), situated on the stem just below the stamens and carpels, and are generally showy structures, but also protective, at least in 
the bud. The perianth, as a lule, gives the eharacters of color and form which in popular usage define a flower. It is a very important aeeession, for it has resulted in some remarkable adaptations and devices on the part of the plant to insure pollination by the visits of inseets (see Chapter xxxir). The strueture of the perianth, with its parts, - sepals and petals, is described in Chapter xur. Besides laving the perianth, the angiosperin flower is peeuliar in that the ovules are not normally exposed on the surfaee of the earpels. This means that the carpels, either singly or in groups, form elosed struetures, whieh may be termed ovule cases. The ovule ease, generally called the ovary (an unfortunate term, for it does not produee eggs but ovules), bears a reecptive surfaee, terined the stirgma, upon which the pollen grains may gerininate. The stignna inay be raised upon a stalk, or style. Orule ease, style, and stigma constitute the pistil (meaning a pestle), which is said to be simple when only a single crirpel is involved, and eompouml if there is a group of earpels. The various arrangements of

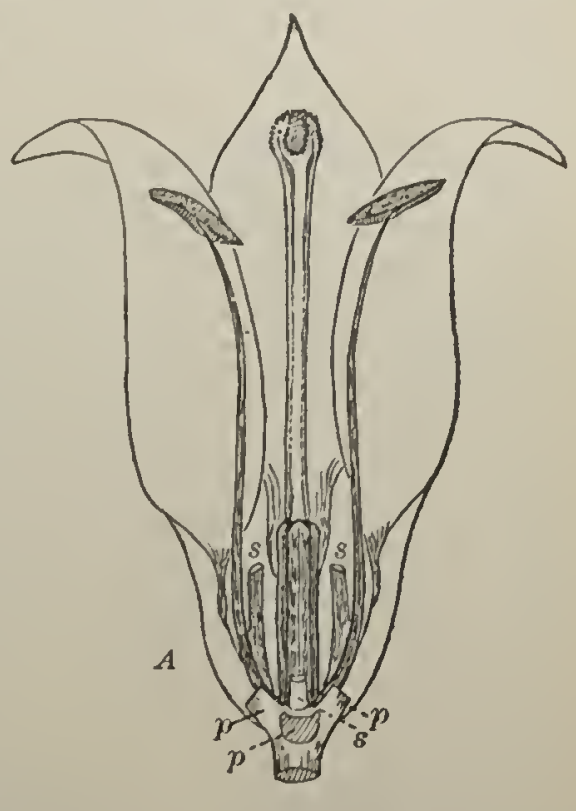

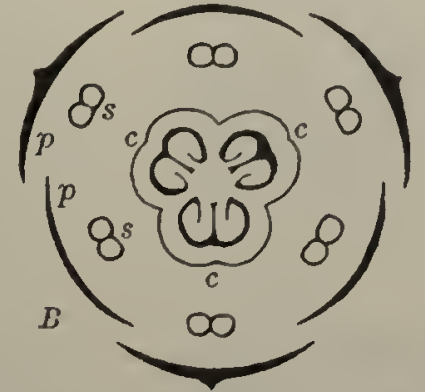

I's.301. 'llye lily (Lilium philadelphicum)

$A$, dissected flower, slıowing thre pistil and stanelis: $\gamma$, parts of the perianth which have been cut away; $z$, bases of stimens eut off. Is. flomal diagram: $p$, perianth, composed of two circles of similar and petal-like parts; $s$, starnens, likewise fll tworireles; section of ovule ease (ovary) shown in the cester, composed of threr: earpols (c) so united as to form three locules containing the ovules 
the carpels to form different types of pistils are described in Secs. 156 and 157.

Another characteristic of the angiosperm is the production of fruit. A fruit is a ripened orule case, or ovary, frequently
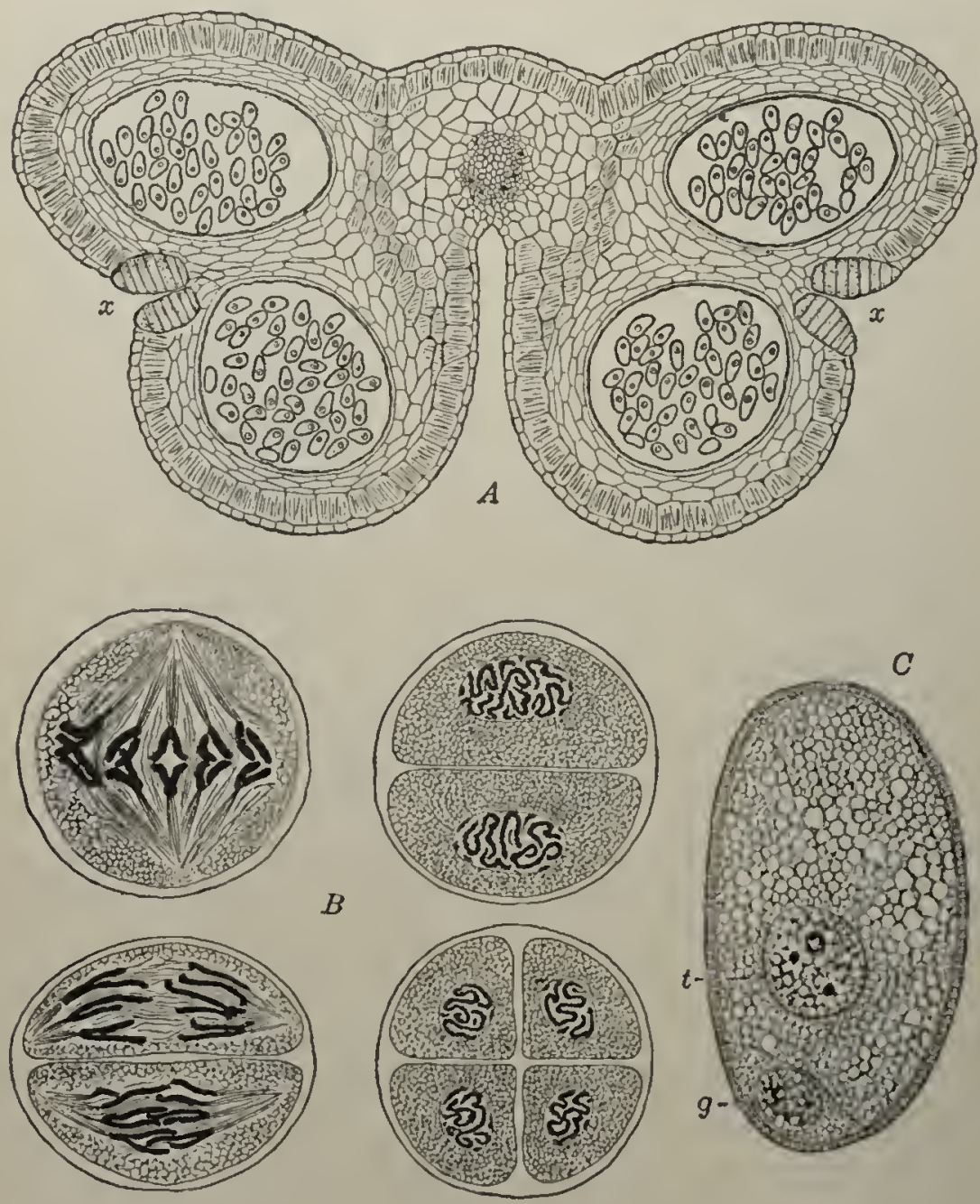

Fig. 302. Anther and pollen of the lily

$A$, mature anther, showing the four locules, or chambers, containing pollen grains: the auther opens lengthwise on hoth sides along the lines of cells shown at $x$. $B$, stages in the formation of pollen grains in a group of four (tetral) within the pollen mother cell. $C$, mature pollen grain with early stages in the development of the male gametoplyte: $t$, tube nucleus; $g$, generative nucleus 
with accessory parts. The gymnospcrms do not have the exact equivalents of fruits, although the berry-like structures of the yew appear at first glance to be similar and the cone is, of course, a protective structure for the seeds. True fruits, as the term is used when applied to the angiosperms, arc seed cases of various forms, - structures which are sometimes mercly protective, and sometimes fleshy and attractive to animals for food. They are described in Chapter Xvi.

The pistil distinguishes the angiosperms from the gymnosperms, and is a more important feature of the angiosperm flower than the periantl, which is frequently inconspicuous, and sometimes wholly or almost wholly absent. But the pistil in combination with a showy perianth of some peculiar and specialized form gives the lighcst type of flower structure. The most important of these are discussed in Chapter XIII. This account will only describe the stamens and carpels in their functions as spore-producing organs developing microspores (pollen) and megaspores (embryo sacs).

359. The stamen and the formation of pollen. The parts of a stamen are described in Secs. 171 to 173 . Pollen formation takes place generally in four regions of the anther, which become pollen saes, or locules (Fig. 302, A). The cells of these regions develop the pollen grains in groups of four, or tetrads (Fig. 302, $B$ ), and are consequently pollen mother cells. This process is identical with that of spore formation in the pteridophytes and bryophytes. ${ }^{1}$ The pollen mother cell is a spore mother cell, and the pollen grain a spore, or more exactly a microspore.

The pollen sacs are sporangia, and like the sporangia of the horsetails, lycopods, Seluginella, and the pollen sacs of the

1 As in the case of the gymnosperms, the count of the chromosomes during pollen fornation shows it to be a periorl of chronosome reduction, when the sporophyte generation passes over to the gamctophyte, as explained in Secs. 3.34 and 33\%. Thus 24 chromosomes have been counterl in various tissues of the lily plant, but nnly 12 appear in the nuclear divisions in the pollen mother cell (Fig. 302, $B$ ). These cells, it may be remarked, are exceedingly good subjects for the study of melear division. 
gymnosperms (Sec. 352), they develop from a group or large region of cells, and not from a single surface cell as in the sporangium of the common ferns. The pollen sacs open along certain lines (Fig. $302, x$ ) or by pores, and the pollen is thus set free. The pollen is carried in various ways to the stigma of the pistil, as described in Chapter xxxI, and its application to this structure

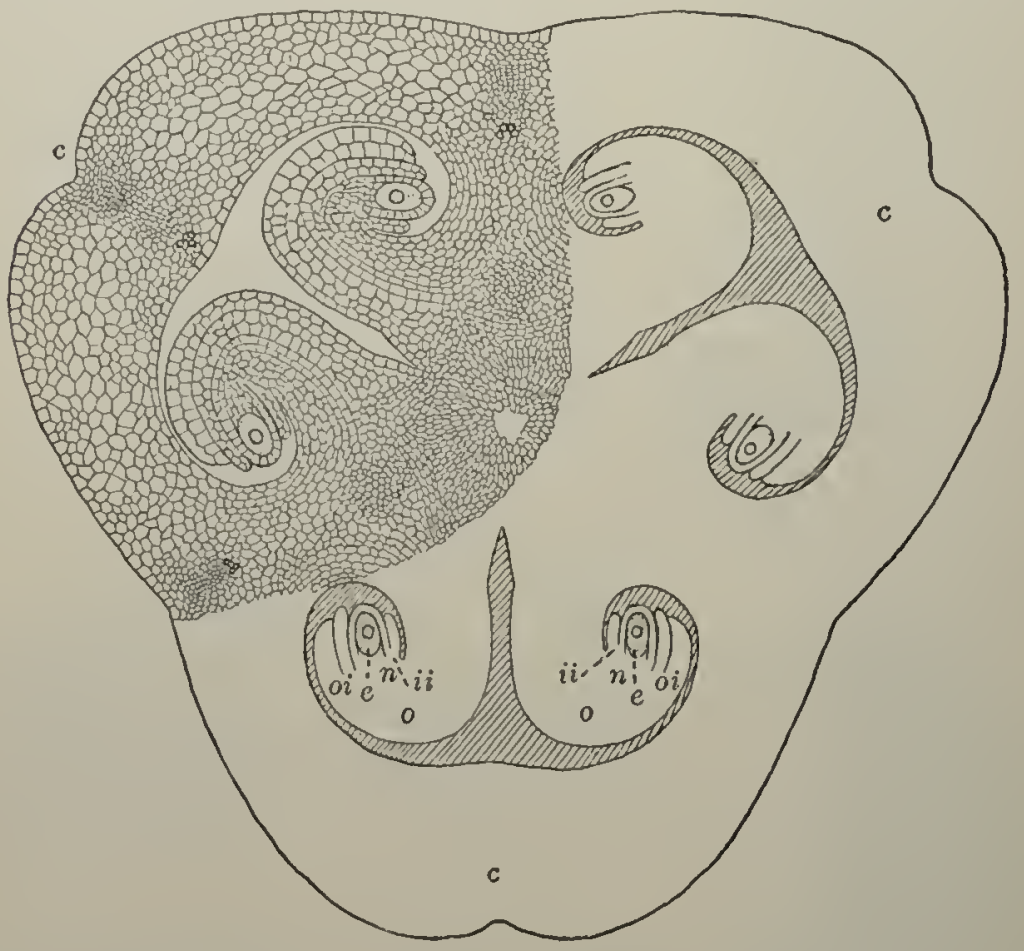

Frg. 303. Section of the ovule case (ovary) of the lily

Diagram of a cross section of a young ovule case, showing the three carpels $c$; each young ovule o has a large embryo sate mother cell $e$ within the small meellus $n$, and shows the developing imer and outer integuments $i i$ and oi

constitutes pollination in the angiosperms. Wind, direct contact of the anthers with the stigma, or the visits of insects are means by which pollination is effected in this group of plants.

360. The carpel and the formation of the ovule. The orules are developed as outgrowths from the surface of the carpels (Fig. 303), or in some cases from regions of the stem, when this 
structure enters into the formation of the ovule case. Each orule consists of a central region called the nucellus (Figs. 303; $306, A ; 309, A, n)$, which becomes enveloped by two protective integuments (Figs. $303 ; 306, A ; 309, A, B, C, \ddot{i i}$, oi) that arise from its base' and grow up around it, forming a small opening above termed the micropylc (meaning little gate). A cell in the interior of the uucellus becomes the cmbryo sac (Figs. 303, c; 306, A, B), which in most cases is the exact equivalent of a megaspore. This is proved by the fact that the embryo sac in such forms is one of a group of four cells, or tetrad (Fig. 304), and that the developinent of this group follows the same history as in pollen and spore formation. The nucellus is therefore a megasporangium. Certain forms of angiosperms, as the lily, have given up the formation of tetrads, and the spore mother cell develops directly into the embryo sac. ${ }^{1}$

361. The gametophytes of an angiosperm. The inale gametophyte (contents of the pollen grain and tube) is clearly similar to that of the gymno-

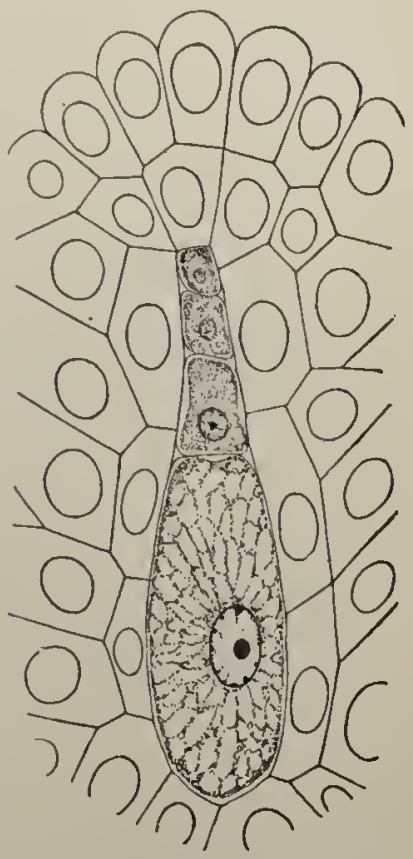

FIG. 304. A group of four megaspores (tetrad) in the nucellus of an ovule (Canna)

The upper three megaspores of the group are breaking down, while the lower is rapidly enlarging to become the embryo sac. - After. Wiegand speru; but the fernale gametophyte of the angiosperm is a very much more reduced structure than anything in the gymnosperins.

1 In these cases the first two muclear divisions within the embryo sae have the peeuliarities of those in all spore mother colls. In the lily the nuclei of the nucellus lave 24 clnomosomes, but the nuclei of the embryo sac have 12. This shows that the two nuelear divisions charaeteristie of spore formation have beeome a part of the gametophyte phase of the plant's life history. 
The male gametophyte. As in the gymnosperms, the male gametophyte begins its history in the pollen grain before the latter has been shed. The first division forms a tube nucleus and a generative eell (Fig. 302, C). The nucleus of the generntive cell divides sooner or later to form two sperm nuclei. These three nuclei, with the rest of the protoplasm, constitute all there is of

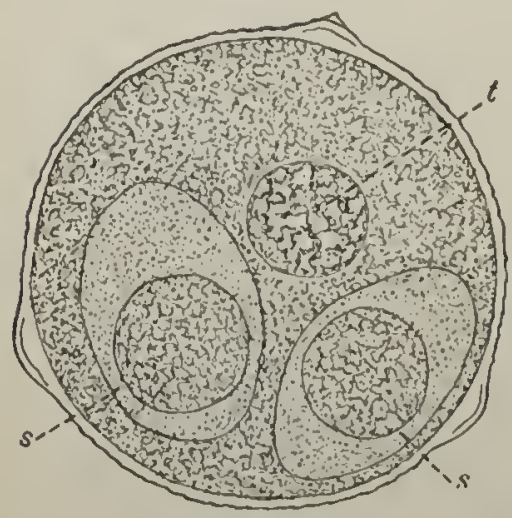

Fig. 305. l'ollen grain of the elder (Sambucus)

The two sperm eells $s$ and the tubo nuelens $t$, with the remaining protoplasin, constitute the entire male gametophyte the male gametophyte (Fig. 305).

The pollen grains germinate on the stigma of the pistil, finding there suitable fluids to start their glowth. Each puts forth a tube (Fig. 156, A, I, C) which penetrates the stigma and grows downward toward the ovule case (ovary). The tube nucleus and the generative cell (or tle two sperm nuclei if already formed) enter the tube and, passing to the tip, accompany its growth (Fig. 156, $D, E, F)$.

The pollen tubes grow through the tissues of the stigma and style (if present) frequently orer definite paths and enter the micropyles of the ovules. This beliavior resembles the way in which parasitic fungi grow through the tissues of their hosts, and it is clear that the pollen tubes live largely or wholly parasitically on the sporophyte. On entering an ovule the pollen tube penetrates the nucellus and grows toward the embryo sac, which by this time lras developed the female gametophyte.

The female gamctophyte. The mature female gametophyte of an angiosperm (Fig. 306, B') contains only eight nuclei, the products of three nuclear divisions in the embryo sac. These are distributed as follows: There is a group of three nuclei at the micropylar end of the enbryo sac (Fig. 306, $I, m$ ), forming the 
egg apparatus, of which one, with surrounding protoplasm, eonstitutes the eyg, and the other two are called synergids (meaning co-workers). There is a group of three nuclei at the opposite end of the sac, called antipodal nuclei (Fig. 306, B, ant), which frequently become inclosed by delieate walls and possibly represent a prothallial region. 'The remaining two nuclei, called polar
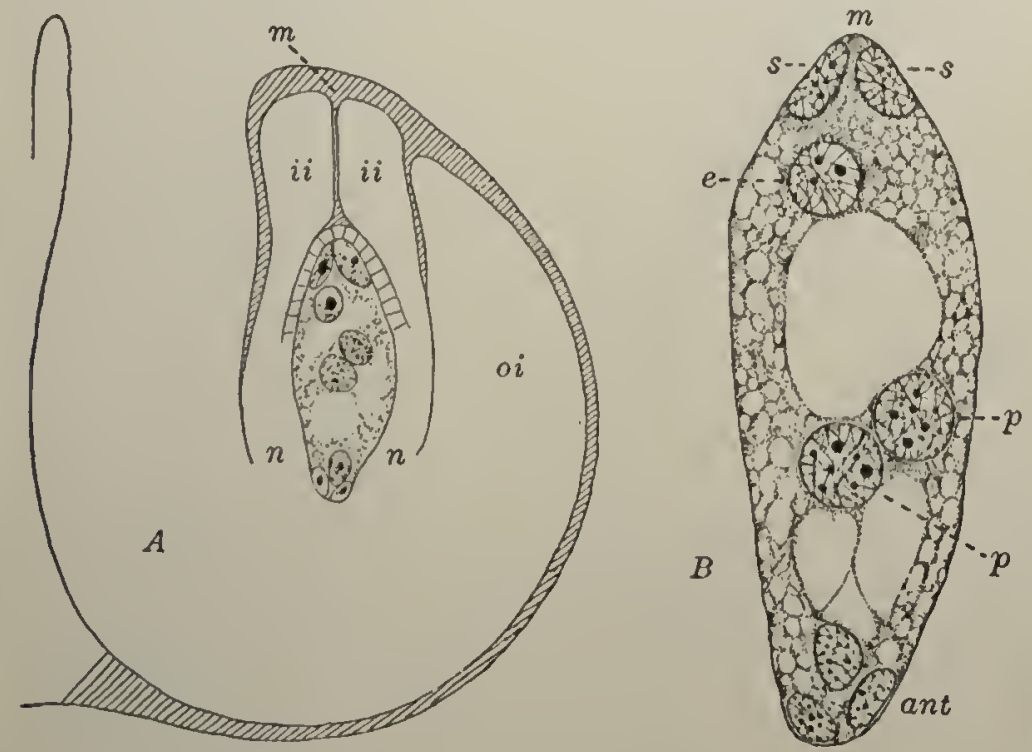

1'sc. 306. 'The ovule and embryo sac of the lily

$A$, ovule with mature embryo sic: the iumer iuterument $i$ has grown beyond the nurellus $n$; oi, outer integument; $m$, micropyle. $J$, mature emblyo site: egg apparatus at the mieropylar eud $m$; $e, \operatorname{egr} ; s$, syuergits; the two polar melei $p$ are about rearly to fuse near the center of the sae; ant, antipotal unclei

nuclci (Fig. 306, B, p), pass from the opposite ends to the center of the embryo sae, where they later unite.

362. Fertilization and double fertilization. The tip of the pollen tube fuses with the end of the mulsyo sac, near the synergids, and the two sperm nuclei are diseharged into the sae. The tube nucleus las generally broken down and disappeared entirely by this time (Fig. 156, $F, G$ ). One of the sperm nuclei unites with the egg mucleus (Fig. 307,e,fs), and this is the process of fertilization. 


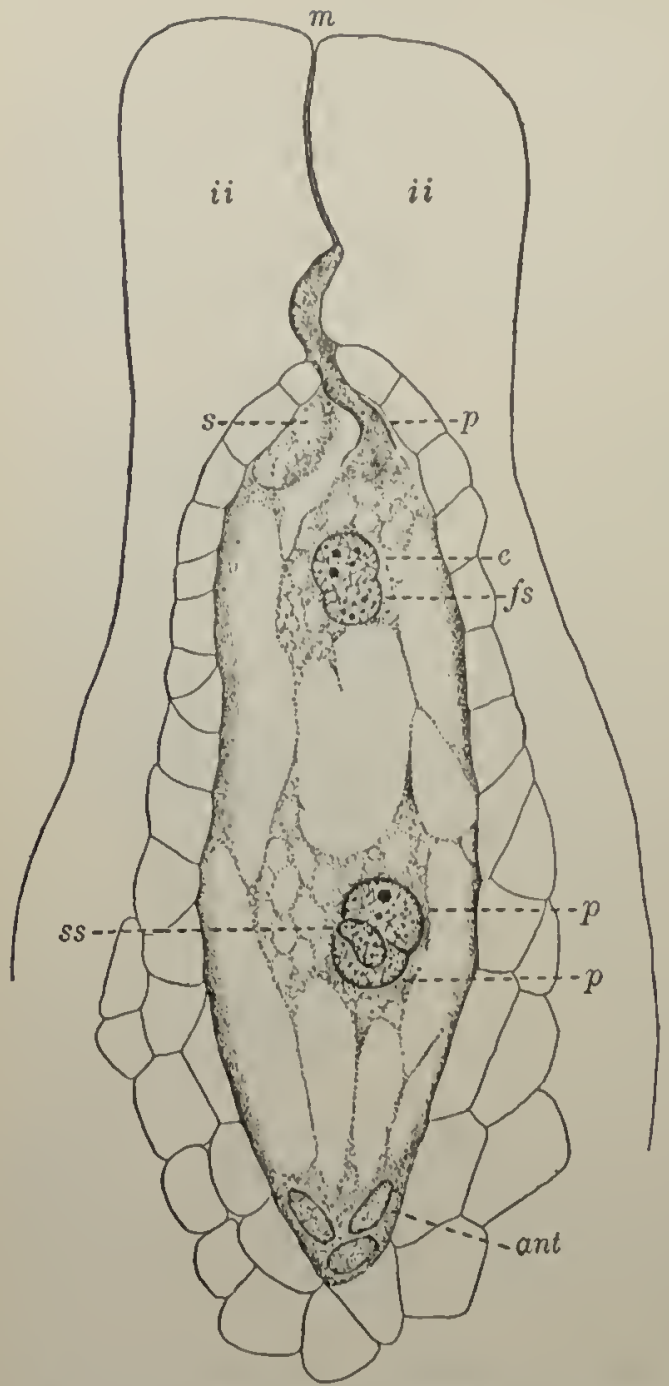

Fig. 307. Fertilization in the embryo sac of the lily

The first sperm unclens $f s$ fusing with the egr muclens $e$; the second sperm uncleds ss is fushug with the two polar molei $p$ near the center of the sar, constituting the so-rilled donble fertilization; $p$, pellen tube; s, syourgid breaking down; ant, antipolals; $i i$ inner intergment; $m$, nicropylo sffect of Pollen in Maize," United States Mepartuent of Acriculture, Division of Vegretable Physiology and l'athology, liulletin $22,1900$.
The other sperm nucleus is known in a number of forms to pass to the center of the sac and unite with the two polar nuclei, constituting a triple fusion (Fig. $307, p, p, s s)$, and forming a large nucleus, called the cndosperm nuclcus. Since the endosperm nucleus has an important history in the development of the seed, this peculiar behavior of the second sperm nucleus is important, and it is called the double fertilization of the enlbryo sac. ${ }^{1}$

1 Double fertilization is probably the explanation of tho phenomenon callet xenia, which is the appearance at once in the seed of some character of the male parent. 'I'hus a yellow or white kind of corn, when pollinated from a blue or red rariety, will produce blue or red kernels. 'This color in the corn is present in the endospern, and the chasactre comes into the seced through tho second sperm muclens. For au accomnt of xirua see 1 rebier, "Xenia, or tlre Immediate
Department of Agrienlure, g, Ihulletin $20,1000$. 
363. The development of the embryo and endosperm. The fertilized egrg develops the embryo, but as in gymuosperms, there is generally a preliminary growth called the suspensor (Fig. 309, D, l;, H, s), which carries the young embryo into the center of the sac. 'The endosjerm nueleus begins to divide at once after its formation, by the triple fusion of the second sperm nueleus with the two polar nuelei (Fig. 307). It gives rise to a large number of nuclei, which become distributed in the protoplasm of the rapidly enlarging embryo sac (Figs. 308, $c$; $309, H, c)$. Later, walls begin to form around these endosperm muclei, first in the outer regions of the embryo sac, and finally the whole sac beeomes filled with a delicate tissue.

This tissue is called the endosperm, and the embryo becomes inbedded within it as in the pine. But this endosperm lias, of course, a very different origin from that of the gymnosperms, and is a special development peculiar to the angiosperms. The group of antipodal cells possibly correspouds to the endosperm in the rymnosperms, and the egg apparatus has been regarded as a

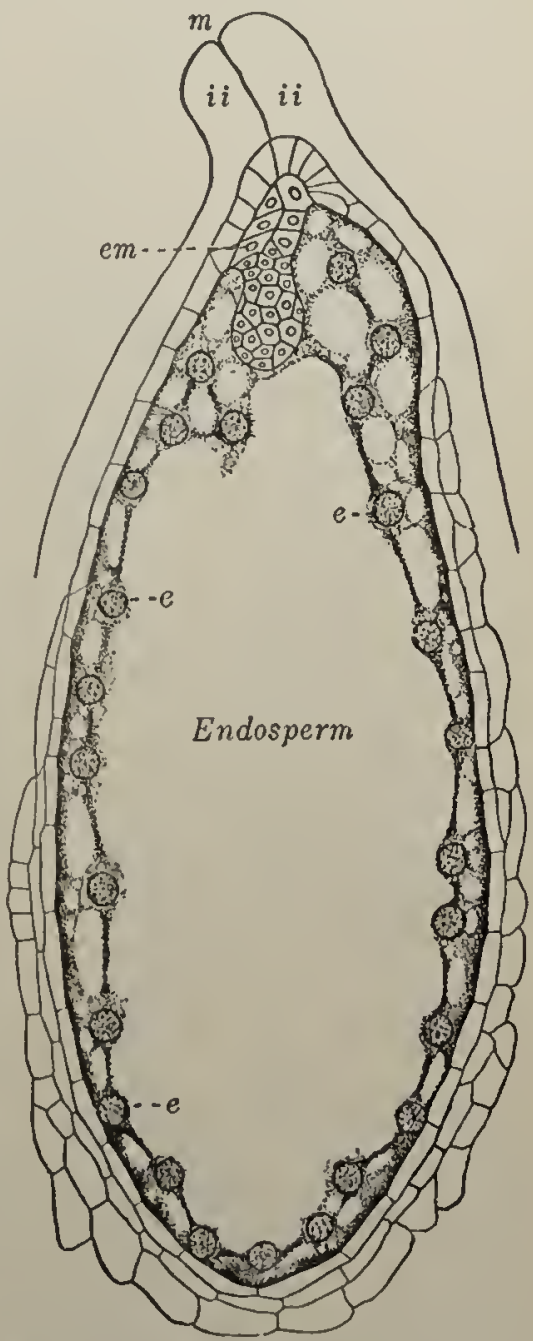

Fig. 308. Development of the embryo and the endosperm of the lily

The embryo $\mathrm{em}$ has developed from the fertilized egg; $e$, endosperm nuclei which have been derived from the triple-fusion nuelens, - that is, the two polar melei united with the second sperm nuclens (eompare with Fig. 307); $i i$, inner integument; $m$, micropyle 


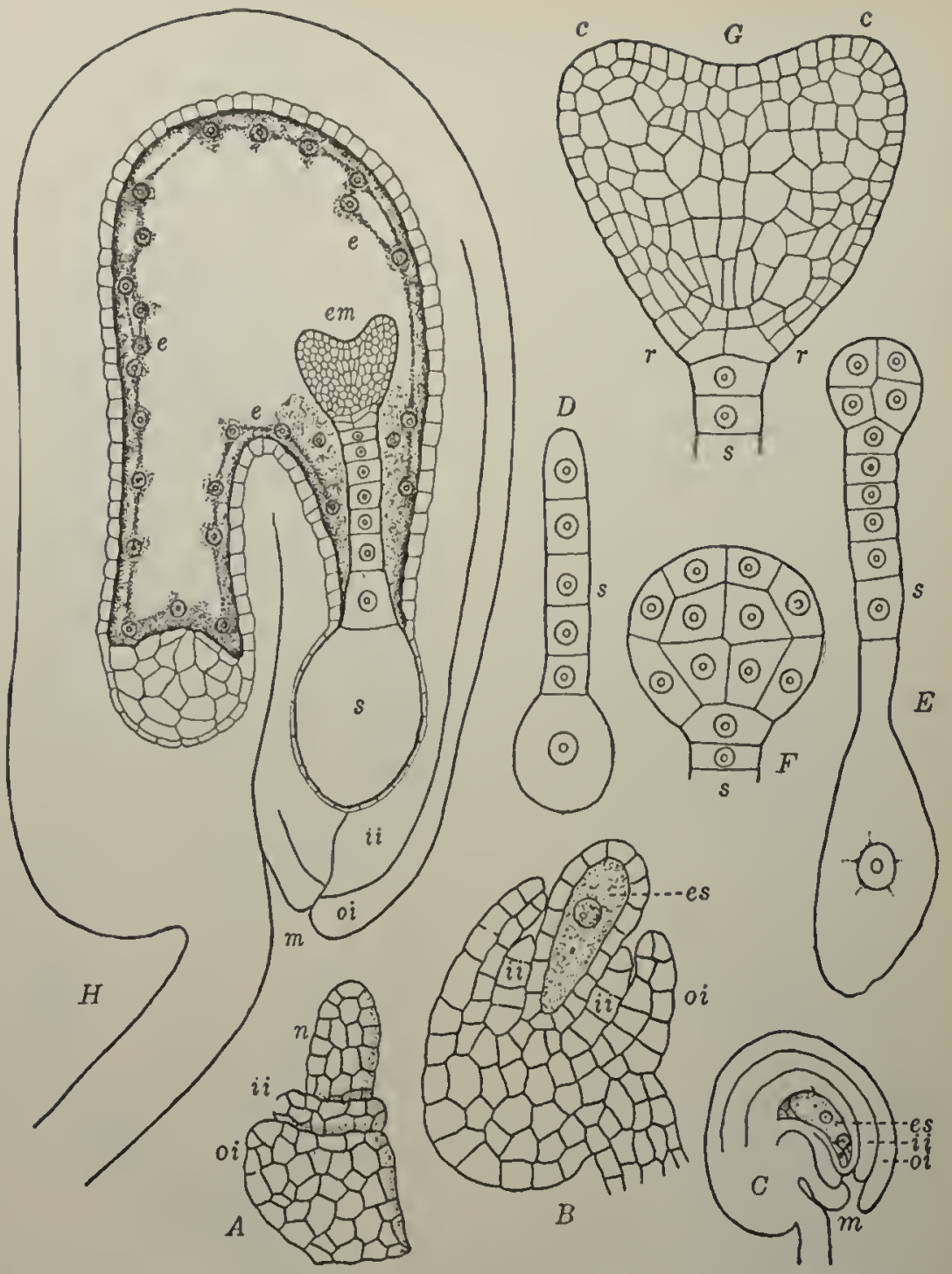

Fig. 309. Development of the ovule and embryo of the shepherd's purse (Capsclla)

$A$, young ovule, showing origin of two integuments at base of meellus $n$. $B$, outer integnment growing beyond the inner, anl the ovnle beginning to bend over: es, embryo sae. (', diagrain of a later stace with matnre embryo sac. J), llevelopment of the suspensor s. $F$, early divisions of the terminal cell (emliryo cell). $F$, later stage, slowing the differentiation of an onter cell layer in the embryo, which is to become the epillermis. $G$, the two eotyledons $c$ and the root region $r$ now clearly lefined. $I I$, lengthwise section of an ovnle, showing the position of an embryo in an embryo sac: $\mathrm{em}$, embryo; s, suspensor; $e$, endosperm; $i i$, iumer integunents; $o i$, onter iutegument; $m$, micropyle. $-A$, $B, C$, adapted after Camplell 
reduced archegonium. However, it is possible that all three of the nuclei in the egrg apparatus represent eggs, only one of which is functional.

While the embryo and endosperm are developing, the ovule increases greatly in size, and its integuments change into the
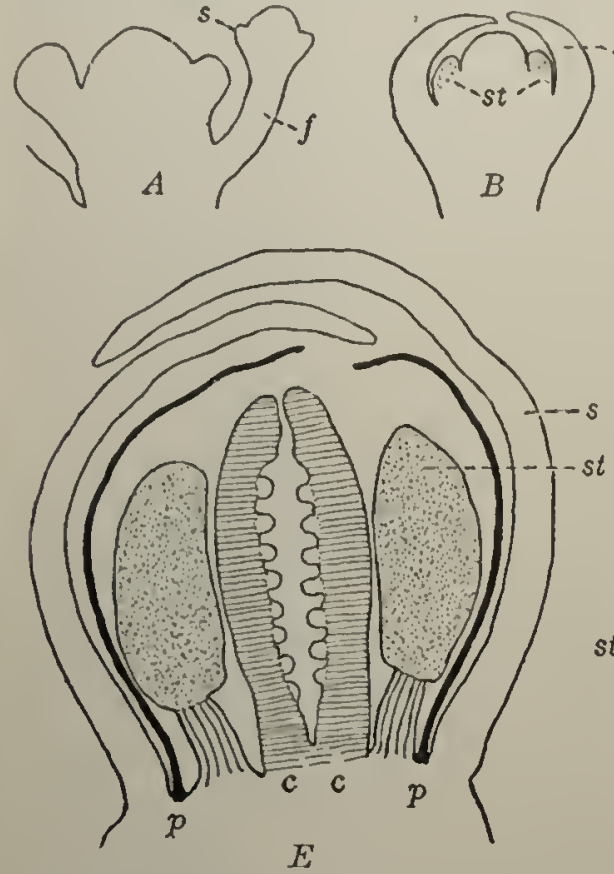

FIG. 310. Development of the flower of the shepherd's purse (Capsella)

A, tip of stem, showing the origin of the flowers: $s$, first appearance of the sepals in the flower $f$. $l i$, sepals well along in their development and stamens st appearing. $c$, later stage, showing tho two young carpels $c$ and the beginnings of the petals $p$. 1), later stage lettered as in the preecting. $E$, the petals now well developed, and the ovules beginning to arise on the inner face of the (arpels, not yet united above to form the closed pistil

seed coats. In some plants, as in the squash (Fig. 1), peas, and benns, the embryo finally fills the entire seed, and the endosperm is almost completely crowded out, being represented by a thin membrane around the embryo. In other forms, as the corn (Fig. 3), asparagus, and poppy (Fig. 4), the embryos remain small, and the endosperm is conspicuous as a tissue richly stored with food material. 
364. The development of the flower. The development of the parts of a flower would be expected to progress in the order of sepals, petals, stamens, and carpels, for this is, of course, the order of their position on the flower stalk, beginning from below. The parts of many flowers do arise in this order, but there are often irregularities due to the delayed appearance of some organs. For example, in the shepherd's purse the petals are formed last, arising between the sepals and carpels when the latter are far along in their development (Fig. 310, C, p).

The carpels are clearly separate in the beginning (Fig. 310, $C, D, c)$, and the ovules at first may be exposed on their surface (Fig. 310, E), but sooner or later the carpels unite above, so that the orules are finally contained in the orule case (orary).

A study of flower development makes elear the significance of perigyny and epigyny (See. 157), for it shows that the apparent fusion of parts, frequently ealled coalescence, when sepals, petals, or stamens seem to be united to one another or to the carpels (see diagrams, Fig. 136), is due to the formation of tubular outgrowths from zones of tissue below the floral parts. The parts which are most frequently affected by these zonal outgrowths are the carpels, and it seems probable that the compound pistil may have arisen from their activities. In many cases the ovules are developed from tissue that is probably really a part of the tip of the flower stalk.

365. The life history of an angiosperm. The formula for the life history of an angiosperm is the same as that of a gymnosperm (Sec. 356). The gametophyte phases, however, occupy generally a much shorter period, so that the seeds are matured in the same season and sometimes within a few weeks after pollination.

The formula is then as follows:

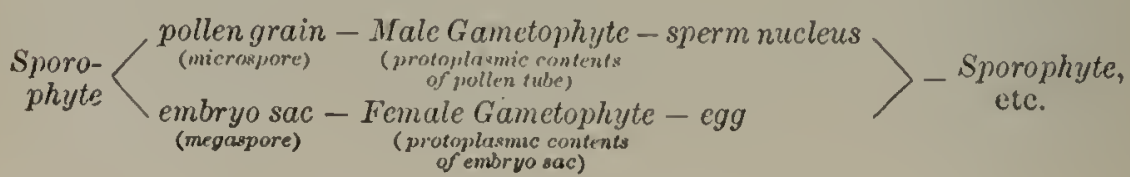




\section{THE ORIGLN OF SEED PLANTS AND THE SEED HABIT *}

366. The origin of seed plants. IVe shall never know exaetly when and how seed plants arose, for that important event in plant evolution probably took place earhier than the Carboniferous Age. We can, however, form some idea of the chief faetors that brought about the seed habit from a study of the life histories of living pteridophytes and spermatophytes. As with a number of other forward steps in the crolution of plants, sueh as the origin of sex, alternation of generations, and heterospory, the seed habit probably was developed by a number of different groups of pteridopliytes independently one of another. Thus the cyeads and the conifers among the gymnosperms are so widely separated that it scems possible that they may have eome from different pteridophyte parentage. Therefore the gymmosperms are generally regarded as a group of divergent crolutionary lines. The angiosperms are even more puzzling. Some botanists believe that they arose quitc independently of the gymnosperms, but others hold that they may be distantly related to Gnctum. Some think that the monoeotyledons and dieotyledons even have had independent origins. However, the view whieh seems to be finding greatest favor at Iresent regards the monoeotyledons not as the aneestors of the dicotyledons, buit as derived from primitive dicotyledons. ${ }^{1}$

367. The origin of the seed habit. The most important factors leading to the seed liabit appear to have been (1) heterospory, (2) the retention of the megaspore in the megasporangium to beeome the embryo sae in which the femaie gametophyte develops parasitieally, and (3) the development of the pollen tube and its parasitic habit of growth through the tissues of the

* To the Isstructor: This subject is very difficult and may be omitted.

1 These topies are far too technical for consideration here. For reviews of the various theories with their evidence, the reader is referred to Coulter and Chamberlain, Morphology of Spermatophytes (Gymnosperms), 1901 and Morphology of Angiosperms, 1903. 
sporopliyte to reach the embryo sac. These principles are associated with the last stages in the long processes of the evolution of the sporophyte and the degencration of the gametophyte, which is briefly outlined in the next chapter.

Heterospory (Sec. 314, Chapter xxvir) has differentiated the spores of the pteridophytes and established male and female gametophytes, the first always developing from the microspores, and the second from the megaspores. At the same time the gametophytes became largely or wholly dependent upon food material stored in the spores, and smaller and simpler in their organization, until they degenerated into structures somewhat similar to those now illustrated in the heterosporous pteridophytes (Marsitia, Selaginella, Isoctes, etc.). Some of them finally lost all their chlorophyll, and adopted parasitic habits.

Heterospory also resulted in the differentiation of the spore leaves into microsporophylls and megasporophylls, and at last, as in many seed plants, the sporophytes themselves became differentiated, some producing only pollen (microspores) and some only embryo sacs (megaspores) in the ovules. In this way sexual characters of the gametophytes were gradually taken up first by the sporophylls and later by the sporophytes themselves, and thus the asexual generation began to assume the peculiarities of sex. The microsporophyll of the seed plant (stamen) took on characteristics of a male organ, and the megasporophyll (carpel) characteristics of a female one. The early botanists regarded the pollen grain as a inale element and the stamen as a male organ, and it is true that these structures have male characters; but of course the actual male gametes are the sperm nuclei with closely associated protoplasm in the pollen tube whose contents represent a male gametoplyte. And similarly, although the carpel has female characters, the female gamete is the egg witlin the embryo sac whose contents represent a female gametophyte. ${ }^{1}$

1 This subject is considered more at length in Chaptor xxvir, Heterospory, Sec. 339. 
The retention of the megaspore in the megasporangium was, perhaps, the most important step in the development of the seed habit. This retention was possibly at first somewhat aceidental; that is, the megaspore simply failed to fall out of the megasporangium (as aetually happens in some speeies of Selaginclla, See. 325), and eonsequently dereloped its gametophytes while mechanically held on the sporophyte. Later the retention beeame more intimate and less meehanical, so that the female gametophyte established a close physiological association with the sporophyte, obtaining protection and certain foods, and perhaps most important of all it was kept moist. At last the megaspore, instead of being developed as a free cell, remained a part of the tissue of the megasporangium (nucellus of the ovule) and at that stage became the embryo sae with its elearly established parasitie relations to the sporophyte.

Some forms of Selaginella actually illustrate a beginning of such parasitic relations in the early stages of the development of its megaspore (Sec. 325), for the female gametophyte begins to develop before the spores are.full grown and ready to be discharged. But the seed habit eould not have been entirely formed until the megaspore became physiologieally a part of the megasporangium, and the latter (as a nueellus), together with the proteetive integuments, became the orule.

The development of the pollen tube is perhaps even more remarkable than the retenition of the megaspore in the megasporangimm. It seems clear that the pollen tube is a development in response to the stimulus of the moisture (eontaining fonl substances) which is exereted by the ovule in the gymnosperms and the stignna of the angiosperms. The habit may readily lave had a very simple beginning if mierospores fell into partially nened megasporangia, as indeed occurs in a speeies of Selayinella (Sec. 325), or among a group of megasporophylls. They wonld have found in such situations moistme and other enditions favorable for the development of outgrowths which later beeame tubes. These outgrowths and 
tubes would be expected to become more and more specialized as conditions arose which led to the final retention of the megaspore within the megasporangium, and at last they assumed pronouneed parasitic habits.

With the parasitic habits of the pollen tube established it is not difficult to imagine the gradual adjustment of the peculiarities of pollination to those of ovule formation. It seems probable that the earliest forms of pollen tubes carried motile sperms to the embryo sac $^{1}$ (for motile sperms are even now present in the cycads and Ginkgo, Sec. 348), but later the complex structure of the sperm degenerated, with that of the whole male gametophyte, until the sperm nuclei became practically all that was left to represent the male gametes of the pteridophytes, bryophytes, and algx. The simplification of the sperm and egg in the spermatophytes does not, however, affect the significance of these sexual elements, because it is known that the nuclei are the most essential structures of gametes.

Thus the peculiarities of the ovule and the pollen tube probably developed side by side, adjusting themselves to one another until the complex phenomena of pollination became established. These processes are relatively simple in the gyunosperms, where the pollen is applied directly to the ovule; but in the angiosperms a new feature was introduced when carpels, or groups of carpels, frequently with aljacent tissue of the stem, developed the ovule cases (ovaries). Yet it is not very difficult to understand how they may have arisen, for the same principles of protecting the megaspore (embryo sac) and providing for the germination

${ }^{1}$ In certain fossil groups (Pteridosperma), intermediate between the pteridophytes and spermatophytes, the evidence indicates that motile sperins were discharged into large pollen chambers filled with water, into which the necks of the archegonia opened so that the sperms were able to swim directly to the eggs. The pollen tube was probably at first an absolbing organ, or haustorium (as in the cycads and Ginkgo to-day, Sec. 348), penetrating the tissue of the ovule to obtain nourishnent for the parasitic inale gannetophyte. Later, with the disappearance of the pollen chamber and motile sperins, the pollen tube took on the added function of carrying the sperm nuclei directly to the embryo sac. 
of the pollen grains are simply carried one step farther, and the megasporopliylls (earpels) become factors in the processes. Thus a receptive surface, the stigma, was developed as a special organ to receive and start the pollen tube in its parasitic development, which is to end with the fertilization of the egg.

The seed is the ripened ovule, for the principle of protection is continued after fertilization, and the integuments form hard seed coats, inclosing the developing embryo, supplied with food material by the parent sporophyte until it has reached an advanced stage of development.

\section{THE EVOLUTION OF THE FLOWER}

368. The evolution of the flower.* The higher types of flowers have been developed by long processes of evolution from the simpler structure of the primitive flowers. We do not know exactly what the primitive flowers were like, but some of their characters may be inferred from the structure of the simplest flowers of the angiosperms and the cones of gymnosperms and certain pteridophytes, as the horsetails and club mosses, which are truly flowers, if one accepts the definition of a flower as a "shoot beset with sporophylls." The most elaborately developed theory of floral evolution is that of Engler, and this brief outline will be a general statement of his views.

Primitive flowers were characterized by indefinite numbers of sporopliylls, usually distributed in spirals, and the absence of the floral envelopes constituting a perianth. These conditions are illustrated in the cones of the pteridophytes and in many

* To тив: Isstri"ctor: This subjeet should only be presented to elasses with a fairly wille lange of experience with flower strueture in various groups of angiosperis.s. An exeellent stukly would he a sieries of types from sueh an assemblage as the huttercup orler, Ranunculules, as the mousetail (Myosurus), buttercups, magnolia, white water lilirs, columbine, larkspur, aconite, etc., where many of the prineiples of flower evolution are illustrated in a single group. Similar sturlies might be planned for the rose order, Rosales, or the lily order, Liliales, followed by the orehids. 
gymnosperms. Spiral arrangements of sporophylls (stamens and carpels) and floral envelopes are also not uncommon in many flowers with well-dereloped perianths, as in representatives of the buttercup order, Ranuneulcles, namely, mousetail (.Myosurus), buttercups, magnolia, white water lilies, and the rose order, Rosales. It is not at all probable that the various advances over the primitive conditions followed any regular order. Some of them were concerned with the differentiation of a perianth; some had to do with the arrangements of the sporophylls and parts of the perianth; some dealt with the apparent fusion of parts, and some concerned the symmetry of the flower.

The differentiation of a perianth has clearly taken place in some flowers through the transformation of sporophylls, which became sterile and assumed perianth characters (generally those of petals). Such transformations are admirably shown in the passage of stamens into the parts of the perianth in the white water lily, and in the doubling of flowers, where stamens and frequently carpels become petals. It is possible, however, that parts of a periantli may be derived in a reverse direction, - that is, from leaves or bracts on the stem just below the sporophylls. That ordinary leares can become highly modified and colored to serve the purpose of a perianth is illustrated by the showy bracts of the painted cup, or the flowering dogwood and other species of Cornus (Frontispiece). The parts of the simplest types of perianth were probably all similar and largely protective, especially to the flower bud. These later became differentiated into the two sets, sepals and petals, - the latter, and frequently also the former, showy and clearly related to pollination by insects or birds (Chapter XXXI).

The arrangements of the sporophylls and parts of the perienth are, as a rule, spiral in simpler types of flowers, but generally in circles or whorls in higher types. In passing from the spiral to the cyclic arrangements the variable and indefinite numbers of parts tend to become constant. Thus three and multiples of three are the prevailing numbers in the flowers of 
monocotyledons, while four and five are common numbers in the dicotyledons. A settling of the parts into fixed numbers would be always an important forward step in floral evolution, according to Engler, whether it concerus the perianth, the sporophylls, or both together; for it tends to give definite form to the flower, and thus leads toward the higher conditions. Sometimes a flower will be mixed in the arrangement of its parts, the perianth being cyclic and the stamens and carpels spiral, as in certain buttercups. The establishment of fixed numbers is frequently accompanied by tlie suppression of some parts (sepals, petals, stamens, or carpels), so that the numbers are variable in different circles.

The apparent fusion of parts, frequently called coalescence, results from the formation of tubular or cup-like outgrowths from zones of tissue below the floral parts, so that they seem to be united. The most complex conditions of flower structure, called cpigyny (Fig. 136, C) and perigymy (Fig. 136, B), are due to these zonal growths (see Secs. $152,157,364$ ). The contrast to epigyny and perigyny is hypogyny (Fig. 136, A). When petals or sepals are borne on zonal outgrowths the conditions are called, respectively, sympetaly and symscpaly (Sec. 152). The compound pistil, - that is, a pistil involving two or more carpels, - is one of the lighest expressions of zonal growth; this condition is called symcarpy (meaning united fruits).

The symmetry of the flower may be either radial or bilateral, that is with a right and a left half (Sec. 150). Hrimitive flowers were radially symmetrical, as would be expected from an indefinite number of parts spirally arranged. Bilateral symmetry appears, however, in very many groups and always represents a. ligh degree of Horal evolution. It is found more commonly in epigynous and perigynous flowers than in hypogynous, but there is no rule about its relations to these conditions. Bilateral symmetry is usually directly related to methods of flower pollination by insects, for the forms of such flowers are especially adapted to the labits of bees, which light on some expanded lip-like region 
of the perianth and rummage around, gathering pollen and nectar, and incidentally effecting the pollination of the stigma (Sec. 401).

Bilateral symmetry is generally accompanied by dorsiventrality, which means that the flower hangs in such a position that there is an upper and a lower portion as well as a right and a left half. Excellent illustrations are such lipped flowers as the snapdragons, the mints, and many orchids. An epigynous flower whose symmetry is bilateral and dorsiventral and whose parts, through suppression or other developments, show irregularities which have a clear relation to insect visitations,- - these cliaracters give the highest types of flower evolution.

According to Engler, the chief steps in the evolution of the flower may be :

1. The differentiation of a perianth.

2. The change from spiral arrangement of parts, with indefinite numbers, to eyclic arrangements, with fixed numbers.

3. The grouping of parts through zonal growths (coalescence), resulting in syncarpy, perigyny, and epigyny.

4. The change from radial to bilateral symmetry, accompanied by dorsiventrality.

5. To these stages in floral evolution should be added the complexity attained by the massing of numerous flowers in groups or heads (Sec. 165), as in the composite family (daisies, sunflowers, etc.). In the highest expressions of this development the flowers are differentiated so that the outermost of the groups become sterile, but by a remarkable lengthening of their corollas into rays the flower cluster becomes very conspicuous.

All flowers do not, by any means, follow the order of evolution as outlined above, and there are very many special irregularities in different groups. Thus certain flowers of the legume family are bilaterally symmetrical and dorsiventral, but there is no epigyny. It is important to note that the higher levels of flower evolution have been developer again and again in unrelated groups of angiosperms entirely independently one of another 
(as, for example, among the orehids, the legumes, the snapdragons, the mints, etc.). While there is generally an upward evolution of flowers, espeeially when insect-pollinated, there are in some groups numerous illustrations of floral degeneration.

\section{THE CLASSIFICATION OF THE ANGIOSPERMS}

369. The classification of the angiosperms. ${ }^{1}$ The subdivision Angiospermee eontains two classes:

Class I. The monocotyledons, or Monocotyledonere, with an embryo having a single eotyledon and a lateral growing point.

CLAss II. The dicotyledons, or Dicotyledonere, with an embryo having generally two cotyledons and a terminal growing point.

SUB-Class 1. The Archichlamydece (ineaning primitive floral envelopes), in which the perianth is wanting, or, if present, has its parts entirely separate from one another.

SuB-Class 2. The Metachlumydece (meaning later floral envelopes), or Sympetalce, in which the petals are united or borne on tubular, eup-like, or other forms of zonal outgrowths from the receptacle (Sec. 152):

370. The monocotyledons. Besides having the single eotyledon in the embryo, this group is distinguished from the dicotyledons by having a stem structure, with scattered fil,ro-vascular bundles, instead of a cyclic arrangement. Consequently there can be no development of a central shaft of wood surrounded by a cylinder of bast, with a eambium tissue lying between the two, as is eommonly found in the larger dieotyledons. The leaves are generally closed (parallel) veined instead of open (netted) veined, and rarely notehed, which means that their fibro-vascular bundles eome together at the tip. or along the edge of the leaf, instead of ending freely as they do in the dicotylectons. The parts of the flower are generally in three or multiples of three.

1 The most generally accepted classifieation of the angiosperms is that of Engler. presented in the Syllabus der Pflanzenfamilien, 1907. $\Lambda$ brief stateinent of the ehief features of this system will be fouml in Coulter and Clamberlain, Morphology of Angiosperms, 1903. 
There are more than 20,000 species of monocotyledons, which are arranged by Engler into 11 orders, the chief of which are:

1. The grass and sedge order, Graminales, including more than 6000 species, one of the most successful assemblages of angiosperms and by far the largest in the number of individuals.

2. The palm order, Palmales, a very characteristic tropical and sub-tropical group.

3. The lily order, Liliales, a large group of almost 5000 species, remarkable for the showiness and symmetry of its flower's.

4. The orchid order, Orehidales, containing the large orchid family with more than 5000 species, the largest family in the Monoeotyledonea, and one of the most remarkable groups of seed plants for the beauty and complexity of its flowers and for its peculiar life habits.

371. The dicotyledons. Besides liaving two cotyledons in the embryo, this group is distinguished from the monocotyledons by having its fibro-rascular bundles formed in a circle. This arrangement makes possible the development of a central shaft of wood (xylem), since the cambium regions of the bundles unite into a cylinder which adds successive layers of wood if the plant is perennial. The bundles in the leaves are strongly developed, much branched, and end freely, so that the leaves are conspicuously open (netted) reined, generally notched, and frequently deeply divided, or compound. The parts of the flowers are mostly in fours and fives in the higher types, except that the number of carpels is conmonly less.

There are more than 100,000 species of dicotyledons, and these are arranged by Engler.into 38 orders (28 in the Archiehlamyder, and 8 in the Metaehlamydec).

372. The Archichlamydeæ. This sub-class is an immense assemblage, very diverse in character, whose flowers range from primitive types, with indefinite numbers of parts in spiral arrangements, to cyclic flowers with definite numbers, perigyny, epigyny, and synearpy. Some of the chief orders are: 
1. The trce orders, including the willows and poplars (Salicalcs); the walnuts and hickories (Juglandales); the birches, alders, becch, chestnut, and oaks (Fagalcs); the elms, figs, mulberries, etc. (Urticalcs).

2. The buttercup order, Ramuneulales, a large assemblage of about 4000 species, full of interesting gradations in floral evolution, the buttercup family (Ranunculacec) being an especially good group for such studies.

3. The poppy order, Puparerales, comprising the poppies and the large mustard family.

4. The rose order, Rosalcs, an immense group of over 14,000 species, with several large families, such as the legume or pea family, the rose family, etc. The flowers present a greater range of structure than in the buttercup order. Some large groups in the legume family have flowers with well-developed bilateral symmetry and dorsiventrality.

5. The geranium order, Geranialcs, containing the geraniums, flax, Euphorbias, etc.

6. The violet order, Violales, comprising a large number of families and more than 4000 species.

7. The cactus order, Cactalcs, a very remarkable American group of more than 900 species, mostly adapted to desert conditions.

8. The umbel order, Umbellalcs, containing more than 2500 species, mostly in the umbel (parsley') and dogwood families, the highest order in the series of the Archichlamydee on account of its cpigynous flowers, the reduced number of carpels, and the massing of the flowers in the characteristic umbel, or in close leads surrounded by a corolla-like involucrc of bracts, as in the dogwoods (Cornacece, see Frontispicce).

373. The Metachlamydeæ. The gencral flower characters of this sub-class are cyclic arrangements of parts with definite numbers, perigyny or epigyny, and a reduced number of carpels in the compound pistil (synearpy). The corollas are usually showy, the petals being borne on tubular or cup-like outgrowths 
(sympetaly). The stamens are usually also borne on the same outgrowth with the petals, so that they appear to arise from them (epipctuly). The chief orders are:

1. The erical order, Ericalcs, containing the heath family, a very characteristic group in the northerly parts of America, Europe, and Asia, especially in the mountains.

2. The gentian order, Gentianales, with more than 4000 species, including the gcntians, olive family, milkweeds, etc.

3. The phlox order, Polcmonialcs, with more than 14,500 species, containing a number of prominent families, as the phloxes, borrages, nightshades, figworts, mints, verbenas, and other's. The two-lipped flowers of the mints, figworts, etc., distinguish these families among the Mctachlamydew as the legumes are distinguished among the Archichlamydca, and the orchids among the monocotyledons.

4. The madder order, Rubialcs, including the large madder family, the honeysuckles, the valerian family, and the teasels.

5. The bellwort order, Campanulalcs, containing the highest of all angiosperm families, the Composite, the largest in the number of species (more than 12,000), and one of the most successful groups of plants.

\section{SUMLARY OF THE SPERMATOPHYTES AND THEIR} ADVANCES OVER THE PTERIDOPHYTES

374. Summary of the spermatophytes. The chief characters of the spermatophytes and their advances over the pteridophytes are:

1. The retention of the megaspore as an intimate part of the megasporangium (nucellus) to become the embryo sac, and the development of the fcmale gametophyte parasitically within this structurc. The degerieration of the female gametophyte in the angiosperms to a group of nuclei within the cmbryo sac.

2. The origin of the ovule as a new structure from the megasporangium (nucellus), together with enveloping integuments. 
3. The development of the pollen tube from the microspore (pollen grain) as a result of the habit of pollination, by which microspores enter the micropyles of the orules in gymnosperms, and fall upon a receptive structure, the stigma, in angiosperms.

4. The degeneration of the male gametophyte until it is liardly more than a group of nuclei, with accompanying protoplasm, in the pollen grain and its tube. The degeneration of the motile sperms until they are represented by two sperm nuclei alone (cycads and Ginkgo excepted, Sec. 348), which are carried by the pollen tube into the embryo sac.

5. The development and retention of the embryo sporophyte within the embryo sac, and the ripening of the orule into the seed.

6. The massing of the sporophylls on the shoot, accompanied by envelopes which constitute the perianth of the flower. The development in the angiosperms of the megasporophyll, or carpel, into the simple pistil, and the grouping of carpels through zonal growth (syncarpy) to form the compound pistil, so that the ovules become inclosed in an ovule case (ovary). The differentiation of a receptive surface, the stigma, on the pistil upon which the pollen grain may germinate.

7. The differentiation of the parts of the perianth into sepals and petals, and their grouping through zonal growth, together with the stamens, to give perigyny, epigyny, sympetaly, synsepaly, and epipetaly. The development of bilateral symmetry and dorsiventrality.

8. A general development of the sporophytes in many particulars, giving them much greater complexities of tissue structure, growth, and form than those of the pteridophytes. 


\section{CHAPTER XXIX}

\section{THE EVOLUTION OF THE SPOROPHYTE AND DEGENERATION OF THE GAMETOPHYTE}

375. The evolution of the sporophyte. Alternation of generations had its beginnings among the thallophytes, and is clearly shown in the life histories of the red alga and the sac fungi, but is not so conspicuous there as in the higher divisions of the plant kingdom. Furthermore, the sporophyte generations of these thallophytes do not seem to be related to the sporophytes of the liverworts and the groups above them, but are probably of independent origin.

Consequently the line of evolution, with the remarkable development of the sporophyte and degeneration of the gametophyte, as illustrated by the pteridophytes and spermatophytes, really had its beginning in the lower bryophytes and in the algal ancestry, probably Chlorophycea, from which they were derived. This algal ancestry, however, is not known, for there are no living algre that have the combination of characters which would be expected of the ancestors of the bryophytes, - namely, the multicelhular sexnal organs, together with clearly established sporophyte and gametophyte phases in the life histories.

The bryophytes were responsible for the first great steps in the evolution of the sporophyte toward the conditions presented in the ferns and seed plants. All of the sporophytes of the liverworts and mosses are to a great extent parasitic upon the gametophytes; that is, they take water from them, and probably certain foods in solution. Two important advances appeared in the bryophytes.

First. The spore-forming tissue gradually came to occupy a relatively smaller part of the sporophyte (compare the sporophytes 
of the Riccia group with those of Marchantia, Porella, and Anthoccros). Thus tissue which originally developel spores, or had spore-forming possibilities, hecane set apart for vegretative functions alone. In this manner the foot and stalk became established in Marchantice and Porella, and the leavy walls of the spore case in Anthoceros. This principle has been called the "sterilization of potential sporogenous tissue," but a simple: expression would be "the assumption of vegetative functions by tissues with spore-forming possibilities."

Sccond. Portions of the chlorophyll-bearing regions of the sporophytes developed stomata as in Anthoceros and certain inosses, and this was the first appearance of the elaborate meehanism for ehloroplyll work (photosynthesis), which later beeame so highly developed in the leaves of ferns and seed plants.

The pteridophytes carried the advance inuch farther, through the third, fourth, fifth, and sixth great steps in the development of the sporophyte.

Third. The sporophyte became independent of the gametuplyte by developing roots, and to these adder stems and fronds.

Fourth. This condition was associated with the differentiation of a vascular tissue that made it possible for the sporopliyte to grow to a considerable height above the ground, (1) by enabling it to inaintain a comnection with a water supply through the roots, and (2) by providing it with a strong framework throughout the stem and leaves. In their strengthening functions the fibro-vaseular bundles were greatly assisted by the development of rigid tissues (sehlerenclyma). In other respects, also, the entire tissue structure, or lnistology, of the sporophyte became much more complicated.

Fifth. Fronds were differentiated into spore leaves, ol sporophylls, and vegetative, or foliage leaves. The spore leaves became grouped into cones, and by heterospory were differentiated into microsporophylls and megasporophylls.

Sixth. The embryo sporophyte of heterosporous pteridophytes, through the shortening of the gametophytic phases, came to use 
and depend upon food stored in the megaspores by the previous sporophyte generation.

The spermatophytes added the final stages in the evolution of the sporophyte, as follows:

Serenth. The orule arose through the retention of the megaspore (embryo sac) in the negasporangium (nucellus) inelosed by integuments. The development of the embryo sporophyte within the embryo sae, and the ripening of the orule, produced the seed.

Eighth. The ovinle case, or ovary, appeared with the development from one or more megasporophylls, or zarpels (frequently with adjacent tissue), of an inclosing strueture, the pistil, upon which was differentiated a speeial region, the stigma, for the reception of the pollen.

Ninth. The stamen was developed from the mierosporophyll.

Tenth. Complicated flowers arose by various groupings of the carpels and stamens, together with.showy or proteetive envelopes constituting the perianth.

Elexenth. The flower cluster, or inflorescenee, appeared, eulminating in the composite head.

Tuelfth. The tissues of the spermatophytes became more eoinplicated in many respects than those of the pteridophytes.

376. The degeneration of the gametophyte. Many steps in the degeneration of the gametophyte were closely related to the adrances of the sporophyte.

In most of the bryophytes the gametophytes appear as organisms equally complex with the sporophytes, and in many forms they are more complex. Thus the gametophytes of the mosses and leafy liverworts show a considerable advanee orer the thalloid gametophytes of the simple bryophytes. The thalloid gametophyte, howerer, seems to have been the type that was passed over to the pteridophytes, and Anthoceros probably gives a fair idea of the relative eomplexity of the two generations at the time when the first pteridophytes arose. 
The beginnings of the degeneration of the gametophyte beeame clearly evident in the pteridophytes when the relatively small and simple prothallium took the place of the large gametophytes, as illustrated in the Riccia and Marchantia groups. Its further simplifieation was greatly aecelerated by heterospory, passing through four prominent stages:

First. Dependenee upon food stored in the mierospore and inegaspore, together with gradual loss of ehlorophyll, redueed the gametophytes to small struetures producing relatively few sexual organs and gametes. Thus the gametophytes in the pteridophytes became dependent upon food supplied by the sporophytes by way of the spores, - a relation exactly the reverse of that in the bryophytes.

Second. The gametophytes became differentiated as male and female in sex, assoeiated with the mierospores and megaspores, respeetively.

The spermatophytes, by means of the seed habit, brought about the greatest changes in the gametophytes, as follows:

Third. The female gametophyte degenerated to sueh an extcnt by the retention of the megaspore (embryo sac) in the megasporangium (nucellus) that the archegouium lost its form and finally became represented in its essentials by the egg alone. The regctative tissue beeame redueed until only a few nuelei of uneertain relationship (antipodal and polar nuclei) remain.

Fourth. The male gametophyte degenerated in strueture in a similar nanner until the antheridium disappeared, and the numerous ciliated sperms of the pteridophytes were represerted iy only two sperm nuclei, with associated protop'ssin. Vegetative tissue was reduced until only a single nuclius remained in the augiosperms to represent sterile cells of a male gametophyte.

There arose, however, by means of the seed habit an activity on the part of the male gametophyte which is one of the most remarkable developments in plant cvolution. The appearanee of the pollen tube, with its parasitic relations to the sporophyte, is a very complex life relation. This was the chief cause of floral 
evolution, with all its wonderful diversities of form and structure in relation to insect life, — diversities assumed to carry out the relation of flowers to insect carriers of pollen.

Part II of this work has given an outline of the evolution and classification of plants based on comparative stuclies of their morphology. The conclusions are necessarily speculative and philosophical, for we have no means of knowing exactly what has happened throughout the geological ages. The fossil remains of plants are very helpful in certain groups, as the pteridophytes and spermatophytes, but they are fragmentary and relatively few, except for such periods as those when coal or coal-like deposits were formed. Consequently our conclusions as to the evolutionary listory of plants must be founded chiefly on studies of life histories and the comparative morphology of living groups. In spite of difficulties, the plant morphologist lias been able to establish a classification of plants, based on kinship, so as to determine tlie framework of evolutionary lines with remarkable clearness, and these conclusions give to botany its chief interest on the side of morphology. It is not strange that the development of exact ideas in regard to plant evolution should have lagged behind the progress made in that line in animal evolution, since the paleontological evidence available for the botanist, as above stated, is so scanty. It is only within a very few years that any attempt has been made to introduce beginuers in botany to the evolutionary history of plants, and popular knowledge of the subject is now no farther advanced than was knowledge of animal evolution more than thirty years ago. 


\section{Part III}

\section{ECOLOGY AND ECONOMIC BOTANY}

\section{CHAPTER XXX}

\section{PARASITES AND CARNIVOROUS PLANTS}

377. Ecology.* Plant ecology discusses the way in which plants get on with their animal and plant neighbors and, above all, the way in which they adjust themselves to the nature of the soil and climate in which they live. Ecology, in short, treats of the relations of plants to the world about them. A good deal of what has been said in previous chapters on such topics as parasitic plants, climbing plants, the movements of leaves, the coating of hairs on stems and leaves, the storage of water in epidermis cells, is rcally ecological botany, although it is not so designated in the sections where it occurs. It is evident enough that much of the subject-matter of ecology is merely a special department of physiology, but another portion of it forms an important part of plant geography.

378. Parasites. By the term parasite in botany, a plant is meant which draws its food supply wholly or partially from another living plant or animal called the host. In Sec. 29 the life lisstory of a familiar parasite, the dodder, was briefly sketched, and the parasitic fungi among spore plants have been discussed in Chapter Xxir.

* To тив Ixstructon: The treatment of the subject of ecology will pertain almost entirely to seed plants. Many eeologieal topies relating to spore plants have been discussed under the various groups described in Part II. 
379. Half-parasitic seed plants. Half parasites, or partial parasites, are those which take a portion of their food, or of raw matcrials to make food, from thcir host and manufacture the rest for themsclves. Usually they take mainly the newly absorbed soil water from the host and do their own starch making by combining the carbon dioxide, which they absorb through their leaves, with the water stolen by the parasitic roots, or haustoria, imbedded in the wood of the host. Evidently the needed water may just as well be taken from the underground parts of the host as from the upper portions, and accordingly many half parasites are parasitic on roots. This is the case with many of the beautiful false foxgloves (Gerardia), with the painted cup (Castillea), and some species of false toadflax (Comandru) and some orchids. Usually these root, parasites are not recognized by non-botanical people as para. sites at all, but in Germany a species common in grain fields* and the eyebright, which abounds in grass fields, are respectively. known as "hunger" and "milk thief," from the injury they do to the plants on which they fasten themselves. The mistletoe is a familiar example of a half parasite which roots on branches. Among the scanty belts of cottonwood trees along streams in New Mexico it is necessary to lop off the mistletoe every year to give the tree any chance to grow. Half parasites may be known from plants that are fully parasitic by having green or greenish foliage, while complete parasites have no chlorophyll and so are not at all green.

380. Wholly parasitic seed plants. These are so nearly destitute of the power of photosynthesis that they must rob other plants of all needed food or die of starvation. Some, like the cancer root (Orobanche), are root parasites; others, like the dodder (Fig. 16), are parasitic on stems above ground. The most dependent species of all, such as the flax dodder, can lives on only one kind of host, while the coarse orange-stemmed

1 See Bergen, Flora of the Northeastern States.

2 Alectorolophis hirsutus. 
dodder, ${ }^{1}$ which is common all over the central and the northeastern states, grows freely on many kinds of plants, from golden-rods to willows.

381. Saprophytes. A saprophyte (meaning decay plant) is a plant of which the nutrition is largely or wholly dependent on the absorption of organic material, usually when in a state of fermentation or decay. Most plants of this kind are fungi (Chapter XxiI), but there are a few saprophytic spermatophytes. Plants like the Indian pipe (Honotropa), of coniferous wools, appear often to be symbiotic saprophytes, their mycorrhiza absorbing much from the decaying materials in which they are rooted. Such plants, destitute of chlorophyll, can do no photosynthetic work.

382. Carnivorous plants. In the ordinary pitcher plants (Fig. 311) the leaf appears in the shape of a more or less hooded pitcher. These pitchers are usually partly filled with water, and in this water very many drowned and decaying

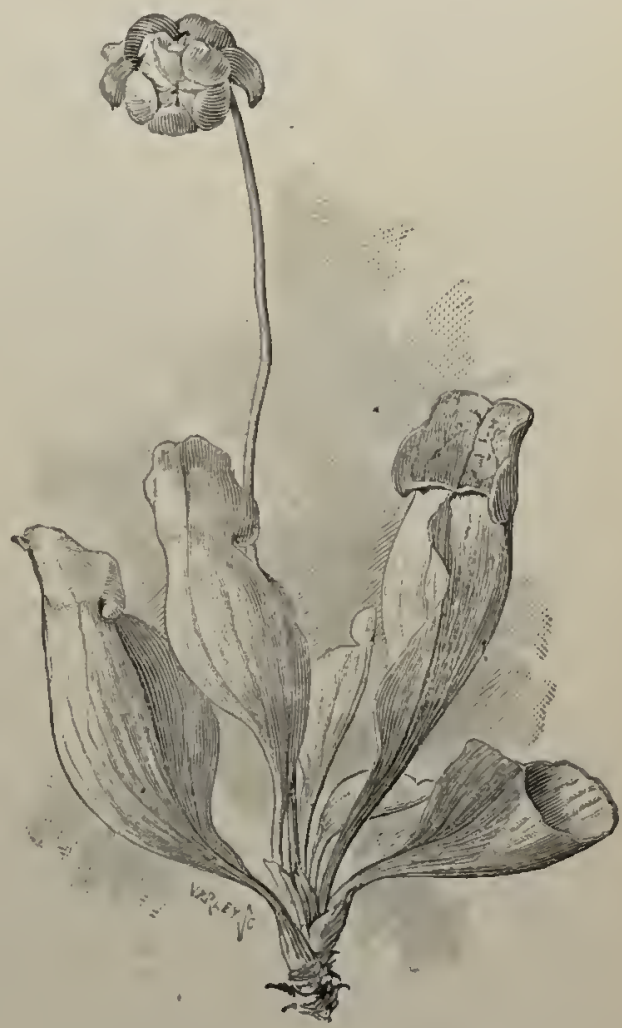

FIG. 311. Common pitcher plant (Sarracenia purpurea)

At the right, one of the pitcher-like leaves is shown in cross section insects are commonly to be found. The insects have flown or crawled into the pitcher, and, once inside, have been unable to escape on account of the dense growth of bristly hairs about the mouth, all pointing inward and downward. How much the

${ }^{1}$ Cuscuta Gronovii. 


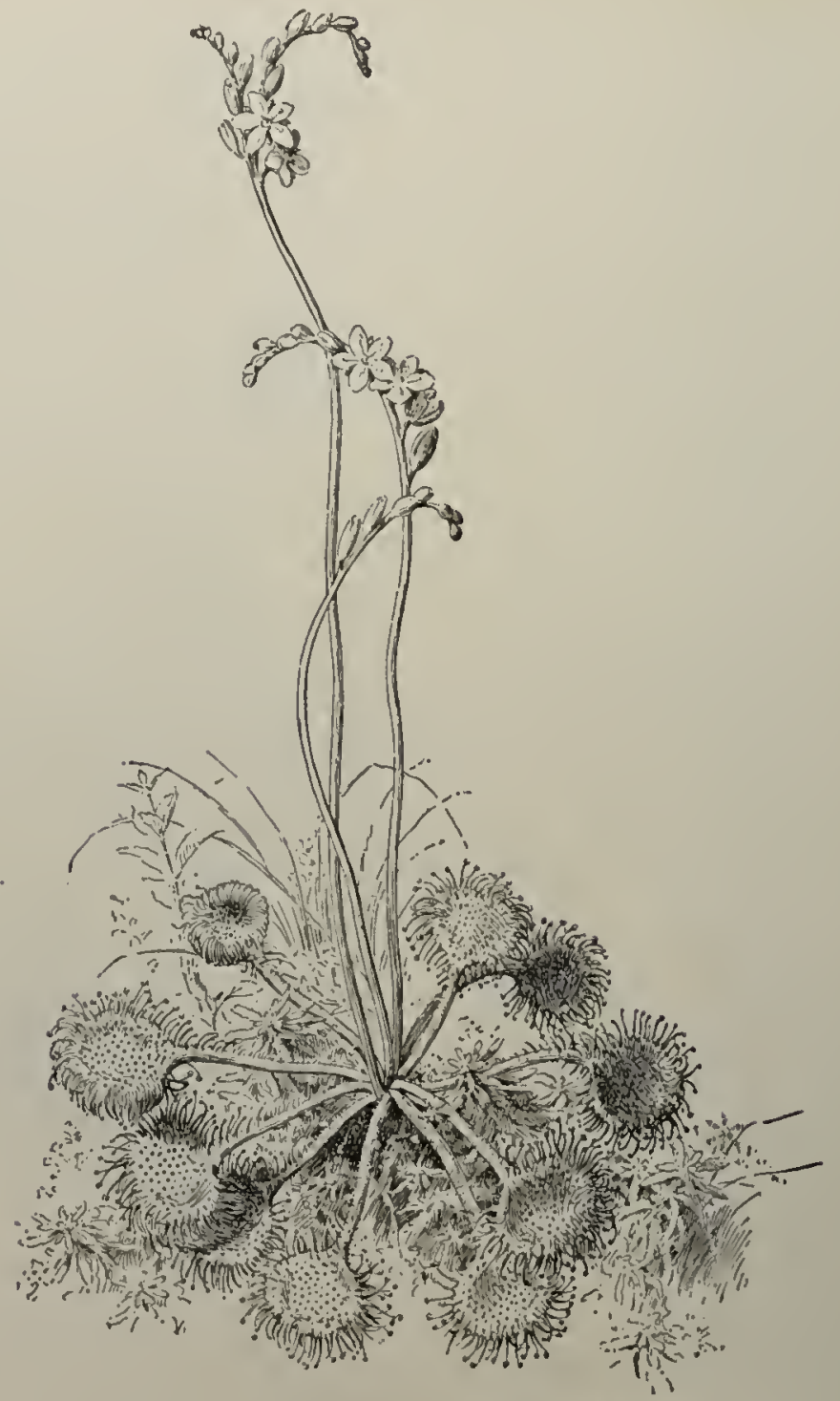

FIG. 312. Sundew (Droscra rotundifolia)

common American pitcher plants depend for nourishment on the drowned insects in the pitchers is not definitely known, but it is certain that some of the tropical species require such food. ${ }^{1}$

1 Where the Sarracenia is abundant it will be found interesting and profitable to make a careful class study of its leaves. Sce Geddes, Chapters in Modern Botany, Chapters I and II. 
In other rather common plants, the sundews, insects are caught by a sticky secretion which proceeds from hairs on the leaves. In one of the conmonest sundews (Fig. 312) the leaves consist of a roundish blade, borne on a moderately long petiole. On the inner surface and round the margin of the blade are borne a considerable number of short bristles, each terminating in a knob, which is covered with a clear, sticky liquid. When a small insect touches one of the sticky knobs it is held fast, and the hairs at once begin to close over it, as slown in Fig. 313. Here it soon dies and then usually remains for many days, while the leaf pours out a juice by which the soluble parts of the insect are digested. The liquid containing the digested portions is then absorbed by the leaf and contributes an important part of the nourishment of the plant, while the undigested
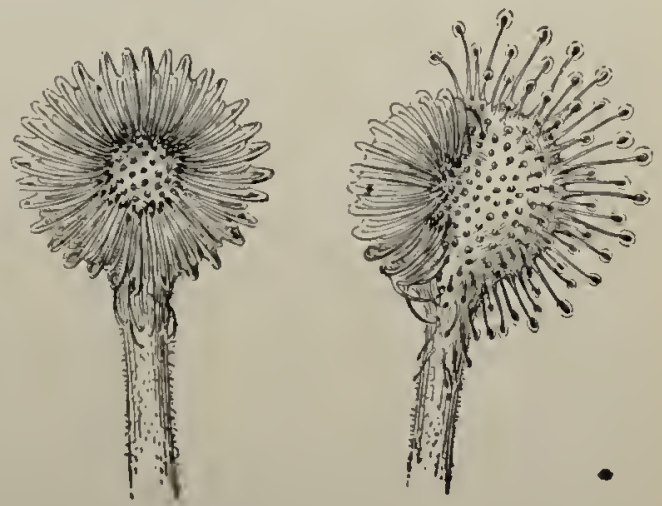

Fir. 313. Leaves of sundew

The one at the left has all its tentacles closed over captured prey; the one at the right has only half of them thus closed. Somewhat magnified. - After Darwin

fragments, such as legs, wing cases, and so on, remain on the surface of the leaf or may drop off after the hairs let go their hold on the captive insect.

In the Venus flytrap, which grows in the sandy regions of eastern North Carolina, the mechanism for catching insects is still more remarkable. 'The leaves, as shown in Fig. 314, terminate in a hinged portion, which is surrounded by a fringe of stiff bristles. On the inside of each half of the trap grow three short lairs. The trap is so sensitive that when these hairs are touched it closes with a jerk and very gencrally succeeds in eapturing the fly or other insect which has sprung it. The imprisoned insect then dies and is digested, somewhat as in the 
case of those cauglit by the sundew, after which the trap reopens and is ready for fresli captures.

383. Object of catching animal food. It is easy to understand why a good many kinds of plants have taken to catching insects and absorbing the digested products. Carnivorous, or flesh-eating, plants belong usually to one of two classes as

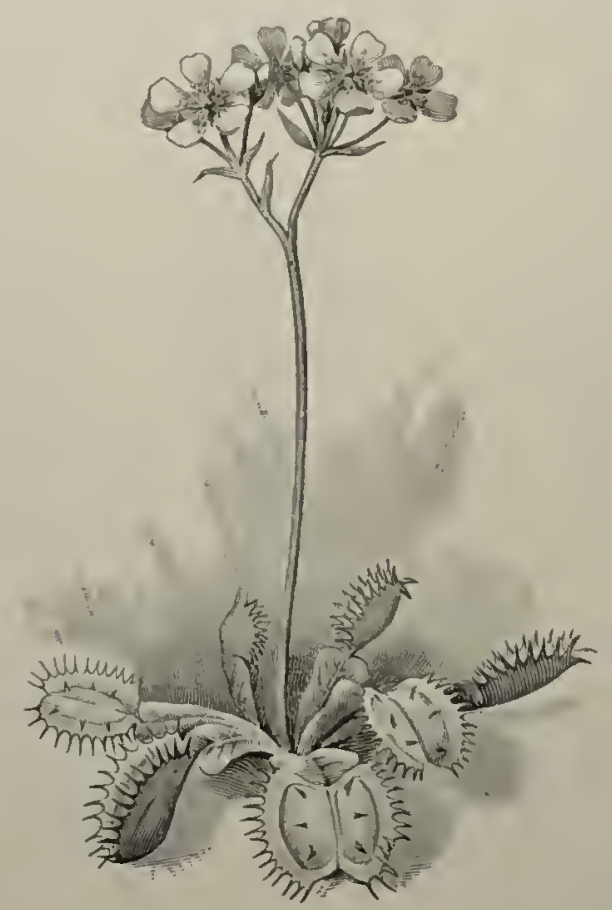

FIa. 314. Venus flytrap (Dioncea muscipula)

regards their place of growth; they are bog plants or air plants. In either case their roots fiud it difficult to secure much nitrogencontaining food, - that is, much food out of which proteid material can be built up. Animal food, being itself largely proteid, is adinirably adapted to nourish the growing parts of plants, and those which could develop insect-catching powers would stand a far better chance to exist as air plants or in the thin, watery soil of bogs than plants which had acquired no such resources. 


\section{CHAPTER XXXI}

\section{HOW PLANTS PROTECT THEMSELVES FROM ANIMALS}

384. Destruction by animals. All animals are supported directly or indirectly by plants. In some cases the animal secures its food without much damage to the plant on which it feeds. Browsing on the lower branches of a trce may do it little injury, and grazing animals, if not numerous, may not seriously harm the pasture in which they feed. Fruit-eating animals may even be of much service by dispersing seeds (Sec. 420). But seed-eating birds and quadrupeds, animals which (like the hog) dig up fleshy roots, rootstocks, tubcrs, or bulbs, and eait them, or animals which (like the sheep) graze so closely as to expose the roots of grasses or even of forest trees to be parchcd by the sun, destroy immense numbers of plants. Many trees, as the apple, peach, and black locust, have the trunk fatally weakened by the boring larve of insects. Lcaf-eating insects, such as grasshoppers and caterpillars, cause immense damage to foliage, and others, like the chinch bug so destructive to grain crops, suck the juices from roots, stems, or leaves.

385. Some modes of protection from animals. Many of the characteristics of plants may be wholly or partly duc to adaptations for protective purposes, whilc in particular cases we cannot be sure of the fact. Perching on lofty rocks or on branches of trees, burying the perennial part (bulb, rootstock, etc.) undcrground, growing in dense masses, like a cancbrake or a thicket of blackberry bushes, - all such habits of plants may be partly or altogether valuable to the plant as means of avoiding the attacks of animals, but this cannot be proved. On the other hand, there are plenty of instances of structures, habits, or accumulations of stored material in their tissue which plants seem 
to have acquired mainly or entirely as means of defense. Some of the most important are:

1. The habit of keeping a bodyguard of ants.

2. Forming tough, corky, woody, limy, or flinty, and therefore nearly uneatable, tissue.

3. Arming exposed parts with cutting edges, sharp or stinging hairs, prickles, or thorns.

4. Accumulating unpleasant or poisonous substances in exposed parts.

386. Ant plants. Some ants live on vegetable food, but most of them eat only animal food, and these latter are extremely voracious. It has been estimated by a careful scientist, an

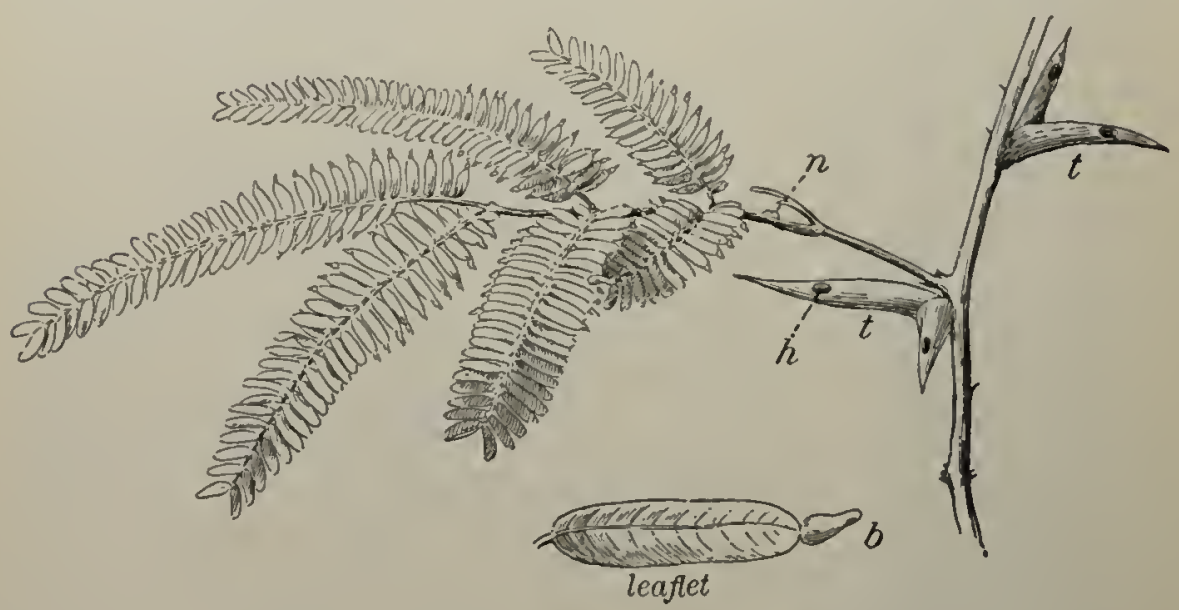

FIG. 315. An ant plant (Acacia spharocephala)

$\ell$, thorns; $h$, hole in thorn; $n$, nectary; $b$, Belt's body on tip of leaflet.-After Schimper

authority on this subject, that the ants of a single nest sometimes destroy as many as one hundred thousand insects in a day. The Chinese orange growers in the province of Canton have found how useful ants may be as destroyers of other insects, and so they place ant nests in the orange trees and extend bamboos across from one tree to another, to serve as bridges for the ants to travel on. 
Certain tropical trees offer ants special inducements to establish colonies on their trunks and branches. The attractions which are offered to ants by various kinds of trees differ greatly. One of the most interesting adaptations is that of an acacia (Fig. 315), which furnishes little growths at the ends of the leaflets which serve as ant food. These little growths are known from their discoverer as Belt's bolies. The ants bore holes into the large, hollow, stipular thorns shown in the figure, live in these thorns, fced on the Belt's bodies, and protect the acacia from insect and other enemies. A nectary on the leaf furnishes additional food to the ant inhabitants of the tree. A great multitude of plants, some of them herbs, offer norc or less important inducements to attract ant visitors; the specics which are known to do this number over three thousand. ${ }^{\mathrm{I}}$

387. Plants of uneatable texture. Whenever tender and. juicy herbage is to be had, plants of hard and stringy texture are left untouclied by grazing animals. The flinty-stemmed horsetails (Equisetum, Sec. 316) and the dry, tough rushes are familiar examples of uneatable plants of damp soil. In pastures there grow such perennials as the bracken fern and thc hardlack of New England and the ironweed and vervains of the central statcs, which are so harsh and woody that the hungriest browsing animal is rarely, if evcr, seen to molest them. Still other plants, like the knotgrass and cinquefoil of our dooryards, are doubly safe, from their growing so close to the ground as to he hard to graze, and from thcir woody and unpalatable nature. The date palm, which can easily be raised from the seed in the botanical laboratory, is an cxcellent instance of the same uneatable quality, found in a tropical or sub-tropical plant. Other good examples are the shrubs of heath lands and of such coriaceous, or leathery-lcafed, thickets as the Australian scrub and the California cliaparral.

1 Possibly in many cases the attractiveness of plants for ants is only incidental and has not been evolved with direct reference to the protection to be rendered by these insects. 
388. Plants with weapons for defense. ${ }^{1}$ Multitudes of plants, which might otherwise have been subject to the attacks of grazing or browsing animals, have acquired what have with reason been called weapons. Siliubs and trees not infrequently produce sharp-pointed branches, familiar in our own crab apple, wild plum, thorn trees, and, above all, in the honey locust (Fig. 35),
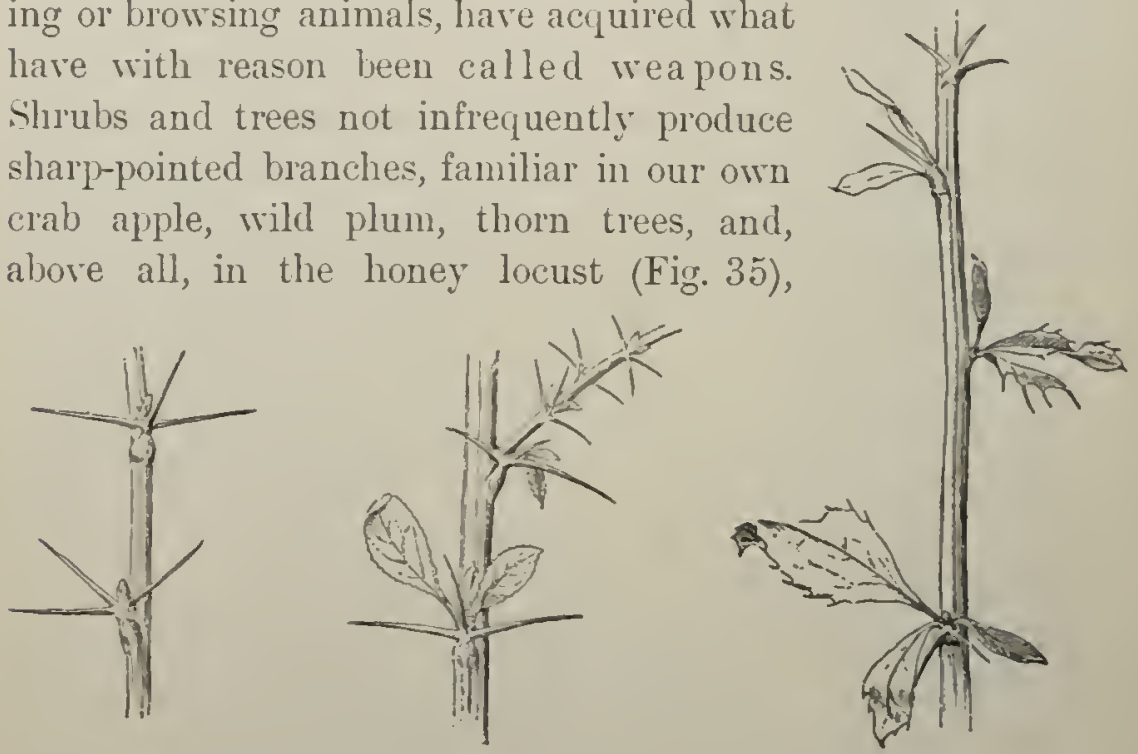

FIG. 316. Spiny leaves of barberry

whose formidable thorus often branch in a rery complicated manner. It is notewortly that the protection given by thor'us

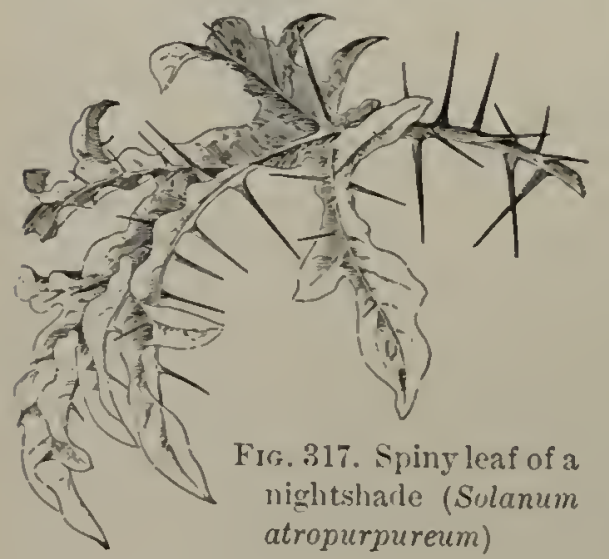
is not from those of the season, but from the dry and hard ones of preceding year's.

Leares modified into thorns are rery perfectly exemplified in the barberry (Fig. 316). It is much commoner, however, to find the leaf extending its midrib or its reins out into spiny points, as the thistle does, or bearing spines or prickles on its midrib, as is the case with some nightshades (Fig. 317) and with so many roses.

1 See Kemer and Oliver, Natural II istory of Plants, Vol. I, p. 430. 
Prickles, which are merely hard, sharp-pointed projections from the epidermis, are of too common occurrence to need illustration.

Thorns are often found to be modified stipules, and in our common locust (Fig. 31,9) the bud, or the very young shoot

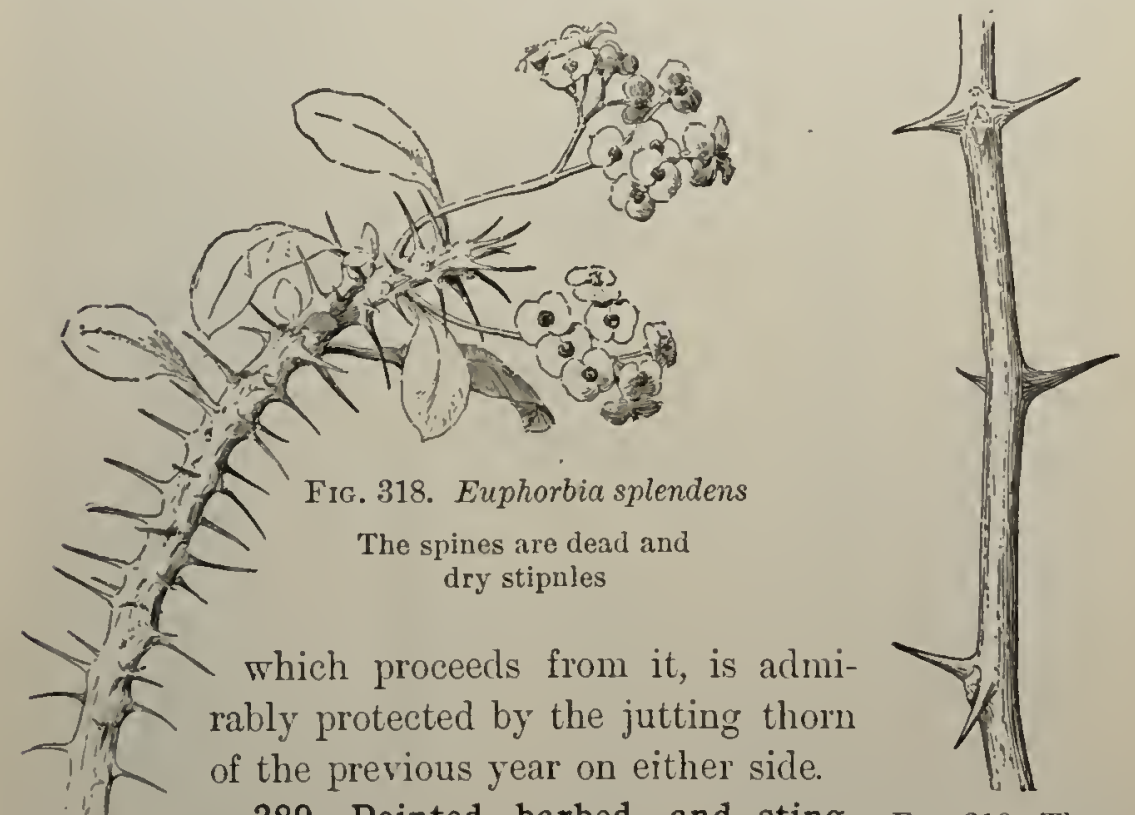

389. Pointed, barbed, and sting- Fig. 319. Thorn ing hairs. On many plants needle- stipules of pointed hairs form efficient defensive weapons. locust

Sometimes these hairs are roughened, like those of the bugloss (Fig. 320, b) ; sometimes they are decidedly barbed. If the barbs are well developed, as they are in the small but formidable bristles of prickly pear cactuses, they may cause the hairs to travel far into the flesh of animals and cause intense pain. In the nettle (Fig. 320,a) the hairs are efficient stings, with a brittle tip, which on breaking off exposes a sharp, jagged tube full of irritating fluid. These tubular hairs, with their poisonous contents, will be found sticking in the skin of the hand or the face after incautious contact with nettles, and the violent itching which follows is only too familiar to most people. 
390. Cutting leaves. Some grasses and sedges are generally avoided by cattle because of the sharp, cutting edges of their leaves, which will readily shit the skin of one's hand if they are drawn rapidly through the fingers. Under the microscope the margins of such leaves are seen to be regularly and thiekly set with sharp teeth like those of a saw (Fig. 320,c, d).
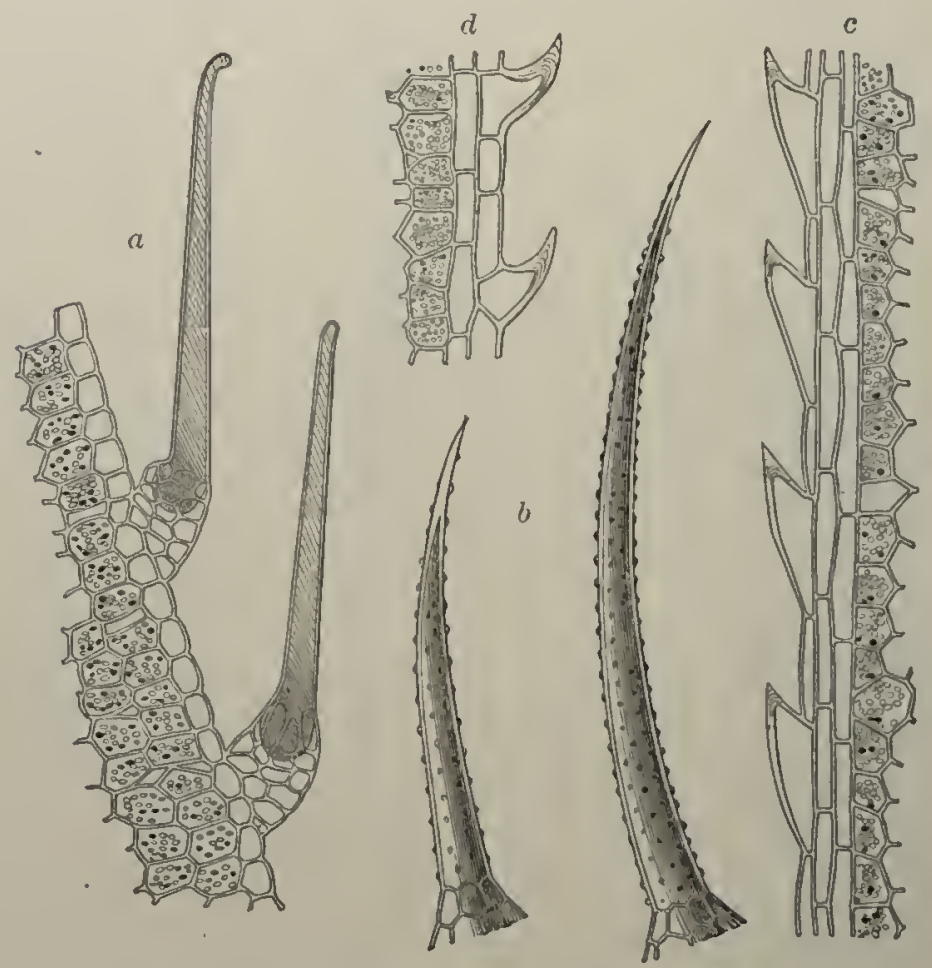

FIG. 320. Stinging hairs and cutting leaves

$a$, stinging hairs on leaf of nettle; $b$, bristle of the bugloss; $c$, barbed margin of

a leaf of selge; $d$, barbed margin of a leaf of grass. All much magnifiel. After Kermer

391. Weapons of desert plants. In temperate regions, where vegetation is usually abundant, such moderate means of protection as have just been described are generally sulticient to insure the safety of the plants which have developed them. But in desert or semi-desert regions the extreme scarcity of plant life especially exposes the few plants that occur there to the attacks 
of herbivorous animals. Accordingly, great numbers of desert plants are characterized by mauseating or poisonous qualities or by the presence of astonishingly developed thorns (Figs. 50, 357 ), while some combine both of these means of defense.

392. Offensive or poisonous plants. A disgusting smell is one of the common saferguards which keep plants from being eaten. The dog fenmel (Fig. 364), the hound's tongue (Cynoglossum), the Martynia, and the tomato plant are common examples of rank-smelling plants which are offensire to most grazing animals and so are let alone by them. Oftentimes, as in the case of the jimson weed (Datura), the tobacco plant, and the poisonous hemlock (Conium), the smell serves as a warning of the poisonous nature of the plant.

A bitter, nauseating, or biting taste protects many plants from destruction by animals. Buckeye, horse-chestnut, and buckthom twigs and leaves are so bitter that browsing animals and most insects let them alone. Tansy, ragweed, boneset, southernwood, and wormwood are safe for the same reason. The nauseous taste of many kinds of leaves and stems, such as those of the potato, and the fiery taste of peppercorns, red peppers, mustard, and horse-radish, make these substances uneatable for most animals. Probably both the smell and the taste of onions serve to insure the safety of the bulbs from the attacks of most grubs, and the hard corm of the jack-in-the-pulpit (Arisama) is carefully let alone on account of the blistering nature of its contents.

Poisonous plants are usually shumned by grown-up animals unless they are famished, though the young ones will sometimes eat such plants and may be killed by them. Almost any part of a poisonous species may contain the poison characteristic of the plant, but, for obvious reasons, such substances are especially apt to be stored in the parts of the plant where its supply of reserve food is kept. 


\section{CHAPTER XXXII}

\section{POLLINATION OF FLOWERS AND PROTECTION OF POLLEN}

393. Topics of the Chapter. The ecology of flowers is concerned mainly with the means by which the transference of pollen, or pollination, is effected, and with the ways in which pollen is kept away from undesirable insect visitors and from rain.

394. Cross pollination and self pollination. It was long supposed by botanists that the pollen of any bisexual flower needed only to be placed on the stigma of the same flower to insure satisfactory fertilization. But in 1857 and 1858 the great English naturalist, Charles Darwin, stated that certain kinds of flowers were entirely dependent for fertilization on the transference of pollen from one plant to another. It was also shown that probably nearly all attractive flowers, even if they can produce some seed when self-pollinated, do far better when pollinated from the flowers of another plant of the same kind. ${ }^{1}$ This inportant fact was established by a long series of experiments on the number and vitality of seeds produced by a flower when treated with its own pollen, or self-pollinated, and when treated with pollen from another flower of the same kind, or crosspollinated. ${ }^{2}$

Another important advantage of cross pollination is that it tends to give the offspring additional variability (Chapter $\mathrm{xI}_{\mathrm{s}}$ ), and thus enables them better to adapt themselves to changing enviromment or to any difficult conditions.

1 See Darwin, Cross and Self Fertilization in the Tegetable Fingdom (especially Chapters I and II).

2 On dispersion of pollen, see Kerner and Oliver, Natural IIstory of Plants, Vol. II, pp. 129-287. 
It should always be kept in mind that many of the most successful plants, including a large number of troublesome weeds, are capable of self pollination.

395. Wind-pollinated flowers. ${ }^{1}$ It has already been mentioned that some pollen is dry and powdery, and other kinds are more or less sticky. Pollen of the dusty sort is light, and therefore adapted to be blown about by the wind. Any one who lias been much in cornfields after the corm lias "tasseled" has noticed the pale yellow, dusty pollen which flies about when a cornstalk is jostled, and which collects in considerable quantities on the blades of the leaves. Corn is monœeious, but fertilization is best accomplished by pollen blown from the "tassel " (stamens) of one plant being carried to the "silk" (stigma and style of the pistils) of another plant. This is well shown by the fact, familiar to every observing farmer's boy, that solitary cornstalks, such as often grow very luxuriantly in an unused barnyard or similar locality, bear very imperfect ears or none at all. The common ragweed is remarkable for the great quantities of pollen which shake off on to the shoes or clothes of the passer-by, and it is wind-pollinated. So, too, are the pines, and these produce so much pollen that it has been mistaken for showers of sulphur, falling often at long distances from the forests where it FIG. 321. Pistil of a grass, was produced. The pistil of wind-pollinated flowers is often feathery and thus adapted to catch flying pollen grains (Fig. 321). Other characteristics of

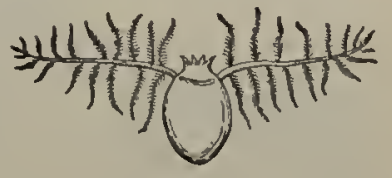
provided with a feathery stigma, adapted for wind-pollination

After Thomé such flowers are the inconspicuous character of their perianth, which is usually green or greenish, the absence of odor and of nectar, the regularity of the corolla, and the development of the flowers before the leaves or their occurrence on stalks raised above the leaves.

${ }^{1}$ See Miss Newell, Botany Reader, Part II, Chapter v1. 
Pollen is, in the case of a few aquatic plants, carried from fluwer to flower by the water in which the plant grows.

396. Insect-pollinated flowers. Most plants which requile cross pollination depend upon insects as pollen carriers, ${ }^{1}$ and it nay be stated as a general fact that the slowy color's and markings of flowers and their odurs all serve as so many advertisements of the nectar (commonly but wrongly called honey) or of the nourishing pollen which the flower has to offer to insect visitors.

Many insects depend mainly or wholly upon the nectar and the pollen of flowers for their food. Such insects usually visit during any given trip only one kind of flower, and therefore carry but one kind of pollen. Going straight from one flower to another with this, they evidently waste far less pollen than the

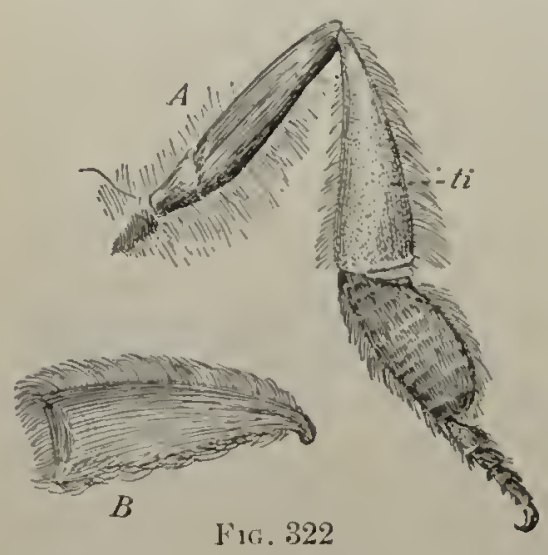

$A$, right hind leg of a honeybee (seen

from behind and within); $B$, the tibia; $t i$, scen from the outside, showing the colleeting basket formed of stiff hairs. - After Müller wind or water must waste. It is therefore clearly advantageous to flowers to develop such adaptations as fit them to attract insect visitors, and to give pollen to the latter and receive it from them.

397. Pollen-carrying apparatus of insects. ${ }^{2}$ Ants and some beetles which visit flowers have smooth bodies, to which little pollen adheres, so that their visits are often of slight value to the flower, but many beetles, all butterflies and moths, and most bees have bodies roughened with scales or hairs, which hold a good deal of pollen entangled. In the common honeybee (and in n11any other kinds) the greater part of the insect is hairy, and there are special collecting baskets, formed by bristle like hairs, on the hind legs (Fig. 322). birds. $\quad 2$ See P. Knuth, Handbuch der Blüthenbiologie, Vol.I.

1 A few are pollinated by snails; many more by liumming birds and other 
It is easy to see the load of pollen accumulated in these baskets after such a bee has visited several flowers. Of course the pollen which the bee packs in the baskets and carries off to the hive, to be stored for food, is of no use in pollination. In fact, such pollen is in one sense entirely wasted. But since such bees as have these collecting baskets arc the most industrious visitors to flowers, they accomplish an immense share of the work of pollination by means of the pollen grains, which stick to their hairy coats and are then transferred to other flowers of the same kind next visited by the bee.

398. Nectar and nectaries. Nectar is a swect liquid which flowers secrete and which attracts insects. After partial digestion in the crop of the bce, nectar becomes honey. Those flowers which seerete nectar usually do so by means of neetar glands, small organs situated often near the base of the flower, as shown in Fig. 323. Sometimes the nectar elings in droplets to the surface of the nectar glands; sometimes it is stored in little eavities or

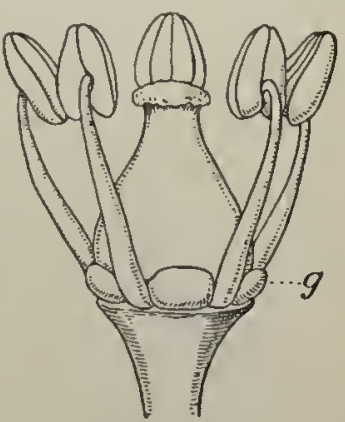

Frg. 823. Stamens and pistil of the grape (magnified), with a nectar gland $g$ between the stamens

After Decaisne pouches called nectaries. The pouches at the bases of columbine petals are annong the most familiar of nectaries.

399. Odors of flowers. The acuteness of the sense of smell among insects is a familiar fact. Flics buzz about the wirc netting which covers a picce of fresh meat or a dish of sirup, and bees, wasps, and hornets will fairly besiege the window screens of a kitehen where preserving is going on. Many plants find it possible to attract as many insect visitor's as they need without giving off any scent perceptible to us, but small flowcrs, like the mignoncttc, and night-blooming ones, like the white tobacco and the evening primrose, are sweet-scented to attract night-flying moths. It is interesting to observe that the majority of the flowers which bloom at night are white or 
yellow, and that they are much more generally sweet-scented than flower's which bloom during the day. Many are odorous during only a few hours of the twenty-four, just at the time when the special insects which pollinate them are on the wing. A few flowers (purplish, brownish, or greenish colored) are carrion-scented and attract flies.

400. Colors of flowers. Flowers which are of any other color than green probably in most eases display their colors to attract insects, or occasionally birds. The principal color of the flower is most frequently due to slowy petals; sometimes, as in the anemone and marsh marigold, it belongs to the sepals; and not infrequently, as in some cornels (Frontispiece) and Euphorbias (Fig. 318), the involucre is more brilliant and conspicuous than any part of the flower strictly so called. In the willows and chestuuts the stamens are the conspicuous parts.

Different kinds of insects appear to be especially attracted by different colors. In general, dull yellow, brownish, or dark purple flowers, especially if small, seem to depend largely on the visits of flies. Red, violet, and blue are the colors by which bees and butterflies are inost readily enticed. The power of bees to distinguish colors has been shown by a most interesting set of experiments in which daubs of honey were put on slips of glass laid on separate pieces of paper, each of a different color, and exposed where bees would find them. ${ }^{1}$

It is certain, however, that colors are less important means of attraction than odors from the fact that insects are extremely near-sighted. Butterflies and moths cannot see distinctly at a distance of more than about five feet, bees and wasps at more than two feet, and flies at more than two and a fourth feet. Probably no insects can make out objects clearly more than six feet away. ${ }^{2}$ Yet it is quite possible that their attention is attracted by colors at distances greater than those mentioned.

1 See Tubbock, Flowers, Fruits, and Lcaves. Chapter I. On the general subject of colors and odors in relation to insects, see P. Knnth, Handbuch der Blithenbiologie.

${ }^{2}$ See Packard, Text-Book of Entomology, p. 260. 
401. Facilities for insect visits. Regular flower's with radial symmetry usually have no special adaptations to make them singly accessible to insects, but lie open to all comers. They do, however, make themselves much more attractive and afford especial inducements in the matter of saving time to flowerflequenting insects by being grouped. This purpose is undoubtedly served by dense flower clusters, such as those of the lilac, the phlox, and the elder, and especially by heads like those of the button bush (Cephalanthus) and by the peculiar form of head found in so-called composite flowers, like the sunflower, the bachelor's button, and the yarrow (Fig. 144). In many such clusters the flowers are specialized, some carrying a showy strap-shaped corolla, to serve as an advertisement of the nectar and pollen contained in the inconspicuous tubular flowers. Flowers with bilateral symmetry probably always are more or less adapted to particular insect (or other) visitors. The adaptations are extremely numerous; here only a very few of the simpler ones will be pointed out. Where there is a drooping lower

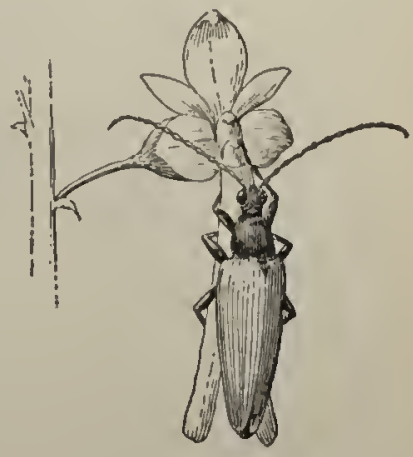

Fir. 324. A beetle on the flower of the twayblade Slightly enlarged.-After Behrens petal or, in the case of a sympetalous corolla, a lower lip, this serves as a pereh upon which flying insects may alight and stand while they explore the flower, as the beetle is doing in Fig. 324. In Fig. 325 one bumblebee stands with her legs partially encircling the lower lip of the dead-nettle flower, while another perehes on the sort of grating made by the stamens of the horse-chestuut flower. The honeybee entering the violet clings to the beautifully bearded portion of the two lateral petals, while she sucks the nectar from the spur beneath. All bilaterally symmetrical flowers seem to be specially adapted to compel visiting insects to enter them in the best way to secure transference of pollen. 
402. Protection of pollen from unwelcome visitors. It is usually desirable for the flower to prevent the entrance of small ereeping insects, such as ants, which carry little pollen and eat a relatively large amount of it. The means adopted to seeure this result are many and eurious. In some plants, as the common catchfly, there is a stieky ring about the pedunele, some distance below the flowers, and this forms an effectual barrier against ants and like insects. In a few plants, as the

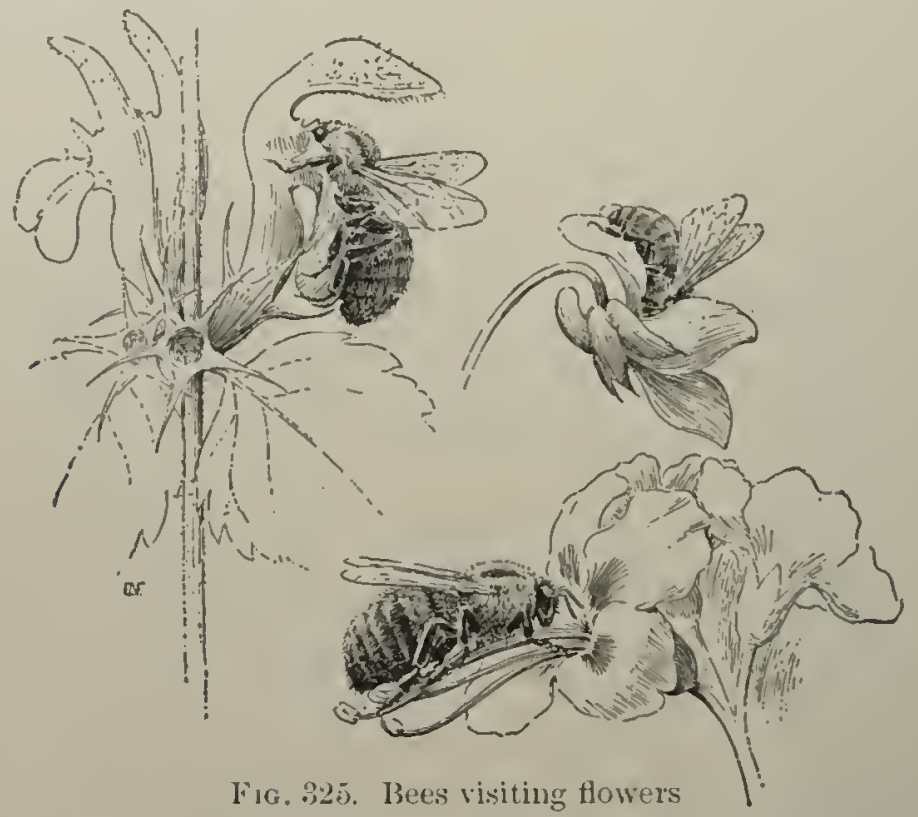

At the left, a bumblebee on the flower of the dead nettle; below, a similar bee in the flower of the horse-chestnut; above, a honeybee in the flower of a violet. Modified. - After Behrens

teasel and the cup plant (Silphium perfoliatum), rain water eolleets at the junetions of the leaves with the stem and forms an effeetual barrier against creeping inseets. Very frequently the calyx tube is coverer with hairs, which are sometimes sticky. How these thickets of hairs may appear to a sma!l insect ean perhaps be realized from Fig. 326.1

1 On protection of pollen, see Kerner and Oliver, Natural History of Plants, Vol. II, pp. 95-109. 
Sometimes the recurved petals or divisions of the corolla stand in the way of creeping insects. In other cases the throat

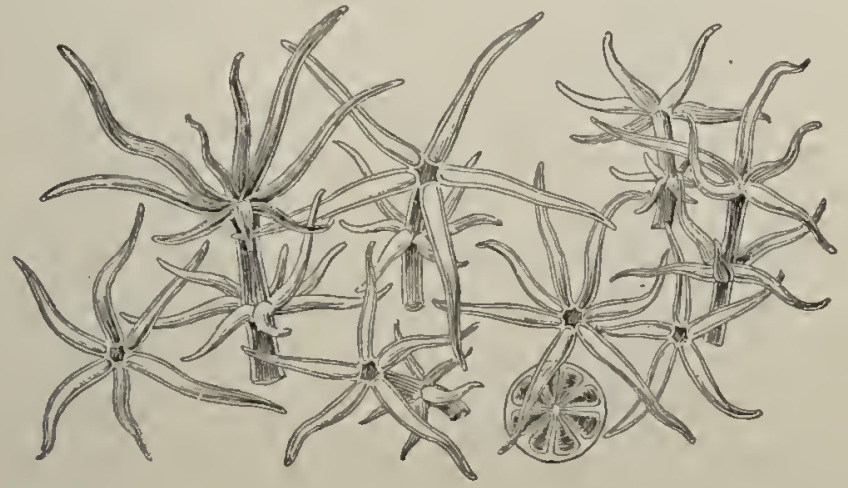

Fic. 326. Branching laairs from the ontside of the corolla of the common mullein

\section{Magnified. - After Tschirch}

of the corolla is much narrowed or closed by hairs, or by appendages. Those flowers which have one or more scpals or petals prolonged into spurs, like the nasturtium and the columbine, are inaccessible to most insects except those which hare

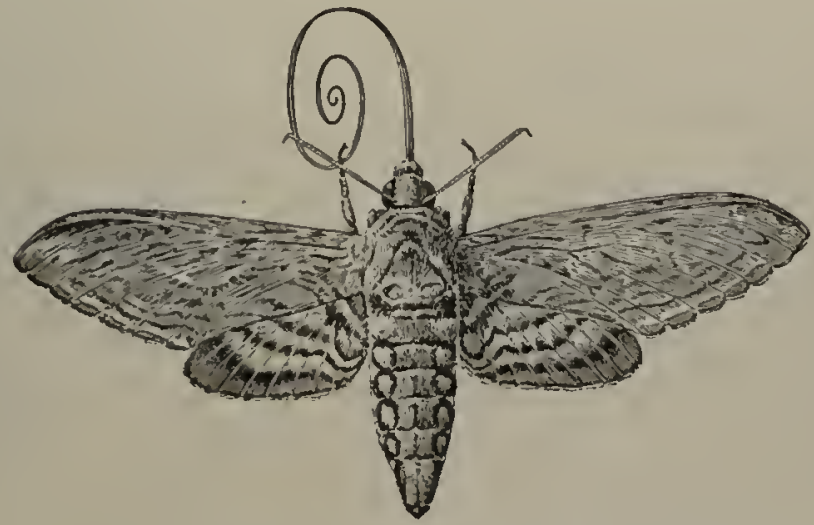

Frg. 327. A sphinx moth, with a long sucking tube

a tongue or a sucking tube long enough to reach to the nectary at the bottom of the spur. The large sphinx moth, shown in Fig. 327, which is a common visitor to the flowers of the 
evening primrose, is an example of an insect especially adapted to reach deep into long tubular flowers.

A little search among flowers, such as those of the columbine and the foxglove, will usually disclose many which have had the corolla bitten through by bees which are unable (or unwilling to talie the trouble) to get at the nectar by fair means, and which therefore steal it.

403. Bird-pollinated flowers. Some flowers with very long tubular corollas depend entirely upon birds to carry their pollen for them. Among garden flowers the gladiolus, the scarlet salvia, the canna, and the trumpet honeysuckle are largely dependent upon humming birds for their pollination. The wild balsam, or jewelweed, the swamp thistle, and the trumpet creeper are also favorite flowers of the humming bird.

404. Prevention of self pollination. Diœcious flowers are, of course, quite incapable of self pollination. Pistillate monocious flowers may be pollinated by staminate ones on the same plant, but this does not secure as good seed as is secured by having pollen brought to the pistil from a different plant of the same kind.

In bisexual flowers self pollination would commonly occur unless it were prevented by the action of the essential organs or by something in the structure of the flower. In reality, many flowers which at first sight would appear to be designed to secure self pollination are almost or quite incapable of it. Frequently the pollen from another plant of the same species prevails over that which the flower may shed on its own pistil, so that when both kinds are placed on the stigma at the same time it is the foreign pollen which causes fertilization. But apart from this fact there are several mcans of insuring the presence of foreign pollen, and only that, upon the stigma, just when it is mature enough to receive pollen tubes.

405. Stamens and pistils maturing at different times. If the stamens mature at a different time from the pistils, self pollination is as effectually prevented as though the plant were 
diceious. This mequal maturing, or dichogamy, oecurs in many kinds of flowers. In some, the figwort and the common plantain for example, the pistil develops before the staineus, but usually the reverse is the case. The Clcrodendron, a tropical African flower (Fis. 328 ), illustrates in a most striking way the development of stamens before the pistil. The insect visitor, on its way to the neetary, ean hardly fail to brush against the protruding stamens of the flower in its earlier stage, $A$, but it cannot deposit any pollen on the stigmas, whieh are imma-

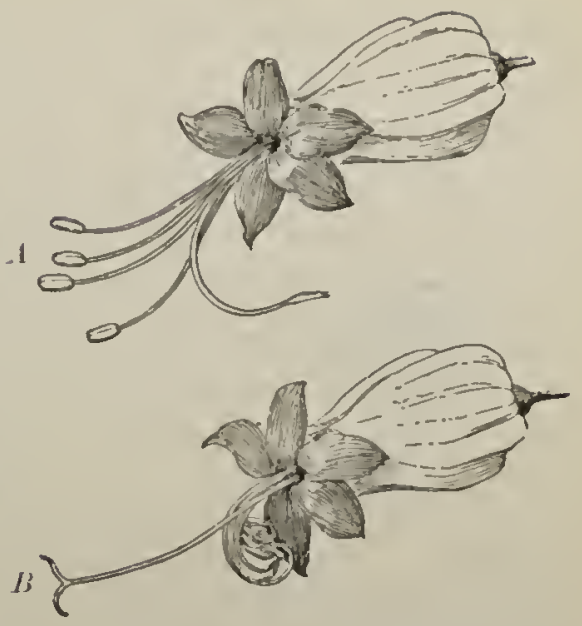

Fur. 328. Flower of Clerodendron int two stages

In $A$ (earlier stage) the stamens are mature, while the pistil is still undereloped and bent to one sile. In $B$ (later stage) the stamens liave withered, and the stigmas havo separated, realy for the reception of pollen. - After Gray ture, shut together, and tueked aside out of reach. On flying to a flower in the later stage the pollen just acquired will be
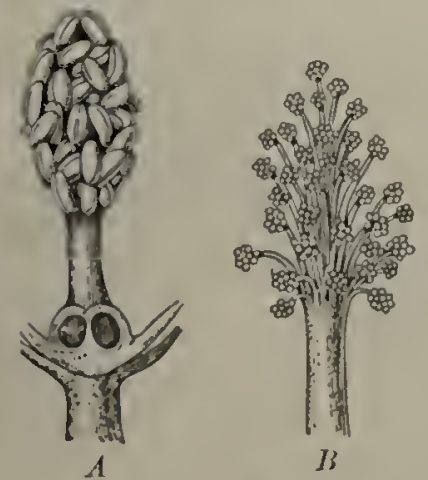

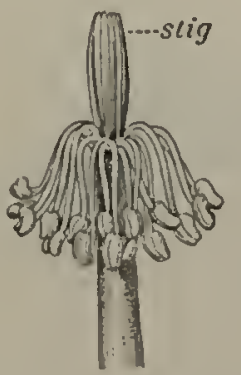

C

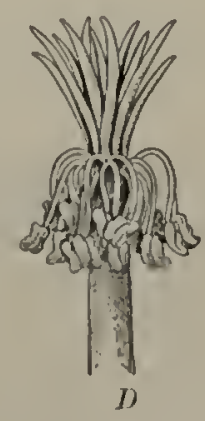

D

Fig. 329. Provisions for cross pollination in the high mallow

$A$, essential organs as fouml in the but: $B$, same in the staminate stage, the anthers discharging pollen, pistils immatnre; $C$, intermediate stage (stig, the united stignas); $D$, pistillate stage, the stiguas separated, stamens withered. - Aiter Miuller

1 C. Thompsonice. 
lodged on the prominent stigmas and thus produce the desired cross pollination.

Closely related flowers often differ in their plan of pollination. The ligh mallow (a plant eultivated for its purplish flowers),

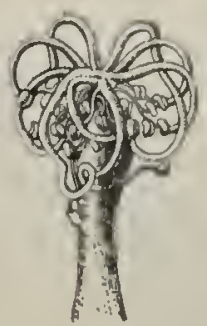

FIg. 330. Stamen s and pistils of roundleafed mallow

Tho stigmas curled round among the stamens to admit of self pollination.-After Miiller which has run wild to some extent, is admirably adapted to secure eross pollination, sinee when its stamens are shedding pollen, as in Fig. $329, B$, the pistils are ineapable of reeeiving it, while when the pistils are mature, as in $D$, the stamens are quite withered. In the eommon low mallow of our dooryards and waysides inseet pollination may oceur, but if it does not, the eurling stigmas finally come in eontaet with the projecting stamens and receive pollen from them, as is indieated in Fig. 330 .

\section{Movements of floral organs to aid in} pollination. Besides the slow movements which the stamens and pistil make in such cases as those of the Clerodendron and
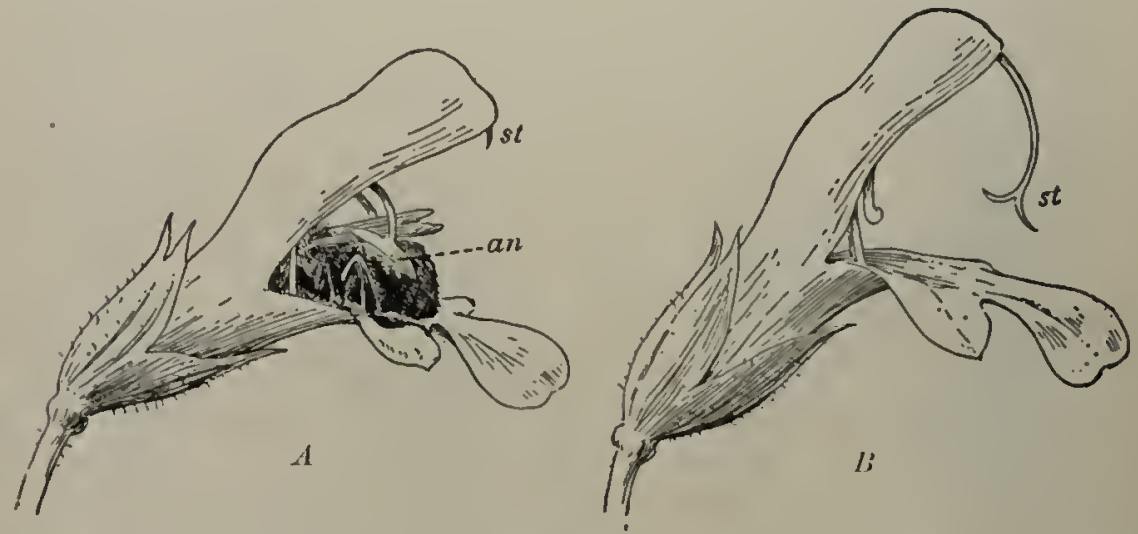

Fig. 331. 'Two flowers of common sage, one of them visited by a bee After Lubbock

the nallow, already deseriber, the parts of the flower often adinit of eonsiderable and rather quiek movements that assist the inseet visitor to beeome dusted or smenred with pollen. 
In some flowers whose stamens perform lapid movements when an insect enters, it is easy to see how directly useful the motion of the stamens is in securing cross pollination. The stamens of the laurel (Kalmia) are held in a bent position by the expanded corolla, and when liberated by a touch throw little masses of pollen, with a quick jerk, against the body of the visiting inscet. Barberry flowers have filaments which are sensitive on the inner side near the base, and when touched make the anther spring up against the visitor and dust him with pollen. The common garden sage matures its anthers earlier than its stigmas. In Fig. 331 , $A$, the young flower is seen, vis-
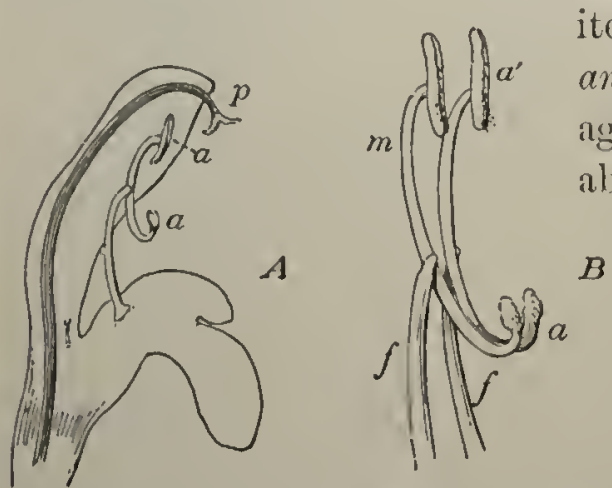
ited by a bee, and one anther, an, is shown juessed closely agrainst the sicle of the bee's abdomen. The stigma, st, is

Fic. 332. Flower and stamens of common sage

$A, p$, stigma; $a$, anthers. $B$, the two stanens in ordinary position; $f$, filaments ; $m$, connective (joining anther cells); $a, a^{\prime}$, anther cells. $C$, the anthers aud connectives bent into a horizontal position ly an insect pushing against $a$. After Lubbock.

hidden within the upper lip of the corolla. In $l$, an older flower, the anthers have withered and the stigma is now lowered so as to brush against the body of any bee which may enter. A little stucly of Fig. 332 will make clear the way in which the anthers are hinged, so that a bee striking the empty or barren anther lobes, a, knocks the pollen-bearing lobes, $a^{\prime}$, into a horizontal position, so that they will lie closely pressed against both sides of its abdomen. Many stigmas, as those of catalpa and trumpet creeper, close as soon as they are pollinated. 
407. Flowers with stamens and pistils each of two lengths. The flowers of bluets, partridge berry, the primroses, and a few other common plants secure cross pollination by having stamens and pistils of two forms (Fig. 333). Such flowers are said to be dimorphous (of two forms). In the short-styled flowers, $B$, the anthers are borne at the top of the corolla tube and the stigma stands about halfway up the tube. In the long-styled flowers, $A$, the stigna is at the top of the tube and the anthers are borne
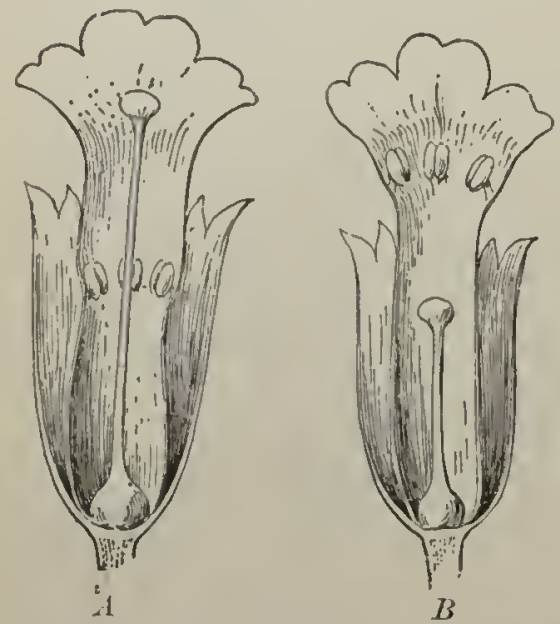

Fig. 333. Dimorphous flowers of the primrose

A, a long-styled flower; $B$, a shortstyled one. - After Frank about halfway up. An insect pressing its head into the throat of the corolla of $B$ would become dusted with pollen, which would be brushed off on the stigma of a flower like $A$. On leaving a long-styled flower the bee's tongue would be dusted over with pollen, some of which might readily be rubbed off on the stigina of the next shortstyled flower that was visited. Cross pollination is insured, since all the flowers on a plant are of one kind, either longstyled or short-styled, and since the pollen is of two sorts, each kind sterile on the stigma of any flower of similar form to that from which it cane.

Trimorphous flowers, with long, medium, and short styles, are found in a species of loosestrife and in the pickerel weed (Pontederia).

408. Cleistogamous flowers. In marked contrast with such flowers as those discussed in the preceding sections, which bid for insect visitors or expose their pollen to be blown about by the wind, are certain flowers which remain elosed even during the pollination of the stigma. These flowers are called 
cleistogamous (meaning with shut-in fertilization) and are of course not cross-pollinated. Usually they occur on plants which also bear flowers adapted for cross pollination, and in this case the closed flowers are much less conspicuous than the others, yet

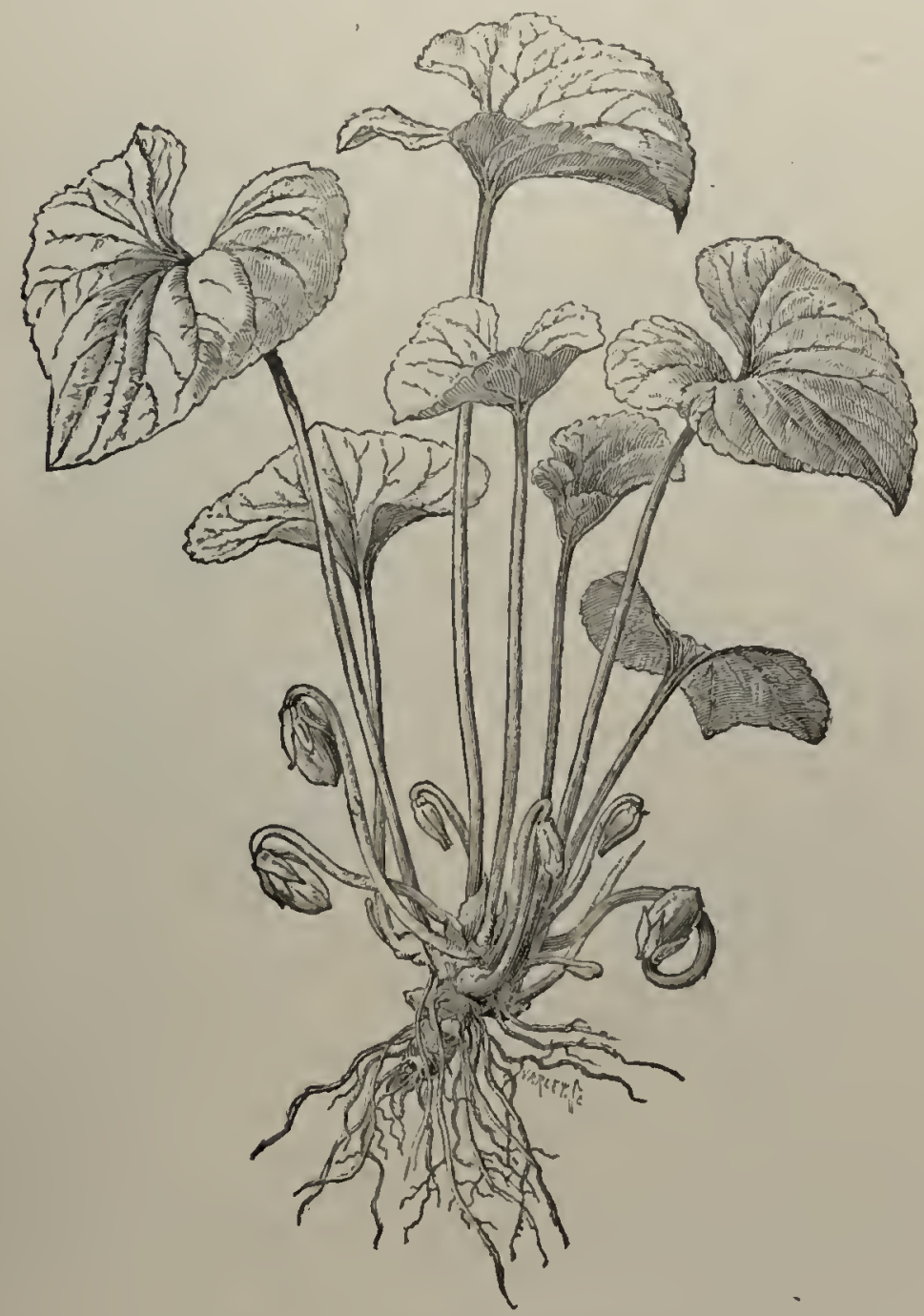

FIG. 334. $\Lambda$ violet, with cleistogamous flowers

The structures which look like flower buds are cleistogamous flowers in various stages of development. The pods are the fruit of similar flowers. The plant is represented as it appears in late July or August, after the ordinary flowers have disappeared 
they produce much seed. Every one knows the ordinary flowers of the violet, but most people do not know that violets very generally, after the blossoming season (of their showy flowers) is over, produce many cleistogamous flowers, as shown in Fig. 334.

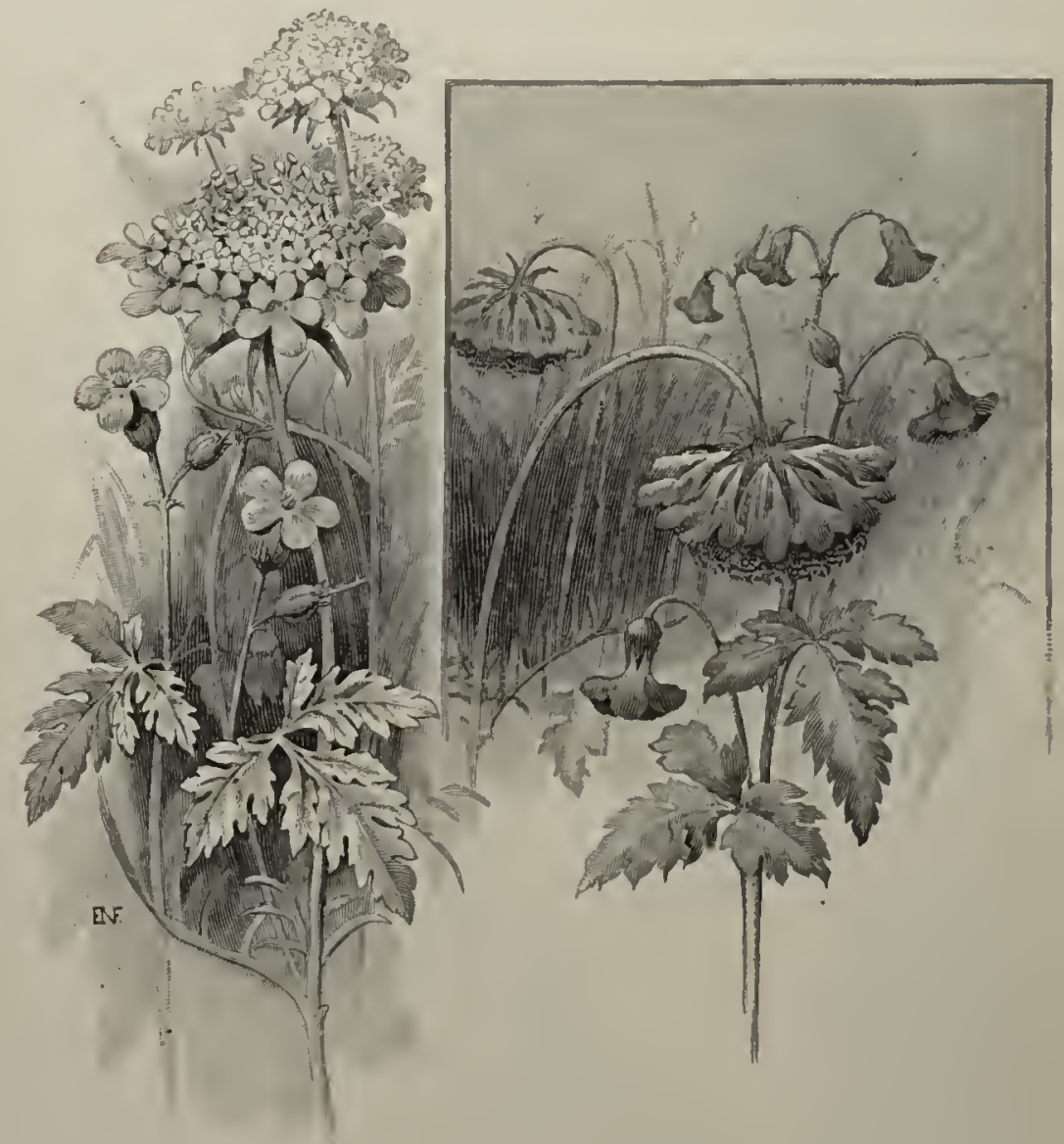

FIG. 335. Protection of pollen from moisture

At the left herb Robert and sweet scabious in sunny weather; at the right the same flowers during rain. - After Kerner

409. Protection of pollen from rain. Pollen is very generally protected from being soaked and spoiled by rain or dew by the natural position of the flower, which prevents rain from entering, as in the case of most sympetalous, nodding flowers, such as the 
lily of the valley and the flowers of the blueber'y, huckleberry, wintergreen, and a multitude of others. Often, in two-lipped flowers, the anthers are more or less completely covered by the upper lip (Fig. 331). In the salver-shaped flowers, such as those of phlox, the mouth of the corolla tube is often so narrow that no rain or dew can 'enter it. Many corollas of the same general type as that of the sweet pea (Fig. 126) have the stamens covered by certain petals. A large number of flowers, such as the crocus, rose, pond lily, magnolia, and many heads, such as those of the dandelion, the chicory, and the hawkweed, close in wet weather and open in the sunshine. Sometimes the flower both changes its position and closes, as is the case with the common cranesbill, the herb Robert, and the sweet scabious (Fig. 335). In the linden and the jewelweed the flowers are covered by the foliage leaves of the plant so that rain can hardly ever enter them. 


\section{CHAPTER XXXIII}

\section{HOW PLANTS ARE SCATTERED AND PROPAGATED}

410. Dispersal of plants by roots and rootstocks. Some of the highest spore plants, as the ferns, spread freely by means of their creeping rootstocks, and the gardener who wishes to get large strong ferns quickly often finds it the easiest plan

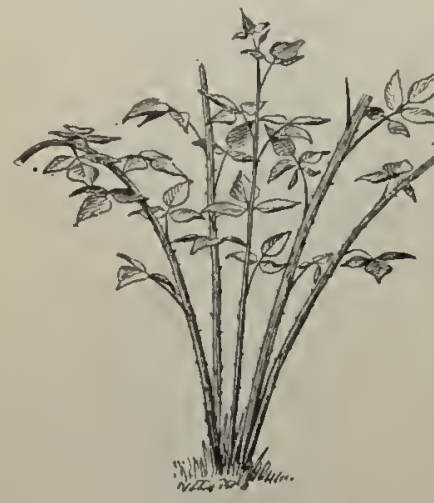

Fig. 336. Plant of a black rasplerry, showing one branch (stolon) with sereral - tips rooting

\section{After Beal}

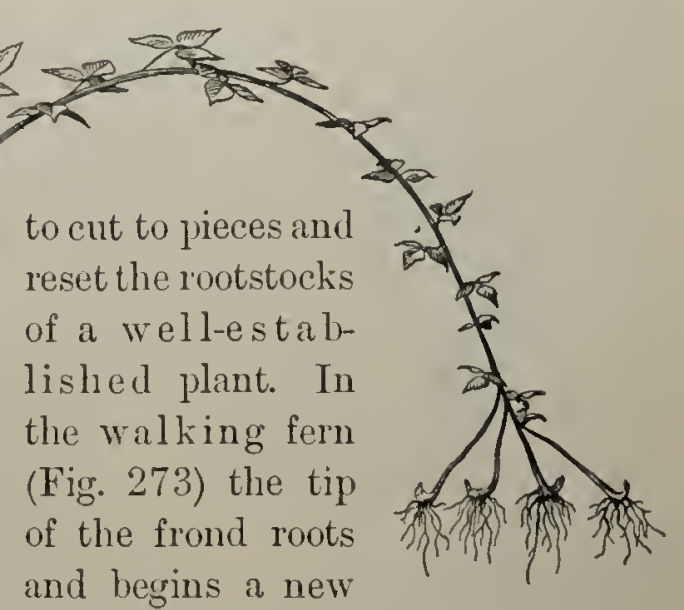

plant. The student has learned (in Chapters IV and vi) that roots and underground stems of many kinds may serve to reproduce the plant. Lither roots or rootstocks may travel considerable distances horizontally in the course of their growth and then shoot up and produce a new plant, which later becomes independent of the parent. The sedges (Fig. 44) are excellent illustrations of this process, and trees like the common locust and the silver-leaf poptar become great nuisances in the neighborhood of lawns and gardens by sending up sprouts in many places. When growing wild, such trees as these 
depend largely upon propagating by the roots to keep up their numbers. ${ }^{1}$

411. Dispersal of seed plants by branches. There is a shrub of the honeysuckle farnily, ${ }^{2}$ common in the northern woods, which is quite generally known as hobblebush, or witch-hobble, and sometimes as trip-toe. This is because the branches take root at the end and so form loops which catch the foot of the passer-by. The same habit of growth is found in the raspberry bush (Fig. 336), in one species of strawberry bush (Euonymus), and in some other shrubs. Many herbs, like the strawberry plant and the cinquefoil, send out long leafless runners which root at intervals and so propagate the plant, carrying the younger individuals off to a considerable distance from the parent.

Living branches may

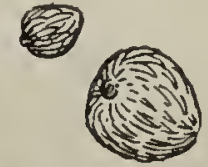

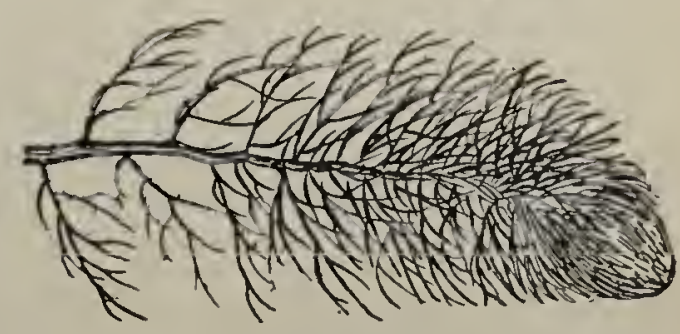

Fig. 337. A free branch and two buds of bladderwort

\section{After Beal} drop freely from the tree and then take root and grow, after having been blown, or carried by a brook or river, to a favorable spot, perhaps hundreds of yards away. The so-called snap willows lose many live twigs under conditions suitable for starting ncw trees.

A slightly different mode of dispersal from that of the raspberry is one in which buds separate from the plant and serve to propagate it. In the bladderwort (Fig. 337), at the close of the growing season, the terminal buds are released by the decay of the stem and sink to the bottom of the water in which the plants live, there to remain dormant until spring. Then each bud starts into life and gives rise to a new individual.

I See Beal, Seed Dispersal, Chapters II and III.

2 Viburnum ulnifolium. 
412. Dispersal of seed plants by bulblets. Almost every farmer's boy knows what "onion sets" are. 'This name is often given to little bulbs produced at the top of a naked flower stalk, or scape, by some kinds of onions which do not usually flower or bear seed. Tiger lilies produce somewhat similar bulblets in the axils of the leaves, and there is a large number of species,

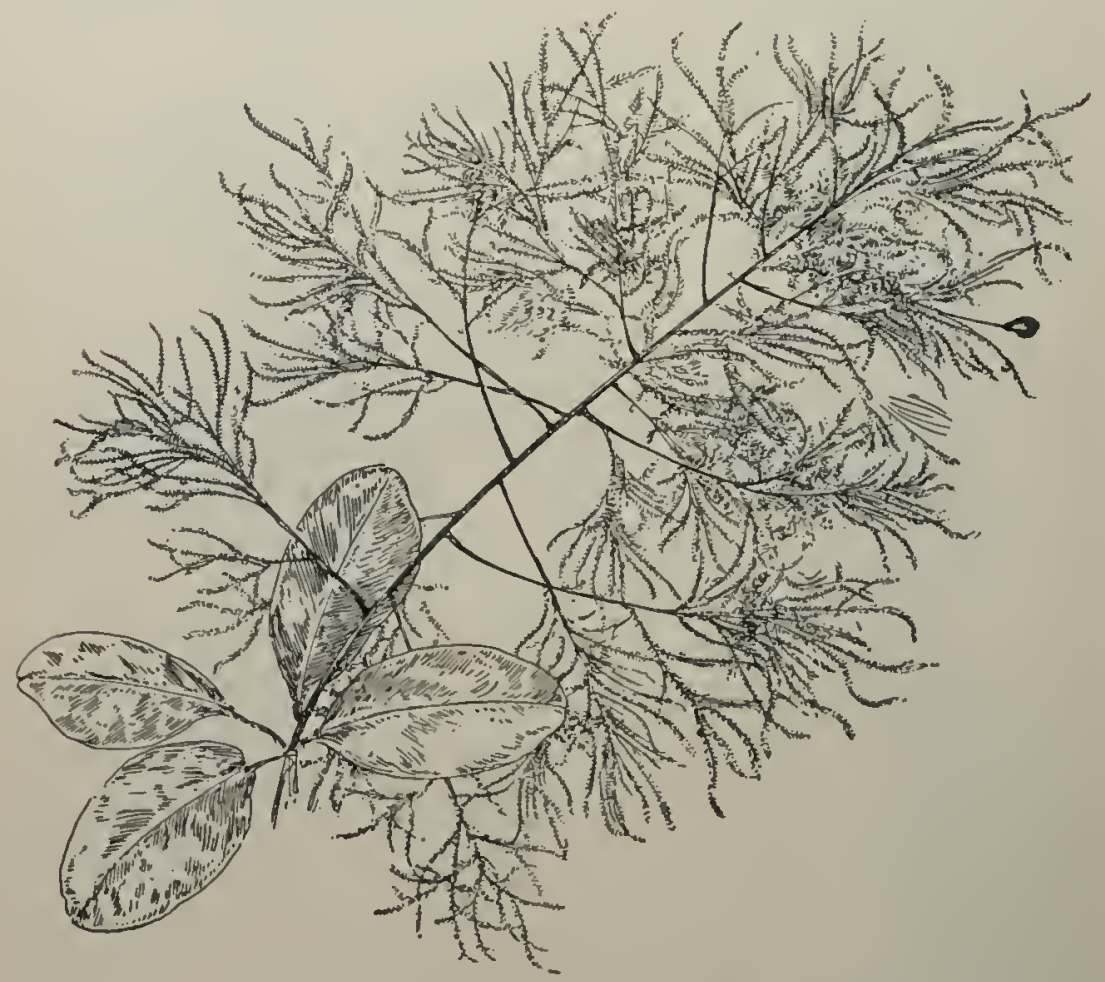

FIG. 338. Fruit of smoke tree (Rhus Cotinus)

Only one pedicel bears a fruit, all the others are sterile, branched, and covered with plumy hairs

scattered among numerous families of plants, all characterized by the habit of producing bulblets or fleshy buds, borne on the stems or leaves above ground and of use in propagation. When mature the bulblets fall off readily, and if they find lodgment on unoccupied soil they grow readily into new plants. Sometimes they are carried moderate distances by wind or water, 
and if the ground slopes they may easily roll far enough to get started in new places.

413. Dispersal of seeds. Seeds are not infrequently scattered by apparatus with the aid of which the plant throws them about. More commonly, however, they depend upon other agencies, such as wind, water, or animals, to carry them. Sometimes the transportation of seeds is due to the structure of the seeds themselves, sometimes to that of the fruit in which they are inclosed; the essential point is to have transportation to a long distance made as certain as possible, to avoid overcrowding.

414. Explosive fruits. Some dry fruits burst open when ripe in such a may as to throw their seeds violently about. Interesting studies may be made, in the proper season, of the fruits of the common blue violet, the pansy, the wild balsam, the garden balsam, the cranesbill, the herb Robert, the witchhazel, the Jersey tea, and some other common plants. The capsule of the tropical American sand-box tree bursts open when throughly dry with a noise like that of a pis-

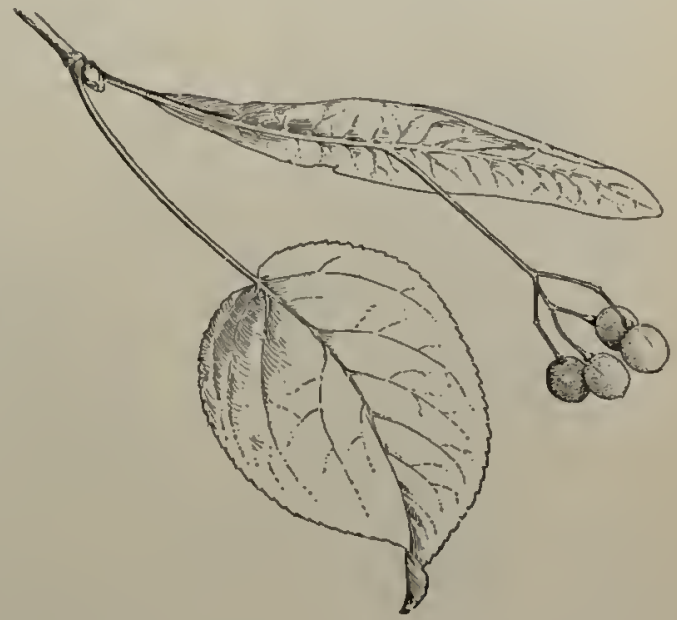

Fri. 339. Fruits of linlen, with a braet joined to the pedunele and forming a wing tol shot. The explosive foree of fruits is derived from the fact that some of their parts on drying are left in a state of tension, some layers of cells being compressed or stretched and tending to readjust their position.

415. Winged or tufted fruits and seeds. The fruits of the ash, box elder, elm, maple (Fig. 160), and many other trees are provided with an expanded membranous wing. Sorue seeds, as those of the catalpa and the trumpet creeper, are similarly 
appendaged. Tinged fruits and seeds are borne on trees or shrubs, and the wing is usually so adjusted as to make its descent slow, with a spinning motion. As a rule, winged fruits and seeds are much heavier than those with a tuft of hairs. The fruits of the dandelion, the thistle, the fleabane, the arnica (Fig. 166, III), and many other plants of the group Compositce, to which these belong, and the seeds of the willow, the milk-

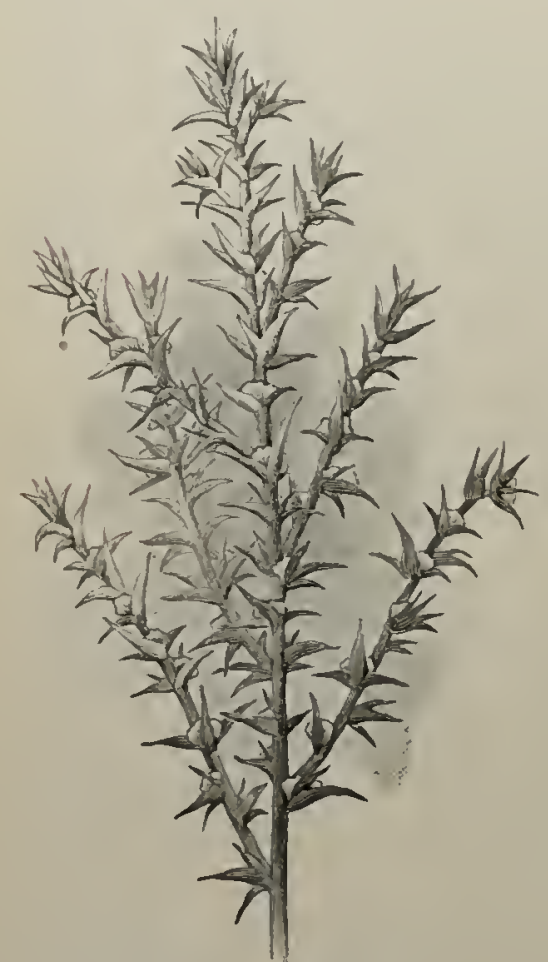

FIg, 340. Russian thistle weed, the willow-herb, and other plants, bear a tuft of hairs. All these seeds and fruits may in windy weather be seen traveling often to great distances.

416. Tumbleweeds. Late in the autumn, fences, particularly on prairie farms that are not carefully tilled, or in pastures, often serve as lodging places for immense numbers of certain dried-up plants known as tumbleweeds. These blow about over the level surface until the first snow falls and even after that (Fig. 341), often traveling for many miles before they come to a stop, and rattling out seeds as they go. Some of the commonest tumbleweeds are the Russian thistle (Salsola Kali var. tenuifolia, Fig. 340), the pigweed (Amaranthus yracizans, Fig. 341), the tickle grass (Fig. 342), and a familiar peppergrass (Lepidium). In order to make a successful tumbleweed, a plant must be pretty nearly globular in form when fully grown and dried, must be tough and light, must break off near the ground, and drop its seeds only a few at a time as it travels. A single plant of Russian thistle is sometimes as much as 
three feet high and six feet in diameter, and carries not less than 200,000 seeds.

417. Many-seeded pods with small openings. There are many fruits which act somewhat like pepper boxes. The capsule of the poppy is a good instance of this kind, and the fruit of lily, monkshood (Fig. 159), columbine, larkspur, velvet leaf (Alutilon Avicennc), aud jimson weed (Fig. 343, C) acts in much the same way. Clamping the dry peduncle of auy one of these ripe

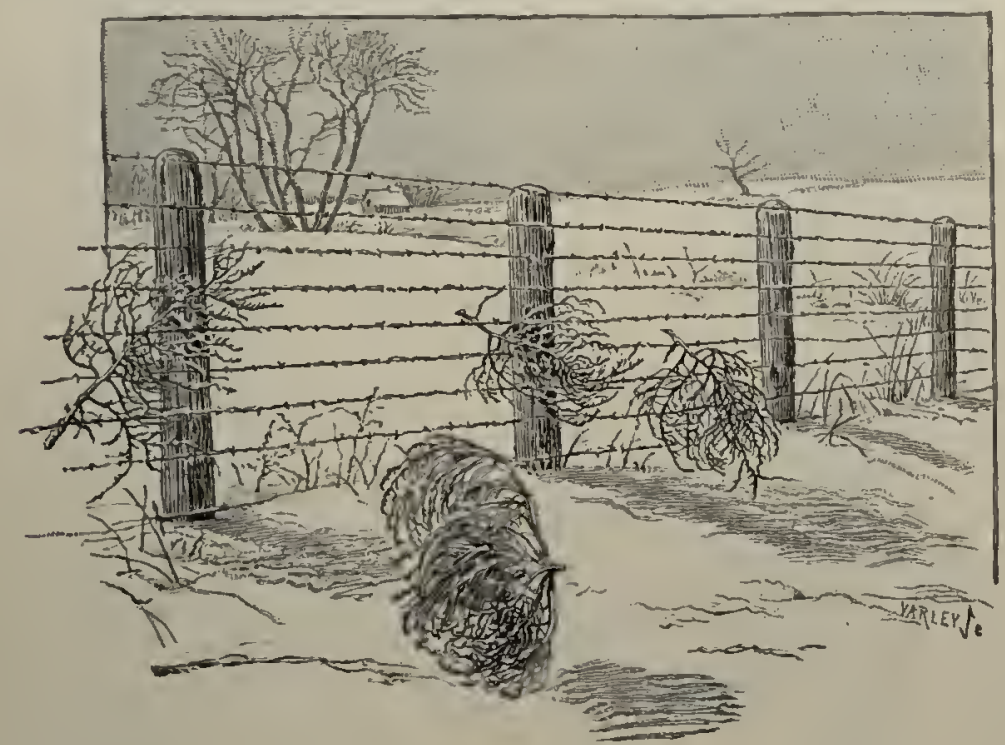

Fig. 341. Tumbleweeds ${ }^{1}$ lodged against a wire fence in winter

After Millspaugh

fruits, so as to hold it upright above the table top, and swinging it back and forth, will readily show its efficiency in seed dispersal.

418. Study of transportation by water. Nothing less than a long series of observations by the pond margin and the brookside will suffice to show how general and important is the work done by water in carrying the seeds of aquatics. Many plants usually have their seeds transported by water, and some appear to have 10 provision for dissemination in any other way.

1 Amarunthux grocizans. 
Ocean currents furnish transportation for the longest journeys that are made by fluating seeds. It is a well-known fact that cocoa palms are among the first plants to spring up on newly formed coral islands. The nuts from which these palms grew may readily have floated a thousand miles or more without

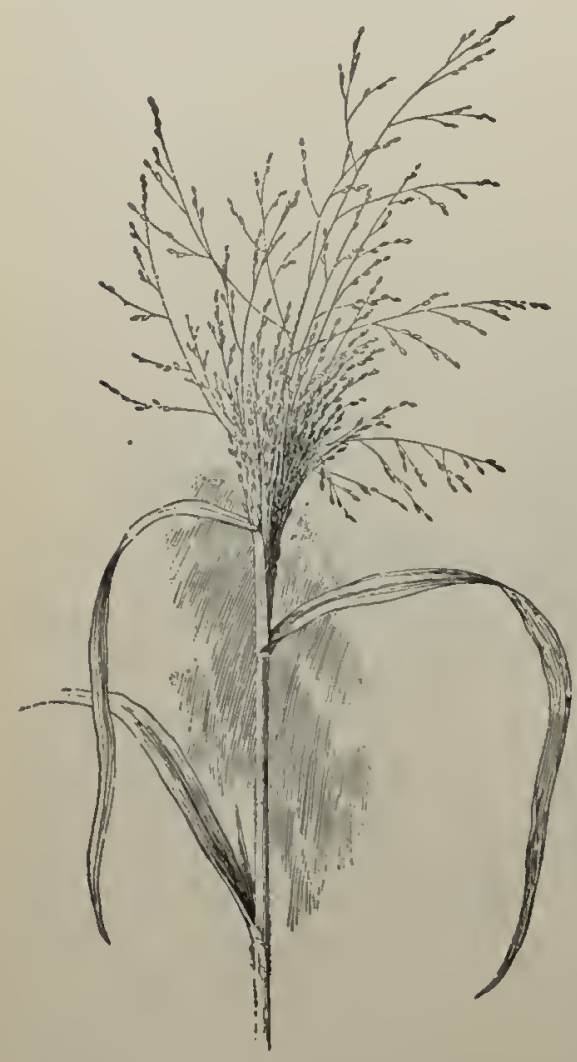

Fin, 342. Panicle of tickle grass, a common tumbleweed

\section{After Host}

injury. On examining a cocoanut with the fibrous husk attached, just as it falls from the tree, it is easy to see how well this fruit is adapted for transportation by water. There are altogether about a bundred drifting fruits known, one (the Maldive nut) reaching a weight of twenty to twenty-five pounds.

419. Burs. A large class of fruits is characterized by the presence of hooks on the outer surface. These are sometimes outgrowths from the ovary, or the style (as in avens), sometimes from the calyx, sometimes from an involucre. Their office is to attach the fruit to the hair or fur of passing animals. Often, as in sticktights (Fig. $344 A, B)$, the looks are comparatively weak, but in other cases, as in the cocklebur (Fig. $344 D$ ), and still more in the Martynia (the fruit of which in the green condition is much used for pickles), the llooks are exceedingly strong. Cockleburs can hardly be removed from the tails of horses and cattle, into which they have become matted, without cutting out all the hairs to which they are fastened. 
A curious case of distribution of this kind occurred in the island of Ternate, in the Malay Archipelago. A buffalo with his
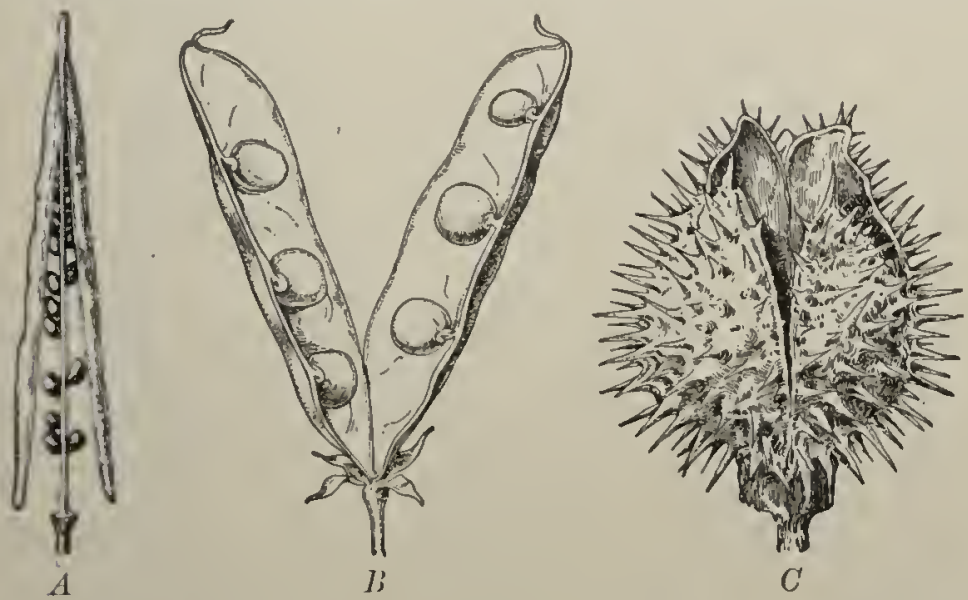

Fig. 343. Three fruits adapted for dispersal by the shaking action of the wind

$A$, celandine; $B$, pea; $C$, jimson weed (Datur $a) .-$ After Decaisue
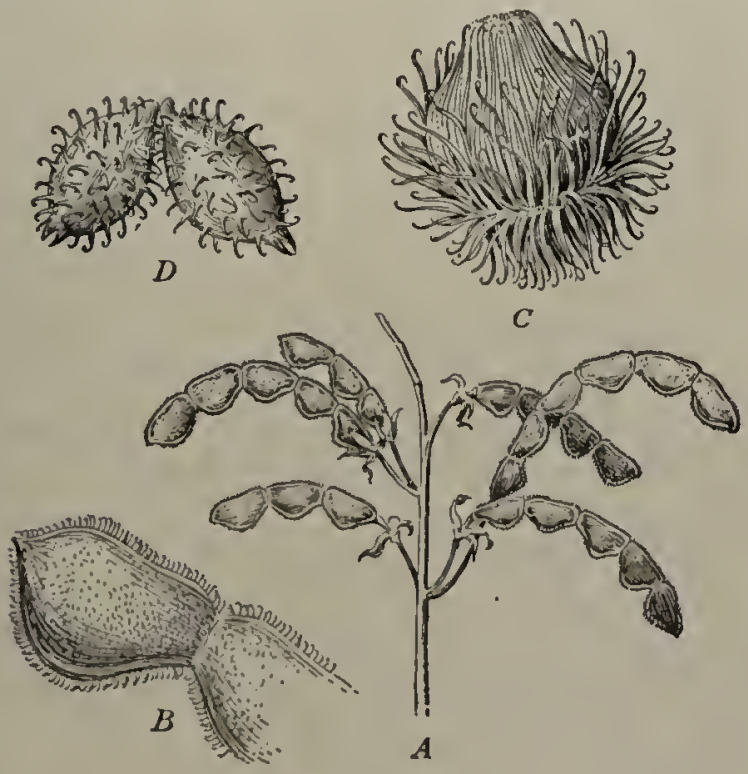

Fin. 344. Burs

$A$, sticktights ; $B$, sticktights, two segments (magnified); $C$, burdoek; $D$, cockleburs. - After Kerner 
hair stuck full of the needle-like fruits of a grass ${ }^{1}$ was sent as a present to the so-called king of Ternate. Scattered from the hair of this single animal, the grass soon spread over the whole island.

420. Uses of stone fruits and fleshy fruits to the plant. Besides the dry fruits, of which some of the principal kinds have been mentioned, there are many kinds of stone fruits and

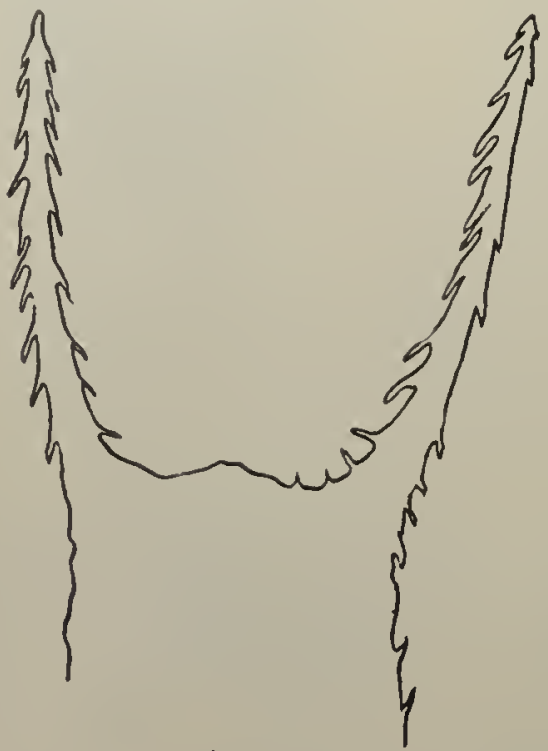

$A$
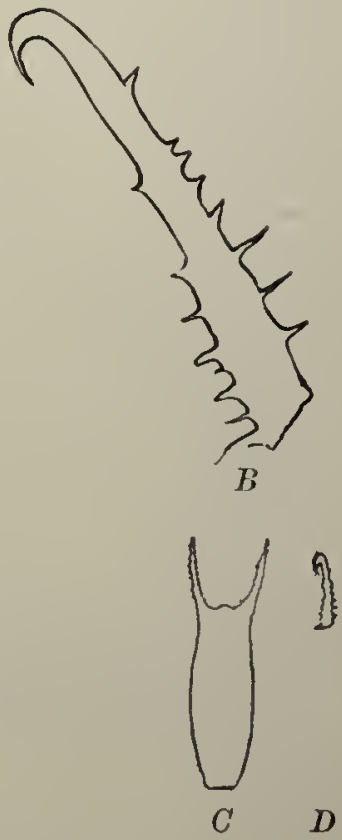

Fic. 345. Barbs and hooks of burs

$A$, barbed points from fruit of beggar's ticks, $\times 11 ; B$, hook of encklebur, $\times 11$;

$C$, beggar's ticks fruit (natural size); $D$, cocklebur hook (11atural size)

other fleshy fruits. Of these the great majority are eatable by man or some of the lower animals, and oftentimes the amount of sugar and other food material which they contain is very considerable. It is a well-recognized principle of botany that plants do not make unrewarded outlays for the benefit of other species. Evidently the pulp of fruits is not to be consumed or 
used as food by the plant itself or, in general, by its seeds. There are, therefore, several points to be explained on the basis of possible advantages to the plant. These are:

1. The eatable nature of the pulp of many fruits.

2. The bitter or other umpleasant taste of many seeds, as those of the orange and lemon.

3. The hardness or toughness of many seeds of pulpy fruits, as the date and the peach.

4. The small size and indigestibility of seeds of pulpy fruits, as the fig and the raspberry.

A little observation in the field suffices to show that most pulpy fruits are habitually eaten by birds or other animals large enough to carry them away from the parent plant. Seeds of disagreeable flavor, and very large hard seeds are often avoided by the animal in eating the fruit which contains them. Small liard seeds are commonly swallowed whole and frequently remain nearly unacted upon by the digestive fluids, so that they traverse the digestive traet of the fruit-eating animal which swallowed them and remain perfectly capable of germination. In this way such instances of dissemination as those of the rasplerry (Fig. 346) and the red cedars (Fig. 347) are readily explained.

\section{Seed carrying purposely} done by animals. In the cases re-

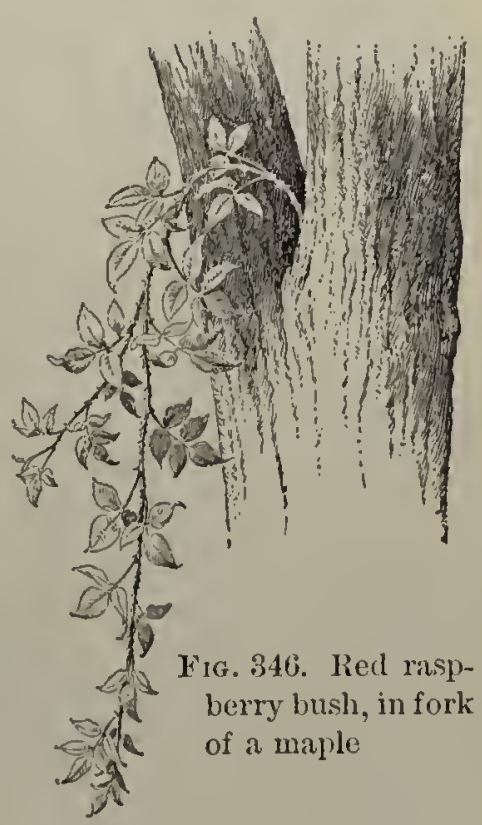
ferred to in the preceding sections, animals have been seen to act as unconscious or even unwilling seed carriers. Sometimes, lowever, they carry off seeds with the plan of storing them for forl. Ants drag away with them to their nests certain seeds which have fleshy growths on their outcr surfaces. Afterwards 
they eat these fleshy parts at their leisure, leaving the seed per fectly fit to grow, as it often does. ${ }^{1}$

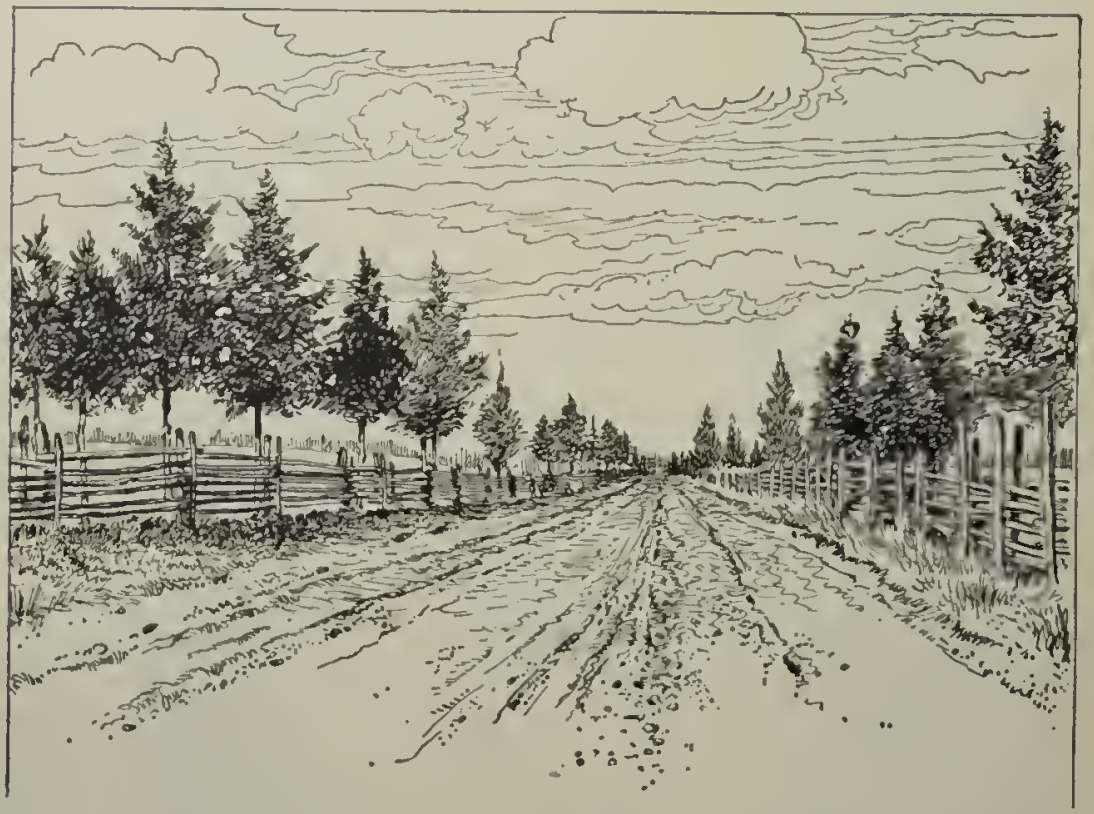

Fig. 347. Red eedar trees planted by birds roosting on fences After Pinchot

Squirrels and blue jays are known to carry nuts and acoms about and bury them for future use. These deposits are often forgotten and so get a chance to grow, and in this way a good deal of tree planting is done.

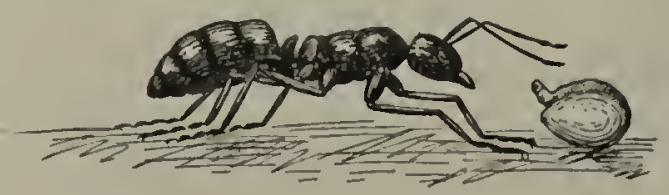

Fig. 348. Seed of bloodroot with caruncle, or erest, which serves as a handle for ants to hold on to. Ant ready to take the seed After lieal

1 See Beal, Seed Dispersal, pp. 69, 70. 


\section{CHAPTER XXXIV}

\section{SOCIAL HABITS OF PLANTS; COMPETITION AND INVASION}

422. Social habits. Those plants which live associated with many individuals of the same species are called social plants. Those kinds which are not social usually occur as member's of plant communities, or assemblages of two or more species. The vegetation of the earth mainly consists of such assemblages, and the total number of solitary plants is comparatively small.

Adult seed plants are usually incapable of locomotion, and only a small proportion of all the kinds of seeds (though a somewhat larger proportion of fruits) is equipped with means for carrying them on long journeys. It is therefore natural that the offspring of any plant or plant community should generally be found near the parent plants. It is not easy to trace the working of this gradual spread of the successive broods in the neighborhood of the parents where there is aheady dense vegetation. But in any region where there are consiclerable areas destitute of any given vegetation form, as in cleared land, the young seedlings of an oak, a hickory, or a black walnut may often be detected in many places near the parent tree.

423. Competition. Every one knows, in a general way, that in a state of nature plants often greatly crowl each other: $\Lambda$ This is evident enough from mere inspection of most meadows, thickets, or tracts of woodland or waste land; but in order to realize how few of all the bidders for each square foot of ground actually fincl a chance to occuy it, a little calculation is needed. A single annual seed plant usually matures hundreds and often thousands of seeds. One common weed of the Midlle West, the Russian thistle ${ }^{1}$ (Fig. 340), often produces as many as 25,000

\section{Salsolu líali var. tenuifolia.}


seeds and accupies as much as four square feet of carth. The offspring of an individual of this specics, therefore, if all the sceds grew to mature plants, would cover nearly 2.3 acres. It may interest the student to calculate in what generation the descendants of one plant would cover the entire area of his state.

424. Statistics of overcrowding. Charles Darwin seems to have been one of the earliest observers, if not the very first, to collect exact statistics in regard to the severity of compctition among plants. He found that out of 20 species which occurred on a plot of turf three by four fect in area nine species died from overcrowding by the others. On a piece of dug and cleared ground he found that 60 weed scedlings to the square foot sprang up and 49 of them were destroyed, chiefly by slugs and insects. ${ }^{1}$

In a rich and weedy bit of land Professor L. H. Bailey found in an area of twenty by twenty square inches ten species of weeds. Rcducel to the number per squarc foot, there were: July 10, 30 plants; August 13, 31 plants; Scptember 25, 25 plants. Several of these were large wecds, such as the redroot (Amurantus retroflexus) and the ragweed (Ambrosia artemisiafolia).

On June 23 of the ncxt year there were on the same plot (which had remained undisturbed) elcven species, numbering 108 plants to the square foot, and now the dominant plants were red clovers. Most of the other plants were puny and suffering from lack of light under the shade of the clovers. ${ }^{2}$

If one selects a plot in which scedlings are just starting, the number of individuals to the square foot will often be found to be much greater than those above given. Under a full-grown trce of the wild black chcrry the writcr lias found on Junc 9 portions of the ground containing hardly any other sced plants except cherry seedlings at the rate of 104 to the square foot. Not one of all the thousands which had begun to grow could 
ever have developed into a full-sized individual on account of the overshadowing from the parent tree.

In a weedy bit of lawn, where the grass had largely been killed by trampling and other disturbing causes, the writer found on June 9 plants at the rate of 1032 to the square foot as follows:

Plantain (Plantago Pugelii) . . . . . . . . 811

Grass (various specien) . . . . . . . 200

Knotgrass (Polygonum ariculare) . . . . . . 18

Sorrel (Oxalis rymmst) . • . • • . . . . $\frac{3}{1032}$

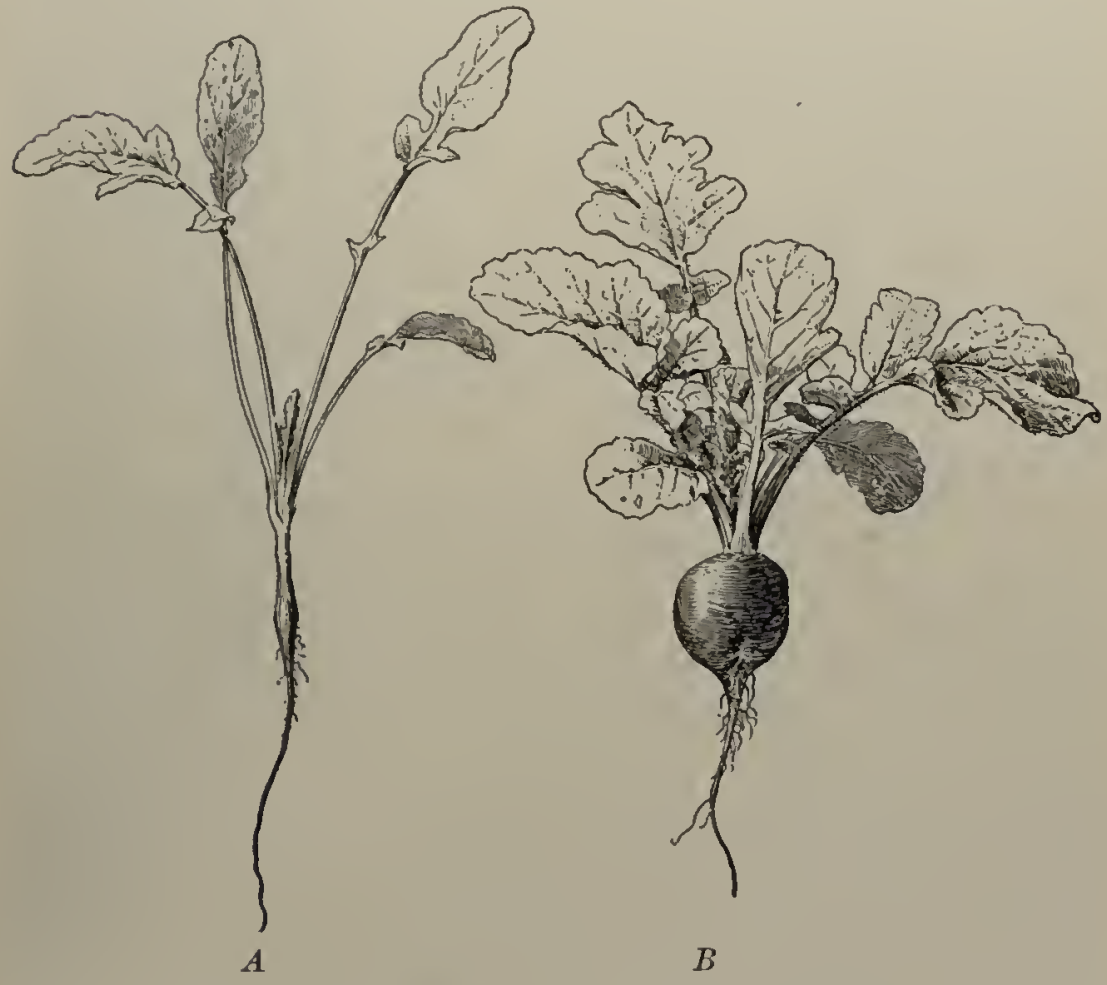

FIG. 349. Effect of competition on radishes

Both plants were grown from the same seed and in the same soil, planted at the same time. I was one of a lot standing so close together that their tap roots nearly touched one another; $B$ had several square feet of ground to itself. About one-quarter natural size 
The majority of the grass plants were apparently seedlings of the preceding autumn, and the plantains were young seedlings, most of them an inch or less in height. A full-grown plantain of this species occupies not less than 100 to 150 square inclies, so that of these alone more than 800 individuals were likely to die of overcrowding.

-425. How overcrowding kills. Of plants grown too elose together many die and others are dwarfed (Fig. 349) and partially or wholly fail to flower or seed. This is one of the first lessons which the beginner in gardening learns, if he negleets properly to thin out his beds. Corn grown in elosely planted drills for fresh fodder or ensilage makes few ears, and none of these are perfect. The weakening or destruetion due to overcrowding results mainly from these three causes ${ }^{1}$ :

1. Insufficient light and heat for plants shaded by their more vigorous neighbors, resulting in imperfect photosynthesis.

2. Scanty water supply, bceause most of the water is absorbed by the more vigorous root systems of the stronger individuals.

3. Deficient supply of dissolved salts (nitrates, phosplates, and so on), on aceount of their being largely eonsumed by the stronger plants.

426. Competition most fatal between similar plants. For obvious reasons, plants of the same general form and mode of growth usually interfere most with each other, and plants which are decidedly unlike interfere less, or even in some eases benefit each other. This principle is unconseiously followed, in many instanees, by farmers and gardeners, as in the case of lawns sown with mixed grass seed, which produce a more perfect turf than those sown with a single speeies of grass. So, too, pumpkins are often planted in cornfields, and in southern Europe beans are raised in rineyards, in the partial shade of the vincs.

If the interests of two or more kinds of plants occupying the same area confliet little or not at all, this may be due not only to their unlikeness of form or of requircments as regards light,

1 As far as terrestrial seed plants are concerned. 
heat, or water, but also to their flowering and seeding at different seasons. Many kinds of weeds flourish in grainfields, making little growth until the grain is reaped, after which they develop rapidly and flower and seed among the stubble.

42\%. Invasion. Some, of the ways in which plants are dispersed have already been described (Chapter XxxiI). The result of carrying seeds or other reproductive parts into new territory is to cause an invasion of that area. If the invaded ground contains no vegetation, the newcomers take full possession. Such a case occurs when the bed of a newly drained lake or bayou, or soil uncovered by landslides, or newly cooled material from volcanic eruptions is populated by vegetation brought in by natural agencies. If the invading species encounter other occupants of the region invaded, the new arrivals may simply share the territory with its previous occupants. But if the immigrants are much better adapted to the conditions of existence in the disputed area than are its actual occupants, the intruders may drive out all before them.

428. Native species ousted by invaders. New Zealand and the pampas of La Plata and Paraguay, in South America, have, during the nineteenth century, furnished wonderful examples of the spread of European species of plants over hundreds of thousands of square miles of territory. The newcomers were more vigorous, or in some way better adapted to get on in the world, than the native plants which they encountered, and so managed to crowd multitudes of the latter out of existence.

In our own country a noteworthy case of the kind has occurred so recently that it is of especial interest to American botanists. The so-called Russian thistle (Fig. 340), which is merely a variety of the saltwort common along the Atlantic coast, was first introduced into South Dakota in flaxseed brought from Russia and planted in 1873 or 1874 . In twenty yenrs from that time the plant had become generally distributed as one of the commonest weeds over an area of about 25,000 square miles. 
Anerican plants, on the other hand, have in many cases overrm other comntries. Elodeu, a common water weed witl us, introduced into Great Britain about 1847, now chokes up) many pools and water courses in England and Seotland. The prickly pear eactus (Opuntiv ficus-indica) and the century plant, both enigrants from North Anerica, are now the nost conspicuous plants along many cliff sides all over southern Italy. A priekly pear has become such a muisance in New South Wales that large rewards are offered for its externination.

429. Weeds. Any flowering plant which is troublesone to the farmer or gardener is commonly known as a weed. 'Though such plants are annoying from their tendency to erowd out others useful to man, they are of extreme interest to the botanist on account of this very hardiness. The principal eharaeteristics of the most successful weels are their ability to live in a variety of soils and exposures, their rapid growth, resist. anee to frost, drought, and dust, their unfitness for the food of inost of the larger animals, in many cases their eapacity to acconplish self pollination, in defanlt of cross pollination, and their ability to produec many seeds and to secure their wide dispersal.

Sometimes the seeds lave great vitulity; those of shepherd's purse and purslane are capable of germinating after fiftecn years or morr Many of the worst weeds, such as sow thistle, somel," witch grass," nut grass, and field garlic, have crepping rootstoeks or bulles or tubers. Not every weed eombines all of these characteristics. For instanee, the velvet leaf, or butter print, common in cornfields, is very easily destroyed ly frost; the pigweed and purslane are greedily eaten by pigs, and the ragweed by some horses. 'The horse-radish does not uswally produce any seeds, but is propagated by vegetative metlods.

It is a curious fact that many plants which have finally proved to be noxious weeds have been purposely introrluecel into the country. 'The fuller's teasel, nelilot, loorse-larlish, wild

${ }^{1}$ Sonchus. $\quad 2$ Rumex. ${ }^{8}$ Agropyrum. 'Cyperus. 'Allium. 
carrot, wild parsnip, tansy, oxeye daisy, and field garlic are instances of this.

430. Origin of weeds. ${ }^{1}$ By far the larger proportion of our weeds are not native to this country. Some have been brought from South America and from Asia, but most of the introduced kinds come from Europe. The importation of various kinds of grain and of garden seeds, mixed with seeds of Furopean weels, will account for the presence of many of the latter among us. Others have been brought over in the ballast of vessels. Once landed, European weeds have succeeded in establishing themselves in so many cases, because they were superior in vitality and in their power of reproduction to our native plants. This may not improbably be due to the fact that the European and western Asiatic vegetation, much of it consisting from very early times of plants growing in comparatively treeless plains, has for ages been habituated to flourish in cultivated ground and to contend with the crops which are tilled there.

1 See the artiele, "Pertinaeity and Predominance of Weeds," in Scientific Papers of $\mathbf{A}$ su Gray, selected by C. S. Sargent, Vol. II, pp. 234-242. 


\section{CHAPTER XXXV}

\section{PLANT SUCCESSIONS *}

431. Nature of plant successions. Whenever a portion of the earth's surface is stripped of its vegetation, or undergoes any decided change in its physical condition, the way is usually opened for invasion of plants from the surrounding territory (Sec. 427). In most cases the immigrants are not all of them thoroughly adapted to their new home, and cannot become so; or the condition of the territory may continue to change, su that a series of new populations appcars, each in turn wholly or partly giving way to that which follows it. Such a set of colonizings is called a plant succession.

432. Causes of successions. It would require too much space to state more than a very few of the causes which originate plant successions.

First. They may be brought about by the introduction into a region of new species which are able, without change of soil or climate, to drive out some or all of the original occupants (Sec. 428).

Second. They may be brought about by changing the supply of light, heat, water, or other important factors in the surroundings of the plant. Such changes are sometimes natural, sometimes produced by man.

Such a river as the Mississippi, with over 12,000 square miles in its delta, affords a good instance of the power of natural agencies to alter the conditions of plant life. Perhaps one third of the delta is a sea inarsh, with the vegetation characteristic of

* To rne Isstructor: As this chapter is somewhat morc technical than many of the others of Part III, it may bc omitted if limitations of time demand a briefer course. 
shallow, salt, or brachish water in a warm-temperate climate, while the remaining portion supports in places a most luxuriant growth of land plants. Year by year, along the margin of the

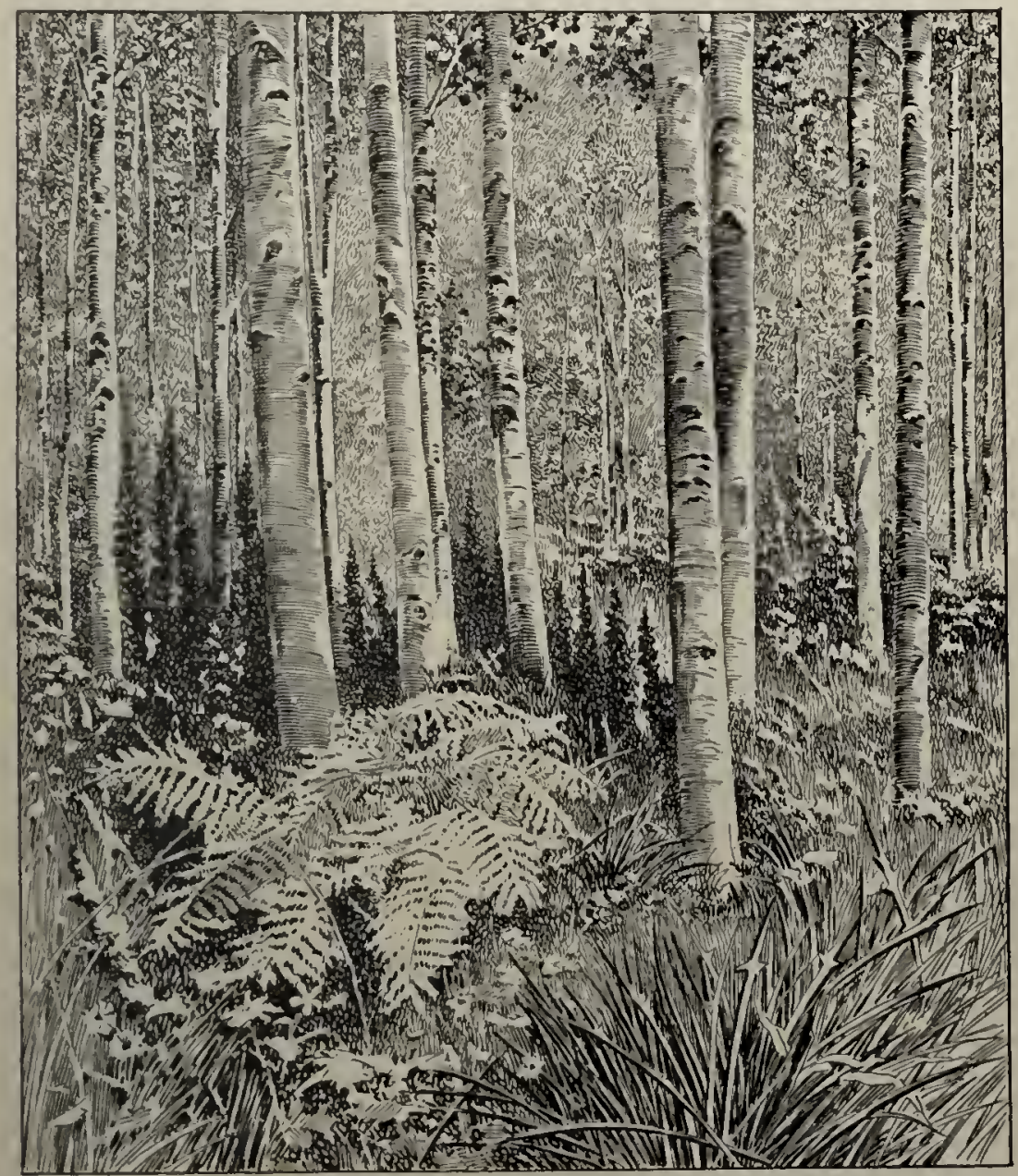

Fıg. 350. Aspen succession after forest fires in coniferous woods, Colorado After Clements

submerged part of the delta, as this emerges from the water, the change from aquatic to land regetation goes on, and year by ren the flora which first establishes itself in the newly emerged mud is succeeded by others more adapted to ordinary soil. 
Man produces most extensive changes in regetation by such operations as draining lakes and swamps, building levees, irrigating deserts and seni-deserts, clearing woodlands, and planting treeless lands witl the seeds of forest trees.

433. Order of succession in special cases. Much study has recently been given to the exact order in which assemblages of plants follow each other in various kinds of succession. Only a very few cases can here be mentioned.

On the island of Krakatoa, which was completely laid waste by a volcanic eruption in 1883 , the first forms of plant life to appear were microscopic blue-green algæ (Secs. 207-211). Three years after the eruption the flora had come to contain many ferns, with here and there a few seed plants, on the mountains or the coast.

In the mountains of Colorado the granite bowlders dislodged from the faces of cliffs are covered first with incrusting lichens; then the gravel produced by the weathering of the granite gives a footing to leaf-like lichens; later the more weathered gravel supports a growth of herbaceous seed plants; afterward follow thickets, then pine forests, and finally spruce forests (PlateXII).

In the pine woods ${ }^{1}$ of central Maine when the trees have been cut away and the clearing (as is too often the case) burned over, the most conspicuous plants which immediately succeed the forest are fireweed, ${ }^{2}$ raspberries, blackberries, wild cherries, ${ }^{3}$ and aspens. ${ }^{4}$ A deciduous forest of poplars and canoe birches ${ }^{5}$ succeeds the thickets above-mentioned. This in turn would doubtless, under natural conditions, after a long period, be displaced by a pine forest.

In eastern Maine the succession is very similar, except that blackberries are not conmon in the burned clearings and the tree growth which follows the thicket stage is usually of gray birch. ${ }^{6}$

1 Pinus Strobus.

4 Populus tremuloilles.

2 Epilobium angustifolium.

- Betula alba var. papyrifera

Prunus pennsylvanica.

6 B. populifolia. 
434. Reasons for order of succession. It is not always possible to explain in detail why each set of plants in a succession takes possession of the ground and later on is itself driven out.

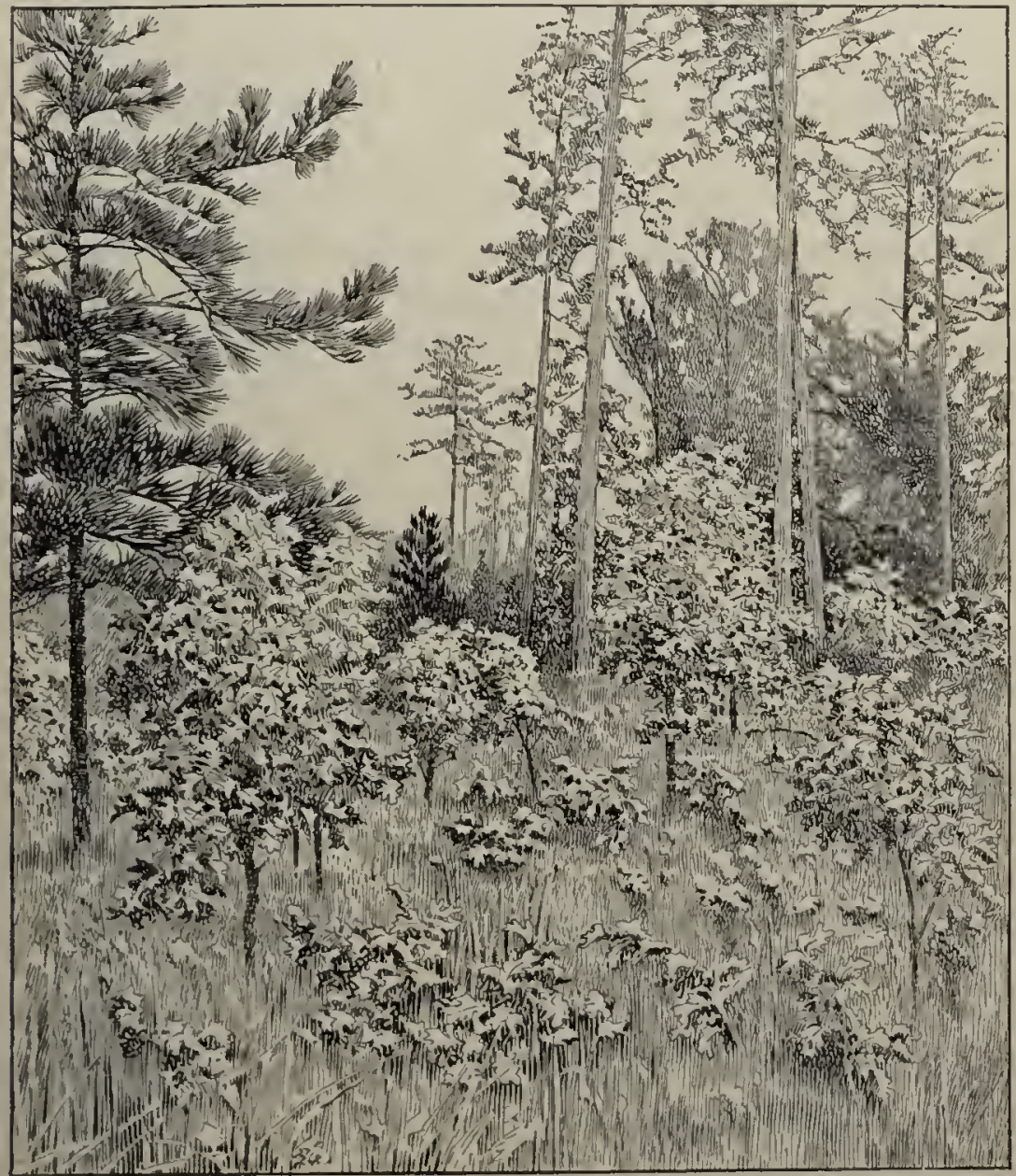

Fic. 251. Young black oaks succeeding loblolly pine and shortleaf pine, southeastern 'Texas

\section{After von Schrenk}

In a general way it is clear that very low spore plants can make a living on bare rock surfaces or on partly decomposed rock where seed plants would find too little available salts, especially nitrates, to support their nutrition. 
On lands where cultivation is abandoned, or which are in other ways suddenly exposed to invasion, weeds of many species often obtain a footing and flourish for some years before the truly wild native plants of the region take final possession. This is, in part at least, on account of the remarkable capacity of most weeds to seed themselves (Sec. 429).

Forest or grass land is the final stage in many successions. The former gains supremacy over the weedy thickets out of which it rises by shading the shrubs and herbs beneath the tree tops until all those not adapted to life in decp, shade are destroyed. Grasses have to an unsurpassed extent the power of living with their roots (and sometimes also rootstocks) intcrwoven in a way which would prove fatal to most herbs. In this way a lawn or meadow, on good ground, may be scen to improve itself by choking out other plants which occur here and thcre among the grass. Salt marshes, with a comparatively scanty vegetation, are often purposely shut away from the sea, so that the rains can wash the excess of salt out of the soil. In four or five years they become thoroughly sclf-sown with the seeds of cultivated grasses and are changed into highly productive meadows. 


\section{CHAPTER XXXVI}

\section{ECOLOGICAL GROUPS AND THEIR CHARACTERISTICS *}

435. Ecological grouping of plants. The ordinary classification of plants, as set forth in Part II, is based, as far as possible, on their actual relationships to each other. But when plants are considered ecologically they are grouped according to their relations to the world about them. They may, therefore, le gathered into as many (or more than as many) different groups as there are important factors influencing their modes of life. We may, for instance, classify plants as light-loving and shade-loring, and so on.

The most important consideration in classifying seed plants on ccological grounds is based on their requirements in regard to water. Grouped with reference to this factor in their life all plants may be designated as:

1. Mylroplyles, or watcr-inhabiting or water-tolerating plants.

2. Xerophyles, or drought-tolerating plants.

3. Mesopleyles, or plants which thrive best with a moderate supply of water.

These three groups do not fully express all the relations of plants to the water supply, so two others are found convenient:

4. Tropophyles, or scasonal plants which are hydrophytes during part of the year and xeroplyytes during another part. ${ }^{1}$

5. Inlophyles, or salt-marsh plants and "alkali" plants, specics whieh can flomish in a very saline soil.

* To thl: Isstrictols: If it is nccessary to shorten the treatincnt of this subject, the latter part of the chipter, beginning with Sec. 442 , may bc omitted.

1 The plants whieh E. Warming, one of the foremost authorities, classcs as mesoplytes arc many of them grouped by another great authority, A. J: W. Schimper, as tropophytes. 
436. Difficulties in ecological grouping. It seems at first sight a simple matter to group plants in regard to their need of water. There can be no difficulty in recognizing as hydrophytes all plants like the bladderworts, water eresses, certain mosses, and most algre which live only in water. Cactuses, aloes, and similar plants are recognized at sight as xerophytes. But the chief difficulty is in dividing mesophytes from the other two assemblages, into which they shade by indefinite gradations. In

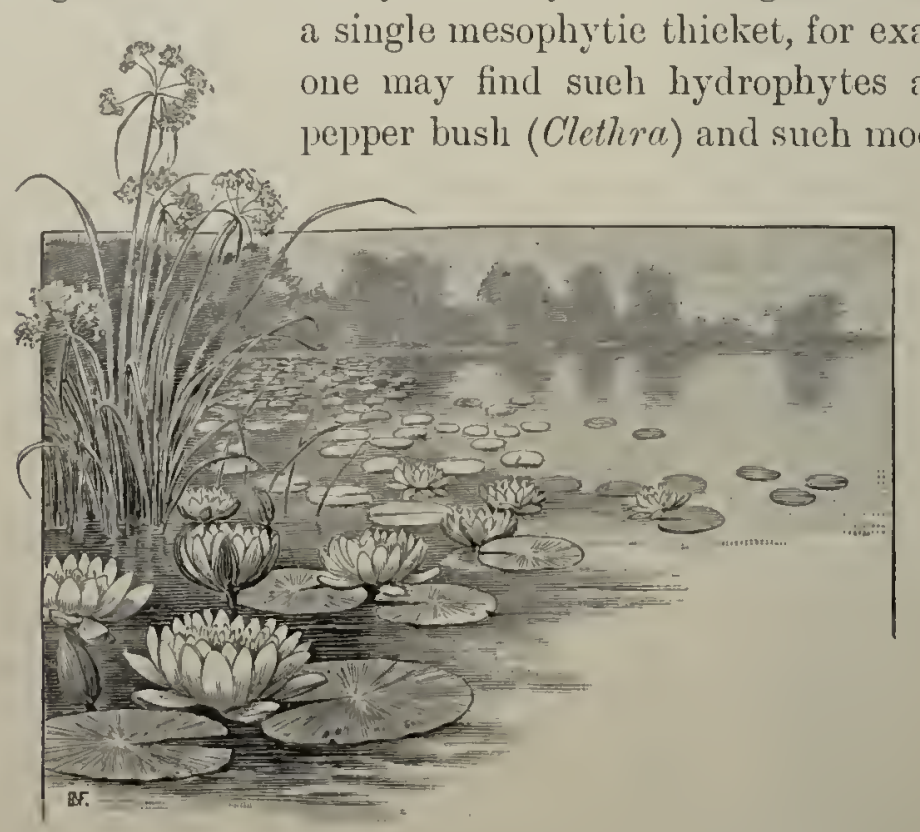

FIG. 352. Aquatic plants : pond lilies with floating leaves, and sedges with aërial leaves

xerophytes as the eatbriers (Smilax). In order to know whether the plants of a region have plenty of water or not, we must know not only how many inehes of yearly rainfall there are, but also what the soil is like, what is the temperature of the soil and air, whether or not there are dry wiuds, and whether there are fogs or heavy dews. A lichen on a bare rock may be living almost under desert eonditions, while a piteher plant in a bog near by has its roots in standing water (or in iee) nearly all the year round. 
437. Hydrophytes. Some of these are herbaceous aquatic plants, like the duckweed, the pickerel weed, the pond lily, and the water crowfoot; others, such as the cultivated "calla" (Richardia), the buck bean, the cat-tail, and the sweet flag, many ferns, mosses, and liverworts, prefer damp air and soil. All of them transpire freely, and many of them cannot live at all under the moisture conditions which suit ordinary plants.

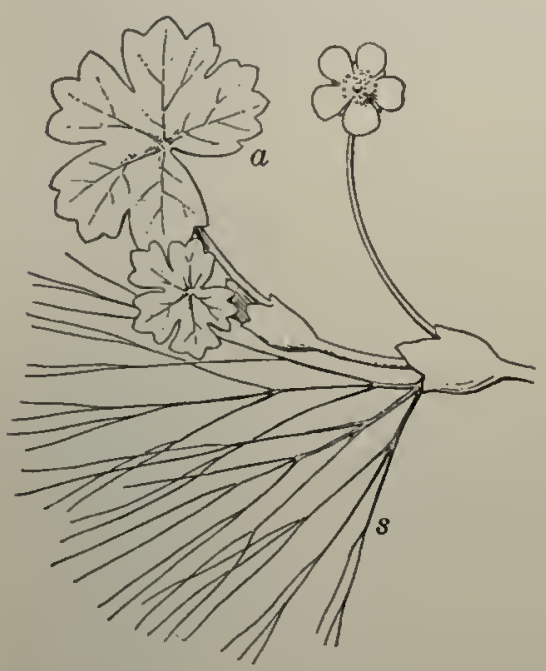

Fra. 353. Submerged and aërial leaves of a crowfoot (Ranunculus aquatilis)

The leaf with thread-like divisions is the submerged one. - After Giesenhagen
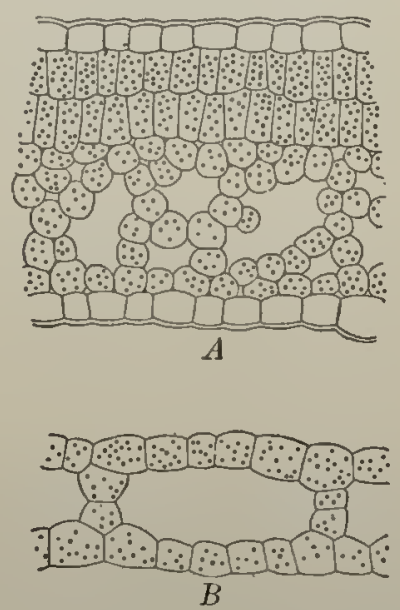

Fig. 35t. Cross sections of leaves of arrowhead (Sagittaria)

$A$, aërial leaf; $B$, submerged leaf. The submerged leaf has no ordinary epidermis and no palisade layer, but large air spaees. Much magnified.-After Bonnier and Sablon

Some aquatics have their leaves wholly submerged, others, such as the duckweed (Fig. 355) and the pond lilies (Fig. 352), have them floating, and still others, like the sedges in the same illustration, have their leaves freely exposed to the air. A few plants have both water lenves and air leaves (Fig. 353). Some aquatic plants are rooted in the mud, while others have no roots at all, or, like the duckweed, have only water roots. ${ }^{1}$

I See grouping in Sec. 454 . 
The leaves of land plants in very rainy sub-tropieal climates are exposed to the attacks of parasitic fungi. To ward off the

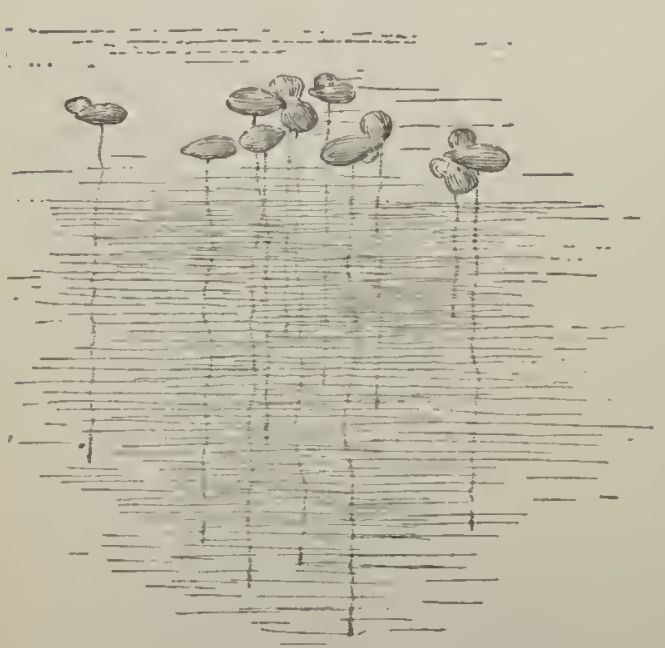
attaeks of these and to allow free transpiration, it is neeessary to keep water from accumulating on the surfaces of the leaves. This result is secured by a waxy deposit on the epidermis, and also by the slender

Fig. 355. The duckweed, a floating aquatic plant

prolongation to drain off surplus water, shown in Fig. 356. That this slender leaf tip is useful in the way suggested is proved by the fact that when it is cut squarely off the leaf no longer sheds water freely.

438. Xerophytes. A xerophyte is a plant whieh is capable of sustaining life with a very scanty supply of water. Since the first plants which existed were aquatics, we must consider that xerophytes are highly specialized and modified forms adapted to extremely trying conditions of life. A typical xerophyte is one which can live in a very dry soil in a nearly rainless region. The yucea and the eactuses (Figs. 50, 357)

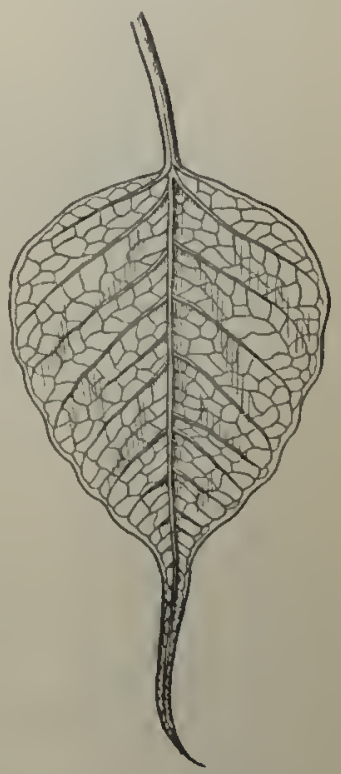

Fig. 350. I,eaf of ar: East Indian fig tree, ${ }^{3}$ with aslender, tapering point to strain off water

After Schimper are good examples of such plants. Less extrenely xerophytic are plants like the date palm (1ig. 53), which flourishes in the

\section{Ficus religiosa.}



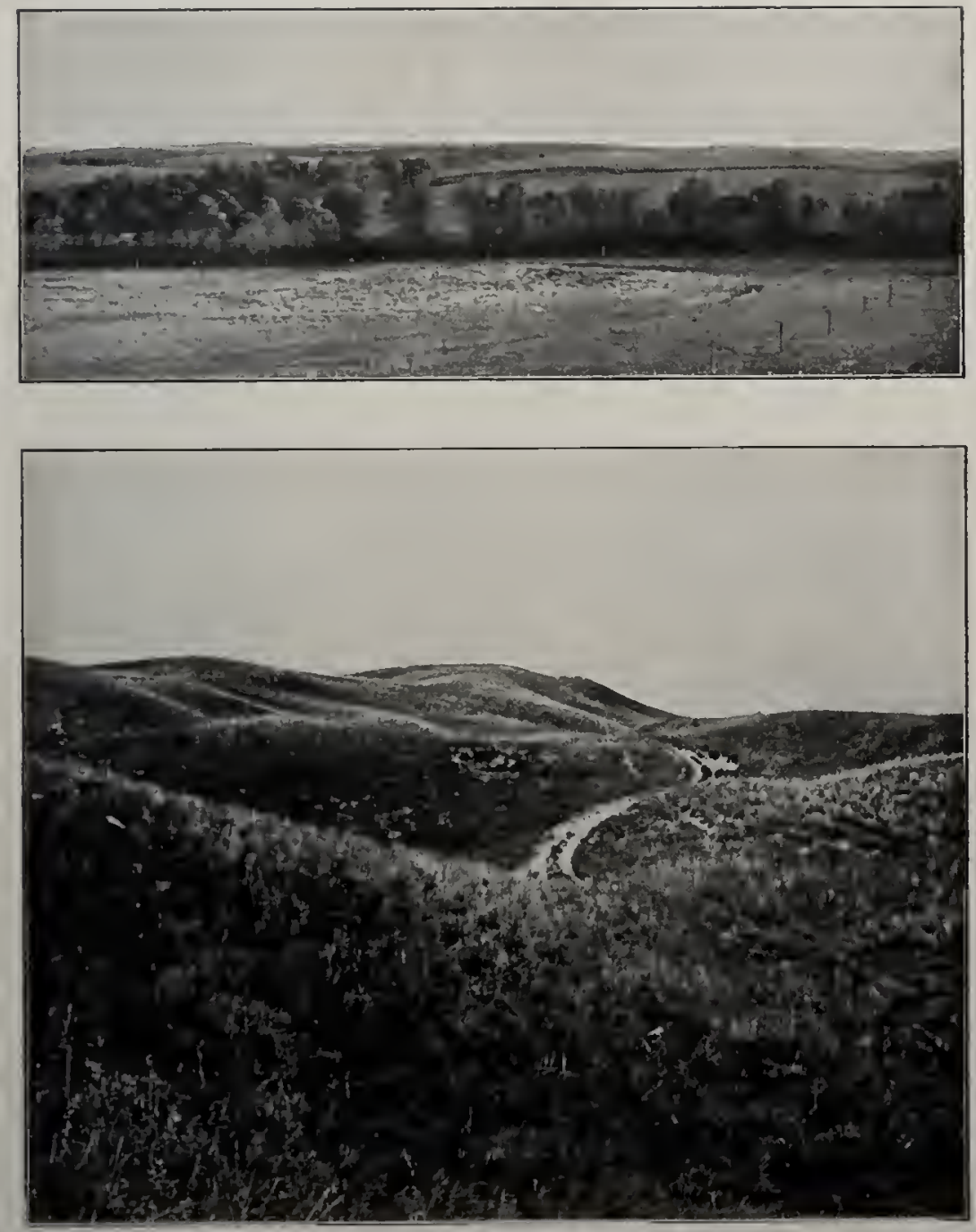

\section{PLate IX.}

The upper picture shows a belt of trees along a Nebraska river After U. G. Cornell

The lower picture shows xerophytic grasses on Nebraska sand hills After R. A. Emerson 


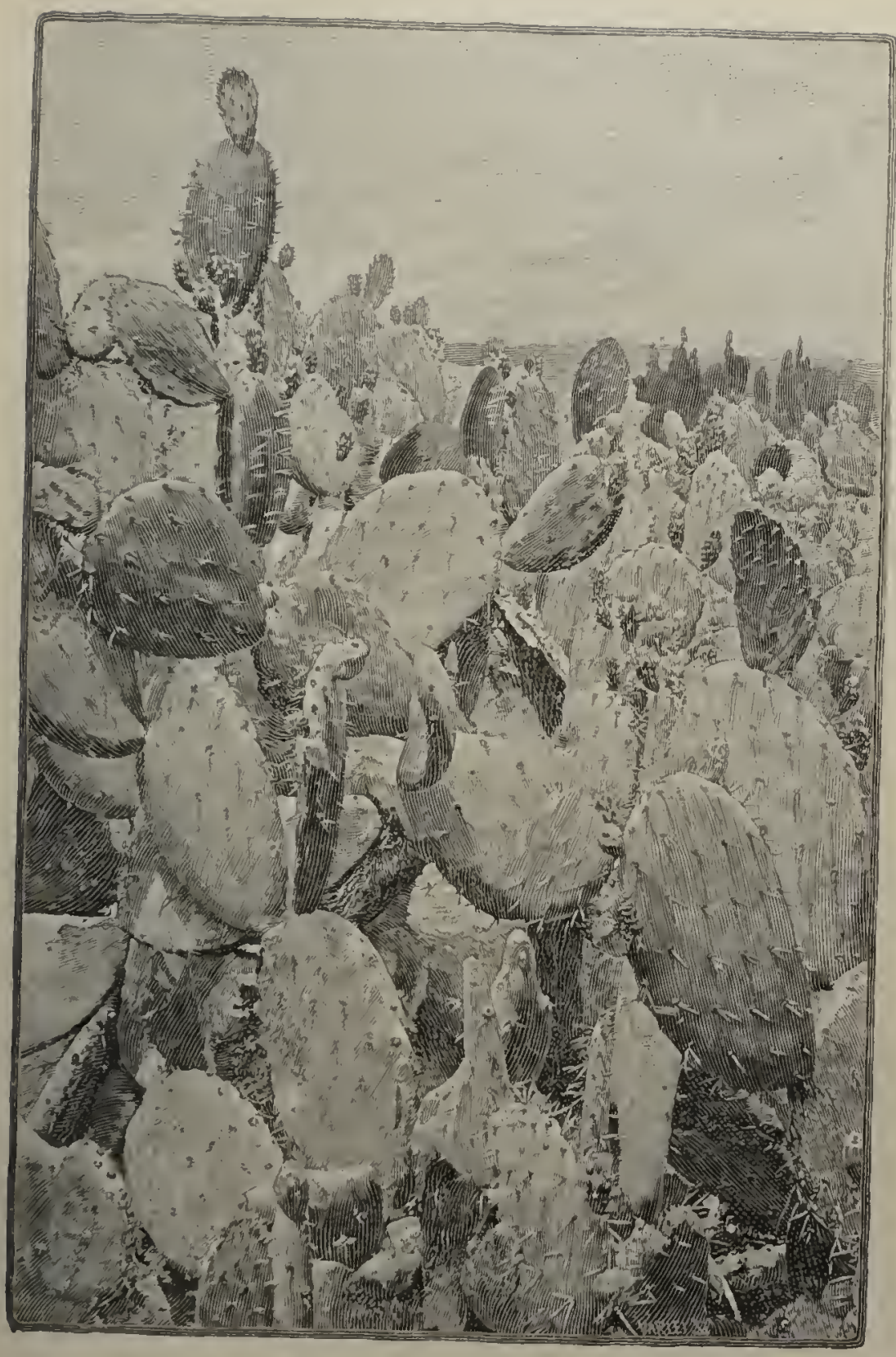

FIG. 357. A field of prickly pear cactus in California 
oases of the Sahara, where the soil is moist from the presence of springs, though rains are almost unknown, or the houseleeks and stonecrops found in many gardens, the so-called Spanish moss (Plate III), and lichens (Figs. 226, 227), all of which grow most rapidly in moist air, but cling to bare rocks and trunks

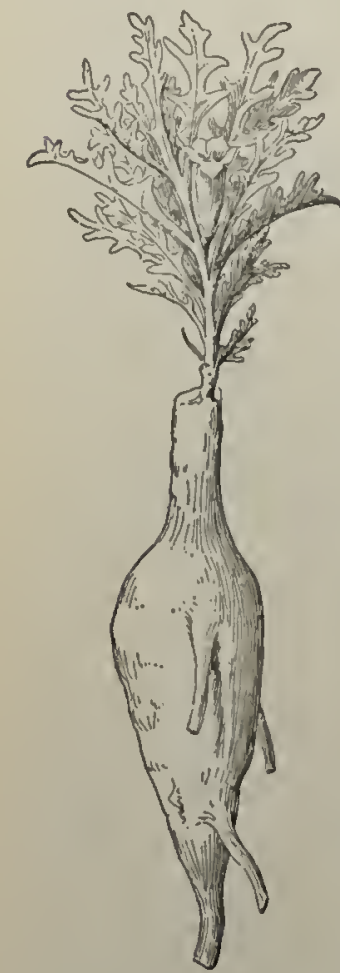

Fic. 358. II arpagophytum, a South African xerophyte

After Schimper of trees, from which they get no water.

It is important to notice that many xerophytes only economize water when foreed to do so. With an abundant supply of water they may transpire almost or quite as much as mesophytes. But a drought which would kill the latter would only cause the xerophytes to close their stomata and greatly lessen transpiration. A xerophyte must be capable of storing water and transpiring very slowly, like cactuses, aloes, stonecrops, and such fleshy plants with a thick epidermis, or else it must be able to revive after being thoroughly dried.

\section{Roots and stems of xerophytic seed} plants. Some xerophytes have roots which show no peculiarities of form or structure, but many make special provision for storing food and water in their roots. Such roots are fleshy and often, as in Harpagophytum (Fig. 358), are of great size compared with the portion of the plant above the ground. Nerophytic stems are frequently very thick in proportion to their length, sometimes even globular (Fig. 50), and they commonly contain large amounts of water. In leafless plants, like the cactuses, the surface for transpiration is much less than that offered by leafy plants. Many species which bear leaves shed most of them at the beginning of the dry season, and some remain thus in a half dormant condition for long periods, as is the case with many Euphorbias (Fig. 318). 
The epidermis, even on the younger portions of the stem, is highly cutinized, and this strueture makes any evaporation very slow.

440. Leaves of xerophytes. Since the leaf is in general the main organ of transpiration, we might expeet to find the leaves of xerophytes highly adapted to their enviromment. This is the

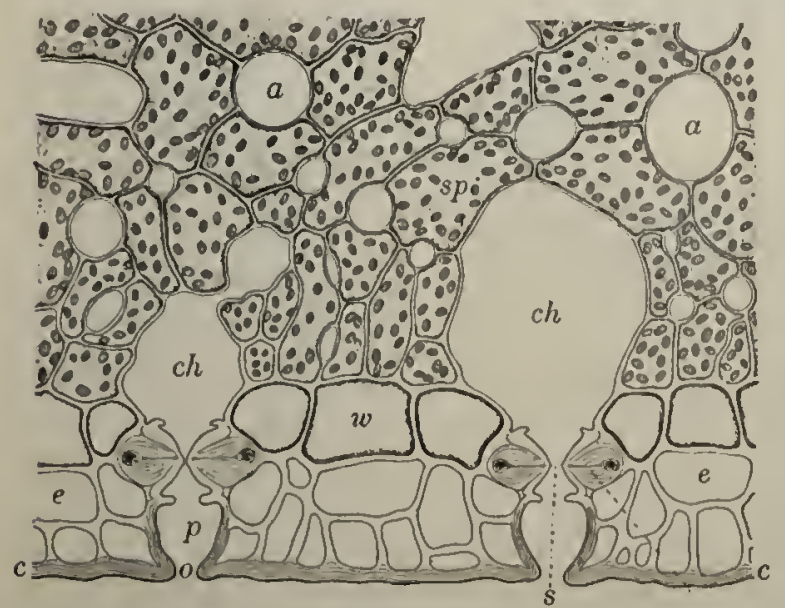

Fig. 359

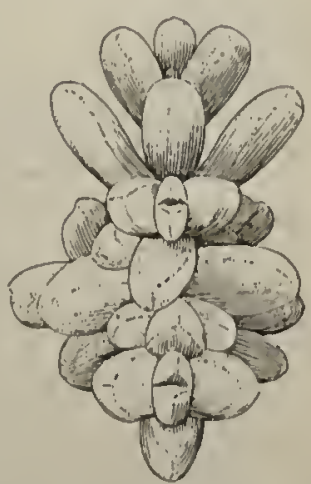

Fig. 360

Fıg. 359. Cross section of leaf of Ficus elastica

$c$, cuticle; o, opening to pit; $p$, pit leading to stoma ; $s$, stoma ; e, epidermal eells ; wo, speeial eells for storago of whter; ch, air chamber from stoma; sp, cells of spongy parenehyma; $a$, intercellular air spaces. Much inagnified

Fig. 360. Fleshy leaves of Mesembryanthemum, with stored water

\section{After Giesenhagen}

ease, and some of their prineipal means of protection from excessive transpiration are as follows ${ }^{1}$ :

1. A thick epidermis, often of several layers of eells (Fig. 359).

2. Storage of water in epidermal cells.

3. Small stomata, often deeply sunken (Fig. 359).

4. Epidermal hairs or seales. These are often extraordinarily abundant, and in some eases give one or both surfaces of the leaf a silky or silvery Iuster.

I See Warming-Groom-Balfour, GEcolngy of I'lants, Oxford, 1909. 
5. Coatings of wax ol varnish or incrustations of salts.

6. Fxtreme development of the palisade layer.

7. Reduction of the intercellular spaces.

S. Mucilaginous, water-retaining cell contents in the spongy

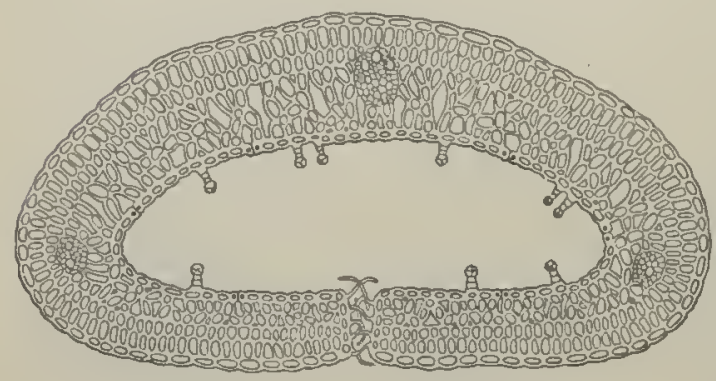

Fig. 361. Cross section of rolled-up leaf of crowberry (Empetrum nigmum)

Magnified. - After Kerner parenclyma of the leaf (usually in fleshy leaves, Fig. 360).

9. Permanent vertical position of leaves (Figs. 45, 110, 111). 10. Leaf movements, presenting only the edges to the sum during the heat of the day (Sec. 114).

11. Polling up of leaves, either permanent, as in Fig. 361 , or temporary, as in Indian corn and in Fig. 362.

12. Reduction of leaf area, - the lenves either few or small, or botl. Sometimes the leaf consists of little else besides a petiole; sometimes, as in Figs. 50 and 357 , foliage leaves are wholly absent.
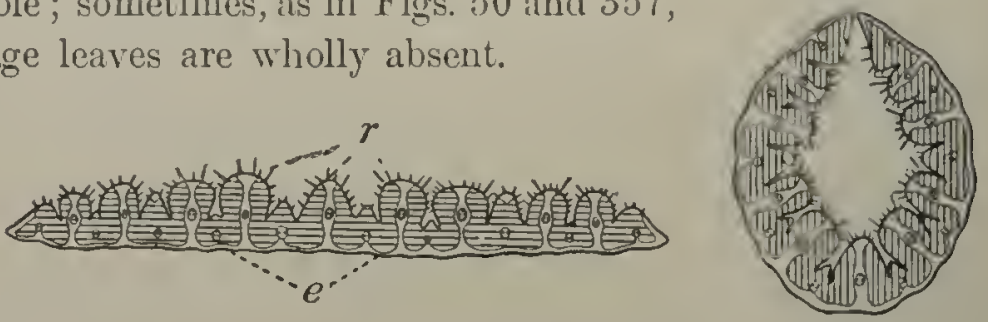

Frg. 362. Cross section of leares of a grass, ${ }^{1}$ unrolled for exposure to sunlight and rolled up to prevent evaporation

$r$, ridges of the upper epidermis, with many stomata on their surfaces; $e$, thick lower epidermis, without stomata. - After Kerner

In regions with a long rainless summer, like that of southern California or the coast of the Mediterranean, many shrubs are summer deciduous, and in their leafless condition the twigs 
lave been found to transpire less than 3 per cent of their maximum rate when leafy.

Some of the principal differences between lydroplytes and xerophytes may be summed up as follows:

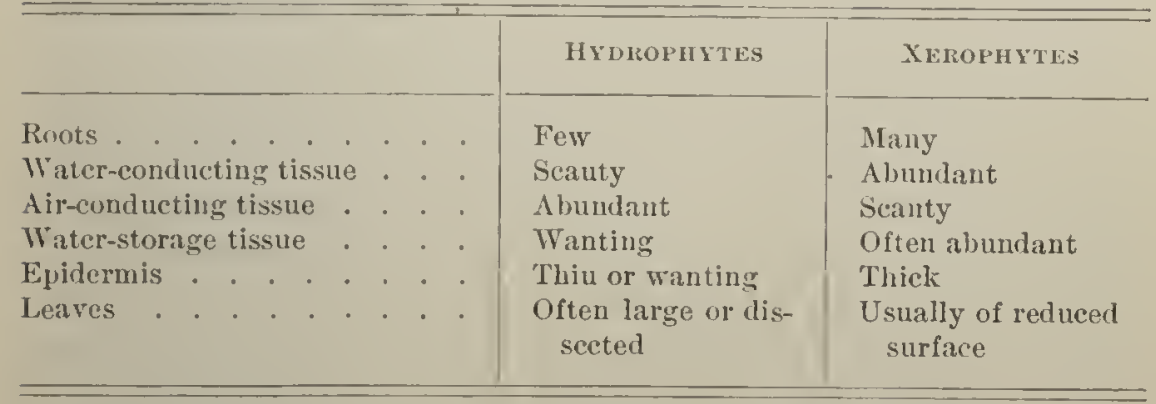

441. Mesophytes. A mesophyte is a plant which thrives best with a molerate supply of water. The great majority of the wild and the cultivated plants of the United States are mesophytes. What lias been lecined from Part I of this book about the forms, structure, and habits of ordinary plants, together with what the student's own observation, aside frum the study of botany, has taught him, should suffice to give him a fair idea of mesophytic plant life.

It is important to notice that most of our mesoplyytic trees and shrubs pass the winter (or in the extreme Southwest the dry season) in a leafless condition, and so transpire very little. So, too, our mesophytic, herbaceous perennials, such plants as the jack-in-the-pulpit, lilies, irises (Fig. 45), violets, and others, lose a large portion of their evapolating surface during part of the year by dying to the ground and leaving only the buried bulls, roots witl buds at the crown, or rootstocks alive.

All of the plants which make decided preparations for the season when water is hard to get may be classed as tropoplytes or periodic xerophytes.

442. Deciduousness an acquired habit. The practice of shedding the leaves before the arrival of severe freezing weather, when it becomes almost impossible to draw moisture from the 
earth, or before the culmination of the severest drought of suminer, may be regarded as a habit gradually acquired by deciduous trees and shrubs for their own protection. The duration of the period of leatlessness depends on the length of the dangerous season. Grapevines, for instance, in central Europe are leafy during about six months and leafless during the following six. But near Cairo, Egypt, the leafless periol is only two months long, and in very warm and moist climates the vines are evergreen. So, too, cherry trees are evergreen in Ceylon, and beeches in Madeira.

A large shrubiy Euphorbia, ${ }^{1}$ common in southern Italy, is foun 1 abso'ute'y leafless during July and August, when growing on the faces of limestone cliffs. But in moist soil, within

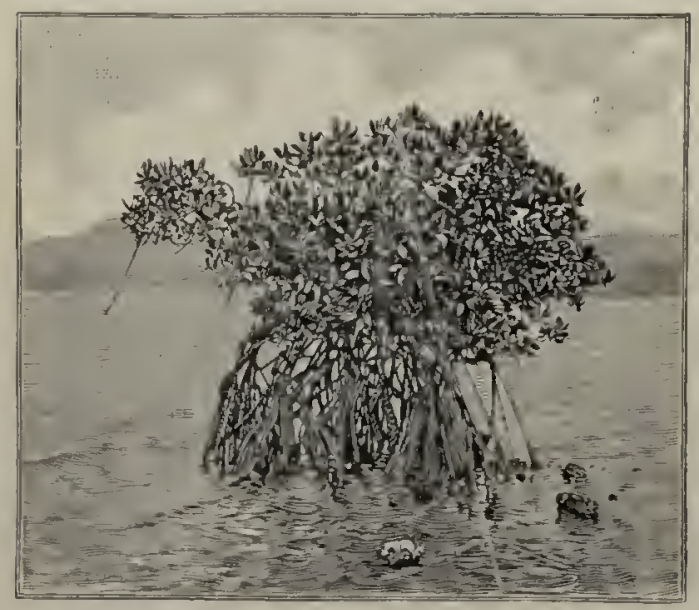

Fr.. 363. 'The mangrove, a halophyte After W. M. Davis a stone's throw of the leafless plants, there may be found others profusely leafy.

443. Halophytes. A halophyte is a plant which can thrive in a soil containing much common salt or other saline substances. The seaside is the principal region of halophytic vegetation, but many halophytic plants are also to be found in the neighborhoods about salt springs and the "alkali" lands of the Southwest and the Pacific slope.

The mangrove tree (Fig. 363) is one of the inost remarkable of halophytes. It grows in shallow water along the seashore, and sends out many aërial roots which at length find their way down into the salt mud. In this way it collects drift material and gradually extends the shore line farther out to sea. 
444. Form and structure of halophytes. Most halophytes present certain peculiarities of form and structure, such as succulence of stem or leaves, or both, a highly developed palisade layer, small intercellular spaces, diminution of evaporating surfice, and often specially, developed tissue for storage of water. These are evidently xerophytic characteristics, and their presence may be lue to two causes:

First, the occurrence of salt in the soil renders absorption of the soil water comparatively difficult, since osmosis takes place more readily between nearly pure water and the liquid contents of the young roots and root hairs than between salt water and the liquills within the root. Halophytes may therefore be on a short allowance of water even when their roots are constantly wet.

Sccond, the absorption of much salt would poison the plant, and therefore it is an advantage to keep down transpiration and with it the rate at which salt water is allowed to enter the roots.

445. Halophytes not dependent on salts. It is worth while to note the fact that halophytes are not usually dependent on a highly saline soil. They are salt tolerators rather than salt lovers. But they flourish in saline localities because they are capable of enduring much more salt than ordinary plants, and so can grow in salt marshes and such localities comparatively unhindered by the competition of non-halophytic species.

446. Other kinds of ecological classes. One may class plants with reference to their hatits in many other regards than aceording to their relative economy of water or their tolerance of salts. Only one other kind of classification need, however, be mentioned in this chapter, - that is, the division into sun-loving and shade-loving plants. Even in very dense forests some plants are found growing on the soil in the twilight formed by the shade of the trees. Some of this undergrowth is of seed plants,

$1 \mathrm{Or}$, in technical terns, the plants which grow in saline soils are facultative halophytes but not obligate halophy tes. 
and there are many ferus and mosses which flourish in such situations. Slade plants commonly have large pale leaves, and generally (except in ferms) the leaves are not much cut or lobed (Fig. 364, A). Sun-loving plants, on the other haud, usually

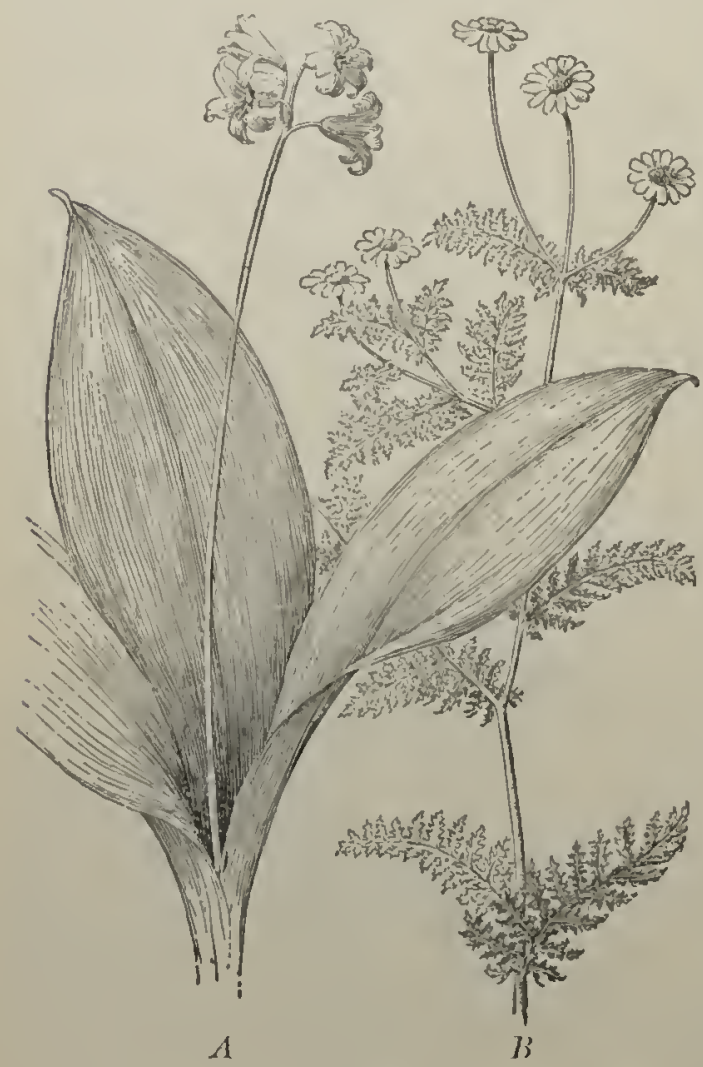

Fic. 361 have comparatively little leaf surface, and the leaves are often cut into narrow divisions (Fig. 364, B). Apparently the broad leaf surfaces in the one class are to expose many green cells to the light for starch making, while in the other class the slender leaf divisions expose enough assimilating cells, and at the same time the narrowness of the division permits plenty of light to penetrate to the plant's lower leaves. It is also, doubtless, much easier for leaves like those of the yarrow,

$A$, a shade plant (Clintoni $a$ ); $B$, a sun plant, ding fennel (Anthemis) the dog fennel, the tausy, the carrot, and their like to withstand the action of severe winds, to which they are often exposed, than it would be for leaves like those of the jack-in-the-pulpit, the trilliums, the lily of the valley, and similar leaves.

447. Sun leaves and shade leaves on the same plant. On plants of the same species, or even on the same individual, sun leaves and shade leaves often differ widely. On comparing the 
leaves from the exterior and the interior of the crown of a deciduous tree, or such an evergrcen species as the live oak or the olive, the sun leaves are usually found to be lighter-colored, of smaller area, thicker, and of more xerophytic structure than the shade leaves. The difference in size may be very great, the smallest sun leaves sometimes not covering more than a tenth of the area of the largest shade leaves on the same plant. There is usually, also, a notable difference in the form of the two kinds, the sun leaves being narrower in proportion to their length. Sun leaves are often scveral times as thick as shade leaves, and have far more completely developed palisade layers. The latter may even (in leaves grown in dense shade) be quite lacking, and the regular palisade cells be replaced by loosely arranged, funnel-shaped cells, witlı their broader ends toward the epidermis. Sun leaves have a much stronger fibro-vascular framework than those devcloped in a comparatively fceble light. In the case of plants which have the leares more or less hairy or scaly, the covering of these epidermal outgrowths is, as might be expected, much more dense on the sun leaves.

Probably the work of all kinds done by the sun lcaves is far greater than that done by shade lcaves of the same species. This is partly due to the much greater supply of encrgy daily received by the former from the sun, and it is also due to their more capacious conducting system and greater supply of chloroplasts. The transpiration of a given area of sun leaves is at times tenfold that of the same area of shade leaves (both being placed for the time in full sunlight).

448. Transition of a plant from shade conditions to sun conditions. It is cliaracteristic of many kinds of forcst trecs that the young seedlings are much morc tolerant of dense shade than the adult trees. Somctimes their seeds will hardly germinate at all unless thoroughly shaded, and the young trecs for the first few years flourish best in the shade. Afterwards most trees need a good deal of sunlight, but they may live long with a scanty supply of light. The red spruce sometimes lingers on for 


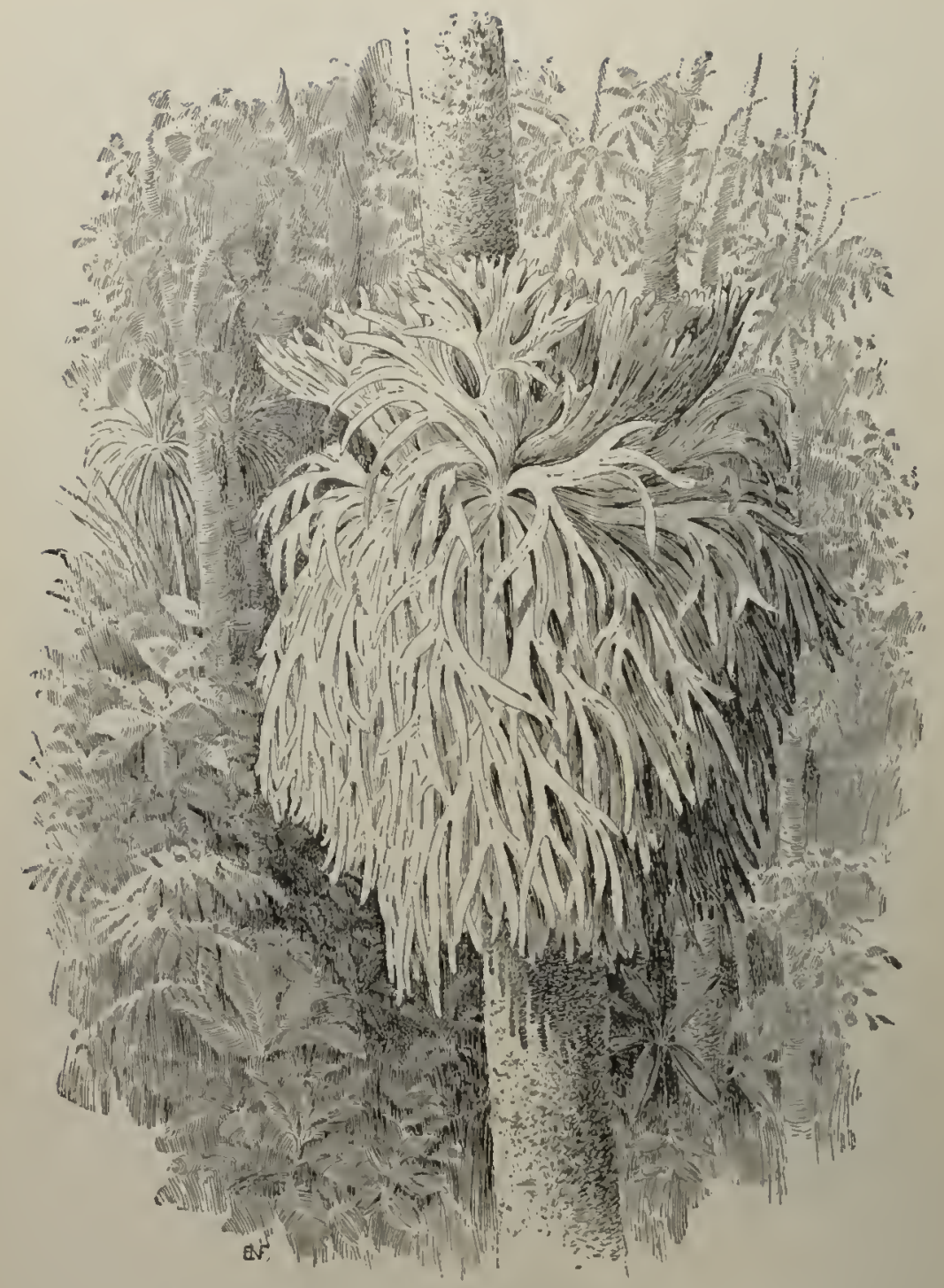

Fig, 365. All epiphytie fern (Platycerium) on a tree trunk

The more upright leares next to the trunk of the tree serve to collect moisture and to aecumulate a deposit of decaying vegetable matter, while the outer leares serve as foliage and bear spores, - After Schimper 
fifty or a hundred years, reaching meantime a dianeter of not more than two inches, and then, on getting nllore light, shoots up into a large and valuable timber tree. ${ }^{1}$

449. Epiphytes. It is even easier for a plant to secure enough sunlight in a forest legion by perching itself upon the trunk, branches, or leaves of a tree than by climbing, as our wild grapevines and the great tropical lianas do. There is a large number of such perched plants, or epiphyles (meaning upon a plant), partieularly in such tropical forests as tliose of Fig. 39 and Plate XIII. Epiphytic forms occur anong many different groups of seed plants and of spore plants, especially lichens. The staghorn fern, shown in Fig. 365, is a good example of an epiphyte. Instances among seed plants are the so-called Florida or Spanish moss (Plate III) and orchids like those in Fig. 13.

450. Water supply of epiphytes. Epiphytes secure their supply of water and dissolved salts in several different ways, some through roots by absorption from the moist bark on which they grow, other's by sending roots down until they reach the earth, others by means of a network of aërial roots fully exposed to the air, - as in the orehid just nientioned, - and still others by means of leaves which function as roots. Some species, like the Florida moss, absorb water very rapidly from dew or rains, while others, as the stag-horn fern (Figs. 272, 365), and Tillandsia bullosa, a relative of the Florida moss, liold water in reservoils at the bases of the leaves, with or without the aid of spongy decaying vegretable matter. From the great vicissitudes in their water supply most epiplyytes among seed plants possess xerophytie cliaracteristics.

1 See the Primer of Forestry, lart I, United States Department of Agriculture, 1899 , pp. 33-35. 


\section{CHAPTER XXXVII}

\section{PLANT ASSOCIATIONS; ZONATION *}

451. Plant associations. One of the first things which the young field botanist learns is the fact that the distribution of plents depends largely on the character of the ground they oceupy. There is in any small territury, such as a county, for example, one assemblage of plants for the waters of ponds and another. for their shores, one for swamps, one for moderately dry uplands, one for very dry hilltops, and so on. The aquatic plants of the sea are very different from those of fresh water. Sandstone and limestone soils have vegetations peculiar to themselves; ${ }^{1}$ the long-leaved pine, the scrub pinc, and the chestnut are characteristic trees of sandy soils, while most of the oaks, the hackberries, and the black walnut are generally found in limestone regions.

The collection of plants as found in any giren kind of station or habitat, especially when prominent and well defined, is called an associatica. Thus we have marine aquatic associations, seabeach associations, pond associations, bog associations, sancihill associations, neadow associations, heath associations, forest associations, and many others.

452. Subdivisions of plant associations. Usually the plant association is divisible into assemblages, which are much more alike in their vegetation than is the association as a whole. Thus a woodland association may consist of pine pateles, oak patches, and birch patches. A grass-land association may consist of

* To the Ixstrictore : If it is necessary to eut hown the diseussion of these topics to little more than definitions, only the first three sections of the chapter need be read.

${ }^{1}$ Perhaps this is sometimes due to physieal rather than to chenical causes. In other words, the chemical differences in soils are usually accompanied hy differenees in their porosity, their capacity for retaining water, for absorbing heat from the sun's rays, and so on, which greatly modify their effect on plants. 
patehes of timothy and others of redtop, and so on. Such minor groups often reeeive speeial names ending in -ctum; e.g. a Pinus assemblage is ealled a pinetum.

In some cases it may be possible to show that the minor group is based on the mutual relations to each other of the plants which compose it, while the assoeiation as a whole depends on the characteristies of the station in which it exists, i.e. on soil, climate, and so on. ${ }^{1}$

453. Zonation. The most striking oecurrence of plant associations is in localities where sharply contrasted eonditions of life exist side by side. It is often possible, within the radius of a few hundred feet, to travel from the floating aquatic vegetation of the deeper waters of a pond, through the rooted aquatie forms of the shallower water, to the sub-aquatic speeies of the wet shore, then past the sand-loving plants of the sand dunes farther baek from the water, and finally into the wood or meadow vegetation of ordinary soil. Such a series of zones is shown in Fig. 366 and in Ilate $\mathrm{X}$.

Similar diagrams may be made to illustrate the distribution of plants about a salt spring or pool, along the scashore or the margin of a salt marsh, on the top and sides of an isolated hill with a dry, ledgy, or sandy summit, or even about an old unused gravel pit or a railroad embankment. Lcss elearly defined but very interesting and extensive zones may be studied with relation to submerged aquaties, partieularly among marine plants, as shown in Fig. 202.

Among the most striking and symmetrienl instances of zonation arc those to be found about the salt marshes of some of the deserts of the far West. The waters of these marshes arc too salt to support vegetation, but encireling their borders may sometimes lo found as many as six broad coneentric bands of abundant vegetation.

I In the admirable Warming-Groom-Balfour $O$ Ecology of Plants (Clarendon Press, Oxford), the term "formation" is userl for the groups here calleil ass?ciations. For examples of associations see Cowles, Ecology, Chapter vit. Anerican Book Conpany, New York. 

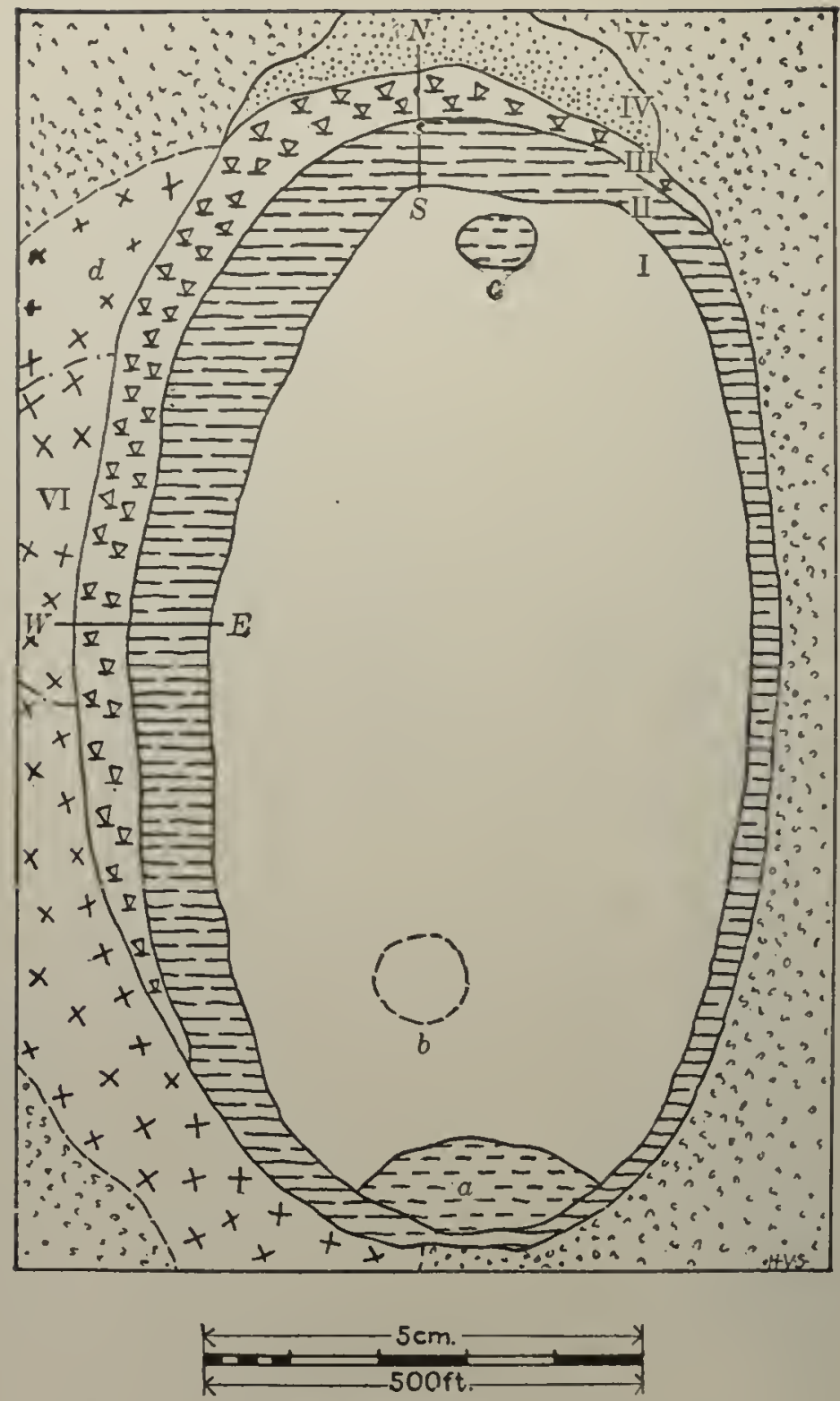

Fri. 366. Zonation about a pond

I, pond; II, bog zone; III, swampy thieket zone; IV, inenmplete zone in arill soil of a sand pit; $\checkmark$, dry mealow zone: Vl, dry wonlland zone; $a$. Hoating mas of Eriocuulon: b, deepest area in pond, six to tun fort: $c$, sulall patch of tall

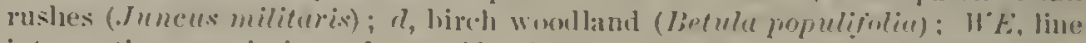
interseeting associations of west side of pout; $\triangle . \checkmark$, line intersceting assuriations of north end of pond 
454. Zonation in Fig. 366. The diagram represents some of the principal associations obscrver in and about a rather shallow pond in eastern Massachusetts in October, 1905.

The pond was almost encircled by six zones of vegetation, only one of which (the bog zone) entirely surrounded the water. All the zones except that of the meadow consisted of wild specics, growing under nearly natural conditions.

The pond itself had a rather scanty algal vegetation, among which the most noticeablc forms were a green alga (Bulbochote), related to Edogonium, and a blue-green alga (Colospharium).

Seed plants were well represented in the waters of the pond. In the deepest portion, at $b$, no seed plants were found extending to the surface, but there were many young specimens of a rush (Juncus mitituris) with filiform leaves deeply submerged. In general the pond was populated by pond lilies (Castalia), cow lilies ( $N$ rymphacu), thrce or morc species of pondweed (Potamogc(on), with much pipewort (Eriocaulon) and duckweed (Lemna). In the shallowest portions, usually in six inches or less of water, were found some six other herbaceous species.

The spermatophytic vegetation of the pond may be divided according to its mode of growth into classes as follows:

Floating plants . . . . . . . . . Lemna

Plants which grow rooted and submerged . Potomogeton

Plants which grow rooted, but with more or less $\left\{\begin{array}{l}\text { Juncus } \\ \text { Pontederin } \\ \text { of the stem or leaf surface in air. } . \cdot . \\ \text { Nymplem }\end{array}\right.$

Plants of shallow water (six inches or less), or which grow on floating rafts like that at $a$, with most of the plant body aërial .

$\int$ Eleocharis Nyris, etc.

455. Contents of the zones. It would involve too much detail to enumerate the species of the several land zones (II-VT), but they may be bricfly summarized as follows:

The bog zone contained some twenty-one conspicuous species, especially peat moss and herbaccous secd plants. 
The swampy thicket zone contained mostly shrubs and small trees, including an alder, a blueberry, a pepper bush (Clethra), gray birch, and red maple.

The arid soil zone contained more than twenty species, mostly sand-frequenting annual séed plants.

The meadow was growing under artificial conditions, and it was merely noted that its flora consisted mainly of cultivated grasses.

The dry woodland zone contained some twenty-thrce conspicuous forms. The three principal trees, in the order of their numbers (omitting the region $d$ ), were white pine, northern pitch pine, and red oak. The forest floor contained an abundant growth of shrubs and herbs. At least five species of the latter were common to the woodland zone and the arid sand zone.

The marked differences in the character of the vegetation of the several zones were almost wholly due to differcnces in the amount of water supply. Not only would the trees have died if transplanted into the pond, or the pond aquatics have died if removed to the dry sandy soil of the woodland, but in general each sct of plants was better off in its own zone than it would have been in any other. The sand-pit flora was, however, only a short-lived succession, soon to be followed by the woodland flora.

456. Similar vegetation due to similar conditions. As soon as one begins to collect plants in a set of localities new to him, he often discovers that his old acquaintances are still to be found grouped as he has becn accustomed to sec them. The muddy borders of ponds from Maine to Minnesota and beyond arc fringed with the same kinds of bur reeds and sedges, set with water plantain and decorated with the soft white blossoms of the arrowhead. The sand duncs along the northem Atlantic coast and those that bordcr Iake Michigan are clothed with a sparse vegetation, which in both cases includes the little bench plum, such coarse grasses as that shown in Plate I, and the straggling sea rocket. Barnyards and waste grounds about farm 


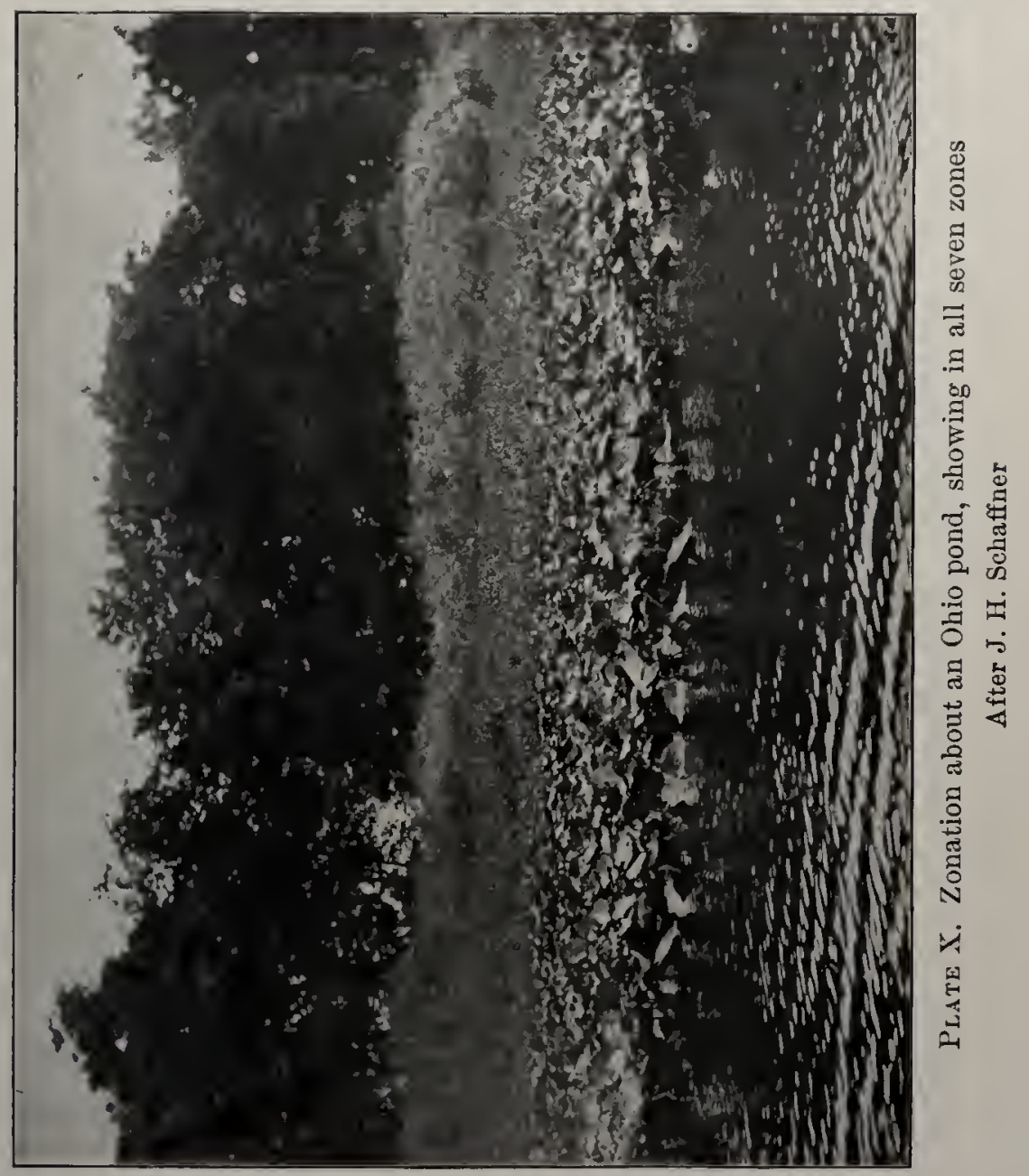



buildings from Massachusetts to Missouri contain such weeds as the $\operatorname{dog}$ fennel, the low mallow ("cheeses"), motherwort, catnip, and some smartweeds.

A little study of such cases soon leads one to the conclusion that these plant associations and multitudes of others exist bccause all the plants in each association are adapted to their spccial cnvironment. Wherever such an environment occurs such an association will be found in it, ${ }^{1}$ or, if not already there, will flourish when introduced.

457. Similar species replace each other. Two sets of localities alike in many respects but unlike in some points are often inhabited by different species of the same genus. For instance, the pine barrens of New England and the adjacent states are commonly corered with the northern pitch pine, ${ }^{2}$ while far southward, in sandy soil, its place is taken by the long-leaved pine. ${ }^{3}$ Along streams and swamps northward the speckled alder ${ }^{4}$ is generally found, while southward the smooth alder ${ }^{5}$ is most common. In rich woods of the northeastern United States the painted trillium ${ }^{6}$ and the erect trillium (" Penjamin," or "squaw loot ") ${ }^{7}$ are the commonest species, while farther south, in similar localities, the sessile trillium, ${ }^{8}$ Underwood's trillium, ${ }^{9}$ and the large-flowered trillium ${ }^{10}$ are abundant.

In all such cases - and they are very numerous - we are to infer that the genus is peculiarly well adapted to some special set of conditions, as sandy soil, brooksides, or the rich, shaded soil of woodlands. The more northerly species are capable of enduring the severe winters and brief summers of their regron, while the more southerly ones perhaps cannot do so. The relative warnth of the climates in which they live may not be the only reason, or even the principal reason, for the

1 That is, in localities not separated by such natural barriers as seas, high mountains, or deserts.
2 Pinus rigida.
${ }^{5}$ A. serrulata.
8 T. sessile.
${ }^{3} P$. palustris.
- Trillium erythrocarpum.
9 T. Underwoodii.
1 Alnus incana.
7 T. erectum.
$10 T$. grandiflorum. 
distribution of such plants as those just mentioned, but it is one factor, at any rate, and it is certain that, on the whole, most of our native and thoroughly naturalized plants are growing under what is, for them, the best environment, since they cannot usually be made to exchange places with one another. If a square mile of land in Louisiana were to be planted with Minnesota species, and a square mile in Minnesota with Louisiana species, it is very improbable that either tract, if left to itself, would long retain its artificial flora. To this rule there are, however, important exceptions.

458. Associations of few species. It is not uncommon to find tracts of land or water inhabited by great numbers of seed plants of the same species, so as almost to exchude all other vegetation except microscopis spore plants. Ponds and slowly flowing streams are often filled in this way with the water hyacintl, 1 the water cress, or the American lotus. ${ }^{2}$ The canebrakes of the South and the wild rice swamps along northern lakes and rivers are other examples of an extremely simple flora spread over large areas. Prairies not infrequently for many square miles are covered mainly (not entirely) with a very few kinds of grasses. The arid plains of the Rocky Mountain region, over thousands of square miles, contain little vegetation except sagebrush (Artemisia tridentata), and immense tracts of snow in the arctic regions are destitute of plant life except for the red-snow alga (Spharella nivalis, Sec. 215), by which they are colored pink.

In all such cases it is evident that the single species or the few species which populate the area can endure the conditions of existence there so well that other plants which migrate into their territory cannot compete with them. 


\section{CHAPTER XXXVIII}

\section{PLANT GEOGRAPHY *}

459. Regions of vegetation. The earth's surfaee (that of the land) has been deseribed by one of the greatest of geographieal botanists ${ }^{1}$ as divided into twenty-four regions of vegetation. IIs grouping takes aeeount of all the prineipal continental areas whieh have a eharacteristie set of plants of their own, as well as of the most important islands. But a simpler arrangement is to consider the plant life of the earth as distributed among the following regions:
1. The tropical region.
2. The temperate regions.
3. The aretie regions.
4. Mountain heights.

5. Bodies of water.

Any good geography gives some account of at least the land vegetation of the earth. It is only necessary in the present chapter to point out a few of the most important characteristics of the plants of the areas mentioned above and to give some reasons why the plant population of eaeh has its speeial eharaeteristies.

460. Tropical vegetation. Within the tropies two of the great faetor's of plant life aud growth, namely, light and heat, are found in a higher degree than elsewhere on the earth. Moisture, the third requisite, is in some regions very abundant (over forty feet of rainfall in a year), or sometimes, in desert areas, almost laeking. We find lere, aeeordingly, the greatest extremes in amount of vegetation, from the bare sands or rocks of the Sahara desert (Fig. 367) to the densely wooded basin of

* To тне Isstructor: Unless the present ehapter ean be discussed in considerable detail, it might better be omitted than hastily dealt with.

${ }^{1} \Lambda$. Grisebach, in Die Vegetation der Erde. 
the Kongo and of the Amazon. The rainy forests of the tropics contain extraordinary numbers of species. For example, near Lagoa Santa in Brazil, in an area of three square miles, there are found about four hundred species of trees. Xerophytic plants, many of them with extremety complete adaptations for supporting life for long periods without water, are characteristic of tropical deserts, while many of the most decided hydrophytes among land plants are found in the dripping sub-tropical forest

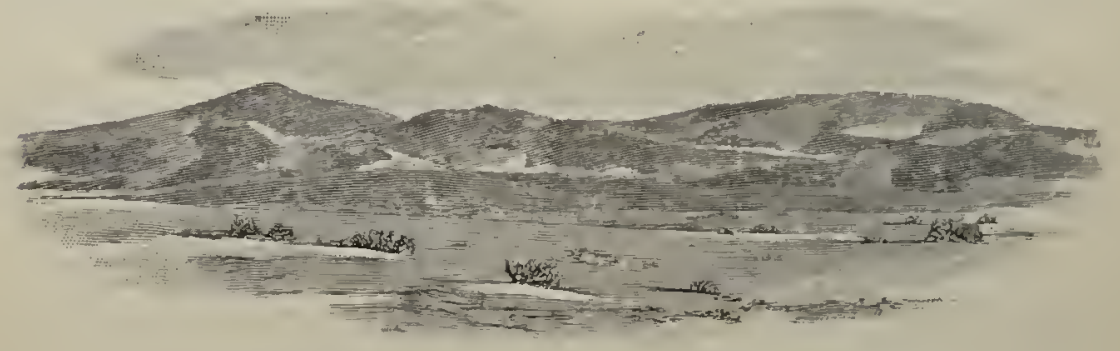

F1G. 367. Ilills of drifted sand in the Sahara After W. M. Davis

interiors. Throughout a large part of the belt, reaching five degrees each way from the equator, there are daily rains the year round.

461. Vegetation of temperate regions. We are all familiar in a general way with the nature of the plant life of the north tcmperate zone; that of the south temperate is in most ways similar to our own. Most of the annuals and biennials are of a medium type, not decided xerophytes nor hydrophytes, and the perennials are mainly tropophytes. There are no descrt areas so large or so ncarly destitute of plants as tlose found in sub-tropical regions, neither are there any such luxuriant growths as occur in the rainy forest regions of the tropies. On the other hand, the largest trees on earth, the giant redwoods, or Sequoias (Fig. 33), occur in the temperate portion of North America, along the Sierra Nevada, and the taller, though less bulky, gum trees (Eucalyptus) of Australia grow in a warm temperate region. 
462. Temperate plant associations due to special conditions of soil. Even where the climate is a moderate one as regards temperature and rainfall, peculiar soils may cause the assemblage of exceptional plant associations. Some of the most notable of such associations in temperate North America are those of the salt marshes, the sand dunes, and the peat bogs.

In salt marshes the water supply is abundant, but plants do not readily absorb salt water by their roots, so that the plants which grow in salt marshes usually have something of the structure and appearance of xerophytes. Some of them are fleshy (Fig. 368), and some species are practically leafless.

Sand dunes, whether along the seacoast or near the Great Lakes, offer a scanty water supply to the roots during much of the year, and the soil water contains less of the raw materials for plant food than is offered by that of ordinary soils. Many grasses thrive, however, in these shifting sands (Plate I), and some, like the beach grass $(A \mathrm{~m}$ mophila) of the Atlantic coast and

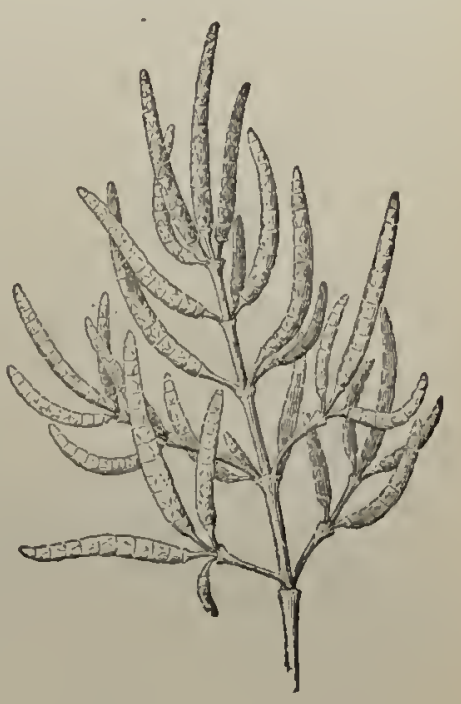

Fif. 368. $\Lambda$ halophyte (Salicornia) the Great Lakes, will continue to grow upward as the sand is piled about them by the winds, until they have risen to a level of a hundred feet above the starting point.

The water of peat bogs contains little mineral natter, and only a very scanty supply of nitrogen, in the form of nitrates dissolved in it. The bog plants, therefore, must either get on with an exceptionally small supply of nitrogen, or they must get it from an unusual source. The peat mosses adopt the former alternative, while the sundews, the pitcher plants, and some other species adopt the latter and derive their nitrogen supply largely from inseets which they eatch, kill, and digest. 
463. Arctic vegetation. The seed plants of the arctic flora are mostly perennials, never trees, though many of the species, as the willow, alder, and birch, belong to groups that are trees in other regions. By the large bulk of the underground portion as compared with that of the part above ground, they are adapted to a climate in which tley must lie dormant for not less than nine months of the year. The flowers are often sliowy and appear very quickly after the brief summer begins. Mosses

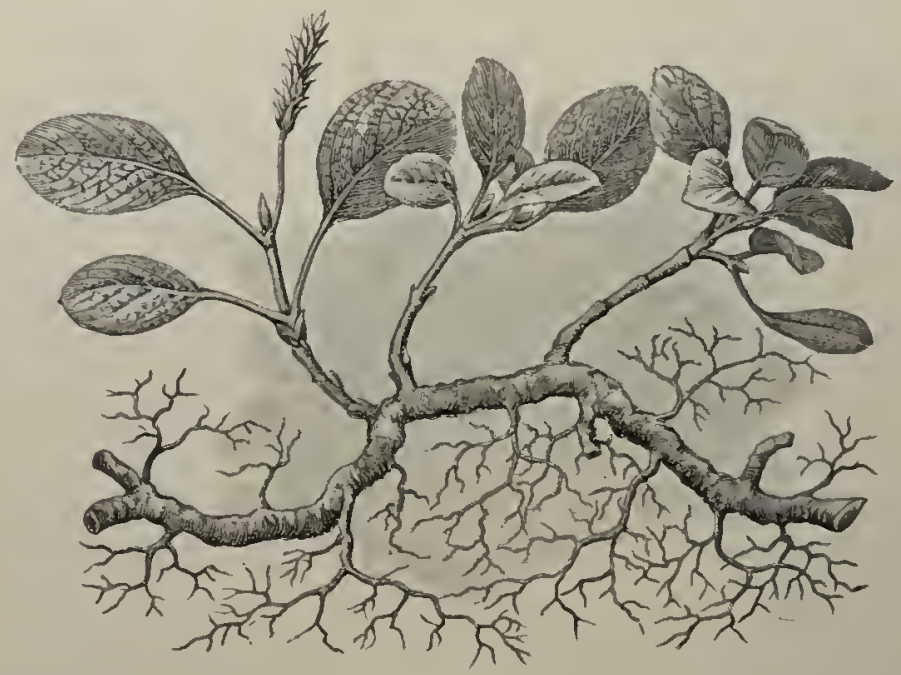

FIG. 369. A plant of aretic willow

About natural size

and lichens are abundant, - the latter of economical importance because they furnish a considerable part of the food of reindeer.

464. Mountain or alpine vegetation. In a general way the effect of ascending a mountain, so far as vegetation is concerned, is like that of traveling into colder regions. It was long ago suggested in regard to Mount Ararat, that on ascending it one traversed first an Armenian, then a south European, then a Firench, then a Scandinavian, and finally an arctic flora. $\mathrm{U}_{\mathrm{p}}$ to a certain height, which varies in different latitudes, the slopes of mountains are very commonly forest-covered. The altitude up to 
which trees can grow, or as it is commonly called in this country the "timber line," is somewhat over twelve thousand feet in the equatorial Andes, and lessens in higher latitudes as one goes either way from the equator, until in the aretic regions it reaches sea level. In the White Mountains, for instance, the timber line only rises to about forty-five hundred feet. The seed plants of alpine regions in all parts of the earth have a peculiar and characteristic appearance. It is easiest to show how such

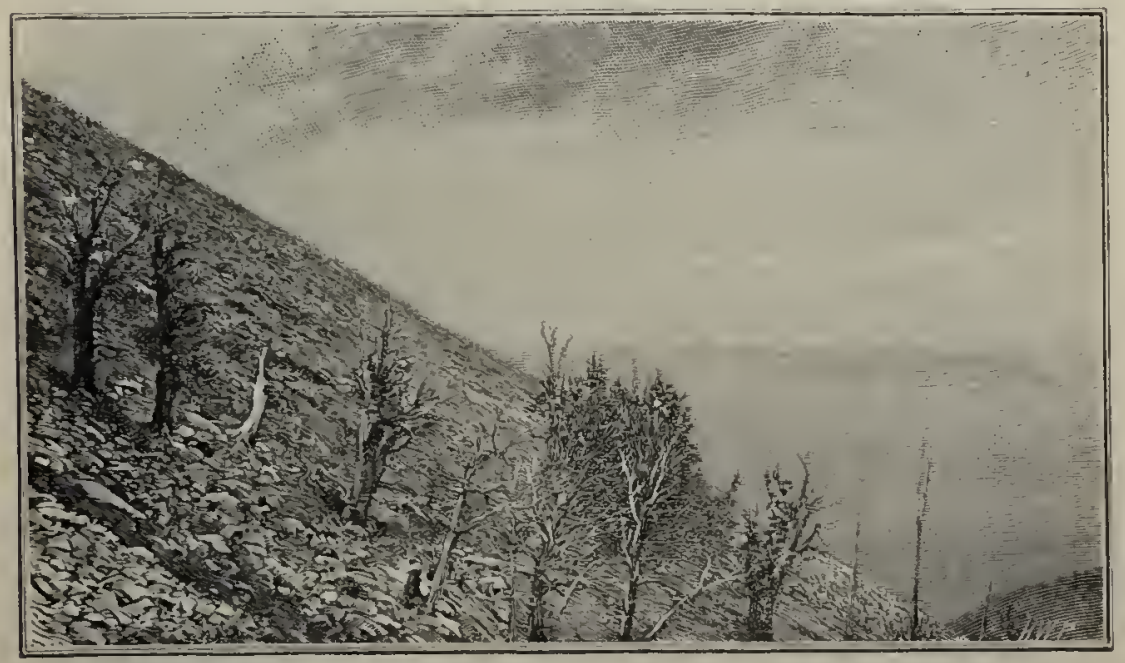

Fic. 370. 'Trees near the timber line on the slope of Pikes Peak After W. M. Davis

plans differ from those of the same species as they look when growing in ordinary situations by reference to the plants themselves or to good pictures of them (see lig. 372). The differences between alpine and non-alpine plants of the same or closely related species liave been summed up as follows : "The alpine individuals have shorter stems, smaller leaves, more strongly developed roots, equally large or somewhat larger and usually somewhat more deeply colored flowers, and their whole structure is drought-loving (xerophilous)."

I By A. F. W. Schimper. 
Trees at great elevations are stunted and gnarled by scanty nutrition and pressure of wind and snow (Fig. 370).

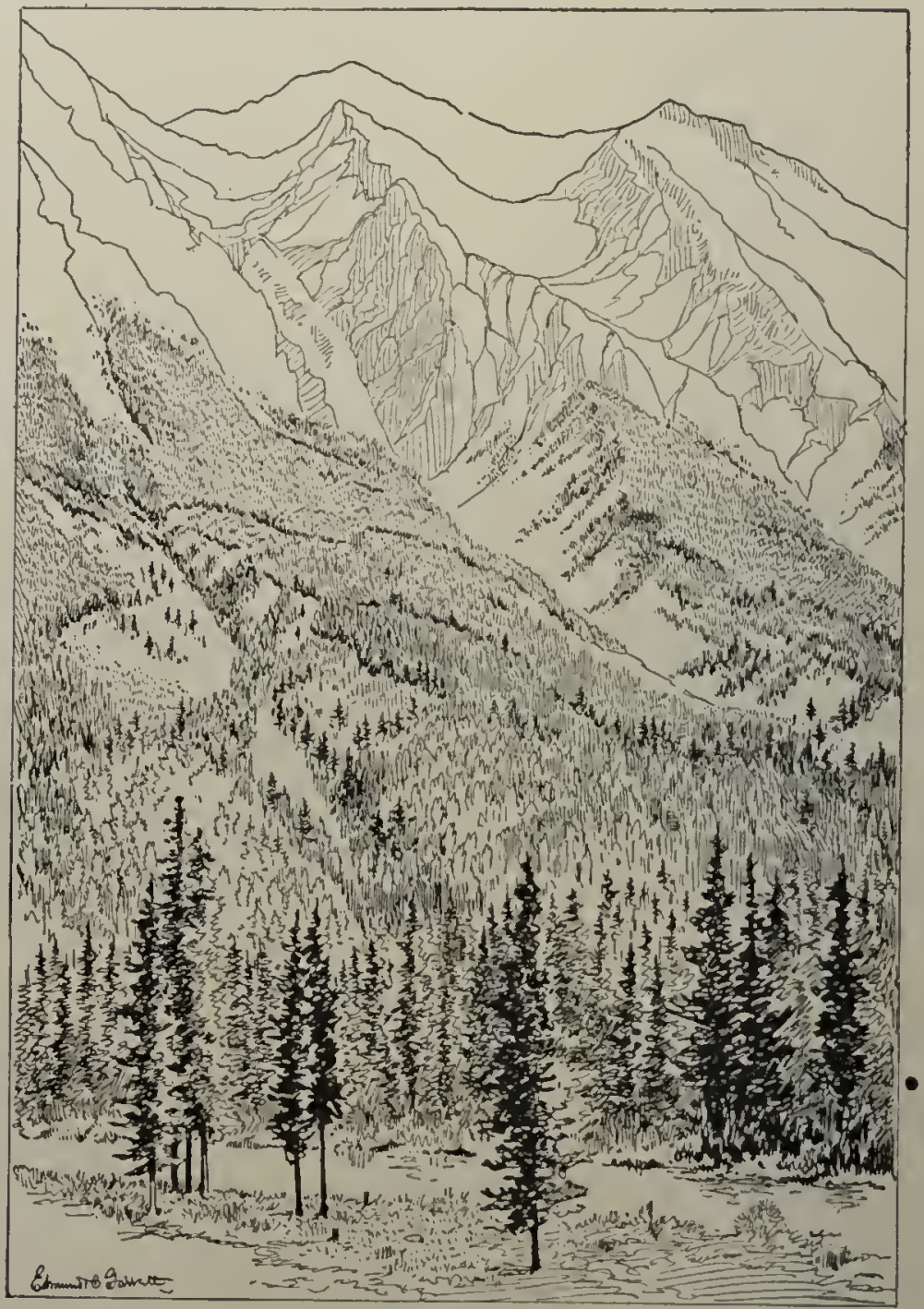

FIG. 371. Decrease in size of trees at high elevations (Canadian Rockies)

Where the prevailing winds come mainly from one quarter, all the trees of considerable areas may be inclined strongly in one direction, as in Plate XI. ${ }^{1}$

1 This phenomenon is also very noticeable along many coasts. 


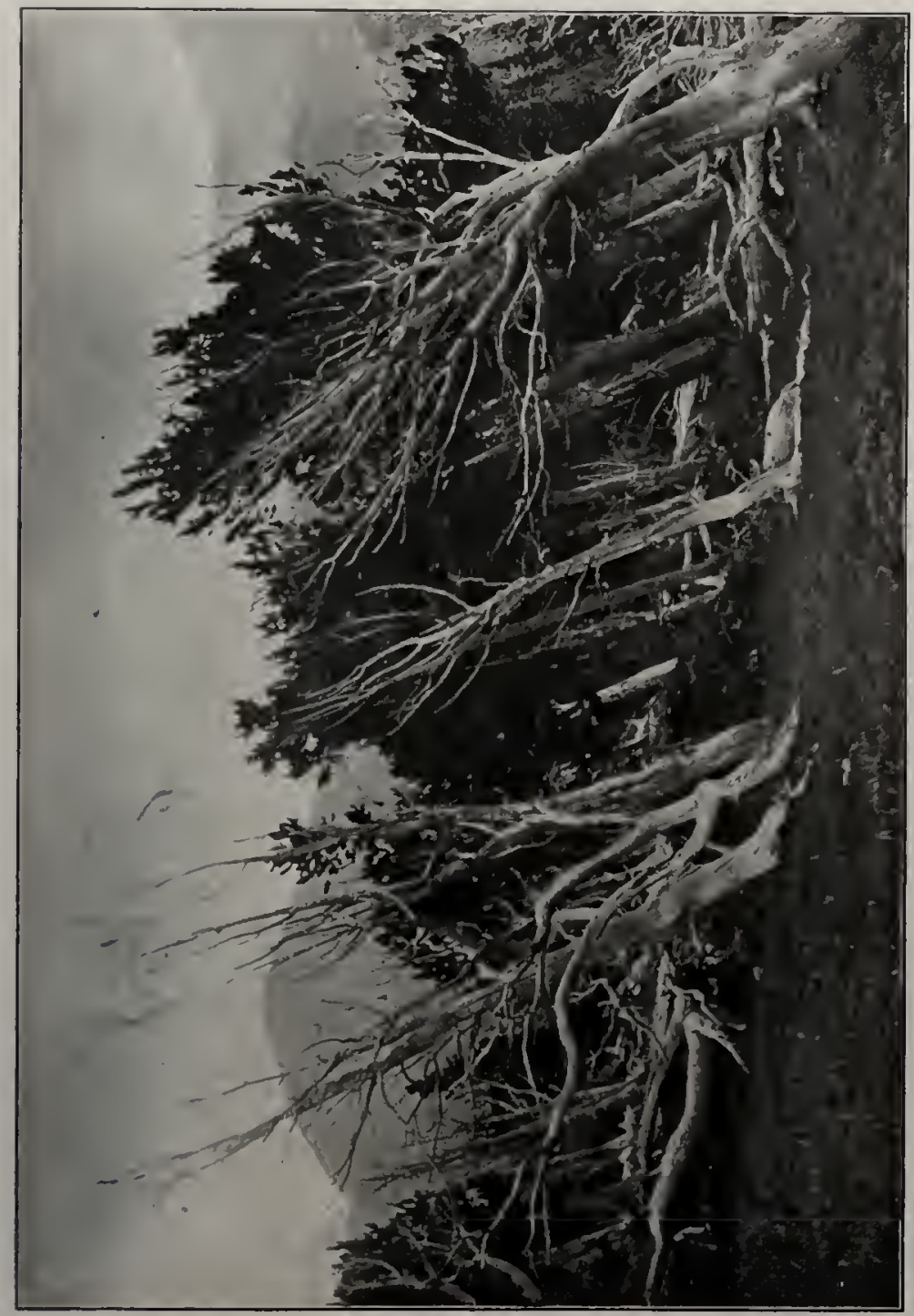

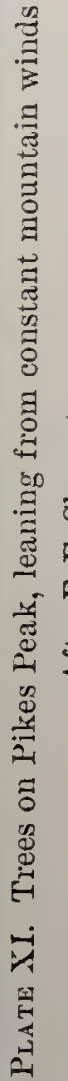


The gradual diminution of the leight of the trees on ascending a nountain is well shown in Fig. 371.1 The treeless character of the mountain summit is also plain.

liecent experiments lave slown that many ordinary plants promptly take on alpine characteristics when they are transferred to moderate heights on mountains. For instance, a rather commonly cultivated sunflower, ${ }^{2}$ when planted at a height of about sixty-five hundred feet, instead of having a tall, leafy stem, produces a rosette of very hairy leaves lying close to the ground, thus beconning almost unrecogni\%able as a sunflower. The change is even greater than that shown in the rock rose (Fig. 372) cultivated by the same experimenter. 'T' he peculiarities of alpine

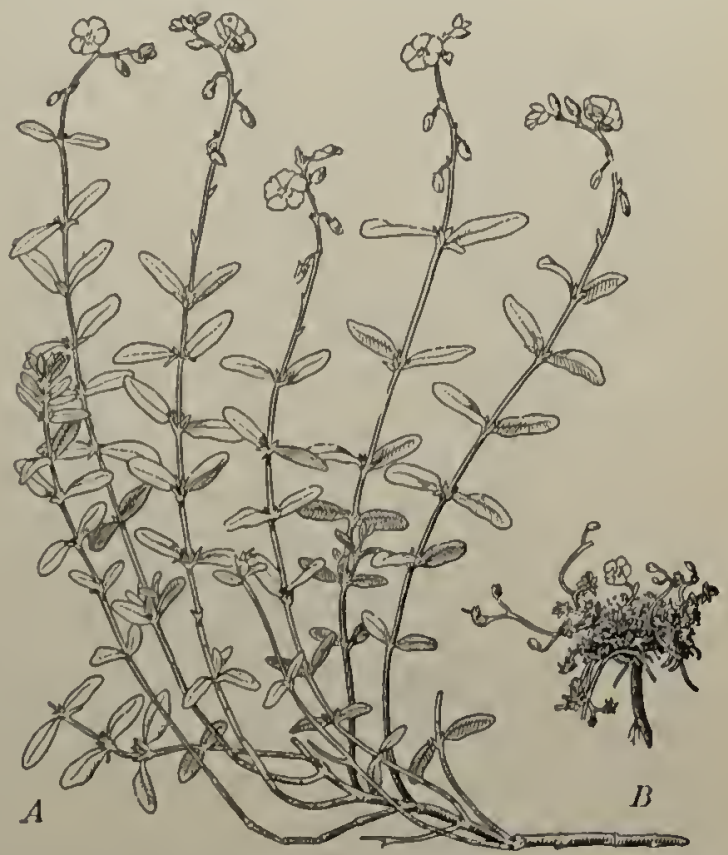
plants appear to the due mainly to the intense light which

Fig. 3i2. 'Two plants of rock rose (Helianthemum) $A$, low ground form; $B$, alpine form. Both drawn to the same scale

they receive during the daytime, ${ }^{3}$ to the strongly drying character of the air in which they grow (due partly to its rarefaction), and to the low temperature which they must endure at night.

1 Part of the diminution is only apparent, - the effect of distance, - but the growth at the highest levels is of ten less than waist high.

2 IIelianthus tuberosus, the so-called Jerusalem artichoke.

${ }^{3}$ The experiments of Professor Frederic F. Clements on Pikes Peak, however, seem to show that light is not a principal factor in the production of alpine characteristics in plants. 
465. Aquatic vegetation. Plants which live wholly in water often need a less complicated system of organs than land plants. True roots may be dispensed with altogether, as in many seawceds, in unost fresli-water algre, and in some seed plants. Many such plants liave mere holdfasts that keep them from being washer out of place. In the duckweeds (Fig. 355) the loots answer the purjose of a keel and keep the flat expanded part of the plant from turning bottom up. The tissues that serve to strengthen the plant body are not much developed in submergel aquatics, since the water supports most, if not all, of the weight of the plant. Stomata are absent, and the alsorption of carbon dioxide and giving off of oxygen go on directly through the delicate cell walls, unprotected by an epidermis (Fig. 354, I;). Submerged aquatic sced plants occur in considerable abundance in sea water as well as in fresh waters, but the marine forms do not include many species.

466. Influence of rainfall in determining regions of vegetation. While the mean annual temperature and the extremes of heat and cold, limmidity of the air, force and direction of winds, elevation above sen level, and nature of the soil are all factors in determining the boundaries of regions of vegetation, there is no factor more important than the annual rainfall. Of course the rainfall itself is largely determined by several of the other circumstances above mentioned.

In the United States this varies greatly, the yearly averages for soine of the inost important arcas being about as follows:

\section{Average Rainfale per Year}

\section{RECION}

Ncw England and Middle States

1NCHES

Eastern Gulf States

Ohio basin

Missouri basin

Rocky Mountains, middle of Pasteru slope . . . . 20

Rocky Mountains plateau, iniddle . . . . . . 9

Pacific slope, northern portion . . . . . . . 37

Pacific slopc, southern portion . . . . . . . 10 
It is evident that the rainfall increases southward along the Atlantic coast, but that on the Pacific coast it diminishes southward. Passing from either coast inland, one finds the rainfall diminishing until it reaches a minimum in the Rocky Mountain region.

467. Plant geography of the United States. All of the continuous territory of the United States ${ }^{1}$ lies in the north temperate zone. There is material for volumes in the discussion of

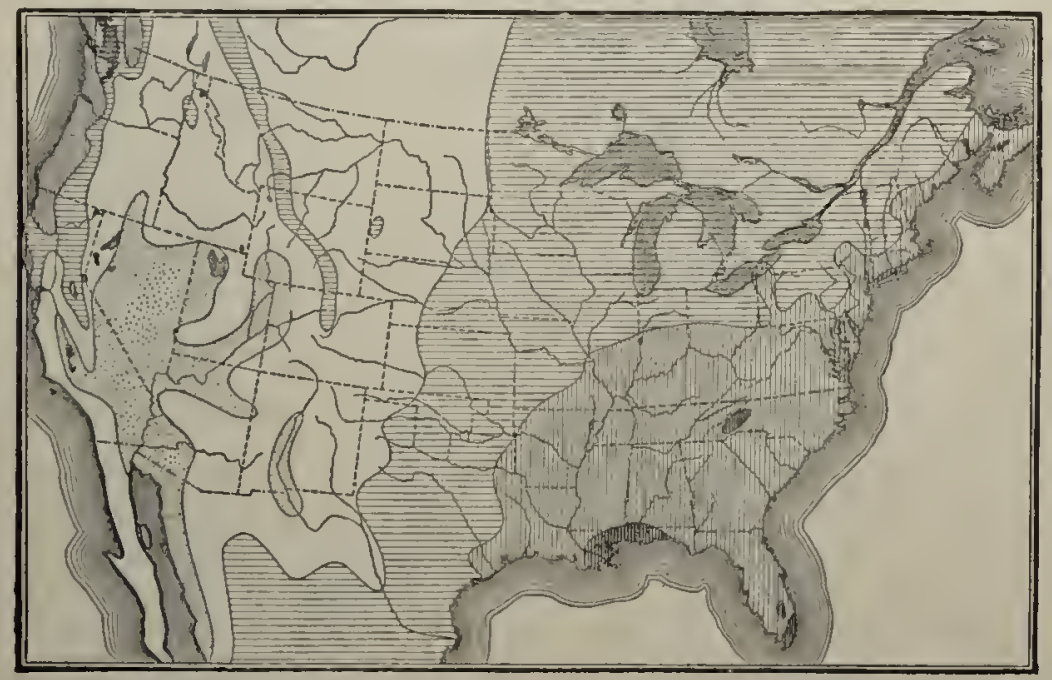

F1G. 373. Annual rainfall of the United States

Darkest shade, over 80 inclues; lighter vertieal lines, from 40 inches to 80 inehes; horizontal lines, from 20 inches 1040 inches; blank, from 10 inches to 20 inehes; dotted, less than 10 inches. - After W. M. Davis

the distribution of plants orer our territory in this continent a!one, but it is possible to sum up a brief outline of the matter in a few pages. Fxcluding the floras of many single mountains and mountain ranges, the land surface of the country may for botanical purposes be divided into four great areas, as follows:

The forest region. This occupies the eastern and central portion of the United States. It is bounded on the west by an

1 That is, not counting in Alaska, our West Indian possessions, the Ilawaiian Islands, or the I'hilippines. 
irregular line, most of which is east of the hundredth meridian. In some places this forest boundary lies considerably east of the Mississippi River, while in others it extends from the river five hundred miles or more to the westward.

The plains region. This stretches westward from the region above-named to the Rocky Mountain plateau.

The Rocky Mountain region. This includes the Rocky Mountains, the Sierra Nevada, and the various plateaus between them.

The Pacific slope. This extends from the Cascade Range and the Sierra Nevada to the sea.

468. The forest region. The forest region is mainly remarkable for its great variety of hardwood trees, of which it contains a larger number of useful species than any equal area of the earth with a temperate climate. Perhaps the most important of these are the oaks; but other genera, such as the hickory, the tulip tree, and the sassafras, are more characteristically American. In the northeasterly portion there are extensive forests of the cone-bearing evergreens, such as pines, spruces, hemlocks, and cedars; the other trees which accompany these are mostly deciduous liardwood species. In the southerly portion the forests are partly of coniferous evergreens (Fig. 392) and partly of deciduous mesophytes, such as hickories, beeches, oaks, elms, hackberries, magnolias, and sycamores. There is also a considerable admixture of such hydrophytes as the water hickory, the sweet bay (Magnolia), the anise tree (Illicium), the custard apple (Anona), the red bay (Pcrsca), the loblolly bay (Gordonia), and the sour gum $(N y s s a)$, due to the mild, moist climate.

This region was never completely forest-covered. Areas of prairie, so-called "openings" in the hardwood forests (Fig. 393), extensive narshes, and some heaths liave for ages been treeless, or nearly so. Generally, in the older states, the land most desirable for cultivation has been tilled so long that it is difficult to find portions in anytling like their primitive condition. It is only in broken country like that of the mountainous regions 


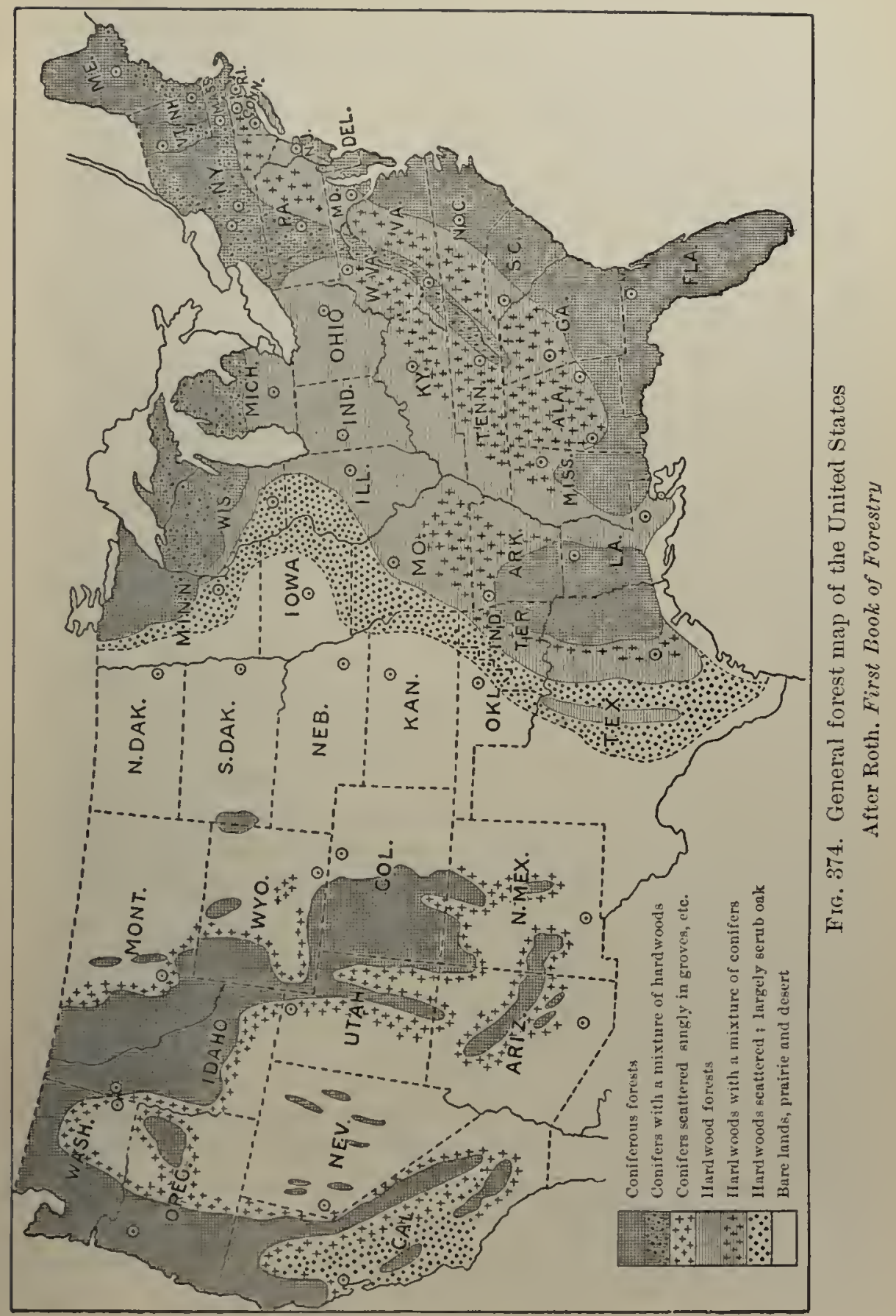


of eastern Tennessee and North Carolina, the Adirondacks and the White Mountains, in swampy liver valleys, in a few great marshes, or in sterile, sandy pine barrens, that one can find the original flora in its natural condition.

Comparing our forest region with the parts of Enrope which resemble it most in soil and climate, our flora differs notably in possessing snch leguminous trees as the locnst and the honey locusts, in the abundance of members of the heath family, and in wealth of Composites, especially asters and golden-rods.

In very many instances our eastern flora when it differs most notably from that of Europe greatly resembles that of China and Japan. This is undoubtedly due to the fact that these American species and kindred Chinese and Japanese ones had in an earlier geological age a common ancestry.

On account of the great length of the territory along a north and sonth axis and the diversified nature of its surface, the flora of the forest region varies from a sub-tropical one in soutliern Florida to one with a plentiful sprinkling of sub-arctic species along portions of the northeru border, particularly on the higher mountains.

469. The plains region. This region rises with a gradual ascent from the prairies (sume of which oecur from Ohio westward and over great areas border the west bank of the Mississippi), until an elevation of five thonsand feet or more is attained, when the plains reach the Rocky Mountain system. There is no sharply defined line of demarcation between the prairies of western Kansas, western Iowa, Minnesota, Nebraska, and South Dakota, with less than 20 per cent of the surface wooded, and the high plains, wholly treeless except along the streams (Plate IX, npper figure), that flank the eastem border of the Rocky Mountains. The lack of trees in the prairie and plains region has been attributer to varions causes, but the principal ones are donbtless forest fires, the scanty rainfall, and the occurrence in winter of severe drying winds, at a time when the roots ean draw no moisture from the frozen soil. 
The vegetation of the prairies consists primarily of a considerable number of vigorous sod-forming grasses intermixed with many other seed plants. Notable among these are sevcral species of the pea family, many golden-rods and asters, and some larger Composites, such as sunflowers and rosinwecds (Silphium). Especially striking is the display in late summer and autumn of many showy Composites, such as the blazing star (Liatris), the cone flower (Rudbeckia), and the tickseed (Coreopsis).

The vegetation of the high treeless plains is, in the eastern portion (Plate IX, lower figure), charactcrized mainly by the close mats of the short, xerophytic buffalo grasses and grama grasses of a grayishl-green color. Among thesc grasses arc scattered prickly pear cactuses (Opuntia), milkweeds (Asclepias), and thistles. After the drying up of the grasses in early July, there is sometimes hardly any living vegetation left above ground except that of the cactuses.

Toward the Rocky Mountains, as the soil becomes more alkaline, various species of wormwood or sagebrush, and members of the pigweed family (Chenopodiacec) become predominant. The universal sagcbrush (Artcmisia tridentata) plainly shows its xeroplytic character by its deep-reaching roots, its reduccd leaf area, and its strongly hairy surface.

470. The Rocky Mountain region. The Rocky Mountain region includes a very great variety of plant formations, from the heavily wooded mountain slopes and valleys to high sterile plains which are almost deserts. Cone-bearing evergreen trees, especially the true spruces, the "Douglas spruce" (Pseudotsuga), and sevcral pines, are very characteristic of the forests (Platc XII). Treat numbers of alpine spccies of herbs and shrubs arc found on the mountains at and above the timber linc. In the "alkali" regions, where the soil is too full of mineral salts to permit ordinary plants to grow, many kinds of halophytes, such as the salty sage (Atriplex), the greasewood (Sareobatus), Sali. cornia, and Suada, occur. 
Most notable among the saline areas is the Great Basin, west of the Great Salt Lake, a dreary region in general, destitute of natural grass lands or trees, but with a scattered vegetation of low gray or dull green shrubs and herbs. In the lower highly alkaline valleys are found such halophytic species as those above-named, while the drier valleys and foothills are somewhat evenly covered with sagebrush.

In the South, cactuses, palms, and tree yuccas abound. Wherever the soil is gravelly throughout the southern arid region, up to an elevation of five thousand feet or somewhat more, the creosote bush (Larrea tridentata) is often as exclusive in its occupancy of the ground as the sagebrush is in the central and northern parts of the Great Basin.

Here are some of the most notable arid regions of the United States, such as the Mohave Desert, the Palston Desert, and the Colorado Desert of southern California. The intense dryness of such areas may be understood from the fact that the average rainfall of ten of these deserts is only five inches a year, and the temperature in one of them (at Fort Yuma, Arizona) remains for weeks as high as $118^{\circ}$ during the day, with sometimes only a little over one half inch of rain a year.

471. The Pacific slope. The Pacific coast region offers far less marked contrasts between the summer and winter temperature than are found along the Atlantic coast.

On the other hand, there is, in the southern portion of the region, a sharply defined division of the year into a dry and a rainy season. At San Diego the dry season begins with April and lasts for seven months. The development of regetation, therefore, as in the northerly part of the plains region east of the Rocky Mountains, is most rapid in spring and largely ceases when the soil has become parched by the summer's heat.

The flora of the Pacific slope is lest known by its extraordinary coniferous evergreen trees. In the moss-carpeted woors of the northern portion (bounded on the south by the forty-first parallel) are found the Port Orford cedar (Cupressus Lausoniana), 


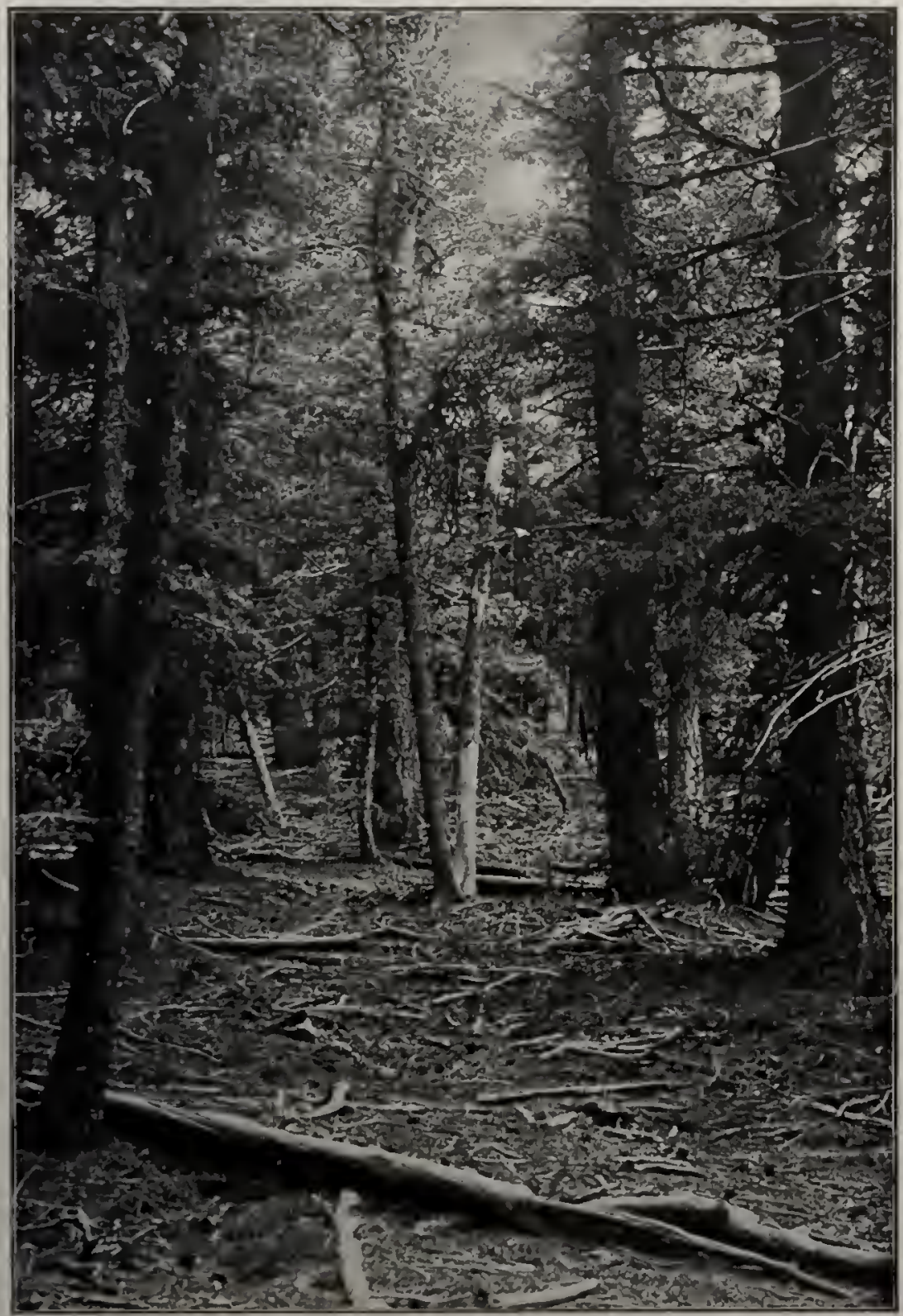

PLATE. XII. A coniferous forest in central Colorado, Jouglas spruce (Pseudotsuga mucronata) After F. E. Clements 

the red cedar, the tide-land spruce (Picea sitehensis), and the hemlock spruce (Tsuga heterophylla). In places there occur dense thickets of hazel and maple, or of shrubs of the heath family.

In the southern portion of the Pacific slope (from the fortyfirst to the thirty-fifth parallel) are found the well-known California evergreen conifers, such as the sugar pine (P. Lambertiana) of the coast, the yellow pine (P. ponderosa), and in the mountains the smaller redwood (Sequoic sempervirens) and the giant redwood (S. gigantea, Fig. 33), the largest and by far the most monumental of trees.

Among the characteristic features of the California flora is the abundance of xerophytic shrubs and small trees, many of them broad-leaved (not coniferous) evergreens, forming the chaparral thickets. Among these are members of the oak, the rose, the sumach, the heath, the buckthorn, the composite family, and many others.

In southern California, on account of the long dry season, plants with large roots or rootstocks, and bulb-bearing plants, many of them belonging to the lily family, are abundant.

In the deserts and on their borders are numerous cactuses and other succulent forms. Among the most characteristic desert plants are the Spanish bayonets, or Yuceas, some of them tree-like in form and size. 


\section{CHAPTER XXXIX}

\section{VARIATION, MUTATION, AND ORIGIN OF SPECIES}

472. Variations of plants. One of the foundation principles of scientific farming and gardening is that seeds will grow into plants like those which produced them. Not only is it assumed that grains of corn will grow into corn plants and beans into bean plants, but also that any special variety of sweet corn will produce its like, ycllow-eyed beans their like, and so with multitudes of familiar cases. Closer observation, however, shows that no two of the hundreds or thousands of plants raised from the secds of a single parent plant will be exactly like cach other or the parent. Generally the variations are very slight, and most of them fail to continue themselves in succeeding generations so as to establish new varieties of plants.

473. Variations in one direction. While variation generally goes on in all directions, so that one of a brood sprung from a given parent will be smaller and another larger, one more and another less hairy than the parent plant, and so on, it is not uncommon to find what nany be called definite variation, in which the changes all lead toward a definite new type. The behavior of lowland forms planted in alpine regions (Scc. 464) is a good instance of the kind. It is well known, too, that secd from northern localities when planted farther south will produce earlier crops than can be obtained from southcrn seed. American varieties of onion, after being grown for a series of years in England, become habituated to the longer mild season there, and when the seed is brought back to America the plants grown from it fail to mature their bulbs before the coming of the frost.

Such facts as these scem to indicate that characteristics which have been impressed upon the plant by external influences, such 
as those of soil and climate, may be transmitted to its descendants. If it be so, then the origination of new forms of plants by the inheritance of such characteristics must be extremely common.

474. Mutations of plants. Much attention has lately been given to the occurrence among plants of seedlings which differ in a marked way from the parents. It would involve too much detail to describe the exact nature of the differences between the seedlings of the evening primrose, ${ }^{1}$ which has been most studied in this connection, and its offspring, but they are as great as those betreen an apple tree and a pear tree. Such abrupt and extensive changes are called mutations. A few of the most important facts so far known in regard to mutation are :

1. New species ${ }^{2}$ appear suddenly among the offspring of the parent form.

2. The individuals of the new species constitute only a small per cent of any given brood.

3. The new species reproduce themselves accurately, showing no decided tendency to return to the parent form.

475. Importance of adaptiveness in plants. It may be inferred from Chapters XxxI and Xxxiv that a premium is set on all changes in structure or habits which may enable plants to resist their living enemies or to live amid partially adverse surroundings of soil or climate. It would take a volume to state, even in a very simple way, the conclusions which naturalists have drawn from this fact of a savage competition going on among living things, and it will be enough to say here that the existing kinds of plants to a great degree ove their structure and habits to the operation of the struggle for existence, together with their response by means of rariation to changes in the conditions by which they are surrounded. How the struggle for existence has brought about such far-reaching results will be briefly indicated in the next section.

1 Enothera Lamarckiana.

2 For a definition of the term species, see Sec. 189. 
476. Survival of the fittest. A change in the eharaeteristies of a species may have no effeet on its ability to eontend with a hostile soil or elimate, with parasitic plants or destruetive inseets or other animal foes; but often alterations in the structure or the habits of a plant may give it a eonsiderable advantage over its unehanged neighbors. For instance, a deeided inerease in Irairiness would tend to protect the plant from damage by long droughts, and also (in countries where suails destroy inuch vegetation) from having its leaves eaten. Nuts with harder shells would escape being destroyed when the ordinary ones would be craeked and eaten by wild animals. Red berries of the European holly are earried off by birds more extensively than yellow ones, and thus the undigested seeds of the former variety are more widely sown.

In meadows which are mown onee a year, only those plants ean surely reproduce themselves by seed whieh ripen their seeds either before or after the time when the grass is eut. Individuals which can do this stand a vastly greater ehanee of perpetuating themselves than do those which are eut down just before their seeds have matured. For this reason eertain kinds of meadow-frequenting plants ${ }^{1}$ have developed early-blooming and late-blooming forms, which would probably never have beeome abundant in regions where the grass was not mown.

Whatever the nature of the advantages given to one form or set of forms over another in the competition which always goes on under. natural conditions, it results in what is sometimes called survival of the fittest, and sometines natural selection.

\section{Have species arisen by variation or by mutation? The} theory that speeies (and later genera and higher groups) arise by slow degrees from the operation of natural seleetion aeting on the slight variations which eonstantly oeeur anong auinals and plants was first fully set forth by Charles Darwiu in $1858 .^{2}$

1 Species of Gentiana, Euphrasia, and Rhinanthus.

2 Darwin's paper on this subjeet was the result of over twenty years of study, and was read by him to aceompany a paper eontaining similar views which had been sent from the East Indies by Alfred Russel Wallace. 
The theory that species spring suddenly from mutations was advanced by Professor Hugo de Vries, of Amsterdam, Holland, in a work on the mutation theory, published in 1901 and 1903.1

Botanists at present are considerably divided on the question of the origin of species, some believing that they are mainly derived from the perpetuation and intensification of slight variations, while mutations are so infrequent as not to signify much in this connection; others, again, believe that mutations are the source of species, and that variations can only give rise to varieties. There seems to be no good reason for doubting that both variation and mutation have been and are efficient in the production of new species.

${ }^{1}$ For an English translation of the German original of this work see De V'ries-Farmer-Darbishire, The Mutation Theory, Chicago, 1910. 


\section{CHAPTER XL}

\section{PLANT BREEDING}

478. Definition of plant breeding. The seleetion and maintenance of the most desirable varieties of cultivated plants must. to some extent, have occupied the attention of agriculturists during all the thousands of years since farming began. ${ }^{1}$ From the writings of Virgil and other Latin authors it is clear that homan farmers practiced careful selection of cereals for seed, knowing that without this their crops would diminish. But it is only within a short period that scientifie prineiples have been brought to bear on the process. In fact, it is stated that the systematic improvement of races of cultivated plants began in the middle of the nineteenth eentury. The intentional production and perpetuation of new varieties is known as plant brecding. It is based upon the methods outlined in Secs. 479 and 480 .

479. Single selection and continued selection. New varieties of plants, whether wild or eultivated, are eonstantly being produced by ordinary variation and by mutation (Secs. 472-474). In a single field, supposed to contain only one kind of wheat, a trained botanist once found $t$ wenty-three well-marked varieties, one of which became the parent of a sort that has remained fanous for over three quarters of a eentury. The plant breeder is constantly on the wateh for promising varieties, preserving all which seem likely to be of use. While it is a slow, uncertain method to await the appearance of variations in any desired direetion, and then to rely on the perpetuation of these, the large number of valuable new varieties thus seeured warrants all growers

${ }^{1}$ In China the cultivation of rice, wheat, two kinds of millet, and soy beans dates back at least 4600 years. 
in being on the lookout for variations which promise new values. The surer plan is to take seed from a considerable number of parent individuals which possess the desired quality in a ligh degree, raise plants from each of these, discard plants of this second generation from all parents whose progeny does not excel, and continue selecting from these superior stoeks. In this way many characteristies, such as abundant yield, hardiness, early ripening, whiteness in the case of flour, increased percentage of sugar in sugar beets, or improved size or flaror in tomatoes may be secured in a few years of eareful brecting. 'This may be called the selection of good parent plants.

480. Production of hybrids. An important method of making new varieties is by crossing, or hybridizing, - that is, by pollinating the pistil of one species or variety with pollen from another species or variety. The offspring of cross pollination is known as a liybrid.

The process of crossing two speeies is comparatively easy. If plum blossoms, for example, are to be hybridized, the operator must gather enough of those from which pollen is to be collected, brush or shake off the pollen, and, if necessary, keep it in a eool place until needed. ${ }^{1}$ Most of the flower buds are removed from the tree the flowers of which are to be pollinated, and just before the opening of those buds which are left the corolla, with its attached anthers, is eut away, as shown in Fig. 375, and pollen applied to the stigmas with a camel's-hair pencil or, better, with the finger tip. If fertilization results, and plums with good seeds are produced, they must be planted, and seedling trees grown from them. These might be allowed to grow until they blossomed, but years of valuable time can be saved by grafting the young seedlings upon other plum trees. When blossous of the hybrid form are secured, some of them may be fertilized with pollen of either of the parent species,

${ }^{1}$ Some kinds of pollen, as that of the pansy and the peony, are said to remain good for weeks, and that of the date palm for more than a year; but in general, pollen should be used as soon as possible. 
and others with pollen of different species of plum. All of the seeds obtained from the various crosses should be planted, and the seedlings which are produced by them should be examined, and retained or destroyed according to their apparent value. To the experienced plant breeder the appearance of the seedling trees, long before they are ohl enough to blossom, indicates so much as

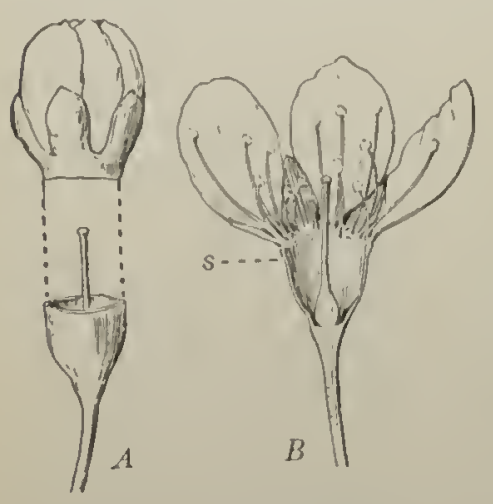

Fir. 375. A plum blossom prepared for lybridizing

A, unopened blossom rut round just below the insertion of the stamens, to remove the latter; li, lengthwise section of a fully opened blossom, showing the level $s$ at whin the enting should be done to the nature of their fruit that many varieties can be discarded as soon as the young plants have developed well-grown shoots. The distinctive work of hylbidizing is to secure parent plants better than any which exist in the foundation species or varieties. The work of choosing a large number of the most promising hybrid plants and of testing their breeding power, so that only the blood, so to speak, of the rery best may be retained, is the same as breeding by selection mentioned above. In the occasional hybrid plant, possibly one out of ten thousand, are combined the best in the two parents, or possibly, as some believe, newly created characters may arise.

481. Some results in breeding by selection. To give an account of the results of selection as applied to cultivated plants would be to write a history of the variations and improvements in all our ormanental and useful plants under cultivation. In this place it must suffice to give a very few illustrations of the kind and amount of improvement brought about by such selection as is outlined in Sec. 479 .

482. Selection among apples. Much of the inprovement in apples was brought about before the literature of plant breeding began. It is not certainly known where the cultivated apple 
originated, but an eatable variety probably occurred in prehistoric times throughout the territory extending from the Caspian Sea nearly to Europe. Small forests of wild apples have been described in modern times, growing near the southeast end of the Black Sea.

The dwellers in pile-built houses in the lakes of northern Italy, Savoy, and Switzerland, several thousands of years ago, laid in stocks of apples cut and dricl for winter use. Some of these apples appear to have becn cultivated, but they were very small, inferior in size to any modern variety except some crab apples. How great a gain in the size of apples lias been brought about by cultivation and selection may be inferred from Fig. 376. This increase in bulk is accompanied by a decrease in the number of matured fruits in a cluster. Originally several of the flowers developed into apples, but in modern improved varieties usually

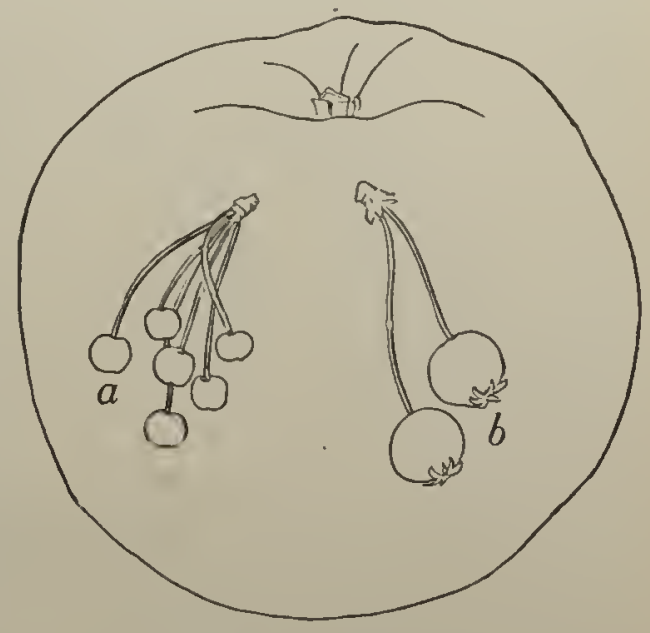

Fig. 3i6. liffect of cultivation upon the size of apples

The Bismarck apple, with $a$, the wild Asiatic crab apple (Pyrus baccata), and $b$, the European wild apple ( $P$. Malus). All half natural size. - After Hodge all but one of the flowers fail, as is shown in the case of the pear (Fig. 83).

Most of the varieties of apples in our present orchards are descendants of seedlings sprung from trees introduced from western Europe. In the Northwest, where only the hardiest kinds can endure the serere climate, some of the most successful sorts are importations from central Russia, and others are from seellings of Russian and the hardier American varieties, or from hybrids produced by accident or design. 
483. Selection among beans. The eommon bean (Phaseolus vulgaris) is of uncertain origin, but there is a good deal of evidence to show that it came from western South America. Its eultivation in Europe appears to have begun soon after the discovery of America. As is well known, the number of varieties in cultivation is very large, and in few plants is it easier than in beans to produce $n \mathrm{cw}$ varieties by selection.

I lean breeding for the large seedsmen is a skilled industry. It is said that a seedsman may even advertise a new kind of bean under an attractive name before the variety has been produced, then order it of his bean grower, and in the course of two or three years have seed ready for his customers. On the farm of one large bean grower nearly 70 standard varieties are raised for seed on a large scale, and some 200 sorts are being tested to establish their value or to produce new kinds. All possible pains are taken by means of high cultivation to increase the bearing qualities of the plants and also to encourage variation. Every variety, whether a standard one or a novelty, is kept to the desired type by the careful inspection of every plant, those which fall short in any respect being earefully destroyed.

While new kinds are nowadays generally seeured by scientific plant breeding, sometimes valuable sorts are obtained from chance seedlings, as in the case of a well-known dwarf Lima bean which sprang from seeds gathered on a Virginia roadside some time before 1885 .

484. Selection among corn. Indian corn was eultivated by the ancient Peruvians and the Mexicans. Its original home as a wild plant was probably on or near the west coast of South or Central Anerica. Numcrous rather permanent kinds which "come true from the seed" (races), such as field corn, sweet corn, and pop corn, have long been known, and some of these races present many varieties.

Scientifie corn breeding has been practiced for much less than a generation, but the results already attained are of great practical importance. 
Leaving out of account the very extensive use of the stems and leaves of the com plant for forage, and considering only the value of the grain produced, corn breeding may be carried on to secure, among other less important qualities, the following results:

1. A larger yield per acré.

2. A higher percentage of any one of the three principal constituents of the grain, _ starch, proteids, and oil.

3. Early maturing, for growth in the more northerly states.

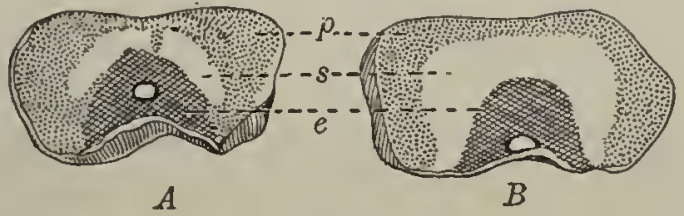

F1c. 377. Kernels of corn with high and with low proteid contents

$A$, high proteids; $B$, low proteids ; $p$, horny layer, consisting largely of proteids; $s$, white starehy portion; e, embryo. - After University of Illinois Agrieultural Experiment Station, Bulletin No. 87

1. Yield. The corn crop of the United States is worth about a billion dollars a year for the grain alone. On farms of the

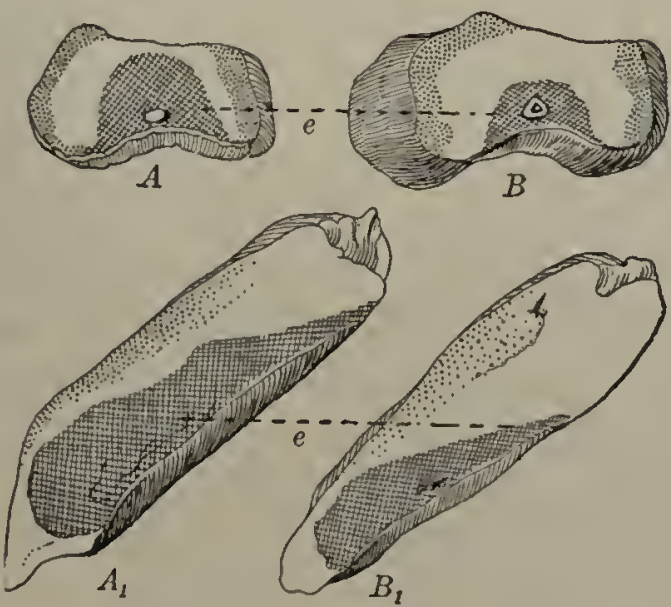

Fig. 378. Kernels of corn with high and with low oil contents

$A, A_{1}$, eross and lengthwise seetion of high oil kernels; $B, B_{1}$, seetions of low oil kernels; $e$, embryo. Most of the oil is contained in the embryo, so that a large einbryo means a large percentage of oil. - After University of Illinois Agricultural Experiment Station, Bulletin No. 87 
greatest producing state, Illinois, the averase crop is hardly thirty bushels fer arere. The use of choice seed has been found to increase the produretion from 10 to 20 per cent, and it is a morlerate estinate which assumes that the universal use of improverl seerl would adr 10 per cent to the total corn crop of the comntry. 'This would add over $\$ 100,000,000$ to the annual receipts of our corn growers.

2. Iinproven quality. In every 100 pounds of ordinary shelled com there are, in round numbers, about
8 Hh. cunbryo (of which :3 lt). are oil);
13) lh. ghuten, or proteids of the cndosperm;
(6) llu. starch.

There is a demand for a limited amount of eorn with a light per cent of oil as a somede of com oil. At the Illinois $A$ gricultural Experinent Station the attempt has been marle to breed varieties of eorn with ligh and with low pereentages of oil. ()ne variety was secured with nearly 7 per cent and another with less than 2 per cent.

In the sane way, that is by neans of continued selection, carried through many generations, varieties with much or little starch can be obtained.

3. Eurly maluring. Corn was originally a tropical or subtropical plant, requiring a long growing scason. (Quickly maturing varieties had, lowever, heen secured by the native races even at the time of the discovery of America by Colmmbus. At present there are varieties ranging all the way from the eighterenfoot kinds that require a growing period of six inonths, to the two- or three-foot kimls that mature in nincty days or less.

The most important problem that jousents itself to the plant lreeder in this comnection is that of increasing the yiehl per acre for each of the agricultural regions where con'n is pronheerl, whether in the North, where slort-stalked, early-maturing kinds ar: needed; in the great corn belt; or in the South, East, or West, where varieties are needed which are bred to make the 
best yield of grain or of fodder, or of grain and fodder eombined. This plant is being especially modified for many agrieultural regions possessing distinetive soil and elimatie conditions, and is more easily adapted to locality than are most plants.

485. Selection among, wheat. Wheat of many varieties has been eultivated for thousands of years throughout a territory ranging all the way from China to western kurope. The original home of the plant is not known, but perhaps it was in Mesopotamia, between the Tigris and Euphrates rivers. In Europe systematic attempts to proeure improved varieties of wheat by seleetion date baek well toward the beginning of the nineteenth eentury. Some good varieties were originater in our own eountry in the early sixties, but more wheat breeding is now done in a single year in the Agrieultural Experiment Station of a great wheat-raising state, like Mimnesota, than was done in the whole United States prior to 1890.

It will give some idea of the extreme care with whieh wheat breeding is now eonducted to give the barest outline of the mode of proeedure in the Minnesota Station.

As a beginning, 10,000 good kernels of some desirable variety of wheat, old or new, are earefully chosen. These grains are planted 4 inches apart (or 5 inches for winter wheat), one seed in a hill, and every plant receives a number. About 95 per eent of the poorer plants are weeded out by hand before harvesting the seed whent, the heads of the remaining plants are eut off, and those of eaeh plant are preserver in an envelope. After drying, the heads are weighed, and those of all but a few of the best-yielding plants are thrown away.

The seeond season there are sown in a separate plot in the wheat-breeding nursery about a hundred secels from each of the plants chosen. Eaeh of these hundred-groups (centyeners), sprung from a single mother plant, is given a distinguishing number. When the wheat is mature the relative sire and strength of the plants in each plot are noted and rerorderl, and by separately harvesting and weighing each little plot the 
breeding power of eaeh parent plant is measured in terms of the arernge of its progeny. A seleet head is chosen from each of sereral of the best plants in every plot, and the seed from these is sared.

A third year and a fourth year liundred-group plots are sown and managed as just deseribed, and at the end of the period the most promising varieties are taken to field trials. Here they are tested, under ordinary farm eonditions, in comparison with the wheats commonly grown, and the best, if it stands severe milling tests, is then propagated for distribution, under suitable designating numbers, to wheat growers throughout the state.

The rate at whieh new varieties can be propagated may be gathered from the history of one of the most famous new wheats, "Minnesota No. 163," a variety bred by seleetion. This sprang from a single grain planted in 1892. In 1893 the product consisted of 75 plants; in 1894 a small field plot was grown; in $189 \mathrm{~S}$ the erop amounted to some 300 bushels of seed wheat, whieh was distributed among about 50 farmers throughout the state. It is estimated that in 15 years from the time of planting the single original seed the entire wheat erop of Minnesota, eovering some 5,300,000 aeres, might have been made to eonsist of this rariety, and that it does aetually eover millions of aeres, adding about two dollars per aere to the value of the crop.

It is not yet possible to state how muel ean be gained in quality and quantity of wheat produetion by eareful eulture and breeding. But it is interesting to note that in a good wheat year (1895), when the average erop per acre on the University of Minnesota farm was 23 bushels, there were 4 inproved varieties whieh yielded orer 40 bushels per aere. In 1896, when the average erop for the state was 14.2 bushels per aere, out of 32 improved varieties on the University farm there were 24 varieties whiel y yelded 21 bushels per acre or more, 2 of them yielding 33 bushels. That is, three quarters of the varieties yielded at least $1 \frac{1}{2}$ times as mueh as ordinary 
wheat on other farms, and 2 varieties yielded about $2 \frac{1}{3}$ times as much. The yield was increased on the farm mentioned botl by goor farm management and by breeding into the varieties stronger power of yielding.

In 1.902 one of the imploved wheats, "Mimesota No. 169," was given an extended trial in various parts of Minnesota. It yielded on the average 3:3 bushels per acre, or 18 per eent more than the ordinary varieties. This variety probably now covers half a million acres, in several states, and yields at least two dollars per acre more value tlan the varieties (mainly the "blne stem," its parent) which it is rapidly rlisplacing over an area of several inillion acres devoted to hard spring wheat. The importance of every incerase in production is evident when one consider's the ammul valne of our wheat crop, from $\$ 250,000,000$ to $\$ 500,000,000$.

486. General results of hybridization. The relative imporlince of liybridization, and of continued selection alone as means of seeuring valuable new varieties of eultivated plants, is largely to he worked out in each class of plants. Hant breeding as a seicuco; is tro new to givo material for answering nearly all the questions that naturally arise in regard to low varieties may be most rapiclly imploved. Hybridizing often brings alout great changes in the offspring, and there are increased chances that sone of the new forms will be more valuahle than any which conld be discovered anong the fommlation varieties. In the cusse of sprecies perpetuated by serafing, as of certain trees, and plants porpangated by roots, rontstocks, or tnlocers, as potatoes, ${ }_{1}$ it is very ensy to secore purelored stocks. In plants grown from seed, especially if the suecies is inore or less ofen-pollinatrel, 2 there is always a most important funstion as to how many generntions must elapse lefore the hybrid varieties can he selected "true to secd."

1 Varioties annong theses are callerl clomel varieties (from clon, meaning a cutling or scions).

2 'That is, if the flowers are open to cross pollination. 
Some of the most important results in variety making lyy hybridization have recently been obtained in experiments on the fruits of the rose family, partieularly cherries, plums, and

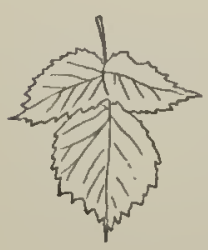

$a$

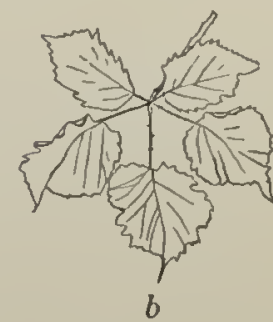

$b$

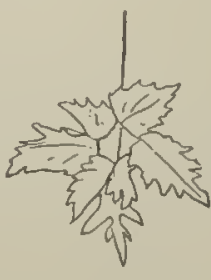

$c$

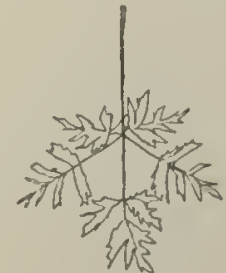

$d$

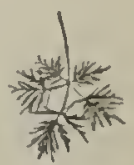

$e$

Fig. 379. Five forms of leaf from hybrid blackberries, all grown from the seed of one plant and showing extraordinary variations in the amount of incision in the margins of the leaflets, forming a regular series from $a$ to $e$

Modified after Burbank

apples, and the citrous fruits. In the case of cotton and wheat much effective work is also being done.

The extraordinary suecesses of Luther Burbank in produeing new hybrid varieties of fruits and ornamental flowers

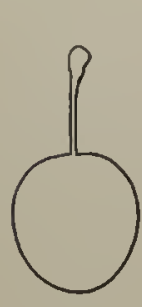

$\boldsymbol{a}$

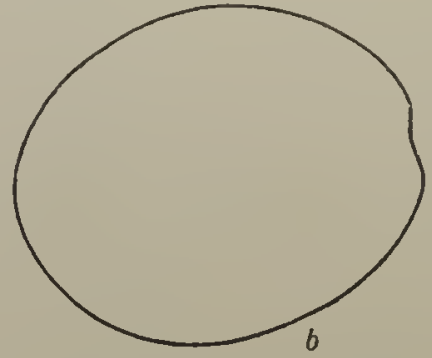

FIG. 380
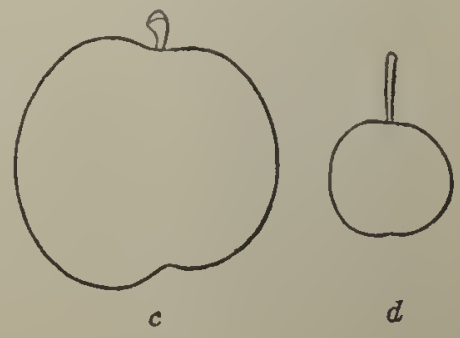

$a$, a stoneless wild plum; $b, c, d$, fruit of hybrids of $a$ with the French prutue. All drawn to the same scale. - Modified after burbank

have been widely diseussel in the popular magrazines. He has bred some remarkable hybrids, such as those between the strawberry and raspbery, the apple and blackberry, the petunia and the tobacco plant. These are of little use, thongh of much scientific interest. Others of his hybrils, especially the plums, are of great commereial value. Many other investigators, whose 
results have not received popular notice, are working more directly for useful hybrids, and a few of these may be very briefly summed up.

487. Results of hybridizing citrous fruits. In the plantbreeding laboratory of the United States Department of Agriculture in 1896 and 1897 hybrids were made of the ordinary sweet orange and the uneatable three-leaved orange (Citrus trifoliata). Three promising varieties of a new kind of fruit known as citranges have thus been obtained. Two of these are likely to serve as substitutes for lemons, and the third may, to some extent, take the place of grape fruit. Their main value lies in the fact that they can be cultivated from two hundred to four hundred miles farther north than ordinary citrous fruits.

Another interesting hybrid is that hetween the tangerine and the grape fruit, called the tangelo, which shows a blending of the claracteristics of the parent species.

488. Results of hybridiz-
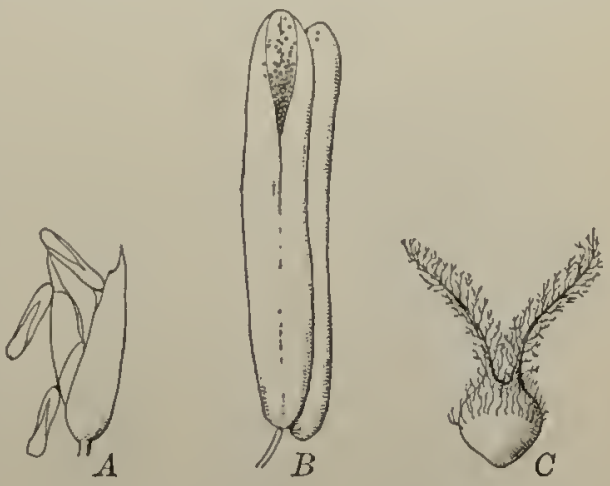

Fig. 381. The flower of the wheat plant

$A$, entire flower as seen at five in the morning, with the stamens protruding, the pistil remaining inside; $D$, the anther enlarged, showing escaping pollen; $C$, the pistil enlarged, showing the feathery stigmas. After University of Miunesota Agricultural Experiment Station ing cotton. The cotton produced in the United States is roughly classed as long staple and short staple. The fibers of the former kind are about one and one-half times as long as those of the latter. For many kinds of goods long staple cotton is indispensahle, and its price is from one and one-half times to nearly twice as great as the price of short staple cotton. The short staple sorts can be grown orer a much larger territory than the others, so that our innual production of long staple cotton is only about one and one-half per cent of our total cotton crop. 
Hylorids have been made between the very long-fibered fine seaisland speeies and the ordinary upland speeies, and after six generations of selection and careful cultivation some valuable hybrid varieties seem to have been developed.

489. Results of hybridizing wheat. The flowers of wheat are naturally self-pollinated, - that is, the stamens of each flower commonly diseharge their pollen upon the feathery stigma of their own flower as soon as the pollen saes open. This faet makes hybridization mueh more effeetive in producing variation
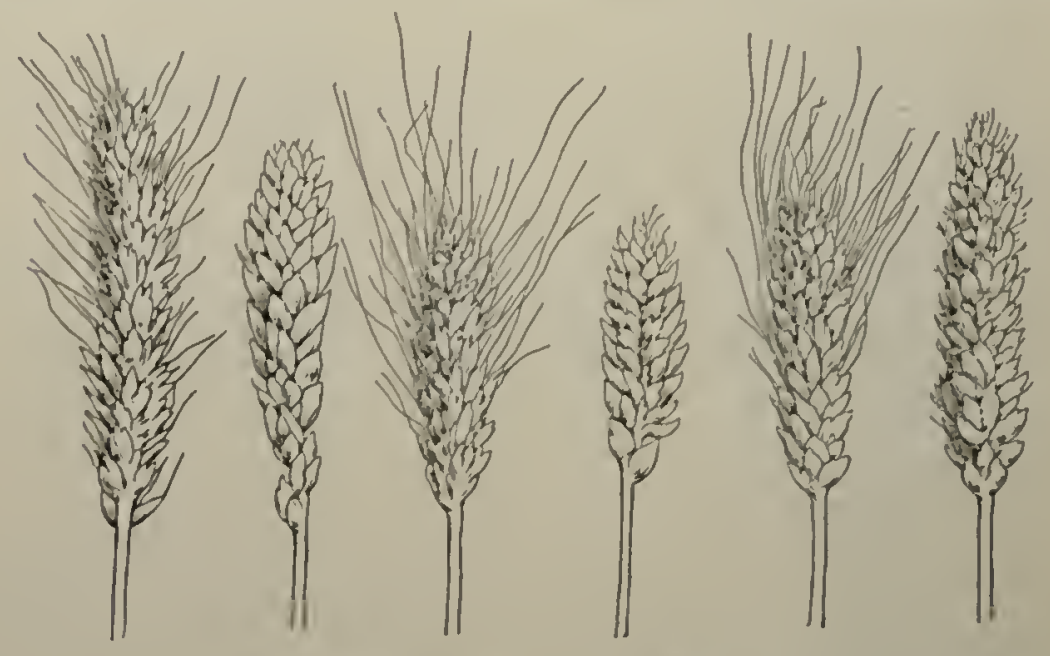

Fig. 382. Variation in wheat, the hybrid offspring of hybrid parents After figure reshawn from Transactions of the Highland and Agricultural Society of Scotland

in wheat than in plants which are generally eross-pollinated; for in the ease of wheat any kind of cross pollination, and especially that between inarkedly different varieties, may be said to give a sort of shock to the operation of reproduction, and thus produce abundant variation. The details of the process of artificial pollination need not be given. It is suecessful in a large proportion of eases, and the offspring inay be of many types, as shown by Fig. 382. It is found that after the fourth generation an oceasional plant may be found whicl 
yields well and will "come true to seed." More important results may be expected in the future from hybridizing wheats than any yet attained. ${ }^{1}$

1 The literature of plant breeding is extensive and rapidly increasing. An excellent general account of the subject and full bibliography is contained in Plant Breeding by L. H. Bailcy, The Macmillan Company, New York and Isondon, 1906.

A valuable summary of the main topics of plant breeding is contained in Bulletin No. 29, 1901, of the Division of Vegetable Physiology and Pathology of the United States Department of Agriculture.

Much information is also given in Hugo de Vries, Species and Varieties: their Origin by Ifutation, Open Court Publishing Company, Chicago, 1905.

Other publications of the Lnited States Department of Agriculture on plant breeding are :

For corn, Farmer's Bulletin No. 229, 190\%.

For wheat, Bureau of Plant Industry, Bulletin No. $78,1905$.

Dirision of Vegetable Physiology and Pathology, Bulletin No. 24, 1900.

The publications of most of the Agricultural Experiment Stations contain much important material for the discussion of plant breeding. A few of these are as follows:

For corn, Lnircrsity of Illinois Agricultural Fxperiment Station, Circular No. $7 t, 1904$; Bulletins Nos. 55, 82, 1902; 87, 1903; 100, 1905.

Ohio Agricultural Fxperiment Station, Bulletin No. 140, 1903.

Kansas Agricultural College, Bulletin No. 10\%, 1902.

Nebraska Agricultural Experiment Station, Bulletin No. 91, 1905.

For wheat, Lnirersity of Minnesota Agricultural Experiment Station, Bulletin No. 6\%, 1899.

Ohio Agricultural Experiment Station, Bulletin No. 165, 1905.

The authors wish to express thcir obligations to all the authorities aborcmentioned. They have also to thank Assistant Secretary Willet M. Hays, of the Department of Agriculture, for his kindness in reading and copiously annotating the present chapter. 


\section{CHAPTER XLI}

\section{SOME USEFUL PLANTS AND PLANT PRODUCTS}

490. Economic botany. The branch of the science which treats of the uses of plants to man is called economic botany. Since whole industries like agriculture, lumbering, paper making, and a multitude of others arc concerned with the utilization of plants or parts of plants, the sulject is a most extensive one and can only be outlined in a general text-book of botany.

A partial classification of useful plant products may be suggested, dividing them into

1. Food products for human use.

2. Medicinal plants and plant products.

3. Food products for domestic animals.

4. Plants used as fertilizers.

5. Plant products used in chemical and other manufactures, as tanning, dyeing, etc.

6. Plant fibers and related products.

7. Timber.

8. Fuel.

9. Ornamental plants.

In general only those members of the classes above given which are of considerable importance in our own country will be mentioned in this chapter.

\section{FOOD PRODUCTS FOR HUMAN USE}

491. The grains form the most important part of our vegetable food; they are the fruits of the cerculs, or food-producing grasses, and for this and other reasons lle grasses, which in all number about 3500 species, are more nseful to man than any other family of plants. The principal genera of cereals are 
wheat, oats, rye, barley, rice, and Indian corn. Most of the cereals are griss-like herbs of moderate height, but corn varies Inuch in size, from some of the dwarf varieties of pop corn not more than two feet ligh to the twenty-foot field corn of the rich river bottoms of the Middle West. All the grains have many varieties, but these are most familiar in the various sorts of wheat - hard, soft, red, white, bearded, beardless, and so on - and in the many qualities of grain of Indian corn (see Chapter XL).

Wheat is the most important of the cereals, on account of its palatableness, high food ralue, and ready digestibility. None

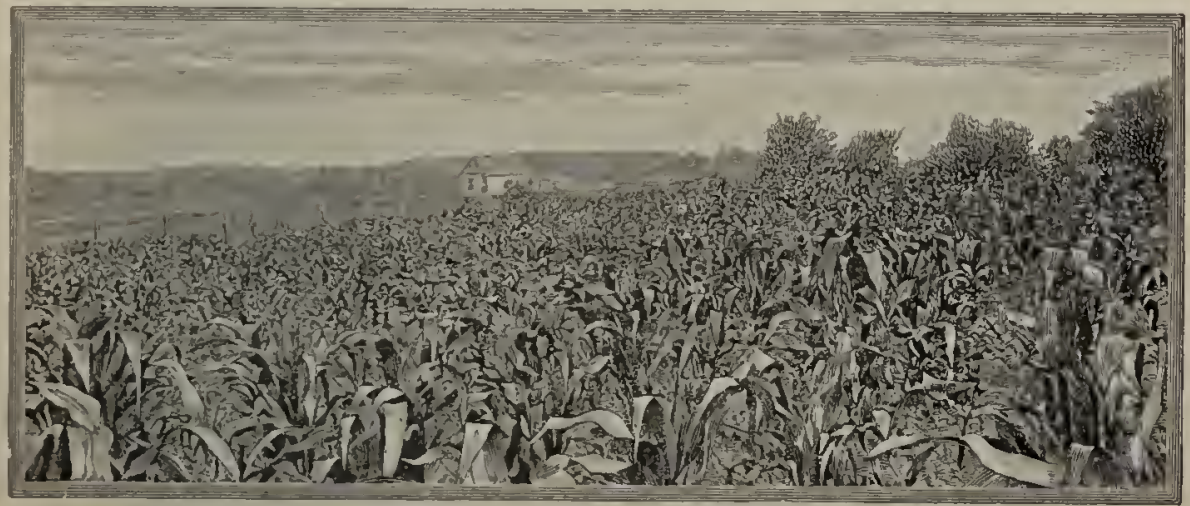

ling. 383. A cornfield in Missouri

After Frye

of the other grains yield a flour which is as well adapted for bread making as wheat flour. Rice is readily digestible, but is inferior to most grains in the relative proportion of proteids to other ingredients; and oats, rye, barley, and Indian corn, as usually prepared, are somewhat difficult of digestion. Corn meal when imperfectly cooked, and eaten to the exclusion of other food, has often giren rise in northern Italy to a mucli-dreaded disease known as pellagra.

The United States is the leading wheat- and corn-raising country, prodicing more than one fourth of the total world's crop of the former grain and four fiftlis of the latter. 
Any of the grains may be made to yicld starel for food or for laundry $0 r^{\circ}$ manufacturing purposes, but the greater part of that produced in this country is obtained from corn, which contains about 60 per cent of it. Moldy or otherwise damaged grain can be utilized to some extent in starch making.

Corn also contains in the embryo of the grain from 3 to 6 or more per ccnt of oil, which is now largely cxtracted for use as food and for various manufacturing purposes.

492. Leguminous seeds. Several kinds of sceds of the pea family (Leguminose) - an immense family, comprising some 7000 species - are important articles of food. Beans, as every onc knows, are used as food in all stages, from the time when the pods are half grown until the sceds are entirely ripe and dry. In the latter condition, when properly cooked, they constitute one of the eheapest and most concentrated forms of proteid food.

Peas, whether "green" or dry, have much the same nutritive value as beans in the same stage of maturity. Various canned products of beans and of peas are now prepared on a large scalc. - Peanuts are the secds of a leguminous plant which forces its growing pods underground, where they remain during and after the process of ripening. The domestic consumption of these sceds is large, and they constitute a considerable article of export.

Several other kinds of leguminous secds, such as broad beans, lentils, and chick peas, arc extensively used as foods in parts of Europe, but arc not as yct important articles of diet in our own country.

493. Other seeds. The remaining kinds of seeds which are important as food are mostly known as nuts. Some of these are really drupes, like the cocoamut and the wahnut (Sec. 183, Fig. 166, V), while others, like the Brazil nut and chestnuts, are secds.

From the palm family, which is of supreme inportance within the tropics, only one kind of so-called nut, the cocoanut, is commonly in use anong us. The abundant endosperm of its seed is largcly eaten raw and wuch used in cookery. 
Three rather closely related families of trees - the wahnuts, the birches, and the beeches - furnish most of our edible nuts. From the first come walnuts, butternuts, pecans, and hickory nuts; from the second, hazelnuts and filberts; and from the third, beechnuts and chestnuts.

The rose family furnishes almonds, which are technically drupes, closely related to peaches (Fig. 164).

Brazil nuts are the seeds of lofty South American trees of a tropical family allied to the mangroves and the myrtles.

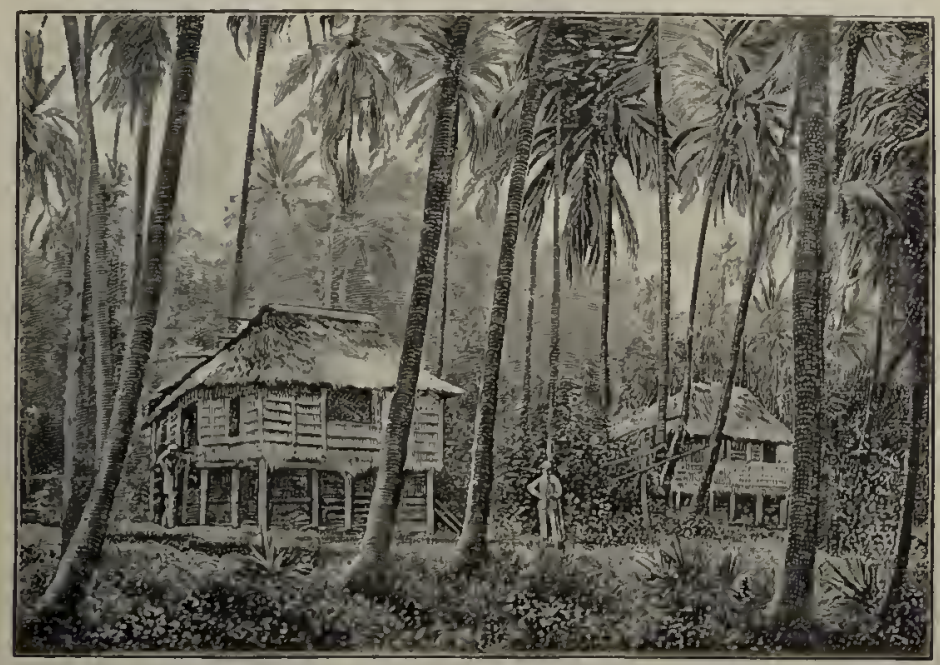

FIg. 384. A grove of cocoa palms in the P'hilippines

After Frye

494. Chocolate, tea, and coffee. These familiar substances are derived from plants of three different families, the first two being somewhat nearly related tropical or sub-tropical ones.

Chocolate consists of the ground or crushed seeds of the cacao tree, a native of Mexico, now widely cultivated throughout the tropics. Removal of a large part of the aromatic fat known as cacao butter, which is considerably used in medicine, leaves cocoa, which forms for some people a more digestible beverage than chocolate. 
Tea is made from the leaves of a shrub long cultivated in China and Japan, and now also in India, Ccylon, and elsewherc. inlike chocolate, tea has no food value, but is a mild stimulant.

Coffee is made from the seeds of a small tree widcly cultivated in hot countries and belonging to the madder family.

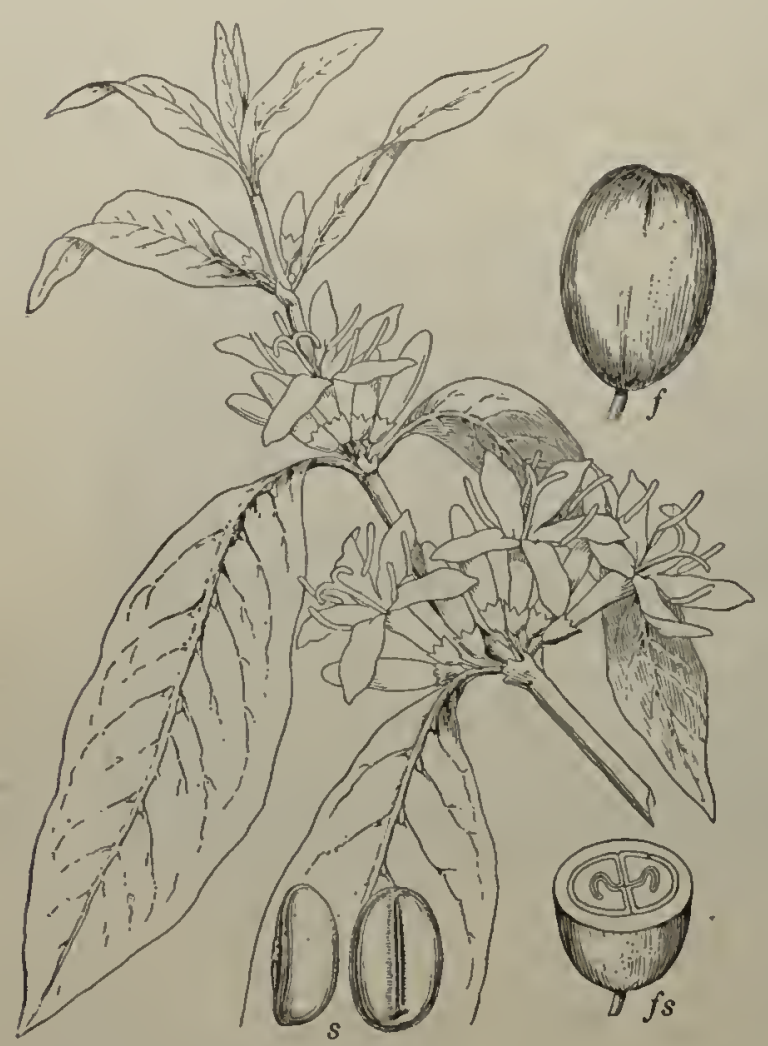

FIG. 385. $\Lambda$ flowering twig of the coffee tree

The seeds are produced in red berries, which are thickly clustered about the twigs of thc tree. Coffee las orly a trifling food value, but is a vigorous stimulant, reënforcing the action of the heart.

\section{Fruits with fleshy pulp.} The kinds of fruit with fleshy pulp, some caten raw and others requiring cooking, are so numerous that they call only be mentioned under the families to

which they belong. Two thirds natural size, with fruit $f$ and $f s$ and seeds $s$, natural size. - After Wossidlo

From the palms arc obtained dates, which are technically berrics with a very hard seed. In the arid portions of Africa and northwestern Asia, where thcy grow, they are of the first importance as food. Successful attempts are now in progress to introduce the culture of the date palm into the desert regions of the extreme southwestern United States. 


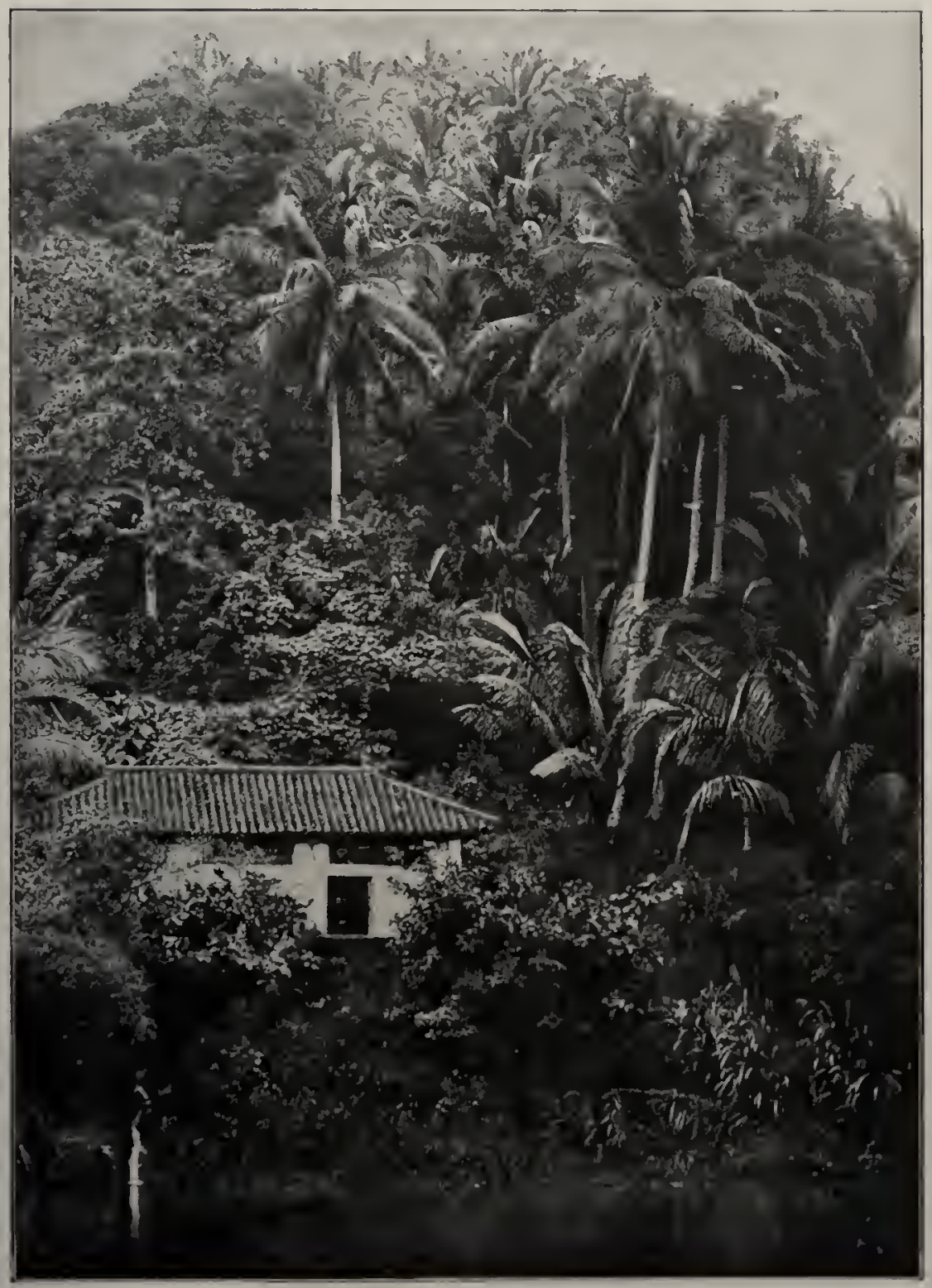

Plate IIII. A tropical forest in the Philippines, mainly palms After F. W. Atkiuson 

From the pineapple family our only edible fruit is the pineapple, largely cultivated in Florida and the West Indies.

The banana family is a very small one, but exceedingly important, since it furnishes, in the shape of bananas, the principal subsistence of multitudes of the inhabitants of the tropics. The plant is herbaceous, but sometimes grows to the height of forty feet, with enormous leaves. It is extraordinarily productive, so that a few square rods of good soil set with hanana plants will supply the fruit for an entire family. Our importation of bananas is very large and rapidly increasing, and what was once an article of luxury or a curiosity is now the staple fruit for the entire year in most of our markets. The principal supply comes from the West Indies and Central America, but bananas are somewhat cultivated in the extreme southern portions of the United States.

The mulberry family supplies the breadfruit, which constitutes the most important food of great numbers of the inhabitants of the south Pacific Islands. Our only fruits of this family are the mulberry and the fig. Most of our figs are still imported, but their culture has recently become a considerable industry in California,

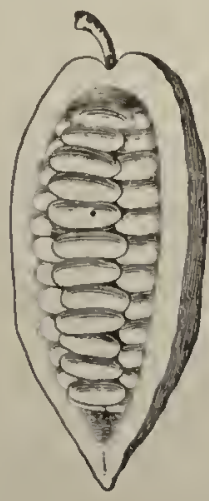

Fir. 386. A cacao pod, cut open to show the seeds

One fourth natural size. - After Schmidt since the variety which can be dried for shipment is now successfully cultivated there.

Two closely related groups, the saxifrage family and the rose family, furnish a large proportion of all our true berries, and some edible fruits which are not berries. From the former family are obtained currants and gooseberries. The rose family consists of five sub-families. Of these the apple subdivision furnishes quinces, pears, and apples; the rose subdivision furnishes strawberries, blackberries, and raspberries; and the plum subdivision furnishes plums, cherries, peaches, apricots, and nectarines 
The rue family contains a rather small number of trees and shrubs, with only two common genera, the prickly ash and the hop tree in temperate North America, and comprises, among others, the orange sub-family. Under this is found the genus Citrus, which embraces all the citrous fruits. The species and varieties which are found in our markets may be classed as oranges, grape fruit, and lemons.

Most of our oranges are now of American growth, coming from California or Florida, and many of the very large fruited species of Citrus from Polynesia, variously known as pomelo and grape fruit, are raised in both these states, while some are also imported from the West Indies. The best lemons are imported from the Mediterranean coast, largely from Sicily.

The grape family numbers about 300 species of climbing shrubs. Only the grape genus Vitis is a source of edible fruits, - the berries so familiar as fresh grapes or raisins.

Of these there are two principal types, one comprising the European (Malaga and other) varieties with solid pulp, found also in such California varieties as the Tokay grape, all of which are descended from one European species. The other type is the one with soft pulp, readily separated from the skin, such as the Catawba, Delaware, Isabella, and Concord varieties. These have to some extent been introduced into Europe, but are descendants of native American species. Grapes are considerably cultivated in most of the states, but nowhere else so extensively as in California, where they are raised for wine making, for the manufacture of raisins, and for shipment in a fresh condition.

The heath family supplies berries of several species, such as the familiar cranberries and the blueberries and huckleberries, which are largely gathered for the market in several of the northeastern states, particularly in Maine, and are somewhat extensively canned.

From the olive family (mostly sub-tropical trees and shrubs) are obtained olives, which constitute a table delicacy, while the oil is a highly valuable food. 
From the nightshade family, many of which are poisonous plants, we get several large edible fruits (true berries, though they are not popularly so called), - the ground cherry, or strawberry tomato (Physalis), the pepper (Capsicum), ${ }^{1}$ the egg plant, and the tomato.

The gourd family furnishes all the melons, cucumbers, squashes, and pumpkins.

496. Edible leaves and shoots. Only a few. of the articles of diet under this head have much commercial importance or form a notable part of the subsistence of people in any portion of the country.

From the lily family we get asparagus; from the pigweed family, spinach; from the mustard family, water cress, cabbage, cauliflower, and Brussels sprouts; from the parsley family, celery; and from the Composita, lettuce and globe artichokes (Cynara).

497. Edible bulbs, rootstocks, tubers, and roots. As is elsewhere explained (Sec.66), reserve material is often stored in underground portions of the plant body. The number of vegetables derived from these is not very large, but they constituie a considerable part of the food of people, especially in temperate and cold climates.

From the lily family onious are obtained, from the yam family yams, from the pigweed family beets, from the mustard family turnips and radishes, from the parsley family carrots and parsnips, from the morning-glory family sweet potatoes, from the nightshade family potatoes, and from the Composite salsify and Jerusalem artichokes (Hclianthus).

498. Starch and sugar from stems and roots. Sago is the purified starchy pith of sinall palms, natives of Siam and of some of the Malayan Islands. A portion of the supply also comes from West Indian cycads (Sec. 346).

Tapioca is a starchy substance obtained from the grated roots of plants of the spurge family (Exuphorbiacece), cultivated in tropical America and the West Indies.

${ }^{1}$ This is not a pulpy fruit. 
Arrowroot is a very pure starchy food obtained from the rootstocks of plants of two or three tropical families, espe-

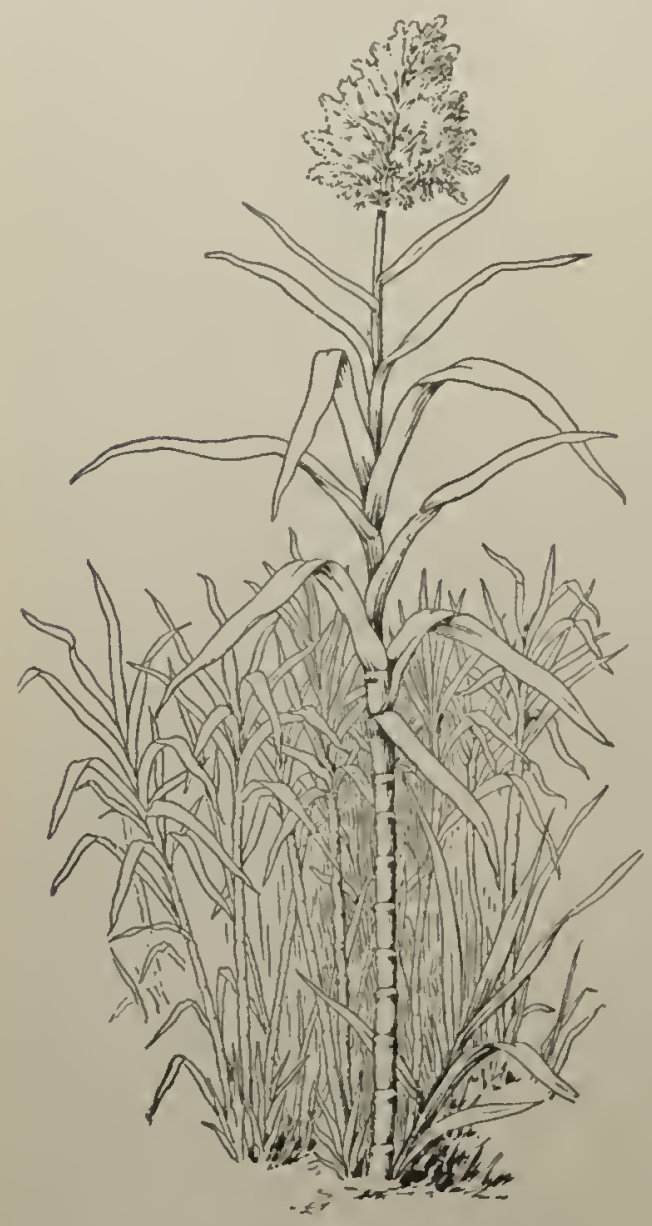

Fig. 387. Sugar cane (Saccharum)

Much reduced. - After Wossidlo cially the arrowroot family (Marantacece).

Sugar is largely manufactured in Europe and to some extent in the United States from the juice of the sugar beet. The remainder of the world's supply of sugar comes from the stem of the sugar cane, a grass which grows to a height of ten feet or more. It is somewhat cultivated in Louisiana, but much more extensively in the West Indies, Java, and the Hawaiiau Islands.

\section{MEDICINAL PLANTS AND PLANT PROD- UCTS}

499. The study of medicinal plants is a special subject, forming an inportant part of the course in every college of pharmacy. Only a few words can be given to the topic in this chapter.

Very many of the families of angiosperms contain species used in medicine. ${ }^{1}$ In some cases, as in the lily fanily, the pea family (which furnishes sixteen remedies), the nint family,

1 In the United States Plıarmacopocia sixty-seven families are represented. 
and the nightshade family, medicinal properties are quite gcnerally distributed throughout the whole family or through certain seetions of it. In other eases, as in the poppy family (which yields opium and morphia), the family Erythroxylacee (which yields coeaine), and the figwort family (which yields digitalis), only one important remedy or group of remedies oceurs. The properties of many medicinal plants were discovered by accident in primitive times, while others have had their valuc established only as a result of careful experiments on man and the lower animals.

\section{FOOD PRODUCTS FOR DOMESTIC ANIMALS}

500. The most important herbivorous domestie animals eattle, hol'ses, and sheep - consume large quantities of the less expensive grains, and in gcneral the roots and tubers whieh are useful for human food are readily eaten by these animals.

A large proportion of the grasses are utilized by grazing animals or fed as hay. Many plants of the pea family, particularly alfalfa, the clovers, soy keans, and cow peas, are eaten by domestic animals.

Both grasses and other plants are eut and fed to eattle and horses, while fresh, as forage. Large quantities of "corn fodder" are used in this way in many parts of the country, and the stems and leaves of eorn ar'c also eut up, placed in large tanks ealled silos, allowed to ferment, and then fed to eattle throughout the winter.

Certain by-products of manufacturing processes are of much value for cattle food. Among the most important of these are linseed meal and eotton-seed meal, whieh are rieh in proteids and still retain some oil after the greater part of it has been extraeted by the most powerful pressure available. The refuse grains from breweries and the sloply boiled eorn meal from distilleries are in a wet state extensively fed to eattle and logs, but are injurious if used alone. They are also dried for 
shipment. The refuse from beet sugar manufacturing establishments is used in a wet condition for cattle feeding, and is also dried and shipped.

Some seeds not eaten by man are highly valuable when fed to the lower animals. Acorns and beechnuts, for example, in some of the wooded portions of the southern Middle States, furnish a considerable part of the subsistence of droves of hogs.

\section{PLANTS USED AS FERTILTZERS}

501. For centuries the advantage of plowing under growing crops as a means of enriching worn-out land has bcen wcll recognized. It is only very recently that the exact significance of this process has been understood. Even now the dctails are not so fully worked out that we know just what crop will yicld the best results for every variety of soil and climate; but in a general way it is established that leguminous plants are the best for this purpose on account of the power which their root tubercles have of utilizing the nitrogen of the atmosphere (Sec. 256). Various clover's and alfalfa arc the crops most commonly emplcyed.

\section{PLANT PRODUCTS USED IN MANUFACTURES}

.502. Under this head there is only space to mention a very few of the vegetable substances used in manufacturing processes, most of thern on account of thcir chemical properties.

Dyeing by means of vegetable coloring matters is far less important than it was before the introduction of the artificially prepared aniline color's. These are so powerful that it is more cconomical to use them, but they do not give soft shades. Valuable dyes, however, are still obtained from a considerable number of plants. Many of these bclong to members of the pea family, which furnislies Brazil wood (red), logwood (red, purple, and black), camwood (red), indigo (dark blue). 
From the buckthorn family are obtaincd yellow and green dyestuffs, known, respectively, as Persian berries and Chinese green indigo.

Varnishes of great value are yielded by trces of the pea family (copal varnish) and of the sumach family (Japanese lacquer).

Tanning is largely carried on by aid of the bark of several species of oak, of which the black oak and the Spanish oak are two of the most used American species. Hemlock bark and the leaves and young twigs of Sicilian and American species of sumach are also used for tanning. Other substances employed for the same purpose are catechu, derived from a species of acacia, and gambier, derived from the evaporated sap of a trec of the madder family, a native of the East Indies.

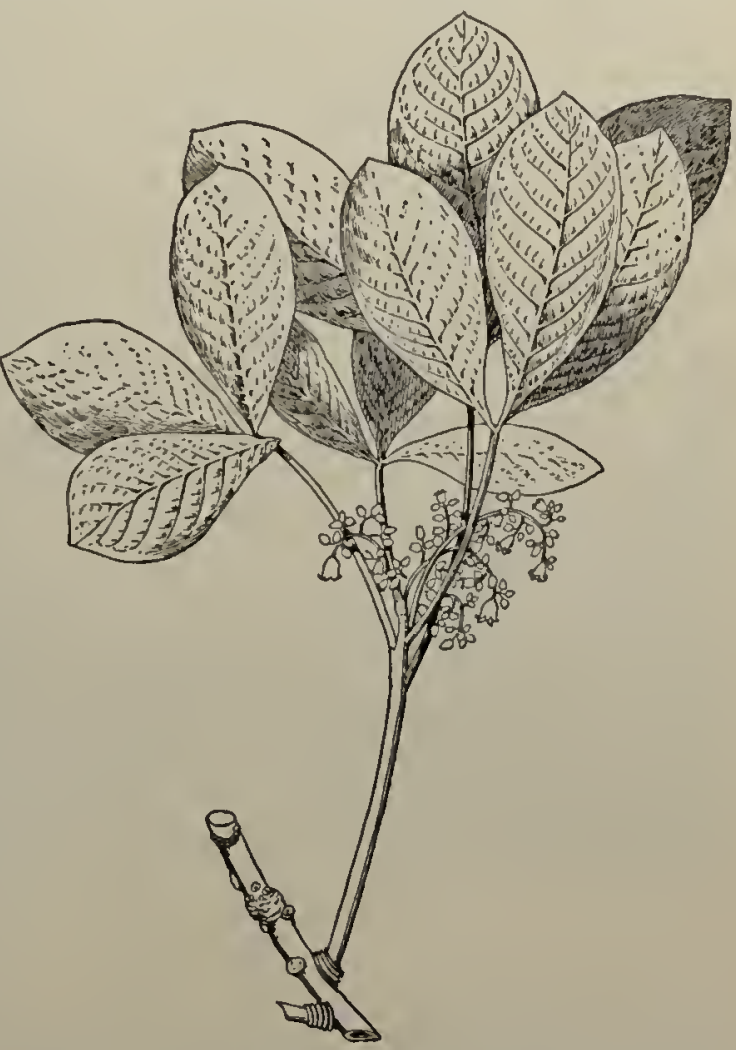

FIG. 388. $\Lambda$ twig of the South $\Lambda$ merican rubber tree (Hevea)

After Schmidt

India rubber is manfactured from the sap of several tropical trees and lianas. The principal one of these is the Para rubber tree (Hevea) of the spurge family.

Gutta-percha is produced by trees of the star apple family (Sapotacece) of the Malay Archipelago, a family of much economic importance. 


\section{PLANT FIBERS AND RELATED PRODUCTS}

503. Fibrous materials for use in spinning into thread, cordage, and rope, also for braiding and weaving, are obtained from mauy parts of the plant body. Some of the most useful of these, such as flax and hemp, are derived from the hard bast, others, as cotton, consist of plant hairs, and others still represent various structural elements of the plant.

A large proportion of the fibrous materials in general use comes from monocotyledonous plants of sereral families.

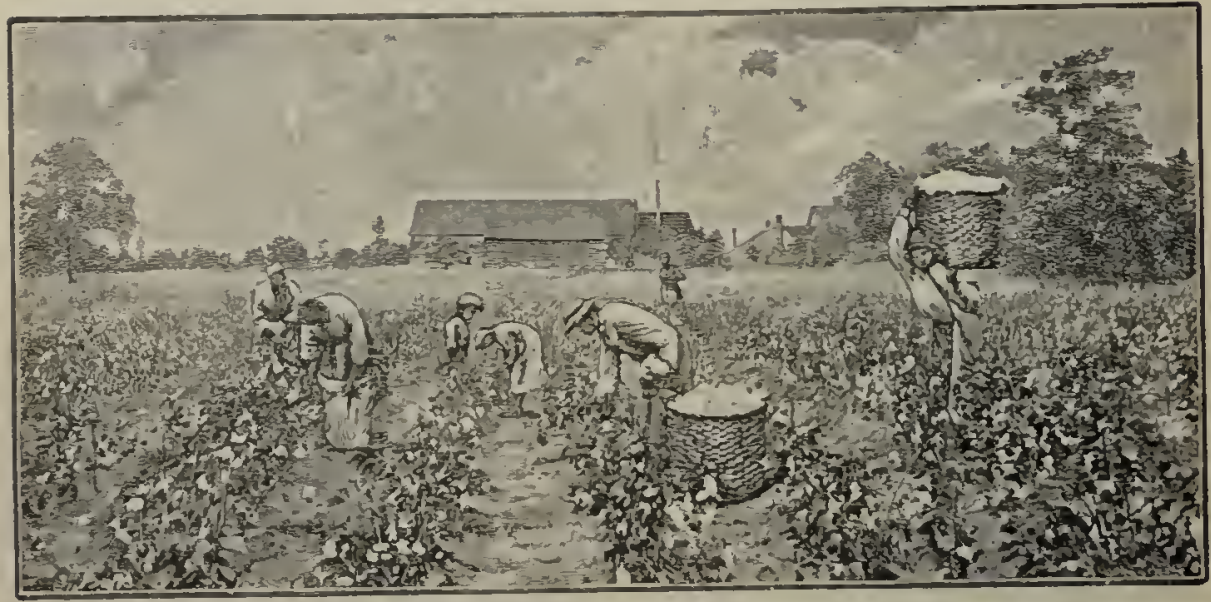

FIG. 389. $\Lambda$ Georgia cotton field

After Frye

Several sedges of the genus Cyperus furnish materials for wearing, and East Indian and Chinese mattings are made from species cultivated for the purpose.

The straw of various grains is employed for braiding into baskets, mats, hats, and other articles. A coarse grass known as esparto is largely exported from Spain and the North African const for use in paper making and for other purposes.

Many palms produce valuable fiber; that of the luusk of the cocoanut is largely used for cordage, mats, bruslies, and similar articles. 
From material obtained from the very young leaves of a somewhat palm-like plant (Corludorica) the well-known Panama hats are woven.

The New Zealand flax of the lily family and the century plant (Fig. 391) of the amaryllis family furnish fibers.

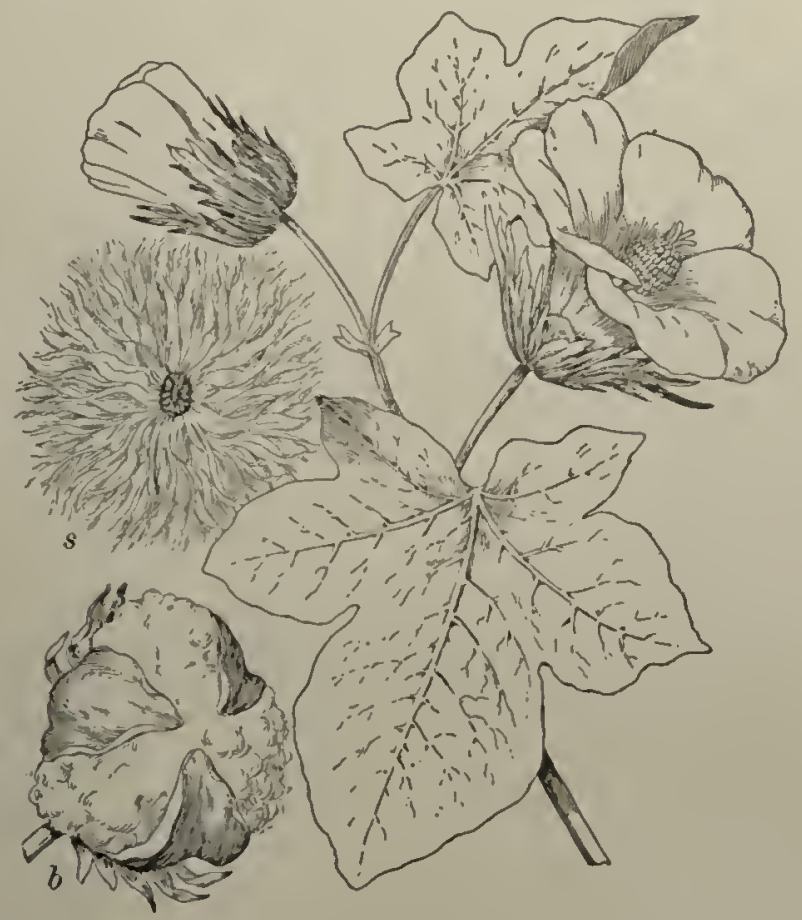

İig. 390

A portion of a cotton plant in hlonm with a ripe capsule or boll $b$ and seed $s$. All slightly reduced. - After Wossidio

From a member of the banana family, a native of the Philippines, but .cultivated also in India, is obtained the extremely valuable manila fiber, one grade of which is so fine as to be woven into delicate shawls and similar fabrics, while the coarser kinds are used in the inanufacture of manila rope.

Among dicotyledonous plants there are a considerable number which serve as sources of commercial fibers. 
To the mulberry family belong the paper mulberries, which furnish bark from which the beautiful Japanese paper is made, and the hemp plant, which is one of the chief rope- and cordagemaking materials.

To the nettle family belongs ramic, an eastern Asiatic plant cultivated in Jamaica and the southern United States, from which Chinese grass cloth and other fabrics are made.

Three closely related groups of plants - the linden family, the mallow family, and the silk cotton family - yield many fibrous or hair-like products of use for spinning and weaving,

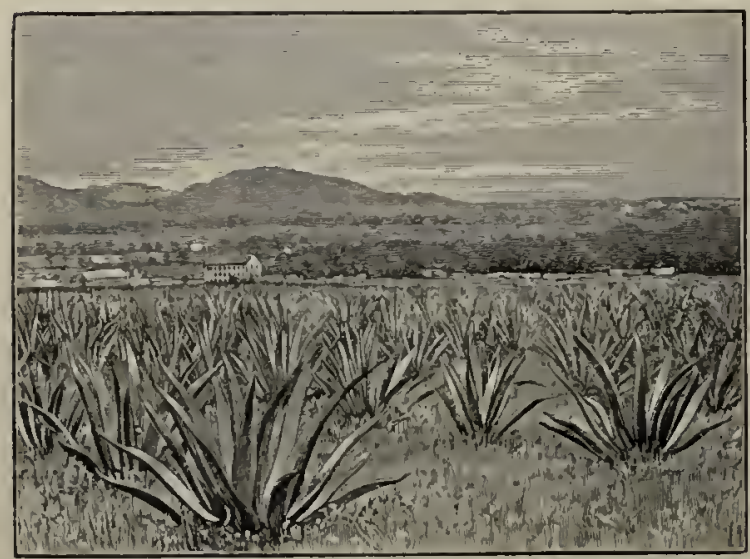

Fig. 391. Century plants (Agave)

After Frye

or for mattress making and similar purposes. From the bark of trees of the first-niamed family is obtained the Russian bass, or bast, used for making rough mats, and the tropical product jute, used to weave with silk, and also for carpets, mats, and coarse bags. From the hairs which clothe the seed of the cotton plant (the most important member of the mallow family) all cotton goods are manufactured. Cotton is largely cultivated in India, Egypt, and our own country. It is an important crop in all of our Gulf states, and in Georgia and South Carolina. The seed hairs of the tropical silk cotton trees (Ceiba) are coming to be much used in pillows and cushions as a substitute for feathers.

Most regretable fibers, such as have been described in this chapter, are useful for paper making, even after the rope or woven fabrics made from. them have been worn until they are dropping to pieces. Large areas of forest, particularly of spruce 
and poplar growth, are now annually eut down to furnish paper pulp. It has been recently proposed to utilize eotton stems for paper pulp. Ten million or more tons of the raw material, worth nearly a dollar a ton for this purpose, are now anmually available in the cotton-growing states.

\section{TIMBER}

504. Coniferous woods. The wood of our eone-bearing trees (mainly of the pine family) is generally known as soft wood,

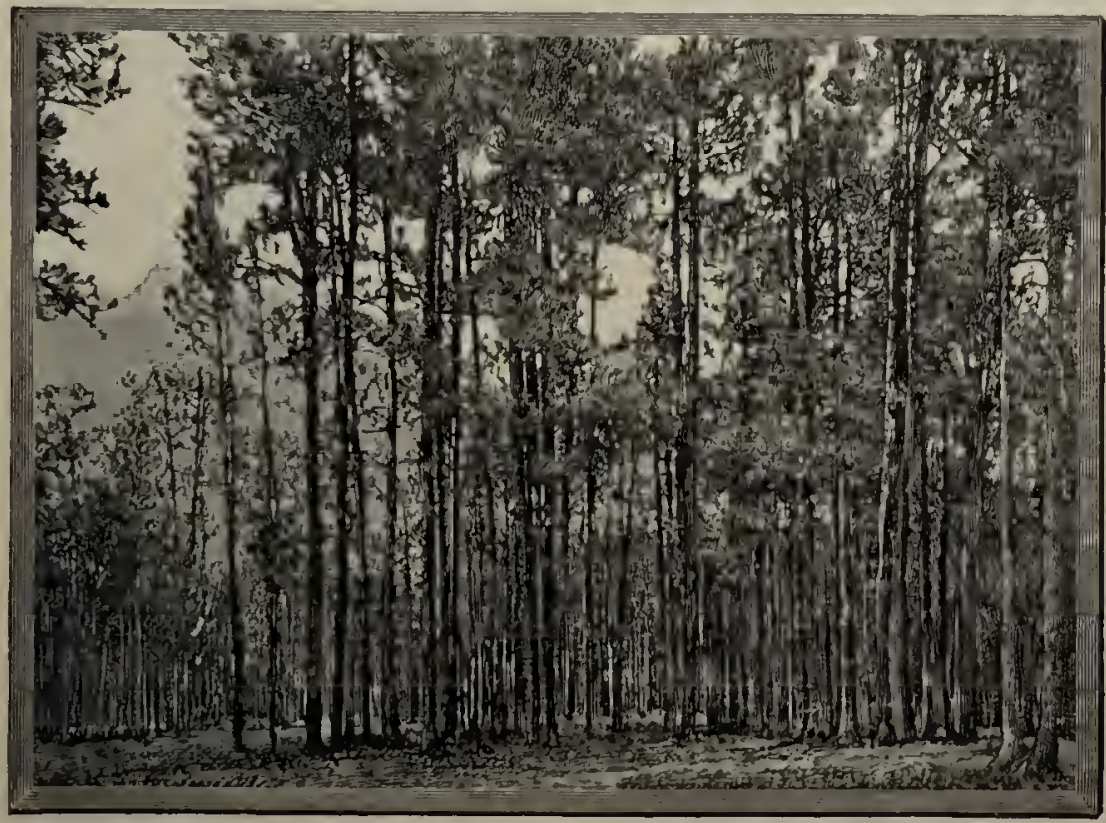

Fig, 392. Forest of hard or yellow pine (I'inus palustris) on southern coastal plain of the United States

After Frye

and that of our broad-leaved, mostly deeiduous trees is known as hard wood. These terms are not quite eorreet, for the eoniferous larehes and yews furnish a harder wood than that of sueh broad-leaved trees as willows, poplars, tulip trees, and buekeyes.

Out of the entire timber supply of the eountry more than three quarters is at present furnished by the thirty-eight or more 
species of cone-bearing trees, especially the pines, which grow within our limits.

The wood of the white pine (Pinus strobus), remarkable for its workableness and freedom from warping or cracking when exposed to the weather, was for years the most important of all our soft woods. Latterly, as the supply is becoming greatly lessened, other kinds of pine, especially the long-leaf pine, the loblolly pine of the southeastern states, and the bull pine (P. ponderosu) of the Pacific and Rocky Mountain regions, are to a considerable extent taking its place.

Among the other most willely used coniferous woods are two species of true spruce (Picea), the "Douglas spruce" (Pscudotsuya), two western species of white fir (Abics), the smaller California redwood (Sequoia), the American or bald cypress (Taxodium), and several distinct kinds of white cedar (Thuya, Chamceeyparis, and Libocedrus). The cypress, larch, and most of the cedars furnish timber of great durability when exposed to the weather or buried in the earth, and therefore are highly valued for posts, telegraph poles, railroad ties, and similar uses.

505. Broad-leaved woods. Our native broad-leaved trees which furnish wood for manufacturing or constructive purposes comprise about eighty species, a larger number than is found in any other equal area of the temperate zones.

The principal hard-wood forests are of oak, though other valuable timber trees, such as maples, hickories, beeches, and elms, are usually scattered among them. Our oak lumber is of three kinds, - white, red, and live oak. White oak is much superior to red for constructive purposes where strength is important, but does not show so conspicuous a grain when polished for cabinet work. More than half of our supply of hard woods comes from various species of oak.

Next in importance is the wood of the tulip tree (Liriodendron), generally known as yellow poplar, or whitewood. This has largely taken the place of white pine in inside woodwork for dwelling houses and other huildings. 
Among the most generally useful of the other broad-leaved woods may be mentioned maple, eln, ash, and ehestnut.

Several kinds are particularly valued for their durability in the ground; among these are chestnut, black locust, and eatalpa.

For cabinet work the nlust prized of our native woods are black walnut, cherry, birch, and some species of oak. None of

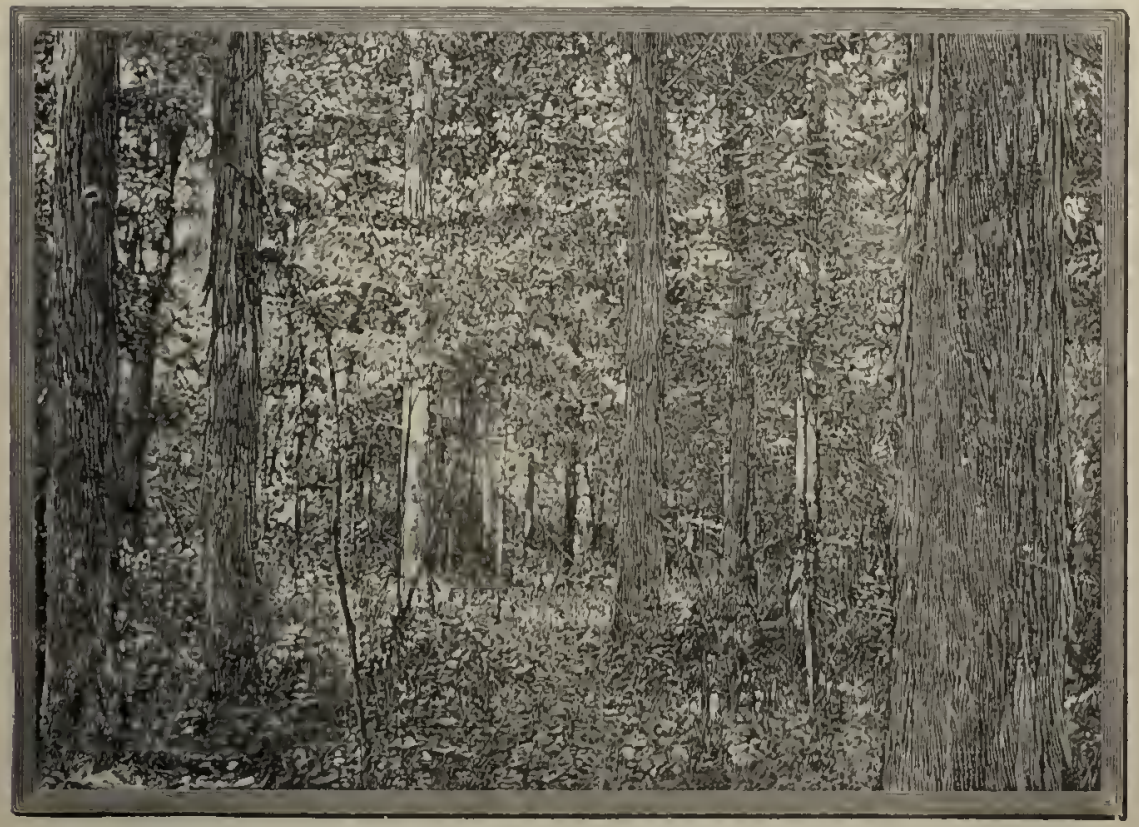

Fig. 393. Hickory (hard wood) forest near sonthern end of Appraluchian highlands

After Frye

these is as beantiful as some of the finer imported kinds, such as malogany, rosewood, and satinwood.

506. Forestry. Juring the time when the country was in process of being settled most portions of the Athantic coast region, and inland as far as the prairies of what are now the states of Illinois and Minnesota, were covered with primitive forest. The rnost difficult task of the settler was to clear enough land for tillage. The finest timber trees were destroyed by hundreds of thousands by the process of girdling, that 
is, by cutting away a ring of sapwood and allowing the trees to die of starvation and lack of water. Cultivation was carried on among them, until after some years the trees would

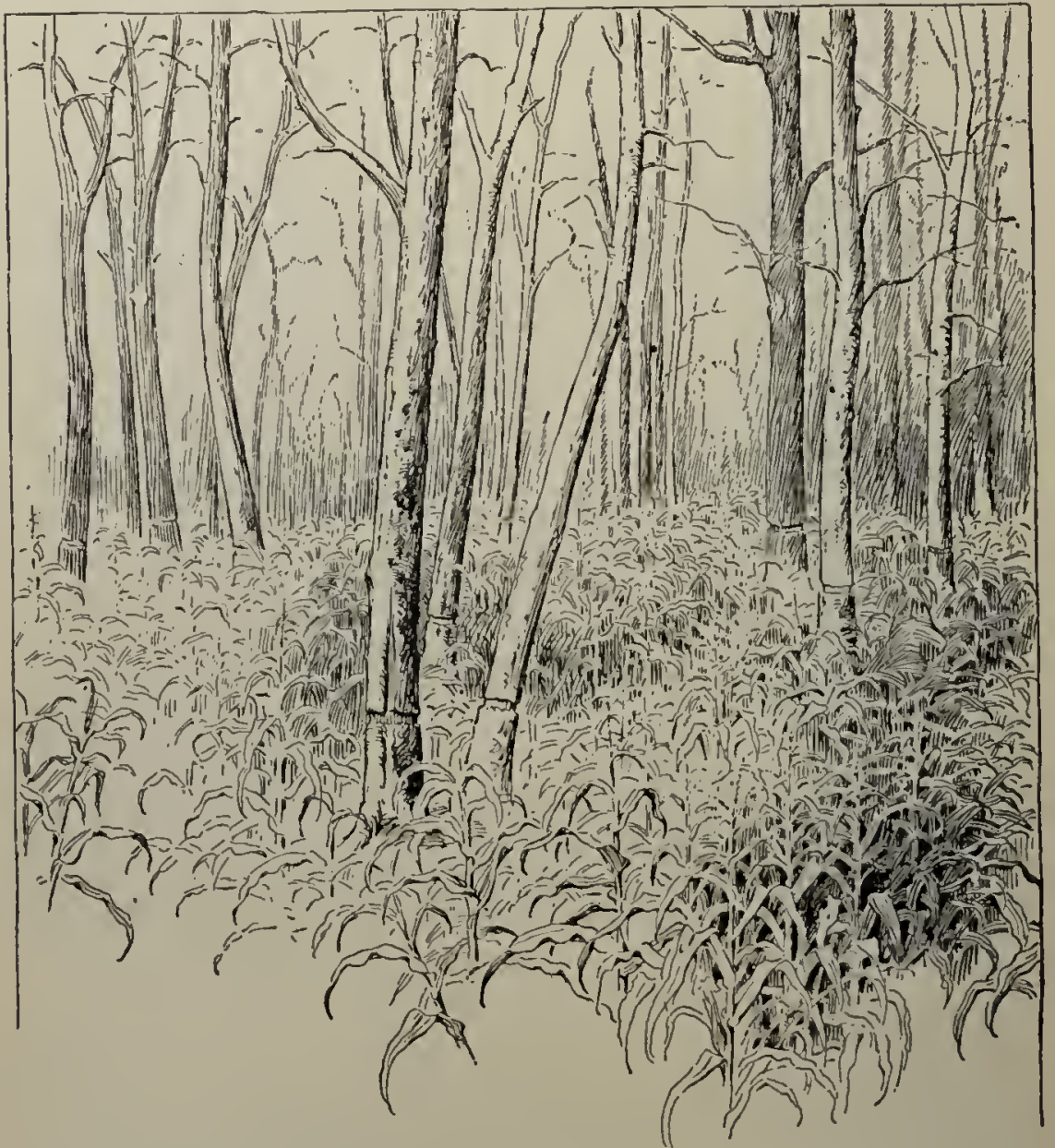

FIG. 394. A corn field in a "deadening" or girdled forest of deciduous trees

Modified after Ayres

fall and then were burned to rid the land entirely of their presence. More than a century and a half of wholesale destruction of trees has finally resulted in stripping large areas of the original forest and preventing the reforestation of the land, until 
a point has been reached when it is difficult to get lumber of good quality for many of the most important purposes for which it is used. In some parts of the country timber is a profitable crop to raise, even if it has to be planted and cared for while growing. The science and art of growing timber and caring for tracts of wooded land is called forestry. Much attention has long been paid to it in the most enlightened countries of Europe, but the subject is a comparatively new one in the United States. The importance of maintaining a suitable proportion of wooded land in any region does not depend merely on the desirability of a supply of timber. The water supply of lakes and streams, the retention of the cultivable layer of loam on the earth's surface, the climate of any region, at least so far as the prevention of severe winds is concerned, - all are dependent on the presence of considerable forest areas.

The principles of forestry cannot be laid down in a few words, and forest management requires years of study in the woods themselves. The literature on the subject is extensive, and courses in forestry are now given in a good many universities. Evidently it is a topic of growing importance in this country. A few useful rules can be given here.

1. Tree cutting should generally be managed on the principle of selecting only mature trees and leaving the others to grow up to replace those cut.

2. Forest fires should be prevented.

3. Destructive fungi should be exterminated wherever found.

4. Insect enemies of trees, such as the seventeen-year locust, the various caterpillar's, and boring insects, should be destroyed.

5 . Sheep and cattle should never be pastured in woods where they can do harm by killing young seedling trees or other useful undergrowth.

6. Tree planting should be carried on whenever it can be made to utilize lands not needed for other purposes, and the species planted should be chosen with extreme care to meet the requirements of the soil and climate. 


\section{FUEL}

507. Nearly all fuel is of vegetable origin. In most civilized countries to-day the principal fuel supply consists of various kinds of coal, that is, of regetable matter which has been buried in the earth for ages and undergone many changes (Sec. 330).

Peat, the consolidated material left after the partial decay of certain bog mosses (Sec. 292), in some countries forms a considerable part of the available fuel, and the deposits in the nortlern United States are of some importance.

Wood, in portions of the country, is still the principal fuel. Certain varieties are preferred for household use on account of their furnishing good beds of glowing coals, or for burning in open fires on account of their freedom from any tendency to snap. But in general the fuel value of thoroughly seasoned wood is nearly proportional to its weight per cubic foot, that is to say, the very heariest woods, such as hickory, the white oaks, black locust, and some kinds of ash, are worth most for lieating.

Other parts of plants besides wood are used to some extent for fuel. In large tanneries the spent bark is often compressed to extract most of the water and then burned. Corncobs are often burned in stoves and under steam boilers. In treeless regions twisted ropes of straw are used as fuel.

\section{ORNAMENTAL PLANTS}

508. Our ornamental plants may be roughly classed into shade trees, shrubs, herbaceous perennials, and annuals. The total number of species and varieties cultivated in the United States runs far into the thousands, but in many cases florists' varieties are distinguished from one another only by color or some other comparatively unimportant characteristic.

Most of our cultivated ornamental plants are of foreign origin, and representatives of almost all parts of the earth except the arctic regions are found among them. In a few instances native 
species are familiar occupants of our flower gardens, as, for example, the native azaleas and Rhododendrons, the bee balm, California poppy, evening primrose, Mariposa lily, Missouri currant, Pentstemon, purple flowering rasplerry (Rubus odoratus), cone flower (Rudlichiu), snow on the mountains (Euphorbic), and wild cucumber.

Some of the families which contribute most largely to our lists of cultivated flowers are the lily, the amaryllis, the pink, the crowfoot, the rose, the yea, the geranium, the heath, the mint, and also the composite family. 


\section{NOTE ON RESPIRATION}

A few additional facts are here given to supplement those stated in Sect. 133.1

Respiration can only be carried on by living protoplasts.

It results in the breaking down of nitrogenous and non-nitrogenous substances in the cell contents.

It may be due to the action of enzymes upon the oxidizable contents of the respiring cells.

It is likely that the oxidizable compounds destroyed in respiration are broken down by the action of hydroxyl $(\mathrm{OH})$ upon their molecules. This hydroxyl is derived from the water present.

Many of the lower plants, especially fungi, regularly perform what is known as anaërobic or intramolecular respiration, in which the breaking down of molecules of their tissues and release of energy is carried on without access of any free oxygen. Some portions of the higher plants, e.g. seeds, of ten manifest anaërobic respiration. This is readily shown by soaked peas.

In the ordinary respiration of the higher plants free oxygen, taken in from the atmosphere, serves to reconstruct the molecules of water destroyed in the formation of hydroxyl.

Ordinary respiration, as already stated (Sec. 133), gires rise to energy, or the power of doing work, and produces carbon dioxide and water. It may also produce organic acids, imperfectly oxidized compounds, such as oxalic, malic, and citric acids. These sometimes remain in the stems, leaves, or fruit of the plant, as, for example, citric acid does in the citrous fruits (lemons, limes, grape-fruits, oranges). Oxalic acid may be deposited as insoluble crystals of calcium oxalate in rarious parts of the plant bods, and any of these acids may be more completely oxidized and then excreted.

The respiratory ratio, or relation of the volume of carbon dioxide pro. duced to that of oxygen consumed, is usually nearly $\frac{\mathrm{CO}_{2}}{\mathrm{O}_{2}}=1$. Some plants, however, may at times give a rery different result from this, as the Crassulacece, in the dark, manufacture so much malic or other acids that little or no carbon dioxide is given off. During the germination of oily seeds, while the oil is being converted into starch, the respiratory ratio is usually less than unity.

1 See Peirce's Text-Book of Plant Physiology, Chapter n, Henry Holt \& Co., New York; and Barnes' paper, "The Theory of Respiration," Botanical Gazette, Vol. xxxtx, pp. 81-98, 1905. 


\section{APPENDIX}

[Additional illustrations, chiefly for use with a flora in determination of species]

\section{LEAF FORMS}

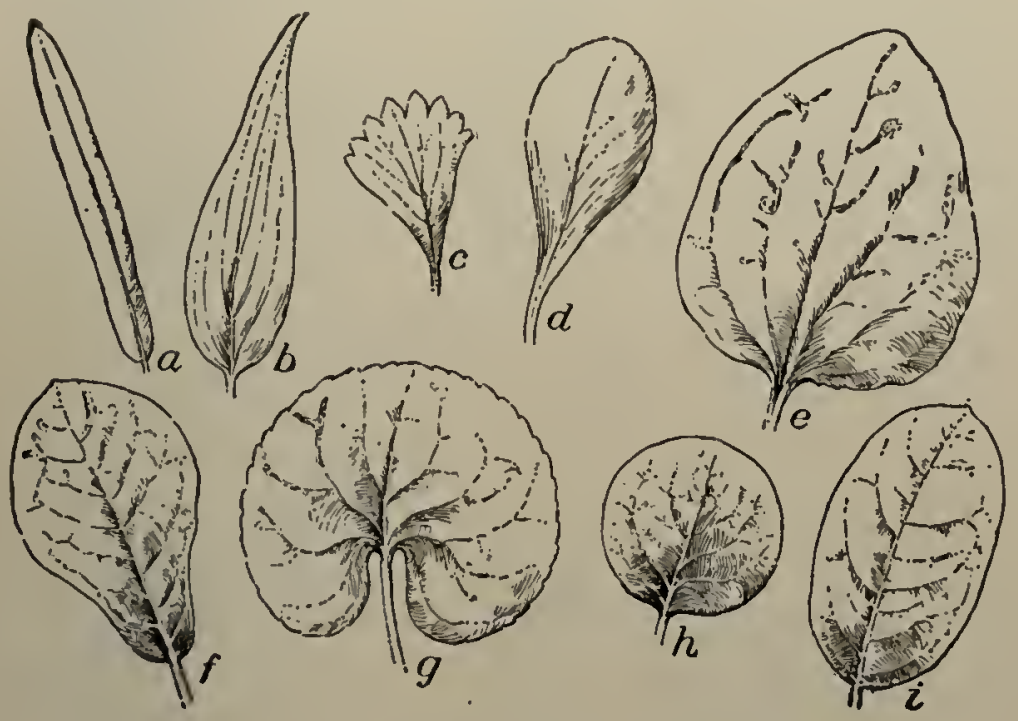

Fig. 1. General outline of leaves

$a$, linear; $b$, lanceolate; $c$, wedge-shaped; $d$, spatulate; $e$, ovate; $f$, obovate; $g$, kidney-shaped; $h$, orbicular; $i$, elliptical 

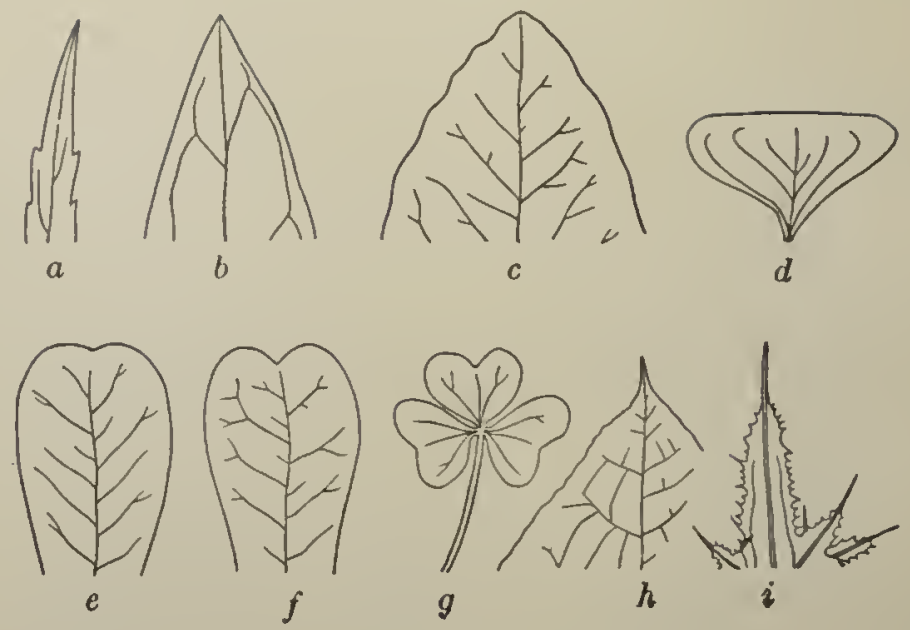

Fı. 2. Tips of leaves

$a$, acuminate or taper-pointed; $b$, acute; $c$, obtuse; $d$, trumcate; $e$, retuse ; $f$, emarginate or notehed; $g$ (end leatlet), obcordate; $h$, cuspidate, - the point sharp and rigid; $i$, mucronate, - the point merely a prolongation of the midrib
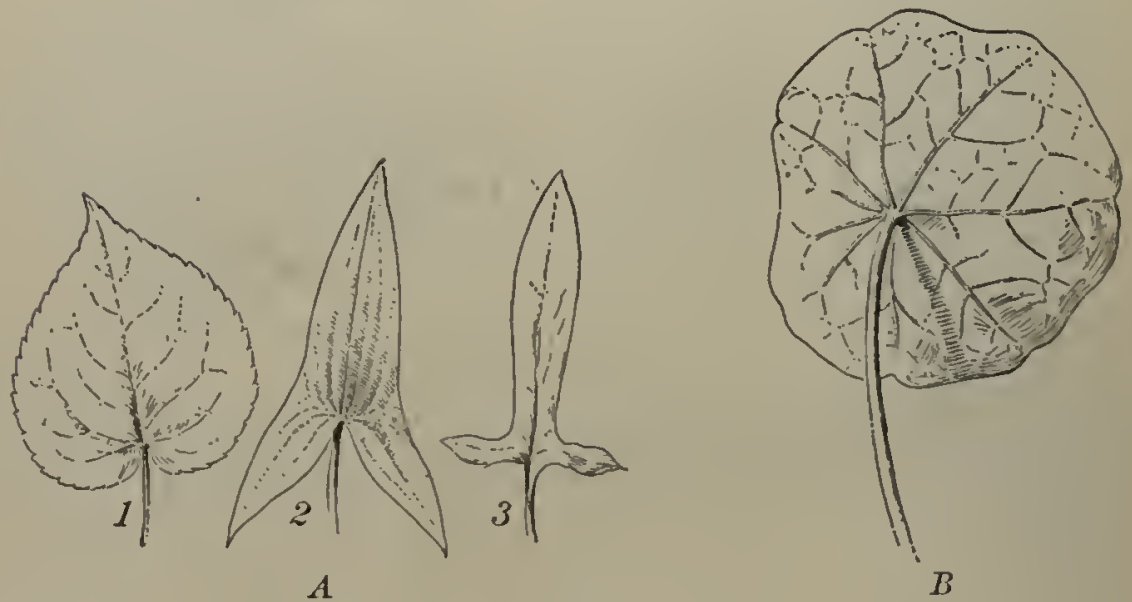

Fig. 3

A, shapes of bases of leares: 1 , heart-shaped; 2 , arrow-shaped ; 3 , halberd-shaped. $B$, peltate leaf of tropacolum 
II. FORMS OF SYMPETALOUS COROLLA

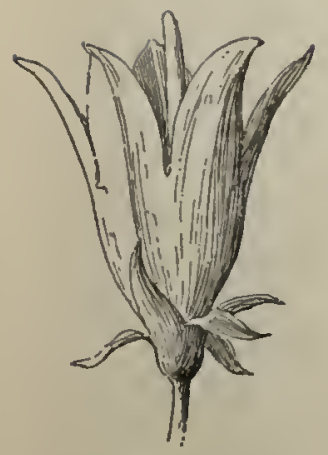

Fig. 4

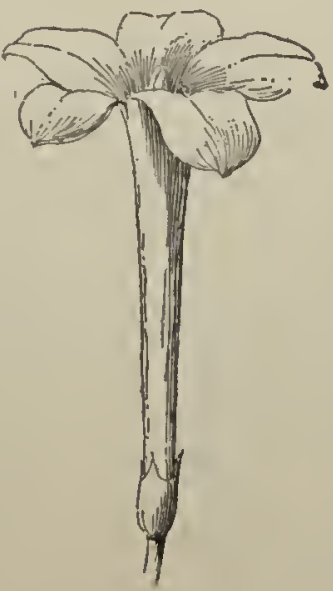

FIG. 5

Salver-shaped corolla of jasmine (magnified)

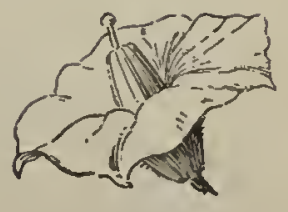

Fig. 6

Wheel-shaped corolla of potato

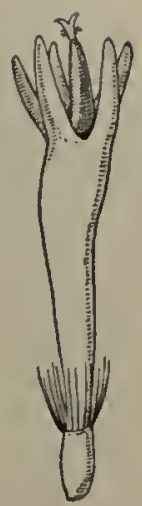

FIG. 7

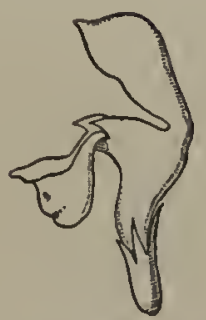

Fig. 8
Tubular corolla, from head of bachelor's button
Labiate or ringent corella of dead nettle 



\section{INDEX}

References to illustrations arc indicated by stars. App. indicatcs Appendix

Absorption of carbon dioxide, 107 , 108

A bsorption of water by roots, 28

$\Lambda$ bsorption, root, 30

$\Lambda$ bsorption, seleetive, 36

Acaeia, leaf of, $98^{*}$

Aceessory bucls, $82 *$, $84 *$

Aecessory fruits, $146,149^{*}, 150 *$

Aetinomorphie, 125

$\Lambda$ cuminate, $\Lambda$ pp. I

Aeute, $\Lambda$ pp. I

$\Lambda$ daptations to eonditions of existence, 496, 497

Arlder's-tongue, 324 *

Adventitious buds, 83,87 *

Adventitious roots, 19

Acidium, 261, 262*

Aërial roots, 19-21*

Agaricus, 267

Age of trees, 46

$\Lambda$ ggregate fruits, $146,149 *, 150 *$

Ailanthus twig, $81 *$

A ir ehamber, 103*, 104*

Air passages, in Hippuris stem, 111*

Ail plants, 47 *

Air, relation to germination, 7

Akene, 147*

Albugo, 245*

Alburninous substanees, 9

Alga-like fungi, 239-247*

Alga-like fungi, sunnmary of, 247

Algre, 172, 173-226;

Algie, distribution of, on rocks, 215*

Alga, evolution of, 225, 226 ;

Alga, life histories of, 221, 222

Alpine vegetation, 484-487*, 49 ?

Alternate branching, 41 *

Alternate leaves, 81 *

Alternation of generations, 220,278 , $345-3,50$

Alternation of generations, protoplasmie basis of, $.34,-9.48$

Amanita, 267
Amoba, 158*; 159

Anabiena, 176,177

Angiospermse, 376-388*

Angiosperm flower, 376-379*

A ngiosperm, life history of, 388

Angiosperms, 128, 376-388*

Angiosperms, elassifieation of, 397

Animal food, need of, 412

Animals and plants, distinetions between, 168,169

Animals, defenses against, 413-419*

Annual growth, lefinite, 42

Annual growth, inclefuite, 42

Annual ring, 66*, 68*

Annuals, 46

Anther, 127*, 139, 140*, 378-380*

Anther, modes of opening, $140^{*}$

Antherilium, 18!* , 204, 275*, 276

Antherozoid, 18!, 204

Anthoeeros, 288*, 289*

Anthocerotales, 288*, 289*

Antiporal cells, 144*, 383*

Antitoxins, 236

Ant plants, 414*, 415

Ants plant seeds, $446^{*}$

$\Lambda$ petalous, $123,124 *$

A pogany, 244, 319, 320

A pospory, 320

Apples, seleetion among, $503 *$

Aquatie plants, 459-462*, 488

Arehegonim, 276*

Arehichlamyders, 397,398

Areh of hypocotyl, (;*, 12*, 13

$A$ retic vegetation, 484

Aretic willow, 484*

Aristoloehia stem, bundle of, 61*

Aristolochia stem, cross seetion of, $60^{*}, 61 *$

A rrangeinent of leaves, 94-101*

Arrow-shaped, App. I

Artemisia, 480, 493, 49.1

Aseoearp, 248, 250

Ascomycetes, 248-257* 
Ascus, 248, 249*, 251*

Asexual generation, 278, 304, 342, 345-350

Ash tree, naturally grafted, $69 *$

Asparagus, $55^{*}$

Aspergillus, 250*

Aspidium, 308*, 314*

Assimilation, 107, 112, 115, 163

Associations, plant, 474, 475

Autumn leaves, coloration of, 121, 122

Auxospore, $196^{*}$

Axillary bud, 81*, 82*

Axillary inflorescence, $132 *$

Bacteria, 228-237*, 238

Bailey, L. H., 448

Barberry, spiny leaves of, $416^{*}$

Bark, 59, 60* 65-67** 71, 72, 366*, 368

Bark cells, 25*

Basidia fungi, 258-271*

Basidiomycctes, 258-271*

Basidium, 258-267*

Bast, 312 , 367

Bast bundle, 25*, 62*

Bast, soft (sieve tubes), 61 63*

Batrachospermum, 217

Beans, selection among, 504

Bees, 422* 423, 426*

Beggar's ticks, 444*

Bell-slıaped, App. II

I3elt's boolies, 414*, 415

Berry, 148*, 150*

Biennial, 26, 46

Bilaterally syumetrical flowcrs, $124 * 125 *$

Bilaterally symmetrical leavcs, 88

Bireh, branehing of, $46 *$

Bird pollination, 428

Bisexual, 123*

Bitter roots, 25

Bitter seeds, 11

Black knot, 252*

Bladderwort, 437 *

Blights, 244-247*

Blister blight, 245*

Bluc-green algæ, 174-178*

Blue-green alga, lifc habits of, 177 . 178

Blue-green algæ, summary of, 178

Bog zonation, 476-478*

Boletus, 265*, 267

Botany, definition of, 1

Botany, economic, 500-535*
Botany, economic, definition of, 3

Botany, systematic, definition of, 2

Botrychium, 324*

Botrydium, 200*

Box elder, buds of, $82 *$

Box elder, radial and cross sections of stem of, $61^{*}$

Brace roots, $21 *$

Bract, 133*, 138*

Branched leaves, 9I-9.3*

Branches formed from adventitious buds, 87

Branching, alternate, $41 *$, 94*

Branching and leaf arrangement, 41-45*

Branehing, opposite, $41 *$

Branch tliorn, 44*

Brecding, plant, 500-513* ,

Brown algae, 205-213*

Brown algæe, life liabits of, 205, 206

Brown algæ, stummary of, 2 I3

Bryales, 293-301*

Bryophyta, 275-305*

Bryopliytes, 275-305*

Bryophytes, evolution of, 302

Bryophytes, origin of, 302

Bryophytes, summary of, 303,304

Buckeye, bud of, 80*

Budding, 238*

Buds, 80-87*

Buds, adventitious, 83,87 *

Buds, dormant, 87

Buds, naked, 80, 81 *

Buds, position of $82 *, 83,87 *$

Buds, structure of, $80-86^{*}$

Bud-scale scar, $40^{*}$

Bud scales, $80 *, 83$

Bulb, 5.\%*

Bulb, liyacintlı, 53*

Bulblets, 438

Bulrush, e ross scetion of stem of, 58*

Burbank, Luther, 510

Burs, 442-444*

Buttcreup, leaf of, 91*, 104-106*

Buttcrnut, buds of, 82*

Buttons, 266*

Cactus, 54*, 463*

Caladium, 52*

Calamites, 339, 340, Plate VIII

Calcium, 28, 29

Calyptra, $277,295,296 * 301 *$

Calyx, 123*, 124*, 126*

Cambiun, 25*, 60-67*, 366*, 367

Cambium ring, 65, 67*, 71, 72, 367 
Camptosorus, 310*

Canal cells, 276*, 277

Canna, 381*

Canna, parallel veining in, 89 *

Cap (pileus) of gill fungi, $266^{*}$

Capsule, 146, 150*

Carbon, 28, 29

Carbon dioxide, 7, 107, 108, 113, 115

Carbon dioxide, absorptiou of, 107 , 108,342

Carboniferous Age, 339-341

Carnivorous plants, 409-412*

Carpel, 127, 358, 369-371*, 380*, 381

Carpogonium, 217*

Carpospore, 217*

Carrion fungi, 269

Castor bean, germination of, $6 *$

Castor-oil plant, early history of stem, 65*

Castor-oil plant, fibro-vascular bundle of, $65^{*}$

Caterpillar and grub fungi, 25.3*

Catharinea, 293*

Caikin, 134*

Cedar apples, 264

Cedar, red, $146 \%$

Cell, $34-39 *, 129,156-167 *$

Cell contents, $34,35 *, 160 *, 161 *$

Cell division, $34,159,164,165 *$

Cell growth, 164

Cell reproduction, 164

Cell sap, 38*, 160

Ccll structure of moss leaf, 161*

Ccll structure of pond scum, 160*

Cell theory of organization, 165-167

Ccll turgor, 161

Cell wall, $34,159,160 *, 161^{*}$

Cells, starch in, 9*

Cellulose, 34, 38, 159

Central cylinder, 24*

Central placcnta, 129*, 130

Cetraria, 256*, 257

Chatophoracere, 190*, 191

Chara, 202*

Charales, 201, 202*

Cherry, buds in axils of leaves, 81 *

Cherry twig. 84*

Chlarnydomonas, 182*

Chloropliycex, 179-204*

Chloropliyll, 105, 109, 160

Chlorophyll bodies, $105,106 *$

Chloroplast, 105, 106*, 107, 160, $161 *$

Choripetalous, 126

Chorisepalous, 126
Chromatin, 164, 165*

Chromatophore, 160 *

Chromatophore, fission of, 161*, 165

Chromosomes, 165*

Cilium, 170*

Circle (whorl), 124*, 126*

Circulation of nitrogen, 231*

Circulation of protoplasm, 201

Citrous fruits, hybridizing of, 511

Cladonia, 257*

Cladoplıora, 191*

Cladophyll, 56*

Class, 153

Classification, 152

Clathrocystis, $174 *, 175$

Clavaria, 264"

Claviceps, 252, 253*

Cleistogamous flowers, 432, 433*

Clerodendron, 42?*

Climbing plants, 20*, 47-50*, 92*

Climbing shrubs, stem structure, 60 \%, 67

Climbing stems, 20*, 47-50*

Closed veining, $89^{*}$

Clover leaf, 98*

Club moss, 329-339*

Cluster cup, 261, 262*

Clustered roots, $23 *$

Coal, 341

Coalescence, 388

Cocklebur, 442, 443*, 444*

Colosphærium, 175

Conocyte, $197,200,201,240$

Conogamete, 242

Coiling, 48*, 49**

Coleochæte, 191, 192*

Collective fruits, 146,150

Collenchyma, 64*

Colocasia, 52*

Colorado coniferous forest, Plate XII

Coloration of autumn leaves, 121, 122

Colors of flowers, 424

Columella, 241, 242*

Common ferns, 311-320*

Coinmon mosses, 293-301*

Coinmon receptacle, $134,135 *$

Comparative sections of fruit, 150*

Compass plant, nearly vertical leaves of, $100 *$

Competition, 447-451*

Compositxe, 135*, 400

Composite head, 134, 135*

Compound cyme, 137* 
Compound leaves, 91, 92*

Compound pistil, 128

Compound umbel, 135*

Conceptacle, 212

Condensed stems, 54*, 56

Cone, 326*, 327

Confervales, 184-192*

Confervas, 184-192*

Conidia, 245

Coniferales, 361-375*

Coniferous forest, Plate XII

Conifers, 364-375*

Conjugales, 193*, 194*

Continuity of protoplasm, 99, 100

Coral fungus, 264*

Cordaiteæ, 340 , Plate VIII

Cordyceps, 253*

Core, 148

Cork, 71

Corn, aërial roots of, 21*

Corn, cross section of stem of, $58^{*}$

Corn, grain of, $7 *$, 50.5*

Corn, section of root tip of, 24*

Corn, selection among, 504-507*

Corn stem, structure of, 57, 58*

Cornus canadensis, Frontispiece

Corolla, 123*, 126*

Cortex, 65*

Cortex of root, 24*

Corymb, 133

Cotton, 526*, 527*

Cotton, hybridizing of, 511,512

Cotyledon, 5-14*, 18*, 370*, 374

Cotyledon, disposition made of, 14

Cover (operculum), 299, 300*

Crossing, 501

Cross pollination, 420, 501, 512

Crowberıy, rolled-up leaf of, 466 *

Cryptogains, 354

Cup fungi, 250, 251*

Cup (volva) of gill fungi, 266, 267

Cup (cupule) of Marchantia, 282*

Cuspidate, App. I

Cuticle, 9*

Cuticle, unequal development of, by epidermis cells, 117*

Cutin, 117

Cutting leaves, 418*

Cyanophyceæ, 174-178*

Cycadales, 360-363*

Cycads, 360-363*

Cycas, 361*

Cyme, 136, 137*

Cypress, 111, Plate III

Cystocarp, 216, 217** 219*
Dahlia, thickened roots of, $23^{*}$

Daily movements of leaves, $97,98 *$

Damping off, 247

Dandelion, 50*

Darwin, Charles, 154, 420, 448

Date palms, $57^{*}, 518$

Datura, 11, 419, 443*

Decay, 230, 231

Deciduous, 121

Defenses against animals, 413-419*

Definite annual growth, 42

Dehiscing. 146*, 147

Descent of water, $75 *, 76$

Desert, Sahara, 482*

Deserts of United States, 493-495

Desıids, 193*, 194

Determinate inflorescence, 136 *

Deutzia leaves, 96*, 97*

De Vries, 499, 513

Diadelphous, 127, 128*

Diagrams, floral, 131*

Diastase, 10

Diatomales, $195,196 *$

Diatoms, 195, 196*

Dichoganiy, 429*

Dicksonia, 309, Plate VII

Dicotyledoneæ, 398-400

Dicotyledonous plants, $18,397-400$

Dicotyledonous stem, annual, gross structure of, $59,60 *$

Dicotyledonous stem, cross section of, $60-67^{*}$

Dicotyledonous stem, minute structure of, 60-66*

Dicotyledonous stem, rise of water in, 73-75*

Dicotyledons, 398-400

Dimorphous flowers, 432*

Diøecious, 124*

Dionæa, 412 *

Disk flowers, 134, 135*

Dispersal of seeds, $439-446 *$

Dispersal of seed plants, $436-446 *$

I)istinct, $123^{*}, 126,127,129 *, 130$ *

Diurnal position, $97,98^{*}$

Divided leaves, 90, 91 *

Division, 153

Dodder, 22*, 23

Dormant buds, 87

Double fertilization, $383,384 *$

Dollble flowers, 139

Downy mildew, 244,247

Draparualdia, 190*

Drip leares, $462^{*}$

Drosera, $410^{*}, 411^{*}$ 
Drought, endurance of, 464

Drought plants, 459

Drupe, 148*, 149, 150*

Dry fruits, $146-148 *$

Duckwecd, 462*

Duct, 25*

Dulse, 214

Earth star, 268, 260*

Ecological groups, 459-473*

Ecology, plant, definition of, 2, 3, 407

Economic botany, 500-535*

Economic botany, definition of, 3

Ectocarpus, 206*, 207

Egg apparatus, 383*

Egg cell, 165, 166, 183*, 189*, 204, 212

Egg, osmosis in, $37 *$

Elater, 285, 287*

Elder, pollen grain of, $382 *$

Elliptical, App. I

Elm, 43*

Elm bud, 85*

Emarginate, App. I

Embryo, 5-12*

Embryo sac, 144*, 356, 373, 382, $383^{*}, 384^{*}$

Endocarp, 150*

Endosperm, 5-9*, 362*, 872*, 373, $384,385^{*}$

Energy, source of, in plants, 7,110 , 111

Enzymes, 10, 232

Epidermis, 24*, 25*, 60*,61*, 64*, 103-105*

Epidermis, uses of, 117*, 118

Epigynous, 130*

Epigyny, 395

Epiphytes, 19*, 47** 309, 310, 471473*

Equisetalcs, 325-329*

Equisetineæ, 325-329*

Equisetu1n, 325-329*

Ergot, 253*

Eubasidiomy cetes, 258, 264-269*

Englena, 170*, 171

Euplororbia splendens, 417*

Evergreen, 121

Evolution, 153, 156

Evolution of algx, 225, 226

Evolution of sex, 223, 224

Excretion of water, 116-120

Existcnce, struggle for, $447-451,497$

Exocarp, 149, 150*
Exogenous, 65

Explosive fruits, 439

External character of dicotyledonous stem, 59

External character of monocotyledonous stein, 57 *

Eyes of potato, 52*, 53

Fall of the leaf, $93 *$, 120-122

Family, 153

Fermentation, 10, 11, 231, 232

Fern, life history of, 319

Ferns, 309-324*

Fertilization, 138-145*, 166

Fibrous roots, 23*

Fibro-vascular bundles, 24, 58*, 59$61 *, 65-67 *, 103 *, 105 *, 106 *$

Fibro-rascular bundles of ferns, 311, $312 *$

Ficus elastica, 80, 465*

Ficus religiosa, drip leaf of, $462 *$

Filament, $127 *$

Filicales, $311-320 *$

Filicineæ, 309-324*

Fission plants, 178

Fittest, survival of the, 498

Fixation of carbon, 107

Flagellates, 170*

Flax, cross section of stem of, $62 *$

Fleshy fruits, uses of, $444,445,518-$ 520

Fleshy roots, 23*

Floating seeds, 441, 442

Floral diagrams, 131*

Floral envelopes, 123*

Floral organs, 138-141*

Flower, 123-145*, 358

Flower, bud scar, 45*, 46*

Flower buds, position of, 45*, 46*, $83 *, 84 *$

Flower, development of, 387*, 388

Flower, evolution of, 393-396

Flower, nature of, 138-140*

Flower, organs of, $123^{*}$

Flower, plan of, 123*, 130, 131*

Flower, symmetry of, 125*, 395

Flowers, ecology of, 420-435*

Flytrap, Venus, 412*

Follicle, 146*, 147

Food cycle, 163, 164

Food in embryo, 9-11*

Food products. See Plant products Food, storage of, in root, 23*, 25, 26* Food, storage of, in stem, 52-54*, 78,79 
Forest map, 491

Forest region, $490-492$

Formations, plant, $474-480 *$

Formative tissue, 64*, $65^{*}, 67^{*}, 366^{* *}$. See growing point

Fossil plants, 339-341, Plate VIII

Foxglove, leaf of, 90*

Free eentral placentation, 120*, 130

Frond, 308*, 309

Frost, aetion of, 121

Fruit, 140-150*

Fruit bud, 83*, 84*

Fueus, 210-212*, Plate IV

Funaria, 294*, 296*, 298*, 299*, 301*

Fungi, 172, 227-273*

Fungi, life histories of, 272,273

Fungi, origin and evolution of, 274

Fusion of parts, 395

Gametangium, 204

Gamete, 166, 182, 185*, 186, 204

Gametophyte, 220

Gametoplyyte, degeueration of, 404 406

Gamopetalous, 126

Gamosepalous, 126

Gastromyeetes, 268*, 269*

Geaster, 268, 269*

Generatious, alternation of, 220,278 , $345-350$

Generative cells in pollen tube, 142 * $363,372 * 373,382 *$

Genus, 153

Geography, plaut, definition of, 2

Geography, plant, of the United States, $489-495$

Geotropism, 31, 32*, 39, 44

Germ diseases, 235,236

Germination, $6-14$ *

Germination, ehemieal ehanges cluring, 6,7

Gill fungi, 265-267*

Gills, 266, 267*

Ginkgo, motile sperms of, 363

Glocoeapsa, 174*

Gloeotrichia, 176* 177

Glueose, 108

Grafting, $68 * 69 *$

Grain, $7 *, 147,505 *, 514-516$

Grape sugar, 79,108

Grapevine blight, 247

Grasses, 398, 514, 515

Grass pistil, 421*

Gravity, 31, 39, 44

Gray, Asa, 46
Green algæ, 179-204*

Green algæ, reproduetive organs of, 204

Green algre, summary of, 203

Green felt, $197,200 *$

Green layer of bark, 71, 72

Ground tissue, 313

Growing point, $24 *, 280 * 316 *$

Growth, measurement of, in stem, $17^{*}$

Growth, seeoudary, 65- $67^{*}$ *

Guard cells, 104*

Gulf weed, 212*, 213

Gymnosperm, life history of, 375

Gyınnospermæ, 359-375*

Gymnosperms, 128, 359-375*

Hæmatocoeeus, 181

IIairs, 417,418

Hairs on leaves, 119

Hairs, root, 15, 16* 24, 25* $27 *, 28$

Hlairs, stinging, 418*

IIalberd-shaped, App. I

Ilalf-inferior ovary, 130 *

Half parasites, 408

Halophytes, 459, 468*, 469, 483*

IIard bast, 25*, 60-66*

Haustoria, 22*, 248

Head, 134*

Heart-shaped, App. I

Heartwood, 71, 72

Helianthemum, 487*

Heliotropie movements, 101*

Heliotropism, 101*

Hepatice, 279-289*

Herbs, 46

Heteroeysts, 176 *

IJeterogamy, 190, 204, 212, 224

leterospory, 320, 322, 324, 351-353

Iligh mallow, provisions for eross pollination of, $429 *$

Hilum, 5*

Homology, 151

Honeybee, leg of, 422*, 423

Honey gland, 423

IIoney locust thorn, $44 *$

Hop, twining of, 49*

Horse-chestnut, leaf arrangement of, 95*

Horsetails, 325-329*

Host, 22*, 23, 407

Hot springs, plants in, 178

IIyacinth, bulb of, 5?*

11 ybrid, 501

IIybrid blackherries, leaves of, 510*

IIybrid plums, 510* 
IIy bridizing, 501, 502*, 509-513*

Hybrids, produetion of, 501, 502*, 50y-513*

Hyclnum. $265 \%$

Hydrogen, 28,29

IIydrophytes, 459-462*, 482, 488

Ilydropterales, 320

Ilymenium, 264, 267*

Il y menom yeetes, 264-267*

Ilypha, 240

Hypoeotyl, 5*, 6*, 12*, 16

Hypocotyl, cross seetion of, $65 *$

Hypogynous, 130*

Ily pogyny, 395

Ietland moss, $256 * 257$

Imperfeet fungi, 254

Indefinite annual growth, 42

Indehiscent fruits, $147-149 *$

Indeterminate infloreseence, 132*, 183

Indian corn, kernel of, $\tau^{*}$

Indian eorn, root tip of, $24 *$

Indian eorn, structure of stem of, $58 *$

India-rubber plant, leaf of, $405 *$

Ind usium, 308*, 313

Inferior ovary, 130* $185 *$ * 150*

Infloreseenee, $132-137 *$

Inflorescenee, determinate, $136,137 *$

Infloreseence, diagrams of, 136 *

Infloreseence, indeterminate, 132*, 133

Insectivorous plants, $400-412$ *

Insect pollination, $422-4.32 \%$

Insects, pollen-earrying apparatus of, $422 *, 423$

Inseets, sense of smell of, $42 \%$, 424

Inseets, vision of, 424

Insect traps, leares as, 400-412*

Insertion of floral organs, $130^{*}$

Integuments, 356, $362 *, 370 *, 371$. $381,383 *, 380 *$

Intereellular spaees, $102 * *$, $111^{*}$

Interual structure of dicotyledonous stem, 59-62*

Internal structure of monocotyledonous stem, $57,58^{*}$

Internode, $16,17 *$

Invasion, 451,452

Involuere, $131,135 \%$

Iris, rootstock of, $51 *$

Irish moss, $214 *, 216$

Iron, 28,29
Irritability in plants, nature and oecurrence of, $35,36,49,97-99 *$

Irritability in roots, 39

Irritability of protoplasm, 35,36

Irritability of tendrils, $48 *, 49$

Isoetes, 338*, 339*

Isogam y, 186, 204, 224

Ivy, aërial roots of, 20 *

Jungermanniales, 285-287*

IKeel, $125 *$.

Kielps, 207*, 208*, 209*

Kidney-shaped, $A$ pp. I

Knees, 111, Plate III

Knot and wart fungi, 252*

Kinots, $67,68 *$

Lirakatoa, 456

Labiate, A pp. II

Laelinea, 251*

Lainina, 88

Laminaria, $207 *$

Laneeolate, App. I

Lateral buds, 40*, 46*, 82*

Leaf, 15-18*, 88-122*

Leaf, accumulation of mineral matter in, 120

Leaf arrangement, $94-101$ *

Leaf bases, $5: 2 *, \Lambda \mathrm{pp}$. I

Leaf blade, 88

Leaf buds, $40,41,45^{*}, 46 *, 83^{*}, 84 *$

Leaf, fall of, 120-122

Leaf forms, 90

Leaflet, $85,86 *$

Leaf, member of plant body, 88

Leaf mosaics, $95 *, 96,97 *$

Leaf outlines, App. I

Leaf sears, $52 *, 81 *$

I Leaf sections, $102,103 *, 465 *$, 460*

Leaf spine, $416 *, 417 *$

Leafstalk, 88

Jeaf tendril, $92 *$

Leaf tips, App. I

Leaf traees, $105 *, 106$

leafy liverworts, 285-287**

Leaves as inseet traps, 409-412*

Leaves, compound, 91-93*

Leaves, eutting, 418*

Leaves, divided, 90, 91*

Leaves, functions of, $102-122 *$

Leaves, movements of, $37-101 *$

Leaves of xerophytes, $465 *, 466 *$

Leaves, simple, 88-91*

Leaves, strueture of, 102-122* 
Legurne, 147, 443*

Lenticels, 71

Lepidodendron, 340, Plate VIII

Leucoplasts, 116

Lianas, $47 *, 48$

Lichen, 254-257, Plate V

Lichens, nature of, 255

Life history, chromosome count in, 348

Light, exposure to, 39

Light, movements away from, 39, 101

liglit, movernents towards, 101

Lignification, 367

Lignin, 114

Ligule, 338*

Lilac inildew, $249 *, 250$

Lily, $377^{*}, 378 *, 380^{*}, 383^{*}, 384 *$, $385 *$

Lily, pollen grains producing tubes on stigma, 142*

Lime, 120

Linden, fruit cluster of, 439*

Linden wood, structure of, $66 *$

Linear, $\Lambda$ pp. I

Linnæus, 153

Linnæus, 153

Living matter, properties peculiar to, 167

Living parts of the stem, 71,72

Lobe, 126*

Locules, 129*, 148*

Locust, pinnately compound leaf of, $92 *$

Locust, thorn stipules of, 417*

Lycoperion, 268*

Lycopodineæ, 329-339*

Iycopodium, 330-332*

Macrocystis, 208*

Magnesium, 28, 29

Magnolia, forking of, $42,45 *, 46^{*}$

Mallows, pollination in, 429*, $430 *$

Malt, 10, 11

Maltose, 79

Mangrove, 468*

Maple fruit, $147 *$

Marchantia, 280-285*

Marcliantiales, 280-285*

Marestail, air passages of, 111*

Marsilia, 321-323*

Mat plants, 51

Mechanics of stem, 58*, 59, 60*, 62*, 312*

Medullary ray, $60 * 66,71,72,367$

Megasporangium, 334
Megaspore, 322

Megasporophyll, 334,369

Melon, leaf of, $89 *$

Mesembryanthemum, 465*

Mesophyll, 103*, 105

Mesopliy tes, $459,467,468$

Mesquite, root system of, 27

Metabolisin, 114, 115

Metabolism, digestive, 114

Metachlamydee, $397,399,400$

Micropyle, 6* $142,144 * 361,362 *$, 381, 383*

M ic rosphæra, 249*, 250

Microsporangium, 334

Microspore, 322

Microsporophyll, 334, 369

Midrib, 89*

Mildews, 248-250*

Mildews, green and yellow, 250*

Mineral inatter accumulated in the leaf, 120

Mistle toe, 408

Mixed buds, 83

Modified leaves, $80,81 *$

Moisture favors rool growth, 39

Molds, 239-242*

Monadelphous, 127, 128*

IIonoblepharis, 247

Monocotyledonex, 397,398

Monocotyledonous plants, 18

Monocotyledonous stems, $57-59$ *

Monocotyledonous stems, growth of, in thickness, 59

Monocotyledonous stems, rise of water in, 75*

Monocotyledons, 397, 398

Monceious, 12:4*

Moonwort, 324 *

Morchel la, 251, 252*

Morel, 251, 252*

Morphology, 1, 151

Mosaics, leaf, $95 *, 96,97 *$

Moss, life history of, 294-297*

Mosses, 275, 289-301*

Mothis, 427 *

Mougeotia, 194

Movement of water in plants, $73-78$ *

Movements of leaves, $97-101^{*}$

MIucor, 243*

Iucorales, 239-242*

Mucronate, A pp. I

Mulberry, 149*

Multiple fruits, 146, 149*, 150

Musci, 275, 289-301*

Mushroom, 265, 267* 
Mutations, $497-499$

Mutilated seedlings, growth of, 8* Myeelium, 240*

Mycorrhiza, 269, 270*

Myrsiphyllum, 56 *

Myxomycetes, $169 \mathrm{n}$.

Naked buds, $80 *, 81 *$

Natural selection, 498

Nebraska vegetation, Platc IX

Nectar, 423

Nectar glands, $428 *$

Nectaries, 423

Ncgundo, radial and cross sections of stciu of, 61 *

Nemalion, 216, 217*

Nereocystis, 209*

Nest fungi, $269 *$

Netted veined, 89*, 90*

Nettle, stinging hair of, $418^{*}$

Nighthtshade, leaf of, $416^{*}$

Nitella, 201

Nitrification, 233

Nitrogen, 28

Nitrogre11, eireulation of, $231 *, 233$

Nitrogen, fixation of, 234,235

Nocturual position, 97, 08*

Node, $16,17 *, 57,69$

Nomenclature, 153

Nostoc, 176,177

Notched, App. I

Nucellus, 356, 371, 372*, 381*, 386*

Nuclear division, 165*

Nueleole, 164

Nucleus, 34, 35*, 104*

Nut, $147 *, 148$

Nutrient substances, 28,29

Nutrition of plants, $106-111$

Oak leaves, arrangement of, $94 *$

()at, root systcm of, 26,27

()beordatc, App. I

Obovatc, $\Lambda$ pp. I

Obtusc, $\Lambda$ pp. I

Odors of flowers, 423,424

(Erlogoniun, 188-190*

Offensive-sinelling plants, 419

Oil, 9, 11

One-celled green algx, 179-184*

Onion leaf, section of, 53*

Onoclca, 315*

Oögoniuın, 188, 189* 204, 212

Oispore, j66, 188*, 189*, 204

Opening, 490, 531*

Open veining, $89 *, 30 *$
Ophioglossum, 324*

Oppositc branching, 41*

Orange, $148 *$

Orbicular, App. I

Orchid, aërial roots of an, 19*

Order, 153

Origin of sex, 187

Oscillatoria, $175,176^{*}$

Osmosis, 36-39*

Osmosis in an cgg, 37*

Osmosis in root hairs, 39

Outlinc of classification, 155

Ovary, $128 *, 377 *$

Ovate, $A$ pp. I

Overcrowding, 448-450*

Ovule, 123*, 128,356

Ovule casc, $377 *, 380 *$

Ovule, structure of, $144 *$

Oxalis leaf, devclopincnt, 86 *

Oxidation, 7

Oxygen making, 7, 28, 29, 113, 115

Pacific slope, 490, 494, 495

I'aleobotany, definition of, 2

Palisade cclls, 102, 103*, 105*, 107

Palmate, 89, $91 *$, $02 *$

I'alms, 57*, 111*', I'late XIII

Pampas region, 451

Paniole, 135*, 136

Pansy, leaf-likc stipules of, 88*

1'apilionaceous corolla, 125*

Papilla on stigma of a lily, 142*

I'arallcl vcining, 8\$*, 90

Paraphysis, 251*, 298*

l'arasites, $22 *, 23,172,227,407-409 *$

Parasitie roots, $22 *, 23$

I'arenchyma, 64*, 106*

Parietal placenta, 129*, 130

Parthenogenesis, 244

Pea pod, 443*

Pea seedling, mutilated, 8*

Pea secdling on whirling disk, 32 *

P'cat, 291, 292

P'cat bogs, 292

l'eat moss, 290-202*

P'cliccl, 133*

Peduncle, 133*

I'cltate, $\Lambda$ pp. I

I'enieilliun, 250*

Pepo, 149

Perennial, 26**, 46

Perianth, 128*, 126*, 129*, 130*, 135*, $\Lambda$ pp. II

Perianth, differentiation of, 394

Pericarp, 149, 150* 
Perigynous, 130*

Perigyny, 395

Peronosporales, 244-247*

Petal, 123, 377*

Petiole, 88

Peziza, 251*

Phæophyceæ, 205-213*

Phanerogams, 354

1’hloëm, 312*

Phosphates, 29

Phosphorus, 28, 29

Photosynthesis, 107-115, 162, 172

Phycomycetes, 239-247*

Phylloxera, 247

Physcia, 1'late V

Physiology, plant, definition of, 2

Phytophthora, 246*

Pine forests, $457^{*}, 490,529^{*}$

Pine needle, 364, 365*

Pine seedling, $18^{*}$

Pine stem, 366-369*

Pinnæ, leaflets of a pinnately compound leaf, $92 *$

Pinnate, 89, 90*, 91*, 92*

Pinnules, leaflets of a pinnately twice compound leaf, 98*

Pistil. 123-126*, 128*, 358, 377*

Pistillate flower, 124*

Pitcher plant, 409 *

Pith, 58-61*, 65*, 67*, 72, 366*

Placenta, 129*, 130

Plains region, 490, 492, 493

Plankton, 195

Plant breeding, 500-513*

Plant cell, 159-101*

Plant communities, 447

Plant ecology, definition of, 2, 3

Plant evolution up to pteridophytes, 306

Plant formations, $474-480$ *

I'lant geography, 481-495*

Plant geography, definition of, 2, 3

1'lant geography of United States, 489-495*

Plant fertilizers, 524

Plant fibers, 526-529*

Plant food for domestic animals, 523, 524

Plant food for human use, 514-522*

Plant fuel, $5.34^{-}$

Plant grains, 514-516*

Plant inanufactures, 524, 525*

Plant medicines, 522, 523

l'lant physiology, definition of, 2

Plant products, 514-535*
Plant societies, 447

Plant successions, 454-458*

Plant timber, 529-53?*

Plants, destruction of, by animals, 413

Plants, groups of, in relation to water economy, 459

Plants of uneatable texture, 415

Plants, ornamental, 534, 585

Plasınolysis, 38*

Plasmopara, 247

Platycerium, 309*, 310, 472*

Pleurococcus, 179-180*

Pleurotus, Plate V1

Plowrightia, 252*

Plumule, 5*, $6,7^{*}, 14,15$

Plurilocular sporangia, 206*, 207

Pod, 441-443*

Poisonous plants, 419

Poisonous roots, 25

Poisonous seeds, 11, 419

Polar nuclei, 38:3*

Pollarded trees, 87

Pollen, 127, 141*, 358

Pollen-carrying apparatus, $422 *, 423$

Pollen chamber, $362 *, 371$

Pollen, discharge of, 140

Pollen grain, germination of, 142 , $143^{*}$

Pollen grains, number of, per ovule, 144,145

Pollen, protection of, $426,427,434$, 435

Pollen sac, 378*, 379, 380

Pollen tubes, $142 *, 143 * *$

Pollination, 142*, 144*, 145, 357, $371,420-434 *$

Pollution of water supply, 171, 178

Polyadelphous, 127

Polypetalous, 126

Polysepalous, 126

Poiysiphonia, 218, 219*

Polytrichum, 296*

Pome, 148

Pond scum, 193-195*

Pond zonation, $476-478$ *

Pore fungi, 204, 265*

1'orella, 286*, 287*

Position of buds, $82 *, 83,87 *$

Postelsia, 209*

Potassium, 28, 29

Potato blight, or rot, $246^{*}$

Potato tuber, 52*, 53, 78, 79

Prairies, 492, 493

Prickle, 416*, 417* 
Prickly leaves, 416*, 417*

Primary root, 6*, 12*, 16* 19

Primitive flowers, 393

Procain bium, 65*

Products, plant. See Plant products

Pro-ellibryo, 144, 145*

Promycelium, 259*, 261*, 271

Propagation by roots, $436^{\circ}$

l'ropagation of plants, $436-446 *$

Prosenchyma, 64

P'rotection of plants from animals, 413-419*

Protection of pollen, 426, 427, 434*, 435

Proteids, 9*, 11*, 25

Prothallial cell, 322*, 323, 335*, 368*, $372 * 373$

Prothallium, 315-317*

Protobasidiomy cetes, 258-264*

Protococcales, 179, 184*

Protonema, 294*

I'rotoplasm, 34 , 35*, 112, 156-168*

Frotoplasm, characteristics of, 3436

Protoplasm, circulation of, 202

Protoplasm, continuity of, 99, 214

Protoplasm, structure of, 157

P'rotoplast, 34, 35*, 161

Protosiplion, 200*

Protozoa, 157

Ptcridophyta, 806-344*

Ptcridophytes, 306-314*

I'teridophytes, evolution of, 343

P'cridophytcs, origin of, 342

Pteridophytes, summary of, 343,344

Pteridosperma, $392 \mathrm{n}$.

I'tomaines, 232, 236

I'ublic health, 230,237

Puccinia, 260-26.3*

I'uff ball, 268*

1'ulsating vacuole, $158 *$

Pulvinus, 99*

I'yrenoid, $160 *, 162$

Pythium, 247

Race, 504

Raccine, 133*

Radial symmetry, 123*, 125, 126*, 138*

Radiating stems, 51

Radishes, competition among, 449*

liainfall, 481, 488, 489*

Raspberry, $4: 36 *, 445 *$

Ray flowers, 134*, 135*

Ray, medullary, 60* $66,71,72$
Receptacle, 123*, 125*, 130*

1Receptacle of brown algæ, $210 *, 212$

Receptaclcs of Marchantia, 282*, $284 *$

Red algæ, 213-220*

Red algre, life liabits of, 214,215

Red algæe, summary of, 219,220

Red clover, leaf of, $98 *$

Red snow, 182

Regions of vegetation, 481

Reindeer moss, 257**

Reproduction,, 35

Reproduction in flowering plants, $138-145 *, 436-446 *$

Resin duct, $366^{*}$

Respiration, 107, 110-115

Resting buds, 80

Resting condition, 112

Resurrection moss, 333

Retuse, App. I

Rhizoids, 280*, 281*

Rhizopus, 240, 241*

Rhodophyceæ, 213-220*

Rhubarb roots, $26 *$

Ricciales, 279, 280*

Ricciocarpus, 280 *

Rigid tissue, 312, 313. See Sclerenchyma

Ring, annual, 66*, 68*

Ringent, App. If

Rise of watcr in stems, $73-75 *$

Rockweeds, 210-212*, Plate 1V

Rocky Mountain region, 490, 493, 494

Root, $6 *$, 12*, 13, 15-33*

Root absorption, 30

Root absorption and temperature, 30

Root, adaptation to work, 33

Root cap, 24*

Root climbers, 20* 48

Root, dicotyledonous, section of, 25*

Root, flesliy, 23*

Root hair, $15,16 * 24,25 * 27 *, 28$

Root pressure, 29*, 30

Root sections, $24 *, 25 *$

Root systein, 26, 27

Root tubercles, 234 *

Roots, absorbing surface of, 27

Roots, adventitious, 19

Roots, aërial, 19-21*

Roots, brace, 21*

Roots, fibrons, 23*

Roots, movements of young, 30,31

Roots, parasitic, 22*, 23

Roots, pinc, lateral extension of, 32* 
Roots, primary, 6*, 12*, 16*, 19

Roots, propagation by, 436

Roots, secolldary, $6^{*}, 12^{*}, 19,32 *$

Roots, selective action in, 36

Roots, storage of nourishment in, $23^{*}, 25,26^{*}$

Roots, structure of, 24, 25

Roots, tertiary, 19

Roots, water, 20

Rootstock, 51*, 52*, 53

Rosette plants, $50 *, 51$

Rotation of protoplasm, 202

Rots, 246*, 253, 251

Russian thistle, 440*, 447,448

Russian thistle, spread of, 451,452

Rusts, 260-264*

Rye grass, Plate I

Saccharomycetes, 238*, 239

Sac fungi, 248-257*

Sac fungi, summary of, 257

Sagebrush, 480, 493, 494

Sage, pollination in flowers of, $430 *$, $431 *$

Sagittaria, leaf of, $461 *$

Sago palm, 78

Sahara, 482*

Salicornia, 483*, 493

Salt marsh plants. See Halophytes

Salt marshes, 458

Salts, 29

Salver-shapcd, App. II

Salvinia, 320 *

Sap, descent of, $74^{*}, 75^{*}, 77$

Sap, rise of, 29*, 30, 74*, 75*, 77

Saprolegnia, 244*

Saprolegniales, 242-244*

Saprophytes, 172, 227, 409

Sapwood, 72

Sargassuin, 212*, 213

Scale, 16, 18

Scalloped, App. I

Scaly buds, 81

Schizocarp, 147*

Schizony cetes, 228-237*

Scion, 68

Scirpus, cross section of stem of, 58*

Scle renchy ma, 58*, 59

Scotcl pine (Pinus sylvestris), 366*, $368 *, 370$ *

Scouring rush, 325

Sca lettuces, $187 *$

Seasonal plants, 459,467

Secondary growtl, $65-67 *$

Secondary root, $6 *, 12^{*}, 19$
Secondary roots, direction of, 32*

Sections, leaf, 102, 103*, 466*

Sections, root, 24*, 25*

Sections, wood, 59-68*

Sedge, rootstock of, 51 *

Seed, 5-12*, 355, 356

Seed coats, 6,13

Seed dispersal, 438-446*

Seed habit, origin of, 389-393

Seed leaf, 5-14*, 18*

Seedlings, 6* 8* $^{*}, 9-18^{*}, 22$

Seedlings, mutilated growth of, $8^{*}$

Seed plants, 5-14*, 18*

Seed plants, origin of, 389

Seeds, bitter, 11, 419

Seeds, poisons in, 11, 419

Selaginella, 332-337*

Selaginetla, Hfelist ory of, 336

Selaginella, summary of, 337

Sclcetion by plant brceder, 500-509

Selection, natural, 498

Selcctive absorption, 36

Self pollination, 420

Sensitive plants, 98, 99

Sepal, 123*, 377

Scquoia, 42, 46, 73, 482, 495

Sessile anthers, 127

Sessile leaves, 88

Sessile stigma, 128

Sex, evolution of, 223,224

Sex, origin of, 187

Sexual characteristics given by heterospory, 352

Shade plants, $470 *, 471$

Shame vine, 98*, 99

Shepherd's purse, development of embryo and ovule, $386^{*}$

Sheplierd's purse, devclopment of flower of, $387^{*}$

Shoot, 15

Short-stemmed plants, $50^{*}, 51$

Shrubs, 45

Sieve plate, $63^{*}$

Sieve tubes, 61-63*, 67, 72, 76, $105^{*}$

Sigillaria, 340, Plate VIII

Silica, 120

Simplc leaves, 91

Simple pistil, 128

Simple umbel of cherry, 133*

Siplionales, $197-201 *$

Siphon alga, $197-201 *$

"Slcep" of plants, $97,98 *$

Slime molds, 169

"Smilax," 56* 
Smoke tree, 438*

Simuts, 250*

Social plants, 447

Soft bast (sieve tubes), 61-63*

Soil, arid, zonation, $476-478 *$

Solomon's seal, parallel-veined leaf of, $89 *$

Sorus, 313

Spatulate, App. I

Species, 153

Sperm, 160, 18:*, 204, 212

Spermagonia, 262*

Spermatia, 262*

Spermiltophyta, 354-401*

Spermatophyte, 35.1-401*

Sperinatophytes, 400

Splharella, 180-182*

Spliagnales, 290*, 291*

Splagnum, 290*, 291*

Spike, 133, 13.4*

Spine, $416^{*}, 417^{*}$

Spriral vessel, ti2*

Spirogyra, 166**

Sporangium, 185*, 204, 313, 314*

Spore, 166

Spore case, 31 ?

Spore formation of ferns, 313

Spore fruit, $321 *$, 322

Sporidia, 259* 261* 271

Sporopliyll, 314, 315*

Sporopliyll, arrangement of, in flowers, 391

Sporopliyte, $220,277,299,318$

Sporoplyyte, evolution of, $402-404$

Sporoplryte, origin of, 34 )

Spot fungi, 253,254

Spreading growtl, 43*

Spring spores of wheat, $261^{*}$

Spruce, Douglas, 40?, Plate X1I

Spur, fruit, 83*, 84*

Squash seed, seetion of, 6)*

Stamen, 123-131*, 358, 368*, 369, $377 *, 378 *, .379, .880$

Stamen, parts of, 127 *

Staninate flower, 124*

Stanilard, 125*

Starch, 9-11*, 25, 107-110

Starch disappears during germination, 10

Starch in leaves, 107-110

Starch making, rate of, 109,110

Stem, 15-3?**, 40-79*

Stem, active portions of, 71

Sten, comparison of monocotyledonous and dicotyledonous, 70
Stem, definition of, $\mathbf{1 0}$

Stom, dicotyledonous, minute structure of, 59-67*

Stein, early history of, $64,65^{*}$

Stem, functions of cells of 71,72

Sten, living parts of, 71-79*

Stem, morliflability of, $(60$

Stem, momocotyl(ilonous, 57-60*

Stem, nature of, 40

Stem, strueture of, $57-70$ *

Sten structure, carly listory of, 64 , $65 *$

Stems, climbing, 47-50*

Stems, condensed, $h^{*}$

Stems, storage of food in, 78, 79

Steıns, twining, 40*, $50 *$

Stemless plants, $60^{*}, 52$

Sterigmata, 260

Stiffening, meclanies for, $68^{*}, 60$, $63^{*}, 6.4 *$

Stigua, 128*, 377

Stimmlus to protoplasm, 35, 36, 30

Stinging lati, 418*

Stipa, cross section of rolled and unrolled leaves of, $466^{*}$

Stipe, 208

Stipules, $80,82 *$

Stock, 69

Stolon, with tips rooting, 430*

Stoma, 288, 28!**, 301*

Stomata, 71, 10?**, 118, 119

Stomata, operation of, 118

Stone fruits, uses of, 444,445

Stoneworts, $201,202^{*}$

Storage of food in the root, 23*, 26, 26 *

Storago of fool in tloseen, 8-11

Storngo of food in tho stem, $52-6.4^{*}$, 78,79

Strawlerry, 148*

Strobilus, 327

Struggle for existence, 447-451, 497

Style, 128*

Suberin, 117

Submerged leavess, 461*

Successions, plant, 454-468*

Sucking roots, 22*

Sugar, 10, 11, 25, 79, 107, 112-116, 522

Sugar, formed during germination, 10,11

Sugar ealle, cross section of a bunalle from, 75 ,

Sulphates, 29

Sulphur, 28, 29 
Summer spores of wheat, 262, 263*

Sundew, 410*, 411*

Sun plants, $470^{*}, 471$

Superiol ovary, $130 *$

Supernumerary buds, 82*

Survival of the fittest, 498

Suspensor, 141, 145*, 335**, 336, 385, $380^{*} *$

Swamp zonation, 476-478*

Swarnı spores, 185*, 186, 201

Sweet pea, flowers of, 125*

Symbiosis, 255

Symmetry, 123*, 125, 126*, 138*

Syinpetale, 397

Sympetalous, 126

Sympetaly, 395

Syncarpy, 395

Synergids, 383*

Synsepalous, 126

Syusepaly, 395

Systematic botany, definition of, 2

Taper-pointed, App. I

'Tap root, 23*

Taxonomy, definition of, 2

Teeth of inoss spore ease, 300*

Teleutospores, 260**, 261

Temperate plant assuciations, 482, 483

Temperature and germination, 7

'Temperature and leaf movement, 97, 98

Temperature and photosynthesis, 108,110

Temperature and respiration, $110-$ 112

Temperature and root absorption, 30

'Temperature and root growth, 39

Temperature and transpiration, 120

Temperature and vegetation, 481488

Tendril, 48*, 49

'Tendril climbers, 48*, $92^{*}$

Terminal bud, $40^{*}, 42^{*}, 43^{*}, 45^{*}, 46^{*}$, $52^{*}, 82^{*}, 83^{*}, 81^{*}$

T'erminal flowers, 13,2*

'Tertiary root, 19

Testa, 5*, 6*, 370*, 375

Tetrad, 219, 277, 280* , 289*, 369

Tetraspores, 219*

Thallophyta, 172-274*

'Thallopliytes, 172-274*

Thallopliytes, summary of, 304,305

Thallıs, 172

Thistle, Russian, 440* 447, 448
Tlyorns, 410*, 417*

'Thorus as branehes, 44*

'liekle grass, 442*

'Timber line, 485*

'I'issue, 64, 1177

'Toalstool, 265-267*

'Tootlı fungi, 265*

'Toxins, 28, 6 '

'Tracheids, 311, 312*, 366*, 367

Transition from stumens to petals. 139**

Transpiration, 107, 116,

Transpiration, amount of, 11!), 120

'Transportation by water, 441, 412

'Tree ferns, 309, I'late VII

Trees, 45

Trees, age of, 46

Triehogyne, 216, 217*

'Trimorphous flowers, 4:32

Troperolum, petiole, eoiling of, 49 *

Tropieal plant associations, $481,482 *$, Ilate X III

Tropopliytes, 459, 482

'I'ruffles, 253

Truneate, $\Lambda \mathrm{pp}$. I

Trumk, 42*, 43*

'Tube nucleus, 372*, 373, 382*

'luber, 52*, 53,

'Iuber brumale, 25.3

Tubereles on roots, 234 *

'T'ubular corolla, App. II

'Tumbleweeds, 440*, 441*, 442*

'Turgor, 118

Turnip seerlling, 16;

Twayblate, bertle on flowel of, 425*

Twigs, 40*, 46*

'Twiners, 48*, 48*, 50

'I'wining, rate of, 50

Ilotlurix, 184-186;*

Ulva, 187

Umbel, 133*, 1.35*

Unibellet, 135*, 136;

Underground sterns, 51*, 52*, 5.3*, $54,78,79$

Uneatalle plants, 50*, 52, 415-410*

Tniloeular sporangia, 206*

Union of earpels. 128, 129*

Union of stamens, 127*, 128*

Unipistillary fruits, 1.46;

Uniscxual flowers, 12.4*

United States, plant geograpliy of, 489-495*

Upriglit growtl, $42 *$

Uredospores, 26\%*, 263* 
Uredinales, 260-264*

Urogleua, 170*, 171, 178

Uses of the components of thc stem, 72

Usnea, 257*

Ustilaginales, $259 *$

Ustilago, 259*

Vacuole, pulsating, 158*

Variation, 496, 497, 499

Varicty, 500, 503, 504, 506-508, $512 *$

Vaucheria, $197-200 *$

Vegetable physiology, 2

Vegetation, alpine, 484-487*, 493

Vegetation, arctic, 484*

Vegetation, rcgions of, 481

Vegetation, tempcrate, 482,483

Vegetation, tropical, 481, 482*

Vegetative organs, 15

Vein, 89*, 106**

Venation, 89*, 106*

Venus flytrap, 411, 412*

Vernation, 85, 86*

Vertically placed leaves, 100*, 101*

Vessel, 61*, 72

Volvox, 182-184*

Walking fern, 310*

Water, absorption by roots, 28

Water, amount transpired, 119, 120

Watcr blooin, 177

Watcr, excretion of, 115-120

Water fern, $320^{*}$

Water lily, flower of, 130*, 139*

Water inolds, 242-244*

Water, movelnclit of, 28-30* 73 -78*, $10 \%, 106 *, 116-120$

Water roots, 20

Water supply, pollution of, 171,178

Weapons of plants, $416-410^{*}$

Wedge-shaped, App. I
Weeds, 452,453

Wheat grain, section of, $9 *$

Wheat, hybridizing of, $512 *, 513$

Wheat rust, $260-263 *$

Wheat, selection among, 507-509

Wheel-shaped, App. II

Whorl, 123*

Willow, adventitious buds of, 87

Willow, arctic, 484*

Willow, flowers of, 124*

Wind pollination, $421^{*}$

Winged fruits and seeds, 439-441*, 442*

Wings, $125 *$

Winter buds, 80

Winter sporcs of wheat, 260*, 261

Witches' brooin, 264

Wood ccll, 25*, 61*, 62*,72, 75*

Wood, coniferous, 366\%*, 367

Wood of linden, $66^{*}$

Wood parchichyma, 64

Wood sections, 59-68*

Wood, structure of, $61 *, 63 *, 66 *$

Xenia, $381 \mathrm{n}$.

Xerophytes, 45., 462-466*, 482, 485

Xcropliytic leaves, 465*, 466*

Xylaria, 252

Xylem, 311, 312*, 366*, 367

Yarrow, head of, 135*

Ycast, 238*, 239

Yucca, 495

Zamia, 360*, 362*

Zonation, 475-478*, Plate $X$

Zoncs, 475-478*, l'late X

Zoösporangiun, 201

Zoöspores, 185*, 204

Zygncina, 194*

Zygomorphic, 125

Zy gosporc, $167,182,185^{*}, 186,193 *$, $194^{*}, 204,206 *$ 




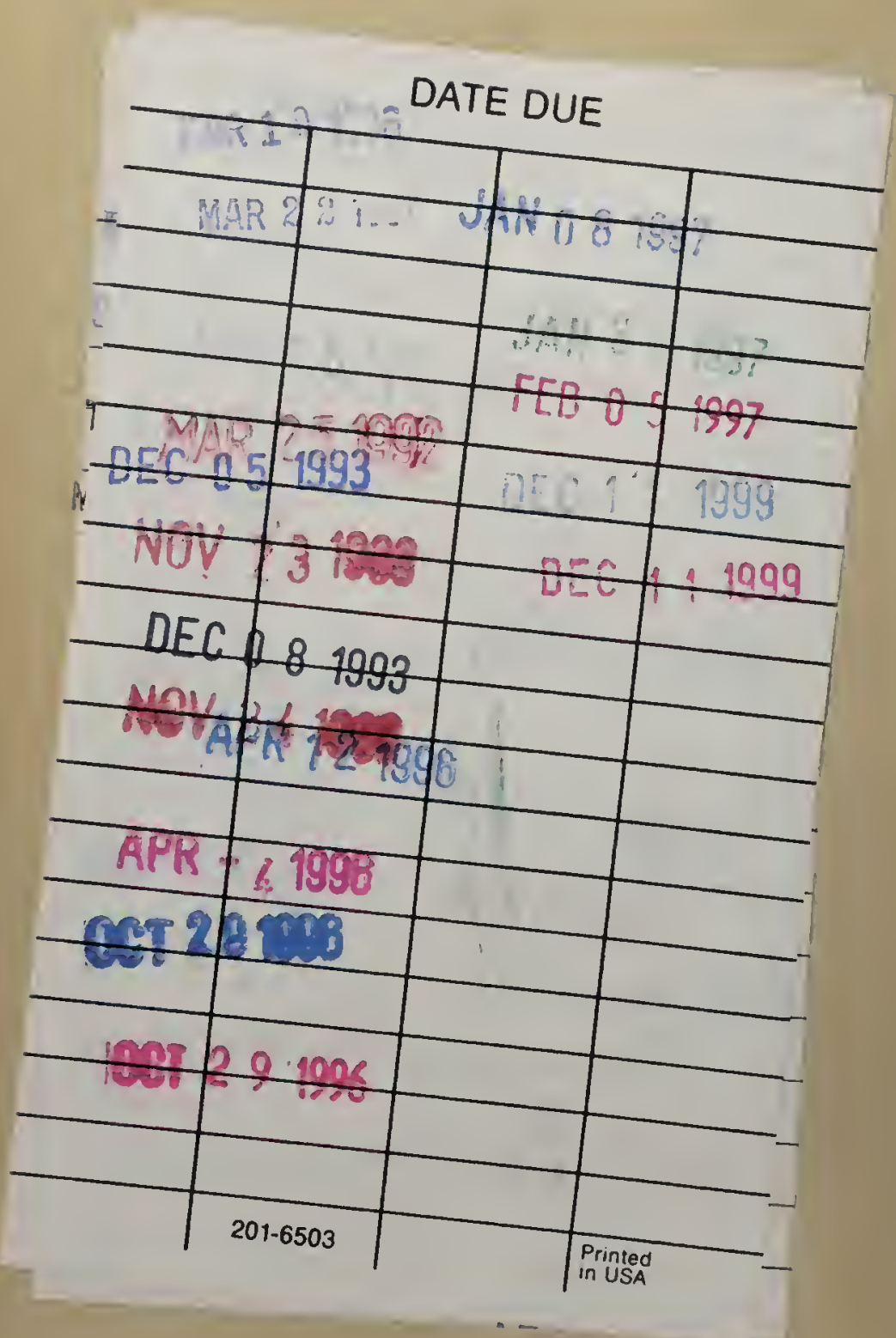




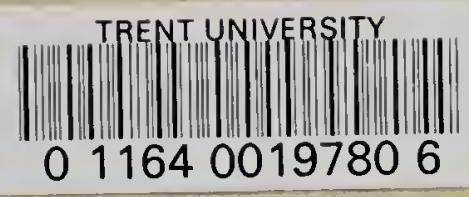

$$
\begin{aligned}
& \text { QK47 } \text {. B525 } \\
& \text { Bergen, Joseph Young } \\
& \text { Principles of botany }
\end{aligned}
$$

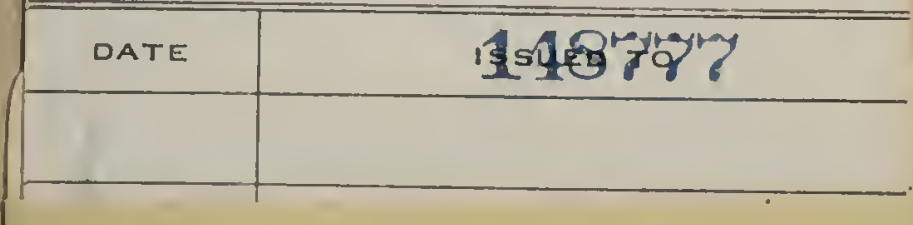

148777 


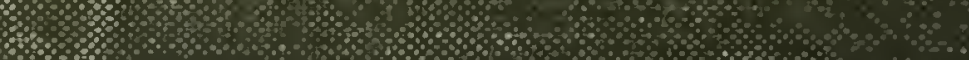

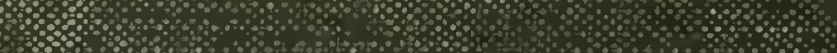

\&8\%

8.8 8

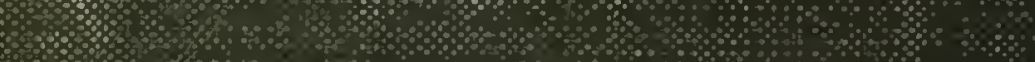

B.

$80.8888^{\circ}, 84$

20

$80 \div \div 0$

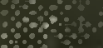

808000

$\because 8: 8 \%: \%$

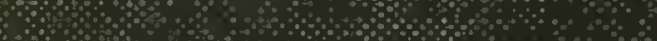

a

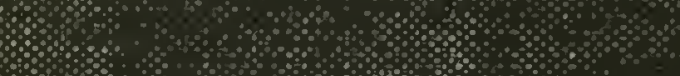

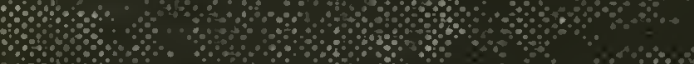

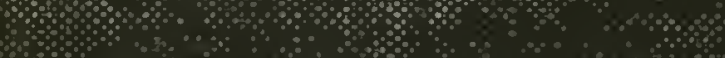

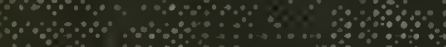

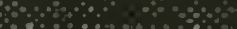

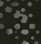

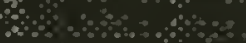

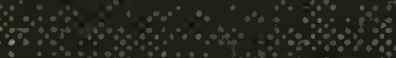

$\therefore 8$

$\because \% 8 \%$

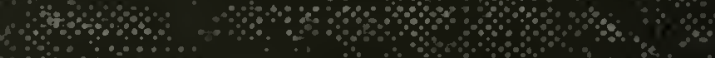

$n$
$\therefore$

